\title{
Effects of cropping systems on plant-associated microbial communities of faba bean and wheat
}

\author{
Dissertation \\ zur Erlangung des Doktorgrades \\ der Fakultät für Agrarwissenschaften \\ der Georg-August-Universität Göttingen
}

vorgelegt von

Sandra Granzow

geboren in Witzenhausen

Göttingen, 2018 
D7

1. Referent:

Prof. Dr. Stefan Vidal

2. Korreferent:

Prof. Dr. Rolf Daniel

Tag der mündlichen Prüfung: 08.11.2018 


\section{Contents}

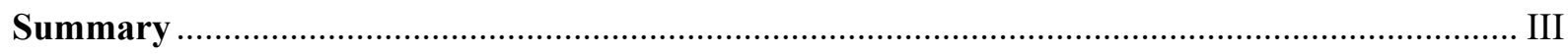

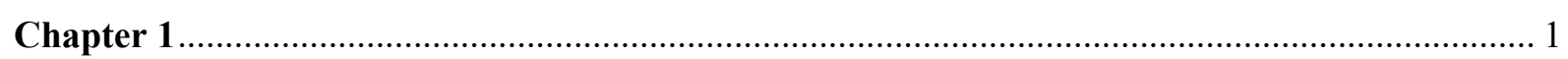

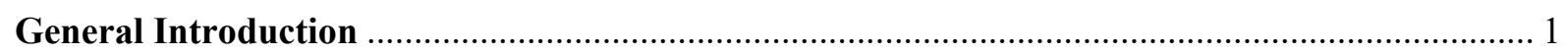

1.1 Current prospects for the development of sustainable agriculture .................................... 2

1.2 Relevance of plant-associated microorganisms in agriculture …........................................... 3

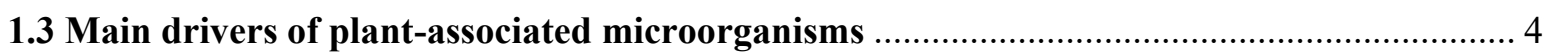

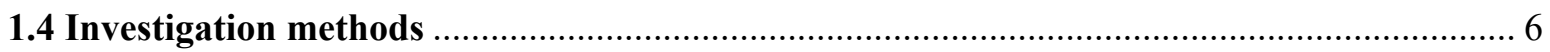

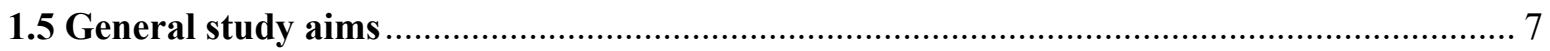

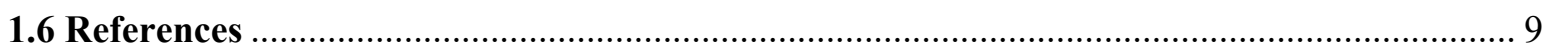

Chapter 2

The effects of cropping regimes on fungal and bacterial communities of wheat and faba bean in a greenhouse pot experiment differ between plant species and compartment ............................ 14

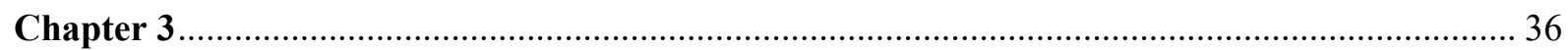

The cropping system matters - Contrasting responses of winter faba bean (Vicia faba $\mathbf{L}$.)

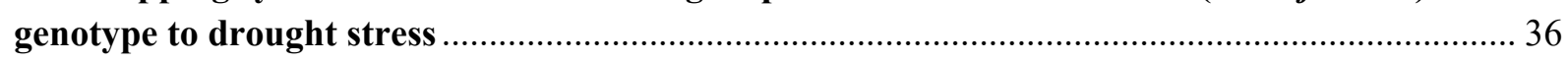

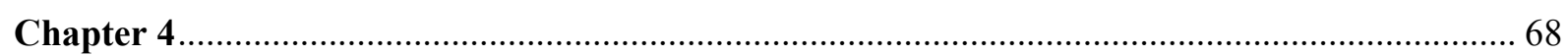

Crop genotype and plant compartment determine the response of the active bacterial

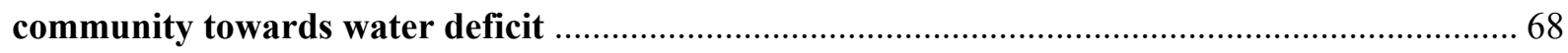

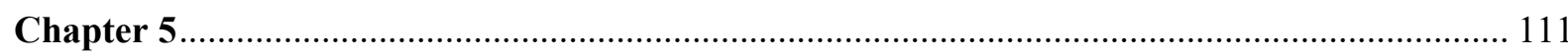

Response of the active bacterial and fungal communities in the rhizosphere differ towards water

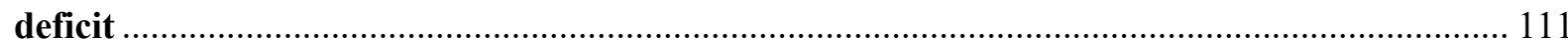

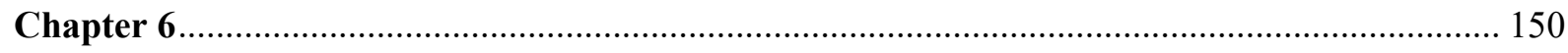

Crop species and cropping system alter the effect of Metarhizium brunneum seed application on

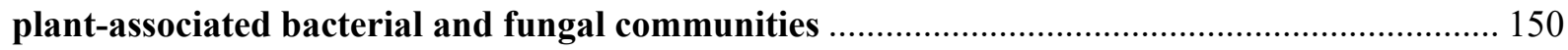

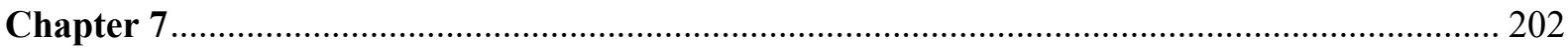

Draft genome sequence of the endophyte Bacillus mycoides strain GM5LP isolated from Lolium

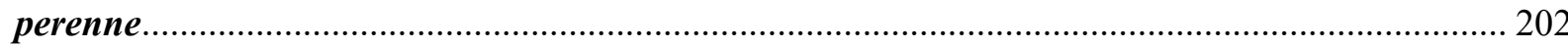

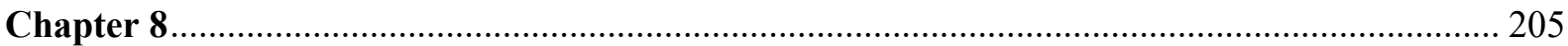

Draft genome sequence of Pseudomonas putida strain GM4FR, and endophytic bacterium

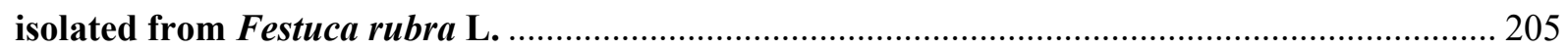

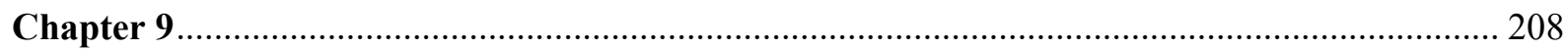

First insights into the draft genome sequence of the endophyte Paenibacillus amylolyticus strain

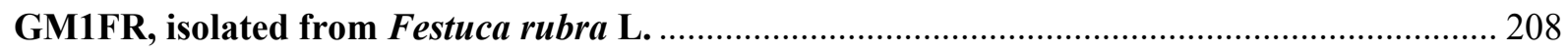

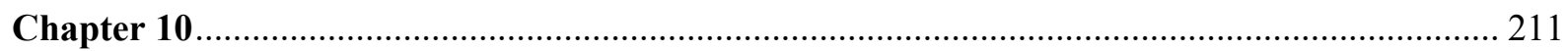

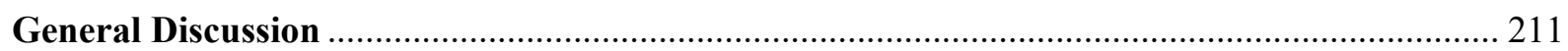


10.1 Plant-associated microbial communities and their response towards cropping systems 214

10.2 Response of the active microbial community towards water deficit 216

10.3 Crop species and cropping system influenced the effect of $M$. brunneum seed application on plant-associated microbial communities 217

10.4 Draft genomes of different endophytic bacteria in grasses. 218

10.5 Concluding remarks and outlook 219

10.6 References 219

Acknowledgment 224

Curriculum Vitae 225

Declarations 227 


\section{Summary}

Beneficial plant-associated microorganisms are widely acknowledged as key promoter in plant growth and health. Although playing crucial roles in ecosystem functioning and in a sustainable agriculture, our knowledge on the effects of agricultural practices on the plant microbiome is still limited. The main focus of this thesis was to understand which factors shape microbial community composition and diversity in response to different cropping systems, namely monoculture and intercropping, in winter wheat (Triticum aestivum L.) and winter faba bean (Vicia faba L.) using next generation-sequencing.

In the second Chapter, we investigated the influence of cropping systems (monoculture, row and mixed intercropping) on bacterial and fungal community composition and interactions in soil and endosphere under greenhouse conditions. We detected significant differences in microbial diversity and richness between mixed and row intercropping as well as between mixed intercropping and monoculture. In addition, microbial communities differed between the crop species wheat and faba bean as well as between plant compartment. This resulted in different response of these communities towards cropping systems. We further recorded changes in microbial interactions. The number of negative inter-domain correlations between fungi and bacteria decreased in bulk and rhizosphere soil in intercropping regimes compared to monocultures. However, the observed differences were plant species-dependent. These results indicate that intra- and interspecific competition between plants had different effects on the plant species and thus on their associated microbial communities.

In the following chapters, we investigated the effect of cropping systems and water deficit on plant physiological parameters (Chapter 3) as well as on the active (RNA-based) fungal and bacterial communities in different plant compartments (Chapter 4, 5). For this purpose, wheat and two genotypes of faba bean were grown in monoculture and in row intercropping with (water-deficit treatments) and without water stress (control treatments) under greenhouse conditions. Plant material and rhizosphere soil of all treatments were collected at three time points with different water availability (beginning, during and after water deficit stress). Plant physiological parameters such as gas exchange, relative water content of leaves, plant biomass production and water use efficiency (WUE) were studied. As a result, we observed that plants exhibited a clear genotype x cropping system effect towards water deficit. For example, water deficit reduced overall biomass and WUE of faba bean for the one genotype in monoculture and for the other genotype grown in intercropping. Furthermore, investigations on the plant microbiome showed that in the rhizosphere bacterial 
and fungal communities were altered by water deficit; however, these alterations in the communities were pronounced differently towards water deficit. Fungal community composition responded stronger towards water deficit, and changes of fungal alpha-diversity were dependent on faba bean genotype. Response of bacterial community composition towards water deficit was dependent on crop species and genotype, whereas bacterial alphadiversity was not affected by water deficit. In contrast, leaf bacterial diversity and richness significantly decreased under water deficit specific for one faba bean genotype. This was mainly related to significant changes of plant physiological parameters, such as sugar concentration and chlorophyll content in leaves. Furthermore, cropping system alone was only a minor factor determining the active plant microbiome. Obtained results highlight that there are complex interactions between plants, associated microorganisms and their environment that influence agricultural productivity.

In the sixth Chapter, we evaluated the impact of cropping systems and Metarhizium brunneum Cb15-III seed application on bacterial and fungal community composition and diversity in soil as well as in the endosphere after five and seven weeks of plant growing. For this purpose, faba bean and wheat were grown in monoculture and in row intercropping under greenhouse conditions. We found that plant compartment, crop species and sampling time altered the influence of fungal inoculation and cropping system on microbial communities in rhizosphere and endosphere. Seed application of M. brunneum changed the fungal community composition in the rhizosphere soil only, whereas bacterial community composition in both the rhizosphere and the leaf endosphere were affected. In addition, microbial diversity and richness showed harvest date- and kingdom-specific responses towards M. brunneum application. A significantly lower fungal diversity and richness was observed in the leaf endosphere and rhizosphere soil of inoculated wheat compared to control plants after seven weeks of growth. Cropping system alone but also in combination with seed application exhibited significantly higher microbial diversity and richness in intercropped wheat compared to wheat in monoculture. However, this was only observed for fungi in the root endosphere and for bacteria in the rhizosphere. Alterations in microbial communities towards cropping system and application were partly explained by changes in total organic carbon and nitrogen in the rhizosphere soil as well as in the plant. The present findings improve our understanding of how the combination of cropping system and application of an entomopathogenic fungus affects microbial communities and plant productivity which might gain further importance for biological control strategies in the future.

As the plant endosphere is a great reservoir of beneficial microorganisms, we further 
investigated the draft genomes of three endophytic bacteria, namely Bacillus mycoides (Strain GM5LP; Chapter 7), Pseudomonas putida (Strain GM4FR; Chapter 8) and Paenibacillus amylolyticus (Strain GM1FR; Chapter 9) isolated from Lolium perenne or Festuca rubra L. We identified several genes, which might be important for plant-growth promotion and biocontrol options. Further research is needed to validate these findings.

In conclusion, plant-associated microbial communities including bacteria and fungi in soil and endosphere are influenced by cropping system as well as fungal inoculation and water deficit. In particular, we observed that bacteria and fungi responded differently towards agricultural practices and environmental changes. However, effects were strongly shaped by plant related traits such as compartment or crop species. Fundamental knowledge of plantassociated microorganisms and their responses towards agricultural practices are important to successfully implement a sustainable agriculture. 
Chapter 1

General Introduction 


\subsection{Current prospects for the development of sustainable agriculture}

Over the past 50 years, the simplification of landscapes in agriculture expanded and changed global environment dramatically (Baessler and Klotz, 2006). The growing demand of global food further increased the utilization of pesticides and fertilizers which in turn also increased crop yield and food production (Carvalho, 2017). However, intensification of agriculture adversely impacts its environment such as degradation of soil, water and air quality (Matson et al., 1997, Stoate et al., 2001) and decrease of the biodiversity (Kleijn et al., 2006; Andreote and Silva, 2017). For example, the homogenizations of agricultural landscapes through monocultures can considerable influence soil microbiome diversity, resulting in an enhanced susceptibility of plants towards pathogens (Eisenhauer et al., 2012; Li et al., 2016; Andreote and Silva, 2017).

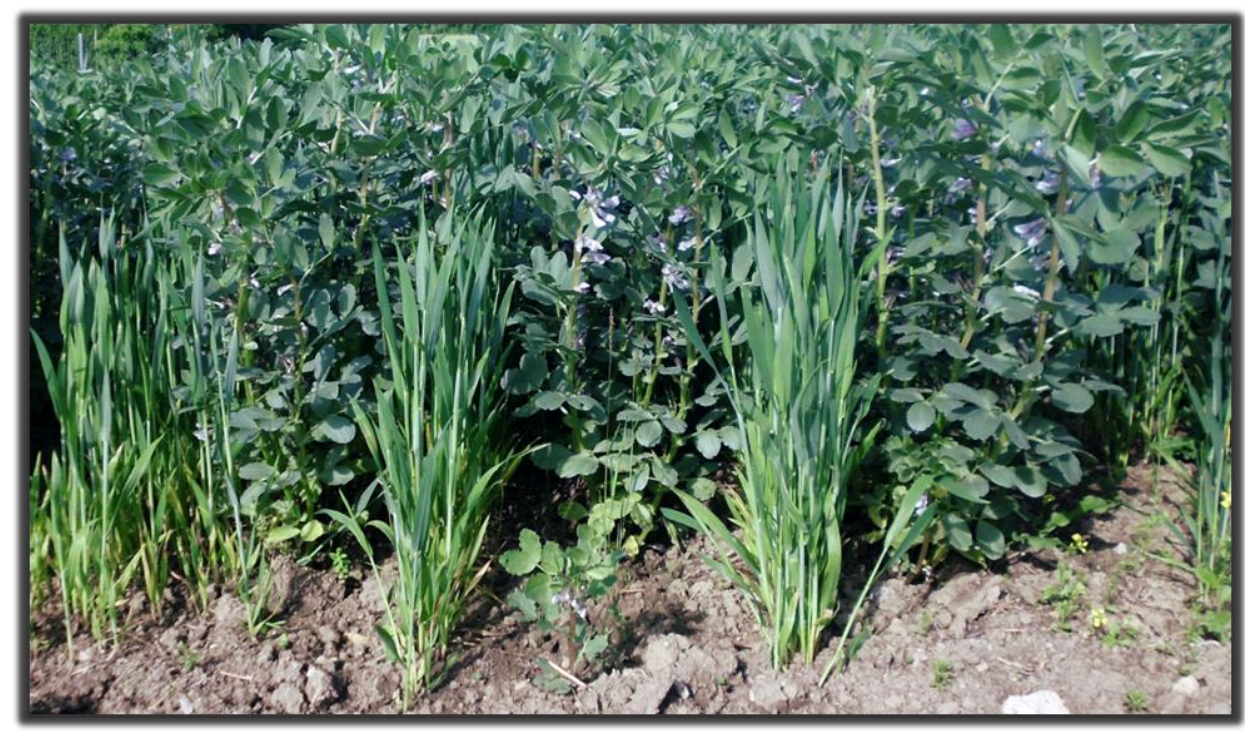

Figure 1. Row intercropping of winter faba bean and winter wheat (photo, Granzow).

Due to the growing public awareness about the intensive use of pesticides and fertilizers and its negative impacts on the environment, sustainable agricultural practices have received more attention (Ansell, 2008; Rockström et al., 2017). Aims in the sustainable agriculture are to increase the biomass production while minimizing resource use and maintaining ecosystem services, soil fertility and its physico-chemical properties through optimal management (Lithourgidis et al., 2011; Rockström et al., 2017). Examples are intercropping systems in which two or more crops are cultivated on the same field at the same time (Vandermeer et al., 1992; Lithourgidis et al., 2011; Figure 1). Intercropping systems provide many beneficial ecological and economical services including the suppression of plant pathogens and pests (Hinsinger et al., 2011; Boudreau, 2013). The most widely 
practiced and studied intercrops are cereal and legume species (Fletcher et al., 2016). The frequently reported enhanced plant productivity of intercropped cereals and legumes (Song et al., 2007b; Zhang et al., 2010) might be attributed to niche differentiation of the two intercropped plants. This includes differences in rooting depths, canopy structure, height as well as nutrient requirements, which results in an improved utilization of growth resources (Hauggaard-Nielsen and Jensen, 2005; Brooker et al., 2015). Another important advantage of intercropping with legumes is the improvement of soil fertility through biological nitrogen fixation (Fujita, 1992; Hauggaard-Nielsen and Jensen, 2005). Legumes form symbiosis with nitrogen-fixing rhizobia and thus have access to atmospheric nitrogen, which is otherwise unavailable for cereals. However, different legume species or even cultivars/genotypes differ in their suitability for intercropping which in turn influence complementary effect between crop species (Davis and Woolley, 1993; Hauggard-Nielson and Jensen, 2001). Thus, there is a need for breeding suitable plant cultivars for intercropping; because breeding for monocultures might be not the best cultivars which are the most applicable for intercropping systems (Hauggard-Nielson and Jensen, 2001; Fletcher et al., 2016). Not only cultivars for specific cropping systems but also in combination with the local climate are needed to result in sustainable crop yields in a changing climate (Davis and Woolley, 1993; Coleman-Derr and Tringe, 2014).

\subsection{Relevance of plant-associated microorganisms in agriculture}

In addition to new crop cultivars and intercropping practices, an increasing number of studies highlight the importance of plant-associated microorganisms in sustainable agriculture development (Berg et al., 2014; Ahkami et al., 2017). Plant growth promoting microorganisms such as Rhizobium spp. or arbuscular mycorrhizal fungi in agriculture are now gaining worldwide importance and acceptance for an increasing number of crops and managed ecosystems as the safe method of nutrient solubilisation and enhancing plant health (Berendsen et al., 2012; Hardoim et al., 2015). It has been shown that plant-associated fungi and/or bacteria are effective agents to alleviate abiotic or biotic factors of the host plant (Coleman-Derr and Tringe, 2014; Vimal et al., 2017). For example, the inoculation of wheat seeds with the entomopathogenic fungi Metarhizium brunneum and M. robertsii increased the mortality rates of Tenebrio molitor larvae (Keyser et al., 2014). Gagné-Bourque et al., (2015) observed that the inoculation with an endophytic Bacillus subtilis strain isolated from switchgrass conferred drought resistance in Brachypodium distachyon via upregulation of drought-response genes, modulation of the DNA methylation process, and increase in soluble 
sugar and starch content of leaves. In addition, microbial communities in the (rhizosphere) soil play key roles in ecological processes, such as decomposition of organic matter, carbon sequestration or nutrient cycling (Ellouze et al., 2014; van der Heijden and Hartmann, 2016). As consequence, it is of crucial interest to better understand the driving forces of plantassociated microbial communities and their interactions.

\subsection{Main drivers of plant-associated microorganisms}

Plants provide three major habitats for microorganisms: the phyllosphere, the rhizosphere and the endosphere (Figure 2). The rhizosphere is defined as soil which is surrounding the roots and is also influenced by plants (Huang et al., 2014). The phyllosphere comprises the aerial plant parts. Microorganisms which colonize the surface of these plant parts are termed epiphytes (Vorholt, 2012). The endosphere is the habitat within plants and the organisms colonizing internal plant tissues are called endophytes (Turner, James and Poole, 2013). The endosphere is more specific and limited in space than the rhizosphere and thus only few welladapted microorganisms can enter and survive within plants (Compant et al., 2010). However, several microorganisms occurring in the rhizosphere have also been shown to colonize the endopshere (and vice versa) such as members of Sphingobacteriacea or Bacillaceae (Edwards et al., 2014; Rathore et al., 2017). Each of these habitats offer distinct niches and are colonized by a plethora of different microorganisms including bacteria, fungi, archaea, protista, oomycotes and nematodes (Turner, James and Poole, 2013; Dupont et al., 2016; Dassen et al., 2017).

Previous studies showed that abiotic factors such as drought (Naylor et al., 2017; Kaurin et al., 2018) as well as biotic factors including herbivores (Dematheis et al., 2013) or pathogens ( $\mathrm{Gu}$ et al., 2016; Taheri et al., 2016) influenced plant-associated microbial communities. In the rhizosphere, interactions between roots, soil and microorganism significantly change soil physical and chemical characteristics which in turn also affect the soil microbiome (Huang et al., 2014). Dependent on the plant species and the development stage of the plant, root exudation patterns can vary according to quantity and quality of the released compounds and thus can alter the microbial community in the rhizosphere soil (Wang et al., 2009; Dawson et al., 2017; Schlemper et al., 2017). In addition, studies observed that soil type altered the microbial communities in the rhizosphere (Wang et al., 2009; Schlemper et al., 2017) and in the endosphere (Nallanchakravarthula et al., 2014; Wagner et al., 2016). Other important driver of endophytic communities are plant species (FonsecaGarcia et al., 2016; Wemheuer et al., 2017), genotype (Santos-Medellin et al., 2017) or plant 
growth stage (Gdanetz et al., 2017; Xu et al., 2018). Agricultural practices also influence soil microbial communities, through changes in nutrient availability, arrangement of plants, soil moisture or texture (Edwards et al., 2014, Wang et al., 2017; Li and Wu, 2018). In addition, the increasingly used application of beneficial microorganism on plant and/or soil has been shown to influence diversity and composition of plant-associated microbial communities (Sheridan et al., 2016; Gadhave et al., 2018).

Over the last years, an increasing number of studies investigated the response of microbial communities in the rhizosphere soil (Song et al., 2007a; Wang et al., 2012; Zhang et al., 2015; Yang et al., 2016) and in the root endosphere (Zhang et al., 2011) towards intercropping. Song et al., (2007a) compared intercropping and monoculture systems and reported differences in the ammonia-oxidizing bacterial community structure using denaturing gradient gel electrophoresis (DGGE). However, less is known on the endophytic community towards intercropping systems because most studies focused on microorganisms in the rhizosphere and/or on specific groups, such as ammonia-oxidizing bacteria (Song et al., 2007a; Wang et al., 2012; Zhang et al., 2015). However, bacteria and fungi co-occur and can interact within the different plant compartments (Sloan and Lebeis, 2015; Cocq et al., 2017). As these microorganisms have different lifestyles within plant, it can be expected that they also respond differently towards agricultural practices. For example, bacteria have been shown to be obligate, facultative or passive passenger endophytes (Hardoim et al., 2008), whereas for endophytic fungi it has been assumed that they remain restricted to a specific organ (Jaber and Vidal, 2010). Thus, it highlights the importance of combined analysis of fungi and bacteria. 


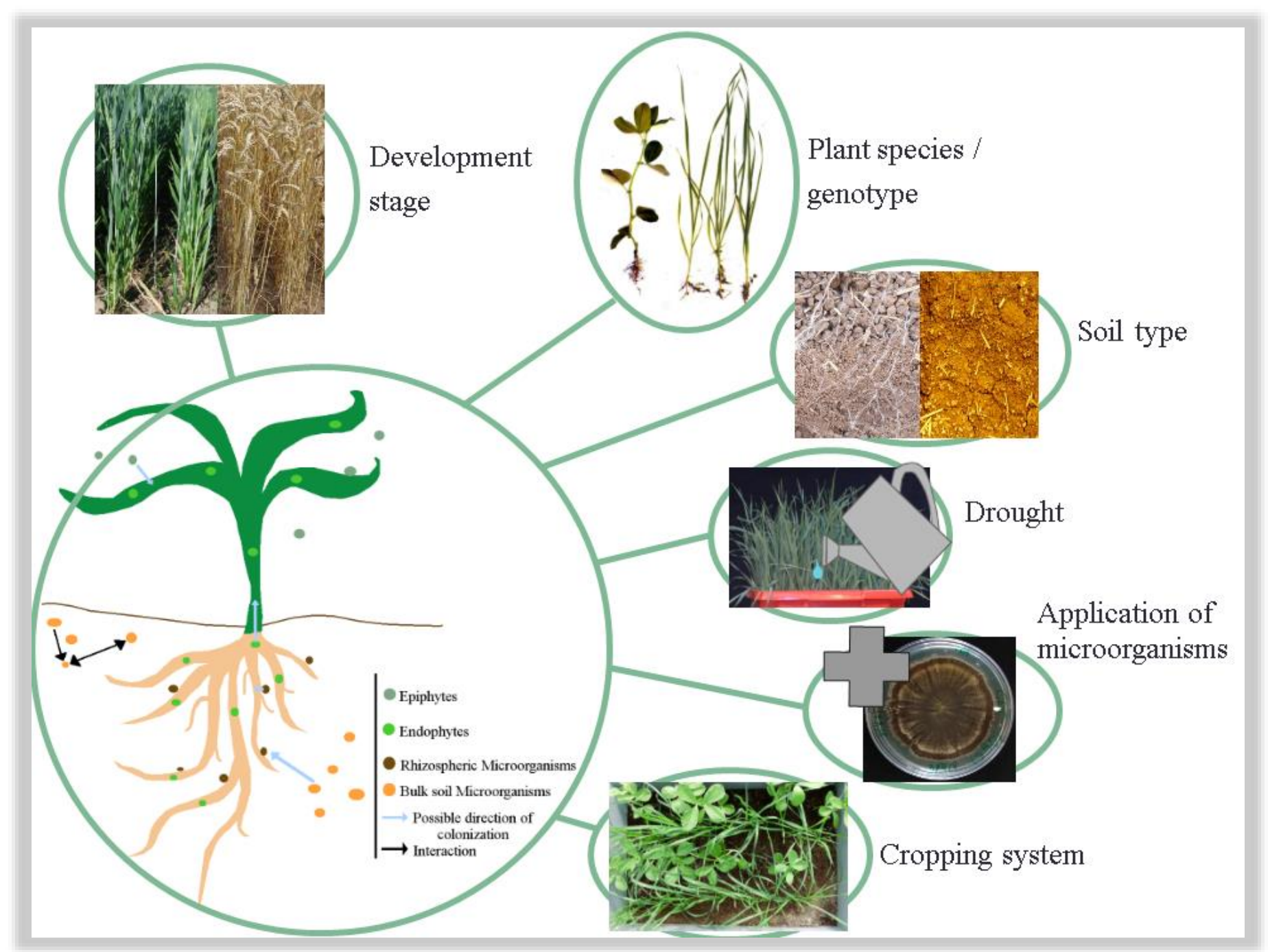

Figure 2. The habitats of plant-associated microorganisms and their determining factors. Blue arrows indicate possible directions of colonization by microorganisms such as recruitment from bulk soil. Black arrows indicate possible interactions between microorganisms.

\subsection{Investigation methods}

Less than $1 \%$ of microorganisms can be cultured under laboratory conditions (Amann, 1995). Furthermore, it has been shown that diversity is largely underestimated with isolation methods when comparing culture-dependent and culture-independent approaches (Kazerooni et al., 2017). In the last decades, next-generation sequencing methods (NGS) have provided important insights into the ecology, diversity and structure of microbial communities in different environments including the endosophere and rhizosphere (Edwards et al., 2014; Santos-Medellin et al., 2017; Wang et al., 2017). These technologies allow direct sequencing of 16S rRNA genes or internal transcribed spacer regions (ITS) which produce fast massive sequencing data that provides high level of taxonomic resolution (Hurd and Nelson, 2009; Prosser et al., 2010). As consequence, the number of studies using NGS increased. On the other hand, studies hightlight the importance of isolates to validate functions of 
microorganisms, which were predicted in sequenced genomes (Garcia, 2016; Levy et al., 2017). In this thesis, Illumina (Miseq) sequencing was used to investigate in plant microbiomes. In addition, we used cultivation-dependent methods to isolate different endophytic bacteria and to sequence their draft genomes.

\subsection{General study aims}

Beneficial plant-associated microorganisms can promote plant growth and health and thus are important in the sustainable agriculture. As consequence, it is of crucial interest to understand the factors determining microbial diversity and community structure (Figure 2). The main focus of this thesis was to investigate the effects of different cropping systems (monoculture versus intercropping) on microbial communities of winter wheat (Triticum aestivum L.) and winter faba bean (Vicia faba L.) and to determine if cropping system alters the effect of drought stress or inoculation with an entomopathogenic fungus on the plant microbiome. In addition, microorganisms in other plant species were studied (Figure 3).

Our main hypotheses were:

(1) Cropping systems (monoculture versus intercropping) influence microbial community composition and diversity.

(2) Plant related traits such as plant species, genotype, and compartment change responses of microbial communities towards cropping system.

(3) Abiotic (e.g. drought) and biotic factors (e.g. inoculation) influence the plant microbiome.

(4) Bacterial and fungal communities respond differently towards agricultural practices and environmental changes. 


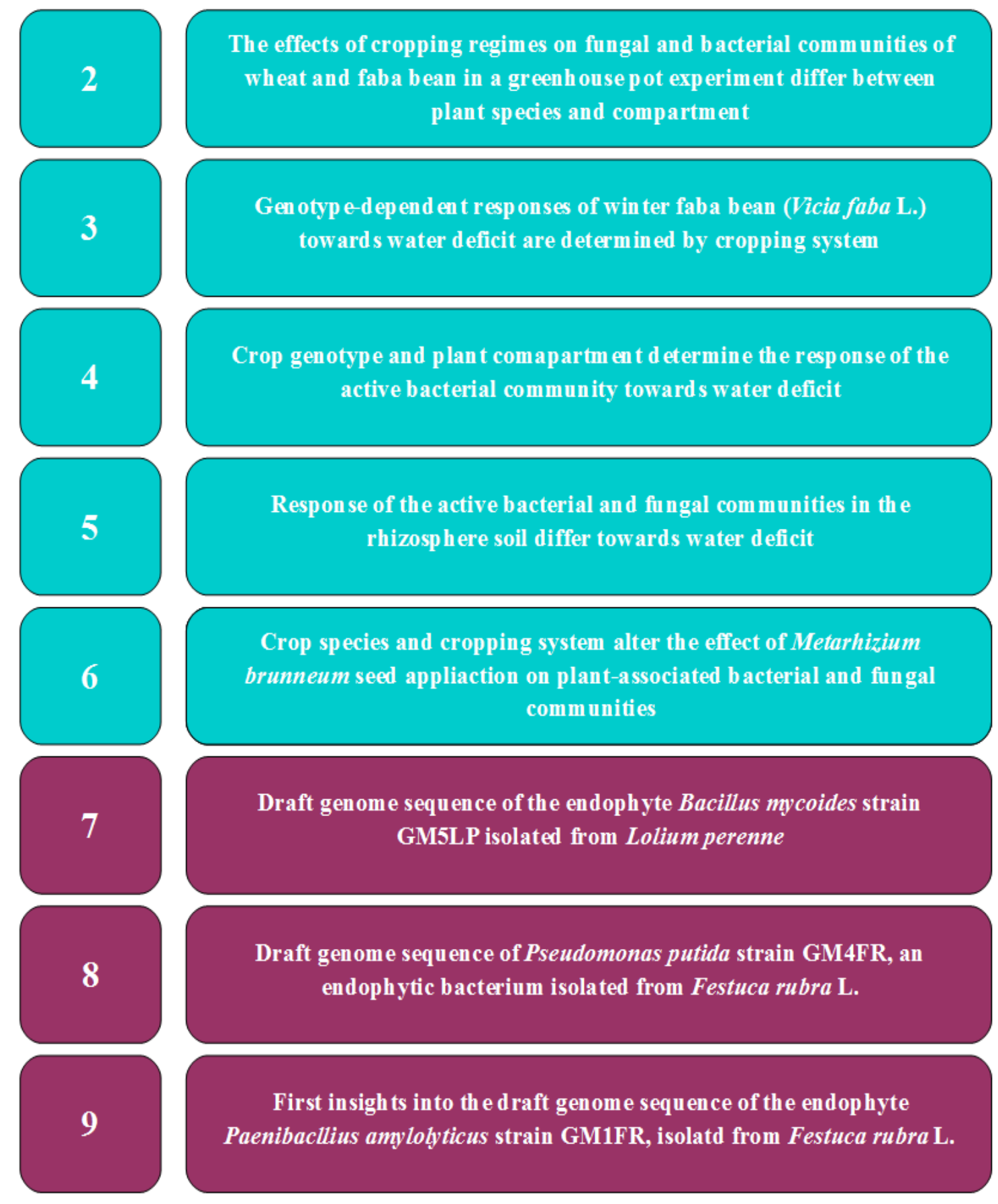

Figure 3. Overview about the studies presented in this thesis. All cropping system studies are highlighted cyan, non-cropping system studies in dark red. 


\subsection{References}

Ahkami AH, White III RA, Handakumbura PP, Jansson C. 2017. Rhizosphere engineering: Enhancing sustainable plant ecosystem productivity. Rhizosphere. Jun; 3: 233-243.

Ansell C. 2008. Pesticide Regulation in the EU and California. Prepared for the California-EU Regulatory Cooperation Project UC Berkeley. Webside: https://escholarship.org/uc/item/7h47100p

Amann RI, Ludwig W, Schleifer KH. 1995. PHYLOGENETIC IDENTIFICATION AND INSITU DETECTION OF INDIVIDUAL MICROBIAL-CELLS WITHOUT CULTIVATION. Microbiological Reviews. Mar;59:143-169.

Andreote FD, Silva M. 2017. Microbial communities associated with plants: learning from nature to apply it in agriculture. Current Opinion in Microbiology. Jun;37:29-34.

Baessler C, Klotz S. 2006. Effects of changes in agricultural land-use on landscape structure and arable weed vegetation over the last 50 years. Agriculture Ecosystems \& Environment. Jul;115:43-50.

Berendsen RL, Pieterse CMJ, Bakker P. 2012. The rhizosphere microbiome and plant health. Trends in Plant Science. Aug;17:478-486.

Berg G, Grube M, Schloter M, Smalla K. 2014. Unraveling the plant nnicrobiome: looking back and future perspectives. Frontiers in Microbiology. Jun;5.

Boudreau MA. 2013. Diseases in Intercropping Systems. Annual Review of Phytopathology, Vol 51.51:499-519.

Brooker RW, Bennett AE, Cong WF, Daniell TJ, George TS, Hallett PD, Hawes C, Iannetta PPM, Jones HG, Karley AJ, et al. 2015. Improving intercropping: a synthesis of research in agronomy, plant physiology and ecology. New Phytologist. Apr;206:107-117.

Carvalho FP. 2017. Pesticides, environment, and food safety. Food and Energy Security. May;6:48-60.

Coleman-Derr D, Tringe SG. 2014. Building the crops of tomorrow: advantages of symbiontbased approaches to improving abiotic stress tolerance. Frontiers in Microbiology. Jun;5.

Compant S, Clement C, Sessitsch A. 2010. Plant growth-promoting bacteria in the rhizo- and endosphere of plants: Their role, colonization, mechanisms involved and prospects for utilization. Soil Biology \& Biochemistry. May;42:669-678.

Dassen S, Cortois R, Martens H, de Hollander M, Kowalchuk GA, van der Putten WH, de Deyn GB. 2017. Differential responses of soil bacteria, fungi, archaea and protists to plant species richness and plant functional group identity. Molecular Ecology. Aug;26:4085-4098.

Davis JHC, Woolley JN. 1993. GENOTYPIC REQUIREMENT FOR INTERCROPPING. Field Crops Research. Sep;34:407-430.

Dawson W, Hor J, Egert M, van Kleunen M, Pester M. 2017. A Small Number of Lowabundance Bacteria Dominate Plant Species-specific Responses during Rhizosphere Colonization. Frontiers in Microbiology. May;8.

Dematheis F, Kurtz B, Vidal S, Smalla K. 2013. Multitrophic interactions among Western Corn Rootworm Glomus intraradices and microbial communities in the rhizosphere and endorhiza of maize. Frontiers in Microbiology. Dec;4.

Dupont AOC, Griffiths RI, Bell T, Bass D. 2016. Differences in soil micro-eukaryotic communities over soil $\mathrm{pH}$ gradients are strongly driven by parasites and saprotrophs. Environmental Microbiology. Jun;18:2010-2024. 
Edwards J, Johnson C, Santos-Medellin C, Lurie E, Podishetty NK, Bhatnagar S, Eisen JA, Sundaresan V. 2015. Structure, variation, and assembly of the root-associated microbiomes of rice. Proceedings of the National Academy of Sciences of the United States of America. Feb;112:E911-E920.

Eisenhauer N, Reich PB, Scheu S. 2012. Increasing plant diversity effects on productivity with time due to delayed soil biota effects on plants. Basic and Applied Ecology. Nov;13:571578.

Ellouze W, Taheri AE, Bainard LD, Yang C, Bazghaleh N, Navarro-Borrell A, Hanson K, Hamel C. 2014. Soil Fungal Resources in Annual Cropping Systems and Their Potential for Management. Biomed Research International.

Fletcher AL, Kirkegaard JA, Peoples MB, Robertson MJ, Whish J, Swan AD. 2016. Prospects to utilise intercrops and crop variety mixtures in mechanised, rain-fed, temperate cropping systems. Crop \& Pasture Science.67:1252-1267.

Fonseca-Garcia C, Coleman-Derr D, Garrido E, Visel A, Tringe SG, Partida-Martinez LP. 2016. The Cacti Microbiome: Interplay between Habitat-Filtering and Host-Specificity. Frontiers in Microbiology. Feb;7:16.

Fujita K, Ofosubudu KG, Ogata S. 1992. BIOLOGICAL NITROGEN-FIXATION IN MIXED LEGUME-CEREAL CROPPING SYSTEMS. Plant and Soil. Mar;141:155-175.

Gadhave KR, Devlin PF, Ebertz A, Ross A, Gange AC. 2018. Soil inoculation with Bacillus spp. modifies root endophytic bacterial diversity, evenness and community composition in a context-specific manner. Microbiology Ecology. Mar; 1-10.

Gagne-Bourque F, Mayer BF, Charron JB, Vali H, Bertrand A, Jabaji S. 2015. Accelerated Growth Rate and Increased Drought Stress Resilience of the Model Grass Brachypodium distachyon Colonized by Bacillus subtilis B26. Plos One. Jun;10.

Garcia SL. 2016. Mixed cultures as model communities: hunting for ubiquitous microorganisms, their partners, and interactions. Aquatic Microbial Ecology.77:79-85.

Gdanetz K, Trail F. 2017. The wheat microbiome under four management strategies, and potential for endophytes in disease protection. Phytobiomes.Oct;158-168.

Gu Y, Wei Z, Wang XQ, Friman VP, Huang JF, Wang XF, Mei XL, Xu YC, Shen QR, Jousset A. 2016. Pathogen invasion indirectly changes the composition of soil microbiome via shifts in root exudation profile. Biology and Fertility of Soils. Oct;52:997-1005.

Hardoim PR, van Overbeek LS, Berg G, Pirttila AM, Compant S, Campisano A, Doring M, Sessitsch A. 2015. The Hidden World within Plants: Ecological and Evolutionary Considerations for Defining Functioning of Microbial Endophytes. Microbiology and Molecular Biology Reviews. Sep;79:293-320.

Hardoim PR, van Overbeek LS, van Elsas JD. 2008. Properties of bacterial endophytes and their proposed role in plant growth. Trends in Microbiology. Oct;16:463-471.

Hauggaard-Nielsen H, Jensen ES. 2001. Evaluating pea and barley cultivars for complementarity in intercropping at different levels of soil $\mathrm{N}$ availability. Field Crops Research. Sep;72:185-196.

Hauggaard-Nielsen H, Jensen ES. 2005. Facilitative root interactions in intercrops. Plant and Soil. Jul;274:237-250.

Hinsinger P, Betencourt E, Bernard L, Brauman A, Plassard C, Shen JB, Tang XY, Zhang FS. 2011. P for Two, Sharing a Scarce Resource: Soil Phosphorus Acquisition in the Rhizosphere of Intercropped Species. Plant Physiology. Jul;156:1078-1086. 
Huang XF, Chaparro JM, Reardon KF, Zhang RF, Shen QR, Vivanco JM. 2014. Rhizosphere interactions: root exudates, microbes, and microbial communities. Botany-Botanique. Apr;92.

Hurd PJ, Nelson CJ. 2009. Advantages of next-generation sequencing versus the microarray in epigenetic research. Functional Genomics. May; 8:174-183.

Jaber LR, Vidal S. 2010. Fungal endophyte negative effects on herbivory are enhanced on intact plants and maintained in a subsequent generation. Ecological Entomology. Feb;35:2536.

Kaurin A, Mihelic R, Kastelec D, Grcman H, Bru D, Philippot L, Suhadolc M. 2018. Resilience of bacteria, archaea, fungi and N-cycling microbial guilds under plough and conservation tillage, to agricultural drought. Soil Biology \& Biochemistry. May;120:233-245.

Kazerooni EA, Maharachchikumbura SSN, Rethinasamy V, Al-Mahrouqi H, Al-Sadi AM. 2017. Fungal Diversity in Tomato Rhizosphere Soil under Conventional and Desert Farming Systems. Frontiers in Microbiology. Aug;8.

Keyser CA, Thorup-Kristensen K, Meyling NV. 2014. Metarhizium seed treatment mediates fungal dispersal via roots and induces infections in insects. Fungal Ecology. Oct;11:122-131.

Kleijn D, Baquero RA, Clough Y, Diaz M, De Esteban J, Fernandez F, Gabriel D, Herzog F, Holzschuh A, Johl R, et al. 2006. Mixed biodiversity benefits of agri-environment schemes in five European countries. Ecology Letters. Mar;9:243-254.

Le Cocq K, Gurr SJ, Hirsch PR, Mauchline TH. 2017. Exploitation of endophytes for sustainable agricultural intensification. Molecular Plant Pathology. Apr;18:469-473.

Levy A, Gonzalez IS, Mittelviefhaus M, Clingenpeel S, Paredes SH, Miao JM, Wang KR, Devescovi G, Stillman K, Monteiro F, et al. 2018. Genomic features of bacterial adaptation to plants. Nature Genetics. Jan;50:138-+.

Li S, Wu F. 2018. Diversity and co-occurance patterns of soil bacterial and fungal communities in seven intercropping systems. Frontiers in Microbiology. Jul; 9:1521.

Li ZG, Zu C, Wang C, Yang JF, Yu H, Wu HS. 2016. Different responses of rhizosphere and non-rhizosphere soil microbial communities to consecutive Piper nigrum L. monoculture. Scientific Reports. Oct; 6 .

Lithourgidis AS, Dordas CA, Damalas CA, Vlachostergios DN. 2011. Annual intercrops: an alternative pathway for sustainable agriculture. Australian Journal of Crop Science. Apr;5:396-410.

Matson PA, Parton WJ, Power AG, Swift MJ. 1997. Agricultural intensification and ecosystem properties. Science. Jul;277:504-509.

Nallanchakravarthula S, Mahmood S, Alstrom S, Finlay RD. 2014. Influence of Soil Type, Cultivar and Verticillium dahliae on the Structure of the Root and Rhizosphere Soil Fungal Microbiome of Strawberry. Plos One. Oct;9.

Naylor D, DeGraaf S, Purdom E, Coleman-Derr D. 2017. Drought and host selection influence bacterial community dynamics in the grass root microbiome. Isme Journal. Dec;11:2691-2704.

Prosser J, Jansson JK, Liu WT. 2010. Nucleic-acid-based characterization of community structure and function. In: Liu W-T, Jannson JK (eds). Environmental Molecular Microbiology. Caister Academic Press: Norfolk, 63-86.

Rathore R, Dowling DN, Forristal PD, Spink J, Cotter PD, Bulgarelli D, Germaine KJ. 2017. Crop Establishment Practices Are a Driver of the Plant Microbiota in Winter Oilseed Rape (Brassica napus). Frontiers in Microbiology. Aug;8. 
Rockstrom J, Williams J, Daily G, Noble A, Matthews N, Gordon L, Wetterstrand H, DeClerck F, Shah M, Steduto P, et al. 2017. Sustainable intensification of agriculture for human prosperity and global sustainability. Ambio. Feb;46:4-17.

Santos-Medellin C, Edwards J, Liechty Z, Nguyen B, Sundaresan V. 2017. Drought Stress Results in a Compartment-Specific Restructuring of the Rice Root-Associated Microbiomes. Mbio. Jul-Aug;8.

Schlemper TR, Leite MFA, Lucheta AR, Shimels M, Bouwmeester HJ, van Veen JA, Kuramae EE. 2017. Rhizobacterial community structure differences among sorghum cultivars in different growth stages and soils. Fems Microbiology Ecology. Aug;93.

Scholz R, Vater J, Budiharjo A, Wang ZY, He YQ, Dietel K, Schwecke T, Herfort S, Lasch P, Borriss R. 2014. Amylocyclicin, a Novel Circular Bacteriocin Produced by Bacillus amyloliquefaciens FZB42. Journal of Bacteriology. May;196:1842-1852.

Sheridan C, Depuydt P, De Ro M, Petit C, Van Gysegem E, Delaere P, Dixon M, Stasiak M, Aciksoz S, Frossard E, et al. 2017. Microbial Community Dynamics and Response to Plant Growth-Promoting Microorganisms in the Rhizosphere of Four Common Food Crops Cultivated in Hydroponics. Microbial Ecology. Feb;73:378-393.

Sloan SS, Lebeis SL. 2015. Exercising influence: distinct biotic interactions shape root microbiomes. Current Opinion in Plant Biology. Aug;26:32-36.

Song YN, Marschner P, Li L, Bao XG, Sun JH, Zhang FS. 2007. Community composition of ammonia-oxidizing bacteria in the rhizosphere of intercropped wheat (Triticum aestivum L.), maize (Zea mays L.), and faba bean (Vicia faba L.). Biology and Fertility of Soils. Dec;44:307-314.

Song YN, Zhang FS, Marschner P, Fan FL, Gao HM, Bao XG, Sun JH, Li L. 2007. Effect of intercropping on crop yield and chemical and microbiological properties in rhizosphere of wheat (Triticum aestivum L.), maize (Zea mays L.), and faba bean (Vicia faba L.). Biology and Fertility of Soils. Jun;43:565-574.

Stoate C, Boatman ND, Borralho RJ, Carvalho CR, de Snoo GR, Eden P. 2001. Ecological impacts of arable intensification in Europe. Journal of Environmental Management. Dec;63:337-365.

Taheri AE, Hamel C, Gan Y. 2016. Cropping practices impact fungal endophytes and pathogens in durum wheat roots. Applied Soil Ecology. Apr; 100: 104-111.

Turner TR, Ramakrishnan K, Walshaw J, Heavens D, Alston M, Swarbreck D, Osbourn A, Grant A, Poole PS. 2013. Comparative metatranscriptomics reveals kingdom level changes in the rhizosphere microbiome of plants. Isme Journal. Dec;7:2248-2258.

van der Heijden MGA, Hartmann M. 2016. Networking in the Plant Microbiome. Plos Biology. Feb;14.

Vandermeer JH. 1992. The ecology of intercropping. New York, NY: Cambridge University Press.

Vimal SR, Singh JS, Arora NK, Singh S. 2017. Soil-Plant-Microbe Interactions in Stressed Agriculture Management: A Review. Pedosphere. Apr;27:177-192.

Vorholt JA. 2012. Microbial life in the phyllosphere. Nature Reviews Microbiology. Dec;10:828-840.

Wagner MR, Lundberg DS, del Rio TG, Tringe SG, Dangl JL, Mitchell-Olds T. 2016. Host genotype and age shape the leaf and root microbiomes of a wild perennial plant. Nature Communications. Jul;7. 
Wang GH, Xu YX, Jin J, Liu JD, Zhang QY, Liu XB. 2009. Effect of soil type and soybean genotype on fungal community in soybean rhizosphere during reproductive growth stages. Plant and Soil. Apr;317:135-144.

Wang Y, Marschner P, Zhang FS. 2012. Phosphorus pools and other soil properties in the rhizosphere of wheat and legumes growing in three soils in monoculture or as a mixture of wheat and legume. Plant and Soil. May;354:283-298.

Wang ZT, Li T, Wen XX, Liu Y, Han J, Liao YC, DeBruyn JM. 2017. Fungal Communities in Rhizosphere Soil under Conservation Tillage Shift in Responseto Plant Growth. Frontiers in Microbiology. Jul;8.

Wemheuer F, Kaiser K, Karlovsky P, Daniel R, Vidal S, Wemheuer B. 2017. Bacterial endophyte communities of three agricultural important grass species differ in their response towards management regimes. Scientific Reports. Jan;7.

Xu L, Naylor D, Dong ZB, Simmons T, Pierroz G, Hixson KK, Kim YM, Zink EM, Engbrecht KM, Wang Y, et al. 2018. Drought delays development of the sorghum root microbiome and enriches for monoderm bacteria. Proceedings of the National Academy of Sciences of the United States of America. May;115:E4284-E4293.

Yang ZP, Yang WP, Li SC, Hao JM, Su ZF, Sun M, Gao ZQ, Zhang CL. 2016. Variation of Bacterial Community Diversity in Rhizosphere Soil of Sole-Cropped versus Intercropped Wheat Field after Harvest. Plos One. Mar;11.

Zhang NN, Sun YM, Li L, Wang ET, Chen WX, Yuan HL. 2010. Effects of intercropping and Rhizobium inoculation on yield and rhizosphere bacterial community of faba bean (Vicia faba L.). Biology and Fertility of Soils. Aug;46:625-639.

Zhang NN, Sun YM, Wang ET, Yang JS, Yuan HL, Scow KM. 2015. Effects of intercropping and Rhizobial inoculation on the ammonia-oxidizing microorganisms in rhizospheres of maize and faba bean plants. Applied Soil Ecology. Jan;85:76-85.

Zhang YZ, Wang ET, Li M, Li QQ, Zhang YM, Zhao SJ, Jia XL, Zhang LH, Chen WF, Chen WX. 2011. Effects of rhizobial inoculation, cropping systems and growth stages on endophytic bacterial community of soybean roots. Plant and Soil. Oct;347:147-161. 


\section{Chapter 2}

The effects of cropping regimes on fungal and bacterial communities of wheat and faba bean in a greenhouse pot experiment differ between plant species and compartment

Sandra Granzow, Kristin Kaiser, Bernd Wemheuer, Birgit Pfeiffer, Rolf Daniel, Stefan Vidal, Franziska Wemheuer

Published in Frontiers Microbiology 8. 


\section{The Effects of Cropping Regimes on Fungal and Bacterial Communities of Wheat and Faba Bean in a Greenhouse Pot Experiment Differ between Plant Species and Compartment}

OPEN ACCESS Klaus Schlaeppi Agroscope, Switzerland

Reviewed by: Sarah Lydia Lebeis,

The University of Tennessee, Knoxville,

United States

Derek Lundberg.

Max Planck Institute for Developmental Biology, Germany

-Correspondence:

Franziska Wermhever

fwemheu@gwdg.de

${ }^{t}$ These authors have contributed equally to this work.

Specialty section: This article was submitted to Plant Microbe Interactions, a section of the journal Frontiers in Microbiology

Received: 26 June 2016 Accepted: 03 May 2017 Published: 29 May 2017

Citation:

Granzow S, Kaiser K. Wemheuer B. Pfeiffer B, Daniel R, Vidal S and Wemhever $F$ (2017) The Effects of Cropping Regimes on Fungal and Bacterial Communities of Wheat and Faba Bean in a Greenhouse Pot Experiment Differ between Plant Species and Compartment.

Front. Microbiol. 8:902. dor: 10.3389/fmicb. 2017.00902
Sandra Granzow ${ }^{1 t}$, Kristin Kaiser ${ }^{2 \dagger}$, Bernd Wemheuer ${ }^{2}$, Birgit Pfeiffer ${ }^{3}$, Rolf Daniel ${ }^{2}$, Stefan Vidal' ${ }^{\prime}$ and Franziska Wemheuer ${ }^{1 *}$

' Section of Agricultural Entomology, Department of Crop Sciences, University of Göttingen, Göttingen, Germary, ${ }^{2}$ Genomic and Applied Microbiology and Göttingen Genomics Laboratory, Institute of Microbiology and Genetics, University of Göttingen, Göttingen, Germany, ${ }^{3}$ Plant Nutrition and Crop Physiology, Department of Crop Sciences, University of Göttingen, Göttingen, Germany

Many bacteria and fungi in the plant rhizosphere and endosphere are beneficial to plant nutrient acquisition, health, and growth. Although playing essential roles in ecosystem functioning, our knowledge about the effects of multiple cropping regimes on the plant microbiome and their interactions is still limited. Here, we designed a pot experiment simulating different cropping regimes. For this purpose, wheat and faba bean plants were grown under controlled greenhouse conditions in monocultures and in two intercropping regimes: row and mixed intercropping. Bacterial and fungal communities in bulk and rhizosphere soils as well as in the roots and aerial plant parts were analyzed using large-scale metabarcoding. We detected differences in microbial richness and diversity between the cropping regimes. Generally, observed effects were attributed to differences between mixed and row intercropping or mixed intercropping and monoculture. Bacterial and fungal diversity were significantly higher in bulk soil samples of wheat and faba bean grown in mixed compared to row intercropping. Moreover, microbial communities varied between crop species and plant compartments resulting in different responses of these communities toward cropping regimes. Leaf endophytes were not affected by cropping regime but bacterial and fungal community structures in bulk and rhizosphere soil as well as fungal community structures in roots. We further recorded highly complex changes in microbial interactions. The number of negative inter-domain correlations between fungi and bacteria decreased in bulk and rhizosphere soil in intercropping regimes compared to monocultures due to beneficial effects. In addition, we observed plant species-dependent differences indicating that intra- and interspecific competition between plants had different effects on the plant species and thus on their associated microbial communities. To our knowledge, this is the first study investigating microbial communities in different plant compartments with respect to multiple cropping regimes 
using large-scale metabarcoding. Although a simple design simulating different cropping regimes was used, obtained results contribute to the understanding how cropping regimes affect bacterial and fungal communities and their interactions in different plant compartments. Nonetheless, we need field experiments to properly quantify observed effects in natural ecosystems.

Keywords: microbial diversity, multiple cropping vs. monoculture, microbial interactions, indicator species, co-occurrence networks

\section{INTRODUCTION}

In the last decades, multiple or mixed cropping systems have received more attention due to their potential for a sustainable intensification of agriculture (Vandermeer, 1992). They provide beneficial ecological and economical services such as reduced plant pathogen damage (Winter et al., 2014). In addition, multiple cropping systems enhance plant productivity by improving the exploitation of available resources (Zhang and Li, 2003; Hauggaard-Nielsen and Jensen, 2005). Previously, it was suggested that (positive) interspecific interactions in the rhizosphere (Li et al., 1999; Zhang and Li, 2003) or changes in microbial communities and chemical soil properties may also be responsible for increased yields (Song et al., 2007b).

Bacteria and fungi play essential roles in biogeochemical cycling of matter and thus ecosystem functioning (Ellouze et al., 2014; van der Heijden and Hartmann, 2016). Many of them are beneficial to plant nutrient acquisition, health, and growth in the plant's rhizosphere and endosphere (Lugtenberg and Kamilova, 2009; Philippot et al., 2013). These microorganisms may also alleviate abiotic stress conditions of their host plants (Malinowski and Belesky, 2000; de Zelicourt et al., 2013). In addition, they can enhance the resistance of their host plant against biotic stressors such as herbivores or plant pathogens (Siddiqui and Shaukat, 2003; Vidal and Jaber, 2015).

Previous studies have addressed the role of cropping systems on microbial communities in endosphere and rhizosphere soil (e.g., Song et al., 2007a; Zhang et al., 2011, 2015). Song et al. (2007a) analyzed ammonia-oxidizing bacteria in the rhizosphere of intercropped wheat, maize, and faba bean using denaturing gradient gel electrophoresis (DGGE) and reported differences in the bacterial community structure when comparing intercropping systems and monocultures. However, most research focused on microorganisms in the rhizosphere and/ or on ammonia-oxidizing bacteria only (Song et al., 2007a; Zhang et al., 2015; Li et al., 2016). So far, entire bacterial and fungal communities and their interactions in different plant compartments of two important crop species under different cropping regimes have not been studied simultaneously using large-scale metabarcoding.

Hence, we investigated the influence of cropping systems on plant-associated fungal and bacterial communities using metabarcoding. The current study is embedded in the IMPAC ${ }^{3}$ project ("Novel genotypes for mixed cropping allow for improved sustainable land use across arable land, grassland and woodland"). To assess structural changes of the studied microbial communities with respect to cropping system or plant species, a greenhouse pot experiment was designed simulating different cropping regimes under controlled conditions. For that purpose, the two crop species winter wheat (Triticum aestivum L.) and winter faba bean (Vicia faba L.) were grown in monoculture and in two different intercropping regimes, i.e., row and mixed intercropping. We used row and mixed intercropping as previous studies have shown that various intercropping regimes influenced facilitative and competitive interactions between intercropped plant species in a different manner due to differences in root systems (Li et al., 1999; Mariotti et al., 2009), which might affect the plant microbiome as well Bacterial and fungal communities in bulk and rhizosphere soil as well as in aerial plant parts and root endosphere were examined using Illumina (MiSeq) sequencing targeting the bacterial $16 \mathrm{~S}$ rRNA gene and the fungal internal transcribed spacer (ITS) region, respectively. Our major aims were as follows: (i) to assess the effect of different cropping regimes on microbial diversity and community structures, (ii) to examine whether this effect differs between plant species and plant compartments as microbial communities most properly exhibit plant species-specific and plant compartment-specific structures, and (iii) to determine whether intercropping regimes decrease the number of negative interactions within the microbial community. Obtained results will further deepen our understanding of how cropping regimes influence the plant microbiome.

\section{MATERIALS AND METHODS}

\section{Experimental Design}

To examine the influence of cropping systems on the entire fungal and bacterial community in soil and endosphere, we developed an experimental system to simulate monoculture and two intercropping settings in agriculture. For this purpose, the two crop species winter faba bean (genotype: Hiverna) and winter wheat (genotype: Hybery) were planted in monoculture or as mixture in polypropylene containers (Semadeni, Eurobehälter, LogiLine ${ }^{\circledR}$ SGL Boden, $\left.600 \times 400 \times 212 \mathrm{~mm}\right)$ in summer 2015. Each container contained $25 \%$ sand and $75 \%$ non-sterile commercial plant substrate (Fruhstorfer Erde Typ T25; N: 200$300 \mathrm{mg} \mathrm{L}^{-1}, \mathrm{P}_{2} \mathrm{O}_{5}$ : 200-300 $\mathrm{mg} \mathrm{L}^{-1}$; Hawita Gruppe $\mathrm{GmbH}$ Vechta, Germany). This commercial plant substrate is a peaty soil with a $\mathrm{pH}\left(\mathrm{CaCl}_{2}\right)$ of 5.5-6.5. We used this homogenous growth substrate for the experiment to maintain constant abiotic soil conditions across the different cropping regimes. The soil was not autoclaved or steamed. In addition, the seeds were not surface-sterilized prior to planting. 
For monocultures, 20 faba bean (FBM) or 80 wheat (WM) plants per container were sawn in rows (Figure 1). In multiple cropping systems, 40 wheat and 10 faba bean plants per container were grown either in distinct rows (row intercropping; RI) or without any distinct row arrangement (mixed intercropping; MI) as defined by Andrews and Kassam (1976). We distinguished between cropping systems (monoculture vs. multiple cropping systems) and cropping regimes (WM, FBM, MI, and RI). Each cropping regime was replicated five times in a randomized block design. All plants were cultured under normal diel light cycles in a semi-closed greenhouse and irrigated daily for a growing period of 4 weeks. We chose controlled greenhouse conditions to reduce the entrance of pests and the variation from other environmental factors. No fertilizer treatments were applied to increase nutrient-limitation as well as intra- and interspecies interactions between the plants. Fungal and bacterial communities in four compartments of healthy plants were studied: the rhizosphere and bulk soil as well as the root and aerial (here regarded as leaf) endosphere (Figure 1).

\section{Soil Sampling and Edaphic Parameters}

After a growing period of 4 weeks, we sampled the rhizosphere soil, defined as soil tightly adhering to the roots, and the bulk soil, defined as root-free soil around the crops. In the two intercropping treatments, bulk soil samples of the two crop species were pooled for each container resulting in 20 bulk soil samples (Table 1). The roots were gently shaken to remove the non-rhizosphere soil. Rhizosphere soil, tightly attached to root surface, was collected by carefully brushing the roots. Ten subsamples were collected for each container, and obtained rhizosphere soil samples were thoroughly mixed in order to obtain one single sample. A total of 30 rhizosphere soil samples was collected. All soil samples were frozen and stored at $-20^{\circ} \mathrm{C}$.

For determination of soil properties, subsamples were dried at $60^{\circ} \mathrm{C}$ for 2 days and sieved to $<2 \mathrm{~mm}$. Soil organic carbon $(\mathrm{C})$ and total nitrogen $(\mathrm{N})$ concentrations from all dried subsamples were determined using a LECO TruSpec $\mathrm{CN}$ analyser (Leco Corp., St. Joseph, MI). The gravimetric soil water content (\%) of all soil samples was calculated from oven-dried subsamples. Soil pHvalues were measured as follows: $2 \mathrm{~g}$ soil of each container was

\begin{tabular}{|c|c|c|c|c|c|}
\hline & Bulk soil & Rhizosphere & Roots & Leaves & Plants/treatment \\
\hline \multicolumn{6}{|c|}{ COMPARTMENTS } \\
\hline WM & $5(5 / 5)$ & $5(5 / 5)$ & $5(5 / 4)$ & $5(5 / 5)$ & 50 \\
\hline FBM & $5(5 / 5)$ & $5(5 / 5)$ & $5(4 / 4)$ & $5(3 / 2)$ & 25 \\
\hline W_MI & $5^{*}(5 / 5)$ & $5(4 / 4)$ & $5(5 / 5)$ & $5(5 / 5)$ & 50 \\
\hline FB_MI & $5^{*}(5 / 5)$ & $5(5 / 5)$ & $5(5 / 5)$ & $5(2 / 3)$ & 25 \\
\hline W_RI & $5^{*}(5 / 5)$ & $5(5 / 5)$ & $5(5 / 5)$ & $5(5 / 5)$ & 50 \\
\hline FB_RI & $5^{*}(5 / 5)$ & $5(5 / 5)$ & $5(5 / 3)$ & $5(5 / 5)$ & 25 \\
\hline Total & 20 & 30 & 30 & 30 & $150(\mathrm{M}) .75(\mathrm{FB})$ \\
\hline
\end{tabular}

In total, 150 wheat and 75 faba bean plants were collected. "Bulk soll samples of both plants in the intercropping regimes were pooled prior analysis. Numbers in brackets refer to the number of samples left after removal of samples with too low sequencing numbers. The first number nefers to bacteria, the second to fungi. W wheat: FB, taba bean: FBM, taba bean $n$ monoculture: WM. whast n monoculture; FB MI, haba, bean samples tom mixed intencropping: FB_Al, faba bean samples from row intercropping; W_MI, wheat samples from mixed intercropping; W_Ril, wheat samples from row intercropping; $M$, samples from mixed intercropping; Fl, samples from row intercropping.

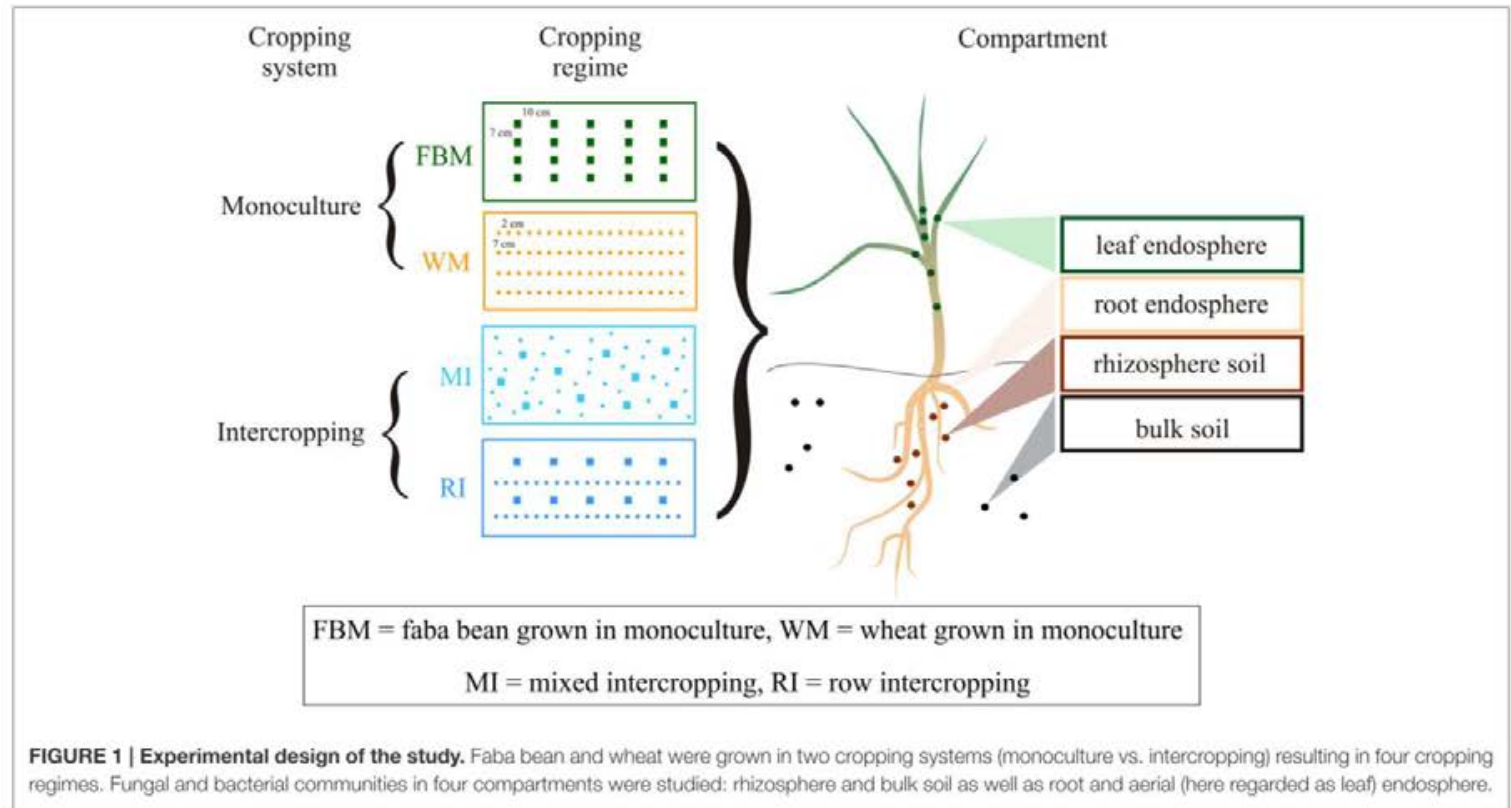


mixed with $5 \mathrm{~mL}$ PCR grade water. After incubation for $24 \mathrm{~h}$, $\mathrm{pH}_{\text {Water }}$ was measured in the supernatant with a glass electrode. Subsequently, $0.37 \mathrm{~g} \mathrm{KCl}$ was added and $\mathrm{pH}_{\mathrm{KCl}}$ was measured. Details on edaphic parameters are provided in Table S1.

\section{Sampling and Plant Growth Characteristics} Above- as well as belowground plant material of the two crop species were harvested separately for each container at a $\mathrm{BBCH}$ of 14-16 (wheat) or 15-18 (faba bean). The BBCH-scale describes the developmental stages of Mono- and Dicotyledonous weed species (Hess et al., 1997). Aboveground (shoots, leaves) and root biomass for each crop species and each container were measured (Table S2). In addition, the heights of 10 faba bean and 20 wheat plants in intercropping regimes and 20 plants of monocultured faba bean and wheat plants were measured. For determination of water content in aerial plant parts, 10 wheat and five faba bean plants without roots per container were weighted and subsequently oven-dried at $60^{\circ} \mathrm{C}$ for $48 \mathrm{~h}$ and re-weighted (Table S2). Ten wheat and five bean plants, which did not show any obvious disease symptoms (Figure 2), were randomly selected from each container for further molecular analysis. In total, 75 faba bean and 150 wheat plants were collected. Plant material derived from the same container and plant species was pooled prior to surface sterilization. In total, 30 leaf and 30 root samples were obtained (for details see Table 1)

\section{Surface Sterilization of Plant Material}

Aerial plant parts (shoots and leaves) of 30 the samples were surface-sterilized by serial washing in $70 \%$ ethanol for $1 \mathrm{~min}$, $2 \%$ sodium hypochlorite for $30 \mathrm{~s}$ and $70 \%$ ethanol for $1 \mathrm{~min}$, followed by two times immersion in sterile, distilled water for $30 \mathrm{~s}$ and once in sterile, diethylpyrocarbonate (DEPC)-treated water. Plant roots were washed with tap water to remove soil. Surface sterilization of roots was performed according to $\mathrm{Li}$ et al. (2010), with slight modifications. In this study, $2 \%$ sodium

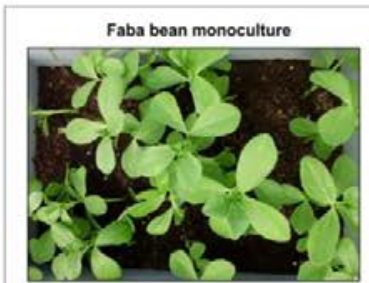

Mixed intercropping

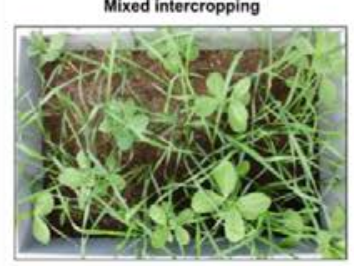

FIGURE 2 | Plants of the four cropping regimes. Photos were taken 3 days before harvesting. hypochlorite and sterile DEPC-treated water were used. To confirm the success of the disinfection procedure, two methods were performed as described previously (Wemheuer et al., 2016). In brief, aliquots of the water used in the final wash step were plated on common laboratory media plates. The plates were incubated in the dark at $25^{\circ} \mathrm{C}$ for at least 1 week. No growth of microorganisms was observed. In addition, water from the same aliquots was subjected to PCR targeting the bacterial $16 \mathrm{~S}$ rRNA gene and ITS region of fungal rDNA. No PCR product was detected. These results confirmed that the surface sterilization was successful in eliminating cultivable as well as non-cultivable epiphytic bacteria and fungi as well as potential DNA traces from the plant surfaces. Surface-sterilized plant material was ground to a fine powder in liquid nitrogen using an autoclaved mortar and pestle. Aliquots of the obtained powder were stored at $-20^{\circ} \mathrm{C}$ until DNA extraction.

\section{Extraction of Total Community DNA}

Total DNA of aerial plant parts and roots was extracted employing the peqGOLD Plant DNA Mini kit (Peqlab, Erlangen, Germany) according to the manufacturer's instructions with two modifications as described previously (Wemheuer et al., 2016). Total environmental DNA of rhizosphere as well as bulk soil samples was extracted employing the PowerSoil ${ }^{(\mathbb{B})}$ DNA Isolation kit (MoBio Laboratories, Inc., Carlsbad, USA) according to the manufacturer's protocol. DNA concentration of DNA extracts was quantified using a NanoDrop ND-1000 spectrophotometer (NanoDrop Technologies, Wilmington, DE, USA). In total, DNA of 110 samples was subjected to PCR targeting the bacterial $16 \mathrm{~S}$ rRNA gene and the fungal ITS region.

\section{Amplification of the 16S rRNA Gene}

Bacterial endophyte and soil communities were assessed by a nested PCR approach targeting the $16 \mathrm{~S}$ rRNA gene. For details of the first PCR mixture and the thermal cycling scheme see Wemheuer et al. (2016). In brief, the primers $799 \mathrm{f}\left(5^{\prime}\right.$ AACMGGATTAGATACCCKG-3') (Chelius and Triplett, 2001) and 1492R (5'-GCYTACCTTGTTACGACTT-3') (Lane, 1991) were used in the first PCR to suppress co-amplification of chloroplast-derived $16 \mathrm{~S}$ rRNA genes (Chelius and Triplett, 2001). PCR amplification resulted in two PCR products: a bacterial product of approximately $735 \mathrm{bp}$ and a mitochondrial product with approximately $1.1 \mathrm{kbp}$. Genomic DNA of Bacillus licheniformis DSM13 was used as template in the positive control for the bacterial product. Obtained PCR products were subjected to nested PCR.

The V6-V8 region of the 16S rRNA gene was amplified with the primers $968 \mathrm{~F}$ and 1401R (Nübel et al., 1996) containing MiSeq adaptors (underlined) (MiSeq-968F $5^{\prime}$ TCGTCGGCAGCGTCAGATGTGTATAAGAGACAGAACGC GAAGAACCTTAC-3'; MiSeq- 1401R 5' -GTCTCGTGGGCTCG GAGATGTGTATAAGAGACAGCGGTGTGTACAAGACCC-

$\left.3^{\prime}\right)$. The PCR mixture $(25 \mu \mathrm{l})$ contained $5 \mu \mathrm{l}$ of 5 -fold Phusion HF buffer, $200 \mu \mathrm{M}$ of each of the four deoxynucleoside triphosphates, $4 \mu \mathrm{M}$ of each primer, $1 \mathrm{U}$ of Phusion high fidelity DNA polymerase (Thermo Scientific, Waltham, MA, USA) and approximately $50 \mathrm{ng}$ of the bacterial product of the first 
PCR as template. Negative controls were performed using the reaction mixture without template. The following thermal cycling scheme was used: initial denaturation at $98^{\circ} \mathrm{C}$ for $30 \mathrm{~s}$, 30 cycles of denaturation at $98^{\circ} \mathrm{C}$ for $15 \mathrm{~s}$, annealing at $53^{\circ} \mathrm{C}$ for $30 \mathrm{~s}$, followed by extension at $72^{\circ} \mathrm{C}$ for $30 \mathrm{~s}$. The final extension was carried out at $72^{\circ} \mathrm{C}$ for $2 \mathrm{~min}$. Three independent PCRs were performed per sample. Obtained PCR products per sample were controlled for appropriate size, pooled in equal amounts, and purified using the peqGOLD Gel Extraction kit (Peqlab). Quantification of the PCR products was performed using the Quant-iT dsDNA HS assay kit and a Qubit fluorometer (Thermo Scientific) as recommended by the manufacturer. Purified PCR products were barcoded using the Nextera XTIndex kit (Illumina, San Diego, USA) and the Kapa HIFI Hot Start polymerase (Kapa Biosystems, Wilmington, USA). The Göttingen Genomics Laboratory determined the sequences of the partial 16S rRNA genes employing the MiSeq Sequencing platform and the MiSeq Reagent Kit v3 $(2 \times 300$ cycles $)$ as recommended by the manufacturer (Illumina). All bacterial samples were sequenced in one single MiSeq run.

\section{Amplification of the ITS Region}

The fungal communities in soil and endosphere were assessed by a nested PCR approach targeting the ITS region as described in Wemheuer and Wemheuer (2017). In the first PCR, the primers ITS1-F_KYO2 (5'-TAGAGGAAGTAAAAGTCGTAA-3') (Toju et al., 2012) and ITS4 (5'- TCCTCCGCTTATTGATATGC- $\left.3^{\prime}\right)$ (White et al., 1990) were used to suppress co-amplification of plant-derived ITS regions. The PCR mixture $(25 \mu \mathrm{l})$ contained: $5 \mu \mathrm{l}$ of 5 -fold Phusion GC buffer, $200 \mu \mathrm{M}$ of each of the four deoxynucleoside triphosphates, $4 \mu \mathrm{M}$ of each primer, $5 \%$ DMSO, $25 \mathrm{mM} \mathrm{MgCl}_{2}, 0.5 \mathrm{U}$ of Phusion High Fidelity DNA polymerase (Thermo Scientific) and approximately $10 \mathrm{ng}$ DNA sample as template. Negative controls were performed using the reaction mixture without template. The following thermal cycle scheme was utilized: initial denaturation at $98^{\circ} \mathrm{C}$ for 30 s followed by 6 cycles of denaturation at $98^{\circ} \mathrm{C}$ for $15 \mathrm{~s}$, annealing at $53^{\circ} \mathrm{C}$ for $30 \mathrm{~s}$ decreasing $0.5^{\circ} \mathrm{C}$ in each cycle, followed by extension at $72^{\circ} \mathrm{C}$ for $30 \mathrm{~s}$ and 29 cycles of denaturation at $98^{\circ} \mathrm{C}$ for $15 \mathrm{~s}$, annealing at $50^{\circ} \mathrm{C}$ for $30 \mathrm{~s}$, followed by extension at $72^{\circ} \mathrm{C}$ for $30 \mathrm{~s}$. The final extension was carried out at $72^{\circ} \mathrm{C}$ for $2 \mathrm{~min}$. Obtained PCR products were subjected to nested PCR.

The ITS2 region was subsequently amplified as described for the first PCR using approximately $50 \mathrm{ng}$ product of the first PCR and the primers ITS3_KYO2 (Toju et al., 2012) and ITS4 (White et al., 1990) containing the MiSeq adaptors (underlined): MiSeq-ITS3_KYO2 (5'TCGTCGGCAGCGTCAGATGTGTATAAGAGACAGGATGAA GAACGYAGYRAA- $3^{\prime}$ ) and MiSeq-ITS4 (5'-GTCTCGTGGG CTCGGAGATGTGTATAAGAGACAGTCCTCCGCTTATTGA TATGC- $\left.3^{\prime}\right)$. Purification and quantification of obtained PCR products were performed as described for the bacterial PCR products. Three independent PCRs were performed per sample and obtained PCR products were pooled in equal amounts. Purified PCR products were barcoded using the Nextera XTIndex kit (Illumina) and the Kapa HIFI Hot Start polymerase (Kapa Biosystems). The Göttingen Genomics Laboratory determined the sequences of the ITS2 region employing the MiSeq Sequencing platform and the MiSeq Reagent Kit v3 $(2 \times$ 300 cycles) as recommended by the manufacturer (Illumina). All fungal samples were sequenced in one single MiSeq run.

\section{Processing of Bacterial and Fungal Datasets}

The Trimmomatic version 0.32 (Bolger et al., 2014) was initially used to truncate low quality reads if quality dropped below 20 in a sliding window of $10 \mathrm{bp}$. Datasets were subsequently processed with Usearch version 8.0.1623 (Edgar, 2010) as described in Wemheuer and Wemheuer (2017). In brief, pairedend reads were merged and quality-filtered. Filtering included the removal of low quality reads (maximum number of expected errors $>1$ and more than 1 ambitious base, respectively) and those shorter than $200 \mathrm{bp}$. Processed sequences of all samples were joined and clustered in operational taxonomic units (OTUs) at $3 \%$ genetic divergence using the UPARSE algorithm implemented in Usearch. A de novo chimera removal was included in the clustering step. All OTUs consisting of one single sequence (singletons) were removed. Afterwards, remaining chimeric sequences were removed using the Uchime algorithm in reference mode with the most recent RDP training set (version 15) as reference dataset (Cole et al., 2009) for bacteria and the most recent Uchime reference data (version 7.0) obtained from the UNITE database (Kôljalg et al., 2013) for fungi, respectively. Afterwards, OTU sequences were taxonomically classified using QIIME (Caporaso et al., 2010) by BLAST alignment against the SILVA database (SILVA SSURef $128 \mathrm{NR}$ ) and the QIIME release of the UNITE database (version 7.1; August 2016), respectively. All non-bacterial or non-fungal OTUs were removed based on their taxonomic classification in the respective database. Subsequently, processed sequences were mapped on OTU sequences to calculate the distribution and abundance of each OTU in every sample. Final OTUs tables for bacteria and fungi are provided as Tables S3, S4, respectively. Only OTUs occurring in more than two samples were considered for further statistical analysis.

\section{Data Analysis}

All data analyses were conducted in $\mathrm{R}$ version 3.3.1 ( $\mathrm{R}$ Core Team, 2016). R code used for statistical analysis is provided as Supplementary Data Sheet 1 . Differences were considered as statistically significant with $P \leq 0.05$ and as marginally significant with $P \leq 0.1$. All bacterial and fungal samples with $>276$ bacterial and $>20$ fungal sequences, respectively, were removed prior to statistical data analysis.

Alpha diversity indices (Richness, Shannon index of diversity, effective number of species, and Michaelis Menten Fit) were calculated in the vegan package version 2.4 (Oksanen et al., 2016) and the drc package (Ritz and Streibig, 2005). In brief, OTU tables were rarefied using the rrarefy function to 276 bacterial and 20 fungal sequences. Richness and diversity were calculated using the specnumber and diversity function, respectively. The effective number of species was calculated from the diversity according to Jost (2006). The Michaelis-Menten Fit was calculated as described previously (Wemheuer et al., 2012). All alpha diversity 
indices were calculated 10 times. The average from each iteration was used for further statistical analysis. Final tables containing bacterial and fungal richness and diversity are provided as Tables S5 and S6, respectively.

Differences in richness and diversity as well as measured edaphic and plant properties between the cropping regimes were tested by Kruskal-Wallis test, respectively. We analyzed the effect of cropping regimes on diversity and richness of fungi and bacteria in all investigated compartments separately to avoid spatial pseudoreplication. Differences between single treatments were tested by pairwise Wilcoxon test without $P$-values correction. To analyze possible effects of plant compartment on richness or diversity, a repeated measures ANOVA (Crawley, 2007) was conducted as communities of different parts of the same plant were compared with each other (spatial pseudoreplication).

Differences in community structure were investigated by permutational multivariate analysis of variance (PERMANOVA) based on Bray-Curtis distance matrices using the vegdist and adonis function within the vegan package. Bacterial and fungal communities were tested separately. In addition, OTU table used for beta-diversity analysis were rarefied to 276 bacterial and 20 fungal sequences, respectively. Differences with regard to crop species were tested after exclusion of bulk soil samples of the intercropping regimes as the communities in these samples are most probably influenced by both plant species. Differences in community structure were visualized using the metaMDS function within the vegan package. Differences of abundant bacterial genera and fungal species were tested by pairwise $t$-test without $p$-value adjustment.

Correlation-based co-occurrence patterns were calculated with respect to cropping regimes to investigate the interactions between fungi and bacteria in soil and endosphere. Therefore, bacterial and fungal OTU tables were combined resulting in a total of 98 samples ( 20 bulk soil samples, 29 rhizosphere samples, 26 root samples, and 23 leaf samples). One subset contained all samples from one cropping regime in one plant compartment of a single plant species. Pairwise correlation based on Spearman's rho were calculated using the cor.test function in $\mathrm{R}$ and the number of significant positive and significant negative correlations were counted. Positive correlations were considered as two taxa co-occurring or cooperation between the two taxa. Negative correlations were considered as two taxa avoiding each other or competition between the two taxa.

To identify OTUs highly associated to cropping regime with respect to plant species and plant compartment, multipattern analyses were applied. For that purpose, fungal and bacterial OTUs were investigated using the multipatt function from the IndicSpecies package (De Cáceres and Legendre, 2009). The resulting biserial coefficients $(R)$ of each OTU with a particular regime were corrected for unequal sample size using the function r.g (Tichy and Chytry, 2006). As a single taxon can occupy a certain niche in several cropping systems, it is necessary to consider all possible combinations to detect these associations (De Cáceres et al., 2010).

\section{Sequence Data Deposition}

Sequence data were deposited in the sequence read archive (SRA) of the National Center for Biotechnology Information (NCBI) under accession number SRA419369.

\section{RESULTS AND DISCUSSION}

\section{Soil Characteristics and Plant Growth}

Soil $\mathrm{pH}$-values were constant among all soil samples $\left(\mathrm{pH}_{\text {water }}\right.$ $=6.82 \pm 0.13 ; \mathrm{pH}_{\mathrm{KCl}}=6.55 \pm 0.09$ ) with no significant differences between the different cropping regimes (Table S1). Soil moisture varied between 13.7 and $38.4 \%$ (Table S1), being significantly lower in bulk soil samples of WM than in bulk soil samples of FBM (Table 2). The C:N ratio in bulk soil samples of the cropping regime MI was significantly higher compared to the other cropping regimes. The $\mathrm{C}: \mathrm{N}$ ratio explains the ability to use soil carbon and nitrogen for microbial processes such as the decomposition of soil organic matter (Wardle, 1992). We speculate that the higher C:N ratio observed in intercropping regime $\mathrm{MI}$ might be related to a smaller distance between the cereal and the legume root system, which influences the $\mathrm{N}$ transfer from the legume to wheat (Fujita et al., 1992).

To analyze the effect of cropping regime on plant growth and yield, aboveground as well as root biomass were measured (Table S2). A significantly higher average root biomass was observed for faba bean and wheat plants grown in rows (RI) compared to those grown in monocultures or in intercropping regime $\mathrm{MI}$ (Table 3 ). One possible explanation is that there is a higher intraspecific competition in RI as environmental stresses increase the relative weight of roots compared to shoots (Eghball and Maranville, 1993). In the present study, the shoot/root ratio for faba bean monocultures was significantly higher than that of faba bean under intercropping regime RI. We speculate that this is caused by a higher above- and belowground competition

\begin{tabular}{|c|c|c|c|c|}
\hline & Soil moisture (\%) & $\mathrm{C}_{\text {total }}(\%)$ & $\mathrm{N}_{\text {total }}(\%)$ & $\mathrm{C}: \mathrm{N}$ ratio \\
\hline \multicolumn{5}{|c|}{ BULK SOIL } \\
\hline FBM & $31.22 \pm 6.25 a$ & $8.42 \pm 2.35 a$ & $0.18 \pm 0.05 a$ & $46.33 \pm 1.09 a$ \\
\hline WM & $18.14 \pm 4.03 c$ & $6.33 \pm 0.54 a$ & $0.14 \pm 0.01 a$ & $45.11 \pm 1.26 \mathrm{a}$ \\
\hline RI & $21.54 \pm 3.61 b, c$ & $7.68 \pm 2.15 \mathrm{a}$ & $0.17 \pm 0.04 a$ & $46.47 \pm 1.08 \mathrm{a}$ \\
\hline MI & $24.99 \pm 2.19 a, b, c$ & $7.83 \pm 1.03 a$ & $0.17 \pm 0.02 a$ & $47.41 \pm 0.37 b$ \\
\hline \multicolumn{5}{|c|}{ FABA BEAN RHIZOSPHERE } \\
\hline FBM & $34.43 \pm 3.16 a$ & $10.50 \pm 1.02 a$ & $0.22 \pm 0.03 a$ & $48.24 \pm 1.68 a$ \\
\hline RI & $29.12 \pm 4.11 \mathrm{a}$ & $13.76 \pm 2.63 a$ & $0.27 \pm 0.05 a$ & $50.13 \pm 1.07 a$ \\
\hline MI & $26.39 \pm 6.33 a$ & $11.89 \pm 2.17 \mathrm{a}$ & $0.24 \pm 0.05 a$ & $49.99 \pm 2.20 \mathrm{a}$ \\
\hline \multicolumn{5}{|c|}{ WHEAT RHIZOSPHERE } \\
\hline WM & $22.33 \pm 2.99 a$ & $10.86 \pm 1.66 \mathrm{a}$ & $0.22 \pm 0.03 a$ & $50.29 \pm 2.25 \mathrm{a}$ \\
\hline RI & $26.44 \pm 3.56 a$ & $12.08 \pm 2.26 a$ & $0.24 \pm 0.05 a$ & $50.92 \pm 1.22 a$ \\
\hline MI & $24.86 \pm 6.14 a$ & $9.48 \pm 1.55 a$ & $0.18 \pm 0.03 a$ & $51.43 \pm 1.55 a$ \\
\hline
\end{tabular}

Different letters within columns indicate significant differences with $P \leq 0.05$. $C_{\text {toten, }}$ total soll organic carbon: $N_{\text {total, }}$ total soll nitrogen: FBM, taba bean in monoculture; WM, wheat in monoculture: $M I$, mixed intercropping; $R t$, row intercropping. 
TABLE 3 | Growth characteristics of faba bean and wheat plants.

\begin{tabular}{|c|c|c|c|c|c|}
\hline & Height $(\mathrm{cm})$ & Aboveground biomass (g) & Water content $(\%)$ & Root biomass (g) & Shoot/root ratic \\
\hline \multicolumn{6}{|c|}{ FABA BEAN } \\
\hline FBM & $21.40 \pm 1.84 a$ & $4.83 \pm 1.16 a$ & $90.47 \pm 0.55 a$ & $2.34 \pm 0.49 a$ & $2.11 \pm 0.52 \mathrm{a}$ \\
\hline RI & $18.80 \pm 1.69 \mathrm{a}$ & $3.27 \pm 0.52 a$ & $87.92 \pm 1.66 b$ & $2.66 \pm 0.65 b$ & $1.29 \pm 0.32 b$ \\
\hline MI & $19.26 \pm 2.68 \mathrm{a}$ & $3.72 \pm 1.40 \mathrm{a}$ & $87.10 \pm 2.49 b$ & $1.98 \pm 0.69 a$ & $1.92 \pm 0.43 a b$ \\
\hline \multicolumn{6}{|c|}{ WHEAT } \\
\hline WM & $38.78 \pm 1.12 a$ & $1.36 \pm 0.18 a$ & $84.58 \pm 4.01 \mathrm{a}$ & $1.94 \pm 0.48 a$ & $0.76 \pm 0.25 a$ \\
\hline RI & $40.30 \pm 3.00 \mathrm{a}$ & $1.64 \pm 0.27 a$ & $82.40 \pm 2.02 a$ & $2.78 \pm 1.22 \mathrm{~b}$ & $0.71 \pm 0.29 a$ \\
\hline MI & $39.76 \pm 1.40 a$ & $1.68 \pm 0.37 a$ & $84.72 \pm 1.12 a$ & $2.05 \pm 0.49 a$ & $0.86 \pm 0.22 a$ \\
\hline
\end{tabular}

Different letters in columns indicate statistically significant differences between groups $(P \leq 0.05$, means $\pm S E$ ). The above-and belowground biomass per plant (g) is shown. For height, approximately 10 faba bean and 20 wheat plants in intercropping regimes and approximately 20 plants of monocultured faba bean and wheat plants were measured. FBM, faba bear in monoculture; WM, wheat in monoculture; MI, mixed intercropping; RI, row intercropping.

between faba bean and wheat for space, nutrients, and water (Mariotti et al., 2009). In addition, these results might be related to interspecific competition and facilitation that act on the crop plants in intercropping systems simultaneously (Ghosh et al., 2006; Mariotti et al., 2009). We suggest that the differences observed for root biomass of plants under MI and RI are related to the fact, that competition and facilitation effects between plants can be altered through different row arrangements, inter-row spacing, sowing time, plant densities, and proportions of plants (Fujita et al., 1992; Mariotti et al., 2009).

\section{Bacterial and Fungal Communities Are Dominated by a Few Phyla}

The response of bacterial and fungal communities of faba bean and wheat toward cropping regimes was assessed by Illumina (MiSeq) sequencing targeting the bacterial 16S rRNA gene and the fungal ITS region, respectively. Sequencing of bacterial 16S rRNA and fungal ITS gene amplicons from all samples resulted in $9,428,318$ and $6,416,722$ paired reads, respectively (Table 57 ). After removal of low quality reads, PCR artifacts (chimeras) and plant-derived contaminations, a total of 897,824 and 282,209 high-quality reads were obtained for bacteria and fungi, respectively. Sequence numbers per sample varied between 4 to 30,936 (average 8,313) for bacteria and 2 to 48,421 (average 2,637) for fungi. We attribute the high loss of fungal sequences to an average low quality of the reverse reads and the high plant-derived contamination (Table S7).

Obtained sequences were grouped into 695 bacterial and 188 fungal OTUs (Tables S3, S4). Richness (number of observed OTUs) and diversity (Shannon indices) for bacterial communities ranged from 8.1 to 70.7 and from 1.32 to 3.23 , respectively (Table 4). For fungal communities, richness, and Shannon indices ranged from 7.0 to 12.7 and from 1.60 to 2.41 . Effective number of species ranged from 3.7 to 25.2 for bacteria and from 5.0 to 11.1 for fungi. Although samples were rarefied to low sequencing numbers (bacteria $=276$ sequences, fungi $=20$ sequences), calculated Michaelis-Menten Fit confirmed that the majority of bacterial and fungal communities was recovered by the surveying effort (Tables S5, S6). All OTUs were classified below phylum level.

The five dominant bacterial phyla ( $>1 \%$ of all sequences across all samples) were Proteobacteria ( $82.73 \%)$, Actinobacteria (5.25\%), Firmicutes (5.21\%), Bacteroidetes $(2.37 \%)$, and Acidobacteria (1.20\%) (Figure 3, Table S3). Fungi were represented by the abundant phyla Ascomycota $(74.70 \%)$ Basidiomycota (14.34\%), Chytridiomycota (2.32\%), Zygomycoto (1.76\%), and Glomeromycota (1.38\%) (Figure 4, Table S4). The abundant bacterial and fungal phyla were present in all samples and accounted for 96.76 and $92.82 \%$, respectively, of all sequences analyzed in this study. These results are in line with previous studies investigating plant-associated bacterial and fungal communities (Bulgarelli et al., 2015; Detheridge et al., 2016; Wemheuer et al., 2017).

At genus level, Rhodanobacter $(29.64 \%)$ was predominant across all samples with higher abundances in soil samples (Figure 3). Other abundant bacterial genera observed in this study were Acinetobacter (6.50\%), Ralstonia (11.06\%), Pelomonas (7.08\%), Pseudomonas (3.52\%), Rhizobium $(2.97 \%)$ Staphylococcus (2.84\%), Aquabacterium (2.49\%), Massilia (2.23\%), Pseudoxanthomonas (1.77\%), and Chitinophaga $(1.30 \%)$. The predominance of Rhodanobacter and the high abundance of Ralstonia are not in line with a recent study investigating soil bacterial communities (Kaiser et al., 2016). In contrast, very high abundances of Rhodanobacter in fertilized soil samples derived from a temperate forest in the Hainich National Park (Germany) were observed (Pfeiffer, 2013). We speculate that the high abundances of Rhodanobacter and Ralstonia are related to the commercial potting soil used as these genera were isolated from different potting media products in a recent study (Al-Sadi et al, 2016).

The predominant fungal OTU observed in the present study belonged to Dipodascus geotrichum. Abundant fungal species were, for example, Candida subhashii $(21.36 \%)$, D. geotrichum (8.93\%), Goidanichiella sphaerospora (7.68\%), Trichosporon dehoogii (4.36\%), one member of Blastobotrys sp. (3.62\%), Bensingtonia musae $(3.13 \%)$, Blumeria graminis $(1.98 \%)$, and Arthrobotrys conoides (1.07\%). The predominance of C. subhashii supports the results of de Souza et al. (2016). They showed that members of the genus Candida accounted for up to $9.4 \%$ 
TABLE 4 | Bacterial and fungal richness and diversity with regard to plant compartment and cropping regimes.

\begin{tabular}{|c|c|c|c|c|c|c|}
\hline & \multicolumn{3}{|c|}{ Bacteria } & \multicolumn{3}{|c|}{ Fungi } \\
\hline & Richness & Diversity & Effective no. of species & Richness & Diversity & Effective no. of species \\
\hline \multicolumn{7}{|c|}{ FABA BEAN BULK SOIL } \\
\hline FBM & $32.2 \pm 4.1 \mathrm{a}$ & $1.62 \pm 1.50 a b$ & $5.0 \pm 0.6 a b$ & $9.8 \pm 1.5 a$ & $2.05 \pm 2.03 a b$ & $7.8 \pm 1.4 a b$ \\
\hline RI & $33.6 \pm 4.2 \mathrm{a}$ & $1.54 \pm 1.47 a$ & $4.7 \pm 0.6 a$ & $9.2 \pm 1.2 a$ & $1.98 \pm 1.96 a$ & $7.2 \pm 1.4 a$ \\
\hline MI & $69.1 \pm 4.9 \mathrm{a}$ & $3.23 \pm 2.83 b$ & $25.2 \pm 2.2 b$ & $11.2 \pm 1.9 \mathrm{a}$ & $2.24 \pm 2.24 \mathrm{~b}$ & $9.4 \pm 1.8 b$ \\
\hline \multicolumn{7}{|c|}{ WHEAT BULK SOIL } \\
\hline WM & $56.0 \pm 4.4 a$ & $2.62 \pm 2.33 a b$ & $13.7 \pm 1.4 a b$ & $10.6 \pm 1.5 \mathrm{a}$ & $2.13 \pm 2.08 a$ & $8.4 \pm 1.6 \mathrm{a}$ \\
\hline RI & $33.6 \pm 4.2 a$ & $1.54 \pm 1.47 \mathrm{a}$ & $4.7 \pm 0.6 a$ & $9.2 \pm 1.2 \mathrm{a}$ & $2.07 \pm 0.16 a$ & $7.2 \pm 1.4 a$ \\
\hline MI & $69.1 \pm 4.9 a$ & $3.23 \pm 2.83 b$ & $25.2 \pm 2.2 b$ & $11.2 \pm 1.9 \mathrm{a}$ & $2.25 \pm 0.11 a$ & $9.4 \pm 1.8 \mathrm{a}$ \\
\hline \multicolumn{7}{|c|}{ FABA BEAN RHIZOSPHERE } \\
\hline FBM & $64.9 \pm 5.3 a$ & $2.91 \pm 2.61 \mathrm{a}$ & $18.3 \pm 1.9 \mathrm{a}$ & $11.4 \pm 1.6 \mathrm{a}$ & $2.21 \pm 2.19 a$ & $9.1 \pm 1.8 \mathrm{a}$ \\
\hline RI & $51.1 \pm 4.2 \mathrm{a}$ & $2.34 \pm 2.12 a$ & $10.4 \pm 1.4 a$ & $10.6 \pm 1.5 a$ & $2.18 \pm 2.16 a$ & $8.8 \pm 1.4 a$ \\
\hline MI & $52.3 \pm 4.6 \mathrm{a}$ & $2.33 \pm 2.27 a$ & $10.3 \pm 1.2 \mathrm{a}$ & $10.7 \pm 1.7 \mathrm{a}$ & $2.18 \pm 2.17 a$ & $8.8 \pm 1.8 \mathrm{a}$ \\
\hline \multicolumn{7}{|c|}{ WHEAT RHIZOSPHERE } \\
\hline WM & $45.2 \pm 3.9 \mathrm{a}$ & $2.19 \pm 2.05 a$ & $8.9 \pm 0.9 a$ & $10.8 \pm 1.7 a$ & $2.20 \pm 2.18 \mathrm{a}$ & $9.0 \pm 1.8 \mathrm{a}$ \\
\hline RI & $47.7 \pm 4.6 \mathrm{ab}$ & $2.03 \pm 1.93 a$ & $7.6 \pm 1.0 \mathrm{a}$ & $9.9 \pm 1.5 \mathrm{a}$ & $2.04 \pm 2.03 a$ & $7.7 \pm 1.5 \mathrm{a}$ \\
\hline MI & $70.7 \pm 5.9 b$ & $3.01 \pm 2.87 a$ & $20.2 \pm 2.8 \mathrm{a}$ & $11.4 \pm 1.6 a$ & $2.24 \pm 2.23 a$ & $9.4 \pm 1.6 a$ \\
\hline \multicolumn{7}{|c|}{ FABA BEAN ROOTS } \\
\hline FBM & $52.7 \pm 3.7 \mathrm{a}$ & $2.76 \pm 2.71 \mathrm{a}$ & $15.8 \pm 1.2 \mathrm{a}$ & $7.7 \pm 1.7 \mathrm{a}$ & $1.70 \pm 1.55 a$ & $5.5 \pm 1.3 a$ \\
\hline RI & $38.2 \pm 3.4 a b$ & $2.24 \pm 2.10 a$ & $9.4 \pm 0.8 a$ & $11.9 \pm 0.4 a$ & $2.18 \pm 2.18 a$ & $8.9 \pm 1.7 a$ \\
\hline MI & $24.5 \pm 2.4 b$ & $1.87 \pm 1.52 \mathrm{a}$ & $6.5 \pm 0.4 a$ & $12.2 \pm 1.3 \mathrm{a}$ & $2.29 \pm 2.28 \mathrm{a}$ & $9.9 \pm 1.6 \mathrm{a}$ \\
\hline \multicolumn{7}{|c|}{ WHEAT ROOTS } \\
\hline WM & $47.5 \pm 3.6 a$ & $2.50 \pm 2.45 a$ & $12.2 \pm 1.1 \mathrm{a}$ & $9.2 \pm 1.1 \mathrm{a}$ & $2.01 \pm 1.78 a$ & $7.4 \pm 1.0 \mathrm{a}$ \\
\hline Ri & $42.3 \pm 4.4 a$ & $2.37 \pm 2.28 a$ & $10.7 \pm 1.3 a$ & $10.0 \pm 1.5 a$ & $2.05 \pm 2.05 a$ & $7.8 \pm 1.5 \mathrm{a}$ \\
\hline MI & $48.5 \pm 3.6 \mathrm{a}$ & $2.61 \pm 2.39 a$ & $13.7 \pm 1.4 \mathrm{a}$ & $11.0 \pm 1.5 \mathrm{a}$ & $2.13 \pm 2.11 \mathrm{a}$ & $8.4 \pm 1.9 \mathrm{a}$ \\
\hline \multicolumn{7}{|c|}{ FABA BEAN LEAVES } \\
\hline FBM & $17.3 \pm 2.1 \mathrm{a}$ & $1.47 \pm 1.34 a$ & $4.3 \pm 0.3 a$ & $11.9 \pm 1.3 \mathrm{ab}$ & $2.30 \pm 2.30 \mathrm{ab}$ & $10.0 \pm 1.4 a b$ \\
\hline RI & $15.3 \pm 1.2 \mathrm{a}$ & $1.32 \pm 1.26 a$ & $3.7 \pm 0.2 \mathrm{a}$ & $10.1 \pm 1.2 \mathrm{a}$ & $1.98 \pm 1.97 a$ & $7.2 \pm 1.3 a$ \\
\hline MI & $16.1 \pm 2.0 \mathrm{a}$ & $1.88 \pm 1.77 a$ & $6.5 \pm 0.5 a$ & $12.7 \pm 0.8 b$ & $2.41 \pm 2.39 b$ & $11.1 \pm 0.9 b$ \\
\hline \multicolumn{7}{|c|}{ WHEAT LEAVES } \\
\hline WM & $9.5 \pm 1.0 \mathrm{a}$ & $1.47 \pm 1.31 a$ & $4.3 \pm 0.2 a$ & $8.7 \pm 1.6 \mathrm{a}$ & $1.88 \pm 1.82 \mathrm{a}$ & $6.5 \pm 1.5 a$ \\
\hline RI & $8.1 \pm 0.8 a$ & $1.34 \pm 1.30 a$ & $3.8 \pm 0.2 \mathrm{a}$ & $7.0 \pm 1.6 a$ & $1.60 \pm 1.39 a$ & $5.0 \pm 1.1 \mathrm{a}$ \\
\hline MI & $10.4 \pm 0.9 a$ & $1.73 \pm 1.70 \mathrm{a}$ & $5.6 \pm 0.3 a$ & $9.2 \pm 1.5 a$ & $1.99 \pm 1.90 \mathrm{a}$ & $7.3 \pm 1.2 \mathrm{a}$ \\
\hline
\end{tabular}

Diversity is expressed as Shannon values and richness is based on the number of observed OTUs. Different lefters in columns indicate statistically significant differences between the cropping regimes for each plant compartment ( $P \leq 0.05$. means \pm SE). FBM, faba bean in monoculture; WM, wheat in monoculture; MI, mixed intercropping; Rl, row intercropping. There was a marginal effect of cropping regimes on bacterial richness in bulk soil of faba bean samples $(P=0.062)$, and on bacterial diversity and the effective number of species in taba bean roots $(P=0.079)$.

of the relative abundances in sugarcane stalks and belonged to the core microbiome. Candida subhashii was considered as human pathogenic yeast as it has been isolated from a patient sample (Adam et al., 2009). Nonetheless, only one case report of $C$. subhashii infections exists so far (Adam et al. 2009). In a recent study, C. subhashii was repeatedly isolated from commercially available potting soil as well as from soil samples indicating that this yeast is a common soil fungus (Hilber-Bodmer et al., 2017). In addition, the yeast occurred in large concentrations in potting substrates, which might explain the high abundance of this yeast observed in the present study.

Overall, predominant endophytic bacterial genera in roots and leaves differed in their distribution (Figure 3). This supports the results of Robinson et al. (2016) who showed that leaf and root endophyte communities of wheat differed in abundance and structure. The authors concluded that below-and aboveground endosphere represent two distinct ecological niches for bacteria in the plant microbiome creating different conditions for colonization and establishment of bacterial endophytes. In the present study, soil and endophyte compartments were dominated by different bacterial genera. Moreover, similar patterns of fungal species were observed for rhizosphere and bulk soil as well as for root endosphere (Figure 4). However, a direct comparison between endosphere and soil communities should be treated with caution as two different DNA extraction methods were used for endophyte and soil communities. 


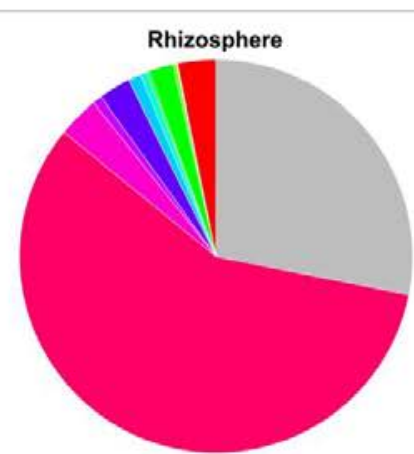

Bulk soil

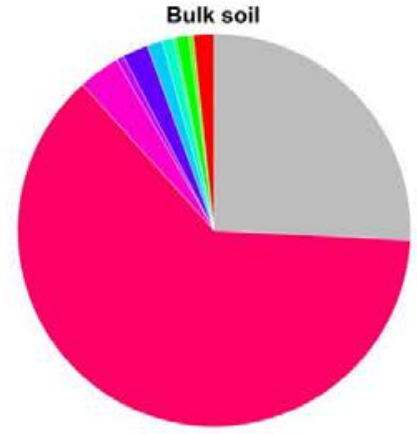

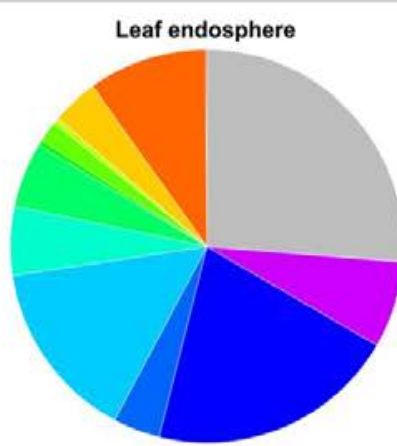

Root endosphere

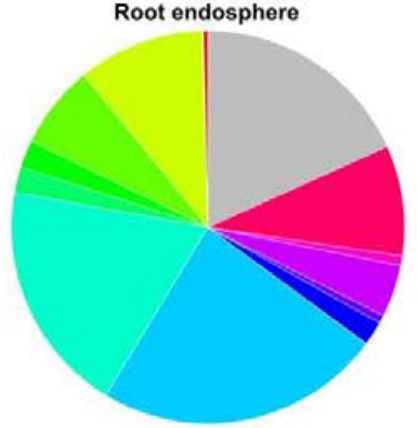

\section{Bacteroidetes}

Chitinophaga

Firmicutes

in Staphylococcus

Alphaproteobacteria

- Paracoccus

Rhizobium

Betaproteobacteria

Aquabacterium

- Burkholderia-Paraburkholderia

a Massilia

- Pelomonas

- Ralstonia

- Tepidimonas

Gammaproteobacteria

- Acinetobacter

- Luteibacter

- Pseudomonas

- Pseudoxanthomonas

- Rhodanobacter

In other bacteria

FIGURE 3 | Abundant bacterial phyla, proteobacterial classes, and genera, derived from the different plant compartments. Only groups with an average abundance $>1 \%$ in at least one of the investigated plant species are shown. Mean relative abundances of each taxa were calculated based on relative abundances calculated for each sample.

\section{Cropping Regime Influenced Microbial Diversity and Richness}

We compared bacterial as well as fungal richness (number of observed OTUs), diversity (represented by the Shannon index $\mathrm{H}^{\prime}$ ), and the number of effective species between the four cropping regimes. Each plant compartment was analyzed separately to prevent spatial pseudoreplication. We detected differences in bacterial diversity and richness between the four cropping regimes (Table 4). Bacterial diversity and the effective number of bacterial species were significantly higher in bulk soil samples of wheat and faba bean grown in MI compared to RI. Bacterial richness was significantly lower in roots of faba bean under MI compared to faba bean monoculture while bacterial diversity was only marginally affected. This is in accordance with a previous study showing that intercropping with maize did not affect bacterial diversity of soybean root endophytes (Zhang et al., 2011).

In the present study, bacterial richness in the rhizosphere of wheat grown in MI was significantly higher compared to that in rhizosphere of wheat monoculture, whereas bacterial diversity was not affected. Contrary, Yang et al. (2016) observed that bacterial diversity in rhizosphere soil of 10 common spring crops in North China was higher under intercropping than under monoculture regime. However, our results are in accordance with a previous study analyzing the effects of intercropping with maize and Rhizobium inoculation on rhizosphere bacterial diversity (Zhang et al., 2010). Here, intercropping did not affect bacterial diversity.

Cropping regimes did not affect fungal richness and diversity with two exceptions (Table 4): fungal diversity, richness, and effective number of species in leaf endosphere of faba bean grown in RI were significantly lower than in MI. In addition, a lower fungal diversity and effective number of species were observed in bulk soil of faba bean under RI compared to intercropping regime MI. Bacterial and fungal richness and diversity in bulk soil samples of faba bean and wheat did not differ between plants derived from monocultures and intercropping regimes. This is not in line with a recent study of Venter et al. (2016). They found a positive effect of an increasing crop diversity on soil microbial richness and diversity. A possible reason for the increased fungal diversity in bulk soil of $\mathrm{MI}$ is the higher $\mathrm{C} / \mathrm{N}$ ratio measured in these samples. This supports the results of Högberg et al. (2007) who showed that the fungal biomass decreased with decreasing soil C:N ratio. In addition, they found that the abundance of bacterial community in soil was significantly and negatively related to soil C:N ratio, which is in contrast to our results. 


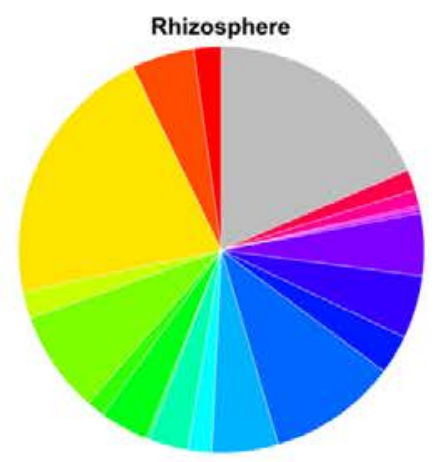

Bulk soil

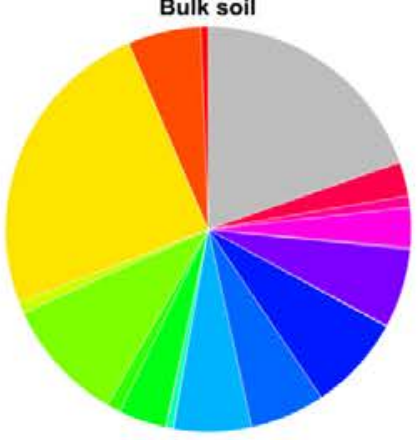

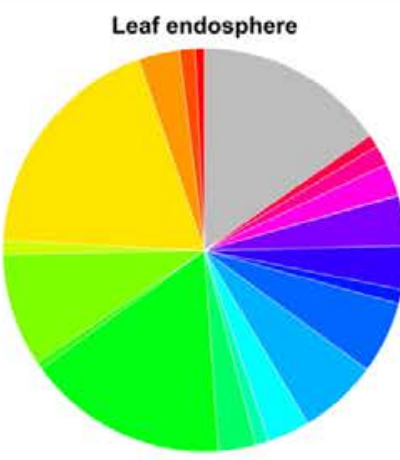

Root endosphere

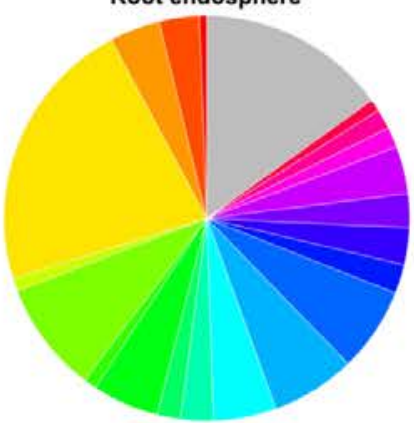

Ascomycota

- Arthrobotrys conoides

Elastobotrys sp.

- Blumeria graminis

Candida subhashii

Chrysosporium pseudomerdarium

Dipodascus geotrichum

Eeomyces sp.

- Goidanichiella sphaerospora

- Mycosphaerella tassiana

- Pseudogymnoascus roseus

- Talaromyces derxil

= Trichosporiella sp.

- unidentified Ascomycota spp.

Basidiomycota

- Atheliaceae sp

- Bensingtonia musae

- Trichosporon dehoogii

- Agaricomycetes sp

Chytridiomycota

- Rhizophlyctis rosea

- Glomeromycota sp.

Zygomycota

Rhizopus arrhizus

=ther fungi

FIGURE 4 | Abundant fungal phyla and species in the investigated plant species, derived from the different plant compartments. Only groups with an average abundance $>1 \%$ in at least one of the investigated plant species are shown. Mean relative abundances of each taxa were calculated based on relative

abundances calculated for each sample.

We speculate that the contrasting effects of cropping regimes on microbial diversity observed here and in other studies are related to differences in plant species, root exudates, plant age, and soil type, as these factors influence microbial diversity (Berg and Smalla, 2009; Zhang et al., 2011). Another possible explanation for the contrasting effects is that synergistic and antagonistic interactions occurred between plants growing in mixed cultures (Wang et al., 2012). This might affect microbial diversity and richness in a different way as plant diversity and proportion differed in the various cropping regimes.

\section{Effect of Cropping Regimes on Microbial Community Structure Is Determined by Crop Species and Plant Compartment}

To identify the influence of the different cropping regimes on microbial community structures, multivariate statistics (nonmetric multidimensional scaling; NMDS) were performed. Distinct clustering with respect to cropping regimes was observed for bacterial and fungal communities only in few plant compartments (Figures 5, 6). For example, fungal communities in bulk soil samples from the cropping regimes FBM and WM differed (Figure 5). In addition, bacterial leaf endophytes of monocropped faba bean and wheat grown under MI formed distinct clusters (Figure 6). We further analyzed the influence of cropping regimes on microbial community profiles by PERMANOVA. Cropping regimes significantly influenced fungal and bacterial communities in bulk soil of faba bean, explaining approximately 25 and $34 \%$ of the variance in the dataset (Table 5). Bacterial community structure in the wheat rhizosphere was significantly affected by cropping regime. Here, intercropping explained more than $28 \%$ of the variance. Moreover, cropping regimes significantly altered fungal communities in rhizosphere soil and root endosphere, explaining more than 21 and $25 \%$ of the variance, respectively.

Furthermore, we analyzed the effect of cropping regimes on bacterial and fungal communities in each plant compartment (Table 5). We found crop species-specific and plant compartment-specific responses of fungal and bacterial communities toward the cropping regimes. Bacterial and/or fungal communities in bulk soil samples of both crop species showed distinct community structures under the cropping regimes RI and MI. Bacterial community structures in bulk soil samples of monocultured wheat or faba bean differed significantly with those of RI or MI, respectively. The results for soil bacteria are in line with a study investigating the effect of 


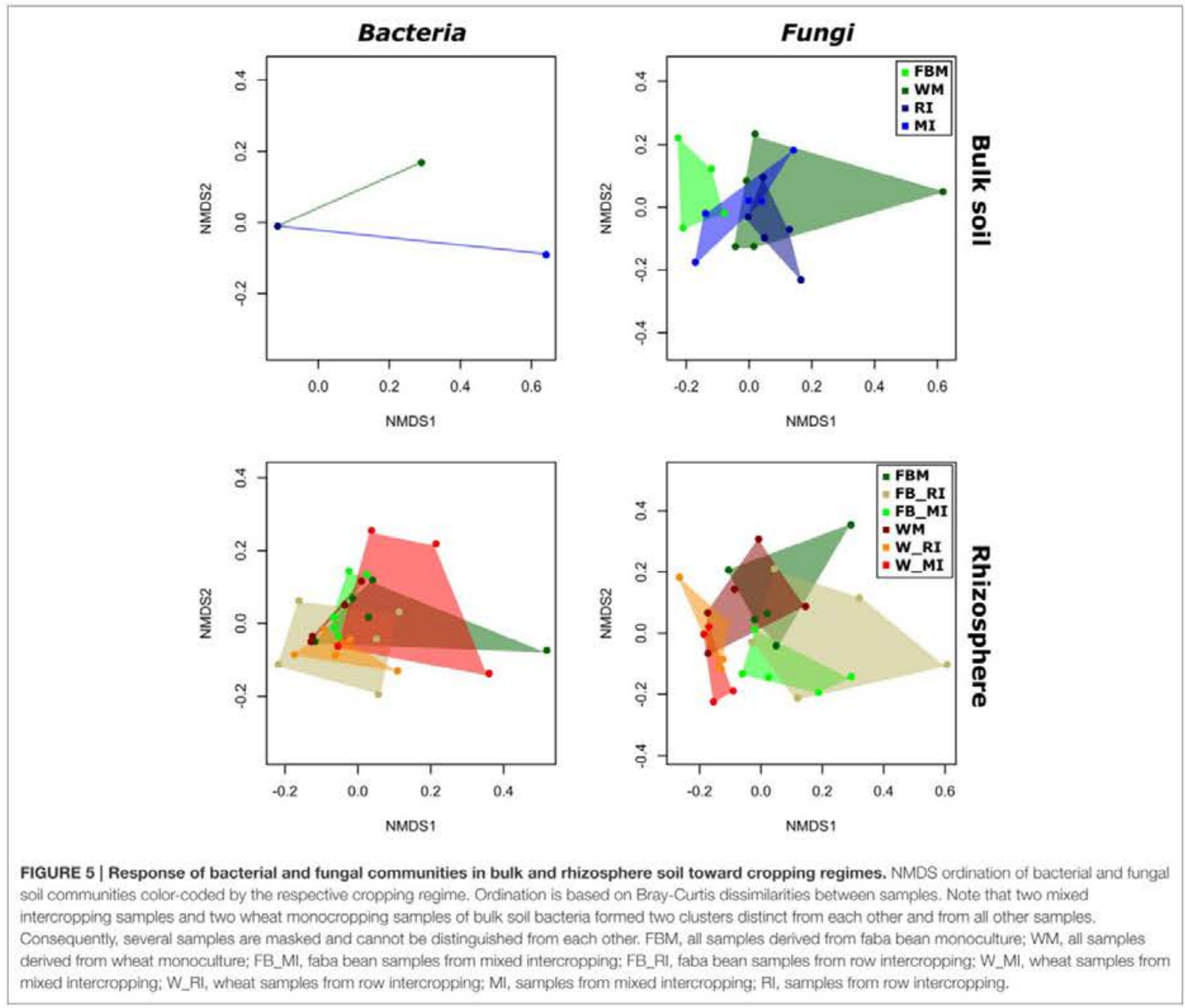

intercropping on bacterial communities (Zhang et al., 2010) in which bacterial communities in intercropped soil were different from those of monoculture soils. We hypothesize that the results of the present study are related to differences in C:N ratio and soil moisture determined in bulk soil samples. As already shown in other studies, these parameters are strong drivers of soil microbial community composition (Högberg et al., 2007; Kaiser et al., 2016).

In the present study, cropping regimes only marginally affected bacterial endophyte community structure in wheat leaves (Table 5). The influence of cropping regimes on fungal endophytes in roots of both faba bean and wheat was more pronounced: the community structure differed significantly between monocultured and intercropped plants. Bacterial and fungal communities in rhizosphere soil of wheat under MI differed significantly from those under WM and/or RI. This is partly supported by the results of Wang et al. (2012) who showed that cropping system exhibited only little impact on fungal and bacterial communities in rhizosphere soil of legumes and wheat. In another study, the composition of rhizosphere bacterial community was apparently altered by intercropping of maize and faba bean (Zhang et al., 2010), which is in contrast to our results. We speculate that the lack of a stronger effect of cropping regimes on bacterial and fungal communities in endosphere and rhizosphere observed in this study is attributed to the short growth period as the developmental stage of plants can influence microbial communities (Berg and Smalla, 2009; Zhang et al., 2011; Wearn et al., 2012; Robinson et al., 2016). This hypothesis is supported by a previous study on rhizosphere ammonia-oxidizing bacteria under different intercropping systems analyzed by DGGE (Song et al., 2007a). Here, intercropping showed a strong impact on these bacteria at anthesis but this effect was less pronounced at the seedling stage of the two crops. 


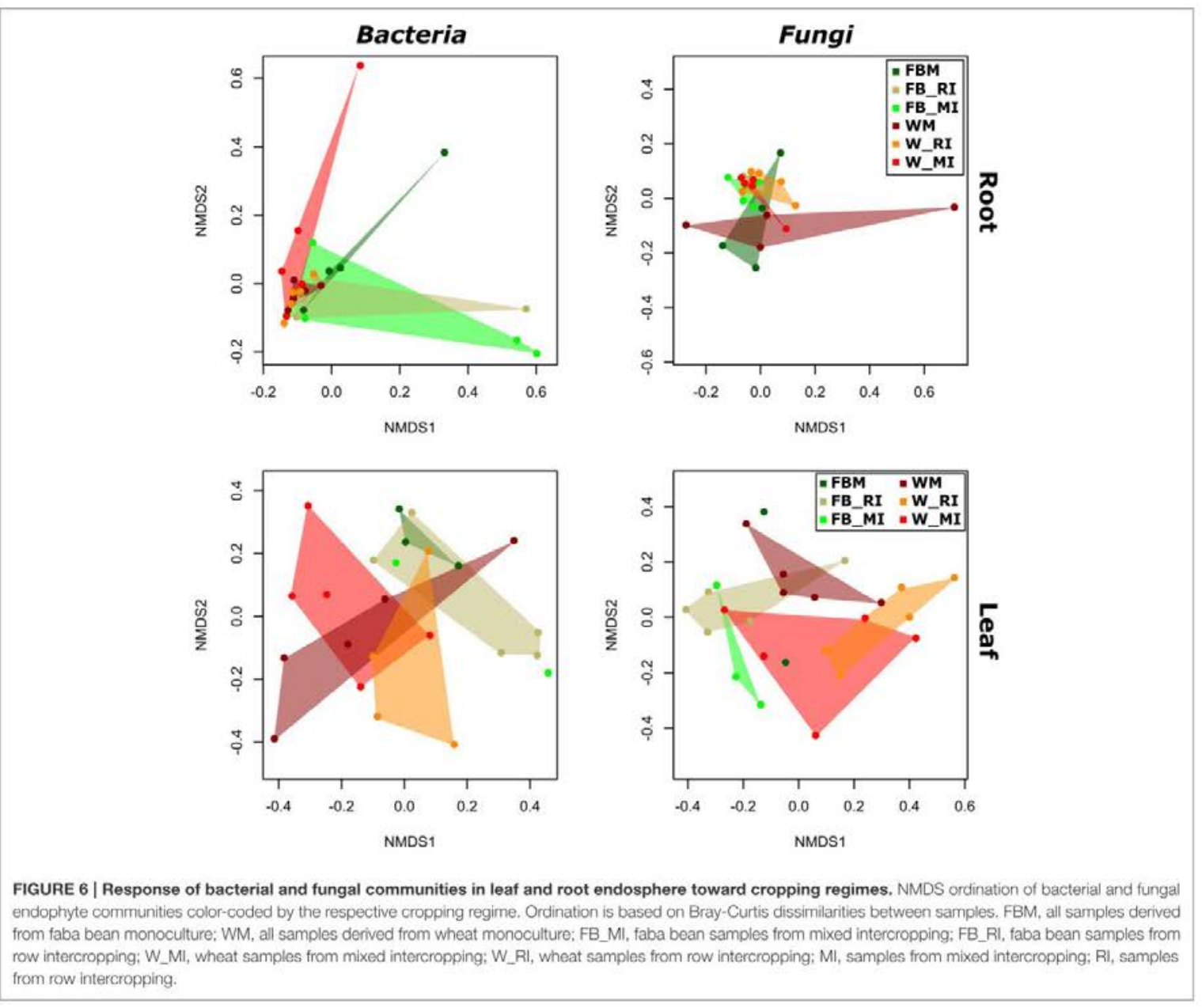

Overall, we found different responses of fungal and bacterial communities toward cropping regimes (Table 6). The effects of cropping regimes were altered by crop species as well as plant compartment and differed between fungal and bacterial communities. We hypothesize that the contrasting effects of cropping regimes on microbial communities in soil and endosphere observed here and in other studies (e.g., Zhang et al., 2011; Wang et al., 2012; Yang et al., 2016) might be related to differences in soil type, plant species, and/or plant compartment investigated. It is well-known that these factors can influence microbial communities (Berg and Smalla, 2009; Wang et al., 2012; Wearn et al., 2012; Wemheuer et al., 2017). Moreover, plant species differ in their root exudates, which also can affect soil microbial communities (Berg and Smalla, 2009; Coleman-Derr et al., 2016). Thus, we further analyzed the impact of crop species and plant compartment on microbial communities (Table 5). Plant species significantly affected the composition of fungal communities but not of bacterial communities, explaining 3.1 and $1.7 \%$ of the variation, respectively. Plant compartment significantly altered bacterial and fungal community structure and explained 46.5 and $9.7 \%$ of the variance, respectively. The interaction of crop species and plant compartment explained 14.1 or $50.5 \%$ (faba bean) and 16.5 or $52.4 \%$ (wheat) of the variance in the dataset for fungal and bacterial communities, respectively. This indicates that fungal and bacterial communities respond differently to environmental changes. These results support the findings of Coleman-Derr et al. (2016) who analyzed fungal and bacterial communities of cultivated and native Agave species. Here, differences in fungal community structures were related to the biogeographical origin of the host species, while the structure of prokaryotic communities was primarily determined by the plant compartment.

We speculate that differences in plant physiology between Fabaceae and Poaceae including root topology or chemical composition (Roumet et al., 2008) are responsible for differences 
TABLE 5 | Effect of cropping regimes, crop species, and plant compartment on bacterial and fungal community structures.

\begin{tabular}{|c|c|c|c|c|c|c|c|c|}
\hline & \multicolumn{4}{|c|}{ Bacteria } & \multicolumn{4}{|c|}{ Fungi } \\
\hline & \multicolumn{2}{|c|}{ Faba bean } & \multicolumn{2}{|c|}{ Wheat } & \multicolumn{2}{|c|}{ Faba bean } & \multicolumn{2}{|c|}{ Wheat } \\
\hline & $R^{2}(\%)$ & $P$ & $R^{2}(\%)$ & $P$ & $R^{2}(\%)$ & $P$ & $R^{2}(\%)$ & $P$ \\
\hline \multicolumn{9}{|l|}{ BULK SOIL } \\
\hline Cropping regime & 34.03 & 0.013 & 25.37 & 0.118 & 25.44 & 0.005 & 20.00 & 0.058 \\
\hline Mo vs. RI & 11.94 & 0.315 & 26.33 & 0.030 & 25.91 & 0.005 & 16.36 & 0.064 \\
\hline Mo vs. MI & 28.94 & 0.024 & 7.64 & 0.508 & 13.65 & 0.194 & 11.23 & 0.438 \\
\hline RI vs. MI & 28.23 & 0.032 & 28.94 & 0.029 & 20.02 & 0.048 & 20.02 & 0.054 \\
\hline \multicolumn{9}{|l|}{ RHIZOSPHERE } \\
\hline Cropping regime & 18.22 & 0.198 & 28.46 & 0.023 & 21.86 & 0.02 & 26.4 & 0.013 \\
\hline Mo vs. RI & 11.15 & 0.41 & 20.28 & 0.085 & 15.17 & 0.141 & 16.40 & 0.124 \\
\hline Mo vs. MI & 14.09 & 0.173 & 25.12 & 0.047 & 21.65 & 0.019 & 20.71 & 0.076 \\
\hline RI vs. MI & 17.70 & 0.127 & 26.10 & 0.042 & 17.23 & 0.072 & 23.71 & 0.036 \\
\hline \multicolumn{9}{|l|}{ ROOT } \\
\hline Cropping regime & 16.87 & 0.343 & 17.42 & 0.206 & 27.6 & 0.013 & 25.82 & 0.012 \\
\hline Mo vs. RI & 10.83 & 0.501 & 4.87 & 0.915 & 27.44 & 0.043 & 22.21 & 0.027 \\
\hline Mo vs. Ml & 19.83 & 0.183 & 14.11 & 0.221 & 20.78 & 0.023 & 26.26 & 0.047 \\
\hline RI vs. MI & 8.37 & 0.317 & 16.26 & 0.149 & 20.54 & 0.154 & 14.33 & 0.245 \\
\hline \multicolumn{9}{|l|}{ LEAF } \\
\hline Cropping regime & 25.22 & 0.36 & 17.71 & 0.10 & 28.4 & 0.145 & 18.91 & 0.151 \\
\hline Mo vs. RI & 24.64 & 0.20 & 17.65 & 0.068 & 23.54 & 0.144 & 20.21 & 0.067 \\
\hline Mo vs. MI & 28.72 & 0.30 & 10.96 & 0.568 & 30.31 & 0.30 & 15.46 & 0.158 \\
\hline Rl vs. Ml & 7.41 & 0.455 & 13.28 & 0.184 & 16.76 & 0.298 & 9.07 & 0.614 \\
\hline Crop species" & 1.7 & 0.127 & 1.7 & 0.127 & 3.1 & 0.003 & 3.1 & 0.003 \\
\hline Compartment' & 46.3 & 0.001 & 46.3 & 0.001 & 9.7 & 0.001 & 9.7 & 0.001 \\
\hline Crop species/compartment & 50.5 & 0.001 & 52.4 & 0.001 & 14.1 & 0.002 & 16.5 & 0.001 \\
\hline
\end{tabular}

Results of the permutational multivanate analysis of vaniance (PERMANOVA) for the different cropping regimes. Statistically significant differences (P $\leq 0.05)$ between the cropping regimes for each plant compartment are written in bold. Marginally significant differences with $P \leq 0.1$ are underined. Mo, Monoculture; MI, mixed intercropping; Rl, row intercropping "The effect of crop species and plant compertment was analyzed for both crop plants.

in endophyte communities. We further hypothesize that the different responses of fungal and bacterial endophytes toward cropping regimes, crop species, and plant compartment are related to different lifestyles of these microorganisms. According to Hardoim et al. (2008), there are three main categories of (bacterial) endophytes: obligate, facultative, and passive (passenger) endophytes. The latter colonize the plant as a result of stochastic events such as open wounds (Hardoim et al., 2008) It has been assumed that fungal endophytes remain restricted to a specific plant organ (Jaber and Vidal, 2010). Thus, many fungal endophytes in roots and shoots of several perennial forbs were tissue-specific (Wearn et al., 2012). However, some endophytic fungi are transmitted horizontally via soil- or airborne spores (Sánchez Márquez et al., 2012), while other fungi are transmitted vertically, from parent to offspring via seeds (Hodgson et al., 2014). Another possible explanation is that plant species harbor a core set of seed-borne endophytes (Johnston-Monje and Raizada, 2011), which might also play a role in the present study. Overall, the results of the present study highlight that fungal as well as bacterial communities in different plant compartments should be analyzed in future studies.

\section{Abundant Microbial Taxa Differ between Cropping Regime, Plant Species, and Plant Compartment}

We further analyzed the abundances of the predominant fungal and bacterial taxonomic groups, as we found that fungal and bacterial communities respond in a crop speciesand plant compartment-dependent manner to cropping regime. The most abundant bacterial genera showed clear trends regarding their preferred habitats (Figure 7). Several bacterial taxa such as Ralstonia, Pseudomonas, and Massilia were almost exclusively found in plant tissues while others including Rhodanobacter, Luteibacter, and Chitinophaga were mainly found in soil. The genera Tepidimonas, Acinetobacter. Paracoccus, and Staphylococcus were almost exclusively detected in leaves whereas Rhizobium was more abundant in roots. The abundances of predominant bacterial genera differed not only between the four plant compartments, but also between cropping regimes and crop species. Some genera including Paracoccus and Tepidimonas were mainly found in wheat leaves with the highest abundance in monocultured wheat plants.

For fungi, we did not observe such clear patterns (Figure 8). However, some fungal species such as B. graminis (causative 
TABLE 6 | Overview of results. Effect of cropping regime on bacterial and fungal richness, diversity, and community structure in faba bean and wheat.

\begin{tabular}{|c|c|c|c|c|}
\hline & \multicolumn{2}{|c|}{ Bacteria } & \multicolumn{2}{|c|}{ Fungi } \\
\hline & Faba bean & Wheat & Faba bean & Wheat \\
\hline & \multicolumn{2}{|c|}{ Cropping regime } & \multicolumn{2}{|c|}{ Cropping regime } \\
\hline \multicolumn{5}{|c|}{ BULK SOIL } \\
\hline Richness & • & - & - & - \\
\hline Diversity & + & + & + & - \\
\hline Structure & + & + & + & * \\
\hline \multicolumn{5}{|c|}{ RHIZOSPHERE } \\
\hline Richness & - & + & - & - \\
\hline Diversity & - & - & - & - \\
\hline Structure & - & + & + & + \\
\hline \multicolumn{5}{|l|}{ ROOTS } \\
\hline Richness & + & - & - & - \\
\hline Diversity & $\cdot$ & - & - & - \\
\hline Structure & - & - & + & + \\
\hline \multicolumn{5}{|l|}{ LEAVES } \\
\hline Richness & - & - & + & - \\
\hline Diversity & - & - & + & - \\
\hline Structure & - & • & - & • \\
\hline
\end{tabular}

+. Significant; -, no significant: : marginally significant.

agent of powdery mildew) and Mycosphaerella tassiana were mainly found in plant tissues, whereas others including D. geotrichum, Geomyces sp., C. subhasii, or T. dehoogii were detected in almost all plant compartments and both crop species regardless of the cropping regime. Goidanichiella sphaerospora was predominant in wheat leaves while an uncultured member of the Agaricomycetes was mainly found in roots of monocultured crop plants. Talaromyces derxii was found in high abundances in roots of monocultured faba beans.

Statistical analysis revealed that several of the abundant bacterial genera and fungal species were significantly affected by cropping regime, crop species, and/or plant compartment (Tables S8, S9). For example, the abundances of Rhizobium in rhizosphere soil samples differed significantly between intercropped faba bean plants and wheat plants under monoas well as intercropping. The abundances of Paracoccus differed significantly between root endosphere samples of faba bean under RI and FBM, leaf endosphere samples of monocropped faba bean and faba bean under MI, monocropped and intercropped wheat. Moreover, rhizosphere samples of faba bean under RI and FBM as well as bulk soil samples of monocropped faba bean and wheat plants and plants under intercropping showed significant changes in the abundances of this genus. In addition, abundances of $M$. tassiana and B. graminis in leaf endosphere were significantly affected by crop species as well as cropping regime. The abundances of Goidanichiella sphaerospora differed significantly between leaf and root endosphere samples of faba bean under the different cropping regimes (FBM, RI,
MI) and leaf endosphere samples of wheat under the cropping regimes WM and $\mathrm{MI}$.

We identified several bacterial and fungal taxa with plant growth-promoting potential, such as Burkholderia, Pseudomonas, Rhizobium, C. subhashii, and Streptomyces bungoensis. For example, the fungal species $T$. derxii can produce several secondary metabolites with antibacterial activity (Zhai et al., 2016). Members of the genera Burkholderia, Pseudomonas, and Rhizobium are well-known as plant growth-promoting bacteria and/or for the production of secondary metabolites including antibiotics or antifungal compounds (Lodewyckx et al., 2002; Lugtenberg and Kamilova, 2009). Moreover, several isolates of Rhodanobacter (Kostka et al., 2012) and Massilia (Zhang et al., 2006) were able to reduce nitrate indicating that these genera play a key role in the nitrogen cycle. Interestingly, Rhizobium was mainly found in roots of intercropped faba bean, with the highest abundance in MI. Legumes such as faba bean are well-known for their symbiosis with nitrogen-fixing rhizobia including members of the genus Rhizobium (Lugtenberg and Kamilova, 2009). We speculate that the higher abundance of this genus in intercropping regimes is related to a higher selection of faba bean for these bacteria as intercropped faba bean and wheat plants compete for nitrogen (Zhang and Li, 2003; Mariotti et al., 2009).

In addition to beneficial microorganisms, we detected various fungal phytopathogens, such as B. graminis and Rhizopus arrhizus, as well as bacterial genera containing widely recognized human and plant pathogens, i.e., Ralstonia and Staphylococcus. However, obtained sequences of Ralstonia and Staphylococcus were predominantly affiliated to uncultured bacteria within these genera. In a previous study on the impact of pest management on bacterial endophyte communities in two grapevine cultivars, Ralstonia was the dominant genus in these communities (Campisano et al., 2014). Recently, members of the genus Ralstonia were observed as endophytes in several grass species (Wemheuer et al., 2017). The observation of these fungi and bacteria in healthy plants indicates that plant endosphere and rhizosphere are an important reservoir for several potential plant as well as human and/or animal pathogens (Mendes et al., 2013; Hardoim et al., 2015). As consequence, a better understanding of the plant microbiome and its responses to cropping regimes is needed.

\section{Bacterial and Fungal Taxa Associated with Cropping Regimes, Crop Species, and Plant Compartment}

As we found different responses of abundant fungal and bacterial taxa to cropping regimes, we performed a multipattern analysis to investigate which microorganism are significantly associated with those regimes (Table S10). In general, soil communities harbored more associated OTUs than endophyte communities, most probably related to higher sequence numbers in soil compared to endosphere samples. The highest number of associated fungal and bacterial OTUs was observed for rhizosphere soil of wheat plants. In general, more endophytic bacteria were associated with faba bean than wheat while the opposite was detected for fungal 


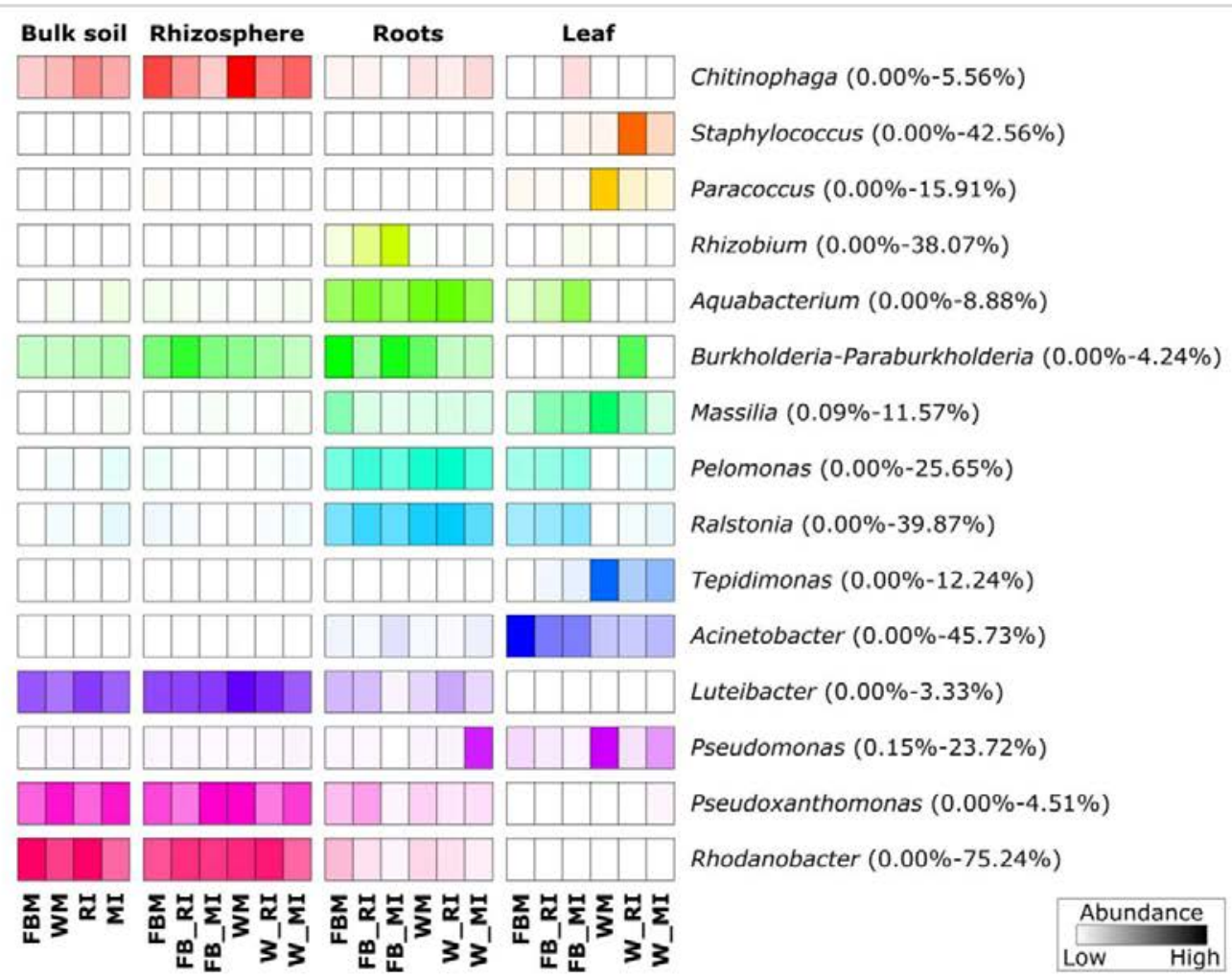

FIGURE 7 | Prominent bacterial genera in different plant compartments. Only groups with an average abundance $>1 \%$ are shown. The color code refers to sequence abundance, with high abundances (dark colored) and low abundances (light colored). Note that rows are standardized. FBM, all samples derived from faba bean monoculture; WM, all samples derived from wheat monoculture; FB_Ml, faba bean samples from mixed intercropping; FB RII, faba bean samples from row intercropping; W_MI, wheat samples from mixed intercropping; W_RI, wheat samples from row intercropping; MI, samples from mixed intercropping; RI, samples from row intercropping. Mean relative abundances of each taxa were calculated based on relative abundances calculated for each sample,

OTUs. Interestingly, only one OTU belonging to Staphylococcus was significantly associated with leaves of wheat under RI.

We identified some species associated with rhizosphere and bulk soil of wheat and/or faba bean, such as Sphingomonas sp. C0503 and an uncultured fungal member of Conlarium sp. Other microorganisms including C. subhasii, Massilia, or Rhodanbacter were significantly associated with endosphere and soil compartments. The yeast $C$. subhashii might play an important role in plant growth promotion as this yeast strongly antagonized a wide range of filamentous fungi (HilberBodmer et al., 2017). The predominant fungus D. geotrichum was associated with the root endosphere of wheat under RI. In addition, this fungus was significantly associated with the leaf endosphere of monocultured faba bean as well as the bulk soil of faba bean under RI.

Other fungi and bacteria were only associated with one plant compartment and/or one crop species. For example, the antibiotic-producing S. bungoensis (Eguchi et al., 1993) was significantly associated with roots of monocultured faba bean. Moraxella osloensis were only associated with leaves of faba bean under MI, while Chrysosporium pseudomerdarium was significantly associated with faba bean rhizosphere in monoculture and intercropping regime RI. The last-mentioned fungus can produce gibberellins and thus might promote the growth of plants (Hamayun et al., 2009). The association of the bacterium $M$. osloensis is interesting due to its potential for the biological control of slugs (Tan and Grewal, 2001). The nematode-trapping fungus $A$. conoides (Yang et al., 2007) and an uncultured member of the Glomeromycota were significantly associated with the rhizosphere of faba bean under cropping regime MI. The Glomeromycota encompass the arbuscular mycorrhizal fungi which are often associated with crops such as wheat and barley (Jensen and Jakobsen, 1980). Recently, it has been shown that mycorrhizal colonization in wheat/faba bean intercropping systems stimulates the transfer of fixed $\mathrm{N}$ from faba bean to wheat (Wahbi et al., 2016) and thus can promote plant growth. Although we identified several associated fungi and bacteria with plant growth-promoting potential, further research 


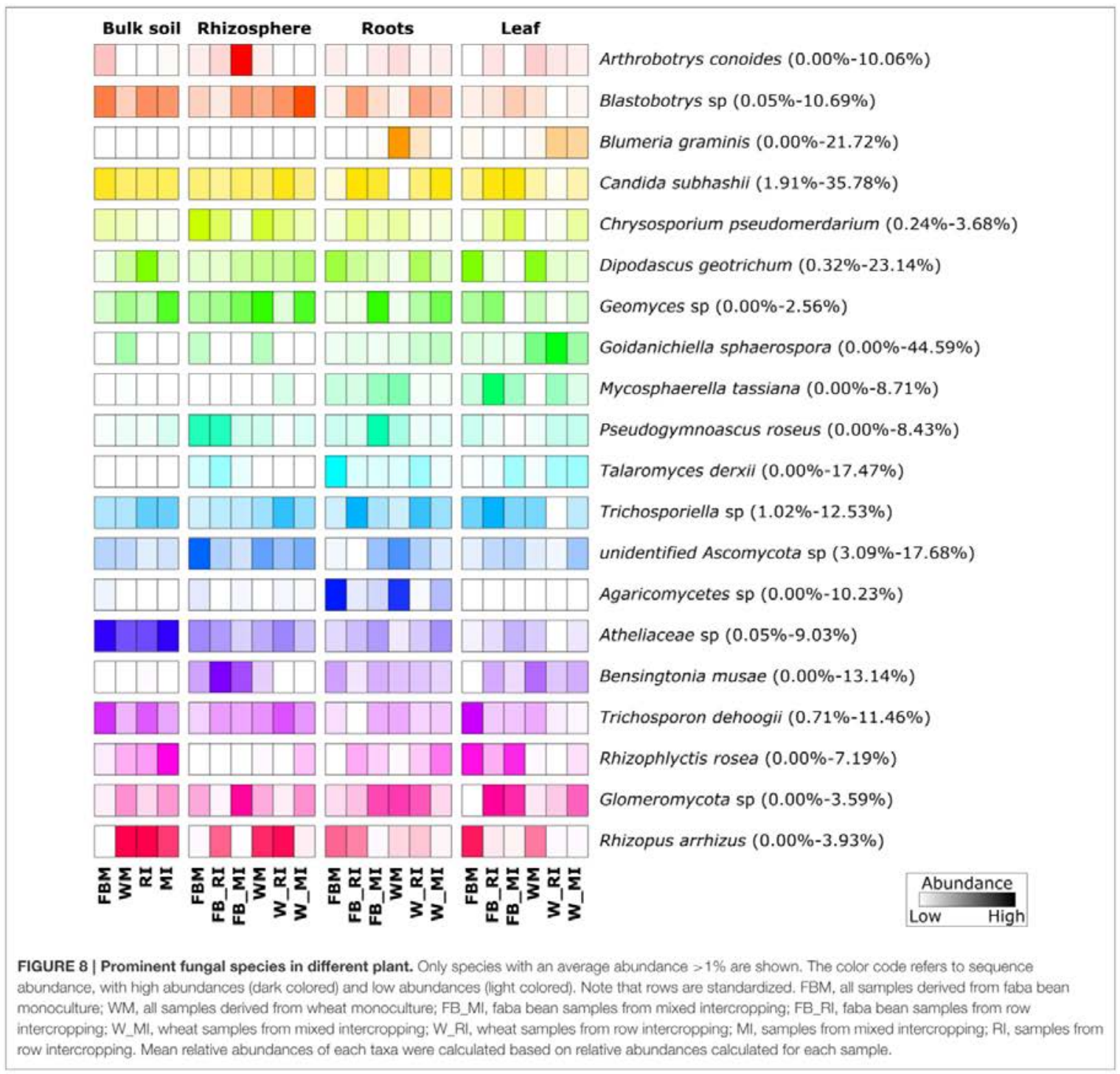

is needed to understand the role of these microorganisms in the plant microbiome and their response to cropping regimes.

\section{Bacterial and Fungal Co-occurrence in the Plant Compartments}

To investigate the effect of cropping regimes on inter- and intra-domain interactions of fungi and bacteria, we calculated the number of significant correlations between OTUs for each compartment (Figure 9, Table S11). Positive interactions (indicating species co-occurrence) are regarded indicative for cooperation, whereas negative interactions indicate avoidance or competition. The abundances of intra-domain negative interactions of bacteria increased strongly in the rhizosphere of faba bean under MI compared to RI and FBM while negative fungal intra-domain interactions remained stable (Figure 9). In contrast, negative fungal intra-domain interactions increased in wheat rhizosphere under MI compared to RI and WM. The number of negative inter-domain correlations between fungi and bacteria decreased in bulk soil of faba bean and wheat under RI and MI compared to monocultures which might be attributed to beneficial effects. Moreover, we observed plant speciesdependent differences. The number of negative interactions for bacteria in wheat roots was higher compared to those in faba bean roots. As mentioned above, legumes and grass species differ in their physiology (Roumet et al., 2008), which might also affect interactions within the plant microbiome. Another possible 

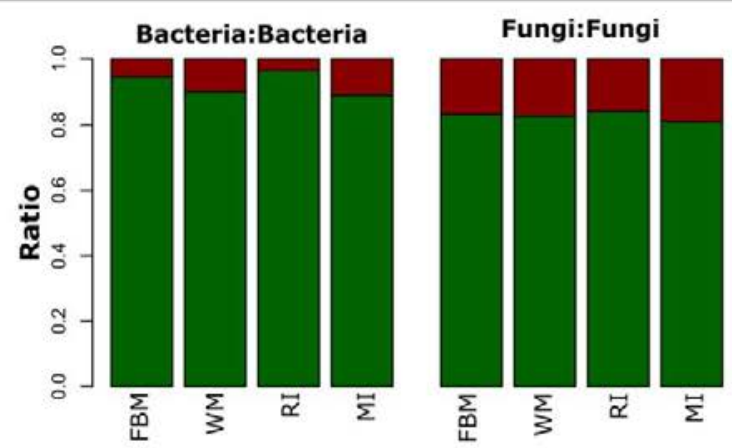

\section{Bacteria:Fungi}
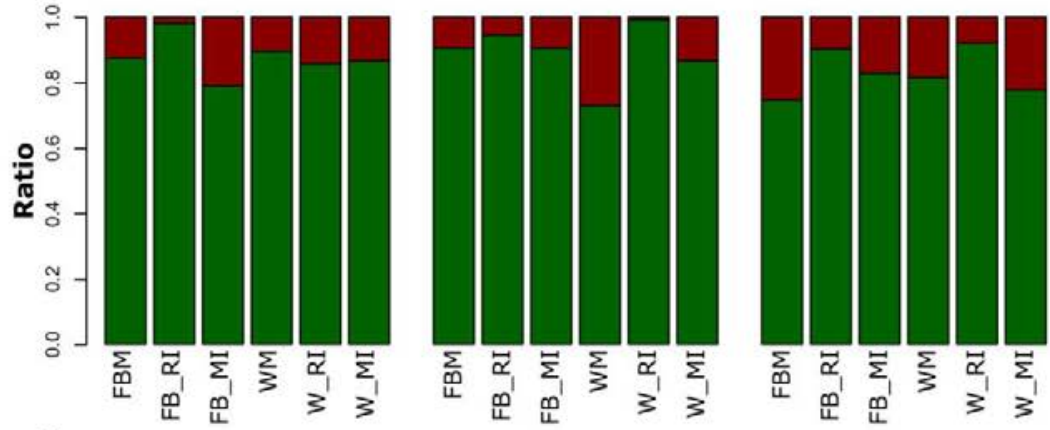

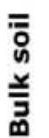
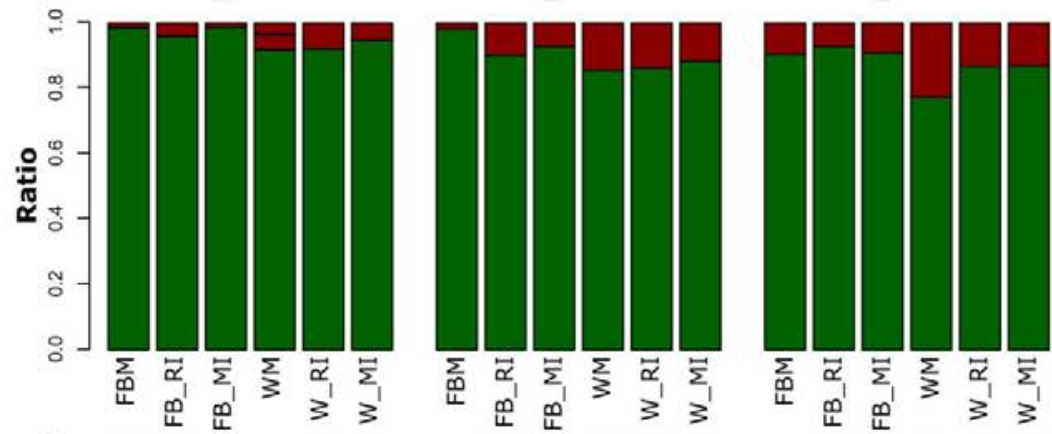

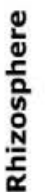
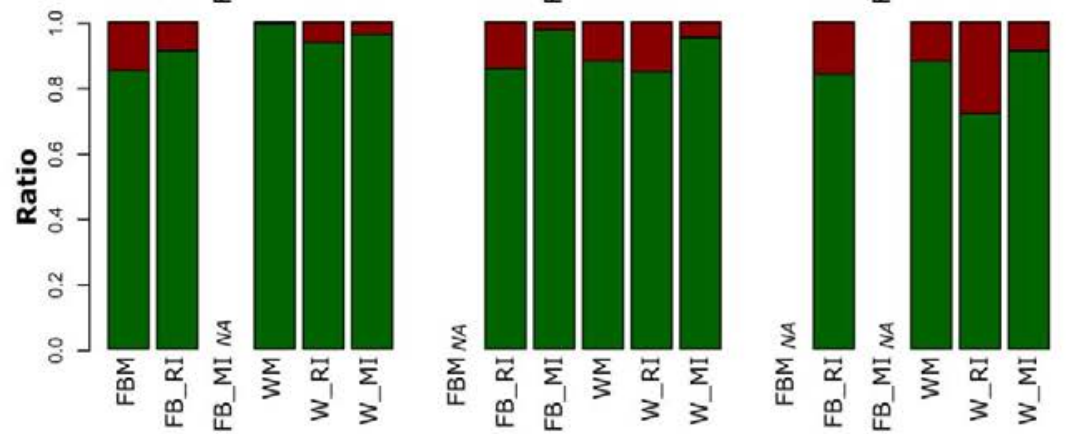

FIGURE 9 | Positive and negative relative interactions in different plant compartments of faba bean and wheat with regard to cropping regime. Positive and negative relative interactions are shown in green and red, respectively. Bulk soll samples of intercropping regimes consisted of both crop plants. FBM, all samples derived from faba bean monoculture; WM, all samples derived from wheat monoculture; FB MI, faba bean samples from mixed intercropping; FB RI, faba bean samples from row intercropping; W_MI, wheat samples from mixed intercropping; W_RI, wheat samples from row intercropping; MI, samples from mixed intercropping; RI, samples from row intercropping; NA: data not available due to low sample numbers. 
et al., 2014). Finally, the 2-step nested approach with 70 cycles of PCR might disproportionally amplify abundant taxa resulting in community profiles of low diversity. Future experiments are required to validate these possible explanations.

The last technical limitation is that we performed a greenhouse pot experiment using commercial plant substrate. Nonetheless, greenhouse experiments allow controlled conditions with a simplification of environmental heterogeneity. In addition, the results of potting mix experiments are easier to interpret as the results are often too complex when natural field soils are used (Ofek et al., 2009). However, a previous study showed that soil type (natural vs. potting soil) had a strong influence on the rhizosphere and endosphere microbiome of sugar beet (Zachow et al., 2014). According to Berg and Smalla (2009), it is difficult to extrapolate results of climate chamber or greenhouse experiments to natural field conditions if the natural rhizosphere cannot develop due to the experimenta design. As non-sterilized soil substrate can provide plants with a microbiome (Berg et al., 2015), we did not sterilize the soil substrate prior to usage.

\section{CONCLUSION}

The present study provides first insights into fungal and bacterial co-occurrence patterns in different plant compartments of two important crop plant species. Our major results were that plant compartment and plant species altered the effects of cropping regimes on microbial communities as well as on microbial interactions. Moreover, we observed different responses of fungal and bacterial communities toward cropping regimes. These findings suggest that future studies should concentrate not only on bacterial and/or fungal communities in one plant compartment and/or one plant species. Although the results of greenhouse experiments cannot be transferred to field conditions, they can serve as background for further field studies. Consequently, the next steps would be to investigate

\section{REFERENCES}

Adam, H., Groenewald, M., Mohan, S., Richardson, S., Bunn, U., Gibas, C F., et al. (2009). Identification of a new species, Candida subhashii, as a cause of peritonitis. Med. Mycol. 47, 305-311. doi: 10.1080/136937808023 80545

Al-Sadi, A. M., Al-Zakwani, H. A., Nasehi, A., Al-Mazroui, S. S., and Al-Mahmooli, I. H. (2016). Analysis of bacterial communities associated with potting media. Springerplus 5:74. doi: 10.1186/s40064-016-1729-(0)

Anderson, I. C. and Cairney, J. W. (2004). Diversity and ecology of soil fungal communities: increased understanding through the application of molecular techniques. Environ. Microbiol. 6, 769-779. doi: $10.1111 / \mathrm{j} .1462-2920.2004 .00675 \times$

Andrews, D., and Kassam, A. (1976). "The importance of multiple cropping in increasing world food supplies," in Multiple Cropping, Vol. 27, eds R. I. Papendick, P. A. Sanchez, and G. B. Triplett (Madison, WI: International Crops American Society of Agronomy, Crop Science Society of America, and Soil Science Society of America), 1-10.

Berg, G., Rybakova, D., Grube, M., and Köberl, M. (2015). The plant microbiome explored: implications for experimental botany. J. Exp. Bot. 67, 995-1002 doi: $10.1093 / \mathrm{jxb} / \mathrm{erv} 466$ microbial communities in different plant compartments of faba bean and wheat grown as mixture and in monoculture under field conditions.

\section{AUTHOR CONTRIBUTIONS}

SV and FW conceived and guided the research. SG, KK, BW, $\mathrm{BP}$, and FW were involved in data acquisition and analysis. SG, $\mathrm{KK}, \mathrm{BW}, \mathrm{BP}$, and FW wrote the first draft of the manuscript. All authors contributed to interpretation of results and were involved in critical revision and approval of the final version.

\section{FUNDING}

This study is part of the project IMPAC ${ }^{3}$ and was funded by the Federal Ministry of Education and Research (FKZ 031A351A). Additionally, we acknowledge support by DFG and the Open Access Publication Funds of the Göttingen University.

\section{ACKNOWLEDGMENTS}

The authors thank Prof Dr. Wolfgang Link from the Working Group "Breeding Research Faba Bean" (Division of Plant Breeding at the University of Göttingen) for providing the seed material, Dr. Jürgen Grotheer (Department of Physical Geography at the University of Göttingen), for the C:N analysis of the soil samples, and Dr. Andrea Thürmer for the help during sequencing. We thank the editor and the two reviewers for their constructive comments, which helped us to improve the manuscript.

\section{SUPPLEMENTARY MATERIAL}

The Supplementary Material for this article can be found online at: http://journal.frontiersin.org/article/10.3389/fmicb. 2017.00902/full\#supplementary-material

Berg, G., and Smalla, K. (2009). Plant species and soil type cooperatively shape the structure and function of microbial communities in the rhizosphere. FEMS Microbiol. Ecol, 68, 1-13. doi: 10.1111/j.1574-6941.2009.00654.x

Bolger, A. M., Lohse, M., and Usadel, B. (2014). Trimmomatic: a flexible trimmer for illumina sequence data. Bioinformatics 30, 2114-2120. doi: 10.1093/bioinformatics/btul70

Bulgarelli, D., Garrido-Oter, R., Münch, P. C., Weiman, A., Drōge, I. Pan, $Y_{n}$ et al. (2015). Structure and function of the bacterial roo microbiota in wild and domesticated barley. Cell Host Microbe 17, 392-403. doi: 10.1016/j.chom.2015.01.011

Campisano, A., Antonielli, L., Pancher, M., Yousaf, S., Pindo, M., and Pertot, I. (2014). Bacterial endophytic communities in the grapevine depend on pest management. PLoS ONE 9:el12763. doi: 10.1371/journal.pone.01 12763

Caporaso. J. G., Kuczynski. J., Stombaugh, J., Bittinger. K., Bushman. F. D., Costello, E. K., et al. (2010). QIIME allows analysis of highthroughput community sequencing data. Nat. Methods 7, 335-336. doi: $10.1038 /$ nmeth.f. 303

Chelius, M. K., and Triplett, E. W. (2001). The diversity of archaea and bacteria in association with the roots of Zea mays L. Microb. Ecol. 41, 252-263. doi: $10.1007 / \mathrm{s} 002480000087$ 
Cole, J. R., Wang, Q., Cardenas, E., Fish, J., Chai, B., Farris, R. J., et al. (2009). The ribosomal database project: improved alignments and new tools for rRNA nalysis. Nucleic Acids Res. 37, D141-D145. doi: 10.1093/nar/gkn879

Coleman-Derr, D., Desgarennes, D., Fonseca-Garcia, C., Gross, S., Clingenpeel, S., Woyke, T., et al. (2016). Plant compartment and biogeography affect microbiome composition in cultivated and native Agave species. New Phytol. 209, 798-811. doi: 10.1111/nph.13697

Crawley, M. J. (2007). The R Book. Chichester: John Wiley \& Sons.

De Cáceres, M. D., and Legendre, P. (2009). Associations between species and groups of sites: indices and statistical inference. Ecology 90, 3566-3574. doi: $10.1890 / 08-1823.1$

De Cáceres, M. D., Legendre, P., and Moretti, M. (2010). Improving indicator species analysis by combining groups of sites. Oikos 119, 1674-1684. doi: $10.1111 / j .1600-0706.2010 .18334 . x$

Desgarennes, D., Garrido, E., Torres-Gomez, M. J., Peña-Cabriales, J. J. and Partida-Martinez, L. P. (2014). Diazotrophic potential among bacterial communities associated with wild and cultivated Agave species. FEMS Microbiol. Ecol. 90, 844-857. doi: 10.1111/1574-6941.12438

de Souza, R. S. C. Okura, V. K., Armanhi, I. S. L., Jorrin, B., Lozano, N., da Silva, M. I., et al. (2016). Unlocking the bacterial and fungal communities assemblages of sugarcane microbiome. Sci. Rep, 6:28774. doi: 10.1038/srep28774

Detheridge, A. P., Brand, G., Fychan, R., Crotty, F. V., Sanderson, R. Griftith, G. W. et al. (2016). The legacy effect of cover crops on so fungal populations in a cereal rotation. Agric. Ecosyst. Environ. 228, 49-61. doi: 10.1016/j.agee.2016.04.022

de Zelicourt, A., Al-Yousif, M., and Hirt, H. (2013). Rhizosphere microbes as essential partners for plant stress tolerance. Mol. Plant 6, 242-245. doi: $10.1093 / \mathrm{mp} / \mathrm{sst} 028$

Edgar, R. C. (2010). Search and clustering orders of magnitude faster than BLAST. Bioinformatics 26, 2460-2246. doi: 10.1093/bioinformatics/btq46

Eghball, B., and Maranville, J. W. (1993), Root development and nitrogen influx of corn genotypes grown under combined drought and nitrogen stresses. Agron. J. 85, 147-152, doi: 10.2134/agronj1993.00021962008500010027x

Eguchi, T., Takada, N., Nakamura, S., Tanaka, T., Makino, T., and Oshima, Y. (1993). Streptomyces bungoensis sp. nov. Int. J. Syst. Evol. Microbiol. 43. 794-798, doi: 10.1099/00207713-43-4-794

Ellouze, W., Esmaeili Taheri, A., Bainard, L. D., Yang, C., Bazghaleh, N. Navarro-Borrell, A., et al. (2014). Soil fungal resources in annual croppin systems and their potential for management. Biomed Res. Int. 2014:531824. doi: $10.1155 / 2014 / 531824$

Fujita, K., Ofosu-Budu, K. G., and Ogata, S. (1992). Biological nitrogen fixation in mixed legume-cereal cropping systems. Plant Soil 141, 155-175. doi: 10.1007/BF00011315

Gange, A. C., Soma, D., Amanda, F. C., and Sutton, B. C. (2007). Site- and speciesspecific differences in endophyte occurrence in two herbaceous plants. $J$. Ecol. $95,614-622$, doi: $10.1111 /$. 1365-2745.2007.01245.x

Ghosh, P. K., Manna, M. C., Bandyopadhyay, K. K., Tripathi, A. K., Wanjari, R. H., Hati, K. M., et al. (2006). Interspecific interaction and nutrient use in soybean/sorghum intercropping system. Agron. J. 98, 1097-1108. doi: 10.2134 /agronj2005.0328

Hamayun, M., Khan, S. A., Iqbal, I., Na, C. I., Khan, A. L., Hwang, Y. H. et al. (2009). Chrysosporium pseudomerdarium produces gibberellins and promotes plant growth. J. Microbiol. 47, 425-430. doi: 10.1007/s12275-009. $0268-6$

Hardoim, P. R., van Overbeek, L. S., Berg, G., Pirttila, A. M., Compant, S. Campisano, A., et al. (2015). The hidden world within plants: ecological and evolutionary considerations for defining functioning of microbial endophytes. Microbiol. Mol. Biol. Rev, 79, 293-320, doi: 10.1128/MMBR.00050-14

Hardoim, P. R., Van Overbeek, L. S, and van Elsas, J. D. (2008). Properties of bacterial endophytes and their proposed role in plant growth. Trends. Microbio 16, 463-471. doi: 10.1016/j.tim.2008.07.008

Hartman, K., van der Heijden, M. G., Roussely-Provent, V., Walser, J. C. and Schlaeppi, K. (2017). Deciphering composition and function of the root microbiome of a legume plant. Microbiome 5:2, doi: 10.1186/s40168. $016-0220-z$

Hauggaard-Nielsen, H., and Jensen, E. S. (2005). Facilitative root interaction in intercrops. Plant Soil 274, 237-250. doi: 10.1007/s11104-0041305-1
Hess, M., Barralis, G., Bleiholder, H., Buhr, L., Eggers, T., Hack, H., et al. (1997). Use of the extended BBCH scale - general for the descriptions of the growth stages of mono; and dicotyledonous weed species. Weed Res. 37, 433-441. doi: 10.1046/j.1365-3180.1997.d01-70.x

Hilber-Bodmer, M., Schmid, M., Ahrens, C. H., and Freimoser, F. M. (2017). Competition assays and physiological experiments of soil and phyllosphere yeasts identify Candida subhashii as a novel antagonist of filamentous fungi. BMC Microbiol. 17:4. doi: 10.1186/s12866-016-0908-2

Hodgson, S., Cates, C., Hodgson, J., Morley, N. J., Sutton, B. C., and Gange, A. C. (2014). Vertical transmission of fungal endophytes is widespread in forbs. Ecol. Evol, 4, 1199-1208, doi: 10.1002/ece3.953

Högberg, M. N., Högberg, P., and Myrold, D. D. (2007). Is microbial community composition in boreal forest soils determined by $\mathrm{pH}, \mathrm{C}$-to- $\mathrm{N}$ ratio, the trees, or all three? Oecologia 150, 590-601. doi: 10.1007/s00442-006-0562-5

Hong, S., Bunge, J., Leslin, C. Jeon, S., and Epstein, S. S. (2009). Polymerase chain reaction primers miss half of rRNA microbial diversity. ISME J. 3, 1365-1373. doi: 10.1038 /ismej.2009.89

Jaber, L. R., and Vidal, S. (2010). Fungal endophyte negative effects on herbivory are enhanced on intact plants and maintained in a subsequent generation. Ecol. Entomol. 35, 25-36. doi: 10.1111/j.1365-2311.2009.01152.

Jensen, A, and Jakobsen, I. (1980). The occurrence of vesicular-arbuscular mycorrhiza in barley and wheat grown in some Danish soils with different fertilizer treatments. Plant Soil 55, 403-414. doi: 10.1007/BF02182701

Johnston-Monje, D., and Raizada, M. N. (2011). Conservation and diversity of seed associated endophytes in Zea across boundaries of evolution, ethnography and ecology. PLoS ONE 6:e20396. doi: 10.1371/journal.pone.0020396

lost, L. (2006). Entropy and diversity. Oikos 113, 363-375. doi: $10.1111 / \mathrm{j} .2006 .0030-1299.14714$.

Kaiser, K., Wemheuer, B., Korolkow, V., Wemheuer, F., Nacke, H., Schöning, I., et al. (2016). Driving forces of soil bacterial community structure, diversity, and function in temperate grasslands and forests. Sci. Rep. 6:33696. doi: $10.1038 /$ srep33696

Kazeeroni, E. A., and Al-Sadi, A. M. (2016). 454-Pyrosequencing reveals variable fungal diversity across farming systems. Front. Plant Sci. 7:314. doi: 10.3389/fpls.2016.00314

Klindworth, A., Pruesse, E., Schweer, T., Peplies, I., Quast, C., Horn, M., et al. (2013). Evaluation of general $16 \mathrm{~S}$ ribosomal RNA gene PCR primers for classical and next-generation sequencing-based diversity studies. Nucleic Acids Res, 41:e1. doi: 10.1093/nar/gks808

Kôljalg, U., Nilsson, R. H., Abarenkov, K., Tedersoo, L., Tavlor, A. F., Bahram, M. et al. (2013). Towards a unified paradigm for sequence-based identification of fungi. Mol, Ecol. 22, 5271-5277, doi: 10.1111/mec.12481

Kostka, J. E., Green, S. J., Rishishwar, L., Prakash, O., Katz, L. S., Marino-Ramirez L... et al. (2012). Genome sequences for six Rhodanobacter strains, isolated from soils and the terrestrial subsurface, with variable denitrification capabilities. $J$ Bacteriol. 194, 4461-4462, doi: 10.1128/JB,00871-12

Lane, D. J. (1991). "16S/23S rRNA sequencing," in Nucleic Acids Techniques in Bacterial Systematics, eds E. Stackebrandt and M. Goodfellow (Chichester: John Wiley \& Sons), 115-147

Li, L., Yang, S., Li, X., Zhang, F., and Christic, P. (1999). Interspecific complementary and competitive interactions between intercropped maize and faba bean. Plant Soil 212, 105-114. doi: 10,1023/A:1004656205144

Li, Q.-S., Wu, L.-K., Chen, J., Khan, M. A., Luo, X.-M., and Lin, W.-X. (2016). Biochemical and microbial properties of rhizospheres under maize/peanut intercropping. J. Integr. Agric. 15, 101-110. doi: 10.1016/S2095-3119 (15)61089-9

Li, Y. H., Zhu, J. N., Zhai, Z. H., and Zhang. Q. (2010). Endophytic bacterial diversity in roots of Phragmites australis in constructed Beijing Cuihu Wetland (China), FEMS Microbiol, Lett. 309, 84-93. doi: $10.1111 /$ j. $1574-6968.2010 .02015 . x$

Lodewyckx, C., Vangronsveld, J., Porteous, F., Moore, E. R. B., Taghavi, S. Mezgeay, M., et al. (2002). Endophytic bacteria and their potential applications. CRC Crit. Rev. Plant Sci. 21, 583-606. doi: 10.1080/0735-260291044377

Lugtenberg, B., and Kamilova, F. (2009). Plant-growth-promoting rhizobacteria. Annu. Rev. Microbol. 63, 541-556. doi: 10.1146/annurev.micro.62.081307. 162918

Malinowski, D. P., and Belesky, D. P. (2000). Adaptations of endophyte-infected cool-season grasses to environmental stresses: mechanisms of drought and 
mineral stress tolerance. Crop Sci. 40, 923-940. doi: 10.2135/cropsci2000. $404923 x$

Mariotti, M., Masoni, A., Ercoli, L., and Arduini, I. (2009). Above- and below-ground competition between barley, wheat, lupin and vetch in a cereal and legume intercropping system. Grass For. Sci. 64, 401-412. doi: $10.1111 /$ j.1365-2494.2009.00705.x

Mendes, R., Garbeva, P., and Raaijmakers, J. M. (2013). The rhizosphere microbiome: significance of plant beneficial, plant pathogenic, and human pathogenic microorganisms. FEMS Microbiol. Rev. 37, 634-663. doi: $10.1111 / 1574-6976.12028$

Nübel, U., Engelen, B., Felske, A., Snaidr, J., Wieshuber, A., Amann, R. I., et al. (1996). Sequence heterogeneities of genes encoding 165 rRNAs in Paenibacillus polymyxa detected by temperature gradient gel electrophoresis. I. Bacteriol. 178, 5636-5643. doi: $10.1128 / \mathrm{jb} .178 .19 .5636-5643.1996$

Ofek, M., Hadar, Y., and Minz, D. (2009). Comparison of effects of compost amendment and of single-strain inoculation on root bacterial communities of young cucumber seedlings. Appl. Environ. Microb. 75, 6441-6450. doi: 10.1128/AEM.00736-09

Oksanen, J., Blanchet, F. G., Kindt, R., Legendre, P., Minchin, P. R., O'Hara, R. B., et al. (2016). Vegan: Community Ecology Package. R Package Version 2.4-0. [WWW document]. Available online at: https://cran.r-project.org/web/ packages/vegan/index.html

Pfeiffer, B. (2013). Impact of Plant Species, N Fertilization, and Ecosystem Engineers on the Structure and Function of Soil Microbial Communities. Ph.D. dissertation, [Göttingen (GER)]: University of Göttingen. Available online at: http://hdl.handle.net/11858/00-1735-0000-0022-5E3E-7

Philippot, L., Raaijmakers, J. M., Lemanceau, P., and Van Der Putten, W. H. (2013). Going back to the roots: the microbial ecology of the rhizosphere. Nat. Rev. Microbiol. 11, 789-799. doi: 10.1038/nrmicro3109

R Core Team (2016), R: A Language and Environment for Statistical Computing. Vienna: R Foundation for Statistical Computing. Available online at: http://www.R-project.org/

Ritz, C, and Streibig, J. C. (2005). Bioassay analysis using R. J. Stat. Softw. 12, 1-22. doi: $10.18637 /$ jss.v012.i05

Robinson, R. J., Fraaije, B. A., Clark, I. M., Jackson, R. W., Hirsch, P. R., and Mauchline, T. H. (2016). Endophytic bacterial community composition in wheat (Triticum aestivum) is determined by plant tissue type, developmental stage and soil nutrient availability. Plant Soil 405, 381-396. doi: $10.1007 /$ s11104-015-2495-4

Roumet, C., Lafont, F., Sari, M., Warembourg, F., and Garnier, E. (2008). Root traits and taxonomic affiliation of nine herbaceous species grown in glasshouse conditions. Plant Soil 312, 69-83, doi: 10.1007/s11104-008-9635-z

Sánchez Márquez, S., Bills, G. F. Herrero, N., and Zabalgogeazcoa, L. (2012). Non-systemic fungal endophytes of grasses. Fungal Ecol. 5, 289-297. doi: $10.1016 / j$.funeco.2010.12.001

Siddiqui, I., and Shaukat, S. (2003). Endophytic bacteria. Prospects and opportunities for the biological control of plant parasitic nematodes. Nematol. Mediterr. 31, 111-120

Song, Y., Marschner, P., Li, L., Bao, X., Sun, J., and Zhang, F. (2007a), Community composition of ammonia-oxidizing bacteria in the rhizosphere of intercropped wheat (Triticum aestivum L.), maize (Zea mays L.), and faba bean (Vicia faba L.). Biol. Fertil. Soils 44, 307-314. doi: 10.1007/s00374-007-0205-y

Song, Y., Zhang, F., Marschner, P., Fan, F., Gao, H., Bao, X., et al. (2007b). Effect of intercropping on crop yield and chemical and microbiological properties in rhizosphere of wheat (Triticum aestivum L.), maize (Zea mays L.), and faba bean (Vicia faba L.). Biol. Fertil. Soils 43, 565-574, doi: 10.1007/s00374-0060139-9

Tan, L., and Grewal, P. S. (2001). Pathogenicity of Moraxella osloensis, a bacterium associated with the nematode Phasmarhabditis hermaphrodita, to the slug Deroceras reticulatum. Appl. Environ. Microbiol. 67, 5010-5016. doi: 10.1128/AEM.67.11.5010-5016.2001

Tichy, L., and Chytry, M. (2006). Statistical determination of diagnostic species for site groups of unequal size. J. Veg. Sci. 17, 809-818. doi: 10.1111/j.1654. 1103.2006.tb02504.x

Toju, H., Tanabe, A. S., Yamamoto, S., and Sato, H. (2012). Highcoverage ITS primers for the DNA-based identification of Ascomycetes and Basidiomycetes in environmental samples. PLOS ONE 7:e40863. doi: 10.1371 /journal.pone. 0040863 van der Heijden, M. G. A., and Hartmann, M. (2016). Networking in the plant microbiome. PLoS Biol. 14:e1002378, doi: 10.1371/journal.pbio.1002378

Vandermeer, J. H. (1992). The Ecology of Intercropping. Cambridge: University Press.

Venter, Z. S., Jacobs, K., and Hawkins, H. J. (2016). The impact of crop rotation on soil microbial diversity: a meta-analysis. Pedobiolgia 59, 215-223. doi: 10.1016/j.pedobi.2016.04.001

Vidal, S, and Jaber, L. R. (2015). Entomopathogenic fungi as endophytes: plantendophyte-herbivore interactions and prospects for use in biological control. Curr. Sci. 109, 1.

Wahbi, S., Maghraoui, T., Hafidi, M., Sanguin, H., Oufdou, K., Prin, Y. et al. (2016). Enhanced transfer of biologically fixed $\mathrm{N}$ from faba bean to intercropped wheat through mycorrhizal symbiosis. Appl. Soil Ecol. 107.91-98. doi: 10.1016/j.apsoil.2016.05.008

Wang. Y., Marschner, P., and Zhang, F. (2012). Phosphorus pools and other soil properties in the rhizosphere of wheat and legumes growing in three soils in monoculture or as a mixture of wheat and legume. Plant Soil 354, 283-298. doi: 10.1007/s11104-011-1065-7

Wardle, D. (1992). A comparative assessment of factors which influence microbial biomass carbon and nitrogen levels in soil. Biol. Rev. 67, 321-358. doi: 10.1111/j.1469-185X.1992.tb00728.x

Wearn, J. A., Sutton, B. C., Morley, N. J., and Gange, A. C. (2012). Species and organ specificity of fungal endophytes in herbaceous grassland plants. J. Ecol. 100, 1085-1092. doi: 10.1111/j.1365-2745.2012.01997.x

Wemheuer, B., and Wemheuer, F. (2017). "Assessing bacterial and fungal diversity in the plants endosphere," in Metagenomics - Methods and Protocols, Vol. 1539, eds W. Streit, and R. Daniel (New York, NY: Humana Press), 75-84.

Wemheuer, B., Wemheuer, F., and Daniel, R. (2012), RNA-based assessment of diversity and composition of active archaeal communities in the German Bight. Archaea 8:695826. doi: 10.1155/2012/695826

Wemheuer, F., Kaiser, K., Karlovsky, P., Daniel, R., Vidal, S., and Wemheuer, B. (2017). Bacterial endophyte communities of three agricultural important grass species differ in their response towards management regimes. Sci. Rep. 7:40914. doi: $10.1038 /$ srep 40914

Wemheuer, F., Wemheuer, B., Kretzschmar, D., Pfeiffer, B., Herzog, S., Daniel, R., et al. (2016). Impact of grassland management regimes on bacterial endophyte diversity differs with grass species. Lett. Appl. Microbiol. 62 323-329, doi: 10.1111/lam. 12551

White, T. J., Bruns, T., Lee, S., and Taylor, J. (1990). "Amplification and direct sequencing of fungal ribosomal RNA genes for phylogenetics," in PCR Protocols. a Guide to Methods and Applications, eds M. A. Innis, D. H. Gelfand, J. I. Sninsky, and T. J. White (New York, NY: Academic Press). 18, 315-322.

Winter, M., de Mol, F., and von Tiedemannm, A. (2014). Cropping systems with maize and oilseed rape for energy production may reduce the risk of stem base diseases in wheat. Field Crops Res. 156, 249-257. doi: 10.1016/i.fcr.2013.10.009

Yan, I. F., Broughton, S. J., Yang, S. L., and Gange, A. C. (2015). Do endophytic fungi grow through their hosts systemically? Fungal Ecol. 13, 53-59. doi: 10.1016/j.funeco.2014.07.005

Yang, J., Li, J., Liang, L., Tian, B., Zhang, Y., Cheng, C., et al. (2007). Cloning and characterization of an extracellular serine protease from the nematodetrapping fungus Arthrobotrys conoides. Arch. Microbiol. 188, 167-174. doi: 10.1007/s00203-007-0233-x

Yang, Z., Yang, W., Li, S., Hao, J., Su, Z., Sun, M., et al. (2016). Variation of bacterial community diversity in rhizosphere soil of sole-cropped versus intercropped wheat field after harvest. PLOS ONE 11:e150618. doi: 10.1371 /journal.pone.0150618

Zachow, C., Müller, H., Tilcher, R., and Berg, G. (2014). Differences between the rhizosphere microbiome of Beta vulgaris ssp. maritima - ancestor of all beet crops - and modern sugar beets. Front. Microbiol. 5:415. doi: $10.3389 /$ fmicb. 2014.00415

Zhai, M.-M., Li, J., Jiang, C.-X., Shi, Y.-P., Di, D-I., Crews, P., et al. (2016). The bioactive secondary metabolites from talaromyces species. Nat. Prod. Bioprospect. 6, 1-24. doi: 10.1007/s13659-015-0081-3

Zhang, F., and Li, L. (2003). Using competitive and facilitative interactions in intercropping systems enhances crop productivity and nutrient-use efficiency. Plant Soil 248, 305-312. doi: 10.1023/A:1022352229863

Zhang, N. N., Sun, Y. M., Wang, E. T., Yang, J. S., Yuan, H. L., and Scow, K. M. (2015). Effects of intercropping and rhizobial inoculation 
on the ammonia-oxidizing microorganisms in rhizospheres of maize and faba bean plants. Appl. Soil Ecol. 85, 76-85. doi: 10.1016/j.apsoil.2014 09.008

Zhang, N., Sun, Y., Li, L., Wang, E., Chen, W., and Yuan, H. (2010). Effects of intercropping and Rhizobium inoculation on yield and rhizosphere bacterial community of faba bean (Vicia faba L.). Biol. Fertil. Soils 46, 625-639. doi: 10.1007/s00374-010-0469-5

Zhang, Y. Q., Li, W. J., Zhang, K. Y., Tian, X. P., liang, Y., Xu, L. H., et al. (2006). Massilia dura sp. nov., Massilia albidiflava sp. nov, Massilia plicata sp. nov. and Massilia lutea sp. nov., isolated from soils in China. Int. J. Syst. Evol. Microbiol. 56, 459-463. doi: 10.1099/ijs.0. 64083-0

Zhang, Y, Z, Wang, E. T., Li, M., Li, Q, Q., Zhang, Y. M., Zhao, S, J., et al. (2011). Effects of rhizobial inoculation, cropping systems and growth stages on endophytic bacterial community of soybean roots. Plant Soil 347, 147-161. doi: $10.1007 /$ s $11104-011-0835-6$

Conflict of Interest Statement: The authors declare that the research was conducted in the absence of any commercial or financial relationships that could be construed as a potential conflict of interest.

Copyright 2017 Granzow, Kaiser, Wemheuer, Pfeiffer, Daniel, Vidal and Wemheuer. This is an open-access article distributed under the terms of the Creative Commons Attribution License (CC BY). The use, distribution or reproduction in other forums is permitted, provided the original author(s) or licensor are credited and that the original publication in this journal is cited, in accordance with accepted academic practice. No use, distribution or reproduction is permitted which does not comply with these terms. 


\section{Chapter 3}

The cropping system matters - Contrasting responses of winter faba bean (Vicia faba L.) genotype to drought stress

Annika Lingner, Sandra Granzow, Franziska Wemheuer, Birgit Pfeiffer

In preparation for submission to Frontiers of Plant Science - Section Abiotic Stress 


\title{
The cropping system matters - Contrasting responses of winter faba bean (Vicia faba L.) genotype to drought stress
}

\author{
Lingner, Annika ${ }^{1,2 *}$, Granzow, Sandra ${ }^{2,3}$, Wemheuer, Franziska ${ }^{3}$, Pfeiffer, Birgit. ${ }^{4}$ \\ ${ }^{1}$ Division of Plant Nutrition and Crop Physiology, Department of Crop Sciences, University of \\ Goettingen, Carl-Sprengel-Weg 1, D-37075 Goettingen, Germany \\ ${ }^{2}$ Center of Biodiversity and Sustainable Land Use, University of Goettingen, Grisebachstr. 6, D-37077 \\ Goettingen, Germany \\ ${ }^{3}$ Division of Agricultural Entomology, Department of Crop Sciences, University of Goettingen, \\ Grisebachstr. 6, D-37077 Goettingen, Germany. \\ ${ }^{4}$ Division of Plant Nutrition and Crop Physiology, Department of Crop Sciences, University of \\ Goettingen, Carl-Sprengel-Weg 1, D-37075 Goettingen, Germany
}

\section{* Correspondence: \\ Annika Lingner, M.Sc. \\ lingner@iapn-goettingen.de}

Keywords: intercropping, mixed cropping, faba bean genotypes, Vicia faba, drought stress, water deficit, re-irrigation.

\begin{abstract}
Intercropping of legumes and cereals provides many ecological advantages and thus contributes to a sustainable agriculture. These agricultural systems face ongoing shifts in precipitation patterns and consequently seasonal drought. Although the effect of drought stress on legumes has been frequently studied, our knowledge about water deficits and reirrigation influencing the performance of legumes under different cropping systems is still limited. In this study, we investigated the impact of water deficit and re-irrigation on two winter faba bean genotypes (S_004 and S_062) and winter wheat (var. Genius) in pure and intercropped stands under greenhouse conditions. To get a comprehensive and detailed look at physiological and biochemical drought stress responses of the crop species, we applied various plant traits such as canopy surface temperature, leaf relative water content and proline content at three time points (beginning of water deficit, end of water deficit, after reirrigation). In addition, dry matter, leaf area and water use efficiency (WUE) were analyzed at the end of the experiment. The overall drought stress tolerance was determined as conceptual analysis of all measured parameters. Water deficit significantly affected WUE, surface temperature and proline content of both winter faba bean genotypes but did not cause impaired productivity regardless of the cropping system. Interestingly, intercropping with wheat resulted in an overall high drought tolerance of genotype S_004, while genotype S_062 had high drought tolerance in pure stands. Under water deficit, pure stands of S_062 remarkably increased WUE by $30.5 \%$. Intercropping of genotype S_004 increased the dry matter per plant by $31.7 \%$ compared to pure stands under water deficit. Contrary, intercropping of genotype S_062 did not improve the dry matter production. These observations were verified by other parameters such as proline content and relative water
\end{abstract}


content of leaves. Biomass and WUE of winter wheat were not significantly affected by water deficit in both crop stands. Our findings indicate that genotype S_004 benefits from resource complementarity in intercropping systems with wheat, whereas S_062 is better suitable for pure stands due to competitive effects. Our study highlights that the drought tolerance of winter faba bean genotypes depends on the cropping system, leading to a demand for droughtadapted cultivars specifically selected for intercropping.

\section{Introduction}

Drastic changes in regional precipitation patterns are predicted to occur with an increased frequency of extreme weather events, due to an ongoing climate change (Brouder and Volenec 2008; Spinoni, Naumann, and Vogt 2015). These extreme weather events account for half of the yield fluctuations worldwide (Fahad et al. 2017; Zampieri et al. 2017). As a consequence, there is a growing demand for sustainable and productive agricultural systems. Intercropping systems, defined as growing two or more species simultaneously on the same field (Vandermeer 1992), are well known to meet both demands (reviewed in Malézieux et al. 2009). Legume-cereal mixtures are most widespread as they can enhance the yield stability and the exploitation of available resources such as water (e.g. Reynolds, Sayre, and Vivar 1994; Hauggaard-Nielsen et al. 2008; Lithourgidis et al. 2011). Previous studies investigating plant responses towards water deficit in intercropping system found contrasting results in dependence of the characteristics of crop species. For instance, the water use efficiency (WUE) of intercropped plant species with different root and shoot architecture such as maize and pea or wheat and faba bean increased compared to sole cropped legumes or cereals due to synergistic effects (Morris and Garrity 1993; Chai et al. 2014; Chapagain and Riseman 2015). Contrary, studies on cowpea/pearl millet, potato/maize and pea/maize observed interspecific competition for water resources, leading to dominance in water uptake of one species over the other or in few cases even to yield reduction (Zegada-Lizarazu, Izumi, and Iijima 2006; Mushagalusa, Ledent, and Draye 2008; Mao et al. 2012).

Among legumes, faba bean is a very sensitive crop in terms of limited water availability (Amede, Schubert, and Stahr 2003). This leads to high yield variability of faba bean throughout the years (Khan et al. 2007; Rubiales and Mikic 2015). Drought tolerant cultivars are therefore essential to assure high productivity and also to maintain yield stability in dry seasons and dry areas. In this context, autumn sawn faba bean plants have advantages compared to spring sown varieties due to their capability to use water resources early after winter. However, winter-hardy faba bean varieties are rare and more extensive breeding is needed (Sallam, Ghanbari, and Martsch 2017).

Within the selection process for winter-hardy faba bean genotypes, maintained photosynthesis and reduced transpiration are important indicators for plant drought tolerance (Link et al. 1999). In pure stands, drought stress significantly influences plant traits such as leaf temperature, grain yield and WUE of faba bean genotypes, which differ in their sensitivity to drought stress (Alghamdi et al. 2015). The recovery after drought can also vary among different genotypes as observed in maize (Chen et al. 2016). Although several drought tolerance-related traits of faba bean have been extensively studied, our knowledge about the drought tolerance of faba bean genotypes in intercropped systems is still limited as most 
previous research has focused on pure stands (e.g. Khazaei et al. 2013; Ali et al. 2016; Belachew, Nagel, and Stoddard 2017).

Hence, we studied the combined influence of water deficit and cropping system on the performance of two winter faba bean genotypes and winter wheat in a greenhouse experiment. Higher growth rates and accordingly higher leaf area are indicators for suitability in intercropping (Semere and Froud-Williams 2001). As a consequence, we chose the two faba bean genotypes S_004 and S_062, which differ in their growth parameters. The genotype S_004 has a high yield production and medium height and is therefore expected to be most suitable for intercropping, whereas S_062 is characterized with a short height and small leaves, suggesting that this genotype might be more suitable for pure stands. Both winter faba bean genotypes were grown in pure stands or intercropped with winter wheat (var. Genius) under two different water supply conditions, i.e., under water deficit as well as under sufficiently irrigated control conditions. Various methods were applied to get a comprehensive insight into physiological and biogeochemical conditions of winter faba bean and winter wheat. The experiment is embedded in the IMPAC ${ }^{3}$-project (Novel genotypes for mixed cropping allow for improved sustainable land use across arable land, grassland and woodland). Obtained results will further deepen our understanding of how the drought tolerance of winter faba bean is determined by interacting effects of genotype and cropping system.

\section{Material and methods}

\subsection{Plant material}

To examine the drought tolerance of two winter faba bean genotypes in pure stands and intercropped with winter wheat, we conducted a pot experiment under controlled greenhouse conditions. The two genotypes of winter faba bean (S_004 and S_062) were selected from a set of field trial-tested inbred lines used within the IMPAC ${ }^{3}$ project. They were provided by the Institute of Plant breeding at the University of Goettingen. The genotype S_004 is characterized by medium height and leaf size, low tillering, late maturity and high yield, while S_062 is very short with small leaflets, high tillering and early maturity. The wheat genotype Genius was provided by Norddeutsche Pflanzenzucht Hans-Georg Lembke KG.

Seeds were surface-sterilized by serial washing according to Andreote et al. (2010). In brief, seeds were immersed in $70 \%$ ethanol for $2 \mathrm{~min}$, in $2 \%$ sodium hypochlorite for 3 minutes and in $70 \%$ ethanol for $30 \mathrm{~s}$. Finally, the seeds were rinsed four times in sterile distilled water. After disinfection, seeds were placed on wetted sterile tissues and germinated at $7{ }^{\circ} \mathrm{C}$ in the dark until the seedlings developed roots of approximately $4 \mathrm{~cm}$ length. The pregermination allowed the identification of dead seed material and ensured same plant numbers in each pot. The inserting of the seeds in the soil is defined as day zero.

\subsection{Soil material and experimental design}

Plants were grown in polypropylene pots (Sunware; $45.5 \times 36 \times 24 \mathrm{~cm}$ ) in a fully randomized design for a period of six weeks. Each pot contained field soil from the experimental study site Reinshof, Germany (51.48 $\mathrm{N}, 9.92^{\circ} \mathrm{E}$ and $157 \mathrm{~m}$ asl.). The soil was classified as Gleyic 
Fluvisol according to the FAO classification system and contained $21 \%$ clay, $68 \%$ silt and $11 \%$ sand with pH 7.3 and $2.8 \%$ humus. The soil was air-dried and sieved $(<10 \mathrm{~mm})$ prior experimental start to avoid plant residues and bigger soil particles. The soil volume of each pot accounted for approximately $20 \mathrm{~L}$ with a dry weight of $18 \mathrm{~kg}$. To prevent soil compaction, the filling of the pots was performed in layers by adding distilled water to each layer. After emergence of the seedlings, the soil was covered by gravel to minimize water losses by evaporation. Phosphorus (50 mg P/kg dry soil) and potassium concentrations (140 mg K/kg dry soil) were in an optimal range according to the German nutrient-availability class system (Kuchenbuch and Buczko 2011) and were measured according to VDLUFA (2009) by ICPOES (Vista-RL ICP-OES, Varian, Palo Alto, USA). Sufficient availability of nitrogen was regularly surveyed by evaluation of chlorophyll concentration by SPAD readings (SPAD502Plus, Konica Minolta, Japan) on the youngest fully expanded leaves (data not shown).

Five different crop stands were established: intercropping of winter faba bean S_004 with winter wheat, intercropping of winter faba bean S_062 with winter wheat, pure stand of S_004, pure stand of S_062 and pure stand of winter wheat. Pure stands of each winter faba bean genotype consisted of six rows with 5 seeds each (in total 30 seeds/pot; Fig. 1). Pure stands of winter wheat consisted of six rows with 12 seeds each (in total 72 seeds/pot). In intercropping systems, 15 faba bean and 36 wheat seedlings per pot were sown in distinct rows in a substitutive design (Vandermeer 1992). Half of the pots of each crop stand was treated with optimal irrigation (control treatments) or with a period of reduced irrigation (water deficit treatments). The ten treatments were replicated four times, resulting in a total of 40 pots.

\subsection{Water management and growth conditions}

In the greenhouse, photosynthetic photon flux density was $400 \mu \mathrm{mol} \mathrm{m} \mathrm{m}^{-2} \mathrm{~s}^{-1}$ at plant level with a 10/14 h day/night photoperiod. The $\mathrm{CO}_{2}$ concentration reached around $450 \mathrm{ppm}$, the average air temperature was $23{ }^{\circ} \mathrm{C}$ and there was a relative humidity of $50 \%$. During the experiment, water loss by transpiration was documented by placing the pots permanently on balances (TQ30, ATP Messtechnik, Germany). The weight reduction was measured every 30 minutes in order to constantly determine water consumption. Additionally, volumetric soil water content was monitored in all treatments using time-domain reflectometry (TDR) probes (EC-5 Moisture Sensor, Decagon Device, USA; data not shown). These systems avoid hidden drought due to higher transpiration of increased biomasses (Senbayram et al. 2015).

The plants of all treatments were sufficiently irrigated with distilled water to $90 \%$ field capacity depending on plant growth and water consumption for a growing period of 24 days when faba bean plants reached the four leaf-stage (BBCH 14/34; Lancashire et al. 1991) (Fig. 2). In water deficit treatments, reduced irrigation was applied over a period of ten days. First, we reduced the amount of irrigated water to $75 \%$ compared to those of the control treatments. At day 28 , we reduced the water amount to $25 \%$. At day 34 , water deficit pots were reirrigated for seven days with the adequate amount of water depending on plant growth and water consumption. Control pots were sufficiently irrigated over the whole experimental period. Total duration of the experiment was six weeks until developmental stage of seven leaves of the winter faba bean (BBCH 17/37). 


\subsection{Harvests and determination of drought stress related parameters}

Three partial harvests were conducted during the experiment to analyze the three stages of water deficit (Fig. 2). Various plant traits such as leaf relative water content, proline content, canopy surface temperature and gas exchange of $\mathrm{CO}_{2}$ and $\mathrm{H}_{2} \mathrm{O}$ were monitored. The first partial harvest (beginning of water deficit) was performed at day 29 when the soil was slightly dried due to ongoing transpiration by the plants and first wilting symptoms on the leaves occurred. The second partial harvest (end of water deficit) was performed at day 34 when the water deficit became severe. The third partial harvest (re-irrigation) was conducted at day 38 . Plants were randomly selected from each pot and crop species. Individual leaf samples of each plant were collected for the analysis of relative water content and proline content. Subsequently, remaining aboveground material of these plants was removed.

At the end of the experiment at day 41, six representative plants per pot and crop species were harvested. Leaf area of the harvested plants was determined with a LiCor 3100 leaf area meter (Licor, NE, USA). Dry matter (DM) of these plants was determined after drying at $105{ }^{\circ} \mathrm{C}$ until weight constancy. Water use efficiency (WUE) in $\mathrm{g} \mathrm{DM} \mathrm{L}^{-1}$ was calculated based on the total aboveground biomass per pot as well as on the total water consumption, in which the water consumption is the amount of water used for irrigation throughout the experiment:

$$
W U E_{\text {Biomass }}\left[g D M L^{-1}\right]=\frac{\text { total dry matter per pot }}{\text { total water consumption }}
$$

\subsubsection{Thermal images and gas exchange}

Gas exchange of $\mathrm{CO}_{2}$ and $\mathrm{H}_{2} \mathrm{O}$ in terms of net ecosystem exchange (NEE) and evapotranspiration (ET) of the crop stands was measured between 9 am and 6 pm under light conditions (Fig. 2). NEE and ET were determined by covering all plants in the pot with a transparent chamber (base area $0.36 \mathrm{~m}^{2}$ ). Changes in $\mathrm{CO}_{2}$ and $\mathrm{H}_{2} \mathrm{O}$ concentrations compared to the surrounding air were measured by using a GFS 3000 (Heinz Walz GmbH, Germany) and calculated from the slopes of these curves according to actual temperature and air volume in the chamber.

Determination of transpiration was based on thermal imaging recording the canopy surface temperature as water loss via stomata is accompanied by cooling of the leaves (Khan et al. 2007). Thus, thermal images were taken with a T640 infrared camera (FLIR Systems, OR, USA). The surface temperature of canopies was evaluated by analyzing the images with the software FLIR ResearchIR version 3.3.12277.1002 (FLIR Systems, OR, USA). Both methods were applied four times during the experimental phase, including an initial measurement before reducing the irrigation in water deficit treatments (Fig. 2).

\subsubsection{Relative water content and proline content of leaves}

For determination of turgidity, the relative water content (RWC) of leaves was investigated according to Barrs and Weatherley (1962). The RWC estimates the cellular hydration and indirectly describes the osmotic adjustment of plants and their ability to absorb soil water (Siddiqui et al. 2015). Therefore, the second fully expanded leaf was sampled and the fresh weight $(\mathrm{FW})$ was recorded around solar noon. The leaf samples were incubated in closed 
boxes with distilled water at $23{ }^{\circ} \mathrm{C}$ for three hours. Afterwards, the turgid weight (TW) was determined and the leaf samples were dried at $60{ }^{\circ} \mathrm{C}$ for $24 \mathrm{~h}$ to examine the dry weight (DW). Finally, the RWC was calculated as follows:

$$
\mathrm{RWC}[\%]=\frac{F W-D W}{T W-D W} * 100
$$

Accumulation of the amino acid proline is considered as common physiological response to water scarcity (Verbruggen and Hermans 2008). The proline content in the leaves was measured according to a modified protocol of Bates, Waldren, and Teare (1973). In brief, the third fully expanded leaf was sampled, immediately frozen in liquid nitrogen and then freezedried. Grinded samples were dissolved in an aqueous solution of $3 \%$ sulfosalicylic acid. After centrifuging (10.000 rpm, $20 \mathrm{~min}$ ), aliquots of the extracts were added to a solution of $2.5 \%$ acid-ninhydrin and glacial acetic acid and then incubated in a $100{ }^{\circ} \mathrm{C}$ water bath for $1 \mathrm{~h}$ to form a color reaction. This color reaction was terminated by placing the samples on ice. The proline color complex was extracted from the solution by addition of toluene and measured with a spectrophotometer (V-650, Jasco Corporation, Japan) at a wavelength of $520 \mathrm{~nm}$. Lproline was used in different concentrations for standard curve settings.

\subsection{Statistical analyses}

Statistical analyses were performed using R version 3.4.1 (R Core Team 2017) and the R package agricolae version 1.2-8 (De Mendiburu 2014). For repeated measurements, data were tested separately for each measurement day. Within these measurement days, data were tested for normal distribution with Shapiro-Wilk-Test (Shapiro and Wilk 1965) and for homogeneity of variance with Levene-Test (Levene 1960). A compliance of the requirements was given. Two-way analysis of Variance (ANOVA) was performed to determine differences between all treatments, followed by Duncan's post-hoc test (Duncan 1955) with a significance level of $\alpha$ $=0.05$. Winter faba bean and winter wheat were tested separately.

\section{Results}

\subsection{Biomass production and water use efficiency}

Plant productivity was evaluated as DM, leaf area and WUE, which were analyzed and calculated at the final harvest. DM of faba bean ranged from $1.27 \pm 0.08$ to $1.89 \pm 0.2 \mathrm{~g}$ per plant, with no significant influence of the water deficit treatments (Fig. 3). Among the crop stands, genotype S_004 had the highest dry matter per plant in intercropping. Under water deficit, there was a significant decrease by $31.7 \%$ comparing the intercropped stands with pure stands of S_004. Wheat was neither significantly affected by the water supply nor by genotype of intercropped faba bean.

Leaf area of faba bean and wheat in general showed a similar pattern as the DM, with genotype S_004 having the highest leaf area of about $340 \mathrm{~cm}^{2}$ per plant in control treatments of both crop stands (Fig. 3). Additional to the trends in DM, significant decreases in the leaf area were observed comparing control and water deficit treatments of pure and intercropped stands of S_004 and S_062, respectively. For wheat under water deficit, intercropping significantly increased the leaf area by $45 \%$ (with S_062) and $65 \%$ (with S_004) compared to pure stands. 
At the end of the experiment, WUE was calculated on the crop stand level. In line with the results described above, water deficit led to a significant increase in WUE in intercropped stands of faba bean S_004 (45\%) and in pure stands of faba bean S_062 (38 \%) (Fig. 4). We observed no differences between the water supply in pure stands of genotype S_004 (average $3.23 \mathrm{~g} \mathrm{DM} / \mathrm{L}$ ). In addition, pure stands of S_004 were both significantly higher than the intercropped control plants. Pure stands of wheat had generally a lower WUE with an average of $1.85 \mathrm{~g} \mathrm{DM} / \mathrm{L}$ and were not affected by the water supply.

\subsection{Leaf gas exchange of $\mathrm{CO}_{2}$ and $\mathrm{H}_{2} \mathrm{O}$}

Net ecosystem exchange of $\mathrm{CO}_{2}$ (NEE) and evapotranspiration (ET) were measured four times throughout the experiment as shown in Fig. 2. The highest NEE for all crops and all treatments was measured before initiation of water deficit (Fig.5A; Table S1). During water deficit and re-irrigation, values of NEE ranged from -0.6 to $6.6 \mu \mathrm{mol} \mathrm{CO}_{2} \mathrm{~m}^{-2} \mathrm{~s}^{-1}$, while ET varied between 0.4 and $2.5 \mathrm{mmol} \mathrm{H}_{2} \mathrm{O} \mathrm{m} \mathrm{m}^{-2} \mathrm{~s}^{-1}$. Water deficit significantly reduced NEE in intercropped and pure stands of both faba bean compared to those of the control plants during the whole period of water deficit. Comparing crop stands, pure stands of genotype S_062 had significantly higher NEE than the intercropped plants under both water supply conditions. Towards the end of water deficit, intercropping of S_004 had significantly higher NEE of on average $3.3 \mu \mathrm{mol} \mathrm{CO} 2 \mathrm{~m}^{-2} \mathrm{~s}^{-1}$ than intercropping of S_062, whereas NEE in pure stands of S_062 was higher than in those of S_004. After re-irrigation, all crop stands including faba bean reached the same NEE level of around $2 \mu \mathrm{mol} \mathrm{CO} 2 \mathrm{~m}^{-2} \mathrm{~s}^{-1}$.

Similar to NEE, the crops in all treatments had highest levels of ET before initiation of water deficit (Fig.5B; Table S2). During the drought period, water deficit significantly reduced ET compared to the respective controls except for the pure stand of S_004. At beginning of water deficit, those differences in intercropped treatments were smaller for genotype S_004 $(0.5$ mmol $\left.\mathrm{H}_{2} \mathrm{O} \mathrm{m}^{-2} \mathrm{~s}^{-1}\right)$ than for $\mathrm{S} \_062\left(0.8 \mathrm{mmol} \mathrm{H}_{2} \mathrm{O} \mathrm{m}^{-2} \mathrm{~s}^{-1}\right)$. In general, the ET values increased towards the end of the water deficit, when pure faba bean S_062 had the highest ET, being significantly higher than pure stands of S_004. After re-irrigation, all intercropped and pure stands of faba bean congregated on a level of about $1 \mathrm{mmol} \mathrm{H}_{2} \mathrm{O} \mathrm{m}^{-2} \mathrm{~s}^{-1}$, only intercropping of genotype S_062 had a significant lower ET of $0.7 \mathrm{mmol} \mathrm{H}_{2} \mathrm{O} \mathrm{m}^{-2} \mathrm{~s}^{-1}$.

Pure stands of wheat had generally low NEE and ET values, ranging between 0.2 and 2.4 $\mu \mathrm{mol} \mathrm{CO} 2 \mathrm{~m}^{-2} \mathrm{~s}^{-1}$ and between 0.4 and $1 \mathrm{mmol} \mathrm{H}_{2} \mathrm{O} \mathrm{m}^{-2} \mathrm{~s}^{-1}$, respectively, after initiation of water deficit. Both parameters were lower under water deficit, being significant only at the end of the water deficit phase.

\subsection{Thermal images}

In correspondence to a reduced ET, surface temperatures of the water deficit treated plants during the drought period were higher than the initial values $\left(23^{\circ} \mathrm{C} \pm 0.9\right)$, and significantly increased compared to control treatments (Fig. 5C; Table S3). Pure stands of faba bean displayed a genotype-dependent response at the beginning of water deficit: S_062 did not differ among water supply conditions (average $26.2{ }^{\circ} \mathrm{C}$ ), while S_004 showed a by $2.9{ }^{\circ} \mathrm{C}$ significantly lower surface temperature under control conditions. Similar to the results for NEE and ET, water deficit treatments of both cropping systems reached surface temperatures of $24.7{ }^{\circ} \mathrm{C}$ after re-irrigation and were thus equal to the respective controls. In pure stands of 
wheat, the water deficit treatment was constant throughout the measurement period (23.5 to $24.7^{\circ} \mathrm{C}$ ) and displayed no significant difference to the control.

\subsection{Leaf relative water content}

In general, genotype S_004 showed comparably high and stable RWC under both water supply conditions and in both cropping systems (Fig. 6; Table S4). Contrastingly, water deficit reduced the RWC of genotype S_062. This effect was most pronounced in intercropping, where the reduction of $11 \%$ and $24.3 \%$ was significant at beginning and end of water deficit, respectively. Pure stands of S_062 showed a significant decrease of $11 \%$ at the end of water deficit only. After re-irrigation, all faba bean in pure stands reach the same level of an average RWC of $91 \%$. However, intercropped S_004 plants had a significantly higher RWC (average $93.8 \%$ ) than intercropped S_062 plants (average 89\%) at that phase.

In general, the RWC of wheat reached high values (above $90 \%$ ). Wheat intercropped with faba bean S_062 showed values of $108.6 \%$ RWC under controlled conditions, which was significantly higher than wheat intercropped with S_004.

\subsection{Proline content}

Proline content of all treatments varied between 300 and $600 \mu \mathrm{g} \mathrm{g} \mathrm{g}^{-1}$ fresh weight (FW) without effects of the water supply at the beginning of water deficit. (Fig. 7; Table S5). At the end of water deficit, the proline content of S_004 in pure stands as well as of S_062 in intercropped stands significantly increased in water deficit treatments (1047 and $1690 \mu \mathrm{g} \mathrm{g}^{-1}$ $\mathrm{FW}$, respectively) compared to controls (489 and $329 \mu \mathrm{g} \mathrm{g}^{-1} \mathrm{FW}$, respectively). After reirrigation, the proline content of all faba bean treatments ranged from 400 to $800 \mu \mathrm{g} \mathrm{g}^{-1} \mathrm{FW}$. Intercropping significantly increased the proline content of genotype S_062 but not of genotype S_004, while the opposite was observed in pure stands.

Proline content of wheat was differently affected by water deficit as pure stands of wheat under control conditions had significantly higher proline content compared to water deficit treatment (end of water deficit). After re-irrigation, wheat intercropped with faba bean S_062 had higher proline contents $\left(726 \mu \mathrm{g} \mathrm{g}^{-1} \mathrm{FW}\right)$ than the intercropping of S_004 $\left(586 \mu \mathrm{g} \mathrm{g}^{-1} \overline{\mathrm{FW}}\right)$.

\subsection{Conceptional analysis of diverse results}

As the aforementioned plant traits showed several similar trends but also some discrepancies, all results of all parameters measured at the end of water deficit are summarized in Table 1. Significant responses to water deficit in comparison to control treatments were classified to get a comprehensive overview on the trends among the applied methodologies. The characterization followed the statement of Link et al. (1999), i.e., drought tolerant responses were defined as maintained production under reduced water use.

We observed that intercropping of S_004 as well as pure stands of S_062 predominantly responded positive in terms of drought tolerance. Intercropping of S_004 showed in six out of eight parameters positive responses to water deficit while pure stands of S_062 responded positively in five parameters. Contrastingly, intercropping of S_062 and pure stands of S_004 predominantly displayed negative characteristics under water deficit. 


\section{Discussion}

The identification and selection of drought tolerant winter faba bean cultivars suitable for intercropping is of crucial interest to assure yield stability under changing climatic conditions with increasing risk for drought events. The evaluation of two contrasting genotypes and their responses under water deficit in pure and intercropping systems was the main aim of this study.

\section{Increased proline content in leaves as stress signal}

Crops exposed to water deficit depend on adaptive mechanisms to maintain productivity. Changes in the proline content are often mentioned as one of the first responses of plants under drought. In our experiment, the proline content of plant leaves drastically increased for faba bean genotype S_062 in intercropping and S_004 in pure stands. As proline plays an important role as signaling molecule and in recovery processes (Szabados and Savouré 2010; Kavi Kishor 2015), we suggest that the observed proline accumulation is a signal for drought induced stress and the subsequent need for adaptation mechanisms. The observed trend in biomass reduction of faba bean probably arised a concentration effect of proline and other important osmotically active substances as shown for Salvadora persica L. by Parida et al. (2016).

We further observed drought tolerance as an incidence of sustained biomass production and concurrently low levels of proline content in pure stands of S_062 and in intercropping of faba bean S_004. Here, we suggest that proline turnover rather than accumulation is linked to drought tolerance as discussed in Bhaskara, Yang, and Verslues (2015). Another potential explanation for the low proline content of faba bean S_004 in the intercropping system is that the interaction with wheat possibly triggers proline transport from leaves to roots, leading to improved belowground osmoregulation and thus increased root activity and growth, which has been shown for soybean and maize (Meyer and Boyer 1981; Voetberg and Sharp 1991). Faba bean genotypes determine RWC differently in cropping systems

The functioning of osmoregulation and cellular hydration in the leaves was measured as RWC. The RWC of faba bean S_004 in both crop stands was not affected by water deficit at any harvest date. This observation is surprising as faba bean usually shows wilting symptoms at early stages of drought stress (McDonald and Paulsen 1997). This loss of turgor has been shown in a similar experiment to be indicative of decreased RWC of faba bean leaves (Siddiqui et al. 2015). The observed maintenance of turgidity under water deficit in faba bean S_004 indicates a good stress adaptation of this genotype in terms of intact physiological processes as demonstrated for other faba bean genotypes in pure stands (Khazaei et al. 2013).

Contrastingly, the RWC of faba bean S_062 was decreased by water deficit to different extends, pointing to a comparably bad stress adaptation. This effect in RWC was observed as indicator for reduced ability in osmotic adjustment in soybean and tobacco (Meyer and Boyer 1981; Flexas et al. 2006), decreased water potential and loss of turgor in faba bean (Mwanamwenge et al., 1999). In line with our contrasting findings for S_062 and S_004, Abid et al. (2017) found different responses in RWC as dependent on the faba bean genotype. The authors explained this by different sensitivities in physiological processes such as stomatal adjustment and photosynthesis which was also observed in our study. 
In line with our findings on proline content, the decline in RWC of S_062 was further intensified in the intercropped stand. These observations point to negative effects of intercropping on the susceptible osmoregulation of genotype S_062. We suggest that faba bean S_062 does not benefit from the mixture with wheat but rather suffers from competition. Dominance effects were also shown for switchgrass and milkvetch as well as for maize and pea (Xu, Li, and Shan 2008; Mao et al. 2012). More pronounced changes in RWC under increasing stress intensity were also observed on faba bean in a greenhouse experiment (Abid et al. 2017). However, this study was conducted in pure stands. We conclude that the combination of water deficit and competition observed in our study led to an inferior performance of genotype S_062 in intercropped stands.

Intercropping promotes gas exchange of faba bean $S_{-} 004$

The high RWC of faba bean S_004 suggests active physiological processes. One of the first physiological responses of grain legumes and other crops to drought is stomatal closure in order to avoid dehydration and water loss and to maintain the water status (Flexas et al. 2006; Stoddard et al. 2006). A strong interrelation therefore exists between NEE, ET and canopy surface temperature.

NEE, ET and canopy surface temperature showed generally similar trends in terms of stress response as observed for the proline content. In our study, canopy surface temperatures of faba bean increased in both stands in response to water deficit, which is an indication on decreased transpiration rates and stomatal closure (Chaves et al. 2002; Khan et al. 2007; Farooq et al. 2010). Overall, stomatal closure was also clearly indicated by NEE and ET. This proves a physiological adaptation of all plants to water deficit in our experiment. However, faba bean genotypes S_062 and S_004 responded to a different extent and were also affected by the cropping system.

Generally, maintenance of photosynthetic processes such as $\mathrm{CO}_{2}$ assimilation supporting high biomass production has been described as desirable for faba bean under low water supply (Link et al. 1999). This principle, however, was developed for plants grown in pure stands. In our study, intercropping improved the physiological activity and drought adaptation of faba bean S_004. Different characteristics in crop architecture of faba bean and wheat could have reduced the amount of unproductive water loss as evaporation in relation to transpiration as described in a study on several cereals (Tambussi, Bort, and Araus 2007). The ET is further dependent on the crop stand and its microclimate (Jákli et al. 2016). In our study, this effect is crucial in intercropped stands where the species complement one another. Especially in the intercropped stands with S_004, where bigger leaflets lead to a denser canopy.

Water use efficiency and growth are determined by genotype and cropping system In correspondence to previously discussed results, we also observed differences between the genotypes regarding their WUE in our experiment. More precisely, we found combined effects of genotype and cropping system. The observation of a higher WUE in pure stands of S_062 and intercropped stands of S_004 is in line with our results in proline content and leaf area and partly reflects results from ET and RWC. The results therefore clearly point to a specific cropping system-dependent drought stress response of the different genotypes. 
The observed variation in RWC, however, did not result in differing biomass production, which was also attested for common bean harvested after eight days of water deficit in a pot experiment by Ramos et al. (2003). This might be attributable to a concentration effect mentioned by Teulat et al. (1997). The authors stated an accumulation of osmotically active compounds due to impaired leaf expansion under water deficit. In fact, leaf area was reduced by water deficit in the drought susceptible treatments, i.e. S_004 in pure stands and S_062 in intercropped stands. According to Mwanamwenge et al. (1999), the reduction of leaf area is a common drought stress response of faba bean. It maintains turgor pressure and allows stomata to remain open for further photosynthetic activity. As a result, plants have a better ability to recover after re-irrigation.

Though water deficit induced significant changes in several parameters, our plants recovered after re-irrigation to the same level as the respective control treatments. This sensitivity and concurrent ability to recover of faba bean was also observed by Mwanamwenge et al. (1999) at the same developmental stage (six leaves-stage). We therefore expect that a longer or more intense period of water deficit may have a stronger impact on the variation among treatments and the plants' capability to recover. As a consequence, future studies should investigate longer periods of water deficit with a focus on recovering abilities of the plants.

Reduced gas exchange and elevated canopy temperature under water deficit are indications of stomatal closure, leading to increases in WUE by $30.5 \%$. This response to water deficit is in accordance with a pot experiment on pure faba bean, where WUE was enhanced by about 50 $\%$ under drastic reductions in water availability (Zabawi and Dennet 2010). The stomatal closure did surprisingly not lead to growth inhibition due to impaired $\mathrm{CO}_{2}$ assimilation as shown in field-grown sugar beet (Jákli et al. 2017). This might be due to different characteristics of the plant species or due to the time span of the growth period, which was shorter in our experiment than the vegetation period in the field. In a comparable greenhouse set up, results similar to our findings were observed in rice (Kamoshita et al. 2004). The osmotic adjustment of rice during drought did not directly affect the biomass production. We thus suggest that the observed results can be explained by previous luxury conductance of the stomata that could have been reduced to a certain extend without negative effects on physiological activity and biomass production.

Other reasons for the absence of water deficit effects on DM production might be the relatively short period of water deficit and the young age of the plants. The experiment ended before initial flowering and there was less mutual shading than in full-grown crop stands. Consequently, we expect that effects on DM production will be more pronounced in a longterm experiment analyzing the whole plant development including the generative state. To that age, only the tall growing genotype S_004 benefited from water use in intercropping when water was scarce. These contrasting responses of the genotypes suggest that not intercropping per se improves the drought tolerance of plants but that the level of interspecific competition with wheat can differ between faba bean genotypes. A dependence of plant characteristics on competition and facilitation has been already observed in field experiments on different grain legume-cereal intercropping (Hauggaard-Nielsen et al. 2008). In the intercropping system of S_004, the interaction between the two crop species avoided competitive situations and resulted in a positive mixture effect even at that plant 
developmental stage. This was probably due to niche complementarity in rooting systems and water uptake that occur in pot experiments with faba bean-wheat intercropping (Bargaz et al. 2016). These oppositional results of the genotypes observed in the present study further supported by data on physiological and biochemical data suggest different suitability of faba bean genotypes for intercropping with wheat. Caviglia et al. (2004) already mentioned that other selection criteria for cultivars are needed for intercropping than for pure stands. Thus, we propose that a cropping system-targeted breeding is necessary for a successful integration of winter faba bean into intercropping systems.

\section{Wheat benefits from intercropping with faba bean $S \_004$}

In order to investigate whether differences in intercropping are derived from the performance of the faba bean genotype only or further affected by the responses of wheat, we evaluated competitive effects on the non-legume partner wheat. In intercropping with S_004, wheat showed higher DM per plant than in pure stands which was similar to the positive responses of faba bean. This indicates a clear beneficial mixture effect and thus superior performance of the intercropping S_004 with wheat with regard to biomass production. Moreover, the previously discussed overall suitability of faba bean S_004 for intercropping positively affected the proline content of wheat. In the recovery phase, the aforementioned stress signal of proline accumulation in wheat was lower in the mixture with S_004 than in the mixture with S_062. We thus conclude both species can increase their productivity in the mixture if suitable genotypes were chosen, as shown in several studies (e.g. Reynolds, Sayre, and Vivar 1994; Yang et al. 2011; Bargaz et al. 2016).

In pure wheat stands, the surface temperature, RWC and WUE as well as the DM were not remarkably affected by water deficit. This suggests high yield stability in intercropped as well as in pure stands. Similar results were found in other studies on wheat, barley and rice (Schonfeld et al. 1988; Teulat et al. 1997; Kumar, Malaiya, and Srivastava 2004). In these studies, high yield stability under drought conditions was derived from maintained water balance, which was reflected by high RWC of leaves. According to Vassileva et al. (2011), drought tolerant wheat genotypes are those with no drastic reductions in physiological mechanisms and fast recovery rates, which is in line with the definition of drought tolerance of faba bean genotypes (Link et al. 1999). Other drought tolerant wheat genotypes should be further investigated in intercropping with faba bean as the combination of faba bean and wheat genotypes is the main driver of successful intercropping systems (Brooker et al. 2015).

\section{Conclusion}

Intercropping of winter faba bean and winter wheat has the potential to increase the sustainability and productivity of agriculture. However, the impact of different genotypic characteristics on the drought stress tolerance within these cropping systems is poorly understood. The aim of this study was to investigate if and how the cropping system alters the impact of water deficit and re-irrigation on two winter faba bean genotypes and winter wheat. Furthermore, we aimed at revealing plant responses in dependence of the interacting effect of genotype, water deficit and cropping system by assessing a wide range of plant traits.

Overall, the two winter faba bean genotypes grown in pure stands differed in their responses towards water deficit. Genotype S_062 revealed a higher ability to adapt to water scarce 
environments in comparison to genotype S_004, which in contrast was more drought susceptible in pure stands. The general idea of enhanced drought tolerance due to positive synergistic effects in intercropping was only partly supported by our study, as we observed beneficial effects for intercropping faba bean S_004 with wheat, while intercropped genotype S_062 did not respond in the expected manner. The same pattern was shown by the WUE of the crop stands. Similarly, the responses in the other observed parameters towards water deficit were highly dependent on the combined effect of cropping system and genotype.

As a consequence, we conclude that for the drought tolerance of intercropping systems, selection of the best winter faba bean genotype regarding complementary stand architecture and rooting patterns matters. Due to the complex physiological processes, we recommend that future studies should consider several traits in conjunction. These genotype-dependent interactions in intercropping further point to a demand for selection specific to intercropping in order to develop suitable cultivars. Here, our study provides a better understanding of plant responses to water deficits, though more detailed research based on relations of different physiological responses as well as replicability in field experiments is of crucial importance for the development of drought-tolerant genotypes and for the improvement of intercropping systems.

\section{Conflict of Interest}

The authors declare that the research was conducted in the absence of any commercial or financial relationships that could be construed as a potential conflict of interest.

\section{Author Contributions}

AL, SG, FW and BP contributed to conception and design of the study; AL performed the statistical analysis and wrote the first draft of the manuscript. BP contributed to interpretation of results and guided the research. All authors contributed to critical manuscript revision, read and approved the submitted version.

\section{Funding}

Funded by the Federal Ministry of Education and Research (FKZ 031A351A). IMPAC ${ }^{3}$ is a project of the Center of Biodiversity and sustainable Land Use at the University of Goettingen.

\section{Abbreviations}

DM: Dry matter

FW: Fresh weight

ET: Evapotranspiration 
NEE: Net ecosystem exchange of $\mathrm{CO}_{2}$

RWC: Relative water content

WUE: Water use efficiency

\section{Acknowledgments}

We would like to acknowledge the Division of Plant breeding at the University of Goettingen for providing the seed material. Furthermore, we thank Isa Bulut for his practical assistance especially in the methodology of proline content. 


\section{Tables}

Table 1: Summary of all measured parameters at the end of water deficit of the two winter faba bean genotypes in intercropped and pure stands. Arrows: significant differences at $p<0.05$, minus: no differences between control and water deficit treatment. Green: considered as positive response, black: considered as negative response.

\section{Parameter Winter faba bean}

\begin{tabular}{llll}
\hline \hline S_004 & & S_062 & \\
intercropping & pure stands & intercropping & pure stands \\
\cline { 2 - 5 }
\end{tabular}

responses under water deficit compared to the respective control

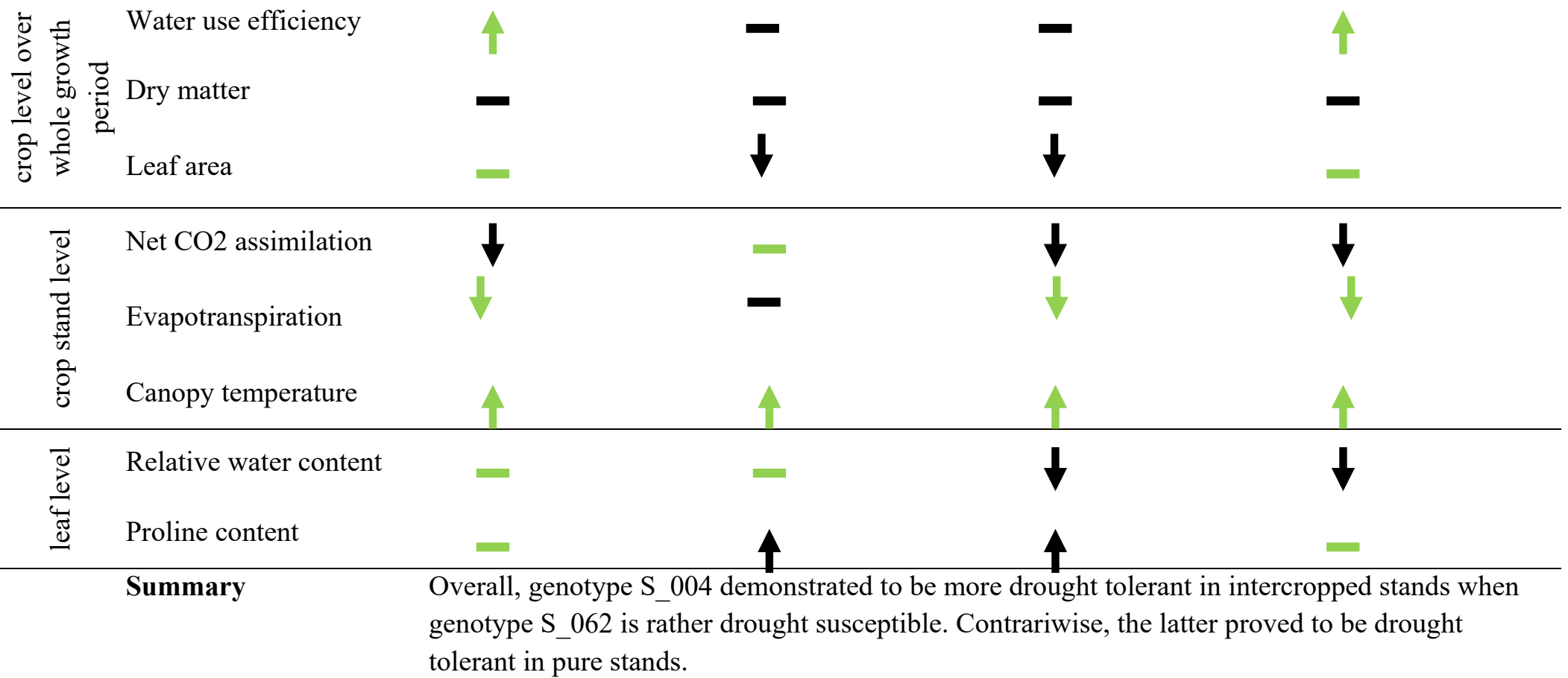




\section{Figures}

Pure stand of

winter faba bean

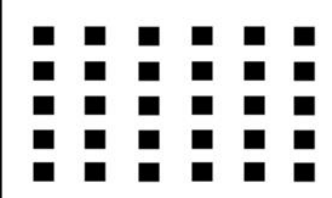

Pure stand of

winter wheat

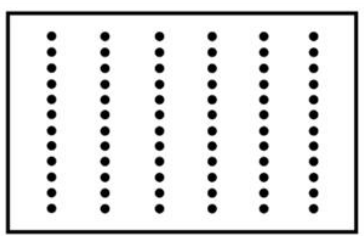

Intercropping

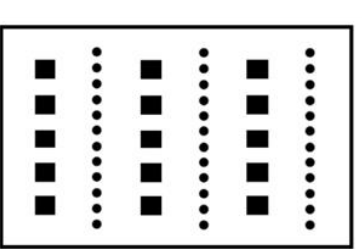

Intercropping Control Water deficit

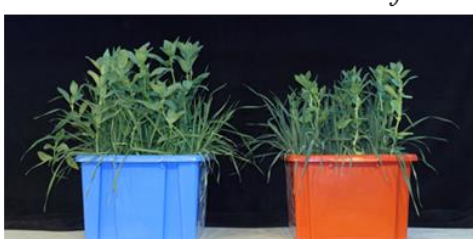

Figure 1: Seeding scheme of winter faba bean and winter wheat in pure stands and intercropping with pot dimensions and row distance. Squares: winter faba bean, circles: winter wheat. The picture (right) shows intercropped stands from control and water deficit treatments at the end of the experiment.

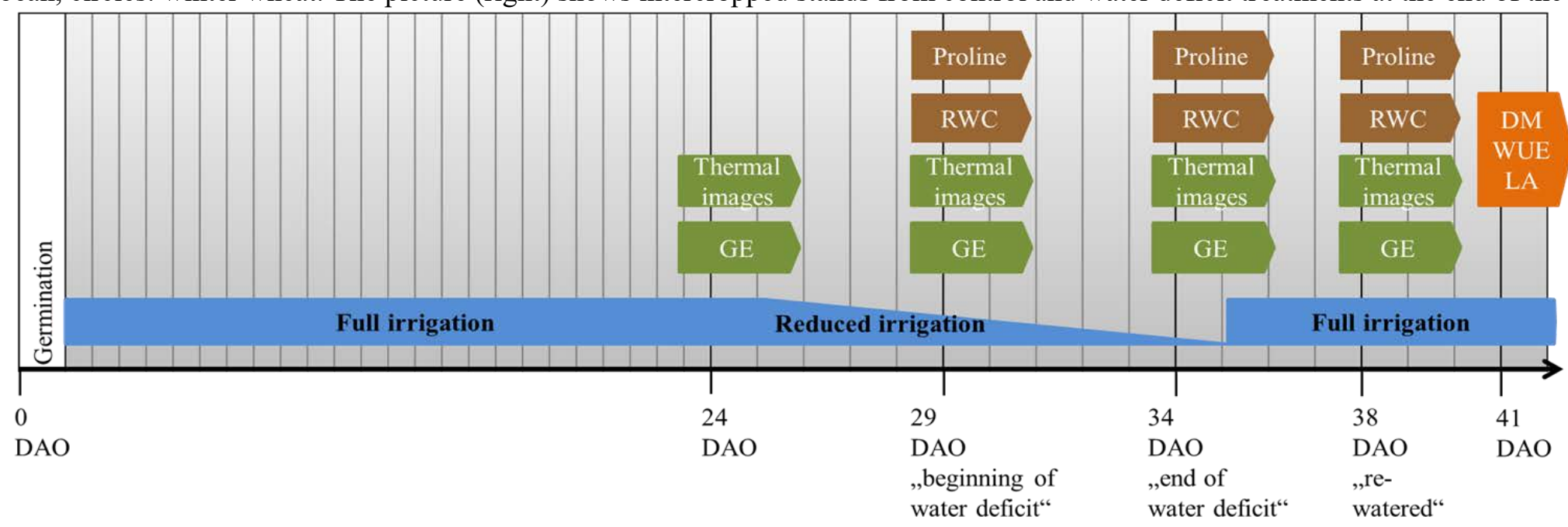

Figure 2: Timeline of the experiment indicating harvests and measurements of canopy surface temperature and net gas exchange of $\mathrm{CO}_{2}(\mathrm{NEE})$ and $\mathrm{H}_{2} \mathrm{O}(\mathrm{ET})$ as well as leaf samplings for relative water content (RWC) and proline content; including the final harvest for dry matter (DM), leaf area (LA) and biomass water use efficiency (WUE). DAO: days after onset of the experiment. Brown: instantaneous measurements on the leaf level; green: instantaneous measurements on the crop stand level; orange: measurements on the crop stand level reflecting the whole growth period. 


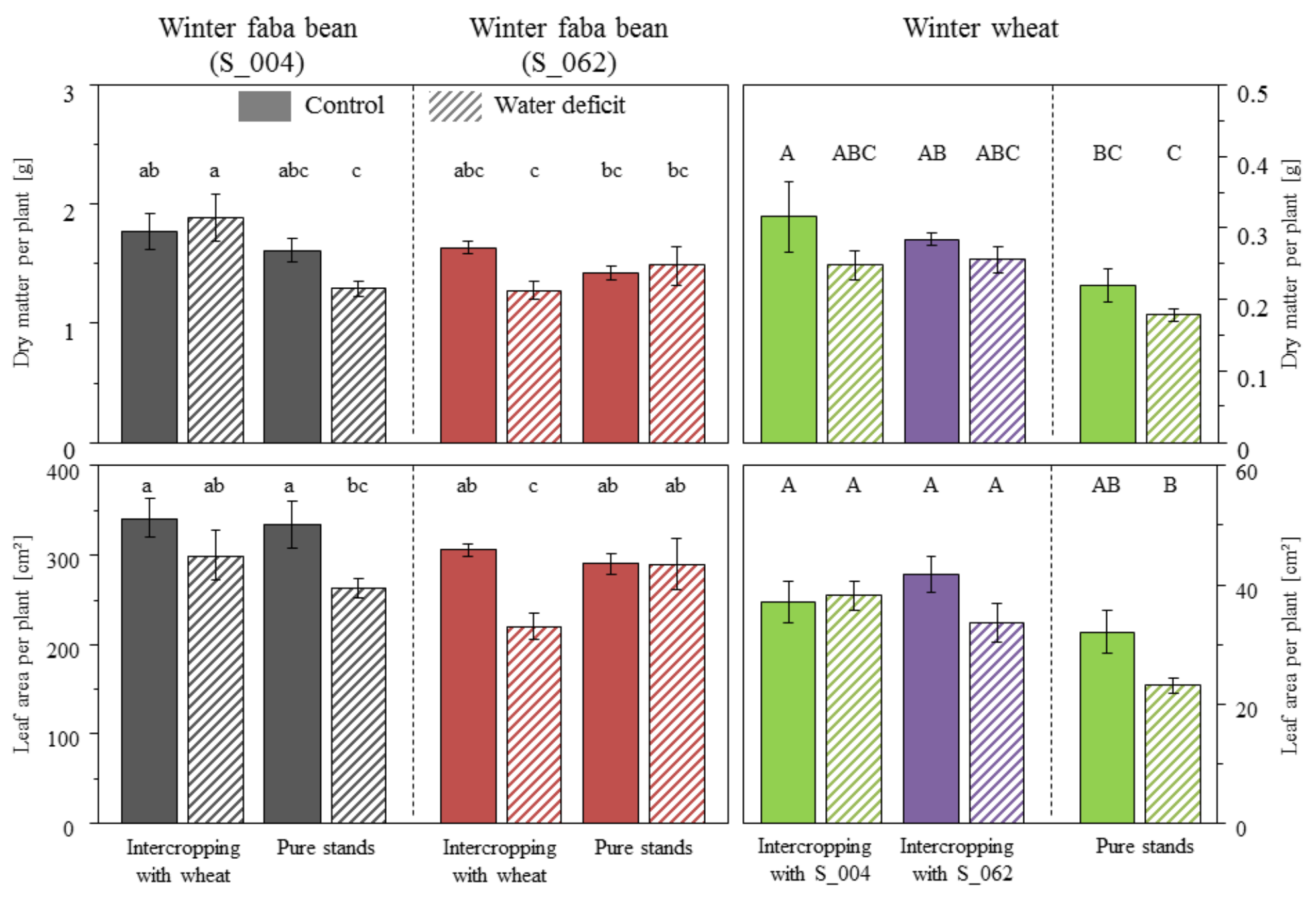

Figure 3: Dry matter and leaf area of winter faba bean genotypes S_004 and S_062 as well as winter wheat in intercropped and pure stands at the end of the experiment. Error bars display the standard error. Different letters indicate significant differences. Duncan-test, $\mathrm{p}<0.05, \mathrm{n}=4$. 


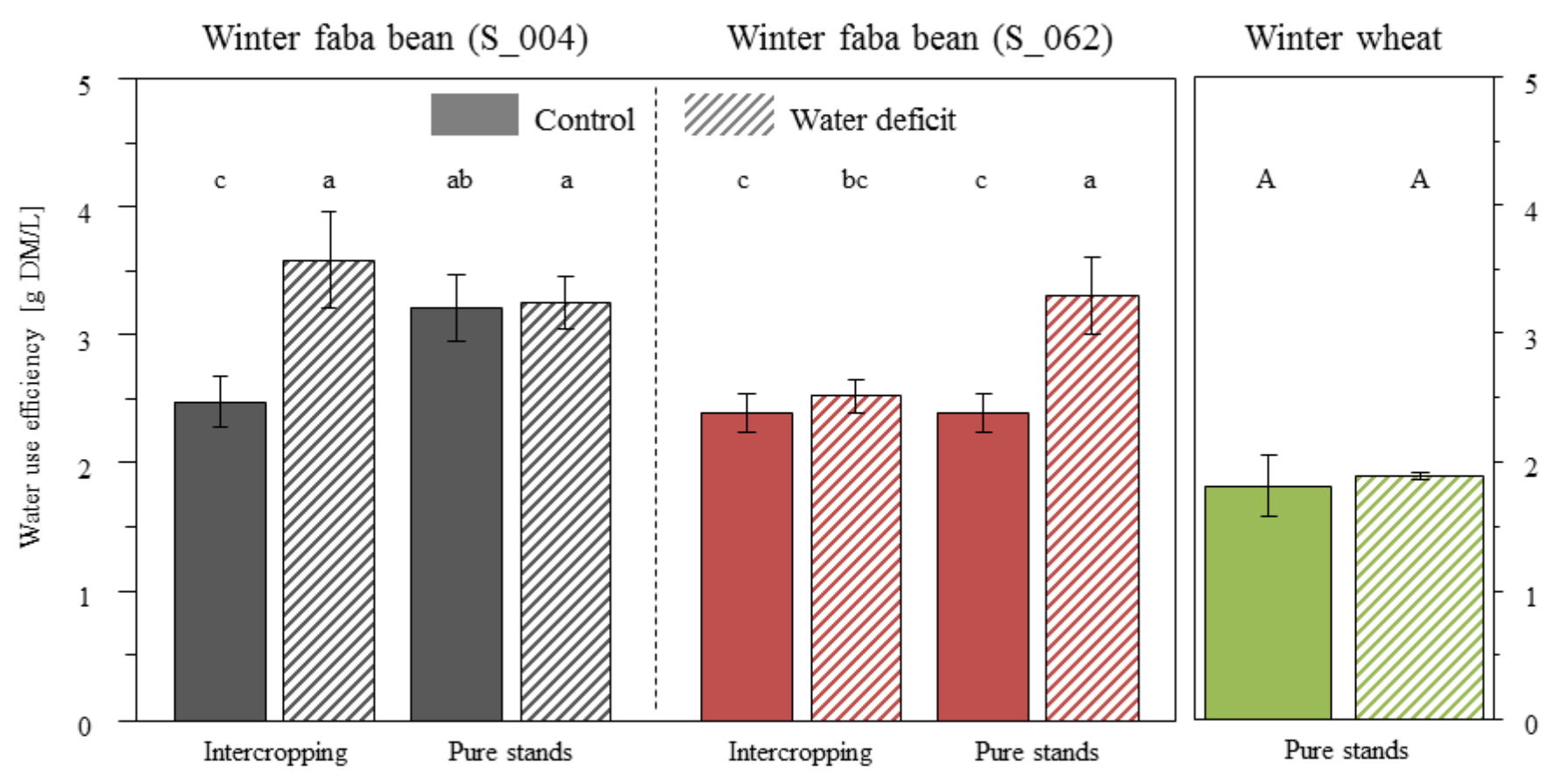

Figure 4: Water use efficiency of winter faba bean genotypes S_004 and S_062 as well as winter wheat in intercropped and pure stands at the end of the experiment (day 41). Intercropping considers the canopy of both species together. Error bars display the standard error. Different letters indicate significant differences. Duncan-test, $\mathrm{p}<0.05, \mathrm{n}=4$. 


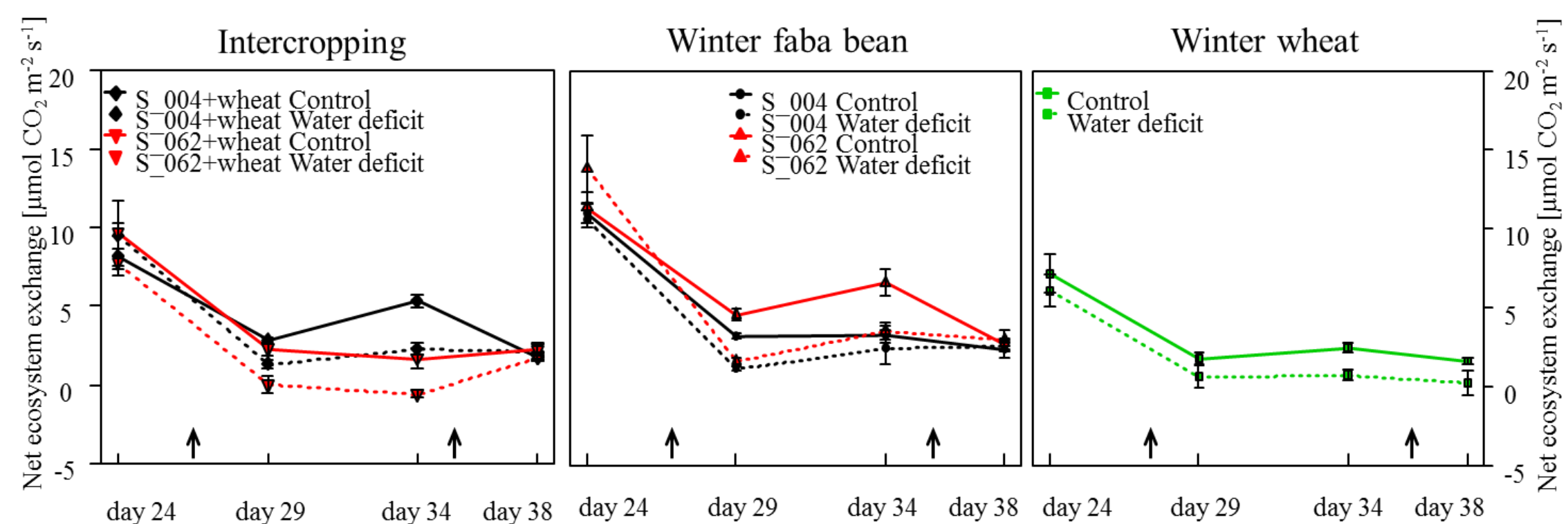

Figure 5: Net ecosystem exchange of $\mathrm{CO}_{2}$ of intercropping and pure stands of winter faba bean and winter wheat. Intercropping considers the canopy of both species together. Arrows mark the beginning and end of water deficit period respectively. Error bars display the standard error. 


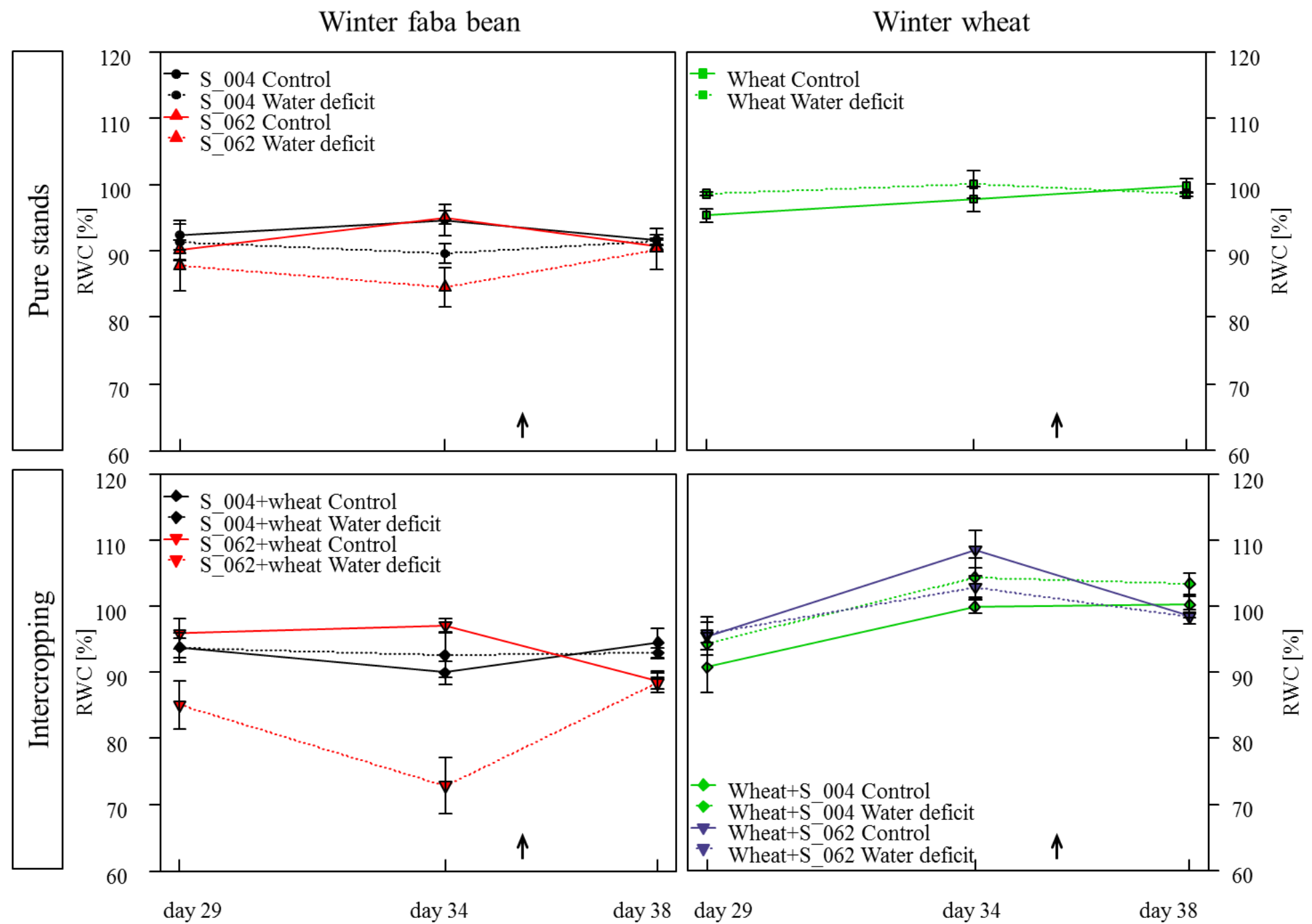

Figure 6: Leaf relative water content (RWC) of winter faba bean and winter wheat in intercropped and pure stands. The arrow marks the end of the water deficit period. Error bars display the standard error. 

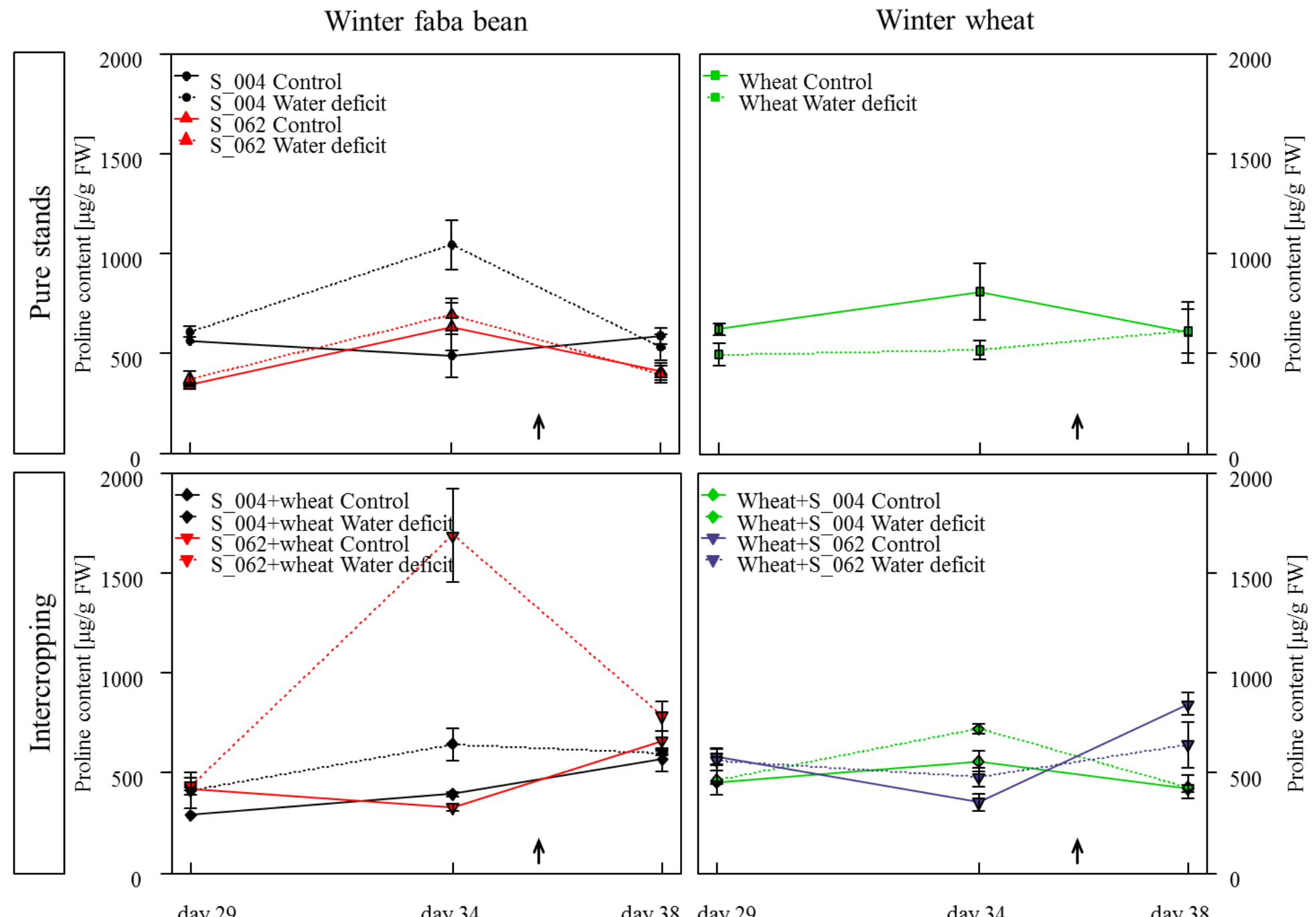

Figure 7: Proline content of winter faba bean and winter wheat in intercropped and pure stands. The arrow marks the end of the water deficit period. Error bars display the standard error. 


\section{References}

Abid, Ghassen, Kamel Hessini, Marwa Aouida, Ibtissem Aroua, Jean-Pierre Baudoin, Yordan Muhovski, Guy Mergeai, et al. 2017. "Agro-Physiological and Biochemical Responses of Faba Bean (Vicia Faba L. Var.'minor') Genotypes to Water Deficit Stress.” Biotechnologie, Agronomie, Société et Environnement= Biotechnology, Agronomy, Society and Environment 21 (2). http://orbi.ulg.ac.be/handle/2268/209948.

Alghamdi, S. S., A. M. Al-Shameri, H. M. Migdadi, M. H. Ammar, E. H. El-Harty, M. A. Khan, and M. Farooq. 2015. "Physiological and Molecular Characterization of Faba Bean (Vicia Faba L.) Genotypes for Adaptation to Drought Stress." Journal of Agronomy and Crop Science 201 (6): 401-9. https://doi.org/10.1111/jac.12110.

Ali, Mohamed B.M., Gregor C. Welna, Ahmed Sallam, Regina Martsch, Christiane Balko, Björn Gebser, Olaf Sass, and Wolfgang Link. 2016. "Association Analyses to Genetically Improve Drought and Freezing Tolerance of Faba Bean ( L.)." Crop Science 56 (3): 1036. https://doi.org/10.2135/cropsci2015.08.0503.

Amede, Tilahun, Sven Schubert, and Karl Stahr. 2003. "Mechanisms of Drought Resistance in Grain Legumes I: Osmotic Adjustment." SINET: Ethiopian Journal of Science 26 (1): $37-46$.

Andreote, Fernando Dini, Ulisses Nunes da Rocha, Welington Luiz Araújo, João Lúcio Azevedo, and Leonard Simon van Overbeek. 2010. "Effect of Bacterial Inoculation, Plant Genotype and Developmental Stage on Root-Associated and Endophytic Bacterial Communities in Potato (Solanum Tuberosum)." Antonie van Leeuwenhoek 97 (4): 389-99. https://doi.org/10.1007/s10482-010-9421-9.

Bargaz, Adnane, Marney E. Isaac, Erik S. Jensen, and Georg Carlsson. 2016. "Nodulation and Root Growth Increase in Lower Soil Layers of Water-Limited Faba Bean Intercropped with Wheat." Journal of Plant Nutrition and Soil Science 179 (4): 537-46. https://doi.org/10.1002/jpln.201500533.

Barrs, H. D., and P. E. Weatherley. 1962. "A Re-Examination of the Relative Turgidity Technique for Estimating Water Deficits in Leaves." Australian Journal of Biological Sciences 15 (3): 413-428.

Bates, L.S., R.P. Waldren, and I.D. Teare. 1973. "Rapid Determination of Free Proline for Water-Stress Studies" 39: 205-7.

Belachew, Kiflemariam Y., Kerstin A. Nagel, and Frederick L. Stoddard. 2017. "Root and Shoot Traits for Drought Tolerance in Faba Bean (Vicia Faba L.)." In . Elche, Spain.

Bhaskara, Govinal B., Tsu-Hao Yang, and Paul E. Verslues. 2015. "Dynamic Proline Metabolism: Importance and Regulation in Water Limited Environments." Frontiers in Plant Science 6 (June). https://doi.org/10.3389/fpls.2015.00484.

Brooker, Rob W., Alison E. Bennett, Wen-Feng Cong, Tim J. Daniell, Timothy S. George, Paul D. Hallett, Cathy Hawes, et al. 2015. "Improving Intercropping: A Synthesis of Research in Agronomy, Plant Physiology and Ecology." New Phytologist 206 (1): 107-17. https://doi.org/10.1111/nph.13132.

Brouder, Sylvie M., and Jeffrey J. Volenec. 2008. "Impact of Climate Change on Crop Nutrient and Water Use Efficiencies." Physiologia Plantarum 133 (4): 705-24. https://doi.org/10.1111/j.1399-3054.2008.01136.x.

Caviglia, O.P, V.O Sadras, and F.H Andrade. 2004. "Intensification of Agriculture in the South-Eastern Pampas.” Field Crops Research 87 (2-3): 117-29. https://doi.org/10.1016/j.fcr.2003.10.002.

Chai, Qiang, Anzhen Qin, Yantai Gan, and Aizhong Yu. 2014. "Higher Yield and Lower Carbon Emission by Intercropping Maize with Rape, Pea, and Wheat in Arid Irrigation Areas." Agronomy for Sustainable Development 34 (2): 535-43. https://doi.org/10.1007/s13593-013-0161-x. 
Chapagain, Tejendra, and Andrew Riseman. 2015. "Nitrogen and Carbon Transformations, Water Use Efficiency and Ecosystem Productivity in Monocultures and Wheat-Bean Intercropping Systems." Nutrient Cycling in Agroecosystems 101 (1): 107-21. https://doi.org/10.1007/s10705-014-9647-4.

Chaves, M.M., J.S. Pereira, J. Maroco, M.L. Rodrigues, C.P.P. Ricardo, M.L. Osório, I. Carvalho, T. Faria, and C. Pinheiro. 2002. "How Plants Cope with Water Stress in the Field. Photosynthesis and Growth" 89: 907-16. https://link.springer.com/article/10.1007/s00442-005-0256-4.

Chen, Daoqian, Shiwen Wang, Beibei Cao, Dan Cao, Guohui Leng, Hongbing Li, Lina Yin, Lun Shan, and Xiping Deng. 2016. "Genotypic Variation in Growth and Physiological Response to Drought Stress and Re-Watering Reveals the Critical Role of Recovery in Drought Adaptation in Maize Seedlings.” Frontiers in Plant Science 6 (January). https://doi.org/10.3389/fpls.2015.01241.

De Mendiburu, Felipe. 2014. "Agricolae: Statistical Procedures for Agricultural Research.” $R$ Package Version 1 (1).

Duncan, David B. 1955. "Multiple Range and Multiple F Tests." Biometrics 11 (1): 1. https://doi.org/10.2307/3001478.

Fahad, Shah, Ali A. Bajwa, Usman Nazir, Shakeel A. Anjum, Ayesha Farooq, Ali Zohaib, Sehrish Sadia, et al. 2017. "Crop Production under Drought and Heat Stress: Plant Responses and Management Options." Frontiers in Plant Science 8 (June). https://doi.org/10.3389/fpls.2017.01147.

Farooq, M., N. Kobayashi, O. Ito, A. Wahid, and R. Serraj. 2010. "Broader Leaves Result in Better Performance of Indica Rice under Drought Stress." Journal of Plant Physiology 167 (13): 1066-75. https://doi.org/10.1016/j.jplph.2010.03.003.

Flexas, J., M. Ribas-Carbó, J. Bota, J. Galmés, M. Henkle, S. Martínez-Cañellas, and H. Medrano. 2006. "Decreased Rubisco Activity during Water Stress Is Not Induced by Decreased Relative Water Content but Related to Conditions of Low Stomatal Conductance and Chloroplast CO2 Concentration." New Phytologist 172 (1): 73-82. https://doi.org/10.1111/j.1469-8137.2006.01794.x.

Hauggaard-Nielsen, Henrik, Bjarne Jørnsgaard, Julia Kinane, and Erik Steen Jensen. 2008. "Grain Legume-Cereal Intercropping: The Practical Application of Diversity, Competition and Facilitation in Arable and Organic Cropping Systems." Renewable Agriculture and Food Systems 23 (1): 3-12. https://doi.org/10.1017/S1742170507002025.

Jákli, Bálint, Merle Tränkner, Mehmet Senbayram, and Klaus Dittert. 2016. "Adequate Supply of Potassium Improves Plant Water-Use Efficiency but Not Leaf Water-Use Efficiency of Spring Wheat.” Journal of Plant Nutrition and Soil Science 179 (6): 733-45. https://doi.org/10.1002/jpln.201600340.

Kamoshita, Akihiko, Reynaldo Rodriguez, Akira Yamauchi, and Len Wade. 2004.

"Genotypic Variation in Response of Rainfed Lowland Rice to Prolonged Drought and Rewatering." Plant Production Science 7 (4): 406-20. https://doi.org/10.1626/pps.7.406.

Kavi Kishor, Polavarapu B. 2015. "Role of Proline in Cell Wall Synthesis and Plant Development and Its Implications in Plant Ontogeny." Frontiers in Plant Science 6. https://doi.org/10.3389/fpls.2015.00544.

Khan, H.R., W. Link, T. J. Hocking, and F. L. Stoddard. 2007. "Evaluation of Physiological Traits for Improving Drought Tolerance in Faba Bean (Vicia Faba L.)." Plant and Soil 292 (1-2): 205-17. https://doi.org/10.1007/s11104-007-9217-5.

Khazaei, Hamid, Kenneth Street, Arja Santanen, Abdallah Bari, and Frederick L. Stoddard. 2013. "Do Faba Bean (Vicia Faba L.) Accessions from Environments with Contrasting Seasonal Moisture Availabilities Differ in Stomatal Characteristics and Related 
Traits?" Genetic Resources and Crop Evolution 60 (8): 2343-57.

https://doi.org/10.1007/s10722-013-0002-4.

Kuchenbuch, Rolf O., and Uwe Buczko. 2011. "Re-Visiting Potassium- and Phosphate-

Fertilizer Responses in Field Experiments and Soil-Test Interpretations by Means of

Data Mining." Journal of Plant Nutrition and Soil Science 174 (2): 171-85.

https://doi.org/10.1002/jpln.200900162.

Kumar, Ravindra, Sanjeev Malaiya, and M. N. Srivastava. 2004. "Evaluation of

Morphophysiological Traits Associated with Drought Tolerance in Rice." Indian Journal of Plant Physiology 9 (3): 305-307.

Lancashire, Peter D., H. Bleiholder, T. Van Den Boom, P. LangelüDdeke, R. Stauss, Elfriede Weber, and A. Witzenberger. 1991. "A Uniform Decimal Code for Growth Stages of Crops and Weeds." Annals of Applied Biology 119 (3): 561-601. https://doi.org/10.1111/j.1744-7348.1991.tb04895.x.

Levene, Howard. 1960. "Robust Tests for Equality of Variances" 1: 278-92.

Link, W., A. A. Abdelmula, E. von Kittlitz, S. Bruns, H. Riemer, and D. Stelling. 1999.

"Genotypic Variation for Drought Tolerance in Vicia Faba." Plant Breeding 118 (6): 477-484.

Lithourgidis, A. S., C. A. Dordas, C. A. Damalas, and D. N. Vlachostergios. 2011. "Annual Intercrops: An Alternative Pathway for Sustainable Agriculture." Australian Journal of Crop Science 5 (4): 396.

Malézieux, E., Y. Crozat, C. Dupraz, M. Laurans, D. Makowski, H. Ozier-Lafontaine, B. Rapidel, S. Tourdonnet, and M. Valantin-Morison. 2009. "Mixing Plant Species in Cropping Systems: Concepts, Tools and Models. A Review." Agronomy for Sustainable Development 29 (1): 43-62. https://doi.org/10.1051/agro:2007057.

Mao, Lili, Lizhen Zhang, Weiqi Li, Wopke van der Werf, Jianhao Sun, Huub Spiertz, and Long Li. 2012. "Yield Advantage and Water Saving in Maize/Pea Intercrop." Field Crops Research 138 (October): 11-20. https://doi.org/10.1016/j.fcr.2012.09.019.

McDonald, G. K., and G. M. Paulsen. 1997. "High Temperature Effects on Photosynthesis and Water Relations of Grain Legumes." Plant and Soil 196 (1): 47-58.

Meyer, R. F., and J. S. Boyer. 1981. "Osmoregulation, Solute Distribution, and Growth in Soybean Seedlings Having Low Water Potentials." Planta 151 (5): 482-89. https://doi.org/10.1007/BF00386543.

Mohamad Zabawi, A.G., and Dennet, M.D.D. 2010. "Responses of Faba Bean (Vicia Faba L. Cv Maris Bead) to Different Levels of Plant Available Water. II. Yield, Water Use and Water Use Efficiency" 38 (2): 145-52.

Morris, R. A., and D. P. Garrity. 1993. "Resource Capture and Utilization in Intercropping: Water." Field Crops Research 34 (3-4): 303-317. https://doi.org/10.1016/03784290(93)90119-8.

Mushagalusa, Gustave Nachigera, Jean-François Ledent, and Xavier Draye. 2008. "Shoot and Root Competition in Potato/Maize Intercropping: Effects on Growth and Yield." Environmental and Experimental Botany 64 (2): 180-88. https://doi.org/10.1016/j.envexpbot.2008.05.008.

Mwanamwenge, J, S.P Loss, K.H.M Siddique, and P.S Cocks. 1999. "Effect of Water Stress during Floral Initiation, Flowering and Podding on the Growth and Yield of Faba Bean (Vicia Faba L.)." European Journal of Agronomy 11 (1): 1-11. https://doi.org/10.1016/S1161-0301(99)00003-9.

Parida, Asish K., Sairam K. Veerabathini, Asha Kumari, and Pradeep K. Agarwal. 2016. "Physiological, Anatomical and Metabolic Implications of Salt Tolerance in the Halophyte Salvadora Persica under Hydroponic Culture Condition." Frontiers in Plant Science 7 (March). https://doi.org/10.3389/fpls.2016.00351. 
R Core Team. 2017. "R: A Language and Environment for Statistical Computing." R Foundation for Statistical Computing, Vienna, Austria. http://www.R-project.org/.

Ramos, Maria Lucrecia Gerosa, Richard Parsons, Janet Irene Sprent, and Euan Kelvin James. 2003. "Effect of Water Stress on Nitrogen Fixation and Nodule Structure of Common Bean." Pesquisa Agropecuária Brasileira 38 (3): 339-347.

Reynolds, M. P., K. D. Sayre, and H. E. Vivar. 1994. "Intercropping Wheat and Barley with N-Fixing Legume Species: A Method for Improving Ground Cover, N-Use Efficiency and Productivity in Low Input Systems." The Journal of Agricultural Science 123 (02): 175. https://doi.org/10.1017/S002185960006843X.

Rubiales, Diego, and Aleksandar Mikic. 2015. "Introduction: Legumes in Sustainable Agriculture." Critical Reviews in Plant Sciences 34 (1-3): 2-3. https://doi.org/10.1080/07352689.2014.897896.

Sallam, Ahmed, Mohammad Ghanbari, and Regina Martsch. 2017. "Genetic Analysis of Winter Hardiness and Effect of Sowing Date on Yield Traits in Winter Faba Bean." Scientia Horticulturae 224 (October): 296-301. https://doi.org/10.1016/j.scienta.2017.04.015.

Schonfeld, Manette A., Richard C. Johnson, Brett F. Carver, and Dolores W. Mornhinweg. 1988. "Water Relations in Winter Wheat as Drought Resistance Indicators." Crop Science 28 (3): 526. https://doi.org/10.2135/cropsci1988.0011183X002800030021x.

Semere, Tzehaye, and Robert J. Froud-Williams. 2001. "The Effect of Pea Cultivar and Water Stress on Root and Shoot Competition between Vegetative Plants of Maize and Pea: Root and Shoot Competition." Journal of Applied Ecology 38 (1): 137-45. https://doi.org/10.1046/j.1365-2664.2001.00570.x.

Senbayram, Mehmet, Merle Tränkner, Klaus Dittert, and Holger Brück. 2015. "Daytime Leaf Water Use Efficiency Does Not Explain the Relationship between Plant N Status and Biomass Water-Use Efficiency of Tobacco under Non-Limiting Water Supply." Journal of Plant Nutrition and Soil Science 178 (4): 682-92. https://doi.org/10.1002/jpln.201400608.

Shapiro, S. S., and M. B. Wilk. 1965. "An Analysis of Variance Test for Normality (Complete Samples).” Biometrika 52 (3/4): 591. https://doi.org/10.2307/2333709.

Siddiqui, Manzer, Mutahhar Al-Khaishany, Mohammed Al-Qutami, Mohamed Al-Whaibi, Anil Grover, Hayssam Ali, Mona Al-Wahibi, and Najat Bukhari. 2015. "Response of Different Genotypes of Faba Bean Plant to Drought Stress." International Journal of Molecular Sciences 16 (5): 10214-27. https://doi.org/10.3390/ijms160510214.

Spinoni, J., G. Naumann, and J. Vogt. 2015. "Spatial Patterns of European Droughts under a Moderate Emission Scenario." Advances in Science and Research 12 (1): 179-86. https://doi.org/10.5194/asr-12-179-2015.

Stoddard, F. L., C. Balko, W. Erskine, H. R. Khan, W. Link, and A. Sarker. 2006. "Screening Techniques and Sources of Resistance to Abiotic Stresses in Cool-Season Food Legumes." Euphytica 147 (1-2): 167-86. https://doi.org/10.1007/s10681-006-4723-8.

Szabados, László, and Arnould Savouré. 2010. "Proline: A Multifunctional Amino Acid." Trends in Plant Science 15 (2): 89-97. https://doi.org/10.1016/j.tplants.2009.11.009.

Tambussi, E.a., J. Bort, and J.1. Araus. 2007. "Water Use Efficiency in C3 Cereals under Mediterranean Conditions: A Review of Physiological Aspects." Annals of Applied Biology 150 (3): 307-21. https://doi.org/10.1111/j.1744-7348.2007.00143.x.

Teulat, B., P. Monneveux, J. Wery, C. Borries, I. Souyris, A. Charrier, and D. This. 1997. "Relationships between Relative Water Content and Growth Parameters under Water Stress in Barley: A QTL Study." New Phytologist 137 (1): 99-107.

Vandermeer, John. 1992. The Ecology of Intercropping. 1. paperback ed. Cambridge: Cambridge Univ. Press. 
Vassileva, Valya, Constant Signarbieux, Iwona Anders, and Urs Feller. 2011. "Genotypic Variation in Drought Stress Response and Subsequent Recovery of Wheat (Triticum Aestivum L.)." Journal of Plant Research 124 (1): 147-54. https://doi.org/10.1007/s10265-010-0340-7.

Verbruggen, Nathalie, and Christian Hermans. 2008. "Proline Accumulation in Plants: A Review." Amino Acids 35 (4): 753-59. https://doi.org/10.1007/s00726-008-0061-6.

Xu, B.C., F.M. Li, and L. Shan. 2008. "Switchgrass and Milkvetch Intercropping under 2:1 Row-Replacement in Semiarid Region, Northwest China: Aboveground Biomass and Water Use Efficiency.” European Journal of Agronomy 28 (3): 485-92. https://doi.org/10.1016/j.eja.2007.11.011.

Yang, Caihong, Gaobao Huang, Qiang Chai, and Zhaoxia Luo. 2011. "Water Use and Yield of Wheat/Maize Intercropping under Alternate Irrigation in the Oasis Field of Northwest China." Field Crops Research 124 (3): 426-32. https://doi.org/10.1016/j.fcr.2011.07.013.

Zampieri, M, A Ceglar, F Dentener, and A Toreti. 2017. "Wheat Yield Loss Attributable to Heat Waves, Drought and Water Excess at the Global, National and Subnational Scales." Environmental Research Letters 12 (6): 064008. https://doi.org/10.1088/1748-9326/aa723b.

Zegada-Lizarazu, Walter, Yasuhiro Izumi, and Morio Iijima. 2006. "Water Competition of Intercropped Pearl Millet with Cowpea under Drought and Soil Compaction Stresses" 9 (2): 123-32. 


\section{Supplemental Material}

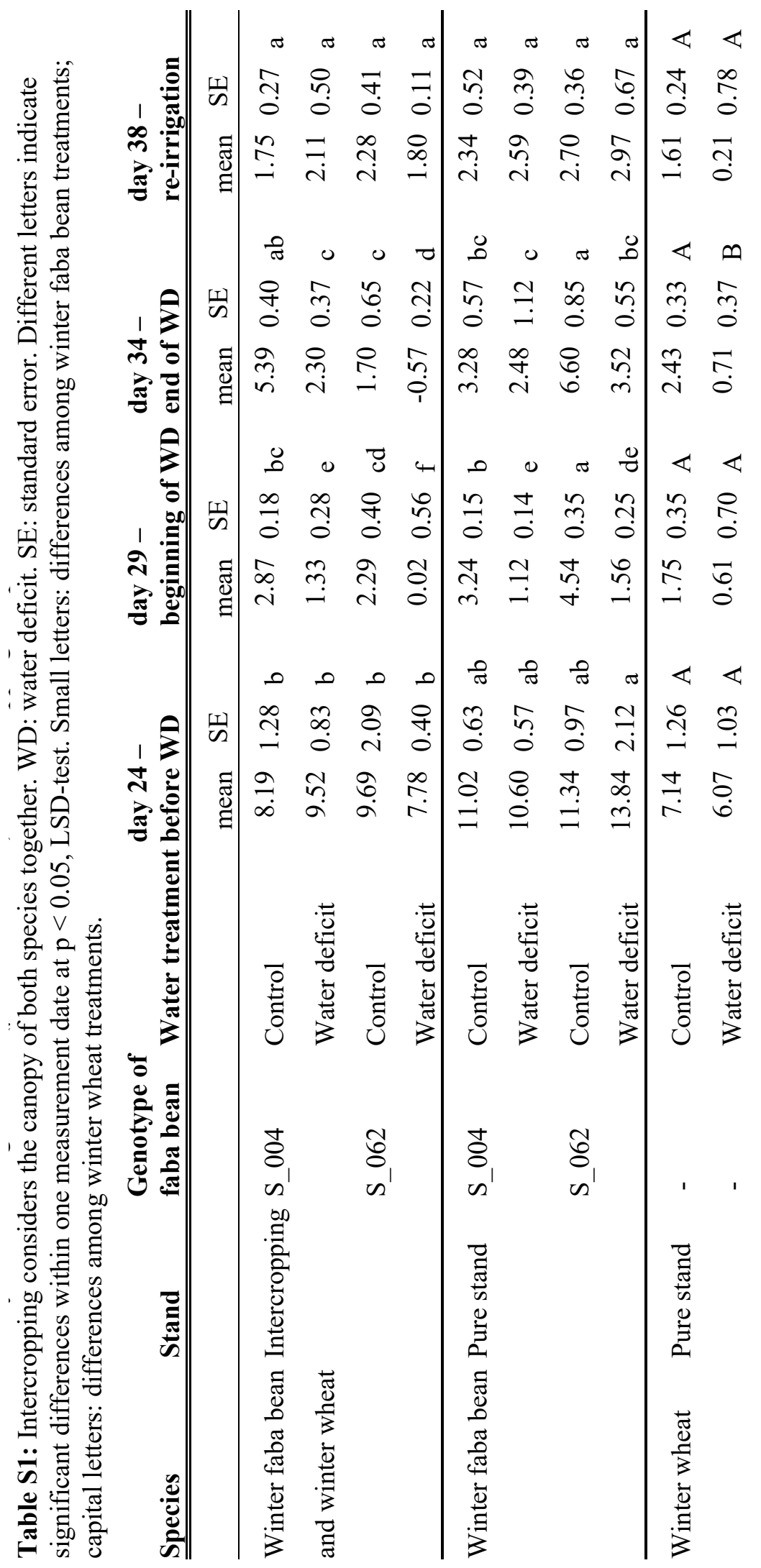


Table S2: Evapotranspiration ( $\mathrm{mmol} \mathrm{H}_{2} \mathrm{O} \mathrm{m}^{-2} \mathrm{~s}^{-1}$ ) of intercropping and pure stands of winter faba bean and winter wheat. Intercropping considers the canopy of both species together. WD: water deficit. SE: standard error. Different letters indicate significant differences within one measurement date at $\mathrm{p}<0.05$, LSD-test. Small letters: differences among winter faba bean treatments; capital letters: differences among winter wheat treatments.

\begin{tabular}{|c|c|c|c|c|c|c|c|c|c|c|c|}
\hline \multirow[t]{2}{*}{ Species } & \multirow[t]{2}{*}{ Stand } & \multirow[t]{2}{*}{$\begin{array}{l}\text { Genotype of } \\
\text { faba bean }\end{array}$} & \multirow[t]{2}{*}{$\begin{array}{l}\text { Water } \\
\text { treatment } \\
\end{array}$} & \multicolumn{2}{|c|}{$\begin{array}{l}\text { day } 24- \\
\text { before WD }\end{array}$} & \multicolumn{2}{|c|}{$\begin{array}{l}\text { day } 29- \\
\text { beginning of WD }\end{array}$} & \multicolumn{2}{|c|}{$\begin{array}{l}\text { day } 34- \\
\text { end of WD }\end{array}$} & \multicolumn{2}{|c|}{$\begin{array}{l}\text { day } 38 \text { - } \\
\text { re-irrigation }\end{array}$} \\
\hline & & & & mean & $\mathrm{SE}$ & mean & SE & mean & $\mathrm{SE}$ & mean & $\mathrm{SE}$ \\
\hline \multirow{4}{*}{$\begin{array}{l}\text { Winter faba bean } \\
\text { and winter wheat }\end{array}$} & \multirow{4}{*}{ Intercropping } & S_004 & Control & 1.5 & $0.07 \mathrm{a}$ & 1.0 & $0.08 \mathrm{a}$ & 1.8 & $0.09 \mathrm{~b}$ & 1.0 & $0.07 \mathrm{ab}$ \\
\hline & & & Water deficit & 2.1 & $0.22 \mathrm{a}$ & 0.5 & $0.05 \mathrm{~b}$ & 0.8 & $0.07 \mathrm{de}$ & 1.0 & $0.07 \mathrm{ab}$ \\
\hline & & S_062 & Control & 1.6 & $0.23 \mathrm{a}$ & 1.1 & $0.15 \mathrm{a}$ & 1.4 & $0.04 \mathrm{bc}$ & 1.0 & $0.06 \mathrm{ab}$ \\
\hline & & & Water deficit & 1.7 & $0.05 \mathrm{a}$ & 0.4 & $0.03 \mathrm{~b}$ & 0.5 & $0.03 \mathrm{e}$ & 0.7 & $0.05 \mathrm{~b}$ \\
\hline \multirow[t]{4}{*}{ Winter faba bean } & \multirow[t]{4}{*}{ Pure stand } & S_004 & Control & 1.7 & $0.21 \mathrm{a}$ & 1.1 & $0.14 \mathrm{a}$ & 1.2 & $0.18 \mathrm{~cd}$ & 1.3 & $0.08 \mathrm{a}$ \\
\hline & & & Water deficit & 1.6 & $0.12 \mathrm{a}$ & 0.4 & $0.07 \mathrm{~b}$ & 0.8 & $0.33 \mathrm{de}$ & 1.2 & $0.19 \mathrm{a}$ \\
\hline & & S_062 & Control & 1.4 & $0.21 \mathrm{a}$ & 1.2 & $0.10 \mathrm{a}$ & 2.5 & $0.19 \mathrm{a}$ & 1.1 & $0.03 \mathrm{a}$ \\
\hline & & & Water deficit & 1.8 & $0.46 \mathrm{a}$ & 0.4 & $0.02 \mathrm{~b}$ & 1.1 & $0.17 \mathrm{~cd}$ & 1.1 & $0.16 \mathrm{a}$ \\
\hline \multirow[t]{2}{*}{ Winter wheat } & \multirow[t]{2}{*}{ Pure stand } & - & Control & 1.5 & $0.22 \mathrm{~A}$ & 0.6 & $0.06 \mathrm{~A}$ & 1.0 & $0.15 \mathrm{~A}$ & 0.7 & $0.09 \mathrm{~A}$ \\
\hline & & - & Water deficit & 1.3 & $0.14 \mathrm{~A}$ & 0.4 & $0.06 \mathrm{~A}$ & 0.6 & $0.03 \mathrm{~B}$ & 0.5 & $0.06 \mathrm{~A}$ \\
\hline
\end{tabular}


Table S3: Canopy surface temperature $\left({ }^{\circ} \mathrm{C}\right)$ of intercropping and pure stands of winter faba bean and winter wheat. Intercropping considers the canopy of both species together. WD: water deficit. SE: standard error. Different letters indicate significant differences within one measurement date at $p<0.05$, LSD-test. Small letters: differences among winter faba bean treatments; capital letters: differences among winter wheat treatments.

\begin{tabular}{|c|c|c|c|c|c|c|c|c|c|c|c|}
\hline \multirow[t]{2}{*}{ Species } & \multirow[t]{2}{*}{ Stand } & \multirow[t]{2}{*}{$\begin{array}{l}\text { Genotype of } \\
\text { faba bean } \\
\end{array}$} & \multirow[t]{2}{*}{$\begin{array}{l}\text { Water } \\
\text { treatment } \\
\end{array}$} & \multicolumn{2}{|c|}{$\begin{array}{l}\text { day } 24- \\
\text { before WD }\end{array}$} & \multicolumn{2}{|c|}{$\begin{array}{l}\text { day } 29 \text { - } \\
\text { beginning of WD }\end{array}$} & \multicolumn{2}{|c|}{$\begin{array}{l}\text { day } 34- \\
\text { end of WD }\end{array}$} & \multicolumn{2}{|c|}{$\begin{array}{l}\text { day } 38 \text { - } \\
\text { re-irrigation } \\
\end{array}$} \\
\hline & & & & mean & $\mathrm{SE}$ & mean & $\mathrm{SE}$ & mean & $\mathrm{SE}$ & mean & $\mathrm{SE}$ \\
\hline \multirow{4}{*}{$\begin{array}{l}\text { Winter faba bean } \\
\text { and winter wheat }\end{array}$} & Intercropping & S_004 & Control & 22.6 & $0.85 \mathrm{ab}$ & 23.2 & $0.39 \mathrm{~d}$ & 23.7 & $0.24 \mathrm{e}$ & 24.6 & $0.12 \mathrm{ab}$ \\
\hline & & & Water deficit & 23.9 & $0.43 \mathrm{a}$ & 24.7 & $0.26 \mathrm{bc}$ & 25.3 & $0.34 \mathrm{bc}$ & 24.3 & $0.17 \mathrm{ab}$ \\
\hline & & S_062 & Control & 23.4 & $0.61 \mathrm{ab}$ & 23.8 & $0.18 \mathrm{~cd}$ & 24.2 & $0.19 \mathrm{de}$ & 24.9 & $0.20 \mathrm{a}$ \\
\hline & & & Water deficit & 22.1 & $0.17 \mathrm{~b}$ & 25.8 & $0.38 \mathrm{ab}$ & 25.4 & $0.16 \mathrm{~b}$ & 25.2 & $0.10 \mathrm{a}$ \\
\hline \multirow[t]{4}{*}{ Winter faba bean } & Pure stand & S_004 & Control & 23.7 & $0.47 \mathrm{ab}$ & 23.1 & $0.28 \mathrm{~d}$ & 23.7 & $0.12 \mathrm{e}$ & 24.5 & $0.29 \mathrm{ab}$ \\
\hline & & & Water deficit & 23.8 & $0.74 \mathrm{ab}$ & 26.0 & $0.46 \mathrm{a}$ & 25.3 & $0.28 \mathrm{bc}$ & 24.0 & $0.34 \mathrm{~b}$ \\
\hline & & S_062 & Control & 22.8 & $0.38 \mathrm{ab}$ & 25.8 & $0.35 \mathrm{ab}$ & 24.7 & $0.19 \mathrm{~cd}$ & 25.2 & $0.56 \mathrm{a}$ \\
\hline & & & Water deficit & 23.8 & $0.37 \mathrm{ab}$ & 26.6 & $0.62 \mathrm{a}$ & 26.4 & $0.23 \mathrm{a}$ & 25.2 & $0.15 \mathrm{a}$ \\
\hline \multirow[t]{2}{*}{ Winter wheat } & Pure stand & - & Control & 23.8 & $0.13 \mathrm{~A}$ & 22.8 & $0.30 \mathrm{~A}$ & 23.8 & $0.20 \mathrm{~A}$ & 23.9 & $0.57 \mathrm{~A}$ \\
\hline & & - & Water deficit & 23.5 & $0.07 \mathrm{~A}$ & 23.6 & $0.44 \mathrm{~A}$ & 24.4 & $0.33 \mathrm{~A}$ & 24.7 & $0.32 \mathrm{~A}$ \\
\hline
\end{tabular}


Table S4: Leaf relative water content (\%) of intercropping and pure stands of winter faba bean and winter wheat. WD: water deficit. SE: standard error. Different letters indicate significant differences within one measurement date at $\mathrm{p}<0.05$, LSD-test. Small letters: differences among winter faba bean treatments; capital letters: differences among winter wheat treatments.

\begin{tabular}{|c|c|c|c|c|c|c|c|c|c|}
\hline \multirow[t]{2}{*}{ Species } & \multirow[t]{2}{*}{ Stand } & \multirow[t]{2}{*}{$\begin{array}{l}\text { Genotype of } \\
\text { faba bean }\end{array}$} & \multirow[t]{2}{*}{$\begin{array}{l}\text { Water } \\
\text { treatment } \\
\end{array}$} & \multicolumn{2}{|c|}{ day 29 - beginning of WD } & \multicolumn{2}{|c|}{ day 34 - end of WD } & \multicolumn{2}{|c|}{ day 38 - re-irrigation } \\
\hline & & & & mean & SE & mean & SE & mean & SE \\
\hline \multirow[t]{8}{*}{ Winter faba bean } & Intercropping & S_004 & Control & 93.8 & $2.17 \mathrm{a}$ & 90.0 & $1.78 \mathrm{ab}$ & 94.6 & $2.22 \mathrm{a}$ \\
\hline & & & Water deficit & 93.8 & $1.54 \mathrm{a}$ & 92.6 & $3.34 \mathrm{a}$ & 93.0 & $0.86 \mathrm{ab}$ \\
\hline & & S_062 & Control & 95.9 & $2.25 \mathrm{a}$ & 97.2 & $0.95 \mathrm{a}$ & 88.9 & $1.37 \mathrm{~b}$ \\
\hline & & & Water deficit & 85.1 & $3.67 \mathrm{~b}$ & 72.9 & $4.27 \mathrm{c}$ & 88.4 & $1.53 \mathrm{~b}$ \\
\hline & Pure stand & S_004 & Control & 92.5 & $2.20 \mathrm{ab}$ & 94.7 & $2.36 \mathrm{a}$ & 91.7 & $0.87 \mathrm{ab}$ \\
\hline & & & Water deficit & 91.5 & $2.78 \mathrm{ab}$ & 89.7 & $1.48 \mathrm{ab}$ & 91.5 & $0.49 \mathrm{ab}$ \\
\hline & & S_062 & Control & 90.3 & $1.46 \mathrm{ab}$ & 95.1 & 0.98 a & 90.8 & $0.94 \mathrm{ab}$ \\
\hline & & & Water deficit & 87.9 & $3.88 \mathrm{ab}$ & 84.5 & $2.95 \mathrm{~b}$ & 90.3 & $3.09 \mathrm{ab}$ \\
\hline \multirow[t]{6}{*}{ Winter wheat } & Intercropping & S_004 & Control & 90.8 & $3.78 \mathrm{~A}$ & 99.9 & $1.00 \mathrm{~B}$ & 100.3 & $1.13 \mathrm{AB}$ \\
\hline & & & Water deficit & 94.3 & $1.63 \mathrm{~A}$ & 104.4 & $2.94 \mathrm{AB}$ & 103.4 & $1.71 \mathrm{~A}$ \\
\hline & & S_062 & Control & 95.5 & $2.04 \mathrm{~A}$ & 108.6 & $2.90 \mathrm{~A}$ & 98.6 & $0.43 \mathrm{~B}$ \\
\hline & & & Water deficit & 95.9 & $2.55 \mathrm{~A}$ & 102.9 & $1.75 \mathrm{AB}$ & 98.4 & $1.10 \mathrm{~B}$ \\
\hline & Pure stand & - & Control & 95.4 & $1.04 \mathrm{~A}$ & 97.8 & $1.89 \mathrm{~B}$ & 99.9 & $1.06 \mathrm{AB}$ \\
\hline & & - & Water deficit & 98.7 & $0.20 \mathrm{~A}$ & 100.1 & $2.03 \mathrm{~B}$ & 98.6 & $0.39 \mathrm{~B}$ \\
\hline
\end{tabular}


Table S5: Leaf proline content ( $\mu \mathrm{g}$ proline $\mathrm{g}^{-1} \mathrm{FW}$ ) of intercropping and pure stands of winter faba bean and winter wheat. WD: water deficit. SE: standard error. Different letters indicate significant differences within one measurement date at $\mathrm{p}<0.05$, LSD-test. Small letters: differences among winter faba bean treatments; capital letters: differences among winter wheat treatments. NA: missing standard error due to single data point.

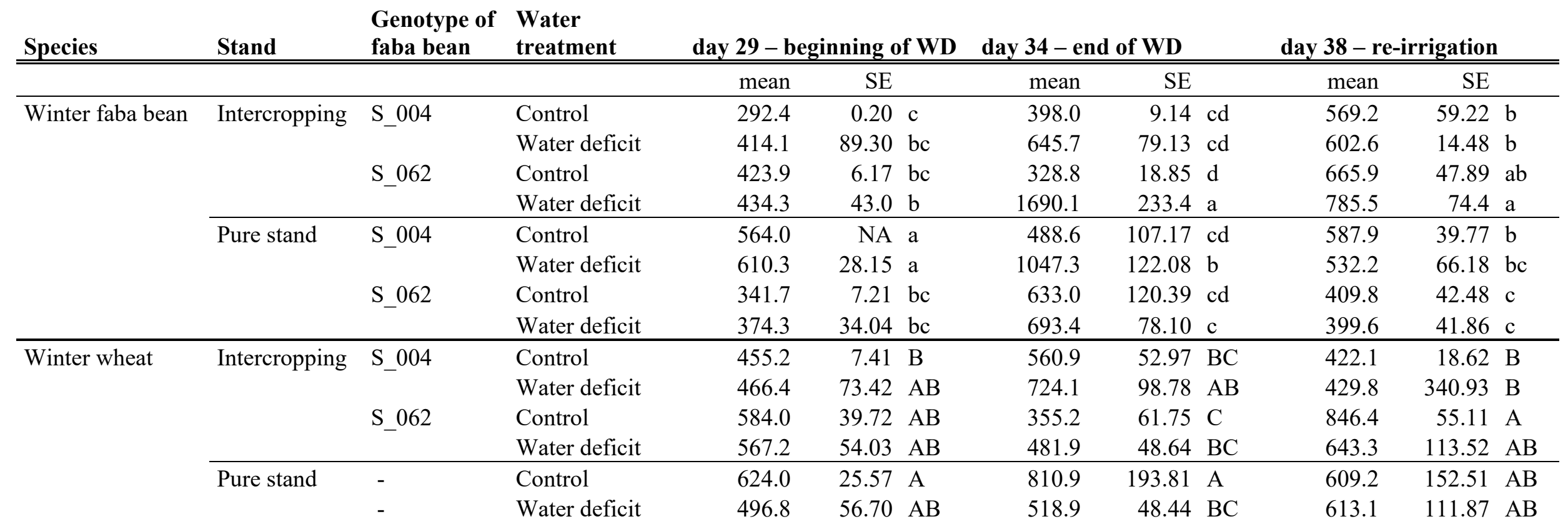




\section{Chapter 4}

Crop genotype and plant compartment determine the response of the active bacterial community towards water deficit

Sandra Granzow, Annika Lingner, Birgit Pfeiffer, Rolf Daniel, Stefan Vidal and Franziska Wemheuer

In preparation for submission 


\title{
Crop genotype and plant compartment determine the response of the active bacterial community towards water deficit
}

\section{Sandra Granzow ${ }^{1,2^{*}}$, Annika Lingner ${ }^{3,2}$, Birgit Pfeiffer ${ }^{3,4}$, Rolf Daniel $^{4}$, Stefan Vidal ${ }^{1}$ and Franziska Wemheuer ${ }^{1}$}

${ }^{1}$ Division of Agricultural Entomology, Department of Crop Sciences, University of Göttingen, Göttingen, Germany

${ }^{2}$ Center of Biodiversity and Sustainable Land Use, University of Göttingen, Göttingen, Germany

${ }^{3}$ Division of Plant Nutrition and Crop Physiology, Department of Crop Sciences, University of Göttingen, Göttingen, Germany

${ }^{4}$ Genomic and Applied Microbiology and Göttingen Genomics Laboratory, Institute of Microbiology and Genetics, University of Göttingen, Göttingen, Germany

* Correspondence:

Sandra Granzow, M.Sc.

sandra.granzow@agr.uni-goettingen.de

Keywords: active bacterial community, intercropping, drought, endophytes, functional profiles

\begin{abstract}
Drought is one of the most important environmental stresses and causes severe decline in crop yields. Sustainable agricultural practices such as new crop genotypes or intercropping might have the potential to alleviate prognosticated changes in precipitation and temperatures. As plant-associated microbial communities are important for plant growth and health, it is of crucial interest to understand how changing environmental conditions such as drought will affect the plant microbiome. However, our understanding about the effects of cropping system and drought on plant microbiome is still scarce. In the present study, we investigated how water deficit change the active bacterial community in the rhizosphere soil and leaf endosphere of winter wheat (genotype: Genius) and two winter faba bean genotypes (S_004; S_062) under different cropping systems. We showed that crop species, genotype and plant compartment significantly influenced the active bacterial community in their composition and diversity. Plant related traits strongly shaped responses of bacteria towards cropping system
\end{abstract}


and water deficit. For example, endophytic bacterial diversity and richness were significantly reduced by water deficit specific for one faba bean genotype which was mainly related in changes of plant physiological parameters such as chlorophyll content and sugar concentration in leaves. In contrast, in the rhizosphere soil alpha-diversity demonstrated a marked resistance towards water deficit, whereas bacterial community composition was significantly altered dependent on faba bean genotype. Predicted functional profiles obtained from 16S rRNA data revealed that similar to composition, crop species and compartment significantly changed functioning; however cropping system and water deficit did not influence these profiles. Obtained results highlight that there are complex interactions between plants, associated microorganisms and their environment that might influence agricultural productivity.

\section{Introduction}

Agricultural droughts can create serious threats to food security by reducing crop yields worldwide (Fahad et al., 2017; Zampieri et al., 2017). It is prognosticated that changes in precipitation and temperatures will increase the duration and frequency of drought periods in Europe in the next 20 years (Christensen and Christensen, 2007; Spinoni et al., 2015). Thus, there is a growing demand for drought tolerant cultivars which improve crop yields even under dry climatic conditions (Nuccio et al., 2018). Plant responses to water deficit include root biomass adjustment, stomatal activity, increased water use efficiency (WUE), or the synthesis of osmolytes such as sugar (Bray, 1997; Osakabe et al., 2014). These responses differ between plant species, genotype, and plant development stage (Mwanamewenge et al., 1999; Abid et al., 2017; Ouyang et al., 2017). In addition, beneficial microorganisms can increase the resistance and resilience to stress conditions such as drought (de Zelicourt et al., 2013). The inoculation with endophytic bacteria including Burkholderia phytofirmans or Bacillus subtilis conferred drought resistance in different plant species including Zea mays (Naveed et al., 2014), Brachypodium distachyon (Gagné-Bourque et al., 2015) and Sorghum bicolor (Xu et al., 2018). For example, Gagné-Bourque et al., (2015) showed that an inoculation of an endophytic Bacillus subtilis strain isolated from switchgrass conferred drought resistance in Brachypodium distachyon via upregulation of drought-response genes, modulation of the DNA methylation process, and an increase in the soluble sugars and starch content of leaves. In addition, endophytic bacteria contribute to nutrient acquisition, promote plant growth and some have also the potential as biocontrol agents (Hardoim et al., 2015; Tian 
et al., 2017). Thus, they are important in a sustainable agriculture (Ryan et al., 2008; Berg et al., 2009).

Previous studies reported significant effects of drought and re-watering on microbial communities (e.g., Xu et al. 2018; Nguyen et al. 2018; Naylor et al., 2017). Recently, Xu et al., (2018) found that drought significantly restructured the bacterial composition in roots of sorghum. In addition, bacteria showed a high degree of resilience after re-watering. Similar effects of drought on the overall bacterial community composition in different rice compartments were observed by Santos-Medellin et al., (2017). The authors concluded that the restructuring of the associated microbiome might contribute to plant survival under extreme environmental conditions. According to Nguyen et al., (2018), agricultural practices such as nitrogen fertilization can restrain the resilience of soil bacterial communities after prolonged drought. Other agricultural practices such as intercropping systems have received more attention in the past decades (Yang et al., 2011; Hu et al., 2017) as intercropping of wheat and maize significantly increased water use and water use efficiency compared to sole cropping (Yang et al., 2011).

So far, most studies investigating the response of microbial communities towards environmental stressors such as drought focused on the entire microbial community (Kaurin et al., 2018; Nguyen et al., 2018; but see Barnard et al., 2013). However, the potentially active microbial community is more sensitive to abiotic stresses and thus is more closely related to ecosystem functionality (Blagodatskaya and Kuzyakov, 2013; Herzog et al., 2015; Taschen et al., 2017). Therefore, it is important to understand how water deficit and different cropping systems alter the active plant-associated bacterial community of important crop species. Hence, the aim of the present study was to investigate the influence of water deficit and rewatering on the metabolically active bacterial communities of winter wheat (Triticum aestivum L.; genotype: Genius) and two genotypes of winter faba bean (Vicia faba L.; S_004 and S_062) under different cropping systems. We hypothesized that (i) composition, diversity and associated taxa of the active bacterial community are affected by crop species, faba bean genotype and plant compartment. We expected further (ii) that response of the bacterial community towards water deficit and cropping system is dependent on these factors. Based on previous findings (Wemheuer et al., 2017), we hypothesized that (iii) bacterial functioning is altered in a different manner towards cropping system and water deficit as the bacterial community composition

To corroborate these hypotheses, wheat and two genotypes of faba bean were grown in monoculture or in row intercropping with (water deficit treatments) or without water stress 
(control treatments). Plant and soil samples were collected at three time points: beginning of water deficit, during water deficit and after re-watering. Bacterial communities in rhizosphere and leaf endosphere were examined by iTag sequencing of bacterial 16S rRNA genes, amplified by two-step reverse transcriptase PCR. Functional profiles of active community members were predicted using Tax4Fun. To our knowledge, this is the first study investigating the combined and separate effect of intercropping and drought stress on the metabolically active plant-associated bacterial community of two important crop species. Obtained results will further deepen our understanding how sustainable agricultural practices and plant-associated microorganisms might mitigate future drought events.

\section{Material and Methods}

\subsection{Plant material}

To examine the combined influence of cropping system and water deficit on the active bacterial community in roots and attached soil (here regarded as rhizosphere soil) and aerial (here regarded as leaf) endosphere, a greenhouse experiment was conducted in autumn 2016. Seeds of the two faba bean genotypes (genotypes: S_004; S_062) were provided by the Institute of Plant breeding of the University of Göttingen. The two winter faba bean genotypes S_004 and S_062) were selected based on a previous field trial-tested inbred lines used within the IMPAC ${ }^{3}$ project (Novel genotypes for mixed cropping allow for improved sustainable land use across arable land, grassland and woodland). The genotype S_004 is characterized by medium height and leaf size, low tillering, late maturity, and high yield. In contrast, genotype S_062 is very short with small leaflets, high tillering, and early maturing. Seeds of winter wheat (genotype: Genius) were provided by Norddeutsche Pflanzenzucht Hans-Georg Lembke KG. All seeds were surface-sterilized by serial washing according to Andreote et al., (2010) with one modification. Immersion in sterile distilled water was performed four times for $30 \mathrm{~s}$. Surface sterilized seeds were placed on wet sterile tissues and germinated at $7{ }^{\circ} \mathrm{C}$ under dark conditions until seedlings developed roots with a length of approximately $4 \mathrm{~cm}$.

\subsection{Experimental design and soil substrate}

Pre-germinated seeds of faba bean and wheat were sown in monoculture or as mixture in polypropylene containers (Sunware; $45.5 \times 36 \times 24 \mathrm{~cm}$ ) in a randomized block design (day 0, DAO, days after onset of experiment). Twelve treatments were established: faba bean monoculture S_004 with or without water deficit (S4_FBM_D/C), faba bean monoculture S_062 with or without water deficit (S62_FBM_D/C), faba bean S_004 intercropped with 
wheat with or without water deficit (S4_FBIC_D/C; WIC_D/C), faba bean S_062 intercropped with wheat with or without water deficit (S62_FBIC_D/C; WIC_D/C), and wheat monoculture with or without water deficit (WM_D/C; Table 1). Each treatment was replicated four times, resulting in a total of 40 containers. We defined two different cropping systems (monoculture and intercropping), whereas cropping regimes compromised each treatment, e.g. WM_D and FBM_C.

For monocultures, 30 faba bean or 72 wheat seeds per container were sown in six rows. For intercropping systems, 36 wheat and 15 bean seeds were sown in alternate rows (Vandermeer, 1992). Each container was filled with air-dried, sieved $(<10 \mathrm{~mm})$ and layered soil from the experimental study site in Reinshof $\left(51.48^{\circ} \mathrm{N}, 9.92^{\circ} \mathrm{E}\right.$ and $157 \mathrm{~m}$ asl.), Germany. The soil volume of each pot accounted for approximately $20 \mathrm{~L}$ with a dry weight of $18 \mathrm{~kg}$. Filling of the pots was performed in layers adding distilled water to each layer to prevent soil compaction. After emergence of the seedlings, the soil was covered by gravel to minimize water loss by evaporation. The soil was classified as Gleyic Fluvisol according to the FAO classification system and contained $21 \%$ clay, $68 \%$ silt and $11 \%$ sand, with $\mathrm{pH} 7.3$ and $2.8 \%$ Humus. Nutrients such as phosphorus (50 mg P/kg dry soil) and potassium (140 $\mathrm{mg} \mathrm{K} / \mathrm{kg}$ dry soil) were in an optimal range according to the German nutrient-availability class system (Kuchenbuch and Buczko 2011).

\subsection{Water management and growth conditions}

During the experiment, photosynthetic photon flux density was $400 \mu \mathrm{mol} \mathrm{m} \mathrm{m}^{-2} \mathrm{~s}^{-1}$ at plant level with a 10/14 h day/night photoperiod. Furthermore, the $\mathrm{CO}_{2}$ concentration reached around $450 \mathrm{ppm}$. There was a relative humidity of $50 \%$ and an average air temperature of $23{ }^{\circ} \mathrm{C}$. Water loss by transpiration was documented by placing the pots permanently on balances (TQ30, ATP Messtechnik, Germany). The weight reduction was measured every 30 minutes in order to constantly determine water consumption. This systems avoids hidden drought due to higher transpiration of increased biomasses (Senbayram et al., 2015). Plants of all treatments were irrigated with distilled water to $90 \%$ field capacity. After a growing period of 24 days and a $\mathrm{BBCH}$ of $14 / 34$ for faba bean and a $\mathrm{BBCH}$ of 14/15 of wheat plants (Lancashire et al.,1991). The amount of water in water deficit treatments was reduced to $75 \%$ compared to control treatments. At day 28, the amount of water in these treatments was further reduced to $25 \%$. Day 34, all water deficit treatments were re-watered with the adequate amount of water according to plant growth and water consumption. All control pots were sufficiently irrigated during the whole experimental duration (6 weeks). 


\subsection{Sampling}

Soil and plant samples were collected from control and water deficit treatments at day 29 (beginning of water deficit), day 34 (during water deficit) and at day 38 (after re-watering of water deficit plants) (Figure 1). For microbial community analysis, one faba bean and two wheat plants per container and harvest were randomly sampled which showed no obvious sign of any disease infection. The roots were gently shaken to remove the non-rhizosphere soil. Rhizosphere soil for $\mathrm{pH}$-value and $\mathrm{C} / \mathrm{N}$ was collected by carefully brushing the roots. Rhizosphere soil and roots of each plant species and each pot were pooled for molecular analysis. All samples for molecular analysis were immediately frozen in liquid nitrogen, transferred to the laboratory and stored at $-80^{\circ} \mathrm{C}$. In total, 96 faba bean (48 plants of each genotype) and 144 wheat plants were collected. Rhizosphere and aerial plant parts of each crop species and container were pooled, resulting in a total of 96 faba bean and 72 wheat samples (Table 1).

\subsection{Edaphic properties and plant stress-related parameters}

For determination of edaphic properties such as total organic carbon and total organic nitrogen subsamples of all rhizosphere samples were dried at $60^{\circ} \mathrm{C}$ for two days and subsequently sieved to $<2 \mathrm{~mm}$. Carbon and nitrogen concentrations from dried subsamples were determined using a NA-1500N analyser (Thermo Fisher Scientific, Waltham, USA). Afterwards, the carbon-to-nitrogen $(\mathrm{C} / \mathrm{N})$ ratio was calculated. The $\mathrm{pH}$ values of all rhizosphere soil samples were measured as follows: $10 \mathrm{~g}$ of dried and sieved soil was added in a small beaker with $25 \mathrm{ml} 0.01 \mathrm{M}$ calcium chloride. Soil solution was homogenized after 30 min and $60 \mathrm{~min}$, and subsequently soil $\mathrm{pH}_{\mathrm{CaCl}}$ was measured.

The height and aerial fresh biomass of all plants used for microbial community analysis were measured. Estimation of chlorophyll concentration was conducted using SPAD502Plus meter (Konica Minolta, Japan) on the youngest fully expanded leaf to survey the availability of plant nitrogen. Three faba beans and one wheat plant per container were measured. For determination of soluble sugar content, approximately $50 \mathrm{mg}$ of plant material

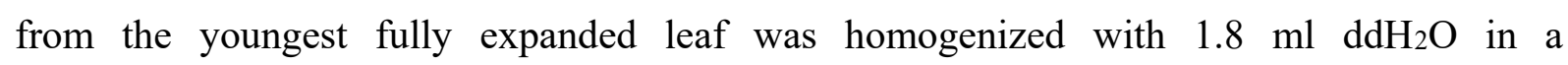
thermoshaker at $60^{\circ} \mathrm{C}$ and subsequently centrifuged at $13,000 \mathrm{rpm}$ for $45 \mathrm{~min}$. Samples were vortexed every 12-15 min. Afterwards, samples were centrifuged at 14,000 rpm for $20 \mathrm{~min}$. Extracted supernatant was stored at $-20^{\circ} \mathrm{C}$ until measurement. Soluble sugar content $(\mathrm{mg} / \mathrm{g}$, dry weight) was determined using the Sucrose/D-Glucose/D-Fructose kit as recommended by the manufacturer (R-Biopharm, Mannheim) with modifications; all volumes were reduced to 
1/4. Moreover, glucose was added to sucrose, and an additional cuvette was used only with glucose and extinction one was measured after 5 minutes. The soluble sugar content was measured spectrophotometrically (V-650, Jasco Corporation, Japan) at $340 \mathrm{~nm}$ using glucose or glucose and sucrose as control. Details on edaphic properties and plant parameters are provided in Table S1.

\subsection{Surface sterilization of pant material}

Leaves were surface sterilized according to Wemheuer and Wemheuer (2017). The effectiveness of applied sterilization process was controlled as described previously (Wemheuer et al., 2016). In brief, aliquots of the water used in the final wash step were plated on common laboratory media plates, i.e., Luria-Bertani agar and potato dextrose agar. The plates were incubated in the dark at $25^{\circ} \mathrm{C}$ for at least one week. No growth of microorganisms was observed. In addition, water from the same aliquots was subjected to PCR targeting the bacterial 16S rRNA gene as described below for microbial community analysis. No PCR products were detected.

\subsection{RNA Extraction and Purification}

Environmental RNA of the rhizosphere was extracted from $2 \mathrm{~g}$ soil per sample employing the RNA PowerSoil total RNA isolation kit as recommended by the manufacturer (MoBio Laboratories, Carlsbad, CA, USA, now Qiagen, Hilden, Germany). RNA was extracted from 100 - 250 mg plant material according to Weinbauer et al., (2002) with slight modifications: 2 $\mathrm{ml}$ tubes were used, and all solution volumes were 10-times reduced. In addition, the first vortexing step was performed with a FastPrep ${ }^{\circledR}$ - 24 Classic Instrument (Biomedicals) at 4m/s for 60s. Extracted RNA was purified employing the RNeasy Mini Kit as recommended by the manufacturer (Qiagen, Hilden, Germany) with modifications according to Streit and Daniel (2010). Residual DNA was removed with the TURBO DNA-free ${ }^{\mathrm{TM}}$ kit (Thermo Scientific) from the extracted RNA according to the manufacturer's protocol. In addition, 1/40 volume Ribolock RNase Inhibitor (40U/ $\mu \mathrm{L}$ ) (Thermo Scientific) was added in the first step of the DNA digestion. The absence of DNA was confirmed by PCR using the partial 16s rRNA as target gene for amplification of bacteria. For details of the PCR reaction and cycling conditions as well as the primers see the first PCR according to Wemheuer and Wemheuer (2017). The DNA-free RNA was further purified according to Streit and Daniel (2012). RNA concentrations were determined using a NanoDrop ND-1000 spectrophotometer (NanoDrop Technologies, Wilmington, DE, USA). 


\subsection{Synthesis of cDNA from total RNA}

Purified RNA from 168 plant and 168 rhizosphere samples were converted to cDNA by employing the SuperScript ${ }^{\mathrm{TM}} \mathrm{III}$ reverse transcriptase Kit as recommended by the supplier (Invitrogen, Karlsruhe, Germany) with two modifications. Same reverse primer $1193 \mathrm{r}(20 \mu \mathrm{M})$ was used for the reaction as for the following PCR. After the last step, $0.5 \mu 1$ RNase $\mathrm{H}$ ( 5 $\mathrm{U} / \mu \mathrm{l}$; Fermentas) was added, and samples were incubated for $15 \mathrm{~min}$ at $37^{\circ} \mathrm{C}$ and subsequently for $10 \mathrm{~min}$ at $65^{\circ} \mathrm{C}$. CDNA was stored at $-20^{\circ} \mathrm{C}$.

\subsection{Amplification of $16 \mathrm{~S}$ rRNA gene}

Bacterial communities in leaves and rhizosphere were assessed by PCR approach targeting the V5-V7 region of the 16S rRNA gene. The following primers were used: 799F (Chelius and Triplett, 2001) and 1193R (Bodenhausen et al., 2013; Hartman et al., 2017) containing MiSeq adaptors (underlined) Miseq-799F TCGTCGGCAGCGTCAGATGTGTATAAGAGACAGAACMGGATTAGATACCCKG-3'; MiSeq$1193 R$ 5'GTCTCGTGGGCTCG GAGATGTGTATAAGAGACAGACGTCATCCCCACCTTCC-3'. The PCR mixture $(25 \mu 1)$ contained $5 \mu \mathrm{l}$ of five-fold Phusion GC buffer, $200 \mu \mathrm{M}$ of each of the four deoxynucleoside triphosphates, $4 \mu \mathrm{M}$ of each primer, $0.5 \mathrm{U}$ of Phusion high fidelity DNA polymerase (Thermo Scientific) and approximately $50 \mathrm{ng}$ of cDNA as template. The following thermal cycling scheme was used: initial denaturation at $98^{\circ} \mathrm{C}$ for $30 \mathrm{~s}, 30$ cycles of denaturation at $98^{\circ} \mathrm{C}$ for $15 \mathrm{~s}$, annealing at $53^{\circ} \mathrm{C}$ for $30 \mathrm{~s}$, followed by extension at $72^{\circ} \mathrm{C}$ for $30 \mathrm{~s}$. The final extension was carried out at $72^{\circ} \mathrm{C}$ for $2 \mathrm{~min}$. Negative controls were performed using the reaction mixture without template. Genomic DNA of Escherichia coli strain DH5a was used as template in the positive control. Three independent PCRs were performed per sample. Obtained PCR products per sample were controlled for appropriate size, pooled in equal amounts, and purified using the NucleoMag NGS Clean up (Macherey-Nagel, Düren, Germany).

Quantification of the purified PCR products was performed using the Quant-iT dsDNA HS assay kit and a Qubit fluorometer (Thermo Scientific) as recommended by the manufacturer. Quantified PCR products were barcoded using the Nextera XT-Index kit (Illumina, San Diego, USA) and the Kapa HIFI Hot Start polymerase (Kapa Biosystems, Wilmington, USA). The Göttingen Genomics Laboratory determined the sequences of the partial 16S rRNA genes 
employing the MiSeq Sequencing platform and the MiSeq Reagent Kit v3 (2 x 300 cycles) as recommended by the manufacturer (Illumina).

\subsection{Processing of bacterial community dataset}

Generated sequencing data were initially quality filtered with the Trimmomatic tool version 0.36 (Bolger et al., 2014). Low quality reads were truncated if the quality dropped below 15 in a sliding window of $4 \mathrm{bp}$. Subsequently, all reads shorter than $100 \mathrm{bp}$ and orphan reads were removed. Remaining sequences were merged, quality-filtered and further processed with USEARCH version 10.0.240 (Edgar, 2010). Filtering included the removal of reads shorter than 300 or longer than $500 \mathrm{bp}$ as well as the removal low quality reads (expected error $>1$ ) and reads with more than one ambitious base.

Processed sequences of all samples were concatenated to one file and subsequently dereplicated into unique sequences. These sequences were denoised with the unoise 3 algorithm implemented in USEARCH (Edgar, 2010). Chimeric sequences were initially removed in denovo mode during denoising. Subsequently, remaining chimeric sequences were removed using UCHIME (Edgar et al., 2011) in reference mode with the SILVA SSU Ref NR 99132 database (Quast et al., 2013) as reference data set for bacteria. All zOTUs consisting of one single sequence (singletons) were removed.

Filtered sequences were mapped on remaining unique sequences to determine the occurrence and abundance of each unique sequence in every sample. To assign taxonomy of bacteria chimera-free sequences were classified by BLAST alignment against the most recent SILVA database (Quast et al., 2013) with an e-value threshold of 1e-20. All non-bacterial zOTUs were removed based on their taxonomic classification in the respective database. Final zOTU table is provided in Table S2. Only zOTUs occurring in more than one sample were considered for further statistical analysis. Samples with less than 145 sequences per sample were removed prior statistical analysis, resulting in 323 samples for bacteria.

\subsection{Statistical Analysis}

All statistical analyses were performed using $\mathrm{R}$ version 3.4.0 ( $\mathrm{R}$ Core Team, 2016). Differences were considered as statistically significant with $\mathrm{P} \leq 0.05$. Differences in alpha- or beta-diversity as well as sequencing depth with regard to cropping system and water treatment (yes/no) were tested by a Kruskal-Wallis test. There were no significant differences of the mean sequencing depths between cropping system and water treatment. In consequence, zOTU tables were not rarefied as recommended by McMurdie and Holmes (2014). 
Alpha-diversity indices (Richness, Shannon index of diversity and Michaelis Menten Fit) were calculated in the vegan package version 2.4.4 (Oksanen et al., 2016) and the $d r c$ package version 3.0-1 (Ritz and Streibig, 2016). zOTU table was rarefied using the rrarefy function in vegan and samples with less than 2,935 (rhizosphere soil) and 1,790 (leaves) were removed prior alpha-diversity analysis. Sample coverage was estimated using the MichaelisMenten Fit calculated in R. For this purpose, richness and rarefaction curves were calculated using the picante package version 1.6-2 (Kembel et al., 2010). Richness and diversity were calculated using the specnumber and diversity function, respectively. The Michaelis-Menten Fit was subsequently calculated from generated rarefaction curves using the $M M 2$ model within the $d r c$ package version 3.0-1 (Ritz and Streibig, 2016). All alpha-diversity indices were calculated 10 times. The average from each iteration was used for further statistical analysis. Final table containing bacterial richness, diversity, Michaelis-Menten Fit and coverage is provided in Table S3.

Data were tested for normal distribution with shapiro and homogeneity of variance with leveneTest function with the package car version 2.1-5 (Fox and Weisberg, 2011). For global differences (for all three harvests) between measured edaphic properties and plant parameters were calculated with a linear mixed model with the function lme and the $\mathrm{R}$ package nlme version 3.1-131 (Pinheiro et al., 2017) with pot number as random factor. Data was log-transformed when not normal distributed. F-values were evaluated with ANOVA and type="marginal". In addition, each harvest was tested separately with a post hoc test using Dunn's test with $p$-value adjustment "BH" and the function dunnTest in the R package FSA version 0.8.17 (Ogle, 2016). Alpha-diversity was evaluated with Kruskal-Wallis-test or the post hoc test using dunnTest. Differences in community composition as well as function were investigated by permutational multivariate analysis of variance (PERMANOVA; Anderson, 2001) based on Bray-Curtis distance matrices using 999 random permutations. OTU tables were subsampled ten times and all tables were summed up to account for low abundant species. Global differences (all three harvests) in crop species and compartment were tested with Adonis and specified with "strata=pot". A significant $p$-value in PERMANOVA for betadiversity can be driven by true biological differences, differences within group (variance) or both (Anderson, 2001). In case of significant $p$-values in PERMANOVA, we tested for differences in homogeneity using permutational analysis of multivariate dispersions (PERMDISP, Anderson, 2006) with 999 permuations. NMDS, PERMANOVA and PERMDISP were run using functions; metaMDS, adonis and betadisper, respectively, in the $\mathrm{R}$ package vegan (Oksanen et al., 2016). Differences in community composition were 
visualized using the metaMDS function within the vegan package (Oksanen et al., 2016). To investigate in differences between cropping cropping regimes, pairwise Adonis with $p$-value adjustment "BH" based on Bray-Curtis distances were used (Martinez Arbizu, 2017).

To identify zOTUs highly associated to cropping regime and crop genotype with regard to plant compartment, multipattern analyses were applied. For that purpose, bacteria were investigated using the multipatt function from the IndicSpecies package version 1.7.6 (DeCáceres and Legendre, 2009). Only bacterial zOTUs found in at least three samples were used. The biserial coefficients $(\mathrm{R})$ with a particular cropping regime or genotype were corrected for unequal sample size using the function r.g (Tichy and Chytry, 2006). For visualization, a bipartite network was generated using the treatment as source nodes and the taxa as target nodes. Network generation was performed using the edge-weighted spring embedded layout algorithm in Cytoscape version 3.3.0 (Shannon et al., 2003). The results of the multipattern analyses are provided in Table S4. Functional profiles were predicted from obtained 16S rRNA gene data using Tax4Fun2 (Aßhauer et al., 2015). Tax4Fun transforms the SILVA-based zOTU classification into a taxonomic profile of KEGG organisms, which is subsequently normalized by the 16S rRNA copy number (obtained from NCBI genome annotations). Afterwards, KEGG profiles are converted into artificial metagenomes by combining functional profiles calculated for each of the KEGG genomes. Genes involved in nutrient cycling, plant-growth promoting and stress were identified in the resulting profiles and visualized in a heatmap using heatmap function.

\section{Results and Discussion}

\subsubsection{Stress-related plant parameters}

As abiotic stress has been shown to affect plant growth and productivity by imposing certain physiological and biochemical changes, we investigated in several plant-stress related parameters such as soluble sugars or chlorophyll content (Abid et al., 2017). Moreover, intercropping systems have been shown to enhance plant growth compared to monoculture (Song et al. 2007b). Here, we found that biomass of faba bean genotype S_004 and wheat was significantly higher in WIC/FBM compared to WM/FBIC (LMM; $\mathrm{df}=13, \mathrm{~F}=6.73, p=0.022$; $\mathrm{df}=21, \mathrm{~F}=11.15, p=0.0031$ ) (Table 2). Effects of cropping system on height were only observed during harvest 3. Genotype S_004 was significantly taller in monoculture compared to intercropping system (Kruskal-Wallis $\left(\mathrm{KW}\right.$ )-test, $\mathrm{x}^{2}=4.21, \mathrm{df}=1, p=0.04$ ). Chlorophyll content of faba bean genotype S_062 and wheat were significantly influenced by water treatment $(\mathrm{LMM}, \mathrm{df}=13, \mathrm{~F}=9.64, p=0.0084)$ and cropping system $(\mathrm{LMM}, \mathrm{df}=21, \mathrm{~F}=12.71$, 
$p=0.0018$ ), respectively (Table 3). Highest chlorophyll values in S_062 were observed for water deficit treatment/FBIC compared to control/FBM. Linear mixed effect model showed that sucrose was significantly influenced by cropping system in wheat leaves (LMM, $\mathrm{df}=21$, $\mathrm{F}=7.61, p=0.0118$ ). Furthermore, we observed significantly lower values of all three soluble sugar concentrations in S_062 under water deficit compared to control for harvest 2 (Table 4; $\mathrm{KW}$-test, glucose, $\mathrm{x}^{2}=6.89, \mathrm{df}=1, p=0.008$; sucrose, $\mathrm{x}^{2}=4.86, p=0.027$; fructose, $\mathrm{x}^{2}=4.42$, $p=0.035)$.

\subsubsection{Edaphic parameters}

We investigated in several edaphic properties including $\mathrm{pH}$-value, total organic carbon and nitrogen, as previous studies have been shown that cropping system or drought can change chemical characteristics in the rhizosphere soil (Song et al., 2007b; Preece and Peñuelas, 2016). We found that cropping system was the most influencing factor on edaphic properties compared to water treatment. Results of linear mixed effect model showed that $\mathrm{pH}$-value was significantly influenced by cropping system in the rhizosphere of wheat (LMM, $\mathrm{df}=21$, $\mathrm{F}=5.72, p=0.00262$ ). This was mainly observed for harvest 2 , with lowest $\mathrm{pH}$ values under WIC (Table 5). In addition, we observed that $\mathrm{pH}$ value was significantly lower in FBIC compared to FBM for both genotypes specific for harvest 2 (KW-test, S_004 $\mathrm{x}^{2}=6.37, \mathrm{df}=1$,

$p=0.0116 ;$ S_062: $\left.\mathrm{x}^{2}=10.63, \mathrm{df}=1, p=0.0011\right) . \mathrm{C}: \mathrm{N}$ ratio as well as carbon were significantly affected by cropping system in the wheat rhizosphere (LMM, C:N ratio: $\mathrm{df}=21, \mathrm{~F}=5.96$, $p=0.023$; carbon: $\mathrm{df}=21, \mathrm{~F}=4.47, p=0.046$ ). Total nitrogen and carbon had significant lower values under WIC compared to WM for harvest 3 whereas the opposite was observed for harvest 2. Cropping system also significantly influenced C:N ratio in S_004 (S_004; LMM, $\mathrm{df}=13, \mathrm{~F}=50.54, p<0.0001)$ and had highest $\mathrm{C}: \mathrm{N}$ ratio was found under FBIC compared to FBM (Table 6).

\subsection{Overall bacterial community}

The response of bacterial communities of faba bean and wheat towards water deficit under different cropping systems was assessed by Illumina (MiSeq) sequencing targeting the bacterial 16S rRNA gene. After removal of low quality reads, PCR artefacts (chimeras) and non-target contaminations, a total of 3,592,483 high quality reads were obtained for bacteria Table S3. Sequence numbers per sample varied between 145 to 71,557 (average 11,120) and obtained sequences were grouped into 6,560 bacterial zOTUs (Table S2). Calculated 
Michaelis-Menten Fit and rarefaction curves confirmed that the majority of the bacterial community was recovered by the surveying effort (Figures S1, S2, Table S3).

Bacteria were dominated by seven phyla ( $>0.5 \%$ of all sequences across all samples): Proteobacteria (74.71\%), Actinobacteria (9.56\%), Bacteroidetes (9.49\%), Gemmatimonadetes (2.77\%), Acidobacteria (1.16\%), Chloroflexi (0.72\%) and Entotheonellaeota (0.58\%) (Figure 2, 3). The Proteobacteria were dominated by Gammaproteobacteria (60.12\%), followed by Alpha- (8.75\%) and Deltaproteobacteria (5.84\%). The abundant bacterial phyla were present in all samples and accounted for $99.0 \%$, of all sequences analysed in this study. At family level, Burkolderiaceae (49.55\%), Microscillaceae (4.19\%) and Halomonaceae (3.11\%) dominated the bacterial dataset. The most frequent bacterial genus was Curvibacter $(29.34 \%)$. Other abundant genera were, for example, Mitsuaria (10.72\%), Halomonas (1.85\%), Rhizobacter (1.64\%), Allorhizobium-Neorhizobium-Pararhizobium-Rhizobium (1.59\%) and Ohtaekwangia (1.59\%). Results are in line with previous studies investigating in plantassociated bacterial communities (Gdanetz et al., 2017; Naylor et al., 2017; Zhou et al., 2017).

\subsection{Bacterial community was strongly affected by crop species and compartment}

According to our first hypothesis that crop species, genotype and compartment affect bacterial community, we calculated diversity (represented by the Shannon index H') and richness (number of observed unique sequences). Leaf bacterial richness was significantly influenced by crop species. We observed significantly higher bacterial richness in faba bean plants for harvest 1 and $2\left(\mathrm{KW}\right.$-test, $\mathrm{H} 1, \mathrm{x}^{2}=5.99, \mathrm{df}=1, p=0.014, \mathrm{H} 2, \mathrm{x}^{2}=6.50, \mathrm{df}=1$, $p=0.011$ ). In the rhizosphere, we found that bacterial richness was significantly higher in wheat compared to faba bean (KW-test, $\mathrm{H} 1, \mathrm{x}^{2}=4.08, \mathrm{df}=1, p=0.043$ ). Genotype did not influence bacterial alpha-diversity.

In line with our hypothesis, plant compartment and crop species significantly influenced microbial community composition (Table 9). Compartment explained $40.7 \%$ of the variance in the bacterial dataset (PERMANOVA, $p=0.001$ ), whereas crop species explained $3.3 \%$ and $1.9 \%$ of the variance in the leaf endosphere and rhizosphere soil (PERMANOVA, leaves, $p=0.001$; rhizosphere, $p=0.003$ ). Faba bean genotype only influenced bacterial community composition in the rhizosphere specific for harvest 1 (Table 9). Here, genotype explained $6.1 \%$ of the variance (PERMANOVA, $p=0.016$ ). Moreover, several bacterial taxa differed in their abundance with regard to crop species and compartment. For example, Curvibacter was the predominant bacterial genus found in the leaf endosphere with an average relative abundance of $53.80 \%$, whereas in the rhizosphere 
Curvibacter was found with $4.72 \%$ abundance (Figure 2, 3). Higher relative abundance of Halomonas was recorded in wheat leaves $(4.83 \%)$ compared to faba bean genotypes (S_004: 1.58\% and S_062: 1.29\%). In addition, Allorhizium-Neorhizobium-Pararhizobium-Rhizobium was more often found in faba bean rhizosphere (4.08\%) compared to wheat $(0.06 \%)$.

In line with our results, previous studies showed significant effects of crop species on bacterial composition and diversity in the rhizosphere soil and plant endosphere (Wemheuer et al., 2017; Zhou et al., 2017). Partly in contrast to our observation, previous studies reported that plant genotype significantly affected bacterial community in the rhizosphere (Mahoney, Yin and Hulbert, 2017; Li et al., 2018) and leaf endosphere (Wagner et al., 2016; Montanari-Coelho et al., 2018). Recently, Mahoney, Yin and Hulbert (2017) found that bacterial community composition in the rhizosphere was significantly influenced by nine wheat genotypes. In addition, only 24 (out of the 1305) most abundant OTUs differed significantly in frequency between genotypes, indicating that host genotype played just a minor but significant role in bacterial diversification. Similar, other studies assumed that plant microbiome composition is more environmentally dependent rather than on the plant genotype per se and that host-adapted microbes may have been selected as they provide some selective advantage for their host (Bulgarelli et al., 2012; Vandenkoornhuyse et al., 2015).

\subsection{Crop genotype and plant compartment influenced response of bacterial community towards water deficit and cropping system}

We further hypothesized that crop species, genotype and compartment would alter the response of bacterial communities towards water deficit and cropping system. Cropping system significantly influenced bacterial diversity and richness but only in the leaf endosphere (Table 8). In leaves of S_062, the cropping system FBIC had significantly higher bacterial diversity and richness compared to FBM only in harvest 1 (KW-test, shannon, $\mathrm{x}^{2}=8.37, \mathrm{df}=1$, $p=0.0038$; richness, $\mathrm{x}^{2}=5.36, p=0.02$ ). In addition, bacterial richness was significantly higher under WIC compared to WM only in harvest 3 (KW-test, $\mathrm{x}^{2}=5.1, p=0.023$ ).

Evaluation of bacterial community composition with NMDS based on Bray-Curtis analysis showed no evident influence of cropping system in the rhizosphere; however a smaller separation between S4_FBIC and S4_FBM was observed in the leaf endosphere specific for harvest 1 (Figure 4). PERMANOVA found that cropping system significantly influenced bacterial community composition in faba bean S_004, and explained $16.0 \%$ of the variance (PERMANOVA, $p=0.026)$. 
Previous studies reported that intercropping significantly influenced bacterial community composition and increased bacterial diversity in soil (Song et al., 2007b; Yang et al., 2016). Yang et al., (2016) investigated in 10 different spring crops grown in monoculture and intercropping system and found that intercropping increased bacterial diversity in the rhizosphere, however, responses were also crop species dependent. So far, most research focused on bacterial communities in the soil but studies which investigated in the leaf endosphere under different cropping systems are scarce (Gdanetz et al., 2017; Granzow et al., 2017). For example, Granzow and coworkers (2017) investigated in different plant compartments of faba bean and wheat grown in monoculture, row intercropping and mixed intercropping system. They reported that changes in bacterial diversity and richness were mainly recorded between mixed and row intercropping or mixed intercropping and monoculture in soil and root endosphere. Furthermore, leaf endophytes were not affected in their diversity or composition through cropping system (Granzow et al., 2017) which is in contrast to our results. We speculate that different soil type, plant species/genotypes or plant growth stage might contribute to the contradictory results, as these factors have been shown to influence microbial communities (Wagner et al., 2016; Gdanetz et al., 2017).

Furthermore, we observed that water deficit significantly influenced bacterial alphadiversity but only in the leaf endosphere (Table 8). In faba bean leaves of S_062, bacterial diversity and richness significantly decreased under water deficit compared to well-watered plants specific for harvest 2 (KW-test, shannon, $\mathrm{x}^{2}=5.33, \mathrm{df}=1, p=0.021$; richness, $\mathrm{x}^{2}=8.04$, $p=0.0046)$. Moreover, the combination of water deficit and cropping system significantly affected leaf bacterial diversity $\left(\mathrm{KW}\right.$-test, $\left.\mathrm{x}^{2}=7.95, \mathrm{df}=3, p=0.05\right)$ and richness (KW-test, $\left.\mathrm{x}^{2}=9.49, \mathrm{df}=3, p=0.02\right)$ in S_062 for harvest 1 . Dunn's test showed that the cropping regime S62_FBIC_D had significantly higher richness compared to S62_FBM_D, whereas diversity was significantly higher in S62_FBIC_D compared to S62_FBM_C.

Bacterial community composition in the rhizosphere of faba bean genotype S_062 showed a distinct clustering between control and water deficit treatments in the NMDS analysis for harvest 1 (Figure 5). PERMANOVA also confirmed that water deficit significantly influenced bacterial community composition in the rhizosphere of genotype S_062 specific or harvest 1, which explained $20.9 \%$ of the variance (PERMANOVA, $p=0.001$ ). However, dispersion among water treatments was not homogenous (PERMDISP, $\mathrm{F}=18.26, p=0.002)$. Cropping regimes did not affect bacterial community composition.

Partly in accordance to our observation, previous studies demonstrated that water deficit decreased bacterial diversity in the root endosphere of several plant species (Naylor et 
al., 2017; Fitzpatrick et al., 2018). For example, Naylor and coworkers (2017) observed that water deficit decreased bacterial diversity in different plant compartments of 18 grass species including the root endosphere. However, they also indicated that water deficit effects were dependent on plant growth stage, and strongest response of bacterial diversity was displayed at early flowering compared to late flowering. On the other hand, Fitzpatrick et al., (2018) reported that bacterial diversity was not significantly influenced by water deficit in the root endosphere of 30 different angiosperms; however a slight decrease was observed in drought treated plants. For the present study, we speculate that drought-induced plant responses including physiological and molecular changes (Abid et al., 2017) were responsible for the genotype specific effect on the leaf microbiome. In line with this assumption, we observed that chlorophyll concentration and all three soluble sugars (glucose, sucrose, and fructose) in leaves significantly changed according to water deficit in genotype S_062 specific for harvest 2 similar to alpha-diversity (Table 3,4$)$.

As previous studies have shown (Henry et al., 2007; Preece and Peñuelas, 2016), plant stress through drought can change root exudation pattern dependent on plant species. Thus, soil microbial communities might be affected indirectly through rhizodeposition (Preece and Peñuelas, 2016). Similar, we recorded changes in bacterial community composition towards water deficit dependent on faba bean genotype. Partly in line with our finding, SantosMedellin and coworkers (2017) investigated in four different rice cultivars and plant compartments and recorded compartment-specific cultivar effects on the drought response for the bacterial community composition. However, they only found few individual OTUs which showed differential responses to drought based on genotype, indicating that communities assembled in each cultivar responded relative similar towards drought.

In contrast to our results, studies found that effect of water deficit on bacterial community composition was most pronounced in plant endosphere compared to rhizosphere (Naylor et al., 2017; Santos-Medellin et al., 2017; Fitzpatrick et al., 2018). As each plant compartment represents distinct niches for microbial communities in terms of exposure towards drought (Wallace et al., 2018), we also assume that response can differ. However, it is a complex interplay of plant specific stress response and plant-microbe associations towards abiotic stress. Thus, bacterial response towards drought might differ dependent on crop species, genotype or plant growth stage as already indicated in previous research (Naylor et al., 2017; Fitzpatrick et al., 2018). Furthermore, contradictory findings between studies might be attributed to experimental settings such as drought intensities or soil characteristics, and precipitation history in soil which has been shown to affect soil microbial communities 
and their response towards drought (Kaisermann et al., 2015; Kaisermann et al. 2017; SantosMedellin et al., 2017).

\subsection{Associated bacterial taxa are altered by cropping regimes and genotypes}

To identify bacterial taxa responsible for the observed differences among water deficit and cropping system or genotypes, we performed a multipattern analysis to investigate which microorganisms are significantly associated with those treatments (Table S4). In general, soil communities harbored more associated zOTUs than endophyte communities which is most probably related with higher sequence numbers in soil compared to endosphere samples. The number of significantly associated taxa in the leaf endosphere decreased in the water deficit treatments for harvest 2 compared to harvest 1 (Figure 6,7). In the rhizosphere soil, wheat cropping regimes harbored the most number of associated bacterial taxa whereas faba bean cropping regimes the least number. In addition, we found that drought cropping regimes especially from faba bean showed more associated bacterial taxa from the phylum Actinobacteria than well-watered plants which was most pronounced for harvest 1 in both compartments. Similar to the community composition, we found significantly associated bacterial taxa dependent on genotype and water treatment (Figure 7). We recorded most associated taxa for genotype S_062 under drought in the leaf endosphere and rhizosphere soil for harvest 1 . Here, associated taxa were mainly assigned to Actinobacteria that belonged to the bacterial genus Mycobacterium spp. in the leaf endosphere and the bacterial family Gaiellales in the rhizosphere soil. For harvest 2, the genus Blastococcus spp. (Actinobacteria) was mainly associated with the genotype S_004 under drought.

In line with our observation, previous studies indicated that specific bacterial phyla are enriched under drought conditions especially in the endosphere (Naylor et al., 2017; SantosMedellin et al., 2017; Fitzpatrick et al., 2018). Naylor et al., (2017) performed quantification of absolute abundance of Actinobacteria in roots under drought and control conditions using qPCR. Results demonstrated that Actinobacteria exhibited a marked increase in absolute abundance in drought-treated roots for different $\mathrm{C} 3$ and $\mathrm{C} 4$ grass species. In addition, they also confirmed that significant indicator taxa for drought-treated plants belonged mainly to Actinobacteria which was similar to our results (Naylor et al., 2017). A possible explanation for these findings might be that Actinobacteria increase in abundance under drought, whereas sensitive taxa diminish because this bacterial phylum is well-known to be highly tolerant for life under stressful abiotic conditions like drought (Bull and Asenjo, 2013; Kavamura et al., 
2013). We further hypothesize that crops under water deficit selected competent microorganisms which provide the crops some degree of tolerance or assist in their development through growth promotion (Goh et al., 2013; Coleman-Derr and Tringe, 2014). In accordance with this assumption, we found the plant-associated bacterium Mycobacteria significantly associated with drought plants which has been reported to possess ACC deaminase activity that is responsible in enhancing plant growth (Cardinale et al., 2015). In addition, the bacterial genus Blastococcus has been often found in arid microbiome surveys as endophyte or soil inhabitant which has also been described as plant growth promoter (Hamedi and Mohammadipanah, 2015; Tahtamouni et al., 2016). Observed taxa are frequently described in plant microbiome surveys (Gdanetz et al., 2017; Naylor et al., 2017) but their specific roles in association with plants under water deficit remains relative unclear.

\subsection{Functional profiles of bacterial communities are altered by crop species and plant compartment}

We further hypothesized that bacterial functioning is altered in a different manner as bacterial community composition towards water deficit and cropping system. To clarify this hypothesis, functional profiles were predicted from obtained 16S rRNA gene data using Tax4Fun2 (Table S5). Functional profiles significantly differed between crop species (PERMANOVA, leaves, $\mathrm{R}^{2}=5.5 \%, \quad p=0.001$; rhizosphere, $\mathrm{R}^{2}=8.7 \%, \quad p=0.001$ ) and compartment (PERMANOVA, $\mathrm{R}^{2}=31.9 \%, p=0.001$ ); however cropping system and water deficit did not alter overall functioning.

To gain deeper insights into bacterial functioning, we focused on predicted abundances of genes involved in nitrogen cycling, i.e., nitrite reductase, plant growth promotion, i.e., amidase or in stress, i.e., catalase (Figure 8, 9). In general, genes involved in dissimilatory nitrate reduction such as nitrate reductase were more abundant in wheat leaves compared to faba bean. In addition, the gene acetolactate decarboxylase [EC: 4.1.1.5] putatively involved in plant growth promotion was more abundant in wheat rhizosphere compared to faba bean. We also found differences between cropping regimes. For example, for harvest 1 we observed in S4_FBM_D rhizosphere higher abundances of predicted genes involved in nitrification such as ammonia monooxygenase [EC: 1.14.99.39] compared to S4_FBM_C. For harvest 2, in average higher predicted abundances of genes involved in stress, plant growth promotion and nitrogen metabolism were found in S4_FBM_D compared to S4_FBM_C. In the leaf endosphere, we found higher predicted abundance of genes involved in dissimilatory nitrate 
reduction [EC: 1.7.1.15; EC: 1.7.5.1 1.7.99.-] in the cropping regime WIC_C compared to WM_C and WIC_D for harvest 1 .

As we already confirmed it for the bacterial community composition, crop species was an important factor in changing functional profiles in the leaf endosphere and rhizosphere soil. In line with this, Wemheuer et al., (2017) demonstrated that the functional profiles of the bacterial endophytic community differed significantly between three different grass species. Moreover, they also reported that response of endophyte community composition and diversity in comparison to functioning differed towards agricultural practices, indicating that function and phylogeny of different bacteria are not necessarily related to each other (Wemheuer et al., 2017). This assumption might further explain our observation that water deficit and cropping system changed community composition but not functioning. Moreover, Vandenkkoornhyuse et al., (2015) suggested that functional differences between crop species might be related to an accessory microbiome unique for each plant. An accessory microbiome contains more dispensable functions or microorganisms whose presence is related to interactions with the surrounding environmental conditions (Vandenkoornhuyse et al., 2015).

\section{Conclusion}

To date, the combined effect of cropping system and water deficit on active bacterial communities in leaf endosphere and rhizosphere soil of two important crop species have not been studied using large-scale metabarcoding. In line with our hypotheses, we demonstrated that crop species, genotype and plant compartment significantly influenced the active bacterial community in their composition, diversity and associated taxa. These plant related traits strongly shaped response of bacteria towards water deficit and cropping system. In accordance with our third hypothesis, functional profiles were not affected by cropping system and water deficit but crop species and compartment altered functioning. Obtained results highlight that there are complex interactions between plants, associated microorganisms and their environment that might influence agricultural productivity.

\section{Acknowledgment}

This study is part of the project IMPAC ${ }^{3}$ and was funded by the Federal Ministry of Education and Research (FKZ 031A351A). The authors thank Prof. Dr. Wolfgang Link from the Working Group "Breeding Research Faba Bean" (Division of Plant Breeding at the University of Göttingen) for providing the seed material. 


\section{Tables}

Table 1. Sampling numbers for each container and harvest.

Treatments /Compartments

ID

Rhizosphere

Leaves

Plants/ Treatment

\begin{tabular}{|c|c|c|c|c|}
\hline \multicolumn{5}{|c|}{ Harvest 1} \\
\hline Faba bean monoculture S_004 & S4_FBM & $1(8, n=8)$ & $1(8, n=8)$ & 8 \\
\hline Faba bean monoculture S_062 & S62_FBM & $1(8, n=8)$ & $1(8, n=8)$ & 8 \\
\hline Faba bean intercropping S_004 & S4_FBIC & $1(8, n=8)$ & $1(8, n=8)$ & 8 \\
\hline Faba bean intercropping S_062 & S62_FBIC & $1(8, n=8)$ & $1(7, n=8)$ & 8 \\
\hline Wheat monoculture & WM & $2(8, n=8)$ & $2(7, n=8)$ & 16 \\
\hline Wheat intercropped & WIC & $2(15, \mathrm{n}=16)$ & $2(16, n=16)$ & 32 \\
\hline \multicolumn{5}{|c|}{ Harvest 2} \\
\hline Faba bean monoculture S_004 & S4_FBM & $1(7, n=8)$ & $1(8, n=8)$ & 8 \\
\hline Faba bean monoculture S_062 & S62_FBM & $1(7, n=8)$ & $1(8, n=8)$ & 8 \\
\hline Faba bean intercropping S_004 & S4_FBIC & $1(8, n=8)$ & $1(8, n=8)$ & 8 \\
\hline Faba bean intercropping $S_{-} 062$ & S62_FBIC & $1(8, n=8)$ & $1(8, n=8)$ & 8 \\
\hline Wheat monoculture & WM & $2(8, n=8)$ & $2(8, n=8)$ & 16 \\
\hline Wheat intercropped & WIC & $2(15, n=16)$ & $2(16, n=16)$ & 32 \\
\hline \multicolumn{5}{|c|}{ Harvest 3} \\
\hline Faba bean monoculture S_004 & S4_FBM & $1(8, n=8)$ & $1(7, n=8)$ & 8 \\
\hline Faba bean monoculture $S \_062$ & S62_FBM & $1(7, n=8)$ & $1(7, n=8)$ & 8 \\
\hline Faba bean intercropping S_004 & S4_FBIC & $1(8, n=8)$ & $1(7, n=8)$ & 8 \\
\hline Faba bean intercropping S_062 & S62_FBIC & $1(8, n=8)$ & $1(8, n=8)$ & 8 \\
\hline Wheat monoculture & WM & $2(8, n=8)$ & $2(8, n=8)$ & 16 \\
\hline Wheat intercropped & WIC & $2(15, n=16)$ & $2(14, n=16)$ & 32 \\
\hline Total (for each harvest) & & 64 & 64 & $32(\mathrm{FB}), 48(\mathrm{~W})$ \\
\hline Total (all) & & 192 & 192 & 240 \\
\hline
\end{tabular}

WM, wheat in monoculture; FBM, faba bean in monoculture, FBIC, faba bean samples in intercropping; WIC, wheat samples in intercropping. Numbers before brackets refer to sampled plants per pot. Numbers in brackets refer to the number of samples left after removal of samples with too low sequencing numbers. Harvest 1 refers to "beginning of water deficit", harvest 2 refers to "during water deficit" and harvest 3 refers to "re-watering". 
Table 2. Height $[\mathrm{cm}]$ and biomass [g] of faba bean and wheat plants.

\begin{tabular}{c|ccc|ccc|}
\hline \multicolumn{7}{c}{ Height } \\
Treatment & Harvest 1 & Harvest 2 & Harvest 3 & Harvest 1 & Harvest 2 & Harvest 3 \\
\hline Wheat_C & $37.8 \pm 0.53$ & $37.4 \pm 0.93$ & $37.2 \pm 0.78$ & $1.2 \pm 0.18$ & $1.2 \pm 0.09$ & $1.4 \pm 0.12$ \\
Wheat_D & $37.5 \pm 0.68$ & $36.7 \pm 0.83$ & $37.4 \pm 1.02$ & $1.4 \pm 0.15$ & $1.0 \pm 0.09$ & $1.3 \pm 0.11$ \\
\hline WM & $37.2 \pm 0.83$ & $36.4 \pm 0.90$ & $36.5 \pm 1.06$ & $1.0 \pm 0.04$ & $\mathbf{0 . 9} \pm \mathbf{0 . 0 6 a}$ & $\mathbf{1 . 1} \pm \mathbf{0 . 1 0 a}$ \\
WIC & $37.9 \pm 0.49$ & $37.4 \pm 0.81$ & $37.7 \pm 0.78$ & $1.5 \pm 0.16$ & $\mathbf{1 . 2} \pm \mathbf{0 . 0 8 b}$ & $\mathbf{1 . 5} \pm \mathbf{0 . 1 0 b}$ \\
\hline S4_C & $38.2 \pm 2.30$ & $45.8 \pm 2.92$ & $46.3 \pm 3.27$ & $9.2 \pm 1.60$ & $12.8 \pm 2.02$ & $15.4 \pm 2.88$ \\
S4_D & $39.5 \pm 1.82$ & $44.5 \pm 1.54$ & $46.0 \pm 2.65$ & $10.1 \pm 1.67$ & $12.4 \pm 1.49$ & $12.4 \pm 2.06$ \\
\hline S4_FBM & $41.3 \pm 1.53$ & $47.0 \pm 2.27$ & $\mathbf{5 0 . 5} \pm \mathbf{2 . 5 3 a}$ & $\mathbf{1 2 . 1} \pm \mathbf{1 . 5 5 a}$ & $13.9 \pm 1.52$ & $17.2 \pm 2.71$ \\
S4_FBIC & $36.4 \pm 2.15$ & $43.3 \pm 2.23$ & $\mathbf{4 1 . 7} \pm \mathbf{2 . 4 0 b}$ & $\mathbf{7 . 2} \pm \mathbf{1 . 1 3 b}$ & $11.3 \pm 1.87$ & $10.6 \pm 1.64$ \\
\hline S62_C & $\mathbf{3 7 . 3} \pm \mathbf{1 . 7 9 A}$ & $\mathbf{4 4 . 4} \pm \mathbf{2 . 4 1 A B}$ & $\mathbf{4 7 . 4} \pm \mathbf{2 . 6 2 B}$ & $9.3 \pm 1.03$ & $\mathbf{1 0 . 8} \pm \mathbf{0 . 6 3 a}$ & $12.0 \pm 1.52$ \\
S62_D & $36.6 \pm 1.68$ & $40.1 \pm 2.20$ & $40.6 \pm 2.39$ & $8.3 \pm 1.19$ & $\mathbf{8 . 7} \pm \mathbf{0 . 7 4 b}$ & $9.8 \pm 0.56$ \\
\hline S62_FBM & $38.7 \pm 1.19$ & $43.7 \pm 1.70$ & $46.0 \pm 1.65$ & $8.3 \pm 1.09$ & $9.4 \pm 0.88$ & $10.6 \pm 0.47$ \\
S62_FBIC & $35.2 \pm 1.95$ & $40.8 \pm 2.91$ & $42.0 \pm 3.48$ & $9.3 \pm 1.14$ & $10.0 \pm 0.67$ & $12.1 \pm 1.70$ \\
\hline
\end{tabular}

Different letters in columns indicate statistically significant differences between treatments (Dunn'sTest or Kruskal-Wallis-test; $p \leq 0.05$, means $\pm \mathrm{SE}$ ). Abbreviations: FBM/WM, faba bean/wheat grown in monoculture; FBIC/WIC, faba bean/wheat intercropped; C, control treatment; D, water deficit treatment. Harvest 1, beginning of water deficit; Harvest 2, during water deficit; Harvest 3, re-watering.

Table 3. Chlorophyll content index measured with a SPAD meter.

\begin{tabular}{c|c|c|c|}
\hline Treatment & Harvest 1 & Harvest 2 & Harvest 3 \\
\hline Wheat_C & $37.5 \pm 1.48$ & $36.6 \pm 1.00$ & $34.4 \pm 1.29$ \\
Wheat_D & $35.4 \pm 1.59$ & $37.1 \pm 1.03$ & $37.7 \pm 1.37$ \\
\hline WIC_C & $\mathbf{3 8 . 9} \pm \mathbf{1 . 7 8 a}$ & $38.0 \pm 1.15$ & $35.8 \pm 1.42$ \\
WIC_D & $\mathbf{3 7 . 7} \pm \mathbf{1 . 1 2 a b}$ & $38.6 \pm 1.02$ & $39.6 \pm 1.45$ \\
WM_C & $\mathbf{3 4 . 8} \pm \mathbf{2 . 3 8 a b}$ & $33.9 \pm 1.02$ & $31.6 \pm 2.20$ \\
WM_D & $\mathbf{2 9 . 2} \pm \mathbf{2 . 8 7 b}$ & $34.1 \pm 1.51$ & $33.9 \pm 1.92$ \\
\hline S4_C & $37.1 \pm 1.33$ & $39.7 \pm 1.54$ & $40.4 \pm 1.40$ \\
S4_D & $\mathbf{3 7 . 6} \pm \mathbf{0 . 9 9 B}$ & $\mathbf{4 2 . 6} \pm \mathbf{1 . 5 7 A B}$ & $\mathbf{4 4 . 9} \pm \mathbf{1 . 4 3 A}$ \\
\hline S4_FBIC_C & $37.6 \pm 0.89$ & $40.7 \pm 2.61$ & $41.4 \pm 2.26$ \\
S4_FBIC_D & $38.2 \pm 1.24$ & $41.8 \pm 2.13$ & $45.0 \pm 2.44$ \\
S4_FBM_C & $36.8 \pm 2.71$ & $38.9 \pm 1.94$ & $39.6 \pm 1.87$ \\
S4_FBM_D & $37.0 \pm 1.65$ & $43.6 \pm 2.54$ & $44.9 \pm 1.89$ \\
\hline S62_C & $\mathbf{3 2 . 0} \pm \mathbf{0 . 6 0 A}$ & $\mathbf{3 6 . 3} \pm \mathbf{0 . 9 6 a B}$ & $\mathbf{3 8 . 2} \pm \mathbf{1 . 3 1 a B}$ \\
S62_D & $\mathbf{3 3 . 4} \pm \mathbf{0 . 7 5 A}$ & $\mathbf{4 2 . 1} \pm \mathbf{0 . 7 5 b B}$ & $\mathbf{4 3 . 3} \pm \mathbf{1 . 3 1 b B}$ \\
\hline S62_FBIC_C & $31.8 \pm 1.05$ & $\mathbf{3 5 . 4} \pm \mathbf{1 . 3 0 a}$ & $\mathbf{3 7 . 4} \pm \mathbf{2 . 5 5 b}$ \\
S62_FBIC_D & $33.5 \pm 1.14$ & $\mathbf{4 3 . 2} \pm \mathbf{0 . 3 3 b}$ & $\mathbf{4 6 . 4} \pm \mathbf{0 . 6 4 a}$ \\
S62_FBM_C & $32.3 \pm 0.73$ & $\mathbf{3 7 . 2} \pm \mathbf{1 . 4 5 a b}$ & $\mathbf{3 9 . 2} \pm \mathbf{1 . 0 2 b}$ \\
S62_FBM_D & $33.5 \pm 1.15$ & $\mathbf{4 1 . 0} \pm \mathbf{1 . 3 1 a b}$ & $\mathbf{4 0 . 3} \pm \mathbf{1 . 2 2 a b}$ \\
\hline
\end{tabular}

Different small and large letters in columns and rows indicate statistically significant differences between treatments (Dunn'sTest or Kruskal-Wallis-test; $p \leq 0.05$, means $\pm \mathrm{SE}$ ). Abbreviations: FBM/WM, faba bean/wheat grown in monoculture; FBIC/WIC, faba bean/wheat intercropped; C, control treatment; D, water deficit treatment. Harvest 1, beginning of water deficit; Harvest 2, during water deficit; Harvest 3, re-watering. 
Table 4. Soluble sugar concentrations [in \%] of glucose, fructose and sucrose in crop leaves.

\begin{tabular}{|c|c|c|c|c|c|c|c|c|c|}
\hline \multirow[b]{2}{*}{ Treatment } & \multicolumn{3}{|c|}{ Glucose } & \multicolumn{3}{|c|}{ Fructose } & \multicolumn{3}{|c|}{ Sucrose } \\
\hline & Harvest 1 & Harvest 2 & Harvest 3 & Harvest 1 & Harvest 2 & Harvest 3 & Harvest 1 & Harvest 2 & Harvest 3 \\
\hline \multirow{2}{*}{$\begin{array}{l}\text { Wheat_C } \\
\text { Wheat_D }\end{array}$} & $8.5 \pm 1.22 \mathrm{AB}$ & $6.4 \pm 0.55 \mathrm{aA}$ & $9.5 \pm 0.60 \mathrm{aB}$ & $10.5 \pm 1.19 A$ & $7.1 \pm 0.80 \mathrm{~B}$ & $16.4 \pm 0.95 \mathrm{C}$ & $35.5 \pm 5.90$ & $51.6 \pm 7.40$ & $43.2 \pm 9.62$ \\
\hline & $9.8 \pm 0.99$ & $8.9 \pm 0.93 b$ & $7.9 \pm 0.64 b$ & $10.5 \pm 0.51 \mathrm{AB}$ & $9.1 \pm 0.85 \mathrm{~A}$ & $14.6 \pm 1.33 B$ & $39.7 \pm 6.26$ & $44.0 \pm 5.52$ & $33.5 \pm 6.24$ \\
\hline \multirow{4}{*}{$\begin{array}{l}\text { WIC_C } \\
\text { WIC_D } \\
\text { WM_C } \\
\text { WM_D }\end{array}$} & $7.1 \pm 1.54 b$ & $6.4 \pm 0.80 \mathrm{ab}$ & $8.7 \pm 0.59$ & $8.5 \pm 1.22 b$ & $7.1 \pm 1.17$ & $17.9 \pm 0.90$ & $31.9 \pm 7.63$ & $49.1 \pm 9.23$ & $38.2 \pm 11.68$ \\
\hline & $11.7 \pm 0.72 a$ & $8.7 \pm 0.98 b$ & $7.8 \pm 0.54$ & $9.9 \pm 0.36 \mathrm{~b}$ & $9.0 \pm 0.77$ & $16.8 \pm 1.19$ & $31.5 \pm 3.91$ & $41.8 \pm 5.94$ & $23.4 \pm 4.14$ \\
\hline & $11.3 \pm 1.21 \mathrm{ab}$ & $6.7 \pm 0.53 a$ & $11.3 \pm 0.85$ & $14.5 \pm 0.90 \mathrm{a}$ & $7.2 \pm 0.72$ & $13.6 \pm 1.42$ & $42.8 \pm 7.63$ & $56.5 \pm 13.87$ & $53.0 \pm 18.23$ \\
\hline & $6.2 \pm 1.25 b$ & $9.3 \pm 2.21 \mathrm{ab}$ & $8.2 \pm 1.75$ & $11.8 \pm 1.18 \mathrm{ab}$ & $9.5 \pm 2.27$ & $10.4 \pm 1.94$ & $56.1 \pm 15.02$ & $48.6 \pm 12.64$ & $53.8 \pm 11.93$ \\
\hline \multirow{2}{*}{$\begin{array}{l}\text { S4_C } \\
\text { S4_D }\end{array}$} & $6.7 \pm 1.04 \mathrm{aA}$ & $3.4 \pm 0.43 B$ & $4.9 \pm 0.37 \mathrm{AB}$ & $4.0 \pm 0.95 \mathrm{AB}$ & $2.2 \pm 0.23 \mathrm{~A}$ & $4.3 \pm 0.52 B$ & $47.8 \pm 8.42$ & $45.5 \pm 5.12$ & $58.6 \pm 5.6$ \\
\hline & $3.7 \pm 0.46 \mathrm{~b}$ & $3.6 \pm 0.39$ & $5.0 \pm 0.56$ & $3.1 \pm 0.28 \mathrm{AB}$ & $2.2 \pm 0.20 \mathrm{~A}$ & $5.6 \pm 1.02 B$ & $40.0 \pm 6.08$ & $41.8 \pm 4.65$ & $58.0 \pm 4.98$ \\
\hline \multirow{4}{*}{$\begin{array}{l}\text { S4_FBIC_C } \\
\text { S4_FBIC_D } \\
\text { S4_FBM_C } \\
\text { S4_FBM_D }\end{array}$} & $8.8 \pm 0.95 a$ & $2.8 \pm 0.35$ & $4.9 \pm 0.55$ & $4.2 \pm 1.85$ & $1.8 \pm 0.12$ & $5.4 \pm 0.71 \mathrm{ab}$ & $37.5 \pm 10.33$ & $48.6 \pm 8.55$ & $56.8 \pm 8.87$ \\
\hline & $4.0 \pm 0.74 a b$ & $3.7 \pm 0.59$ & $4.9 \pm 1.14$ & $3.4 \pm 0.19$ & $2.5 \pm 0.34$ & $7.6 \pm 1.52 a$ & $41.7 \pm 8.28$ & $37.9 \pm 7.55$ & $54.4 \pm 8.93$ \\
\hline & $4.7 \pm 1.13 \mathrm{ab}$ & $4.2 \pm 0.65$ & $5.1 \pm 0.55$ & $3.9 \pm 0.83$ & $2.8 \pm 0.25$ & $3.3 \pm 0.21 b$ & $58.0 \pm 12.44$ & $42.3 \pm 6.53$ & $60.5 \pm 8.29$ \\
\hline & $3.4 \pm 0.62 \mathrm{~b}$ & $3.5 \pm 0.58$ & $5.1 \pm 0.41$ & $3.0 \pm 0.55$ & $2.1 \pm 0.21$ & $3.8 \pm 0.33 \mathrm{ab}$ & $38.4 \pm 10.10$ & $45.7 \pm 5.82$ & $61.5 \pm 5.23$ \\
\hline \multirow{2}{*}{$\begin{array}{l}\text { S62_C } \\
\text { S62_D }\end{array}$} & $4.7 \pm 0.38$ & $5.5 \pm 1.05 a$ & $5.1 \pm 0.36$ & $4.4 \pm 0.33$ & $5.5 \pm 1.11 \mathrm{a}$ & $7.3 \pm 0.64$ & $45.9 \pm 4.87$ & $39.9 \pm 5.45 \mathrm{a}$ & $39.0 \pm 4.95$ \\
\hline & $4.9 \pm 0.52 \mathrm{~A}$ & $3.2 \pm 0.18 \mathrm{bB}$ & $5.4 \pm 0.24 \mathrm{~A}$ & $4.4 \pm 0.45 \mathrm{~A}$ & $3.1 \pm 0.28 \mathrm{bA}$ & $8.7 \pm 0.64 \mathrm{~B}$ & $38.2 \pm 5.64 \mathrm{AB}$ & $25.7 \pm 2.23 \mathrm{bA}$ & $47.1 \pm 3.73 B$ \\
\hline \multirow{4}{*}{$\begin{array}{l}\text { S62_FBIC_C } \\
\text { S62_FBIC_D } \\
\text { S62_FBM_C } \\
\text { S62_FBM_D }\end{array}$} & $5.3 \pm 0.59$ & $7.3 \pm 1.70 \mathrm{a}$ & $5.1 \pm 0.30$ & $5.0 \pm 0.44$ & $7.5 \pm 1.72 \mathrm{a}$ & $8.0 \pm 0.41$ & $50.0 \pm 6.84$ & $46.0 \pm 9.59$ & $38.9 \pm 10.36$ \\
\hline & $5.2 \pm 0.91$ & $3.3 \pm 0.20 \mathrm{ab}$ & $5.1 \pm 0.19$ & $4.2 \pm 0.66$ & $3.4 \pm 0.48 \mathrm{ab}$ & $8.0 \pm 0.95$ & $42.3 \pm 10.65$ & $24.2 \pm 2.03$ & $55.1 \pm 4.07$ \\
\hline & $4.1 \pm 0.30$ & $3.8 \pm 0.37 a b$ & $5.2 \pm 0.71$ & $3.9 \pm 0.33$ & $3.5 \pm 0.38 \mathrm{ab}$ & $6.8 \pm 1.23$ & $41.8 \pm 7.26$ & $33.9 \pm 4.72$ & $39.0 \pm 2.68$ \\
\hline & $4.7 \pm 0.63$ & $3.2 \pm 0.34 b$ & $5.7 \pm 0.43$ & $4.6 \pm 0.70$ & $2.9 \pm 0.32 b$ & $9.6 \pm 0.77$ & $34.0 \pm 4.83$ & $27.2 \pm 4.19$ & $39.1 \pm 2.41$ \\
\hline
\end{tabular}

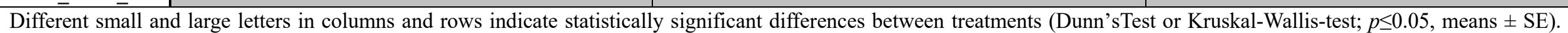
Abbreviations: FBM/WM, faba bean/wheat grown in monoculture; FBIC/WIC, faba bean/wheat intercropped; C, control treatment; D, water deficit treatment. Harvest 1, beginning of water deficit; Harvest 2, during water deficit; Harvest 3, re-watering. 
Table 5.pH-value in the rhizosphere of wheat and faba bean genotypes.

Treatment $\quad$ Harvest 1

Harvest 2

Harvest 3

\begin{tabular}{c|c|c|c|}
\hline Wheat_C & $\mathbf{7 . 1 0} \pm \mathbf{0 . 0 6 A}$ & $\mathbf{7 . 0 5} \pm \mathbf{0 . 0 6 A}$ & $\mathbf{7 . 3 9} \pm \mathbf{0 . 0 1 B}$ \\
Wheat_D & $\mathbf{7 . 1 1} \pm \mathbf{0 . 0 6 A}$ & $\mathbf{7 . 0 2} \pm \mathbf{0 . 0 5 B}$ & $\mathbf{7 . 4 3} \pm \mathbf{0 . 0 2 C}$ \\
\hline WIC_C & $7.05 \pm 0.08$ & $\mathbf{6 . 9 3} \pm \mathbf{0 . 0 4 a}$ & $7.39 \pm 0.01$ \\
WIC_D & $7.12 \pm 0.08$ & $\mathbf{6 . 9 1} \pm \mathbf{0 . 0 2 a}$ & $7.42 \pm 0.03$ \\
WM_C & $7.20 \pm 0.09$ & $\mathbf{7 . 3 0} \pm \mathbf{0 . 0 6 b}$ & $7.40 \pm 0.02$ \\
WM_D & $7.08 \pm 0.10$ & $\mathbf{7 . 2 3} \pm \mathbf{0 . 0 2 b}$ & $7.44 \pm 0.04$ \\
\hline S4_C & $\mathbf{7 . 1 2} \pm \mathbf{0 . 0 9 A B}$ & $\mathbf{7 . 1 1} \pm \mathbf{0 . 0 4 A}$ & $\mathbf{7 . 3 7} \pm \mathbf{0 . 0 1 B}$ \\
S4_D & $\mathbf{7 . 1 0} \pm \mathbf{0 . 0 9 A}$ & $\mathbf{7 . 0 0} \pm \mathbf{0 . 0 5 A}$ & $\mathbf{7 . 3 6} \pm \mathbf{0 . 0 1 B}$ \\
\hline S4_FBIC_C & $7.25 \pm 0.13$ & $\mathbf{7 . 0 3} \pm \mathbf{0 . 0 6 a b}$ & $7.39 \pm 0.01$ \\
S4_FBIC_D & $7.24 \pm 0.10$ & $\mathbf{6 . 9 4} \pm \mathbf{0 . 0 3 a}$ & $7.37 \pm 0.01$ \\
S4_FBM_C & $7.03 \pm 0.12$ & $\mathbf{7 . 2 0} \pm \mathbf{0 . 0 1 b}$ & $7.35 \pm 0.00$ \\
S4_FBM_D & $6.97 \pm 0.13$ & $\mathbf{7 . 0 7} \pm \mathbf{0 . 0 8 a b}$ & $7.35 \pm 0.02$ \\
\hline S62_C & $\mathbf{7 . 1 8} \pm \mathbf{0 . 0 8 A B}$ & $\mathbf{6 . 9 1} \pm \mathbf{0 . 0 4 A}$ & $\mathbf{7 . 3 6} \pm \mathbf{0 . 0 1 B}$ \\
S62_D & $\mathbf{7 . 0 2} \pm \mathbf{0 . 0 7 A}$ & $\mathbf{6 . 9 5} \pm \mathbf{0 . 0 4 A}$ & $\mathbf{7 . 3 6} \pm \mathbf{0 . 0 1 B}$ \\
\hline S62_FBIC_C & $7.03 \pm 0.12$ & $\mathbf{6 . 8 2} \pm \mathbf{0 . 0 3 a}$ & $\mathbf{7 . 3 8} \pm \mathbf{0 . 0 0 a}$ \\
S62_FBIC_D & $7.02 \pm 0.10$ & $\mathbf{6 . 8 4} \pm \mathbf{0 . 0 4 a b}$ & $\mathbf{7 . 3 6} \pm \mathbf{0 . 0 0 a b}$ \\
S62_FBM_C & $7.34 \pm 0.01$ & $\mathbf{7 . 0 1} \pm \mathbf{0 . 0 1 a b}$ & $\mathbf{7 . 3 4} \pm \mathbf{0 . 0 1 b}$ \\
S62_FBM_D & $7.01 \pm 0.11$ & $\mathbf{7 . 0 3} \pm \mathbf{0 . 0 1 b}$ & $\mathbf{7 . 3 6} \pm \mathbf{0 . 0 1 a b}$ \\
\hline
\end{tabular}

Different small and large letters in columns and rows indicate statistically significant differences between treatments (Dunn'sTest or Kruskal-Wallis-test; $p \leq 0.05$, means $\pm \mathrm{SE}$ ). Abbreviations: FBM/WM, faba bean/wheat grown in monoculture; FBIC/WIC, faba bean/wheat intercropped; C, control treatment; D, water deficit treatment. Harvest 1, beginning of water deficit; Harvest 2, during water deficit; Harvest 3, re-watering. 
Table 6. Total organic carbon and nitrogen [\%] in the rhizosphere of wheat and faba bean genotypes.

\begin{tabular}{|c|c|c|c|c|c|c|c|c|c|}
\hline \multirow[b]{2}{*}{ Treatment } & \multicolumn{3}{|c|}{$C: N$ ratio } & \multicolumn{3}{|c|}{$\mathrm{C}_{\text {total }}[\%]$} & \multicolumn{3}{|c|}{$\mathbf{N}_{\text {total }}[\%]$} \\
\hline & Harvest 1 & Harvest 2 & Harvest 3 & Harvest 1 & Harvest 2 & Harvest 3 & Harvest 1 & Harvest 2 & Harvest 3 \\
\hline Wheat_C & $11.12 \pm 0.21$ & $10.99 \pm 0.21$ & $10.78 \pm 0.34$ & $2.02 \pm 0.04 A$ & $2.03 \pm 0.04 \mathrm{~A}$ & $1.56 \pm 0.14 B$ & $0.18 \pm 0.00 A$ & $0.19 \pm 0.01 A$ & $0.14 \pm 0.01 B$ \\
\hline Wheat_D & $11.46 \pm 0.15$ & $10.97 \pm 0.25$ & $11.28 \pm 0.14$ & $2.04 \pm 0.04 A$ & $2.02 \pm 0.03 A$ & $1.74 \pm 0.08 B$ & $0.18 \pm 0.00 A$ & $0.19 \pm 0.00 A$ & $0.15 \pm 0.01 B$ \\
\hline WIC_C & $11.02 \pm 0.31$ & $10.59 \pm 0.14 a$ & $10.67 \pm 0.51$ & $2.03 \pm 0.03$ & $2.05 \pm 0.02$ & $1.34 \pm 0.16 \mathrm{a}$ & $0.19 \pm 0.00$ & $0.19 \pm 0.00$ & $0.12 \pm 0.01 a$ \\
\hline WIC_D & $11.32 \pm 0.17$ & $10.96 \pm 0.38 a$ & $11.16 \pm 0.20$ & $2.01 \pm 0.04$ & $2.07 \pm 0.03$ & $1.60 \pm 0.07 a$ & $0.18 \pm 0.01$ & $0.19 \pm 0.01$ & $0.14 \pm 0.01 \mathrm{a}$ \\
\hline WM_C & $11.34 \pm 0.21$ & $11.81 \pm 0.19 b$ & $11.01 \pm 0.20$ & $2.01 \pm 0.10$ & $1.98 \pm 0.12$ & $2.02 \pm 0.02 b$ & $0.18 \pm 0.01$ & $0.17 \pm 0.01$ & $0.18 \pm 0.00 b$ \\
\hline WM_D & $11.75 \pm 0.25$ & $11.00 \pm 0.08 \mathrm{ab}$ & $11.53 \pm 0.10$ & $2.12 \pm 0.05$ & $1.92 \pm 0.02$ & $2.04 \pm 0.03 b$ & $0.18 \pm 0.00$ & $0.18 \pm 0.00$ & $0.18 \pm 0.00 b$ \\
\hline S4_C & $11.15 \pm 0.35$ & $11.28 \pm 0.48$ & $11.50 \pm 0.27$ & $2.03 \pm 0.04$ & $2.06 \pm 0.13$ & $1.87 \pm 0.08$ & $0.18 \pm 0.01$ & $0.19 \pm 0.01$ & $0.16 \pm 0.00$ \\
\hline S4_D & $11.43 \pm 0.15$ & $11.26 \pm 0.33$ & $11.47 \pm 0.31$ & $2.10 \pm 0.03$ & $2.07 \pm 0.16$ & $1.85 \pm 0.09$ & $0.18 \pm 0.00 \mathrm{~A}$ & $0.19 \pm 0.02 A$ & $0.16 \pm 0.01 B$ \\
\hline S4_FBIC_C & $10.32 \pm 0.23 a$ & $10.21 \pm 0.20 \mathrm{a}$ & $11.32 \pm 0.54$ & $2.08 \pm 0.05$ & $2.09 \pm 0.01$ & $1.79 \pm 0.12 \mathrm{ab}$ & $0.20 \pm 0.00 \mathrm{a}$ & $0.21 \pm 0.01$ & $0.16 \pm 0.01$ \\
\hline S4_FBIC_D & $11.10 \pm 0.15 a b$ & $10.46 \pm 0.16 a b$ & $10.88 \pm 0.05$ & $2.08 \pm 0.02$ & $2.05 \pm 0.02$ & $1.63 \pm 0.17 a$ & $0.19 \pm 0.00 a b$ & $0.20 \pm 0.00$ & $0.15 \pm 0.01$ \\
\hline S4_FBM_C & $11.98 \pm 0.24 b$ & $12.35 \pm 0.51 b$ & $11.67 \pm 0.13$ & $1.98 \pm 0.07$ & $2.03 \pm 0.28$ & $1.96 \pm 0.09 \mathrm{ab}$ & $0.17 \pm 0.01 b$ & $0.17 \pm 0.02$ & $0.17 \pm 0.01$ \\
\hline S4_FBM_D & $11.76 \pm 0.12 b$ & $12.06 \pm 0.23 b$ & $12.05 \pm 0.46$ & $2.13 \pm 0.05$ & $2.09 \pm 0.35$ & $2.06 \pm 0.03 b$ & $0.18 \pm 0.00 a b$ & $0.17 \pm 0.03$ & $0.17 \pm 0.01$ \\
\hline S62_C & $11.47 \pm 0.10$ & $11.63 \pm 0.26$ & $11.34 \pm 0.33$ & $1.96 \pm 0.04$ & $1.88 \pm 0.10$ & $1.79 \pm 0.09$ & $0.17 \pm 0.00$ & $0.16 \pm 0.01$ & $0.16 \pm 0.01$ \\
\hline S62_D & $12.11 \pm 0.37 \mathrm{~A}$ & $10.88 \pm 0.35 B$ & $11.41 \pm 0.19 \mathrm{AB}$ & $1.86 \pm 0.09$ & $1.70 \pm 0.19$ & $1.64 \pm 0.11$ & $0.16 \pm 0.01$ & $0.15 \pm 0.02$ & $0.14 \pm 0.01$ \\
\hline S62_FBIC_C & $11.35 \pm 0.17$ & $11.06 \pm 0.29 a$ & $11.16 \pm 0.57$ & $2.01 \pm 0.03$ & $2.12 \pm 0.04 a$ & $1.69 \pm 0.08$ & $0.18 \pm 0.00$ & $0.19 \pm 0.00 a$ & $0.15 \pm 0.01$ \\
\hline S62_FBIC_D & $11.53 \pm 0.19$ & $11.12 \pm 0.14 a b$ & $11.41 \pm 0.39$ & $1.93 \pm 0.07$ & $2.09 \pm 0.04 a$ & $1.42 \pm 0.15$ & $0.17 \pm 0.01$ & $0.19 \pm 0.01 \mathrm{a}$ & $0.13 \pm 0.01$ \\
\hline S62_FBM_C & $11.59 \pm 0.11$ & $12.19 \pm 0.12 b$ & $11.53 \pm 0.41$ & $1.90 \pm 0.08$ & $1.65 \pm 0.07 \mathrm{ab}$ & $1.90 \pm 0.17$ & $0.16 \pm 0.01$ & $0.14 \pm 0.01 b$ & $0.17 \pm 0.02$ \\
\hline S62_FBM_D & $12.68 \pm 0.62$ & $10.65 \pm 0.72 a b$ & $11.41 \pm 0.14$ & $1.79 \pm 0.16$ & $1.32 \pm 0.26 b$ & $1.85 \pm 0.05$ & $0.15 \pm 0.02$ & $0.12 \pm 0.02 b$ & $0.16 \pm 0.00$ \\
\hline
\end{tabular}

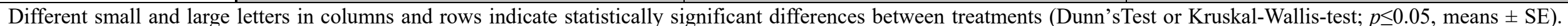

Abbreviations: FBM/WM, faba bean/wheat grown in monoculture; FBIC/WIC, faba bean/wheat intercropped; C, control treatment; D, water deficit treatment. Harvest 1, beginning of water deficit; Harvest 2, during water deficit; Harvest 3, re-watering. 
Table 7. Bacterial diversity and richness in the rhizosphere soil with regard to water treatment and cropping system.

\begin{tabular}{|c|c|c|c|c|c|c|}
\hline & \multicolumn{3}{|c|}{ Richness } & \multicolumn{3}{|c|}{ Diversity } \\
\hline Treatment & 1 & 2 & 3 & 1 & 2 & 3 \\
\hline Wheat_C & $845.25 \pm 74.03$ & $866.07 \pm 55.6$ & $794.57 \pm 223.71$ & $6.19 \pm 0.22$ & $6.24 \pm 0.12$ & $5.82 \pm 1.12$ \\
\hline Wheat_D & $841.90 \pm 48.62$ & $818.37 \pm 105.68$ & $691.02 \pm 341.75$ & $6.18 \pm 0.13$ & $6.03 \pm 0.59$ & $5.35 \pm 1.8$ \\
\hline WIC_C & $826.56 \pm 87.46$ & $859.44 \pm 68.18$ & $845.96 \pm 67.03$ & $6.14 \pm 0.26$ & $6.22 \pm 0.14$ & $6.10 \pm 0.33$ \\
\hline WIC_D & $848.04 \pm 56.29$ & $802.91 \pm 115.8$ & $609.23 \pm 433.16$ & $6.20 \pm 0.14$ & $5.94 \pm 0.71$ & $4.87 \pm 2.26$ \\
\hline WM_C & $877.98 \pm 26.99$ & $877.68 \pm 26.91$ & $657.53 \pm 442.47$ & $6.29 \pm 0.05$ & $6.27 \pm 0.06$ & $5.08 \pm 2.19$ \\
\hline WM_D & $831.15 \pm 36.04$ & $849.28 \pm 88.03$ & $813.70 \pm 64.94$ & $6.14 \pm 0.12$ & $6.21 \pm 0.22$ & $6.09 \pm 0.24$ \\
\hline S4 C & $744.71 \pm 295.43$ & $516.54 \pm 382.25$ & $805.37 \pm 95.79$ & $5.76 \pm 1.17$ & $4.49 \pm 2.14$ & $5.93 \pm 0.62$ \\
\hline S4_D & $795.20 \pm 40.3$ & $792.59 \pm 113.95$ & $751.91 \pm 145.78$ & $6.04 \pm 0.14$ & $5.85 \pm 0.86$ & $5.77 \pm 0.78$ \\
\hline S4_FBIC_C & $806.70 \pm 118.42$ & $470.05 \pm 384.88$ & $753.83 \pm 108.6$ & $6.09 \pm 0.21$ & $4.50 \pm 1.9$ & $5.58 \pm 0.88$ \\
\hline S4_FBIC_D & $821.95 \pm 31.61$ & $833.45 \pm 70.86$ & $630.77 \pm 129.17$ & $6.14 \pm 0.06$ & $6.17 \pm 0.2$ & $5.19 \pm 0.9$ \\
\hline S4_FBM_C & $698.23 \pm 398.1$ & $578.53 \pm 453.94$ & $844.03 \pm 76.41$ & $5.51 \pm 1.59$ & $4.47 \pm 2.89$ & $6.19 \pm 0.17$ \\
\hline S4_FBM_D & $759.53 \pm 5.82$ & $738.10 \pm 153.72$ & $842.78 \pm 75.47$ & $5.91 \pm 0.1$ & $5.43 \pm 1.29$ & $6.21 \pm 0.26$ \\
\hline S62_C & $780.94 \pm 87.63$ & $867.72 \pm 47.53$ & $740.08 \pm 289.75$ & $5.99 \pm 0.34$ & $6.21 \pm 0.15$ & $5.51 \pm 1.63$ \\
\hline S62_D & $835.76 \pm 39.45$ & $614.13 \pm 368.85$ & $820.79 \pm 90.57$ & $6.15 \pm 0.18$ & $4.94 \pm 1.94$ & $6.15 \pm 0.26$ \\
\hline S62_FBIC_C & $771.65 \pm 117.25$ & $859.73 \pm 64.46$ & $816.08 \pm 136.46$ & $6.02 \pm 0.33$ & $6.16 \pm 0.21$ & $5.91 \pm 0.79$ \\
\hline S62_FBIC_D & $846.80 \pm 32.91$ & $562.87 \pm 420.59$ & $834.40 \pm 75.33$ & $6.18 \pm 0.15$ & $4.71 \pm 1.86$ & $6.17 \pm 0.24$ \\
\hline S62_FBM_C & $793.33 \pm 44.83$ & $875.70 \pm 36.08$ & $664.08 \pm 402.33$ & $5.94 \pm 0.43$ & $6.26 \pm 0.07$ & $5.12 \pm 2.27$ \\
\hline S62_FBM_D & $824.73 \pm 47.16$ & $652.58 \pm 386.75$ & $802.63 \pm 123.42$ & $6.11 \pm 0.23$ & $5.11 \pm 2.26$ & $6.12 \pm 0.34$ \\
\hline
\end{tabular}

Diversity is expressed as Shannon values (H') and richness is based on the number of unique sequences Different small and large letters in columns and rows indicate statistically significant differences between treatments (Dunn'sTest or Kruskal-Wallis-test, $p \leq 0.05$, means $\pm \mathrm{SD}$ ). Abbreviations: FBM/WM, faba bean/wheat grown in monoculture; FBIC/WIC, faba bean/wheat intercropped; C, control treatment; D, water deficit treatment. Harvest 1, beginning of water deficit; Harvest 2, during water deficit; Harvest 3, re-watering. 
Table 8. Bacterial diversity and richness in the leaf endosphere with regard to water treatment and cropping system.

\begin{tabular}{|c|c|c|c|c|c|c|}
\hline & \multicolumn{3}{|c|}{ Richness } & \multicolumn{3}{|c|}{ Diversity } \\
\hline Treatment & 1 & 2 & 3 & 1 & 2 & 3 \\
\hline Wheat_C & $\begin{array}{c}125.65 \pm \\
168.19\end{array}$ & $70.35 \pm 26.13$ & $\begin{array}{c}107.66 \pm \\
78.49\end{array}$ & $2.62 \pm 1.01$ & $2.07 \pm 0.53$ & $2.60 \pm 0.82$ \\
\hline Wheat_D & $68.05 \pm 17.04$ & $\begin{array}{c}100.05 \pm \\
172.80\end{array}$ & $\begin{array}{c}122.65 \pm \\
190.28\end{array}$ & $2.22 \pm 0.55$ & $2.05 \pm 1.21$ & $2.46 \pm 1.28$ \\
\hline WIC_C & $\begin{array}{c}143.13 \pm \\
207.28\end{array}$ & $75.25 \pm 30.63$ & $\begin{array}{c}118.01 \pm \\
91.69\end{array}$ & $2.85 \pm 1.16$ & $1.97 \pm 0.50$ & $2.67 \pm 0.81$ \\
\hline WIC_D & $64.99 \pm 18.91$ & $49.94 \pm 18.99$ & $\begin{array}{c}164.06 \pm \\
233.55\end{array}$ & $2.05 \pm 0.52$ & $1.62 \pm 0.35$ & $2.89 \pm 1.41$ \\
\hline WM_C & $90.70 \pm 32.02$ & $60.55 \pm 11.10$ & $86.95 \pm 45.97$ & $2.15 \pm 0.40$ & $2.27 \pm 0.60$ & $2.47 \pm 0.96$ \\
\hline WM_D & $76.20 \pm 7.97$ & $\begin{array}{c}200.28 \pm \\
297.58 \\
\end{array}$ & $50.18 \pm 24.54$ & $2.68 \pm 0.38$ & $2.91 \pm 1.89$ & $1.69 \pm 0.51$ \\
\hline S4_C & $139.64 \pm 89.81$ & $\begin{array}{c}103.45 \pm \\
53.81\end{array}$ & $\begin{array}{c}118.65 \pm \\
103.71\end{array}$ & $2.44 \pm 0.60$ & $2.20 \pm 0.45$ & $2.44 \pm 0.52$ \\
\hline S4_D & $105.95 \pm 53.26$ & $\begin{array}{c}102.79 \pm \\
39.44\end{array}$ & $72.45 \pm 29.70$ & $2.22 \pm 0.45$ & $2.21 \pm 0.33$ & $1.88 \pm 0.48$ \\
\hline S4_FBIC_C & $93.90 \pm 50.16$ & $94.93 \pm 59.90$ & $\begin{array}{c}142.37 \pm \\
151.43\end{array}$ & $2.17 \pm 0.21$ & $2.07 \pm 0.59$ & $2.49 \pm 0.82$ \\
\hline S4_FBIC_D & $85.05 \pm 33.80$ & $93.90 \pm 58.12$ & $79.68 \pm 19.92$ & $2.09 \pm 0.39$ & $2.03 \pm 0.29$ & $2.18 \pm 0.01$ \\
\hline S4_FBM_C & $\begin{array}{c}185.38 \pm \\
103.56\end{array}$ & $\begin{array}{c}111.98 \pm \\
54.53\end{array}$ & $94.93 \pm 47.66$ & $2.71 \pm 0.77$ & $2.33 \pm 0.28$ & $2.40 \pm 0.39$ \\
\hline S4_FBM_D & $126.85 \pm 65.66$ & $111.68 \pm 6.38$ & $65.23 \pm 39.01$ & $2.36 \pm 0.53$ & $2.40 \pm 0.28$ & $1.58 \pm 0.60$ \\
\hline S62_C & $107.70 \pm 48.28$ & $\begin{array}{c}117.55 \pm \\
54.97 b\end{array}$ & $\begin{array}{c}108.86 \pm \\
71.58\end{array}$ & $2.36 \pm 0.41$ & $2.26 \pm 0.42 a$ & $2.33 \pm 0.56$ \\
\hline S62_D & $146.20 \pm 91.11$ & $\begin{array}{c}54.93 \pm 12.60 \\
a \\
\end{array}$ & $81.06 \pm 41.94$ & $2.55 \pm 0.54 A$ & $\begin{array}{c}1.84 \pm \\
0.18 B b \\
\end{array}$ & $\begin{array}{c}2.27 \pm \\
0.45 A B \\
\end{array}$ \\
\hline S62_FBIC_C & $\begin{array}{l}129.15 \pm \\
42.91 \mathrm{ab}\end{array}$ & $\begin{array}{c}107.68 \pm \\
77.06\end{array}$ & $\begin{array}{c}145.90 \pm \\
86.89\end{array}$ & $2.67 \pm 0.30 \mathrm{ab}$ & $2.23 \pm 0.59$ & $2.68 \pm 0.60$ \\
\hline S62_FBIC_D & $\begin{array}{c}224.83 \pm \\
42.23 b\end{array}$ & $52.85 \pm 12.37$ & $95.28 \pm 51.44$ & $3.01 \pm 0.30 a$ & $1.89 \pm 0.06$ & $2.20 \pm 0.46$ \\
\hline S62_FBM_C & $\begin{array}{c}86.25 \pm 48.70 \\
\mathrm{ab}\end{array}$ & $\begin{array}{c}127.43 \pm \\
29.20\end{array}$ & $71.83 \pm 27.33$ & $2.05 \pm 0.24 b$ & $2.30 \pm 0.24$ & $1.99 \pm 0.23$ \\
\hline S62_FBM_D & $87.23 \pm 67.77 a$ & $57.00 \pm 14.36$ & $62.10 \pm 19.11$ & $2.21 \pm 0.41 \mathrm{ab}$ & $1.80 \pm 0.26$ & $2.36 \pm 0.51$ \\
\hline
\end{tabular}

Diversity is expressed as Shannon values (H') and richness is based on the number of unique sequences. Different small and large letters in columns and rows indicate statistically significant differences between treatments (Dunn'sTest or Kruskal-Wallis-test, $p \leq 0.05$, means \pm SD). Abbreviations: FBM/WM, faba bean/wheat grown in monoculture; FBIC/WIC, faba bean/wheat intercropped; C, control treatment/ sufficiently irrigated; Dwater deficit treatment. Harvest 1, beginning of water deficit; Harvest 2, during water deficit; Harvest 3, rewatering. 
Table 9. Effect of the tested parameter on the bacterial community composition for each harvest.

Rhizosphere Soil

Leaves

\begin{tabular}{|c|c|c|c|c|c|c|c|c|c|c|c|c|}
\hline \multirow[b]{2}{*}{ Treatment } & \multicolumn{2}{|c|}{ Harvest 1} & \multicolumn{2}{|c|}{ Harvest 2} & \multicolumn{2}{|c|}{ Harvest 3} & \multicolumn{2}{|c|}{ Harvest 1} & \multicolumn{2}{|c|}{ Harvest 2} & \multicolumn{2}{|c|}{ Harvest 3} \\
\hline & $\begin{array}{c}\mathbf{R}^{2} \\
(\%)\end{array}$ & $p$ & $\begin{array}{c}\mathbf{R}^{2} \\
(\%)\end{array}$ & $p$ & $\begin{array}{c}R^{2} \\
(\%)\end{array}$ & $p$ & $\begin{array}{l}R^{2} \\
(\%)\end{array}$ & $p$ & $\begin{array}{c}R^{2} \\
(\%)\end{array}$ & $p$ & $\begin{array}{c}R^{2} \\
(\%)\end{array}$ & $p$ \\
\hline Cropping system & 2.1 & 0.23 & 1.1 & 0.922 & 1.2 & 0.918 & 1.6 & 0.446 & 1.7 & 0.366 & 1.4 & 0.652 \\
\hline Crop species & 4.2 & 0.008 & 3.4 & 0.047 & 2.0 & 0.347 & 7.1 & 0.002 & 4.5 & 0.048 & 4.5 & 0.019 \\
\hline Genotype & 6.1 & 0.016 & 2.7 & 0.595 & 2.6 & 0.712 & 1.4 & 0.891 & 1.8 & 0.642 & 3.5 & 0.221 \\
\hline Water-deficit & 2.5 & 0.12 & 2.2 & 0.206 & 1.6 & 0.577 & 1.3 & 0.637 & 0.8 & 0.832 & 1.7 & 0.553 \\
\hline Harvest & 1.6 & 0.003 & & & & & 0.4 & 0.613 & & & & \\
\hline
\end{tabular}

Results of the permutational multivariate analysis of variance (PERMANOVA) with Bray-Curtis distances testing for the different treatments. Statistically significant differences $(p \leq 0.05)$ between the treatments for each plant compartment are written in bold. Cropping system compares monoculture versus intercropping. Genotype compares S_004 versus S_062. Harvest was tested for all harvests together without strata. 


\section{Figures}

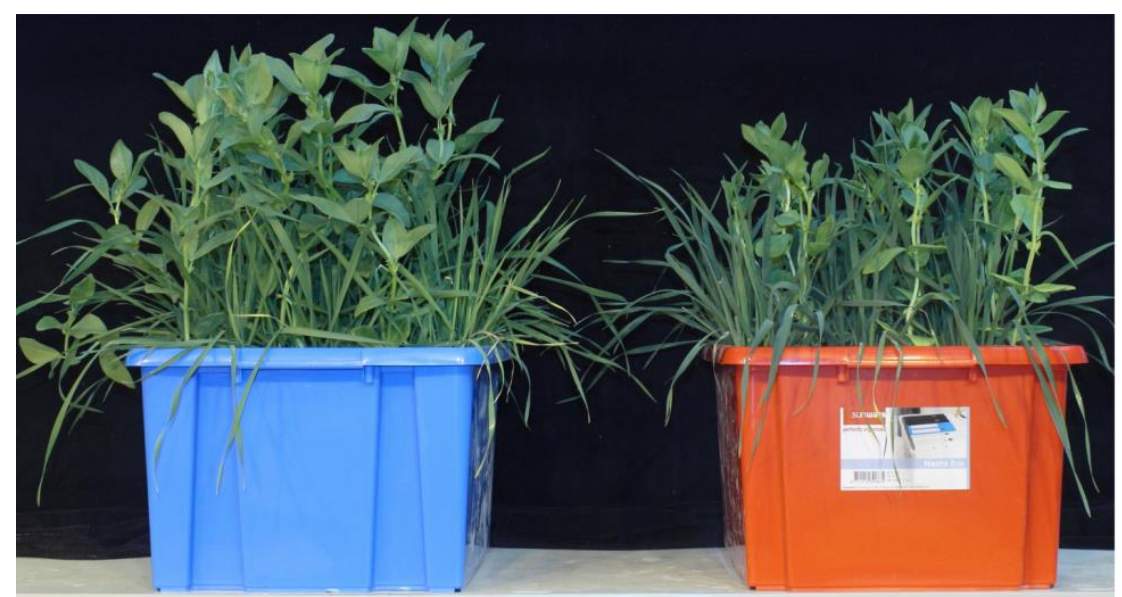

\section{IC C/ IC D}
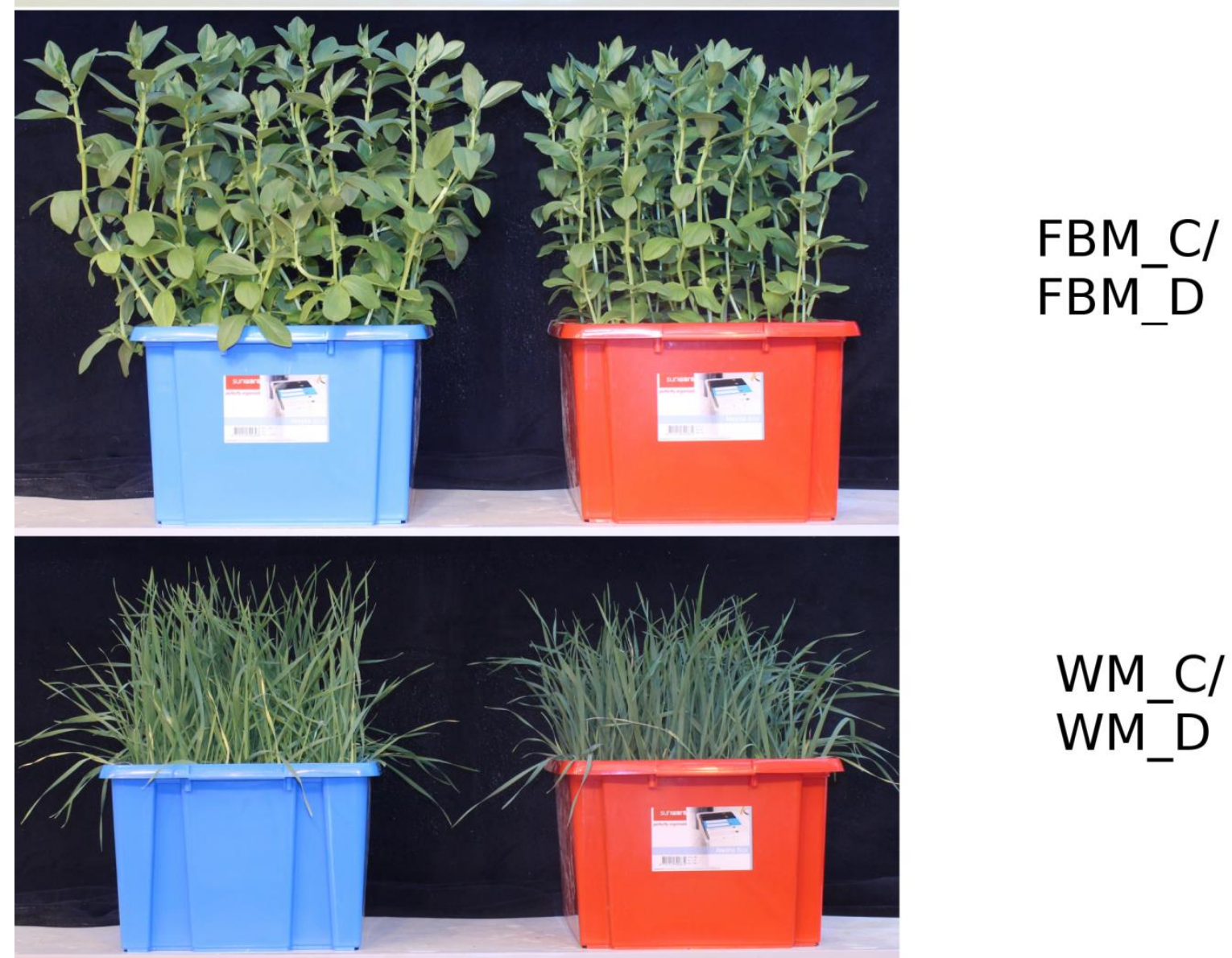

Figure 1. Experimental design. Abbreviations: FBM/WM, faba bean/wheat monoculture; IC, intercropping; C, control (blue container); D, water deficit treatment (red container). 


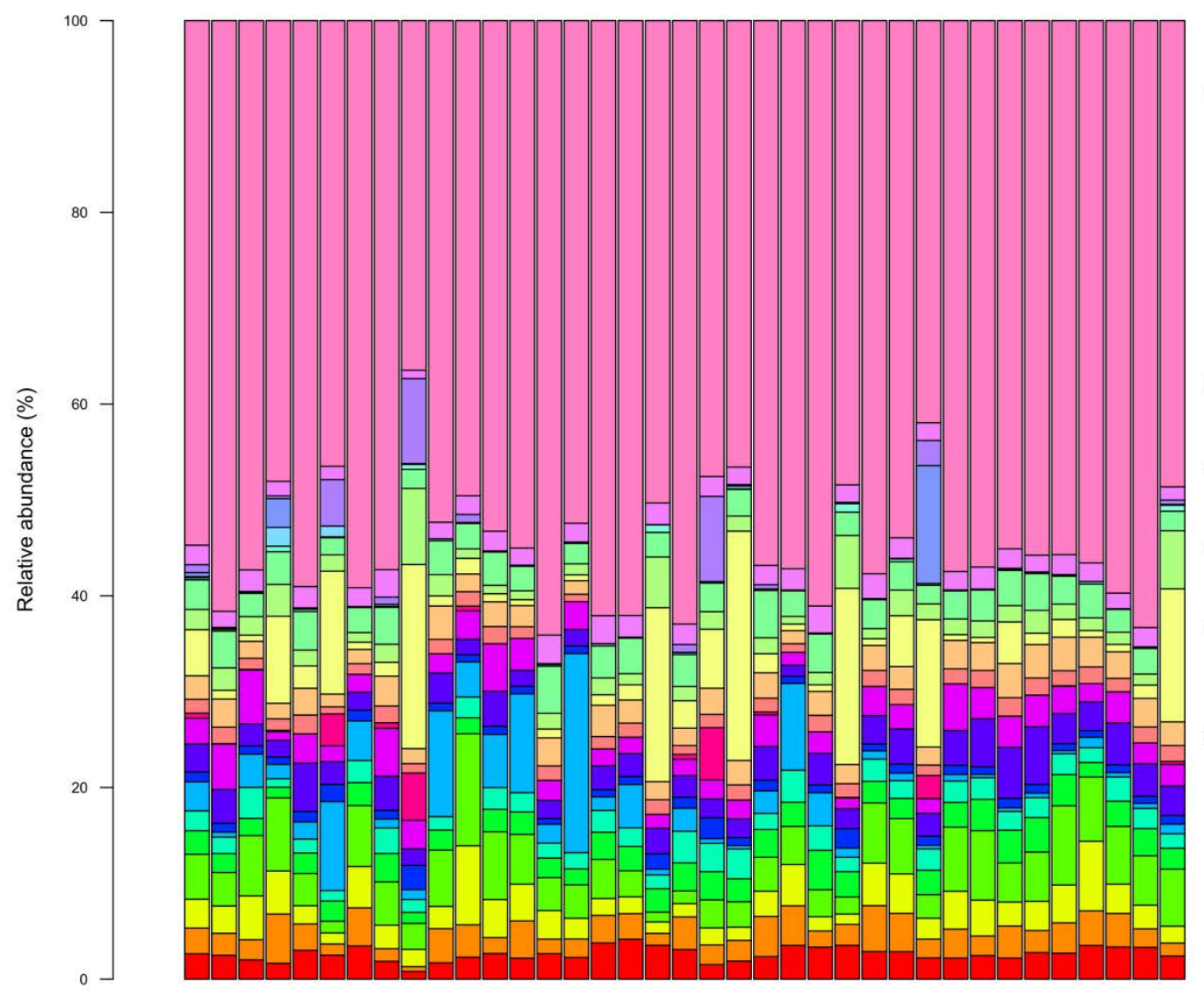

In others

Gammproteobacteria

- Xanthomonadales:Xanthomonadaceae:Lysobacter

" Oceanospirillales:Halomonadaceae:Candidatus_Portiera

* Enterobacteriales:Enterobacteriaceae:Escherichia-Shigella

Betaproteobacteriales: Burkholderiaceae:Rhodoferax

Betaproteobacteriales:Burkholderiaceae:Rhizobacter

Betaproteobacteriales:Burkholderiaceae:Curvibacter

Betaproteobacteriales:Burkholderiaceae:Comamonas

- Alteromeobactenales.Burkholderiaceae.Aquabacterim

Deltaproteobacteria

Myxococcales:Polyangiaceae:uncultured

Myxococcales:Blrii4

Alphaproteobacteria

Sphingomonadales:Sphingomonadaceae:Sphingomonas

Rhizobiales:Rhizobiaceae:Allorhizobium-Neorhizobium-Pararhizobium-Rhizobium

Gemmatimonadetes

- Gemmatimonadalesimicrobiales:Longimicrobiaceae

Bacteroidetes

- Bacteroidia:Cytophagales:Microscillaceae:uncultured

Bacteroidia:Cytophagales:Microscillaceae:Ohtaekwangia

Bacteroidia:Cytophagales:Hymenobacteraceae:Adhaeribacter

- Thermoleophilia:Gaiellales:uncultured

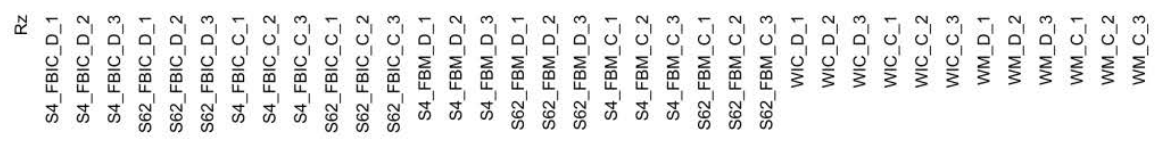

Figure 2. Abundant bacterial genera in the rhizosphere soil and the investigated cropping systems with regard to water treatment and harvest. Only genera with an abundance $>1 \%$ in at least one of the investigated cropping system are shown. Mean relative abundances of each taxon were calculated based on relative abundances calculated for each sample. Abbreviations: C, control treatment; D, water deficit treatment; S4/S62, faba bean genotype; FBM/WM, faba bean/ wheat monoculture, FBIC/WIC, faba bean/wheat intercropped. 

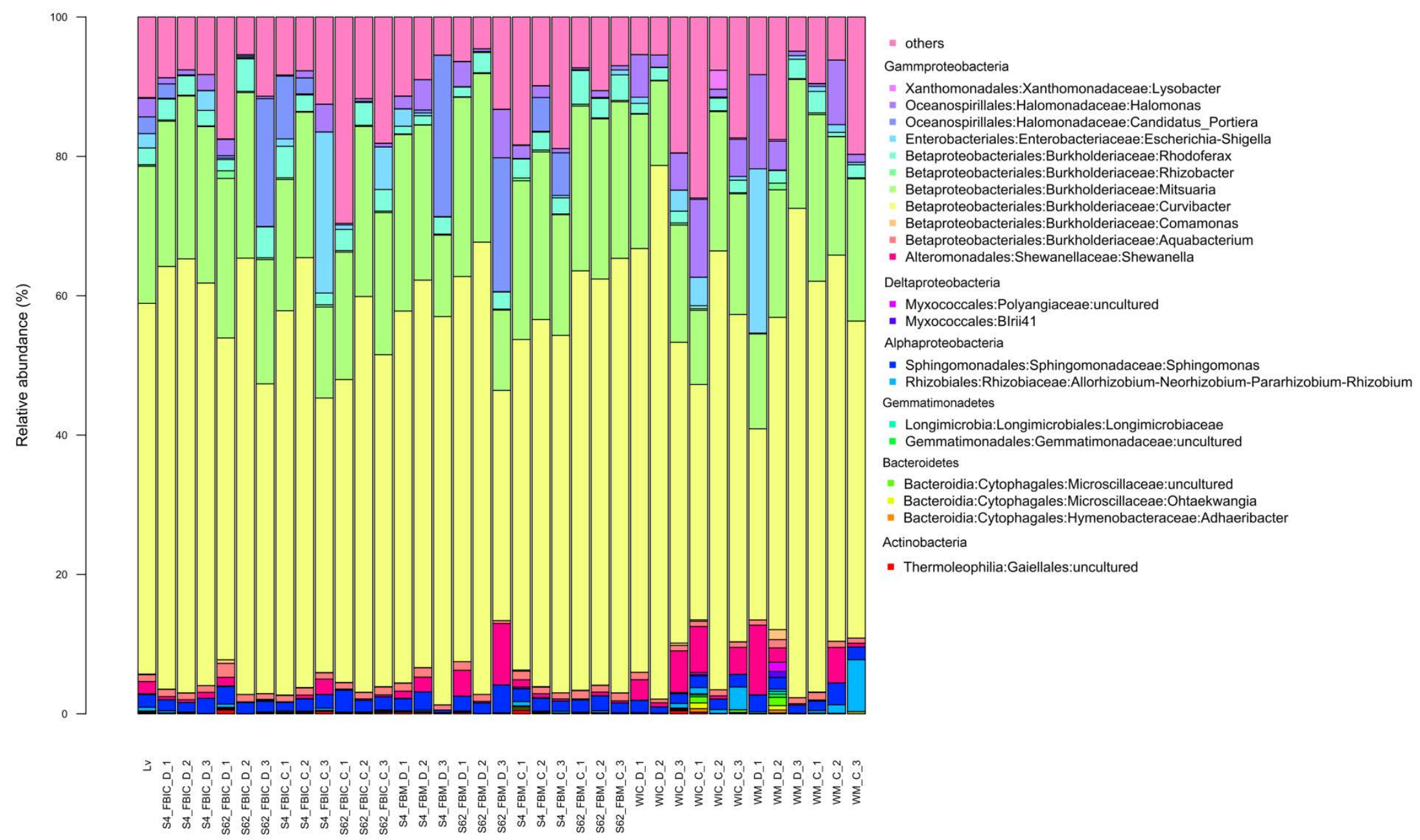

Figure 3. Abundant bacterial genera in the leaf endosphere and the investigated cropping systems with regard to water treatment and harvest. Only genera with an abundance $>1 \%$ in at least one of the investigated cropping system are shown. Mean relative abundances of each taxon were calculated based on relative abundances calculated for each sample. Abbreviations: C, control treatment; D, water deficit treatment; S4/S62, faba bean genotype; FBM/WM, faba bean/ wheat monoculture, FBIC/WIC, faba bean/wheat intercropped. 

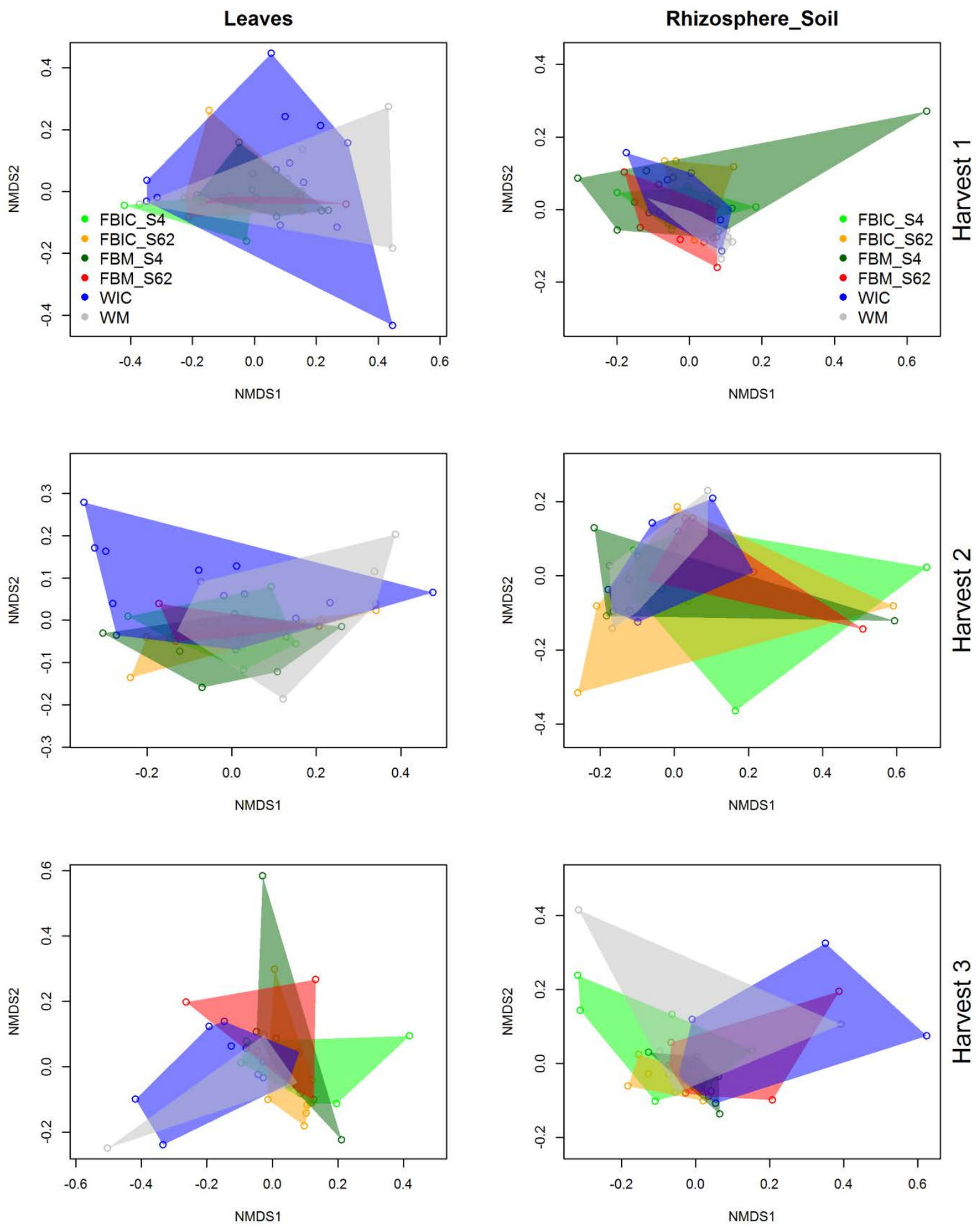

Figure 4. Response of bacterial communities in the leaf endosphere and rhizosphere soil towards cropping system. Ordination is based on Bray-Curtis dissimiliarties between samples. NMDS ordination of microbial community is color-coded by the respective cropping system and genotype. Abbreviations: FBM/WM, faba bean/ wheat monoculture; FBIC/WIC, faba bean/wheat intercropping system. S4/S62, faba bean genotype. 

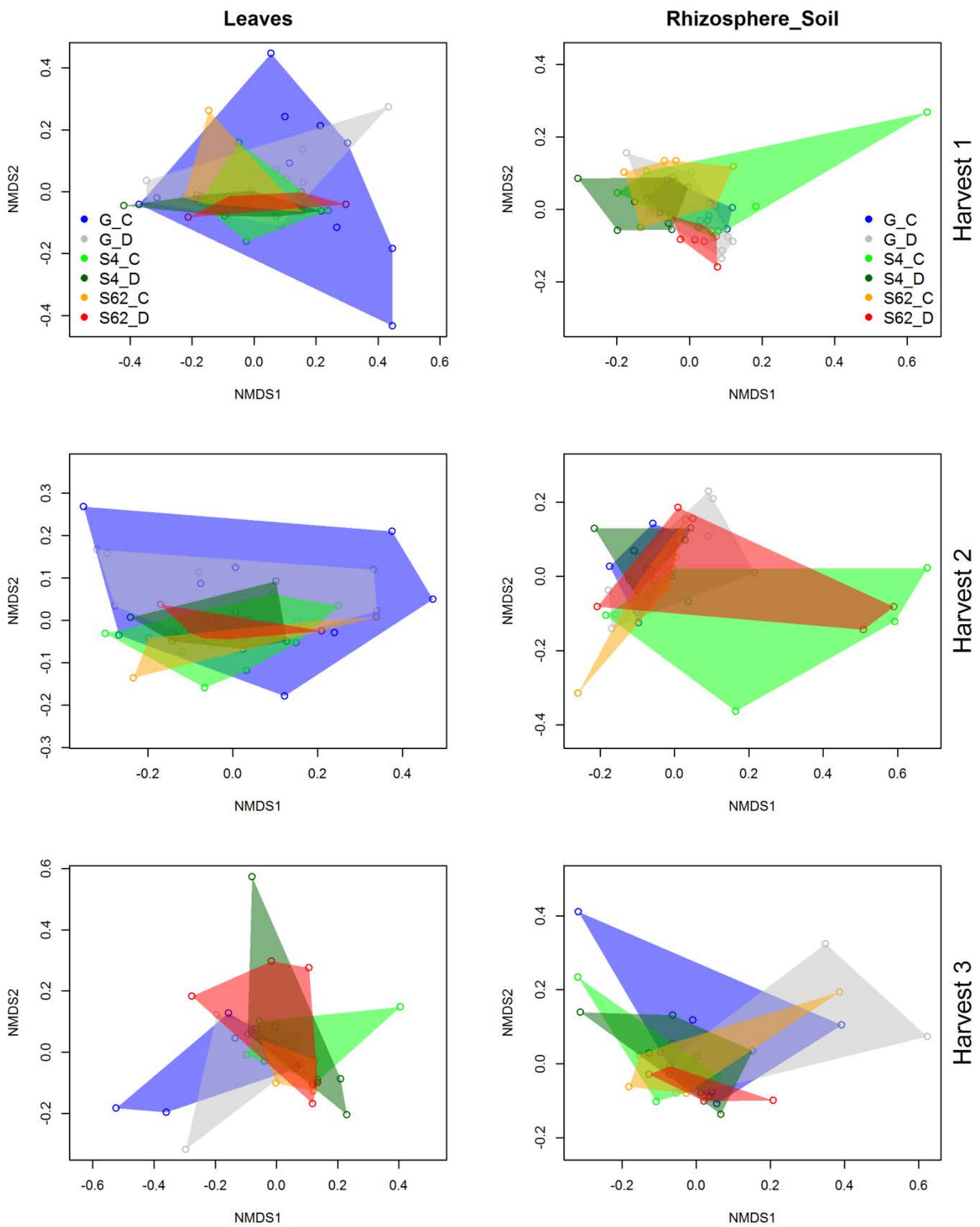

Figure 5. Response of bacterial communities in the leaf endosphere and rhizosphere soil towards water treatment regarding the different crop genotypes. Ordination is based on Bray-Curtis dissimiliarties between samples. NMDS ordination of microbial community is color-coded by the respective water treatment and genotype. Abbreviations: S4/S62, faba bean genotype; G, genius (wheat); C, control/well-watered conditions; D, water deficit. 

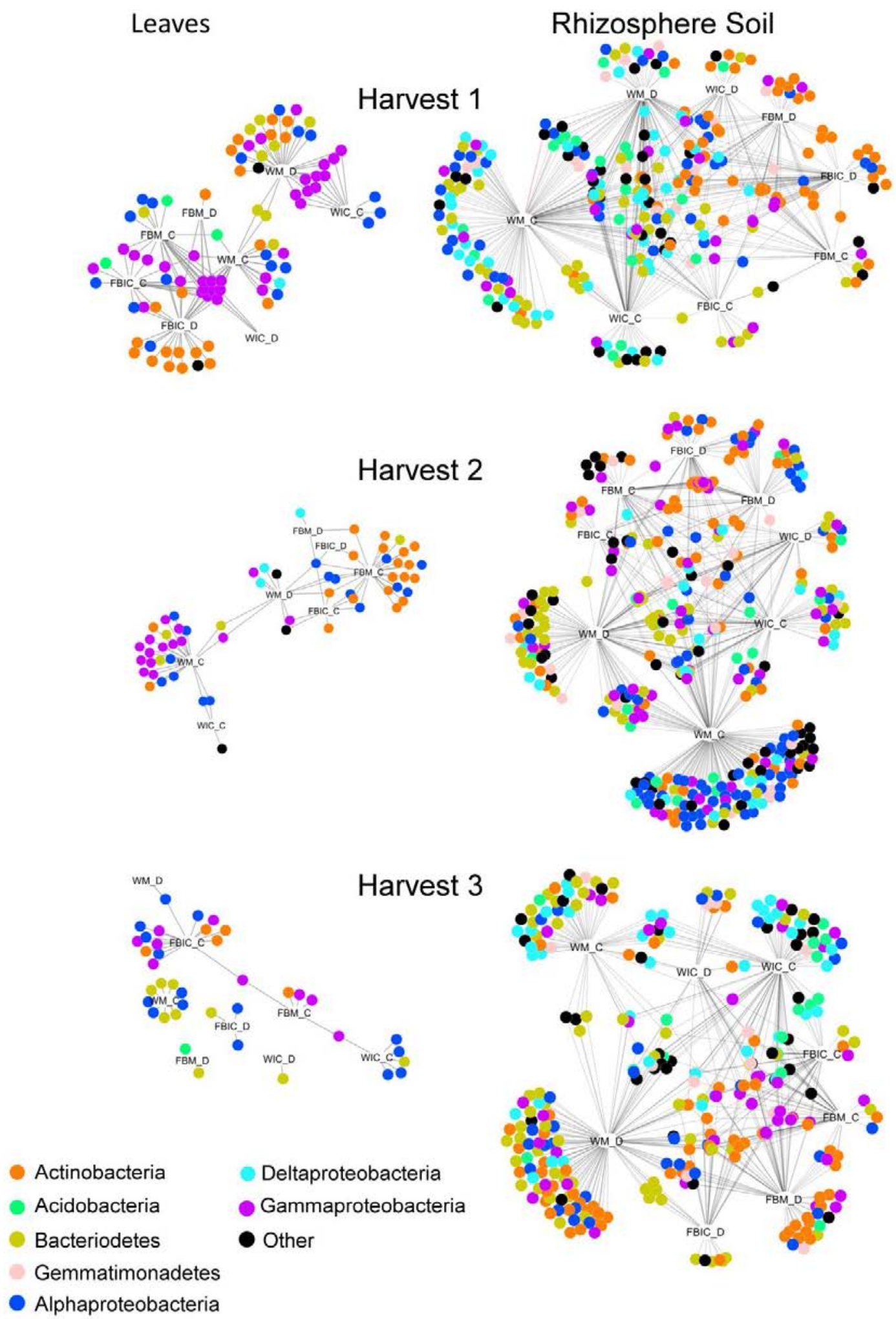

Figure 6. Bipartitie association network for bacterial taxa within different cropping regimes for the three harvests. Significant associated taxa are shown. Abbreviations: FBM/WM, faba bean/ wheat monoculture; FBIC/WIC, faba bean/wheat intercropped; C, control/well-watered conditions; D, water deficit. 

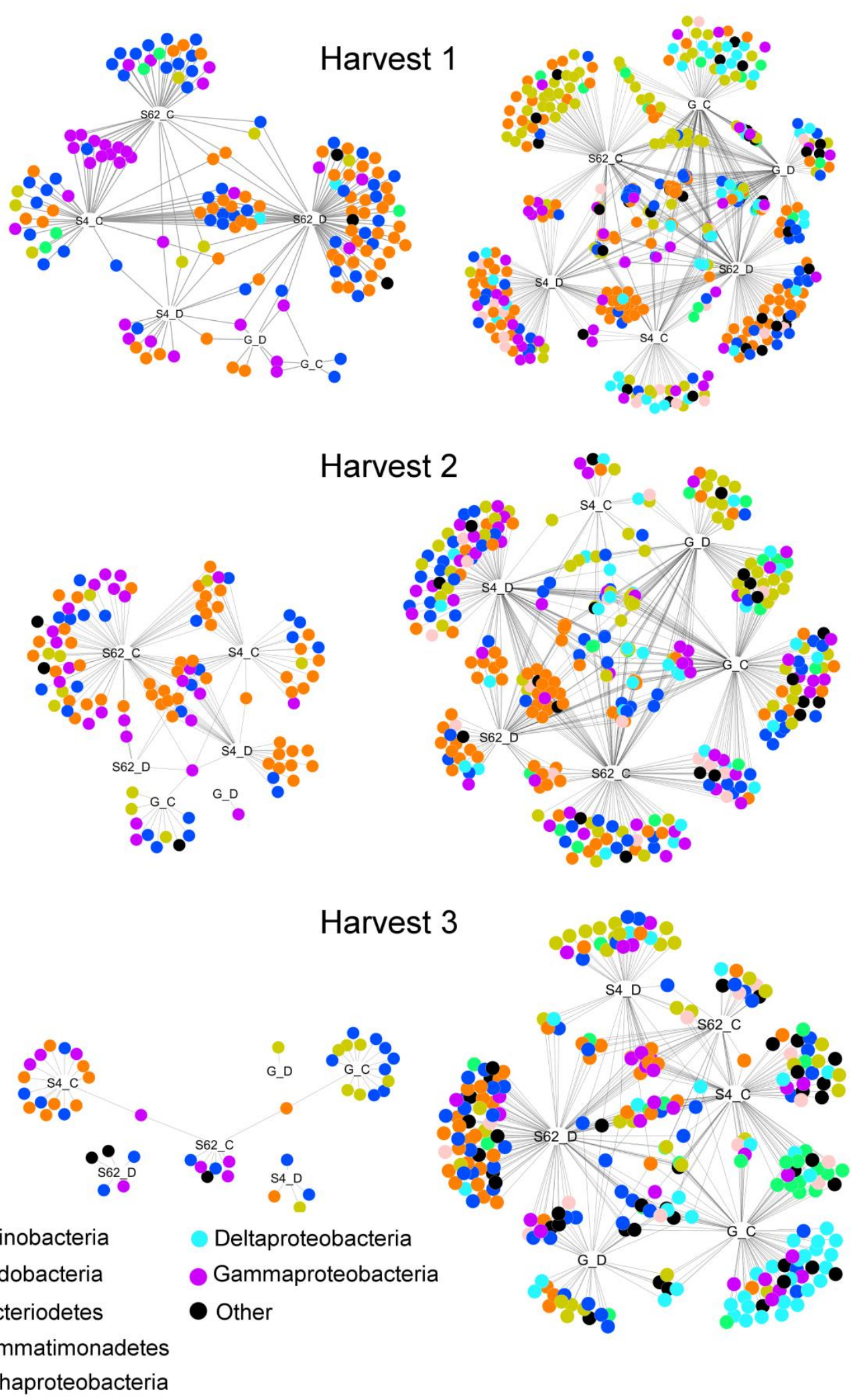

Figure 7. Bipartite association network for bacterial taxa within the different genotypes and water treatments. Significant associated taxa are shown. Abbreviations: G, genius (wheat); S4/S62, faba bean genotypes; C, control/well-watered conditions; D, water deficit. 


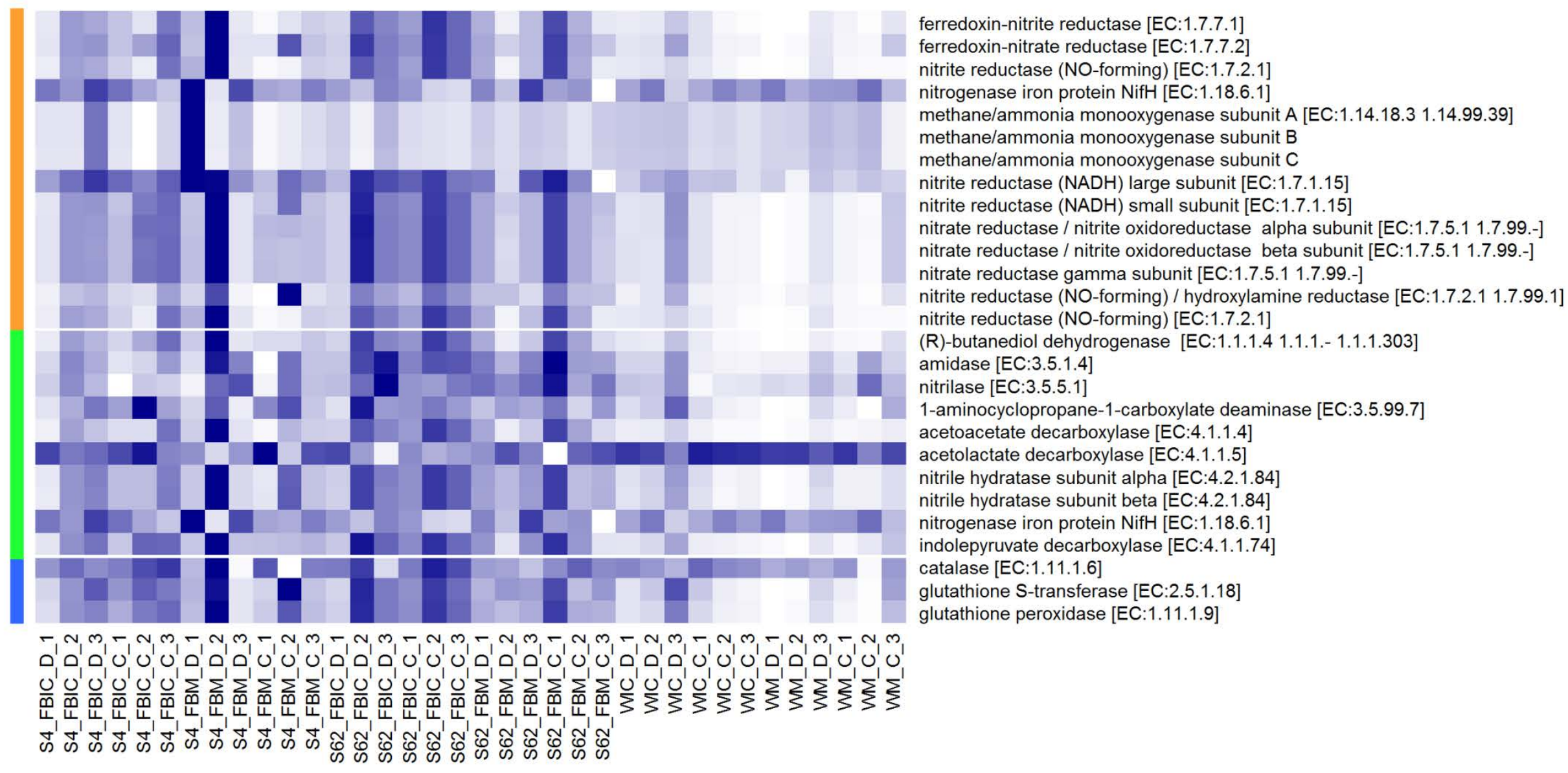

Figure 8. Predicted abundances of enzyme-encoding genes involved in nitrogen cylcing (orange), plant growth promotion (green) and stress (blue) in the rhizosphere. Colour code of the heatmap refers to gene abundance, with high predicted abundances (dark blue) and low predicted abundances (white). Abbreviations: 1-3, sampling time; S4/S62, faba bean genotype; D/C, water deficit/control treatment; FBIC/WIC, faba bean/ wheat intercropped; FBM/WM, faba bean/wheat monoculture. 


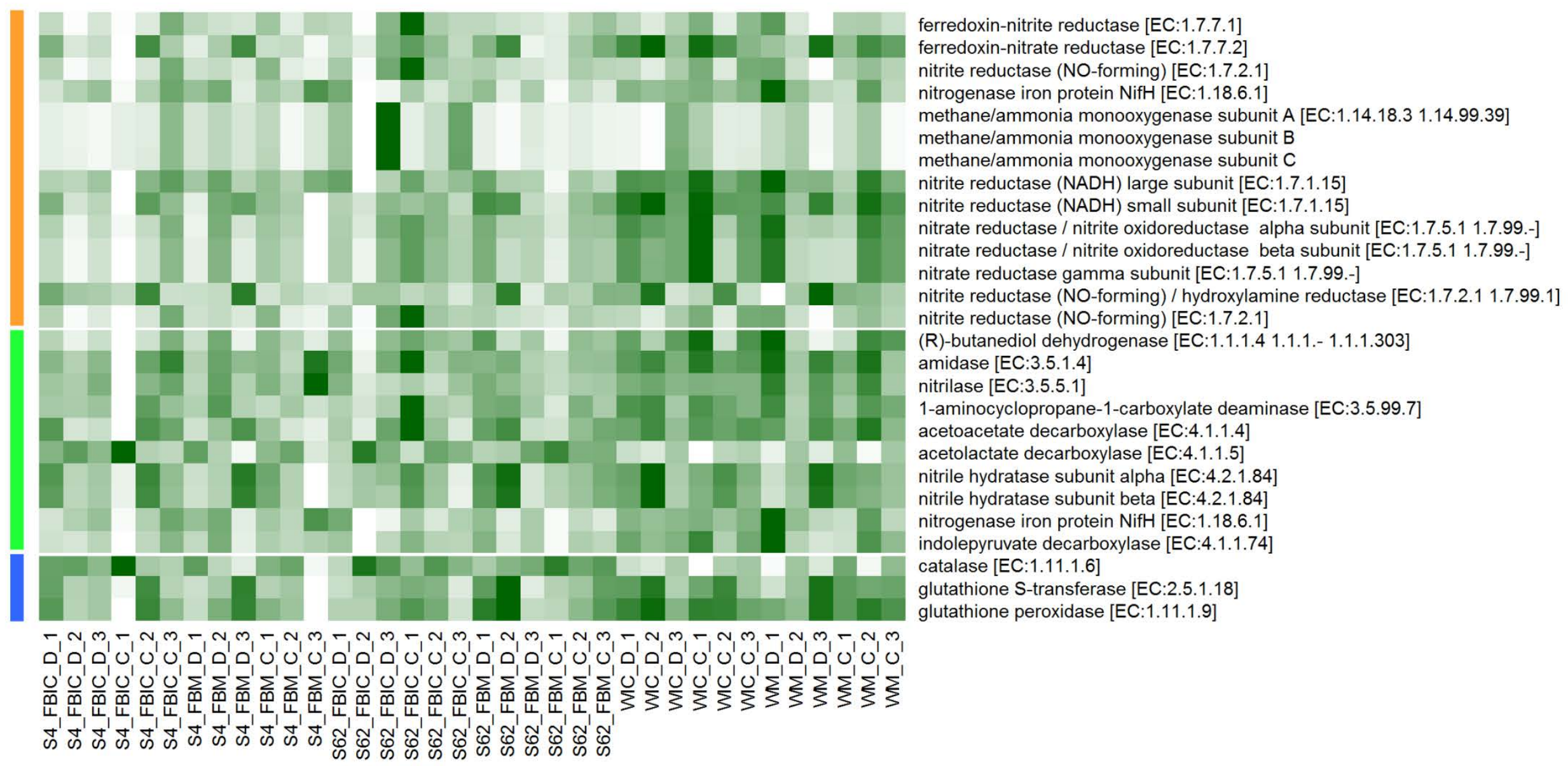

Figure 9. Predicted abundances of enzyme-encoding genes involved in nitrogen cylcing (orange), plant growth promotion (green) and stress (blue) in the leaf endosphere. Colour code of the heatmap refers to gene abundance, with high predicted abundances (dark green) and low predicted abundances (white). Abbreviations: 1-3, sampling time; S4,S62, faba bean genotype; D/C, water deficit/control treatment; FBIC/WIC, faba bean/ wheat intercropped; FBM/WM, faba bean/wheat monoculture. 


\section{References}

Abid G, Hessini K, Aouida M, Aroua I, Baudoin JP, Muhovski Y, Mergeai G, Sassi K, Machraoui M, Souissi F, et al. 2017. Agro-physiological and biochemical responses of faba bean (Vicia faba L. var. 'minor') genotypes to water deficit stress. Biotechnologie Agronomie Societe Et Environnement.21:146-159.

Anderson MJ. 2001. A new method for non-parametric multivariate analysis of variance. Austral Ecology. Feb;26:32-46.

Anderson MJ. 2006. Distance-based tests for homogeneity of multivariate dispersions. Biometrics. Mar;62:245-253.

Andreote FD, da Rocha UN, Araujo WL, Azevedo JL, van Overbeek LS. 2010. Effect of bacterial inoculation, plant genotype and developmental stage on root-associated and endophytic bacterial communities in potato (Solanum tuberosum). Antonie Van Leeuwenhoek International Journal of General and Molecular Microbiology. May;97:389-399.

Asshauer KP, Wemheuer B, Daniel R, Meinicke P. 2015. Tax4Fun: predicting functional profiles from metagenomic 16S rRNA data. Bioinformatics. Sep;31:2882-2884.

Barnard RL, Osborne CA, Firestone MK. 2013. Responses of soil bacterial and fungal communities to extreme desiccation and rewetting. Isme Journal. Nov;7:2229-2241.

Berg G. 2009. Plant-microbe interactions promoting plant growth and health: perspectives for controlled use of microorganisms in agriculture. Applied Microbiology and Biotechnology. Aug;84:11-18.

Blagodatskaya E, Kuzyakov Y. 2013. Active microorganisms in soil: Critical review of estimation criteria and approaches. Soil Biology \& Biochemistry. Dec;67:192-211.

Bodenhausen N, Horton MW, Bergelson J. 2013. Bacterial Communities Associated with the Leaves and the Roots of Arabidopsis thaliana. Plos One. Feb;8:9.

Bray EA. 1997. Plant responses to water deficit. Trends in Plant Science. Feb;2:48-54.

Bulgarelli D, Rott M, Schlaeppi K, van Themaat EVL, Ahmadinejad N, Assenza F, Rauf P, Huettel B, Reinhardt R, Schmelzer E, et al. 2012. Revealing structure and assembly cues for Arabidopsis root-inhabiting bacterial microbiota. Nature. Aug;488:91-95.

Bull AT, Asenjo JA. 2013. Microbiology of hyper-arid environments: recent insights from the Atacama Desert, Chile. Antonie Van Leeuwenhoek International Journal of General and Molecular Microbiology. Jun;103:1173-1179.

Cardinale M, Ratering S, Suarez C, Montoya AMZ, Geissler-Plaum R, Schnell S. 2015. Paradox of plant growth promotion potential of rhizobacteria and their actual promotion effect on growth of barley (Hordeum vulgare L.) under salt stress. Microbiological Research.181:22-32.

Christensen JH, Christensen OB. 2007. A summary of the PRUDENCE model projections of changes in European climate by the end of this century. Climatic Change. May;81:7-30.

Coleman-Derr D, Tringe SG. 2014. Building the crops of tomorrow: advantages of symbiontbased approaches to improving abiotic stress tolerance. Frontiers in Microbiology. Jun;5.

De Caceres M, Legendre P. 2009. Associations between species and groups of sites: indices and statistical inference. Ecology. Dec;90:3566-3574.

de Zelicourt A, Al-Yousif M, Hirt H. 2013. Rhizosphere Microbes as Essential Partners for Plant Stress Tolerance. Molecular Plant. Mar;6:242-245. 
Edgar RC. 2010. Search and clustering orders of magnitude faster than BLAST. Bioinformatics. Oct;26:2460-2461.

Edgar RC, Haas BJ, Clemente JC, Quince C, Knight R. 2011. UCHIME improves sensitivity and speed of chimera detection. Bioinformatics. Aug;27:2194-2200.

Fahad S, Bajwa AA, Nazir U, Anjum SA, Farooq A, Zohaib A, Sadia S, Nasim W, Adkins S, Saud S, et al. 2017. Crop Production under Drought and Heat Stress: Plant Responses and Management Options. Frontiers in Plant Science. Jun;8.

Fitzpatrick CR, Copeland J, Wang PW, Guttman DS, Kotanen PM, Johnson MTJ. 2018. Assembly and ecological function of the root microbiome across angiosperm plant species. Proceedings of the National Academy of Sciences of the United States of America. Feb;115:E1157-E1165.

Fox J, Weisberg S. 2011. An R companion to applied regression. Second Edition. Sage.

Gagne-Bourque F, Mayer BF, Charron JB, Vali H, Bertrand A, Jabaji S. 2015. Accelerated Growth Rate and Increased Drought Stress Resilience of the Model Grass Brachypodium distachyon Colonized by Bacillus subtilis B26. Plos One. Jun;10.

Gdanetz K, Trail F. 2017. The wheat microbiome under four management strategies, and potential for endophytes in disease protection. Phytobiomes. Oct; 158-168.

Goh CH, Vallejos DFV, Nicotra AB, Mathesius U. 2013. The Impact of Beneficial PlantAssociated Microbes on Plant Phenotypic Plasticity. Journal of Chemical Ecology. Jul;39:826-839.

Hamedi J, Mohammadipanah F. 2015. Biotechnological application and taxonomical distribution of plant growth promoting actinobacteria. Journal of Industrial Microbiology \& Biotechnology. Feb;42:157-171.

Hardoim PR, van Overbeek LS, Berg G, Pirttila AM, Compant S, Campisano A, Doring M, Sessitsch A. 2015. The Hidden World within Plants: Ecological and Evolutionary Considerations for Defining Functioning of Microbial Endophytes. Microbiology and Molecular Biology Reviews. Sep;79:293-320.

Hartman K, van der Heijden MGA, Roussely-Provent V, Walser JC, Schlaeppi K. 2017. Deciphering composition and function of the root microbiome of a legume plant. Microbiome. Jan;5.

Henry A, Doucette W, Norton J, Bugbee B. 2007. Changes in crested wheatgrass root exudation caused by flood, drought, and nutrient stress. Journal of Environmental Quality. May-Jun;36:904-912.

Herzog S, Wemheuer F, Wemheuer B, Daniel R. 2015. Effects of Fertilization and Sampling Time on Composition and Diversity of Entire and Active Bacterial Communities in German Grassland Soils. Plos One. Dec;10.

Hu FL, Feng FX, Zhao C, Chai Q, Yu AZ, Yin W, Gan YT. 2017. Integration of wheat-maize intercropping with conservation practices reduces $\mathrm{CO} 2$ emissions and enhances water use in dry areas. Soil \& Tillage Research. Jun;169:44-53.

Kaisermann A, de Vries FT, Griffiths RI, Bardgett RD. 2017. Legacy effects of drought on plant-soil feedbacks and plant-plant interactions. New Phytologist. Sep;215:1413-1424.

Kaisermann A, Maron PA, Beaumelle L, Lata JC. 2015. Fungal communities are more sensitive indicators to non-extreme soil moisture variations than bacterial communities. Applied Soil Ecology. Feb;86:158-164. 
Kaurin A, Mihelic R, Kastelec D, Grcman H, Bru D, Philippot L, Suhadolc M. 2018. Resilience of bacteria, archaea, fungi and N-cycling microbial guilds under plough and conservation tillage, to agricultural drought. Soil Biology \& Biochemistry. May;120:233-245.

Kavamura VN, Taketani RG, Lanconi MD, Andreote FD, Mendes R, de Melo IS. 2013. Water Regime Influences Bulk Soil and Rhizosphere of Cereus jamacaru Bacterial Communities in the Brazilian Caatinga Biome. Plos One. Sep;8.

Kembel SW, Cowan PD, Helmus MR, Cornwell WK, Morlon H, Ackerly DD, Blomberg SP, Webb CO. 2010. Picante: R tools for integrating phylogenies and ecology. Bioinformatics. Jun;26:1463-1464.

Kuchenbuch RO, Buczko U. 2011. Re-visiting potassium- and phosphate-fertilizer responses in field experiments and soil-test interpretations by means of data mining. Journal of Plant Nutrition and Soil Science. Apr;174:171-185.

Lancashire PD, Bleiholder H, Vandenboom T, Langeluddeke P, Stauss R, Weber E, Witzenberger A. 1991. A UNIFORM DECIMAL CODE FOR GROWTH-STAGES OF CROPS AND WEEDS. Annals of Applied Biology. Dec;119:561-601.

Li P, Ye SF, Liu H, Pen AH, Ming F, Tang XM. 2018. Cultivation of Drought-Tolerant and Insect-Resistant Rice Affects Soil Bacterial, but Not Fungal, Abundances and Community Structures. Frontiers in Microbiology. Jun;9.

Mahoney AK, Yin CT, Hulbert SH. 2017. Community Structure, Species Variation, and Potential Functions of Rhizosphere-Associated Bacteria of Different Winter Wheat (Triticum aestivum) Cultivars. Frontiers in Plant Science. Feb;8.

Martinez Arbizu P. 2017. Pairwiseadonis: Pairwise multilevel comparison using adonis. R Package Version 0.0.1.

McMurdie PJ, Holmes S. 2014. Waste Not, Want Not: Why Rarefying Microbiome Data Is Inadmissible. Plos Computational Biology. Apr;10.

Montanari-Coelho KK, Costa AT, Polonio JC, Azevedo JL, Marin SRR, Fuganti-Pagliarini R, Fujita Y, Yamaguchi-Shinozaki K, Nakashima K, Pamphile JA, et al. 2018. Endophytic bacterial microbiome associated with leaves of genetically modified (AtAREB1) and conventional (BR 16) soybean plants. World Journal of Microbiology \& Biotechnology. Apr;34.

Mwanamwenge J, Loss SP, Siddique KHM, Cocks PS. 1999. Effect of water stress during floral initiation, flowering and podding on the growth and yield of faba bean (Vicia faba L.). European Journal of Agronomy. Jun;11:1-11.

Naveed M, Mitter B, Reichenauer TG, Wieczorek K, Sessitsch A. 2014. Increased drought stress resilience of maize through endophytic colonization by Burkholderia phytofirmans PsJN and Enterobacter sp FD17. Environmental and Experimental Botany. Jan;97:30-39.

Naylor D, DeGraaf S, Purdom E, Coleman-Derr D. 2017. Drought and host selection influence bacterial community dynamics in the grass root microbiome. Isme Journal. Dec;11:2691-2704.

Nguyen LTT, Osanai Y, Lai K, Anderson IC, Bange MP, Tissue DT, Singh BK. 2018. Responses of the soil microbial community to nitrogen fertilizer regimes and historical exposure to extreme weather events: Flooding or prolonged-drought. Soil Biology \& Biochemistry. Mar;118:227-236.

Nuccio ML, Paul M, Bate NJ, Cohn J, Cutler SR. 2018. Where are the drought tolerant crops? An assessment of more than two decades of plant biotechnology effort in crop improvement. Aug; 273: 110-119. 
Ogle DH. 2016. Introductory fisheries analyses with R. Chapman \& Hall/CRC.

Oksanen O, Blanchet FG, Kindt R, Legendre P, Minchin PR, O'Hara RB, Simpson GL, Solymos P, Stevens MHH, Wagner H. 2016. Vegan: Community Ecology Package. R Package Version 2.3-5.

Osakabe Y, Osakabe K, Shinozaki K, Tran LSP. 2014. Response of plants to water stress. Frontiers in Plant Science. Mar;5.

Ouyang WJ, Struik PC, Yin XY, Yang JC. 2017. Stomatal conductance, mesophyll conductance, and transpiration efficiency in relation to leaf anatomy in rice and wheat genotypes under drought. Journal of Experimental Botany. Aug;68:5191-5205.

Pinheiro J, Bates D, DebRoy S, Sarkar D and R Core Team. 2017. nlme: Linear and Nonlinear Mixed Effects Models. R package version 3.1-131.

Preece C, Peñuelas J. 2016. Rhizodeposition under drought and consequences for soil communities and ecosystem resilience. Plant and Soil. Dec;409:1-17.

R Core Team. 2016. R: A Language and Environment for Statistical Computing. Vienna: R Foundation for Statistical Computing. Available online at: http://www.R-project.org

Ritz C, Streibig JC. 2016. Package 'drc' Analysis of dose-response curves. Version 3.0-1.

Ryan RP, Germaine K, Franks A, Ryan DJ, Dowling DN. 2008. Bacterial endophytes: recent developments and applications. Fems Microbiology Letters. Jan;278:1-9.

Santos-Medellin C, Edwards J, Liechty Z, Nguyen B, Sundaresan V. 2017. Drought Stress Results in a Compartment-Specific Restructuring of the Rice Root-Associated Microbiomes. Mbio. Jul-Aug;8.

Senbayram M, Trankner M, Dittert K, Bruck H. 2015. Daytime leaf water use efficiency does not explain the relationship between plant $\mathrm{N}$ status and biomass water-use efficiency of tobacco under non-limiting water supply. Journal of Plant Nutrition and Soil Science. Aug; 178:682-692.

Shannon P, Markiel A, Ozier O, Baliga NS, Wang JT, Ramage D, Amin N, Schwikowski B, Ideker T. 2003. Cytoscape: A software environment for integrated models of biomolecular interaction networks. Genome Research. Nov;13:2498-2504.

Song YN, Zhang FS, Marschner P, Fan FL, Gao HM, Bao XG, Sun JH, Li L. 2007. Effect of intercropping on crop yield and chemical and microbiological properties in rhizosphere of wheat (Triticum aestivum L.), maize (Zea mays L.), and faba bean (Vicia faba L.). Biology and Fertility of Soils. Jun;43:565-574.

Spinoni J, Naumann G, Vogt J. 2015. Spatial patterns of European droughts under a moderate emission scenario. Adv. Sci. Res.12: 179-186.

Streit W, Daniel R. 2010. Metagenomics. Methods and Protocols. Springer Science+Business Media, LLC. Series Volume 668.

Tahtamouni ME, Khresat S, Lucero M, Sigala J, Unc A. 2016. Diversity of endophytes across the soil-plant continuum for Atriplex spp. in arid environments. Journal of Arid Land. Apr;8:241-253.

Taschen E, Amenc L, Tournier E, Malagoli P, Fustec J, Bru D, Philippot L, Bernard L. 2017. Cereal-legume intercropping modifies the dynamics of the active rhizospheric bacterial community. Rhizosphere 3: 191-195. 
Tian BY, Zhang CJ, Ye Y, Wen JM, Wu YM, Wang HZ, Li HM, Cai SX, Cai WT, Cheng $Z Q$, et al. 2017. Beneficial traits of bacterial endophytes belonging to the core communities of the tomato root microbiome. Agriculture Ecosystems \& Environment. Sep;247:149-156.

Tichy L, Chytry M. 2006. Statistical determination of diagnostic species for site groups of unequal size. Journal of Vegetation Science. Dec;17:809-818.

Vandenkoornhuyse P, Quaiser A, Duhamel M, Le Van A, Dufresne A. 2015. The importance of the microbiome of the plant holobiont. New Phytologist. Jun;206:1196-1206.

Vandermeer JH. 1992. The ecology of intercropping. New York, NY: Cambridge University Press.

Wagner MR, Lundberg DS, del Rio TG, Tringe SG, Dangl JL, Mitchell-Olds T. 2016. Host genotype and age shape the leaf and root microbiomes of a wild perennial plant. Nature Communications. Jul;7.

Wallace J, Laforest-Lapointe I, Kembel SW. 2018. Variation in the leaf and root microbiome of sugar maple (Acer saccharum) at an elevational range limit. Peerj. Aug;6.

Weinbauer MG, Fritz I, Wenderoth DF, Hofle MG. 2002. Simultaneous extraction from bacterioplankton of total RNA and DNA suitable for quantitative structure and function analyses. Applied and Environmental Microbiology. Mar;68:1082-1087.

Wemheuer F, Kaiser K, Karlovsky P, Daniel R, Vidal S, Wemheuer B. 2017. Bacterial endophyte communities of three agricultural important grass species differ in their response towards management regimes. Scientific Reports. Jan; 7.

Wemheuer F, Wemheuer B, Kretzschmar D, Pfeiffer B, Herzog S, Daniel R, Vidal S. 2016. Impact of grassland management regimes on bacterial endophyte diversity differs with grass species. Letters in Applied Microbiology. Apr;62:323-329.

Wemheuer B, and Wemheuer F. 2017. "Assessing bacterial and fungal diversity in the plants endosphere," in Metagenomics - Methods and Protocols, Vol. 1539, edsW. Streit, and R. Daniel (New York, NY: Humana Press), 75-84.

Xu L, Naylor D, Dong ZB, Simmons T, Pierroz G, Hixson KK, Kim YM, Zink EM, Engbrecht KM, Wang Y, et al. 2018. Drought delays development of the sorghum root microbiome and enriches for monoderm bacteria. Proceedings of the National Academy of Sciences of the United States of America. May;115:E4284-E4293.

Yang CH, Huang GB, Chai Q, Luo ZX. 2011. Water use and yield of wheat/maize intercropping under alternate irrigation in the oasis field of northwest China. Field Crops Research. Dec;124:426-432.

Yang ZP, Yang WP, Li SC, Hao JM, Su ZF, Sun M, Gao ZQ, Zhang CL. 2016. Variation of Bacterial Community Diversity in Rhizosphere Soil of Sole-Cropped versus Intercropped Wheat Field after Harvest. Plos One. Mar;11.

Zampieri M, Ceglar A, Dentener F, Toreti A. 2017. Wheat yield loss attributable to heat waves, drought and water excess at the global, national and subnational scales. Environmental Research Letters. Jun;12.

Zhang NN, Sun YM, Li L, Wang ET, Chen WX, Yuan HL. 2010. Effects of intercropping and Rhizobium inoculation on yield and rhizosphere bacterial community of faba bean (Vicia faba L.). Biology and Fertility of Soils. Aug;46:625-639.

Zhang NN, Sun YM, Wang ET, Yang JS, Yuan HL, Scow KM. 2015. Effects of intercropping and Rhizobial inoculation on the ammonia-oxidizing microorganisms in rhizospheres of maize and faba bean plants. Applied Soil Ecology. Jan;85:76-85. 
Zhang YZ, Wang ET, Li M, Li QQ, Zhang YM, Zhao SJ, Jia XL, Zhang LH, Chen WF, Chen WX. 2011. Effects of rhizobial inoculation, cropping systems and growth stages on endophytic bacterial community of soybean roots. Plant and Soil. Oct;347:147-161.

Zhou Y, Zhu HH, Fu SL, Yao Q. 2017. Variation in Soil Microbial Community Structure Associated with Different Legume Species Is Greater than that Associated with Different Grass Species. Frontiers in Microbiology. May;8.

\section{Supplementary Material}

Supplementary figures and tables are provided on DVD, under the following paths:

Chapter 4/ Figure S1-S2 Rarefaction curves

Chapter 4/ Table S1 Edaphic and plant parameters

Chapter 4/ Table S2 Bacterial OTU Table

Chapter 4/ Table S3 SequenceCharacteristics Bacteria

Chapter 4/ Table S4 Associated Taxa

Chapter 4/ Table S5 Functional profiles

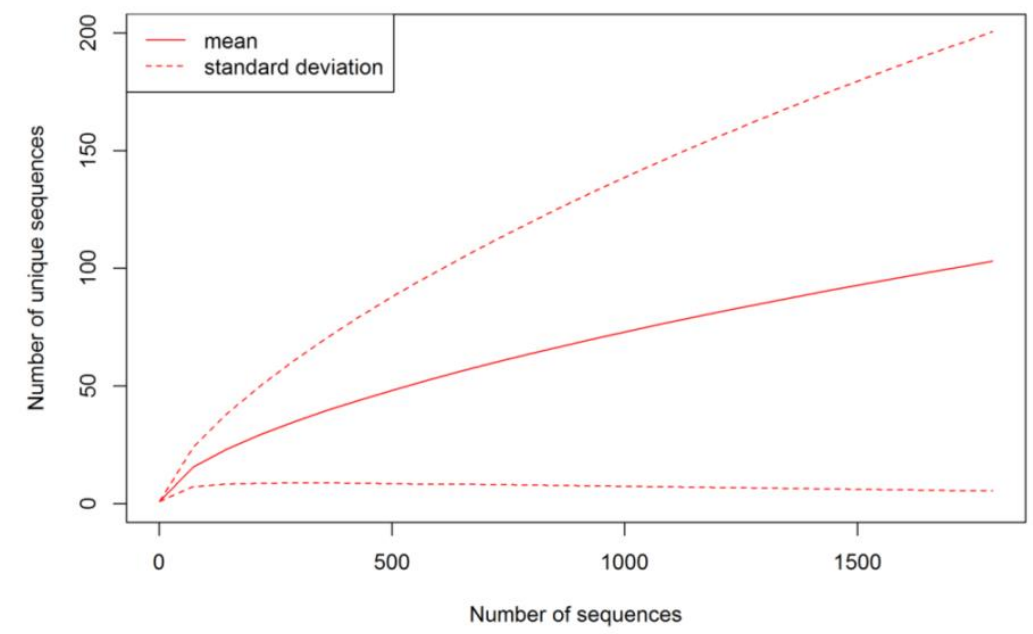

Figure S1. Rarefaction curve for bacterial leaf endophytes. Only the mean of all curves and the standard deviation are shown

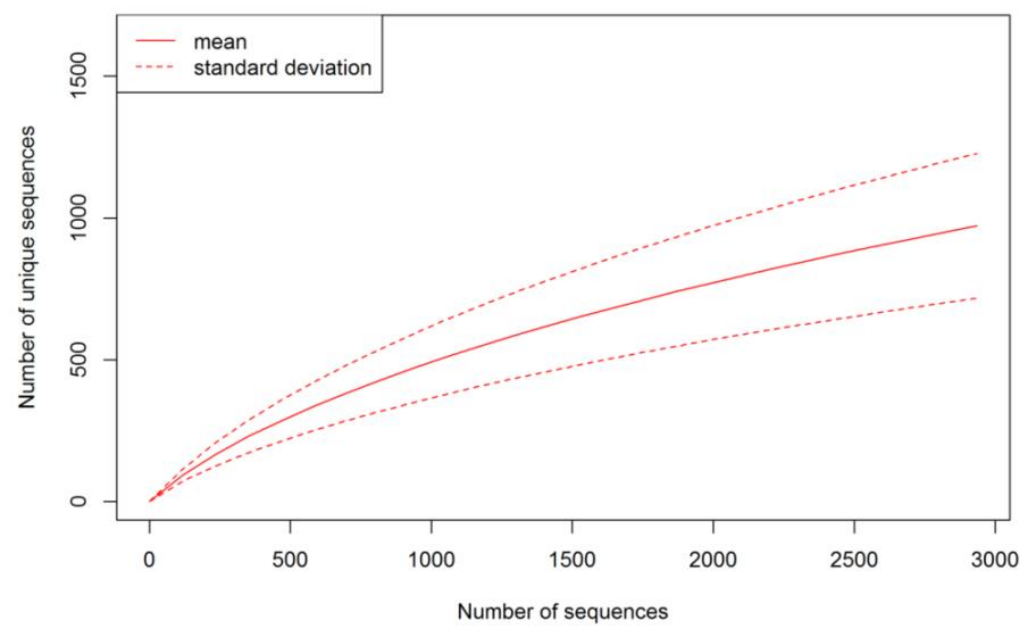

Figure S2. Rarefaction curve for bacteria in the rhizosphere. Only the mean of all curves and the standard deviation are shown. 


\section{Chapter 5}

Response of the active bacterial and fungal communities in the rhizosphere differ towards water deficit

Sandra Granzow, Annika Lingner, Birgit Pfeiffer, Rolf Daniel, Stefan Vidal and Franziska Wemheuer

In preparation for submission 


\title{
Response of the active bacterial and fungal communities in the rhizosphere differ towards drought
}

\section{Sandra Granzow ${ }^{1,2^{*}}$, Annika Lingner ${ }^{3,2}$, Birgit Pfeiffer ${ }^{3,4}$, Rolf Daniel $^{4}$, Stefan Vidal ${ }^{1}$ and Franziska Wemheuer ${ }^{1}$}

${ }^{1}$ Division of Agricultural Entomology, Department of Crop Sciences, University of Göttingen, Göttingen, Germany

${ }^{2}$ Center of Biodiversity and Sustainable Land Use, University of Göttingen, Göttingen, Germany

${ }^{3}$ Division of Plant Nutrition and Crop Physiology, Department of Crop Sciences, University of Göttingen, Göttingen, Germany

${ }^{4}$ Genomic and Applied Microbiology and Göttingen Genomics Laboratory, Institute of Microbiology and Genetics, University of Göttingen, Göttingen, Germany

\section{* Correspondence:}

Sandra Granzow, M.Sc.

sandra.granzow@agr.uni-goettingen.de

Keywords: active bacterial and fungal community, intercropping, water deficit, microbial interactions

\begin{abstract}
Drought limits plant growth and yield, but can also impact soil ecosystem functioning. Integrated soil management including new genotypes and intercropping of plants might improve the sustainability of agricultural production in a changing climate. As plantassociated microorganisms play key roles in enhancing plant tolerance to environmental stressors such as drought, it is of crucial interest to better understand how water deficit affects the active microbial community of important crops. In the present study, we investigated how water deficit changes the active bacterial and fungal community in the rhizosphere soil of winter wheat (genotype: Genius) and two winter faba bean genotypes (S_004; S_062) under different cropping systems. Our major results were that both bacterial and fungal communities were altered by water deficit; however they responded differently towards drought. Changes
\end{abstract}


of bacterial community composition were dependent on crop species and genotype, whereas alpha-diversity showed a marked resistance towards water deficit. In contrast, fungal community composition responded more sensitive but response of fungal alpha-diversity was dependent on crop genotype. Cropping system alone only influenced fungal community composition but not bacteria. Furthermore, we recorded complex microbial interactions dependent on cropping system and water deficit. For example, under water deficit the number of positive correlations in bacteria increased in wheat cropping systems compared to wellwatered plants. For fungi, we observed an increase in positive correlations under intercropped wheat compared to monoculture under well-watered conditions. To our knowledge, this is the first study investigating the combined and separate effect of intercropping and water deficit on the metabolically active plant-associated bacterial and fungal communities of two important crop species. Obtained results highlight that the combination of crop species, genotype and cropping system play key roles in the response of the active microbiome in the rhizosphere soil towards drought. Further research on field-scale might deepen our understanding how sustainable agricultural practices and plant-associated microorganisms might mitigate future drought events.

\section{Introduction}

Drought is the one of the key abiotic stressors that limits plant growth and yield worldwide (Fahad et al., 2017; Zampieri et al., 2017). Previous studies showed that drought events can also significantly influence soil ecosystem functioning, including biogeochemical cycling or soil organic matter dynamics (Austin et al., 2004; Preece and Peñuela, 2016). Drought is thus a serious threat for food security in agricultural production. The development of new genotypes and intercropping of plants are key elements of integrated soil management to improve the sustainability of agricultural production in a changing climate (Coleman-Derr and Tringe, 2014; Daryanto, Wang and Jacinthe, 2016). For example, intercropping of wheat and maize significantly increased water use and water use efficiency compared to sole cropping (Yang et al., 2011). On the other hand, Saharan et al., (2018) showed that the combination of intercropping of pigeon pea/finger millet and beneficial microorganisms such as arbuscular mycorrhizal fungi and rhizobacteria increased biomass production and nutrient uptake even under dry conditions. Soil-derived beneficial microorganism can form symbiotic and/or mutualistic associations with roots of host plants and can be important promoter of plant growth and health through better nutrient acquisition or alleviation of abiotic stressors (Coleman-Derr and Tringe, 2014; Vimal et al., 2017). Hence, changes in abundance or 
composition of root-associated microbial communities as response to environmental stressors might also impact plant performance (Berg et al., 2014; Ahkami et al., 2017). As consequence, it is of crucial interest to better understand how environmental changes such as drought alter the microbiome in the plant rhizosphere.

Previous studies on microbial responses towards drought and re-watering reported significant changes of bacterial and fungal communities (Kaisermann et al., 2015, Schmidt et al. 2017; Meisner et al., 2018). For example, Santos-Medellin et al. (2017) found that drought significantly changed bacterial and fungal community composition in different rice compartments. The authors concluded that the restructuring of the associated microbiome might contribute to plant survival under extreme environmental conditions. Recently, de Vriese et al., (2018) investigated in the response of soil bacterial and fungal communities over time towards drought in a field-based mesocosm experiment consisting of common grassland species. The authors showed that bacterial co-occurrence networks were characterised by properties that indicate low stability under disturbances, whereas fungal networks were more stable towards drought. In addition, they indicated that changes in bacterial communities were linked more strongly to soil functioning during drought recovery than do changes in fungi.

As most previous studies have focused on bacterial or fungal responses separately (Mahoney, Yin and Hulbert, 2017; Xue et al., 2018; but see Li and Wu, 2018; deVriese et al., 2018), bacterial-fungal interactions in the rhizosphere of intercropped plants under water deficit remain poorly understand. In a previous study, we found that plant compartment and plant species altered the effects of cropping systems on microbial communities and we observed different responses of fungal and bacterial communities towards cropping systems (Granzow et al., 2017). Moreover, the number of negative inter-domain interactions between fungi and bacteria decreased in bulk and rhizosphere soil in intercropping regimes compared to monoculture indicating beneficial effects (Granzow et al., 2017). So far, most studies investigating the response of microbial communities towards drought focused on the entire microbial community (Santos-Medellin et al., 2017; deVriese et al., 2018, but see Barnard et al., 2013). However, the potentially active microbial community might be more sensitive to abiotic stresses and thus is more closely related to ecosystem functionality (Blagodatskaya and Kuzyakov, 2013; Herzog et al., 2015).

Hence, the aim of the present study was to investigate the influence of water deficit and re-watering on the metabolically active fungal and bacterial communities and their interactions in the rhizosphere of two important crop species under different systems. For this purpose, winter wheat (Triticum aestivum L.; genotype: Genius) and two genotypes of winter 
faba bean (Vicia faba L.; S_004 and S_062) were grown in monoculture or in row intercropping with (water deficit treatments) or without water stress (control treatments). Rhizosphere soil was collected at three time points: beginning of water deficit, during water deficit and after re-watering. Bacterial and fungal communities in rhizosphere were examined by iTag sequencing of bacterial $16 \mathrm{~S}$ rRNA genes and the fungal internal transcribed spacer (ITS) region, respectively, amplified by two-step reverse transcriptase (RT) PCR.

We hypothesized that (i) water deficit changes microbial community composition and diversity and (ii) bacterial and fungal communities respond differently towards water deficit as they differ in their lifestyles in terms of colonization area in the rhizosphere soil (Deveau et al., 2018). We expected further that (iii) crop species, faba bean genotype and cropping system would alter the response of bacterial and fungal communities towards water deficit. Finally, we hypothesized that (iv) co-associations and microbial interactions are also influenced by water deficit and cropping systems.

\section{Material and Methods}

\subsection{Plant material}

To examine the combined influence of cropping system and water deficit on the active fungal and bacterial community in roots and attached soil (here regarded as rhizosphere soil) a greenhouse experiment was conducted in autumn 2016. Seeds of the two faba bean genotypes (genotypes: S_004; S_062) were provided by the Institute of Plant breeding of the University of Göttingen. The two winter faba bean genotypes (S_004 and S_062) were selected based on a previous field trial within the IMPAC ${ }^{3}$ project (Novel genotypes for mixed cropping allow for improved sustainable land use across arable land, grassland and woodland). The genotype S_004 is characterized by medium height and leaf size, low tillering, late maturity, and high yield. In contrast, genotype S_062 is very short with small leaflets, high tillering, and early maturing. Seeds of winter wheat (genotype: Genius) were provided by Norddeutsche Pflanzenzucht Hans-Georg Lembke KG. All seeds were surface-sterilized by serial washing according to Andreote et al. (2010) with one modification. Immersion in sterile distilled water was performed four times for $30 \mathrm{~s}$. Surface sterilized seeds were placed on wet sterile tissues and germinated at $7{ }^{\circ} \mathrm{C}$ under dark conditions until seedlings developed roots with a length of approximately $4 \mathrm{~cm}$.

\subsection{Experimental design and soil substrate}


Pre-germinated seeds of faba bean and wheat were sown in monoculture or as mixture in polypropylene containers (Sunware; $45.5 \times 36 \times 24 \mathrm{~cm}$ ) in a randomized block design (day 0, DAO, days after onset of experiment). Twelve treatments were established: faba bean monoculture S_004 with or without water deficit (S4_FBM_D/C), faba bean monoculture S_062 with or without water deficit (S62_FBM_D/C), faba bean S_004 intercropped with wheat with or without water deficit (S4_FBIC_D/C; WIC_D/C), faba bean S_062 intercropped with wheat with or without water deficit (S62_FBIC_D/C; WIC_D/C), and wheat monoculture with or without water deficit (WM_D/C; Table 1). Each treatment was replicated four times, resulting in a total of 40 containers. We defined two different cropping systems (monoculture and intercropping), whereas cropping regimes compromised each treatment, e.g. WM_D and FBM_C.

For monocultures, 30 faba bean or 72 wheat seeds per container were sown in six rows. For intercropping systems, 36 wheat and 15 bean seeds were sown in alternate rows (Vandermeer, 1992). Each container was filled with air-dried, sieved $(<10 \mathrm{~mm})$ and layered soil from the experimental study site in Reinshof $\left(51.48^{\circ} \mathrm{N}, 9.92^{\circ} \mathrm{E}\right.$ and $157 \mathrm{~m}$ asl.), Germany. The soil volume of each pot accounted for approximately $20 \mathrm{~L}$ with a dry weight of $18 \mathrm{~kg}$. Filling of the pots was performed in layers adding distilled water to each layer to prevent soil compaction. After emergence of the seedlings, the soil was covered by gravel to minimize water loss by evaporation. The soil was classified as Gleyic Fluvisol according to the FAO classification system and contained $21 \%$ clay, $68 \%$ silt and $11 \%$ sand, with $\mathrm{pH} 7.3$ and $2.8 \%$ Humus. Nutrients such as phosphorus (50 mg P/kg dry soil) and potassium (140 $\mathrm{mg} \mathrm{K} / \mathrm{kg}$ dry soil) were in an optimal range according to the German nutrient-availability class system (Kuchenbuch and Buczko 2011).

\subsection{Water management and growth conditions}

During the experiment, photosynthetic photon flux density was $400 \mu \mathrm{mol} \mathrm{m} \mathrm{m}^{-2} \mathrm{~s}^{-1}$ at plant level with a 10/14 h day/night photoperiod. Furthermore, the $\mathrm{CO}_{2}$ concentration reached around $450 \mathrm{ppm}$. There was a relative humidity of $50 \%$ and an average air temperature of $23{ }^{\circ} \mathrm{C}$. Water loss by transpiration was documented by placing the pots permanently on balances (TQ30, ATP Messtechnik, Germany). The weight reduction was measured every 30 minutes in order to constantly determine water consumption. This systems avoids hidden drought due to higher transpiration of increased biomasses (Senbayram et al., 2015). Plants of all treatments were irrigated with distilled water to $90 \%$ field capacity. After a growing period of 24 days and a $\mathrm{BBCH}$ of $14 / 34$ for faba bean and a $\mathrm{BBCH}$ of $14 / 15$ of wheat plants 
(Lancashire et al., 1991). The amount of water in water deficit treatments was reduced to $75 \%$ compared to control treatments (beginning of water deficit). At day 28, the amount of water in these treatments was further reduced to $25 \%$ (during water deficit). Day 34, all water deficit treatments were re-watered with the adequate amount of water according to plant growth and water consumption. All control pots were sufficiently irrigated during the whole experimental duration (6 weeks).

\subsection{Sampling}

Soil and plant samples were collected from control and water deficit treatments at day 29 (beginning of water deficit), day 34 (during water deficit) and at day 38 (after re-watering of water deficit plants) (Figure 1). For microbial community analysis, one faba bean and two wheat plants per container and harvest were randomly sampled which showed no obvious sign of any disease infection. The roots were gently shaken to remove the non-rhizosphere soil. Rhizosphere soil for $\mathrm{pH}$-value and $\mathrm{C} / \mathrm{N}$ was collected by carefully brushing the roots. Rhizosphere soil and roots of each plant species and each pot were pooled for molecular analysis. All samples for molecular analysis were immediately frozen in liquid nitrogen, transferred to the laboratory and stored at $-80^{\circ} \mathrm{C}$. In total, 96 faba bean (48 plants of each genotype) and 144 wheat plants were collected. Rhizosphere and aerial plant parts of each crop species and container were pooled, resulting in a total of 96 faba bean and 72 wheat samples (Table 1).

\subsection{Edaphic properties}

For determination of edaphic properties such as total organic carbon and total organic nitrogen, subsamples of all rhizosphere samples were dried at $60^{\circ} \mathrm{C}$ for two days and subsequently sieved to $<2 \mathrm{~mm}$. Carbon and nitrogen concentrations from dried subsamples were determined using a NA-1500N analyser (Thermo Fisher Scientific, Waltham, USA). Afterwards, the carbon-to-nitrogen $(\mathrm{C} / \mathrm{N})$ ratio was calculated. The gravimetric soil water content (\%) of all soil samples was calculated based on the fresh weight and the oven-dried weight. The $\mathrm{pH}$ values of all rhizosphere soil samples were measured as follows: $10 \mathrm{~g}$ of dried and sieved soil was added in a small beaker with $25 \mathrm{ml} 0.01 \mathrm{M}$ calcium chloride. Soil solution was homogenized after $30 \mathrm{~min}$ and $60 \mathrm{~min}$, and subsequently soil $\mathrm{pH} \mathrm{CaCl}_{\mathrm{Cl}}$ was measured. Details on soil properties are provided in Table S1.

\subsection{RNA Extraction and Purification}


Environmental RNA of the rhizosphere was extracted from $2 \mathrm{~g}$ soil per sample employing the RNA PowerSoil total RNA isolation kit as recommended by the manufacturer (MoBio Laboratories, Carlsbad, CA, USA, now Qiagen, Hilden, Germany). Residual DNA was removed with the TURBO DNA-free ${ }^{\mathrm{TM}}$ kit (Thermo Fisher Scientific, Waltham, USA) from the extracted RNA according to the manufacturer's protocol. In addition, 1/40 volume Ribolock RNase Inhibitor (40U/ $\mu \mathrm{L}$ ) (Thermo Fisher Scientific, Waltham, USA) was added in the first step of the DNA digestion. The absence of DNA was confirmed by PCR using the internal transcribed spacer region as target gene for amplification of fungi. For details of the PCR reaction and cycling conditions as well as the primer see the first PCR according to Wemheuer and Wemheuer (2017). The DNA-free RNA was purified according to Streit and Daniel (2012). RNA concentrations were determined using a NanoDrop ND-1000 spectrophotometer (NanoDrop Technologies, Wilmington, DE, USA).

\subsection{Synthesis of cDNA from total RNA}

Purified RNA from 168 rhizosphere samples were converted to cDNA by employing the SuperScript ${ }^{\mathrm{TM}} \mathrm{III}$ reverse transcriptase Kit as recommended by the supplier (Invitrogen, Karlsruhe, Germany) with two modifications. Same reverse primer $1193 \mathrm{r}(20 \mu \mathrm{M})$ and ITS4 $(20 \mu \mathrm{M})$ were used for the reaction as for the following PCR. After the last step, $0.5 \mu 1$ RNase $\mathrm{H}\left(5 \mathrm{U} / \mu \mathrm{l}\right.$; Fermentas) was added, and samples were incubated for $15 \mathrm{~min}$ at $37^{\circ} \mathrm{C}$ and subsequently for $10 \mathrm{~min}$ at $65^{\circ} \mathrm{C}$. CDNA was stored at $-20^{\circ} \mathrm{C}$.

\subsection{Amplification of 16S rRNA gene}

Bacterial community in the rhizosphere was assessed by PCR approach targeting the V5-V7 region of the 16S rRNA gene. The following primers were used: 799F (Chelius and Triplett, 2001) and 1193R (Bodenhausen et al., 2013; Hartman et al., 2017) containing MiSeq adaptors (underlined) Miseq-799F 5 'TCGTCGGCAGCGTCAGATGTGTATAAGAGACAGAACMGGATTAGATACCCKG-3'; MiSeq1193R

5'GTCTCGTGGGCTCG GAGATGTGTATAAGAGACAGACGTCATCCCCACCTTCC-3'. The PCR mixture $(25 \mu \mathrm{l})$ contained $5 \mu \mathrm{l}$ of five-fold Phusion GC buffer, $200 \mu \mathrm{M}$ of each of the four deoxynucleoside triphosphates, $4 \mu \mathrm{M}$ of each primer, $0.5 \mathrm{U}$ of Phusion high fidelity DNA polymerase (Thermo Scientific) and approximately $50 \mathrm{ng}$ of cDNA as template. The following thermal cycling scheme was used: initial denaturation at $98^{\circ} \mathrm{C}$ for $30 \mathrm{~s}, 30$ cycles of denaturation at $98^{\circ} \mathrm{C}$ for $15 \mathrm{~s}$, annealing at $53^{\circ} \mathrm{C}$ for $30 \mathrm{~s}$, followed by extension at $72^{\circ} \mathrm{C}$ for $30 \mathrm{~s}$. The final extension 
was carried out at $72^{\circ} \mathrm{C}$ for $2 \mathrm{~min}$. Negative controls were performed using the reaction mixture without template. Genomic DNA of Escherichia coli strain DH5a was used as template in the positive control. Three independent PCRs were performed per sample. Obtained PCR products per sample were controlled for appropriate size, pooled in equal amounts, and purified using the NucleoMag NGS Clean up (Macherey-Nagel, Düren, Germany).

Quantification of the purified PCR products was performed using the Quant-iT dsDNA HS assay kit and a Qubit fluorometer (Thermo Scientific) as recommended by the manufacturer. Quantified PCR products were barcoded using the Nextera XT-Index kit (Illumina, San Diego, USA) and the Kapa HIFI Hot Start polymerase (Kapa Biosystems, Wilmington, USA). The Göttingen Genomics Laboratory determined the sequences of the partial 16S rRNA genes employing the MiSeq Sequencing platform and the MiSeq Reagent Kit v3 (2 x 300 cycles) as recommended by the manufacturer (Illumina).

\subsection{Amplification of ITS region}

The fungal community in the rhizosphere was assessed by PCR targeting the ITS2 region with the primers ITS3_KYO2 (Toju et al., 2012) and ITS4 (White et al., 1990) containing the

MiSeq adaptors (underlined): MiSeq-ITS3_KYO2 (5'-
TCGTCGGCAGCGTCAGATGTGTATAAGAGACAGGATGAAGAACGYAGYRAA-3')

and

MiSeq-ITS4

$\left(5^{\prime}-\right.$

GTCTCGTGGGCTCGGAGATGTGTATAAGAGACAGTCCTCCGCTTA TTGATATGC $\left.3^{\prime}\right)$. The PCR mixture $(25 \mu \mathrm{l})$ contained: $5 \mu \mathrm{l}$ of five-fold Phusion GC buffer, $200 \mu \mathrm{M}$ of each of the four deoxynucleoside triphosphates, $4 \mu \mathrm{M}$ of each primer, $5 \% \mathrm{DMSO}, 25 \mathrm{mM} \mathrm{MgCl}$, $0.5 \mathrm{U}$ of Phusion High Fidelity DNA polymerase (Thermo Scientific) and approximately 10 ng DNA sample as template. For details in the thermal cycling conditions see (Wemheuer and Wemheuer, 2017; Granzow et al. 2017). Negative controls were performed using the reaction mixture without template. Genomic DNA of Aspergillus nidulans was used as template in the positive control. Three independent PCRs were performed per sample. Obtained PCR products per sample were controlled for appropriate size, pooled in equal amounts, and purified using the NucleoMag NGS Clean up (Macherey-Nagel). Quantification of the PCR products was performed using the Quant-iT dsDNA HS assay kit and a Qubit fluorometer (Thermo Scientific) as recommended by the manufacturer. Purified PCR products were barcoded using the Nextera XT-Index kit (Illumina) and the Kapa HIFI Hot Start polymerase (Kapa Biosystems). The Göttingen Genomics Laboratory determined the 
sequences of the the ITS2 region employing the MiSeq Sequencing platform and the MiSeq Reagent Kit v3 ( 2 x 300 cycles) as recommended by the manufacturer (Illumina).

\subsection{Processing of microbial community dataset}

Generated sequencing data were initially quality filtered with the Trimmomatic tool version 0.36 (Bolger et al., 2014). Low quality reads were truncated if the quality dropped below 15 in a sliding window of $4 \mathrm{bp}$. Subsequently, all reads shorter than $100 \mathrm{bp}$ and orphan reads were removed. Remaining sequences were merged, quality-filtered and further processed with USEARCH version 10.0.240 (Edgar, 2010). Filtering included the removal of reads shorter than 350 (bacteria) and 100 (fungi) or longer than $450 \mathrm{bp}$ (bacteria) and 586 (fungi) as well as the removal low quality reads (expected error $>1$ ) and reads with more than one ambitious base.

Processed sequences of all samples were concatenated to one file and subsequently dereplicated into unique sequences. These sequences were denoised with the unoise 3 algorithm implemented in USEARCH (Edgar, 2010). All OTUs consisting of one single sequence (singletons) were removed. Subsequently, remaining chimeric sequences were removed using UCHIME (Edgar et al., 2011) in reference mode with the QIIME release of the UNITE database version 7.2 (Kõljalg et al., 2013) for fungi. Filtered sequences were mapped on remaining unique sequences to determine the occurrence and abundance of each unique sequence in every sample. To assign taxonomy of fungal chimera-free sequences were classified by BLAST alignment against the most recent UNITE database (Kõljalg et al., 2013) with an e-value threshold of 1e-20. Concatenated sequences of all sequences were mapped on the final set of unique sequences to calculate the evenness and abundance of each unique sequence in all samples. All non-fungal or non-bacterial zOTUs were removed based on their taxonomic classification in the respective database. Final zOTU tables for bacteria and fungi are provided in Table S2 and S3. Only zOTUs occurring in more than one sample were considered for further statistical analysis. Samples with less than 445 (bacteria) and 63 (fungi) sequences per sample were removed prior statistical analysis, resulting in 160 and 126 samples for bacteria and fungi.

\subsection{Statistical Analysis}

All statistical analyses were performed using $\mathrm{R}$ version 3.4.0 ( $\mathrm{R}$ Core Team, 2016). Differences in edaphic, plant and bacterial community data were considered as statistically significant with $\mathrm{P} \leq 0.05$. Differences in alpha or beta diversity as well as sequencing depth 
with regard to cropping system and water treatment (yes/no) were tested by a Kruskal-Wallis test. There were no significant differences of the mean sequencing depths between the cropping systems and water treatments. In consequence, zOTU tables were not rarefied as recommended by McMurdie and Holmes (2014).

Alpha diversity indices (Richness, Shannon index of diversity and Michaelis Menten Fit) were calculated in the vegan package version 2.4.4 (Oksanen et al., 2016) and the $d r c$ package version 3.0-1 (Ritz and Streibig, 2016). OTU tables were rarefied using the rrarefy function in vegan and samples with less than 2060 (bacteria) and 213 (fungi) sequences were removed prior alpha diversity analysis. Sample coverage was estimated using the MichaelisMenten Fit calculated in R. For this purpose, richness and rarefaction curves were calculated using the picante package version 1.6-2 (Kembel et al., 2010). Richness and diversity were calculated using the specnumber and diversity function, respectively. The Michaelis-Menten Fit was subsequently calculated from generated rarefaction curves using the MM2 model within the $d r c$ package version 3.0-1 (Ritz and Streibig, 2016). All alpha diversity indices were calculated 10 times. The average from each iteration was used for further statistical analysis. Final tables containing bacterial and fungal richness, diversity, Michaelis-Menten Fit and coverage are provided in Table S4 and S5.

Data were tested for normal distribution with shapiro and homogeneity of variance with leveneTest function with the package car version 2.1-5 (Fox and Weisberg, 2011). For global differences (for all three harvests) between measured edaphic properties and plant parameters were calculated with a linear mixed model with the function lme and the $\mathrm{R}$ package nlme version 3.1-131 (Pinheiro et al., 2017) with pot number as random factor. Data was log-transformed when not normal distributed. F-values were evaluated with ANOVA and type="marginal". In addition, each harvest was tested separately with a post hoc test using Dunn's test with $p$-value adjustment "BH" and the function dunnTest in the R package FSA version 0.8.17 (Ogle, 2016). Alpha-diversity was evaluated with Kruskal-Wallis test or post hoc test using dunnTest. Differences in community composition were investigated by permutational multivariate analysis of variance (PERMANOVA; Anderson, 2001) based on Bray-Curtis distance matrices using 999 random permutations. Bacterial and fungal communities were tested separately. OTU tables were subsampled ten times and all tables were summed up to account for low abundant species. Global effects (calculated for all three sampling times together) for crop species on fungal and bacterial communities were tested with strata $=$ pot, as we had pseudoreplicated data. A significant $p$-value in PERMANOVA for beta-diversity can be driven by true biological differences, differences within group (variance) 
or both (Anderson, 2001). In case of significant $p$-values in PERMANOVA, we tested for differences in homogeneity using permutational analysis of multivariate dispersions (PERMDISP, Anderson, 2006) with 999 permuations. NMDS, PERMANOVA and PERMDISP were run using functions; metaMDS, adonis and betadisper, respectively, in the $\mathrm{R}$ package vegan (Oksanen et al., 2016). Differences in community composition were visualized using the metaMDS function within the vegan package (Oksanen et al., 2016). To investigate in differences between cropping regimes, pairwise Adonis with $p$-value adjustment "BH" based on Bray-Curtis distances were used (Martinez Arbizu, 2017).

To identify zOTUs highly associated to cropping regime, multipattern analyses were applied. For that purpose, bacteria and fungi were investigated using the multipatt function from the IndicSpecies package version 1.7.6 (DeCáceres and Legendre, 2009). Only bacterial and fungal zOTUs found in at least three samples were used. The biserial coefficients (R) with a particular cropping regime were corrected for unequal sample size using the function r.g (Tichy and Chytry, 2006). For visualization, a bipartite network was generated using the treatment as source nodes and the taxa as target nodes. Network generation was performed using the edge-weighted spring embedded layout algorithm in Cytoscape version 3.3.0 (Shannon et al., 2003). The results of the multipattern analyses are provided in Table S6.

Correlation-based co-occurrence patterns were calculated with respect to cropping regime to investigate the interactions between bacteria and fungi in the rhizosphere soil. Therefore, bacterial and fungal zOTU tables were combined resulting in 126 samples for each kingdom. To enhance reliability of the co-occurrence patterns, only zOTUs with an average abundance of more than $0.01 \%$ were considered. Additionally, zOTUs present in at least three samples were taken into account. Pairwise correlation based on Spearman's rho was calculated using the cor.test function in $\mathrm{R}$ and the numbers of significant positive and significant negative correlations were counted. Positive correlations were considered as two taxa co-occurring or cooperation between the two taxa. Negative correlations were considered as two taxa avoiding each other or competition between the two taxa.

\section{Results and Discussion}

\subsection{Edaphic properties}

We investigated in several edaphic properties including $\mathrm{pH}$-value, total organic carbon and nitrogen, as previous studies have been shown that cropping system or drought can change chemical characteristics in the rhizosphere soil (Song et al., 2007b; Preece and Peñuelas, 2016). Partly in line, we found that cropping system was the most influencing factor on 
edaphic properties compared to water treatment. Results of linear mixed effect model showed that $\mathrm{pH}$-value was significantly influenced by cropping system in the rhizosphere of wheat (LMM, df=21, $\mathrm{F}=5.72, p=0.0026$ ). This was mainly observed for harvest 2, with lowest $\mathrm{pH}$ values under WIC (Table 2). In addition, we observed that $\mathrm{pH}$-value was significantly lower in FBIC compared to FBM for both genotypes specific for harvest 2 (Kruskal-Wallis (KW)test, S_004 $\left.\mathrm{x}^{2}=6.37, \mathrm{df}=1, p=0.012 ; \mathrm{S} \_062: \mathrm{x}^{2}=10.63, \mathrm{df}=1, p=0.001\right) . \mathrm{C}: \mathrm{N}$ ratio as well as carbon were significantly affected by cropping system in the wheat rhizosphere (LMM, C:N ratio: $\mathrm{df}=21, \mathrm{~F}=5.96, p=0.023$; carbon: $\mathrm{df}=21, \mathrm{~F}=4.47, p=0.046$ ). Total nitrogen and carbon had significant lower values under WIC compared to WM for harvest 3 whereas the opposite was observed for harvest 2. Cropping system also significantly influenced C:N ratio in S_004 (S_004; LMM, df=13, F=50.54, $p<0.0001$ ) and had highest $\mathrm{C}: \mathrm{N}$ ratio was found under FBIC compared to FBM (Table 3).

\subsection{Overall microbial community}

The response of the bacterial and fungal communities of faba bean and wheat towards water deficit under different cropping systems were assessed by Illumina (MiSeq) sequencing targeting the bacterial 16S rRNA gene and internal transcribed spacer region. After removal of low quality reads, PCR artefacts (chimeras) and non-target contaminations, a total of 1,309,304 and 860,402 high quality reads were obtained for bacteria and fungi (Table S4, S5). Sequence numbers per sample varied between 445 to 71,551 (average 8,182.2) for bacteria and 63 to 104,940 for fungi. Obtained sequences were grouped into 5,809 bacterial and 1,073 fungal zOTUs (Table S2, S3). Calculated Michaelis-Menten Fit and rarefaction curves confirmed that the majority of microbial communities were recovered by the surveying effort (Figure S1, S2; Table S4, S5).

Bacteria were dominated by eight phyla $(>0.5 \%$ of all sequences across all samples):

Proteobacteria (53.71\%), Bacteroidetes (17.30\%), Actinobacteria (16.94\%), Gemmatimonadetes (5.50\%), Acidobacteria (2.28\%), Chloroflexi (1.36\%), Entotheonellaeota $(1.12 \%)$ and Fibrobacteres (0.55\%). The Proteobacteria were dominated by Gammaproteobacteria (29.95\%), followed by Alpha- (12.40\%) and Deltaproteobacteria (11.35\%). The abundant bacterial phyla were present in all samples and accounted for $98.81 \%$, of all sequences analysed in this study. At family level, Burkolderiaceae (19.94\%), Microscillaceae (7.89\%) and Polyangiceae (5.01\%) dominated the bacterial dataset. The most frequent bacterial genera were Curvibacter (4.79\% \%), Rhizobacter (3.14\%), Comamonas (3.02\%), Blrii41 (3.07\%) and Ohtaekwangia (3.02\%) (Figure 2). 
Fungi were dominated by six abundant phyla: Ascomycota (30.77\%), Glomeromycota (12.98\%), Basidiomycota (8.70\%), Mucoromycota (1.06\%), Zoopagomycota $(0.62 \%)$ and Mortierellomycota $(0.54 \%)$. Approximately $45.16 \%$ of all sequences belonged to unidentified fungi. At family level, Mycosphaerellaceae (15.78\%), Gigasporaceae (6.08\%) and Glomeraceae $(5.45 \%)$ dominated the fungal dataset. The most frequent fungal genera were Polythrincium (15.67\%), Dentiscutata (6.08\%), Cladosporium (1.58\%), Periconia (1.18\%) and Rhizopus (1.01\%) (Figure 3). Abundant bacterial and fungal taxa were also found in previous studies investigating in microbial communities in the rhizosphere soil (Zhou et al., 2017; Li et al., 2018).

\subsection{Fungal community in the rhizosphere soil was more sensitive towards water deficit than bacteria}

According to our first hypothesis that water deficit affects microbial community diversity and composition, we calculated diversity (represented by the Shannon index H') and richness (number of observed unique sequences) with regard to harvest. A general influence of water deficit on bacterial and fungal alpha-diversity was not found. Furthermore, differences between water treatments on beta-diversity were not immediately evident with the NMDS (non-metric multidimensional scaling) analysis based on Bray-Curtis dissimilarities (Figure 4). However, PERMANOVA found that water deficit significantly influenced fungal community composition in harvest 1 and 2 which explained $7.7 \%$ and $6.8 \%$ of the variance (PERMANOVA, $p=0.006(\mathrm{H} 1) ; p=0.049(\mathrm{H} 2))$ whereas bacteria were not influenced (Table 6). In accordance with this observation was the study by Schmidt et al., (2017). They investigated how reduced moisture conditions impacted soil fungal communities from temperate grassland over the course of an entire season. As a result, they reported that fungal diversity was not different between the experimental moisture levels, whereas fungi changed in their composition, in both abundances and presence/absence of species (Schmidt et al., 2017). In contrast to our results, Naylor et al., (2017) showed that bacterial diversity and composition was significantly influenced by drought in the root endosphere, rhizosphere and bulk soil of different grasses. In our study, results indicate that fungal communities were more sensitive towards water deficit compared to bacteria in the rhizosphere. In accordance with this assumption were previous findings (Kaisermann et al., 2015; He et al., 2017). On the other hand, studies have shown that fungi were more resistant towards drought compared to bacteria (Barnard et al., 2013; Meisner et al., 2018) or that both exhibited a similar response (Sayer et al., 2017; Kaurin et al., 2018). For example, Barnard et 
al., (2013) investigated in active (RNA-based) and entire (DNA-based) bacterial and fungal communities in grassland bulk soil. They found that fungal community composition exhibited a marked resistance to changes in water availability, whereas only the active bacterial community responded towards desiccation (Barnard et al., 2013). These contradictory findings between studies might be attributed to different investigated compartments (bulk vs. rhizosphere soil), differences in experimental settings such as drought intensities or soil characteristics, and precipitation history in soil which has been shown to affect microbial communities and their response towards drought (Santos-Medellin et al., 2017; Kaisermann et al., 2015; Kaisermann et al. 2017).

\subsection{Crop species and genotype influenced response of bacteria and fungi towards water deficit}

We further evaluated whether crop species and genotypes had an influence on microbial communities. We found a significant higher fungal diversity in wheat rhizosphere compared to faba bean specific for harvest $2\left(\mathrm{KW}\right.$-test, $\left.\mathrm{x}^{2}=4.3, \mathrm{df}=1, p=0.038\right)$, whereas bacterial diversity was unaffected by crop species. A significant difference between genotypes on bacterial and fungal alpha-diversity was not observed. In general, crop species explained $2.1 \%$ (PERMANOVA, $p=0.003$; PERMDISP, $\mathrm{F}=4.73, p=0.029$ ) and 2.0\% (PERMANOVA, $p=0.001)$ of the variance in the bacterial and fungal dataset. Faba bean genotype significantly influenced bacterial community composition specific for harvest 1 but fungi were complete unaffected. Here, genotype explained $6.1 \%$ of the variance (PERMANOVA, $p=0.01$ ). Moreover, several taxa were more abundant in one of the two crop species or faba bean genotypes (Figure2, 3). Higher relative abundances of the bacterial genus Rhizobium was more often found in faba bean rhizosphere $(4.12 \%)$ compared to wheat $(0.6 \%)$. In addition, the fungal genus Polythrincium was frequent in faba bean rhizosphere especially in genotype S_004 with 27.8\% relative abundance compared to S_062 (19.04\%) and wheat (3.34\%).

In line with our results, previous studies reported that plant identity is one of the important factors shaping the microbial community in the rhizosphere soil (Dawson et al., 2017; Zhou et al., 2017). For example, Zhou et al., (2017) investigated in three legume and grass species grown in a mesocosms and demonstrated that legume and grass differentially shaped the bacterial and fungal community composition and diversity in the soil. They also found that fungal diversity was significantly higher in grass compared to different legume species, whereas bacteria showed the opposite effect, indicating that bacteria and fungi respond differently towards plant identity (Zhou et al., 2017). In accordance to our results, 
Li et al., (2018) found that bacterial community composition in the rhizosphere was substantially different between two rice cultivars. However, bacterial alpha-diversity and fungi displayed no responsiveness. In addition, they indicated that cultivar dependent effects were stronger for bacteria than for fungi ( $\mathrm{Li}$ et al., 2018) which was similar to our observation. They explained that observed changes in bacterial community composition were related to alterations in $\mathrm{pH}$ and $\mathrm{Bt}$ protein concentration in the soil ( $\mathrm{Li}$ et al., 2018). Similar, legume and grass species not only differently affect edaphic properties such as $\mathrm{pH}$ but also differ in their quantity and quality of root exudates (Siczek et al., 2018; Zhou et al., 2017) which might also explain observed changes towards crop species.

We further hypothesized that crop species and genotype would alter the response of bacterial and fungal communities towards water deficit. In the rhizosphere of S_004, we recorded significantly lower fungal diversity and richness in water deficit compared to well-watered plants specific for harvest 1 (KW-test, shannon, $\mathrm{x}^{2}=5.0, \mathrm{df}=1, p=0.025$; richness, $\mathrm{x}^{2}=5.0, \mathrm{df}=1, p=0.025$ ) (Table 5).

Evaluation of microbial community with NMDS showed that only bacterial community composition for faba bean genotype S_062 exhibited a distinct clustering between control and water deficit treatment for harvest 1 (Figure 5). PERMANOVA also confirmed that water deficit significantly influenced bacterial community composition for genotype S_062 and explained 21.1\% of the variance (PERMANOVA, $p=0.002$ ). However, dispersion among water treatments was not homogenous (PERMDISP, $\mathrm{F}=18.63, p=0.002$ ).

Previous studies indicated that indirect environmental factors such as plant species which are also influenced by drought might play a larger role in altering microbial communities than direct effects of desiccation (Kaisermann et al., 2017; deVries et al., 2018). Water deficit can lead to plant stress that changes plant metabolism including the composition and quality of plant residuals such as root exudates (Henry et al., 2007; Preece and Peñuelas, 2016). As crop species but also genotypes differ in their susceptibility towards water deficit, changes in root exudation might be also different and thus, the response of the microbial community (Preece and Peñuelas, 2016). Similarly, Santos-Medellin and coworkers (2017) investigated in four different rice cultivars and plant compartments and recorded compartment-specific cultivar effects on drought response for the bacterial community composition. However, they only found few individual OTUs which showed differential responses to drought based on genotype, indicating that communities assembled in each cultivar responded relative similar towards drought. Partly in line with this study, we observed 
that response of bacterial community composition towards water deficit was dependent on faba bean genotype.

\subsection{Cropping system influenced fungal community but not bacteria in the rhizosphere soil}

We further evaluated the influence of cropping system on the microbial community composition and diversity. We found no significant effect of cropping system on bacterial and fungal diversity and richness. NMDS analysis showed for fungi a clustering between the cropping system WIC and WM especially for harvest 1 and 2 (Figure 6). However, PERMANOVA found that cropping system only significantly affected fungal community composition in wheat for harvest 2 . Here, cropping system explained $9.8 \%$ of the variance in the fungal dataset (PERMANOVA, $p=0.024$ ). In contrast, bacterial community composition was complete unaffected by cropping system. In accordance to this result, Wang et al. (2012) showed that fungal community composition in the rhizosphere of wheat in monoculture was significantly different compared to wheat in intercropping system whereas bacteria were not influenced. They also explained that soil type and crop species were the main effects which influenced microbial communities in the rhizosphere soil (Wang et al., 2012). Other studies reported that intercropping and monoculture significantly affected bacterial and/or fungal diversity which was in contrast to our results (Yang et al., 2016; Li and Wu, 2018). Li and Wu (2018) showed that from seven intercropping systems only the combination of cucumber/mustard and cucumber/trifolium increased bacterial and fungal diversity in bulk soil compared to cucumber monoculture, indicating that crop species exhibited a strong influence on microbial communities.

Moreover, we found that differences between water treatments were pronounced for a specific cropping system. For example, fungal diversity and richness was significantly lower in the rhizosphere of S_004 in FBM_D compared to FBM_C for harvest 1 (KW-test, shannon, $\mathrm{x}^{2}=4.5, \mathrm{df}=1, p=0.033$; richness, $\left.\mathrm{x}^{2}=4.5, \mathrm{df}=1, p=0.033\right)$. In the cropping system $\mathrm{WM}$, we observed significant higher fungal richness (KW-test, $\mathrm{H} 2, \mathrm{x}^{2}=3.85, \mathrm{df}=1, p=0.049$ ) under water deficit, whereas bacterial diversity (KW-test, $\mathrm{H} 1, \mathrm{x}^{2}=4.08, \mathrm{df}=1, p=0.043$ ) showed significant lower diversity compared to control treatment. In contrast, microbial community composition was not influenced by the combination of water deficit and cropping system. We speculate that the response of bacterial and fungal diversity and/or richness towards water deficit under a specific cropping system might be attributed to intraspecific below-ground 
water competition which was increased under monoculture resulting in a more sensitive microbial community.

\subsection{Associated bacterial and fungal taxa as well as microbial interactions are altered by water deficit and cropping system}

To identify bacterial and fungal taxa responsible for the observed differences among water deficit and cropping system, we performed a multipattern analysis to investigate which microorganisms are significantly associated with those treatments (Table S6). In general, the wheat cropping regimes harbored the highest number of associated bacterial and fungal taxa, whereas faba bean cropping regimes the least number (Figure 7). Most significant associated bacterial taxa were shared between cropping regimes and we found that the cropping regimes WM_C and WM_D had the most uniquely associated bacterial taxa for all sampling times. However, identity of associated bacterial taxa changed over time and between cropping regimes. For example, drought cropping regimes especially from faba bean plants showed more associated bacterial taxa from the phylum Actinobacteria than well-watered plants which was most pronounced for harvest 1. In addition, Bacteroidetes was associated more often with FBIC_D for harvest 3 than in harvest 1 or 2. In contrast, number of associated fungal taxa varied between the three harvests (Figure 7). For example, most unique associated fungal taxa were found in the cropping regime WM_D for harvest 1 and 2, whereas for harvest 3 most unique associated fungi were found in WM_C. The main fungal classes associated with drought especially in WM were assigned to Agaricomycetes and Dothideomycetes for harvest 1 and 2.

In accordance to our results, previous studies observed an enrichment of the bacterial phylum Actinobacteria under drought stress in root endosphere, bulk as well as rhizosphere soil (Kavamura et al., 2013; Naylor et al., 2017; Santos-Medellin et al., 2017). As Actinobacteria are well-known to be highly tolerant for life in arid environments, they might increase in abundance under drought, whereas sensitive taxa diminish (Bull and Asenjo, 2013; Kavamura et al., 2013). Similarly, Kavamura et al., (2013) found that the phylum Bacteroidetes strongly correlated with rainy season in soil, whereas Actinobacteria with dry season. Moreover, Meisner and coworkers (2018) showed that the bacterial phylum Bacteriodetes was enriched when soil had a drought history which might additionally explain the increased number of associated bacterial taxa in the water deficit treatment for the rewatering phase. They also indicated that fungal OTUs belonging to Dothideomycetes but also to Agaricomycetes responded sensitive towards drought which is in accordance to our result. 
Observed taxa are frequently described in plant microbiome surveys (Gdanetz et al., 2017; Naylor et al., 2017) but their specific roles in association with plants under water deficit remains relative unclear. However, we speculate that crops under water deficit selected competent microorganisms which provide the crops some degree of tolerance or assist in their development through growth promotion (Goh et al., 2013; Coleman-Derr and Tringe, 2014).

We further investigated the effect of cropping regimes on inter-and intra-domain interactions of fungi and bacteria. We calculated the number of significant correlations between OTUs for each harvest. Positive interactions (indicating species co-occurrence) are regarded indicative for cooperation, whereas negative interactions indicate avoidance or competition. In general, bacteria had more total significant interactions but less positive interactions than fungi (Table 7). Inter-domain interactions displayed less positive interactions than bacteria or fungi. In addition, faba bean rhizosphere had more positive intra-and interdomain interactions than wheat. We observed a marked increase of positive intra-domain interactions in the fungal community in WIC_C compared to WM_C in each harvest. For bacteria, we recorded more positive correlations under water deficit in wheat compared to well-watered conditions. For example, the cropping regime WIC_D (67.58\%) and WM_D (64.34\%) showed more positive bacterial intra-domain interactions compared to WIC_C (57.19\%) or WM_C (56.25\%) for harvest 2. For inter-domain interactions between bacteria and fungi, we observed no consistent pattern. For example, number of positive inter-domain correlations decreased in the cropping regime FBM_D (25.25\%) and FBIC_D (38.49\%) compared to FBIC_C $(77.75 \%)$ in the re-watering phase. In contrast, higher abundance of positive inter-domain interactions were observed in WM_D (43.08\%) and WIC_C $(55.99 \%)$ compared to WM_C $(18.19 \%)$ for harvest 3 .

Similar to our results, deVries et al., (2018) found that in general, fungal networks contained fewer negative correlations than bacterial networks in grassland bulk soil. Furthermore, deVries et al., 2018 showed that drought reduced the proportion of negative correlations in bacteria which was in accordance with our observations but specific in the wheat rhizosphere. Another study by $\mathrm{Li}$ and $\mathrm{Wu}$ (2018) reported that only a specific crop species combination from seven intercropping systems showed an increase of positive bacterial and/or fungal correlations compared to monoculture which was in line with our observations in fungi under WIC. For our findings, we speculate that changes in interactions might be related to shifts in water availability that might reduce competitive ability of dominant microbial taxa towards other taxa which are better adapted to the current moisture content (Kaisermann et al., 2015). As mentioned above, different crop species differ in their 
root exudation profile which might also affect interactions within the plant microbiome (Zhou et al., 2017). As indicated by previous research (Granzow et al., 2017; Kaisermann et al., 2017), we further assume that inter- and intraspecific competition between plants for water (or nutrients) in the specific cropping system had different effects on each crop species and thus on their associated microbial communities. Bacteria and fungi co-occur in the same habitat, the rhizosphere; however they differ in their lifestyle in terms of colonization area which might further explain differences in the observed results towards water deficit and cropping systems. For example, bacterial habitats are reduced to soil particle of few $\mathrm{mm}^{3}$ or in specific zones in a biofilm on roots (Deveau et al., 2018). In contrast, fungi have an extended and exploratory hyphal network with which they locally interact with other plants, microorganisms and microfauna (Deveau et al., 2018).

\section{Conclusion}

Our study provides novel findings of the response of the active microbial communities in the rhizosphere soil towards water deficit and cropping system in two important agricultural crops using Illumina MiSeq sequencing. In accordance to our hypotheses we found that both bacterial and fungal communities were altered by water deficit; however they responded differently towards drought. Changes of bacterial community composition were dependent on crop species and genotype, whereas alpha-diversity showed a marked resistance towards water deficit. In contrast, fungal community composition responded more sensitive towards water deficit but fungal alpa-diversity was altered dependent on crop genotype. Cropping system alone changed only fungal community composition but not bacteria. However, we recorded complex changes in microbial interactions when considering water deficit and cropping system. Obtained results highlight that the combination of crop species, genotype and cropping system play key roles in the response of the active microbiome in the rhizosphere soil towards drought. Further research on field-scale might deepen our understanding how sustainable agricultural practices and plant-associated microorganisms might mitigate future drought events.

\section{Acknowledgment}

This study is part of the project IMPAC ${ }^{3}$ and was funded by the Federal Ministry of Education and Research (FKZ 031A351A). The authors thank Prof. Dr. Wolfgang Link from the Working Group "Breeding Research Faba Bean" (Division of Plant Breeding at the University of Göttingen) for providing the seed material. 


\section{Tables}

Table 1. Sampling numbers for each container and harvest.

Treatments /Compartments

ID

Rhizosphere

Plants/treatment

\begin{tabular}{|c|c|c|c|}
\hline \multicolumn{4}{|c|}{ Harvest 1} \\
\hline Faba bean monoculture S_004 & S4_FBM & $1(8 / 7)$ & 8 \\
\hline Faba bean monoculture $S \_062$ & S62_FBM & $1(8 / 7)$ & 8 \\
\hline Faba bean intercropping S_004 & S4_FBIC & $1(8 / 8)$ & 8 \\
\hline Faba bean intercropping S_062 & S62_FBIC & $1(8 / 4)$ & 8 \\
\hline Wheat monoculture & WM & $2(8 / 5)$ & 16 \\
\hline Wheat intercropped & WIC & $2(15 / 12)$ & 32 \\
\hline \multicolumn{4}{|c|}{ Harvest 2} \\
\hline Faba bean monoculture S_004 & S4_FBM & $1(7 / 6)$ & 8 \\
\hline Faba bean monoculture $S \_062$ & S62_FBM & $1(7 / 6)$ & 8 \\
\hline Faba bean intercropping S_004 & S4_FBIC & $1(8 / 8)$ & 8 \\
\hline Faba bean intercropping S_062 & S62_FBIC & $1(8 / 8)$ & 8 \\
\hline Wheat monoculture & WM & $2(8 / 6)$ & 16 \\
\hline Wheat intercropped & WIC & $2(15 / 11)$ & 32 \\
\hline \multicolumn{4}{|c|}{ Harvest 3} \\
\hline Faba bean monoculture S_004 & S4_FBM & $1(8 / 6)$ & 8 \\
\hline Faba bean monoculture $S \_062$ & S62_FBM & $1(7 / 4)$ & 8 \\
\hline Faba bean intercropping S_004 & S4_FBIC & $1(8 / 6)$ & 8 \\
\hline Faba bean intercropping $\mathrm{S} \_062$ & S62_FBIC & $1(8 / 6)$ & 8 \\
\hline Wheat monoculture & $\mathbf{W M}$ & $2(7 / 6)$ & 16 \\
\hline Wheat intercropped & WIC & $2(14 / 10)$ & 32 \\
\hline Total (for each harvest) & & 64 & $32(\mathrm{FB}), 48(\mathrm{~W})$ \\
\hline Total (all) & & 192 & 240 \\
\hline
\end{tabular}

WM, wheat in monoculture; FBM, faba bean in monoculture, FBIC, faba bean samples in intercropping; WIC, wheat samples in intercropping. Numbers before brackets refer to sampled plants per pot. Numbers in brackets refer to the number of samples left after removal of samples with too low sequencing numbers. First number in brackets refers to bacteria, second to fungi. Harvest 1 refers to "beginning of water deficit", harvest 2 refers to "during water deficit" and harvest 3 refers to "re-watering". Sample size (n) for the cropping system WIC was 16 and for the other cropping systems, $\mathrm{n}=8$. 


\begin{tabular}{c|c|c|c|}
\multicolumn{1}{c}{ Treatment } & Harvest 1 & Harvest 2 & Harvest 3 \\
\hline Wheat_C & $\mathbf{7 . 1 0} \pm \mathbf{0 . 0 6 A}$ & $\mathbf{7 . 0 5} \pm \mathbf{0 . 0 6 A}$ & $\mathbf{7 . 3 9} \pm \mathbf{0 . 0 1 B}$ \\
Wheat_D & $\mathbf{7 . 1 1} \pm \mathbf{0 . 0 6 A}$ & $\mathbf{7 . 0 2} \pm \mathbf{0 . 0 5 B}$ & $\mathbf{7 . 4 3} \pm \mathbf{0 . 0 2 C}$ \\
\hline WIC_C & $7.05 \pm 0.08$ & $\mathbf{6 . 9 3} \pm \mathbf{0 . 0 4 a}$ & $7.39 \pm 0.01$ \\
WIC_D & $7.12 \pm 0.08$ & $\mathbf{6 . 9 1} \pm \mathbf{0 . 0 2 a}$ & $7.42 \pm 0.03$ \\
WM_C & $7.20 \pm 0.09$ & $\mathbf{7 . 3 0} \pm \mathbf{0 . 0 6 b}$ & $7.40 \pm 0.02$ \\
WM_D & $7.08 \pm 0.10$ & $\mathbf{7 . 2 3} \pm \mathbf{0 . 0 2 b}$ & $7.44 \pm 0.04$ \\
\hline S4_C & $\mathbf{7 . 1 2} \pm \mathbf{0 . 0 9 A B}$ & $\mathbf{7 . 1 1} \pm \mathbf{0 . 0 4 A}$ & $\mathbf{7 . 3 7} \pm \mathbf{0 . 0 1 B}$ \\
S4_D & $\mathbf{7 . 1 0} \pm \mathbf{0 . 0 9 A}$ & $\mathbf{7 . 0 0} \pm \mathbf{0 . 0 5 A}$ & $\mathbf{7 . 3 6} \pm \mathbf{0 . 0 1 B}$ \\
\hline S4_FBIC_C & $7.25 \pm 0.13$ & $\mathbf{7 . 0 3} \pm \mathbf{0 . 0 6 a b}$ & $7.39 \pm 0.01$ \\
S4_FBIC_D & $7.24 \pm 0.10$ & $\mathbf{6 . 9 4} \pm \mathbf{0 . 0 3 a}$ & $7.37 \pm 0.01$ \\
S4_FBM_C & $7.03 \pm 0.12$ & $\mathbf{7 . 2 0} \pm \mathbf{0 . 0 1 b}$ & $7.35 \pm 0.00$ \\
S4_FBM_D & $6.97 \pm 0.13$ & $\mathbf{7 . 0 7} \pm \mathbf{0 . 0 8 a b}$ & $7.35 \pm 0.02$ \\
\hline S62_C & $\mathbf{7 . 1 8} \pm \mathbf{0 . 0 8 A B}$ & $\mathbf{6 . 9 1} \pm \mathbf{0 . 0 4 A}$ & $\mathbf{7 . 3 6} \pm \mathbf{0 . 0 1 B}$ \\
S62_D & $\mathbf{7 . 0 2} \pm \mathbf{0 . 0 7 A}$ & $\mathbf{6 . 9 5} \pm \mathbf{0 . 0 4 A}$ & $\mathbf{7 . 3 6} \pm \mathbf{0 . 0 1 B}$ \\
\hline S62_FBIC_C & $7.03 \pm 0.12$ & $\mathbf{6 . 8 2} \pm \mathbf{0 . 0 3 a}$ & $\mathbf{7 . 3 8} \pm \mathbf{0 . 0 0 a}$ \\
S62_FBIC_D & $7.02 \pm 0.10$ & $\mathbf{6 . 8 4} \pm \mathbf{0 . 0 4 a b}$ & $\mathbf{7 . 3 6} \pm \mathbf{0 . 0 0 a b}$ \\
S62_FBM_C & $7.34 \pm 0.01$ & $\mathbf{7 . 0 1} \pm \mathbf{0 . 0 1} \mathbf{a b}$ & $\mathbf{7 . 3 4} \pm \mathbf{0 . 0 1 b}$ \\
S62_FBM_D & $7.01 \pm 0.11$ & $\mathbf{7 . 0 3} \pm \mathbf{0 . 0 1 b}$ & $\mathbf{7 . 3 6} \pm \mathbf{0 . 0 1} \mathbf{a b}$ \\
\hline
\end{tabular}

\section{Table 2.pH-value in the rhizosphere of wheat and faba bean genotypes.}

Different small and large letters in columns and rows indicate statistically significant differences between treatments (Dunn's-test or Kruskal-Wallis-test, $\mathrm{p} \leq 0.05$, means $\pm \mathrm{SE}$ ). Abbreviations: FBM/WM, faba bean/wheat grown in monoculture; FBIC/WIC, faba bean/wheat intercropped; C, control treatment; D, water deficit treatment. Harvest 1, beginning of water deficit; Harvest 2, during water deficit; Harvest 3, re-watering. 
Table 3. Carbon and nitrogen [\%] in the rhizosphere of wheat and faba bean genotypes.

\begin{tabular}{|c|c|c|c|c|c|c|c|c|c|}
\hline \multirow{4}{*}{$\begin{array}{l}\text { Treatment } \\
\text { Wheat_C } \\
\text { Wheat_D }\end{array}$} & \multicolumn{3}{|c|}{ C:N ratio } & \multicolumn{3}{|c|}{$\mathrm{C}_{\text {total }}[\%]$} & \multicolumn{3}{|c|}{$\mathbf{N}_{\text {total }}[\%]$} \\
\hline & Harvest 1 & Harvest 2 & Harvest 3 & Harvest 1 & Harvest 2 & Harvest 3 & Harvest 1 & Harvest 2 & Harvest 3 \\
\hline & $11.12 \pm 0.21$ & $10.99 \pm 0.21$ & $10.78 \pm 0.34$ & $2.02 \pm 0.04 A$ & $2.03 \pm 0.04 A$ & $1.56 \pm 0.14 B$ & $0.18 \pm 0.00 A$ & $0.19 \pm 0.01 A$ & $0.14 \pm 0.01 B$ \\
\hline & $11.46 \pm 0.15$ & $10.97 \pm 0.25$ & $11.28 \pm 0.14$ & $2.04 \pm 0.04 A$ & $2.02 \pm 0.03 A$ & $1.74 \pm 0.08 B$ & $0.18 \pm 0.00 \mathrm{~A}$ & $0.19 \pm 0.00 A$ & $0.15 \pm 0.01 B$ \\
\hline WIC_C & $11.02 \pm 0.31$ & $10.59 \pm 0.14 a$ & $10.67 \pm 0.51$ & $2.03 \pm 0.03$ & $2.05 \pm 0.02$ & $1.34 \pm 0.16 \mathrm{a}$ & $0.19 \pm 0.00$ & $0.19 \pm 0.00$ & $0.12 \pm 0.01 a$ \\
\hline WIC_D & $11.32 \pm 0.17$ & $10.96 \pm 0.38 a$ & $11.16 \pm 0.20$ & $2.01 \pm 0.04$ & $2.07 \pm 0.03$ & $1.60 \pm 0.07 a$ & $0.18 \pm 0.01$ & $0.19 \pm 0.01$ & $0.14 \pm 0.01 a$ \\
\hline WM_C & $11.34 \pm 0.21$ & $11.81 \pm 0.19 b$ & $11.01 \pm 0.20$ & $2.01 \pm 0.10$ & $1.98 \pm 0.12$ & $2.02 \pm 0.02 b$ & $0.18 \pm 0.01$ & $0.17 \pm 0.01$ & $0.18 \pm 0.00 b$ \\
\hline WM_D & $11.75 \pm 0.25$ & $11.00 \pm 0.08 \mathrm{ab}$ & $11.53 \pm 0.10$ & $2.12 \pm 0.05$ & $1.92 \pm 0.02$ & $2.04 \pm 0.03 b$ & $0.18 \pm 0.00$ & $0.18 \pm 0.00$ & $0.18 \pm 0.00 b$ \\
\hline S4_C & $11.15 \pm 0.35$ & $11.28 \pm 0.48$ & $11.50 \pm 0.27$ & $2.03 \pm 0.04$ & $2.06 \pm 0.13$ & $1.87 \pm 0.08$ & $0.18 \pm 0.01$ & $0.19 \pm 0.01$ & $0.16 \pm 0.00$ \\
\hline S4_D & $11.43 \pm 0.15$ & $11.26 \pm 0.33$ & $11.47 \pm 0.31$ & $2.10 \pm 0.03$ & $2.07 \pm 0.16$ & $1.85 \pm 0.09$ & $0.18 \pm 0.00 \mathrm{~A}$ & $0.19 \pm 0.02 A$ & $0.16 \pm 0.01 B$ \\
\hline S4_FBIC_C & $10.32 \pm 0.23 a$ & $10.21 \pm 0.20 \mathrm{a}$ & $11.32 \pm 0.54$ & $2.08 \pm 0.05$ & $2.09 \pm 0.01$ & $1.79 \pm 0.12 a b$ & $0.20 \pm 0.00 \mathrm{a}$ & $0.21 \pm 0.01$ & $0.16 \pm 0.01$ \\
\hline S4_FBIC_D & $11.10 \pm 0.15 a b$ & $10.46 \pm 0.16 a b$ & $10.88 \pm 0.05$ & $2.08 \pm 0.02$ & $2.05 \pm 0.02$ & $1.63 \pm 0.17 a$ & $0.19 \pm 0.00 a b$ & $0.20 \pm 0.00$ & $0.15 \pm 0.01$ \\
\hline S4_FBM_C & $11.98 \pm 0.24 b$ & $12.35 \pm 0.51 b$ & $11.67 \pm 0.13$ & $1.98 \pm 0.07$ & $2.03 \pm 0.28$ & $1.96 \pm 0.09 a b$ & $0.17 \pm 0.01 b$ & $0.17 \pm 0.02$ & $0.17 \pm 0.01$ \\
\hline S4_FBM_D & $11.76 \pm 0.12 b$ & $12.06 \pm 0.23 b$ & $12.05 \pm 0.46$ & $2.13 \pm 0.05$ & $2.09 \pm 0.35$ & $2.06 \pm 0.03 b$ & $0.18 \pm 0.00 \mathrm{ab}$ & $0.17 \pm 0.03$ & $0.17 \pm 0.01$ \\
\hline S62_C & $11.47 \pm 0.10$ & $11.63 \pm 0.26$ & $11.34 \pm 0.33$ & $1.96 \pm 0.04$ & $1.88 \pm 0.10$ & $1.79 \pm 0.09$ & $0.17 \pm 0.00$ & $0.16 \pm 0.01$ & $0.16 \pm 0.01$ \\
\hline S62_D & $12.11 \pm 0.37 \mathrm{~A}$ & $10.88 \pm 0.35 B$ & $11.41 \pm 0.19 A B$ & $1.86 \pm 0.09$ & $1.70 \pm 0.19$ & $1.64 \pm 0.11$ & $0.16 \pm 0.01$ & $0.15 \pm 0.02$ & $0.14 \pm 0.01$ \\
\hline S62_FBIC_C & $11.35 \pm 0.17$ & $11.06 \pm 0.29 a$ & $11.16 \pm 0.57$ & $2.01 \pm 0.03$ & $2.12 \pm 0.04 a$ & $1.69 \pm 0.08$ & $0.18 \pm 0.00$ & $0.19 \pm 0.00 a$ & $0.15 \pm 0.01$ \\
\hline S62_FBIC_D & $11.53 \pm 0.19$ & $11.12 \pm 0.14 \mathrm{ab}$ & $11.41 \pm 0.39$ & $1.93 \pm 0.07$ & $2.09 \pm 0.04 a$ & $1.42 \pm 0.15$ & $0.17 \pm 0.01$ & $0.19 \pm 0.01 a$ & $0.13 \pm 0.01$ \\
\hline S62_FBM_C & $11.59 \pm 0.11$ & $12.19 \pm 0.12 b$ & $11.53 \pm 0.41$ & $1.90 \pm 0.08$ & $1.65 \pm 0.07 a b$ & $1.90 \pm 0.17$ & $0.16 \pm 0.01$ & $0.14 \pm 0.01 b$ & $0.17 \pm 0.02$ \\
\hline S62_FBM_D & $12.68 \pm 0.62$ & $10.65 \pm 0.72 \mathrm{ab}$ & $11.41 \pm 0.14$ & $1.79 \pm 0.16$ & $1.32 \pm 0.26 b$ & $1.85 \pm 0.05$ & $0.15 \pm 0.02$ & $0.12 \pm 0.02 b$ & $0.16 \pm 0.00$ \\
\hline
\end{tabular}

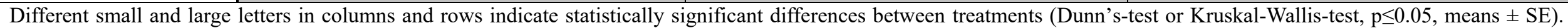

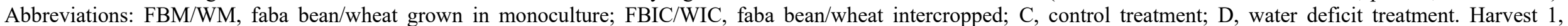

beginning of water deficit; Harvest 2, during water deficit; Harvest 3, re-watering. 
Table 4. Bacterial richness and diversity in the rhizosphere soil with regard to water treatments and cropping systems.

\begin{tabular}{|c|c|c|c|c|c|c|}
\hline & \multicolumn{3}{|c|}{ Richness } & \multicolumn{3}{|c|}{ Diversity } \\
\hline Treatment & 1 & 2 & 3 & 1 & 2 & 3 \\
\hline Wheat_C & $845.25 \pm 74.03$ & $866.07 \pm 55.6$ & $794.57 \pm 223.71$ & $6.19 \pm 0.22$ & $6.24 \pm 0.12$ & $5.82 \pm 1.12$ \\
\hline Wheat_D & $841.90 \pm 48.62$ & $818.37 \pm 105.68$ & $691.02 \pm 341.75$ & $6.18 \pm 0.13$ & $6.03 \pm 0.59$ & $5.35 \pm 1.8$ \\
\hline WIC_C & $826.56 \pm 87.46$ & $859.44 \pm 68.18$ & $845.96 \pm 67.03$ & $6.14 \pm 0.26$ & $6.22 \pm 0.14$ & $6.10 \pm 0.33$ \\
\hline WIC_D & $848.04 \pm 56.29$ & $802.91 \pm 115.8$ & $609.23 \pm 433.16$ & $6.20 \pm 0.14$ & $5.94 \pm 0.71$ & $4.87 \pm 2.26$ \\
\hline WM_C & $877.98 \pm 26.99$ & $877.68 \pm 26.91$ & $657.53 \pm 442.47$ & $6.29 \pm 0.05$ & $6.27 \pm 0.06$ & $5.08 \pm 2.19$ \\
\hline WM_D & $831.15 \pm 36.04$ & $849.28 \pm 88.03$ & $813.70 \pm 64.94$ & $6.14 \pm 0.12$ & $6.21 \pm 0.22$ & $6.09 \pm 0.24$ \\
\hline S4_C & $744.71 \pm 295.43$ & $516.54 \pm 382.25$ & $805.37 \pm 95.79$ & $5.76 \pm 1.17$ & $4.49 \pm 2.14$ & $5.93 \pm 0.62$ \\
\hline S4_D & $795.20 \pm 40.3$ & $792.59 \pm 113.95$ & $751.91 \pm 145.78$ & $6.04 \pm 0.14$ & $5.85 \pm 0.86$ & $5.77 \pm 0.78$ \\
\hline S4_FBIC_C & $806.70 \pm 118.42$ & $470.05 \pm 384.88$ & $753.83 \pm 108.6$ & $6.09 \pm 0.21$ & $4.50 \pm 1.9$ & $5.58 \pm 0.88$ \\
\hline S4_FBIC_D & $821.95 \pm 31.61$ & $833.45 \pm 70.86$ & $630.77 \pm 129.17$ & $6.14 \pm 0.06$ & $6.17 \pm 0.2$ & $5.19 \pm 0.9$ \\
\hline S4_FBM_C & $698.23 \pm 398.1$ & $578.53 \pm 453.94$ & $844.03 \pm 76.41$ & $5.51 \pm 1.59$ & $4.47 \pm 2.89$ & $6.19 \pm 0.17$ \\
\hline S4_FBM_D & $759.53 \pm 5.82$ & $738.10 \pm 153.72$ & $842.78 \pm 75.47$ & $5.91 \pm 0.1$ & $5.43 \pm 1.29$ & $6.21 \pm 0.26$ \\
\hline S62_C & $780.94 \pm 87.63$ & $867.72 \pm 47.53$ & $740.08 \pm 289.75$ & $5.99 \pm 0.34$ & $6.21 \pm 0.15$ & $5.51 \pm 1.63$ \\
\hline S62_D & $835.76 \pm 39.45$ & $614.13 \pm 368.85$ & $820.79 \pm 90.57$ & $6.15 \pm 0.18$ & $4.94 \pm 1.94$ & $6.15 \pm 0.26$ \\
\hline S62_FBIC_C & $771.65 \pm 117.25$ & $859.73 \pm 64.46$ & $816.08 \pm 136.46$ & $6.02 \pm 0.33$ & $6.16 \pm 0.21$ & $5.91 \pm 0.79$ \\
\hline S62_FBIC_D & $846.80 \pm 32.91$ & $562.87 \pm 420.59$ & $834.40 \pm 75.33$ & $6.18 \pm 0.15$ & $4.71 \pm 1.86$ & $6.17 \pm 0.24$ \\
\hline S62_FBM_C & $793.33 \pm 44.83$ & $875.70 \pm 36.08$ & $664.08 \pm 402.33$ & $5.94 \pm 0.43$ & $6.26 \pm 0.07$ & $5.12 \pm 2.27$ \\
\hline S62_FBM_D & $824.73 \pm 47.16$ & $652.58 \pm 386.75$ & $802.63 \pm 123.42$ & $6.11 \pm 0.23$ & $5.11 \pm 2.26$ & $6.12 \pm 0.34$ \\
\hline
\end{tabular}

Diversity is expressed as Shannon values (H') and richness is based on the number of unique sequences. Different small and large letters in columns and rows indicate statistically significant differences between treatments (Dunn's-test or Kruskal-Wallis-test, $\mathrm{p} \leq 0.05$, means \pm SD). Abbreviations: FBM/WM, faba bean/wheat grown in monoculture; FBIC/WIC, faba bean/wheat intercropped; C, control treatment; D, water deficit treatment. Harvest 1, beginning of water deficit; Harvest 2, during water deficit; Harvest 3, re-watering. 
Table 5. Fungal richness and diversity in the rhizosphere soil with regard to water treatments and cropping systems.

\begin{tabular}{|c|c|c|c|c|c|c|}
\hline & \multicolumn{3}{|c|}{ Richness } & \multicolumn{3}{|c|}{ Diversity } \\
\hline Treatment & 1 & 2 & 3 & 1 & 2 & 3 \\
\hline Wheat_C & $69.09 \pm 25.61$ & $66.66 \pm 17.21$ & $57.80 \pm 23.82$ & $3.29 \pm 0.94$ & $3.22 \pm 0.75$ & $3.05 \pm 0.71$ \\
\hline Wheat_D & $49.07 \pm 32.26$ & $58.94 \pm 29.1$ & $48.44 \pm 34.02$ & $2.50 \pm 1.3$ & $3.22 \pm 0.98$ & $2.24 \pm 1.65$ \\
\hline WIC_C & $66.34 \pm 28.71$ & $66.48 \pm 21.59$ & $49.57 \pm 23.93$ & $3.19 \pm 1.06$ & $3.06 \pm 0.9$ & $2.78 \pm 0.67$ \\
\hline WIC_D & $42.54 \pm 36.48$ & $43.98 \pm 31.06$ & $50.43 \pm 42.9$ & $2.29 \pm 1.52$ & $2.80 \pm 1.16$ & $2.40 \pm 2.08$ \\
\hline WM_C & $78.70 \pm 8.2$ & $67.00 \pm 4.42$ & $77.00 \pm 6.72$ & $3.64 \pm 0.19$ & $3.53 \pm 0.15$ & $3.67 \pm 0.27$ \\
\hline WM_D & $65.40 \pm 13.15$ & $78.90 \pm 6.89$ & $45.45 \pm 30.33$ & $3.04 \pm 0.39$ & $3.79 \pm 0.12$ & $2.00 \pm 1.44$ \\
\hline S4_C & $73.90 \pm 24.99 a$ & $49.20 \pm 30.59$ & $59.80 \pm 14.86$ & $3.49 \pm 0.86 a$ & $2.59 \pm 1.26$ & $3.21 \pm 0.63$ \\
\hline S4_D & $47.11 \pm 27.59 b$ & $50.93 \pm 30.07$ & $42.78 \pm 22.46$ & $2.30 \pm 1.18 b$ & $2.58 \pm 1.16$ & $2.54 \pm 0.95$ \\
\hline S4_FBIC_C & $65.65 \pm 32.2$ & $60.65 \pm 19.38$ & $64.00 \pm 13.3$ & $3.26 \pm 1.14$ & $3.18 \pm 0.6$ & $3.34 \pm 0.66$ \\
\hline S4_FBIC_D & $46.97 \pm 28.04$ & $46.15 \pm 37.35$ & $28.30 \pm 22.2$ & $2.36 \pm 1.24$ & $2.29 \pm 1.35$ & $2.20 \pm 0.55$ \\
\hline S4_FBM_C & $84.90 \pm 0.5$ & $37.75 \pm 38.19$ & $43.00 \pm \mathrm{NA}$ & $3.80 \pm 0.15$ & $2.01 \pm 1.57$ & $2.70 \pm \mathrm{NA}$ \\
\hline S4_FBM_D & $47.23 \pm 31.6$ & $60.50 \pm 7.78$ & $50.03 \pm 21.6$ & $2.26 \pm 1.32$ & $3.16 \pm 0.44$ & $2.71 \pm 1.14$ \\
\hline S62_C & $21.38 \pm 22.65$ & $58.14 \pm 25.79$ & $30.20 \pm 39.29$ & $1.57 \pm 1.37$ & $2.86 \pm 0.79$ & $1.62 \pm 1.69$ \\
\hline S62_D & $57.18 \pm 23.84$ & $36.77 \pm 30.85$ & $27.06 \pm 31.05$ & $2.82 \pm 1.01$ & $2.32 \pm 1.41$ & $1.77 \pm 1.37$ \\
\hline S62_FBIC_C & $34.10 \pm \mathrm{NA}$ & $44.75 \pm 27.04$ & $47.97 \pm 43.63$ & $2.97 \pm \mathrm{NA}$ & $2.45 \pm 0.77$ & $2.36 \pm 1.88$ \\
\hline S62_FBIC_D & $61.90 \pm 23.96$ & $29.08 \pm 17.46$ & $25.63 \pm 37.18$ & $2.92 \pm 1.11$ & $2.45 \pm 1.04$ & $1.55 \pm 1.65$ \\
\hline S62_FBM_C & $17.13 \pm 25.72$ & $76.00 \pm 7.85$ & $3.55 \pm 0.07$ & $1.11 \pm 1.23$ & $3.41 \pm 0.44$ & $0.51 \pm 0.45$ \\
\hline S62_FBM_D & $52.47 \pm 27.93$ & $47.03 \pm 46.05$ & $29.20 \pm 32.81$ & $2.71 \pm 1.13$ & $2.13 \pm 2.07$ & $2.10 \pm 1.29$ \\
\hline
\end{tabular}

Diversity is expressed as Shannon values $\left(\mathrm{H}^{\prime}\right)$ and richness is based on the number of unique sequences Different small and large letters in columns and rows indicate statistically significant differences between treatments (Dunn's-test or Kruskal-Wallis-test, $\mathrm{p} \leq 0.05$, means $\pm \mathrm{SD}$ ). Abbreviations: FBM/WM, faba bean/wheat grown in monoculture; FBIC/WIC, faba bean/wheat intercropped; C, control treatment; D, water deficit treatment. Harvest 1, beginning of water deficit; Harvest 2, during water deficit; Harvest 3, re-watering.

Table 6. Effects of the tested parameters on bacterial and fungal community composition for each harvest.

\begin{tabular}{|c|c|c|c|c|c|c|c|c|c|c|c|c|}
\hline \multirow[b]{3}{*}{ Treatment } & \multicolumn{6}{|c|}{ Bacteria } & \multicolumn{6}{|c|}{ Fungi } \\
\hline & \multicolumn{2}{|c|}{ Harvest 1} & \multicolumn{2}{|c|}{ Harvest 2} & \multicolumn{2}{|c|}{ Harvest 3} & \multicolumn{2}{|c|}{ Harvest 1} & \multicolumn{2}{|c|}{ Harvest 2} & \multicolumn{2}{|c|}{ Harvest 3} \\
\hline & $\begin{array}{c}\mathbf{R}^{2} \\
(\%) \\
\end{array}$ & $p$ & $\begin{array}{c}R^{2} \\
(\%) \\
\end{array}$ & $p$ & $\begin{array}{c}R^{2} \\
(\%) \\
\end{array}$ & $p$ & $\begin{array}{c}R^{2} \\
(\%) \\
\end{array}$ & $p$ & $\begin{array}{c}\mathbf{R}^{2} \\
(\%) \\
\end{array}$ & $p$ & $\begin{array}{c}\mathbf{R}^{2} \\
(\%)\end{array}$ & $p$ \\
\hline Cropping system & 2.1 & 0.23 & 1.1 & 0.916 & 1.3 & 0.826 & 1.7 & 0.812 & 1.7 & 0.832 & 2.7 & 0.382 \\
\hline Crop species & 4.2 & 0.005 & 3.4 & 0.049 & 2.1 & 0.319 & 5.8 & 0.001 & 4.9 & 0.001 & 4.7 & 0.003 \\
\hline Genotype & 6.1 & 0.01 & 2.7 & 0.649 & 2.6 & 0.724 & 3.2 & 0.735 & 2.9 & 0.823 & 5.4 & 0.221 \\
\hline Water deficit & 2.5 & 0.125 & 2.2 & 0.227 & 1.7 & 0.559 & 4.1 & 0.017 & 3.2 & 0.049 & 2.9 & 0.243 \\
\hline Harvest & 2.2 & 0.015 & & & & & 2.0 & 0.033 & & & & \\
\hline
\end{tabular}

Results of the permutational multivariate analysis of variance (PERMANOVA) with Bray-Curtis distances testing for the different treatments. Statistically significant differences $(\mathrm{p} \leq 0.05)$ between the treatments for each plant compartment are written in bold. Cropping systems compares monoculture versus intercropping. Genotype compares S 004 versus S 062. Harvest was tested for all harvests together without strata. 
Table 7. Positive $(+)$ and negative (-) relative interactions with regard to cropping regimes.

Harvest 1

Harvest 2

Harvest 3

\begin{tabular}{|c|c|c|c|c|c|c|c|c|c|c|}
\hline \multirow{9}{*}{ B:B } & Treatment & Total & $+(\%)$ & $-(\%)$ & Total & $+(\%)$ & $-(\%)$ & Total & $+(\%)$ & $-(\%)$ \\
\hline & FBIC_D & 67155 & 56.16 & 43.84 & 182063 & 97.49 & 2.51 & 89622 & 80.96 & 19.04 \\
\hline & FBIC_C & 26456 & 58.88 & 41.12 & 79873 & 98.29 & 1.71 & 105301 & 87.93 & 12.07 \\
\hline & FBM_D & 94036 & 76.59 & 23.41 & 49951 & 64.31 & 35.69 & 151945 & 58.16 & 41.84 \\
\hline & FBM_C & 59102 & 54.93 & 45.07 & 99886 & 98.09 & 1.91 & 75704 & 54.82 & 45.18 \\
\hline & WIC_D & 47469 & 62.88 & 37.12 & 81741 & 67.58 & 32.42 & 8 & 62.50 & 37.50 \\
\hline & WIC_C & 91633 & 57.54 & 42.46 & 109847 & 57.19 & 42.81 & 173569 & 65.40 & 34.60 \\
\hline & WM_D & 0 & NA & NA & 49164 & 64.34 & 35.66 & 49641 & 53.36 & 46.64 \\
\hline & WM_C & 119471 & 52.52 & 47.48 & 48673 & 56.26 & 43.74 & 4251 & 85.42 & 14.58 \\
\hline \multirow{8}{*}{$F: F$} & FBIC_D & 950 & 87.68 & 12.32 & 545 & 100 & 0 & 1 & 100 & 0 \\
\hline & FBIC_C & 550 & 91.09 & 8.91 & 3326 & 99.10 & 0.90 & 1812 & 100 & 0 \\
\hline & FBM_D & 8672 & 97.52 & 2.48 & 190 & 100 & 0 & 305 & 100 & 0 \\
\hline & FBM_C & 668 & 100.00 & 0.00 & 1771 & 99.94 & 0.06 & 0 & NA & NA \\
\hline & WIC_D & 4996 & 99.98 & 0.02 & 66 & 100 & 0 & 0 & NA & NA \\
\hline & WIC_C & 5419 & 98.41 & 1.59 & 1915 & 72.17 & 27.83 & 4240 & 99.88 & 0.12 \\
\hline & WM_D & 0 & NA & NA & 178 & 56.74 & 43.26 & 22 & 100 & 0 \\
\hline & WM_C & 31 & 87.10 & 12.90 & 479 & 52.40 & 47.60 & 2556 & 71.48 & 28.52 \\
\hline \multirow{8}{*}{$B: F$} & FBIC_D & 13123 & 56.15 & 43.85 & 7629 & 68.62 & 31.38 & 317 & 38.49 & 61.51 \\
\hline & FBIC_C & 4691 & 59.41 & 40.59 & 10866 & 64.64 & 35.36 & 19946 & 77.49 & 22.51 \\
\hline & FBM_D & 22273 & 73.05 & 26.95 & 2471 & 54.11 & 45.89 & 10765 & 25.25 & 74.75 \\
\hline & FBM_C & 7747 & 62.99 & 37.01 & 15845 & 71.65 & 28.35 & 71 & 45.07 & 54.93 \\
\hline & WIC_D & 7182 & 44.46 & 55.54 & 2025 & 41.73 & 58.27 & 0 & NA & NA \\
\hline & WIC_C & 39402 & 52.97 & 47.03 & 23299 & 53.80 & 46.20 & 32121 & 55.99 & 44.01 \\
\hline & WM_D & 0 & NA & NA & 5213 & 52.31 & 47.69 & 1706 & 43.08 & 56.92 \\
\hline & WM_C & 3738 & 48.50 & 51.50 & 9400 & 53.59 & 46.41 & 5482 & 18.19 & 81.81 \\
\hline
\end{tabular}

Total refers to total number of significant interactions. Abbreviations: C, control treatment/ sufficiently irrigated; $\mathrm{D}$, water deficit, drought treatment; FBM/WM, faba bean/ wheat monoculture; FBIC/WIC, faba bean/ wheat intercropped; B:B, bacterial intra-domain interactions; F:F, fungal intra-domain interations; B:F, bacterial and fungal inter-domain interactions. 


\section{Figures}

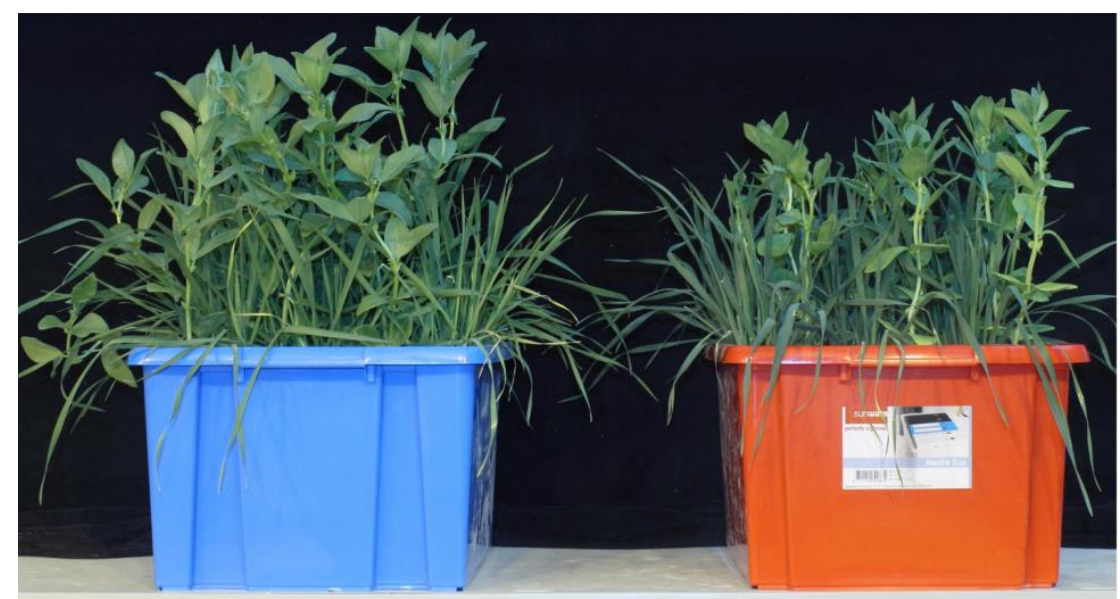

\section{IC_Cl \\ IC_D}

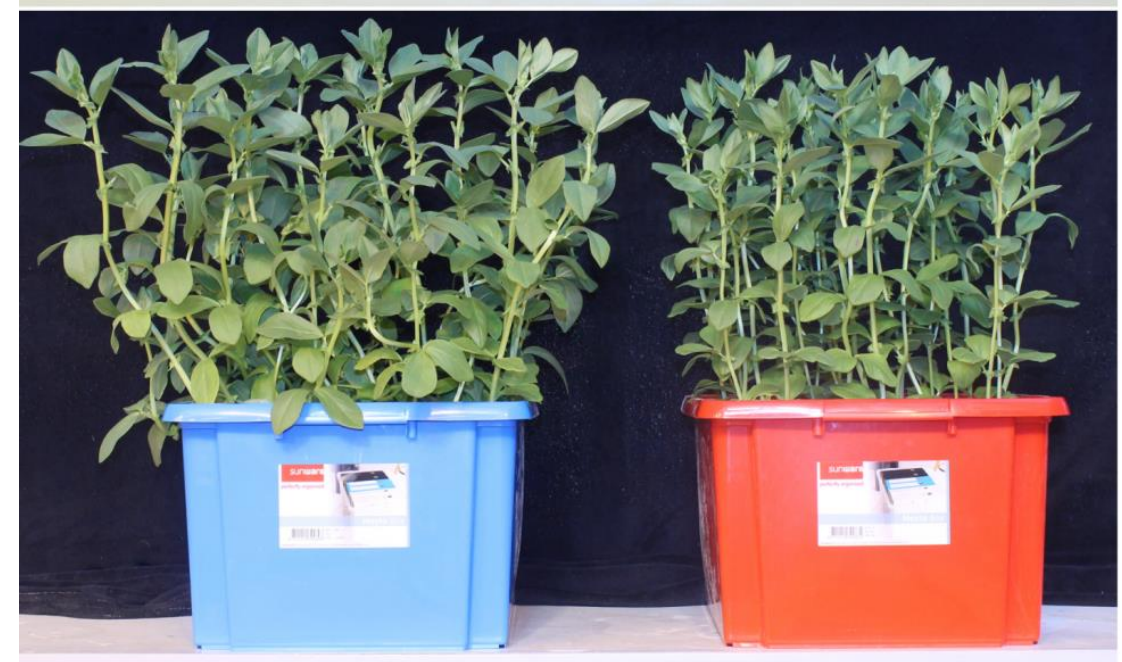

FBM C/

FBM-D

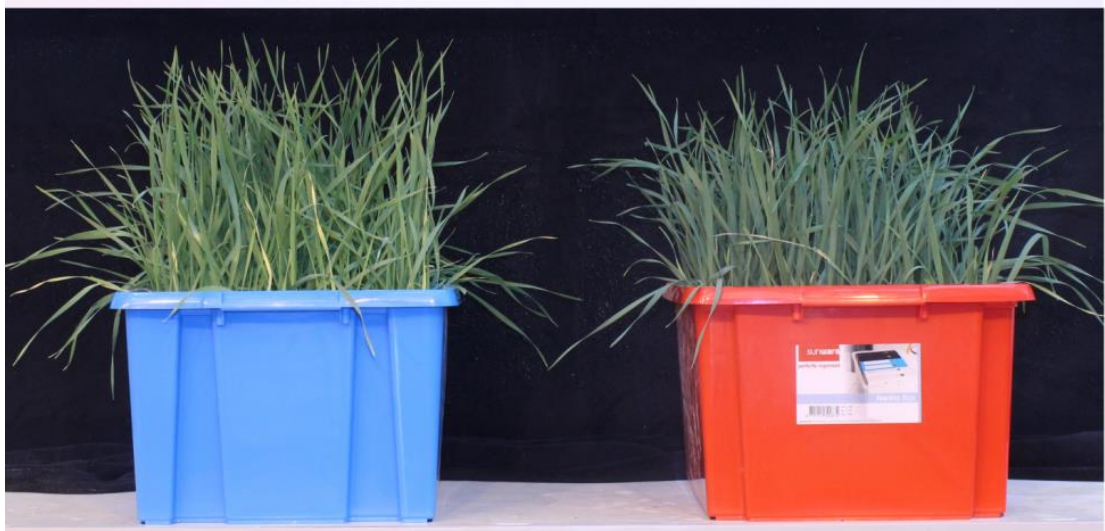

WM_Cl
WM_D

Figure 1. Experimental design. Abbreviations: FBM/WM, faba bean/wheat monoculture; IC, intercropping; C, control (blue container); D, water deficit treatment (red container). 


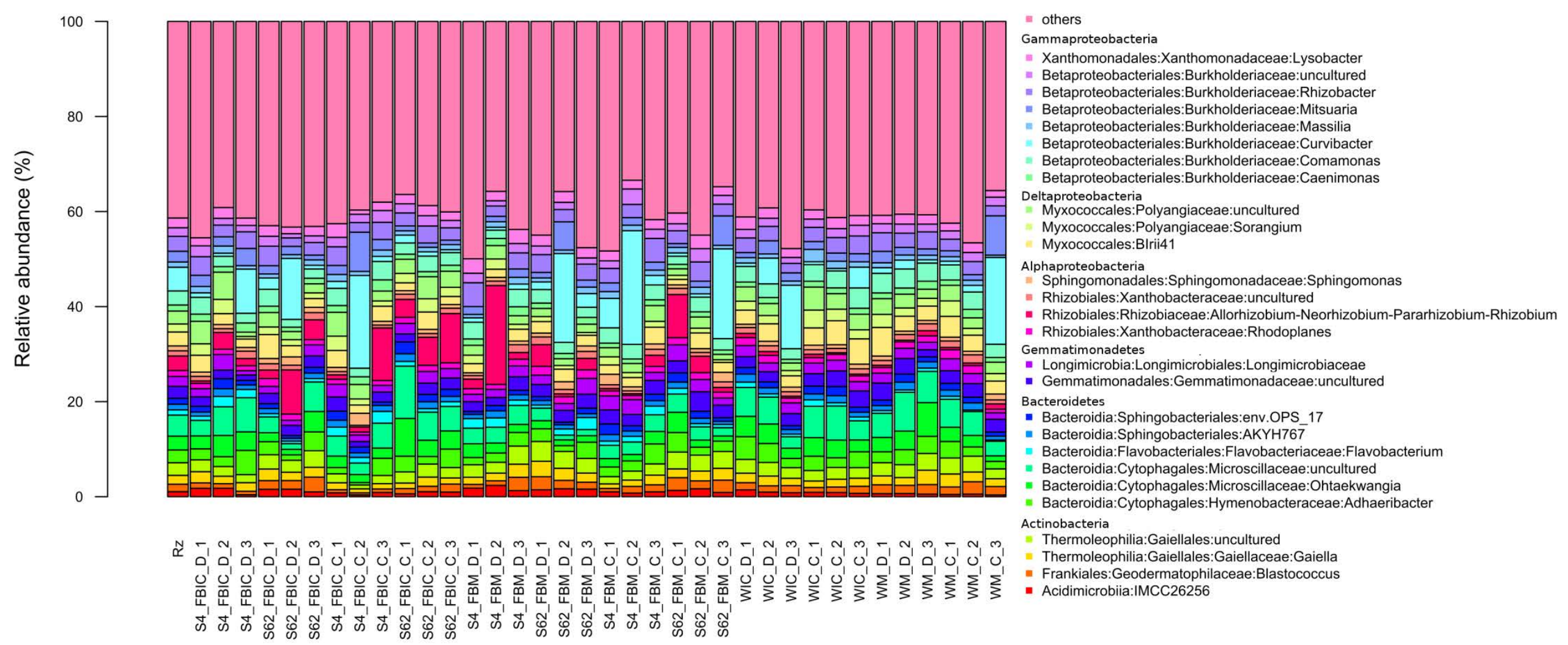

Figure 2. Abundant bacterial genera in the rhizosphere soil and the investigated cropping systems with regard to water treatment and harvest. Only genera with an abundance $>1 \%$ in at least one of the investigated cropping system are shown. Mean relative abundances of each taxon were calculated based on relative abundances calculated for each sample. Abbreviations: C, control treatment; D, water deficit treatment; S4/S62, faba bean genotype; FBM/WM, faba bean/ wheat monoculture, FBIC/WIC, faba bean/wheat intercropped. 


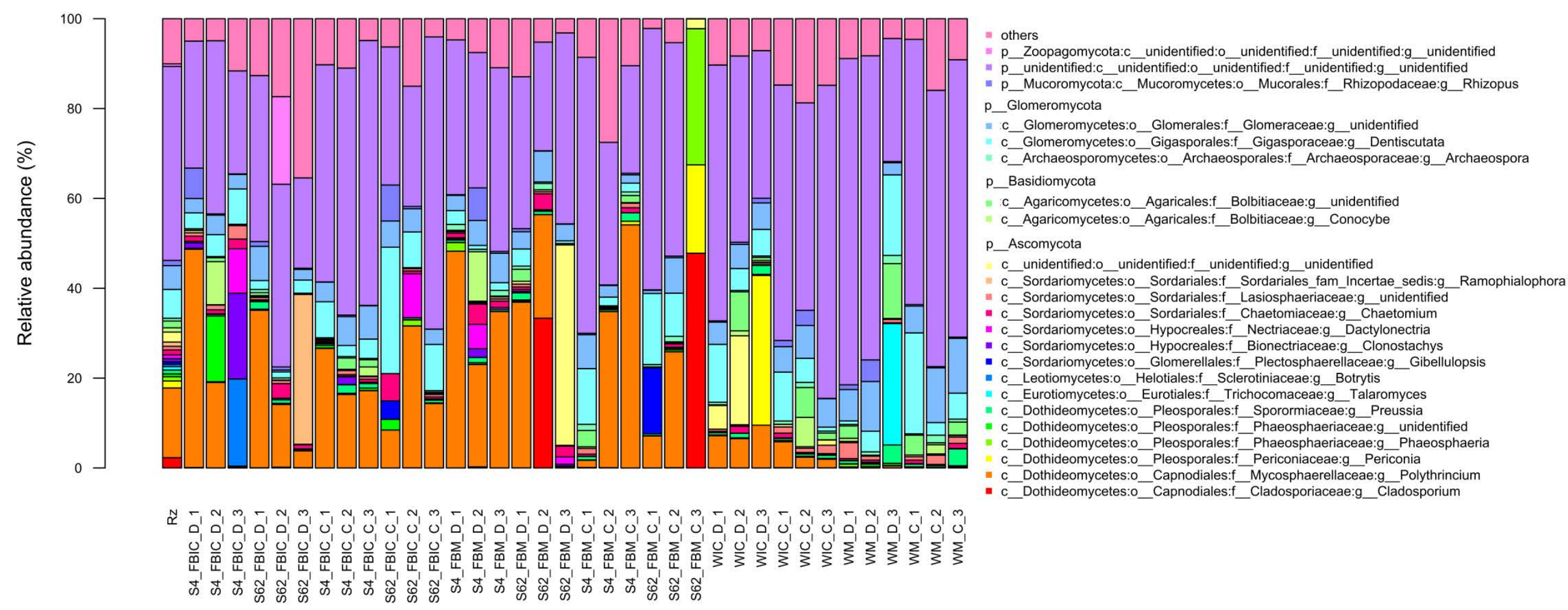

Figure 3. Abundant fungal genera in the rhizosphere soil and the investigated cropping systems with regard to water treatment and harvest. Only genera with an abundance $>0.05 \%$ in at least one of the investigated cropping system are shown. Mean relative abundances of each taxon were calculated based on relative abundances calculated for each sample. Abbreviations: C, control treatment; D, water deficit treatment; S4/S62, faba bean genotype; FBM/WM, faba bean/ wheat monoculture, FBIC/WIC, faba bean/wheat intercropped. 

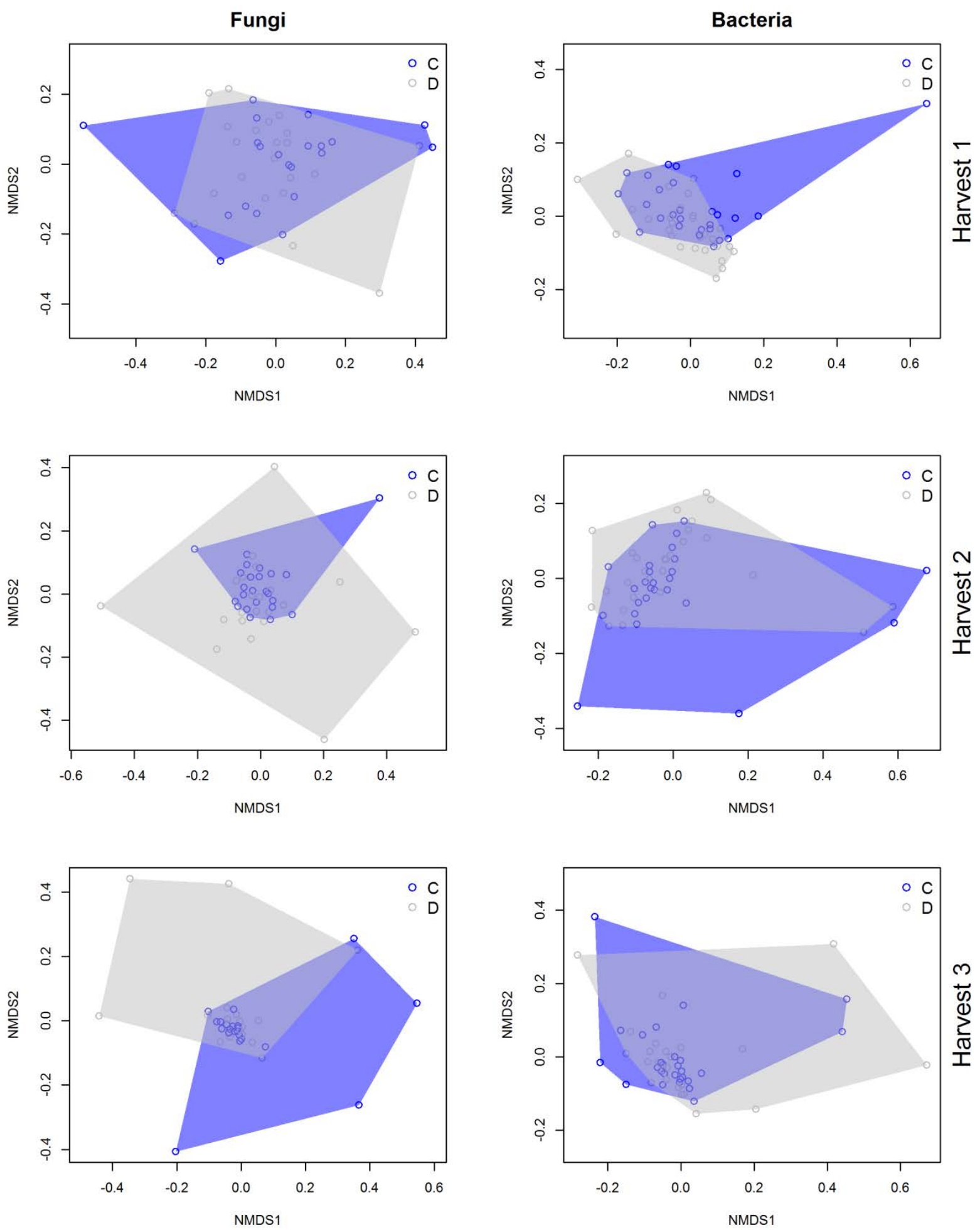

Figure 4. Response of bacterial and fungal communities in the rhizosphere soil towards water treatment. Ordination is based on Bray-Curtis dissimiliarties between samples. NMDS ordination of microbial community is color-coded by the respective water treatment. Abbreviations: C, control treatment; D, water deficit treatment. 

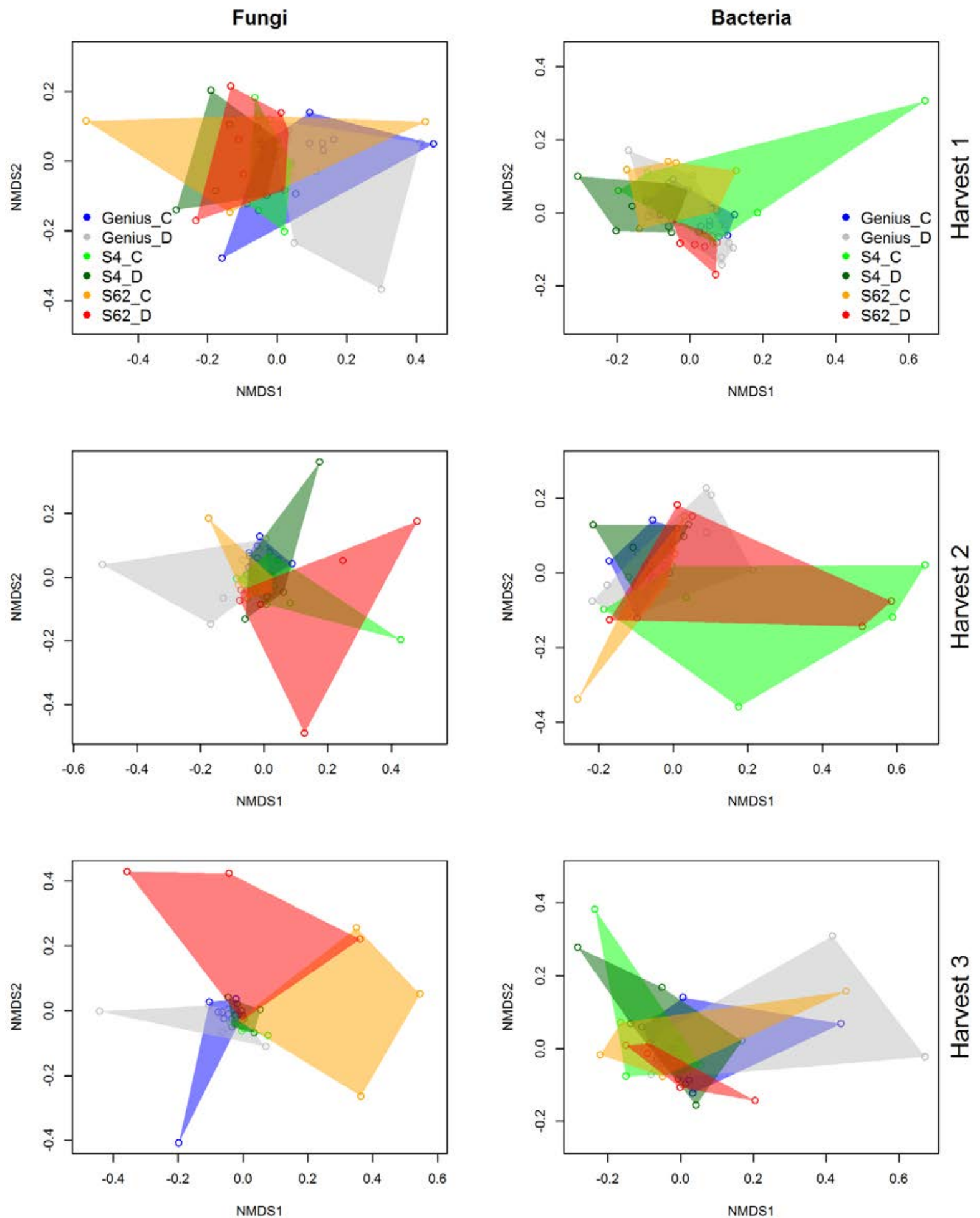

Figure 5. Response of bacterial and fungal communities in the rhizosphere soil towards water treatment regarding the different crop genotypes. Ordination is based on BrayCurtis dissimiliarties between samples. NMDS ordination of microbial community is colorcoded by the respective water treatment and genotype. Abbreviations: S4/S62, faba bean genotype; C, control; D, water deficit. 

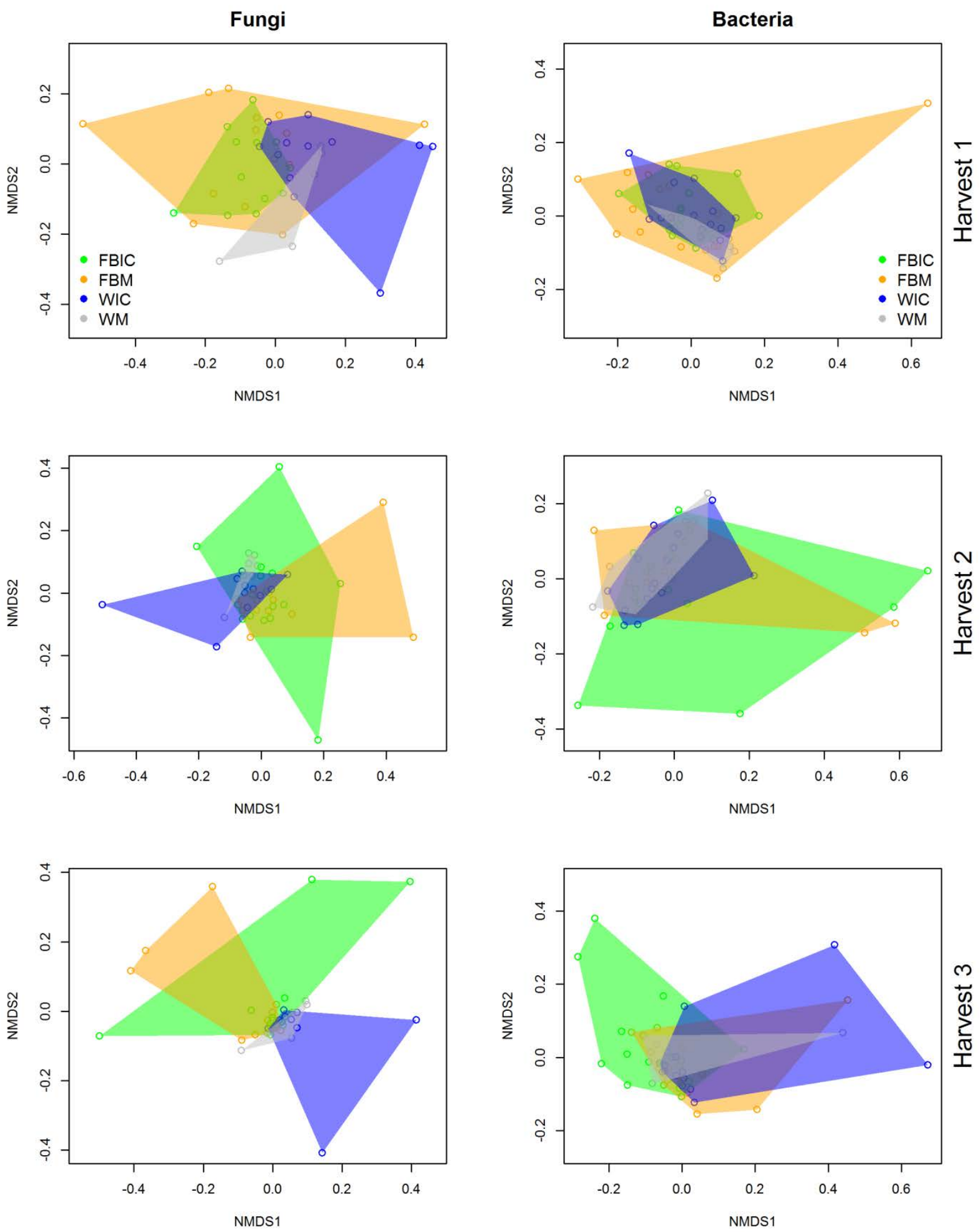

Figure 6. Response of bacterial and fungal communities in the rhizosphere soil towards cropping system. Ordination is based on Bray-Curtis dissimiliarties between samples. NMDS ordination of microbial community is color-coded by the respective cropping system. Abbreviations: FBM/WM, faba bean/ wheat monoculture; FBIC/WIC, faba bean/wheat intercropping. 


\section{Fungi}
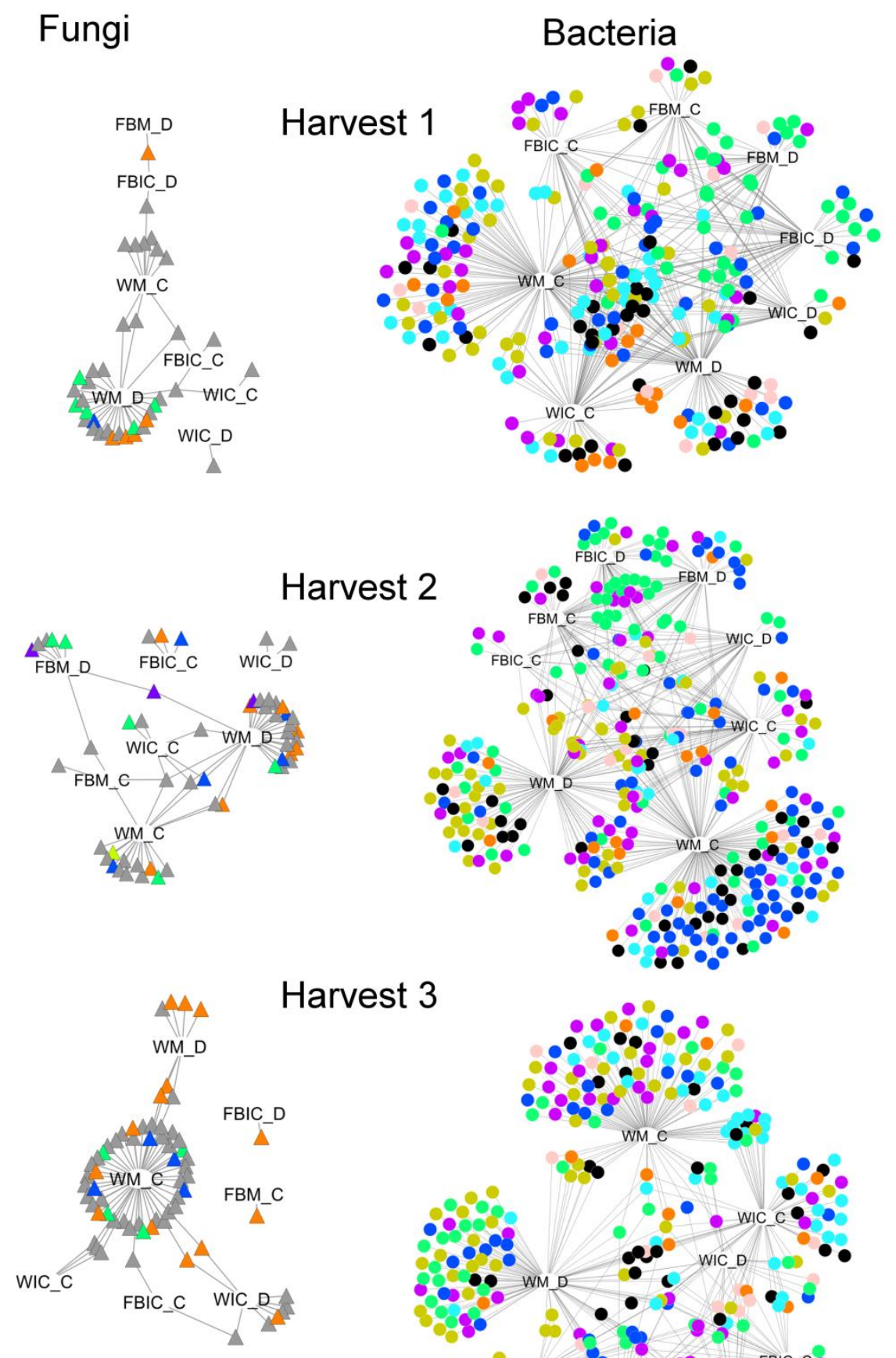
Ascomycota Unidentified
- Basidiomycota
- Glomeromycota
- Mortierellomycetes
Mucoromycota

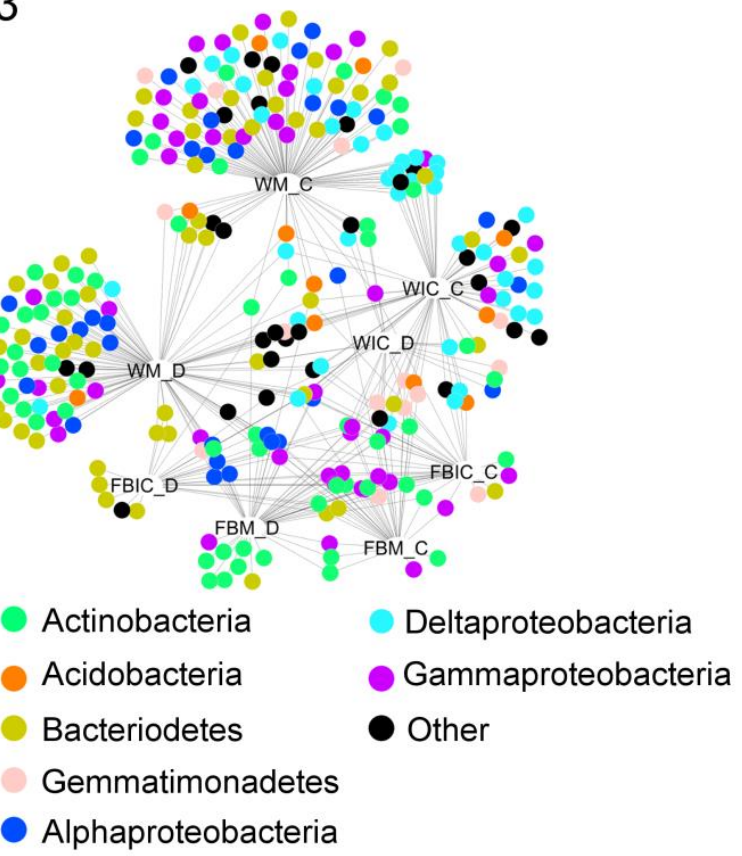

Figure 7. Bipartitie association network for bacterial and fungal taxa within different cropping regimes for the three harvests. Significant associated taxa are shown. Abbreviations: FBM/WM, faba bean/ wheat monoculture; FBIC/WIC, faba bean/wheat intercropped; C, control; D, water deficit. 


\section{References}

Ahkami A, White RA, Handakumbura P, Jansson C. 2017. Rhizosphere Engineering: Enhancing Sustainable Plant Ecosystem Productivity in a Challenging Climate. Rhizosphere. Jun;3:233-243.

Anderson MJ. 2001. A new method for non-parametric multivariate analysis of variance. Austral Ecology. Feb;26:32-46.

Anderson MJ. 2006. Distance-based tests for homogeneity of multivariate dispersions. Biometrics. Mar;62:245-253.

Andreote FD, da Rocha UN, Araujo WL, Azevedo JL, van Overbeek LS. 2010. Effect of bacterial inoculation, plant genotype and developmental stage on root-associated and endophytic bacterial communities in potato (Solanum tuberosum). Antonie Van Leeuwenhoek International Journal of General and Molecular Microbiology. May;97:389-399.

Austin AT, Yahdjian L, Stark JM, Belnap J, Porporato A, Norton U, Ravetta DA, Schaeffer SM. 2004. Water pulses and biogeochemical cycles in arid and semiarid ecosystems. Oct; 141: 221-235.

Barnard RL, Osborne CA, Firestone MK. 2013. Responses of soil bacterial and fungal communities to extreme desiccation and rewetting. Isme Journal. Nov; 7:2229-2241.

Berg G, Grube M, Schloter M, Smalla K. 2014. Unraveling the plant nnicrobiome: looking back and future perspectives. Frontiers in Microbiology. Jun;5.

Blagodatskaya E, Kuzyakov Y. 2013. Active microorganisms in soil: Critical review of estimation criteria and approaches. Soil Biology \& Biochemistry. Dec;67:192-211.

Bodenhausen N, Horton MW, Bergelson J. 2013. Bacterial Communities Associated with the Leaves and the Roots of Arabidopsis thaliana. Plos One. Feb;8:9.

Bolger AM, Lohse M, Usadel B. 2014. Trimmomatic: a flexible trimmer for Illumina sequence data. Bioinformatics. Aug;30:2114-2120.

Bull AT, Asenjo JA. 2013. Microbiology of hyper-arid environments: recent insights from the Atacama Desert, Chile. Antonie Van Leeuwenhoek International Journal of General and Molecular Microbiology. Jun;103:1173-1179.

Chelius MK, Triplett EW. 2001. The diversity of archaea and bacteria in association with the roots of Zea mays L. Microbial Ecology. Apr;41:252-263.

Coleman-Derr D, Tringe SG. 2014. Building the crops of tomorrow: advantages of symbiontbased approaches to improving abiotic stress tolerance. Frontiers in Microbiology. Jun;5.

Daryanto S, Wang LX, Jacinthe PA. 2017. Global synthesis of drought effects on cereal, legume, tuber and root crops production: A review. Agricultural Water Management. Jan;179:18-33.

Dawson W, Hor J, Egert M, van Kleunen M, Pester M. 2017. A Small Number of Lowabundance Bacteria Dominate Plant Species-specific Responses during Rhizosphere Colonization. Frontiers in Microbiology. May;8.

de Caceres M, Legendre P. 2009. Associations between species and groups of sites: indices and statistical inference. Ecology. Dec;90:3566-3574.

Deveau A. Bonito G, Uehling J, Paoletti M, Becker M, Bindschedler S, Hacquard S, Herve V, Labbe J, Lastovetsky OA, Mieszkin S, Millet LJ, Vajna B, Junier P, Bonfante P, Krom BP, Olsson S, Elsas JD, Wick LY. 2018.Bacterial-fungal interactions: ecology, mechanisms and challenges. FEMS Microbiol Rev. May; 42: 335-352. 
de Vries FT, Griffiths RI, Bailey M, Craig H, Girlanda M, Gweon HS, Hallin S, Kaisermann A, Keith AM, Kretzschmar M, et al. 2018. Soil bacterial networks are less stable under drought than fungal networks. Nature Communications. Aug;9.

Edgar RC. 2010. Search and clustering orders of magnitude faster than BLAST. Bioinformatics. Oct;26:2460-2461.

Edgar RC, Haas BJ, Clemente JC, Quince C, Knight R. 2011. UCHIME improves sensitivity and speed of chimera detection. Bioinformatics. Aug;27:2194-2200.

Fahad S, Bajwa AA, Nazir U, Anjum SA, Farooq A, Zohaib A, Sadia S, Nasim W, Adkins S, Saud S, et al. 2017. Crop Production under Drought and Heat Stress: Plant Responses and Management Options. Frontiers in Plant Science. Jun;8.

Fox J, Weisberg S. 2011. An R companion to applied regression. Second Edition. Sage.

Goh CH, Vallejos DFV, Nicotra AB, Mathesius U. 2013. The Impact of Beneficial PlantAssociated Microbes on Plant Phenotypic Plasticity. Journal of Chemical Ecology. Jul;39:826-839.

Granzow S, Kaiser K, Wemheuer B, Pfeiffer B, Daniel R, Vidal S, Wemheuer F. 2017. The Effects of Cropping Regimes on Fungal and Bacterial Communities of Wheat and Faba Bean in a Greenhouse Pot Experiment Differ between Plant Species and Compartment. Frontiers in Microbiology. May;8.

Hartman K, van der Heijden MGA, Roussely-Provent V, Walser JC, Schlaeppi K. 2017. Deciphering composition and function of the root microbiome of a legume plant. Microbiome. Jan;5.

He D, Shen WJ, Eberwein J, Zhao Q, Ren LJ, Wu QLL. 2017. Diversity and co-occurrence network of soil fungi are more responsive than those of bacteria to shifts in precipitation seasonality in a subtropical forest. Soil Biology \& Biochemistry. Dec;115:499-510.

Henry A, Doucette W, Norton J, Bugbee B. 2007. Changes in crested wheatgrass root exudation caused by flood, drought, and nutrient stress. Journal of Environmental Quality. May-Jun;36:904-912.

Herzog S, Wemheuer F, Wemheuer B, Daniel R. 2015. Effects of Fertilization and Sampling Time on Composition and Diversity of Entire and Active Bacterial Communities in German Grassland Soils. Plos One. Dec;10.

Kaisermann A, de Vries FT, Griffiths RI, Bardgett RD. 2017. Legacy effects of drought on plant-soil feedbacks and plant-plant interactions. New Phytologist. Sep;215:1413-1424.

Kaisermann A, Maron PA, Beaumelle L, Lata JC. 2015. Fungal communities are more sensitive indicators to non-extreme soil moisture variations than bacterial communities. Applied Soil Ecology. Feb;86:158-164.

Kaurin A, Mihelic R, Kastelec D, Grcman H, Bru D, Philippot L, Suhadolc M. 2018. Resilience of bacteria, archaea, fungi and N-cycling microbial guilds under plough and conservation tillage, to agricultural drought. Soil Biology \& Biochemistry. May;120:233-245.

Kavamura VN, Taketani RG, Lanconi MD, Andreote FD, Mendes R, de Melo IS. 2013. Water Regime Influences Bulk Soil and Rhizosphere of Cereus jamacaru Bacterial Communities in the Brazilian Caatinga Biome. Plos One. Sep;8.

Kembel SW, Cowan PD, Helmus MR, Cornwell WK, Morlon H, Ackerly DD, Blomberg SP, Webb CO. 2010. Picante: R tools for integrating phylogenies and ecology. Bioinformatics. Jun;26:1463-1464. 
Kõljalg U, Nilsson RH, Abarenkov K, Tedersoo L, Taylor AFS, Bahram M, Bates ST, Bruns TD, Bengtsson-Palme J, Callaghan TM, et al. 2013. Towards a unified paradigm for sequence-based identification of fungi. Molecular Ecology. Nov;22:5271-5277.

Kuchenbuch RO, Buczko U. 2011. Re-visiting potassium- and phosphate-fertilizer responses in field experiments and soil-test interpretations by means of data mining. Journal of Plant Nutrition and Soil Science. Apr;174:171-185.

Lancashire PD, Bleiholder H, Vandenboom T, Langeluddeke P, Stauss R, Weber E, Witzenberger A. 1991. A UNIFORM DECIMAL CODE FOR GROWTH-STAGES OF CROPS AND WEEDS. Annals of Applied Biology. Dec;119:561-601.

Li P, Ye SF, Liu H, Pen AH, Ming F, Tang XM. 2018. Cultivation of Drought-Tolerant and Insect-Resistant Rice Affects Soil Bacterial, but Not Fungal, Abundances and Community Structures. Frontiers in Microbiology. Jun;9.

Li S, Wu FZ. 2018. Diversity and Co-occurrence Patterns of Soil Bacterial and Fungal Communities in Seven Intercropping Systems. Frontiers in Microbiology. Jul;9.

Mahoney AK, Yin CT, Hulbert SH. 2017. Community Structure, Species Variation, and Potential Functions of Rhizosphere-Associated Bacteria of Different Winter Wheat (Triticum aestivum) Cultivars. Frontiers in Plant Science. Feb;8.

Martinez Arbizu P. 2017. Pairwiseadonis: Pairwise multilevel comparison using adonis. R Package Version 0.0.1.

McMurdie PJ, Holmes S. 2014. Waste Not, Want Not: Why Rarefying Microbiome Data Is Inadmissible. Plos Computational Biology. Apr; 10.

Meisner A, Jacquiod S, Snoek BL, ten Hooven FC, van der Putten WH. 2018. Drought Legacy Effects on the Composition of Soil Fungal and Prokaryote Communities. Frontiers in Microbiology. Mar;9.

Naylor D, DeGraaf S, Purdom E, Coleman-Derr D. 2017. Drought and host selection influence bacterial community dynamics in the grass root microbiome. Isme Journal. Dec;11:2691-2704.

Ogle DH. 2016. Introductory fisheries analyses with R. Chapman \& Hall/CRC.

Oksanen O, Blanchet FG, Kindt R, Legendre P, Minchin PR, O'Hara RB, Simpson GL, Solymos P, Stevens MHH, Wagner H. 2016. Vegan: Community Ecology Package. R Package Version 2.3-5.

Pinheiro J, Bates D, DebRoy S, Sarkar D and R Core Team. 2017. nlme: Linear and Nonlinear Mixed Effects Models. R package version 3.1-131.

Preece C, Peñuelas J. 2016. Rhizodeposition under drought and consequences for soil communities and ecosystem resilience. Plant and Soil. Dec;409:1-17.

Quast C, Pruesse E, Yilmaz P, Gerken J, Schweer T, Yarza P, Peplies J, Glockner FO. 2013. The SILVA ribosomal RNA gene database project: improved data processing and web-based tools. Nucleic Acids Research. Jan;41:D590-D596.

R Core Team. 2016. R: A Language and Environment for Statistical Computing. Vienna: R Foundation for Statistical Computing. Available online at: http://www.R-project.org

Ritz C, Streibig JC. 2016. Package 'drc' Analysis of dose-response curves. Version 3.0-1.

Saharan K, Schütz L, Kahmen A, Wiemken A, Boller T, Mathimaran N. 2018. Finger Millet Growth and Nutrient Uptake Is Improved in Intercropping With Pigeon Pea Through 
"Biofertilization" and "Bioirrigation" Mediated by Arbuscular Mycorrhizal Fungi and Plant Growth Promoting Rhizobacteria. Front. Environ. Sci. Jun; 11.

Santos-Medellin C, Edwards J, Liechty Z, Nguyen B, Sundaresan V. 2017. Drought Stress Results in a Compartment-Specific Restructuring of the Rice Root-Associated Microbiomes. Mbio. Jul-Aug;8.

Sayer EJ, Oliver AE, Fridley JD, Askew AP, Mills RTE, Grime JP. 2017. Links between soil microbial communities and plant traits in a species-rich grassland under long-term climate change. Ecology and Evolution. Feb;7:855-862.

Schimel J, Balser TC, Wallenstein M. 2007. Microbial stress-response physiology and its implications for ecosystem function. Ecology. Jun;88:1386-1394.

Senbayram M, Trankner M, Dittert K, Bruck H. 2015. Daytime leaf water use efficiency does not explain the relationship between plant $\mathrm{N}$ status and biomass water-use efficiency of tobacco under non-limiting water supply. Journal of Plant Nutrition and Soil Science. Aug; 178:682-692.

Shannon P, Markiel A, Ozier O, Baliga NS, Wang JT, Ramage D, Amin N, Schwikowski B, Ideker T. 2003. Cytoscape: A software environment for integrated models of biomolecular interaction networks. Genome Research. Nov;13:2498-2504.

Siczek A, Frac M, Kalembasa S, Kalembasa D. 2018. Soil microbial activity of faba bean (Vicia faba L.) and wheat (Triticum aestivum L.) rhizosphere during growing season. Applied Soil Ecology. Sep;130:34-39.

Song YN, Zhang FS, Marschner P, Fan FL, Gao HM, Bao XG, Sun JH, Li L. 2007. Effect of intercropping on crop yield and chemical and microbiological properties in rhizosphere of wheat (Triticum aestivum L.), maize (Zea mays L.), and faba bean (Vicia faba L.). Biology and Fertility of Soils. Jun;43:565-574.

Streit W, Daniel R. 2010. Metagenomics. Methods and Protocols. Springer Science+Business Media, LLC. Series Volume 668.

Tichy L, Chytry M. 2006. Statistical determination of diagnostic species for site groups of unequal size. Journal of Vegetation Science. Dec;17:809-818.

Toju H, Tanabe AS, Yamamoto S, Sato H. 2012. High-Coverage ITS Primers for the DNABased Identification of Ascomycetes and Basidiomycetes in Environmental Samples. Plos One. Jul;7.

Vandermeer JH. 1992. The ecology of intercropping. New York, NY: Cambridge University Press.

Vimal SR, Singh JS, Arora NK, Singh S. 2017. Soil-Plant-Microbe Interactions in Stressed Agriculture Management: A Review. Pedosphere. Apr;27:177-192.

Wan XH, Huang ZQ, He ZM, Yu ZP, Wang MH, Davis MR, Yang YS. 2015. Soil C:N ratio is the major determinant of soil microbial community structure in subtropical coniferous and broadleaf forest plantations. Plant and Soil. Feb;387:103-116.

Wang Y, Marschner P, Zhang FS. 2012. Phosphorus pools and other soil properties in the rhizosphere of wheat and legumes growing in three soils in monoculture or as a mixture of wheat and legume. Plant and Soil. May;354:283-298.

Wemheuer F, Kaiser K, Karlovsky P, Daniel R, Vidal S, Wemheuer B. 2017. Bacterial endophyte communities of three agricultural important grass species differ in their response towards management regimes. Scientific Reports. Jan;7. 
Wemheuer F, Wemheuer B, Kretzschmar D, Pfeiffer B, Herzog S, Daniel R, Vidal S. 2016. Impact of grassland management regimes on bacterial endophyte diversity differs with grass species. Letters in Applied Microbiology. Apr;62:323-329.

Wemheuer B, and Wemheuer F. 2017. "Assessing bacterial and fungal diversity in the plants endosphere," in Metagenomics - Methods and Protocols, Vol. 1539, edsW. Streit, and R. Daniel (New York, NY: Humana Press), 75-84.

White TJ, Bruns T, Lee S, and Taylor J. 1990. "Amplification and direct sequencing of fungal ribosomal RNA genes for phylogenetics," in PCR Protocols: a Guide to Methods and Applications, eds M. A. Innis, D. H. Gelfand, J. J. Sninsky, and T. J.White (New York, NY: Academic Press). 18, 315-322.

Xue C, Penton CR, Zhu C, Chen H, Duan YH, Peng C, Guo SW, Ling N, Shen QR. 2018. Alterations in soil fungal community composition and network assemblage structure by different long-term fertilization regimes are correlated to the soil ionome. Biology and Fertility of Soils. Jan;54:95-106.

Yang CH, Huang GB, Chai Q, Luo ZX. 2011. Water use and yield of wheat/maize intercropping under alternate irrigation in the oasis field of northwest China. Field Crops Research. Dec;124:426-432.

Yang ZP, Yang WP, Li SC, Hao JM, Su ZF, Sun M, Gao ZQ, Zhang CL. 2016. Variation of Bacterial Community Diversity in Rhizosphere Soil of Sole-Cropped versus Intercropped Wheat Field after Harvest. Plos One. Mar;11.

Zampieri M, Ceglar A, Dentener F, Toreti A. 2017. Wheat yield loss attributable to heat waves, drought and water excess at the global, national and subnational scales. Environmental Research Letters. Jun;12.

Zhou Y, Zhu HH, Fu SL, Yao Q. 2017. Variation in Soil Microbial Community Structure Associated with Different Legume Species Is Greater than that Associated with Different Grass Species. Frontiers in Microbiology. May;8. 


\section{Supplementary Material}

Supplementary figures and tables are provided on DVD, under the following paths:

Chapter 5/ Figure S1-S2 Rarefaction curves

Chapter 5/ Table S1 Edaphic properties

Chapter 5/ Table S2 Bacterial OTU Table

Chapter 5/ Table S3 Fungal OUT Table

Chapter 5/ Table S4 SequenceCharacteristics Bacteria

Chapter 5/ Table S5 SeqiuenceCharacteristics Fnugi

Chapter 5/ Table S6 Associated Taxa

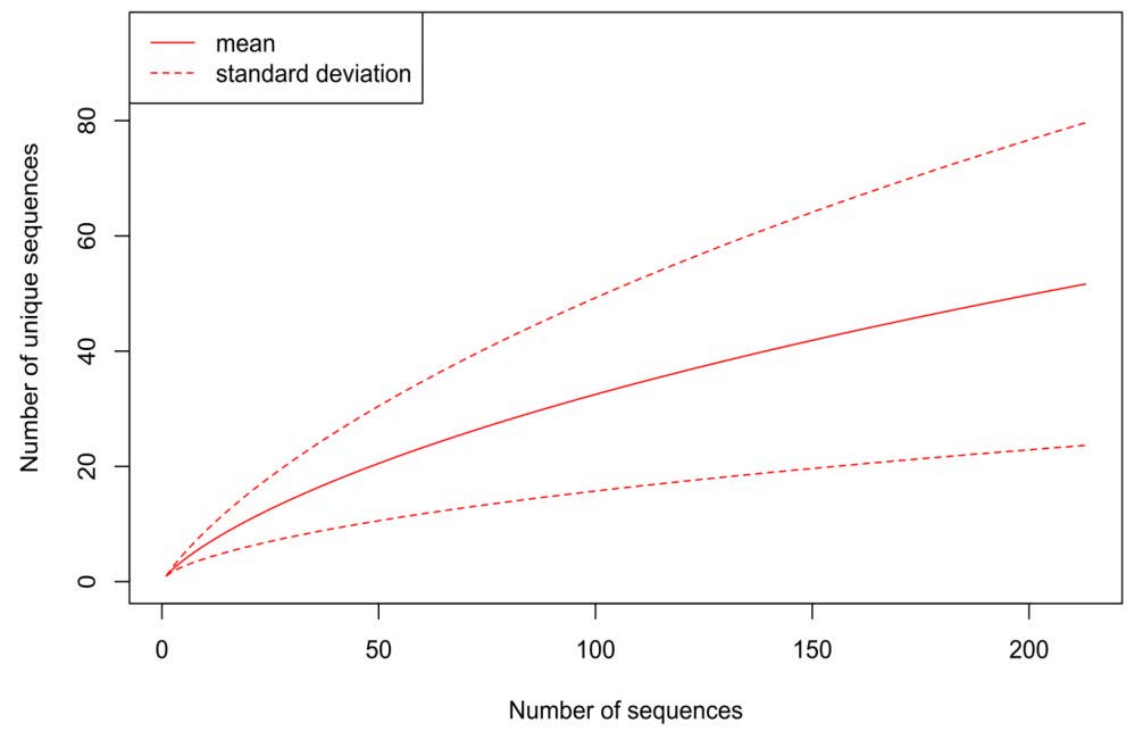

Figure S1. Rarefaction curve of the fungal community in the rhizosphere. Only the mean of all curves and the standard deviation are shown.

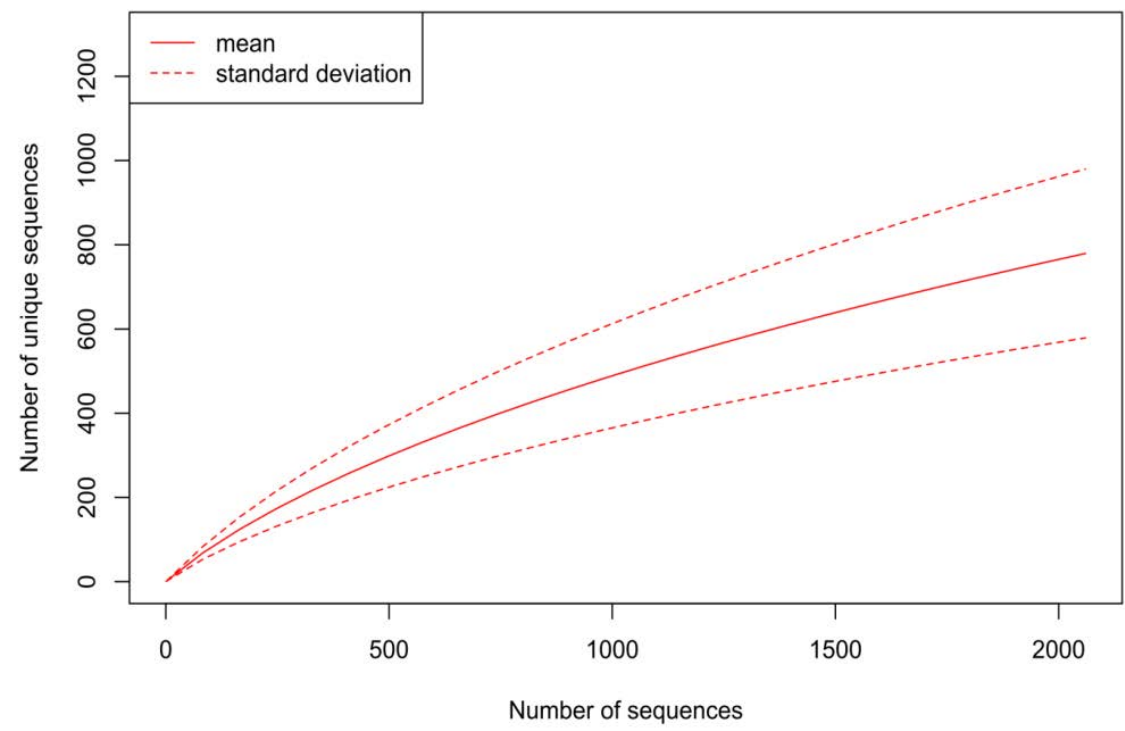

Figure S2. Rarefaction curve of the bacterial community in the rhizosphere. Only the mean of all curves and the standard deviation are shown. 


\section{Chapter 6}

Crop species and cropping system alter the effect of Metarhizium brunneum seed application on plant-associated bacterial and fungal communities

Granzow Sandra, Jayanti Hadis, Lingner Annika, Pfeiffer Birgit, Daniel Rolf, Vidal Stefan and Wemheuer Franziska

In preparation for submission 


\title{
Crop species and cropping system alter the effect of Metarhizium brunneum seed application on plant-associated bacterial and fungal communities
}

\author{
Granzow Sandra ${ }^{1,2^{*}}$, Jayanti Hadis ${ }^{1}$, Lingner Annika ${ }^{2,3}$, Pfeiffer Birgit ${ }^{3,4}$, Daniel Rolf ${ }^{4}$, \\ Vidal Stefan $^{1}$ and Wemheuer Franziska ${ }^{1}$. \\ ${ }^{1}$ Division of Agricultural Entomology, Department of Crop Sciences, University of Göttingen, \\ Göttingen, Germany \\ ${ }^{2}$ Center of Biodiversity and Sustainable Land Use, University of Göttingen, Göttingen, Germany \\ ${ }^{3}$ Division of Plant Nutrition and Crop Physiology, Department of Crop Sciences, University of \\ Göttingen, Göttingen, Germany \\ ${ }^{4}$ Genomic and Applied Microbiology and Göttingen Genomics Laboratory, Institute of Microbiology \\ and Genetics, University of Göttingen, Göttingen, Germany
}

* Correspondence:

Sandra Granzow, M.Sc.

sandra.granzow@agr.uni-goettingen.de

Keywords: microbial communities, intercropping, Metarhizium brunneum, seed inoculation

\begin{abstract}
Entomopathogenic fungi are frequently used as biocontrol agents in a sustainable agriculture. In the last years, they received more attention due to their various ecological functions as endophytes such as plant growth promotion. To date, our knowledge how the application of entomopathogenic fungi influences microbial communities in soil and plant endosphere in different cropping systems is still limited. Hence, we investigated the separate and combined effect of seed inoculation with Metarhizium brunneum Cb15-III and cropping system on bacterial and fungal communities in the rhizosphere soil, root as well as leaf endosphere of winter faba bean (Vicia faba L.) and winter wheat (Triticum aestivum L.) using large-scale metabarcoding. For this purpose, faba bean and wheat were grown in monoculture and in row intercropping under greenhouse conditions. Plant and soil samples were collected after five (harvest 1) and seven weeks (harvest 2). In accordance to our first hypothesis we found that
\end{abstract}


crop species and plant compartment exhibited a strong influence on the plant microbiome. Furthermore, M. brunneum application altered the fungal and bacterial community composition in the rhizosphere soil, and bacterial community composition in the leaf endosphere for both sampling times. In addition, microbial diversity and richness showed sampling time- and kingdom-specific responses towards M. brunneum application. For example, a significantly lower fungal diversity and richness in leaf endosphere and rhizosphere soil of inoculated wheat compared to control plants was observed at harvest 2 only. Moreover, cropping system alone but also the combination of cropping system and application significantly affected plant microbiome. Fungal diversity and richness in root endosphere were significantly higher in intercropped wheat compared to monoculture and these differences were most pronounced between inoculated wheat cropping systems for harvest 2. For bacteria, we observed the same trend but in the rhizosphere, bacterial diversity and richness was significantly higher in intercropped wheat compared to monoculture which was most pronounced in inoculated wheat cropping systems for harvest 1 . In addition, fungal application induced proliferation of specific bacteria in the rhizosphere, namely Shewanella spp. and Halomonas spp., which might be putatively important in plant growth promoting, biological control or in bioremediation. Overall, our findings highlight the importance to investigate the separate and combined effect of cropping system and application of entomopathogenic fungi on plant-associated microbial communities. The present findings increase our understanding of how the application of an entomopathogenic fungus affects microbial community which might gain further importance for biological control strategies in the future.

\section{Introduction}

Entomopathogenic fungi (EPF) are frequently used as biocontrol agents in sustainable agriculture worldwide, mainly applied as spore suspension to the aerial plant parts (Bing and Lewis, 1991; Batta et al., 2013). Batta et al., (2013) showed that leaf inoculation of Metarhizium anisopliae on Brassica napus plants resulted in an increased mortality rate of Plutella xylostella larvae. Results indicated that the fungus colonized the internal tissue and acted as endophyte antagonistic against P. xylustella larvae (Batta et al., 2013). In the last years, EPF have received more attention due to their various ecological functions as endophytes (Lacey et al., 2015; Vidal and Jaber, 2015). EPF as endophytes have been shown to promote plant growth and yield (Sasan and Bidochka, 2012; Jaber and Enkerli, 2016, Sánchez-Rodriguez et al., 2018) and improve plant nutrition (Raya-Diaz et al., 2017; Krell et 
al., 2018). Recently, Krell et al., (2018) demonstrated that endophytism of M. brunneum through encapsulated application significantly enhanced biomass, as well as nitrogen and phosphorus content in potato. Consequently, the application of EPF may contribute to more sustainable production systems in certain crop plants (de Faria and Wraight, 2007; OrtizUrquiza, Luo and Keyhani, 2015).

While progress has been made in understanding the effects of entomopathogenic fungal application on the plant host and/or plant herbivore pest interactions (e.g., Raya-Diaz et al., 2017; Clifton et al., 2018), our knowledge how the application of EPF influences microbial communities still limited as most of these studies focused on the soil microbiome (Hirsch et al., 2013; Mayerhofer et al., 2017; McKinnon et al., 2018, but see Hong et al., 2017). Recently, Mayerhofer et al., (2017) examined the potential effect of M. brunneum application on fungal and prokaryotic communities in the bulk soil using high-throughput sequencing. They observed that fungal application did not affect the indigenous microbial community under field conditions, whereas smaller shifts in the soil fungal community were observed under greenhouse conditions. In a study by Hong et al., (2017), the application of M. anisopliae strain CQMa421 slightly affected bacterial diversity and community composition in the rice phyllosphere during the first 6 days in the booting stage of rice growth, while no significant changes in fungal diversity were observed during this period. Other studies investigating the effects of agricultural practices on soil-borne EPF reported that pesticides (Hummel et al., 2002) or cropping practices (Kepler et al., 2015; Clifton et al.,2015) significantly affected EPF such as Beauveria bassiana or M. anisopliae. However, it remains largely unknown how different cropping systems might influence the effect of EPF application on plant-associated microbial communities.

Hence, the aim of the present study was to investigate the combined effect of M. brunneum Cb15-III seed inoculation and a specific cropping system on plant-associated bacterial and fungal communities of two important crop species. For this purpose, winter wheat (Triticum aestivum L.) and winter faba bean (Vicia faba L.) were grown in monoculture and in row intercropping in a greenhouse pot experiment. Half of the plant seeds of both crops were treated with M. brunneum (inoculated plants), the other half was left untreated (control plants). M. brunneum was chosen because it has been reported that this species is able to transfer nutrients to their host plants (Behie and Bidochka, 2014; Krell et al., 2018). Plant and soil samples were collected after five and seven weeks of plant growing. Bacterial and fungal communities in rhizosphere and unplanted soil as well as in root and leaf endosphere were examined using Illumina Miseq sequencing targeting the bacterial 16S rRNA gene and the 
fungal internal transcribed spacer (ITS) region, respectively. We focused on four main hypotheses: (i) bacterial and fungal community composition and diversity depends on crop species and plant compartment. (ii) The application and establishment of an endophytic fungus in plant tissues creates a long-lasting effect on these bacterial and fungal communities (thus: no resilience). We further expected that (iii) cropping system influences effects of fungal application on plant microbiome and that (iv) response of bacterial and fungal communities differ between the different plant compartments.

\section{Material and Methods}

\subsection{Plant material}

To examine the influence of cropping systems and seed inoculation with M. brunneum strain $\mathrm{Cb} 15-\mathrm{III}$ on the entire fungal and bacterial community in the soil and the plant endosphere, a greenhouse experiment was conducted in autumn 2016. This experiment was part of the $\mathrm{IMPAC}^{3}$-project (Novel genotypes for mixed cropping allow for improved sustainable land use across arable land, grassland and woodland). Seeding material from winter faba bean (genotype: S_062) was selected from field trial-tested inbreed lines used within the IMPAC 3 project and was provided by the Institute of Plant breeding at the University of Göttingen. Seeds of winter wheat (genotype: Genius) were provided by Norddeutsche Pflanzenzucht Hans-Georg Lembke KG. Seeds of the two crop species were surface-sterilized by serial washing according to Andreote et al., (2010), with one modification: after immersion in sterile, distilled water for two times and $30 \mathrm{~s}$, seeds were additionally washed in sterile, diethylpyrocarbonate (DEPC)-treated water. Surface-sterilized seeds germinated on a moistened filter paper with sterile distilled water at $4^{\circ} \mathrm{C}$ in darkness for 72 hours. To determine how the host plant itself alters the response of plant-associated fungal and bacterial communities towards seed inoculation, sterile glass beads (Merck, Germany; $\varnothing 6 \mathrm{~mm}$ ) were used as controls in unplanted container. Glass beads were treated in the same way as described above for plant seeds.

\subsection{Fungal material}

The entomopathogenic fungus M. brunneum strain Cb15-III was obtained from the fungal collection of the Agricultural Entomology Laboratory at the University of Göttingen, Germany, originally isolated from a luvisoil arable field. Fresh cultures of this strain were prepared prior experimental start. Therefore, M. brunneum was cultivated on Potato Dextrose 
Agar (PDA; Carl Roth, Karlsruhe, Germany) at $24^{\circ} \mathrm{C}$ for 10 to 14 days. Fungal conidia were harvested with a sterile object plate under sterile conditions and suspended in autoclaved $0.9 \% \mathrm{NaCl}$ bidest water according to $\mathrm{Gu}$ et al., 2016. The conidial suspension was filtered through one layer of sterile gauze to remove hyphae and agar remnants. Subsequently, the conidia suspension was carefully mixed in a flask. Conidial concentrations were determined under a microscope using a haemocytometer (Thoma) and adjusted to a concentration of $6^{*} 10^{7}$ conidia $\mathrm{ml}^{-1}$. The viability of spore suspension was controlled on PDA plates. Seeds and glass beads were placed in the spore suspension (inoculated treatments) or in $0.9 \% \mathrm{NaCl}$ (none-inoculated control treatments) for 16 hours

\subsection{Experimental design}

Inoculated and non-inoculated seeds of faba bean and wheat were sown as monoculture or mixture in polypropylene containers (Sunware; 455 x 360 x $240 \mathrm{~mm}$ ). Each container was filled with air-dried, sieved $(<10 \mathrm{~mm})$ and layered soil from the experimental study site in Reinshof $\left(51.48^{\circ} \mathrm{N}, 9.92^{\circ} \mathrm{E}\right.$ and $157 \mathrm{~m}$ asl.), Germany. The soil was classified as Gleyic Fluvisol according to the FAO classification system and contained $21 \%$ clay, $68 \%$ silt and $11 \%$ sand. The soil volume of each container accounted for approximately $20 \mathrm{~L}$ with a dry weight of $18 \mathrm{~kg}$. Filling of the container was performed in layers adding distilled water to each layer to prevent soil compaction. For monocultures, 30 faba bean or 72 wheat seeds per container were sown in rows. For the intercropping treatment, 36 wheat and 15 bean seeds were sown in alternate rows. Unplanted container with inoculated or non-inoculated (control) glass beads were treated in the same way as described for the monoculture treatment.

In total, there were 10 different treatments: faba bean monoculture non-inoculated or inoculated with the fungus M. brunneum strain Cb15-III (MB/MBF), wheat monoculture noninoculated or inoculated (MW/MWF), faba bean intercropped non-inoculated or inoculated $(\mathrm{XB} / \mathrm{XBF})$, wheat intercropped non-inoculated or inoculated (XW/XWF) and unplanted soil non-inoculated or inoculated $(\mathrm{C} / \mathrm{CF})$ (Figure 1). Each treatment was replicated five times in a randomized block design. We defined two different cropping systems (monoculture and intercropping), whereas cropping regimes compromise each treatment, e.g. XB and XBF. All plants were cultured under light (12:12 h light/dark regime) and irrigated regularly for a growing period of seven weeks. The position of all containers was changed weekly to avoid spatial effects. To increase nutrient-limitation as well as intra- and interspecies interactions between the plants, no fertilizer treatments were applied. 


\subsection{Sampling}

To investigate the effect of M. brunneum application on the plant microbiome over time, we collected samples from all treatments after a growing period of five weeks (harvest 1; H1) and seven weeks (harvest 2; H2). Fungal and bacterial communities in three different plant compartments were studied: the rhizosphere soil as well as the root and aerial (here regarded as leaf) endosphere. Moreover, fungal and bacterial communities in the soil of unplanted containers treated with inoculated and non-inoculated glass beads were analysed to investigate how the two crop plant species alter the response of these communities towards seed inoculation. To gain insights into the starting soil microbial community (CS), three composite soil samples of all unplanted soil containers were collected prior to the experimental start.

At harvest 1, plants reached $\mathrm{BBCH}$ stage 14-18 (wheat) and 14-16 (faba bean). The BBCH-scale describes the developmental stages of Mono- and Dicotyledonous weed species (Hess et al., 1997). For molecular analysis, one faba bean plant as well as two wheat plants were randomly collected from each container (Table 1). At harvest 2, plants reached a BBCH stage 15-21 (wheat) and 18-21 (faba bean). For molecular analysis, two faba bean plants and three wheat plants were harvested as described for harvest 1 . All collected plants showed no obvious sign of any disease infection. In addition, rhizosphere soil samples (the soil tightly attached to the roots) were taken. For this purpose, the roots were gently shaken to remove the non-rhizosphere soil and the rhizosphere soil was collected by carefully brushing the roots. Rhizosphere samples were pooled per container and plant species. In total, 60 faba bean plants and 100 wheat plants were collected for molecular analysis, resulting in 160 plant and 80 rhizosphere samples (Table 1). All samples were immediately stored at $-20^{\circ} \mathrm{C}$ until further analyses. Additional rhizosphere and soil samples of the unplanted containers were collected at both harvests for determination of edaphic properties including the soil organic $\mathrm{C}$ and $\mathrm{N}$ content. For determination of plant properties such as the water content, or organic $\mathrm{C}$ and $\mathrm{N}$ in roots and leaves were sampled at harvest 2. For a detailed description of the sampling procedure see Table S1.

\subsection{Edaphic and plant parameters}

As temperature of leaf canopy can be a stress indicator for fungal infection (Yao et al., 2018), we evaluated the transpiration of the plant canopy. Thermal images were taken weekly from the $4^{\text {th }}$ to the $7^{\text {th }}$ week using a T640 infrared camera (FLIR Systems, OR, USA). The thermal images were analyzed with the software FLIR ResearchIR version 3.3.12277.1002 (FLIR Systems, OR, USA). In addition, the height of five faba bean and wheat plants per container 
was measured weekly. The fresh biomass of plants (including roots and aerial parts) collected for molecular analysis was measured separately for below and aerial parts at both harvest times. Additionally, at harvest 1, ph-values and water content in unplanted and rhizosphere soils were measured. Total nitrogen $(\mathrm{N})$ and carbon $(\mathrm{C})$ in roots and leaves as well as the water content from roots and aerial parts of ten faba bean and twenty wheat plants per container were collected at harvest 2. Finally, relative water content (RWC) in leaves from two plants of each crop species and container were determined at harvest 2.

For the determination of edaphic and plant properties, subsamples of homogenized and mixed plant and soil material were dried at $60^{\circ} \mathrm{C}$ for two days and sieved to $<2 \mathrm{~mm}$. Soil $\mathrm{pH}-$ values were measured as follows: $2 \mathrm{~g}$ rhizosphere soil or unplanted soil of each container was mixed with $5 \mathrm{ml}$ PCR grade water. After incubation for $24 \mathrm{~h}$, $\mathrm{pH}$ bidest was measured in the supernatant with a glass electrode (WTW, inoLab). Finally, $0.37 \mathrm{~g} \mathrm{KCl}$ was added and $\mathrm{pH} \mathrm{KCl}$ was measured. Soil and plant organic $\mathrm{C}$ and $\mathrm{N}$ concentrations were determined using a LECO TruSpec CN analyser (Leco Corp., St. Joseph, MI). The gravimetric soil and plant water content (\%) was calculated from oven-dried subsamples. Relative water content (RWC) of leaves was determined according to Barrs and Weatherley (1962). In brief, the youngest fully expanded leaf was taken around solar noon and the fresh weight (FW) was measured. Afterwards, the leaf samples were incubated in distilled water in closed boxes at approximately $23{ }^{\circ} \mathrm{C}$ for three hours. Then, the turgid weight (TW) was determined and the leaf samples were dried at $60{ }^{\circ} \mathrm{C}$ for $24 \mathrm{~h}$ to examine the dry weight (DW). RWC was calculated as follows: RWC $[\%]=[(\mathrm{FW}-\mathrm{DW}) /(\mathrm{TW}-\mathrm{DW})] * 100$. Details on edaphic and plant parameters are provided in Table S2 and S3.

\subsection{Surface sterilization of plant material}

Foliar plant material was surface-sterilized according to Wemheuer and Wemheuer (2017). Surface sterilization of plant roots was performed as described in Granzow et al. (2017). The effectiveness of the sterilization process used was controlled as described previously (Wemheuer et al., 2016). In brief, aliquots of the water used in the final wash step were plated on common laboratory media plates, i.e., Luria-Bertani agar and potato dextrose agar. The plates were incubated in the dark at $25^{\circ} \mathrm{C}$ for at least one week. No growth of bacteria or fungi was observed. Moreover, water from the same aliquots was subjected to PCR targeting the bacterial 16S rRNA gene and the ITS region of fungi as described below. No PCR products were detected. Surface sterilized plant samples were grounded using a sterile mortar and pestle with liquid nitrogen and subsequently stored at $-20^{\circ} \mathrm{C}$ until further analyses. 


\subsection{Extraction of total microbial community DNA}

Total DNA of aerial plant parts and roots was extracted employing the peqGOLD Plant DNA Mini kit (Peqlab, Erlangen, Germany) according to the manufacturer's instructions with two modifications described previously (Wemheuer et al., 2016). In brief, glass beads (Ø 3-6 mm) were used in the first step and $10 \mu 1$ Proteinase K (20 mg ml ${ }^{-1}$; Carl Roth, Karlsruhe, Germany) was added. Total environmental DNA of rhizosphere as well as unplanted soil was extracted employing the PowerSoil ${ }^{\circledR}$ DNA Isolation kit (Qiagen, Venlo, Netherlands) according to the manufacturer's protocol. DNA concentrations of DNA extracts were quantified using a NanoDrop ND-1000 spectrophotometer (NanoDrop Technologies, Wilmington, DE, USA). In total, 253 samples (Table 1) were subjected to PCR targeting the bacterial 16S rRNA gene and the fungal ITS region.

\subsection{Amplification of the 16S rRNA gene}

Bacterial endophyte and soil communities were assessed by a nested PCR approach targeting the 16S rRNA gene as described in Wemheuer and Wemheuer (2017). For details of the first PCR reaction mixture and the thermal cycling scheme see Wemheuer et al. (Wemheuer et al., 2016). Briefly, the primers 799f (5'-AACMGGATTAGATACCCKG-3') (Chelius \& Triplett, 2001) and 1492R (5'-GCYTACCTTGTTACGACTT-3') (Lane, 1991) were used in the first PCR to suppress co-amplification of chloroplast-derived 16S rRNA genes. Obtained PCR products were subjected to nested PCR. The V6-V8 region of the 16S rRNA gene was amplified with primers $968 \mathrm{~F}$ and 1401R (Nübel et al., 1996) containing MiSeq adaptors (underlined)

(MiSeq-968F

5 TCGTCGGCAGCGTCAGATGTGTATAAGAGACAGAACGCGAAGAACCTTAC-3'; MiSeq$1401 \mathrm{R}$ $5^{\prime}-$ GTCTCGTGGGCTCGGAGATGTGTATAAGAGACAGCGGTGTGTACAAGACCC-3') as described previously (Wemheuer and Wemheuer, 2017) with one modification: $0.5 \mathrm{U}$ of Phusion high fidelity DNA polymerase (Thermo Scientific, Waltham, MA, USA) was used. Three independent PCRs were performed per sample.Genomic DNA of Escherichia coli was used as control. Negative controls were performed using the reaction mixture without template. Obtained PCR products were pooled in equal amounts and purified using the NucleoMag NGS Clean up (Macherey-Nagel). Quantification of the PCR products was performed using the Quant-iT dsDNA HS assay kit and a Qubit fluorometer (Thermo Scientific) as recommended by the manufacturer. PCR products were barcoded using the Nextera XT-Index kit (Illumina, San Diego, USA) and the Kapa HIFI Hot Start polymerase 
(Kapa Biosystems, Wilmington, USA). The Göttingen Genomics Laboratory determined the sequences of the partial 16S rRNA employing the MiSeq Sequencing platform and the MiSeq Reagent Kit v3 ( 2 x 300 cycles) as recommended by the manufacturer (Illumina).

\subsection{Amplification of the ITS region}

Fungal communities in soil and endosphere were assessed by a nested PCR approach targeting the ITS region as described previously (Granzow et al., 2017; Wemheuer and Wemheuer, 2017). In the first PCR, the primers ITS1-F_KYO2 (5'TAGAGGAAGTAAAAGTCGTAA-3') (Toju et al., 2012) and ITS4 (5'TCCTCCGCTTATTGATATGC-3') (White et al., 1990) were used to suppress coamplification of plant-derived ITS regions. Obtained PCR products were subjected to nested PCR. The ITS2 region was subsequently amplified as described for the first PCR using approximately $50 \mathrm{ng}$ product of the first PCR and the primers ITS3_KYO2 (Toju et al., 2012) and ITS4 (White et al., 1990) containing the MiSeq adaptors (underlined): MiSeqITS3_KYO2

TCGTCGGCAGCGTCAGATGTGTATAAGAGACAGGATGAAGAACGYAGYRAA-3')

and

MiSeq-ITS4

GTCTCGTGGGCTCGGAGATGTGTATAAGAGACAGTCCTCCGCTTATTGATATGC 3'). Genomic DNA of Aspergillus nidulans was used as template in the positive control. Negative controls were performed using the reaction mixture without template. Three independent PCRs were performed per sample. Obtained PCR products were pooled in equal amounts and quantified as described for the bacterial PCR products. Pooled PCR products were barcoded using the Nextera XT-Index kit (Illumina, San Diego, USA) and the Kapa HIFI Hot Start polymerase (Kapa Biosystems, Wilmington, USA). The Göttingen Genomics Laboratory determined the sequences of the ITS2 region employing the MiSeq Sequencing platform and the MiSeq Reagent Kit v3 ( 2 x 300 cycles) as recommended by the manufacturer (Illumina, San Diego, USA).

\subsection{Detection of Metarhizium brunneum Cb15-III with conventional PCR}

For the identification of the inoculated Metarhizium isolate in the soil and the endosphere, a nested PCR approach was applied. Metarhizium clade 1 specific primers, namely Ma1763 (5'CCAACTCCCAACCCCTGTGAAT-3') Ma2079 AAAACCAGCAGCCTCGCCGAT-3') were used to amplify an approximately 320-bp region

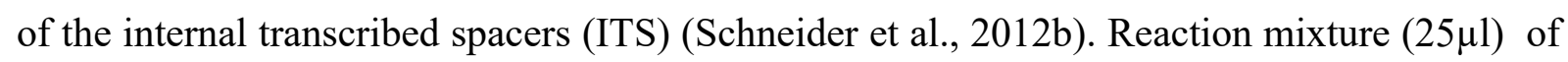


the first PCR contained: $2.5 \mu \mathrm{l}$ of 10-fold Mg-free Taq-polymerase buffer (Thermo Fisher Scientific, Braunschweig, Germany), $200 \mu \mathrm{M}$ of each of the four desoxynucleoside triphosphates, $25 \mathrm{mM} \mathrm{MgCl} 2,4 \mu \mathrm{M}$ of each primer, $5 \%$ DMSO, $1 \mathrm{U} / \mu \mathrm{l}$ of Taq DNA polymerase (Thermo Fisher Scientific) and approximately 25ng DNA samples as template. The following thermal cycling scheme was utilized: initial denaturation at $95^{\circ} \mathrm{C}$ for $2 \mathrm{~min}$ followed by 40 cycles of denaturation at $95^{\circ} \mathrm{C}$ for $1 \mathrm{~min}$, annealing at $55^{\circ} \mathrm{C}$ for $1 \mathrm{~min}$, extension at $72^{\circ} \mathrm{C}$ for $1.5 \mathrm{~min}$ and followed by final extension at $72^{\circ} \mathrm{C}$ for $5 \mathrm{~min}$. Obtained PCR products were subjected to nested PCR with the same primer pair. Reaction mixture

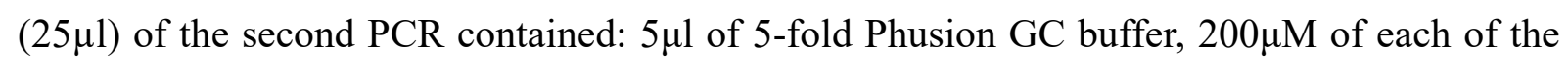
four desoxynucleoside triphosphates, $4 \mu \mathrm{M}$ of each primer, $5 \% \mathrm{DMSO}, 25 \mathrm{mM} \mathrm{MgCl}, 0.5 \mathrm{U}$ of Phusion High Fidelity DNA polymerase (Thermo Fisher Scientific). The following thermal cycling scheme was utilized: initial denaturation at $98^{\circ} \mathrm{C}$ for $30 \mathrm{sec}$ followed by 30 cycles of denaturation at $98^{\circ} \mathrm{C}$ for $15 \mathrm{sec}$, annealing at $56^{\circ} \mathrm{C}$ for $30 \mathrm{sec}$, extension at $72^{\circ} \mathrm{C}$ for $30 \mathrm{sec}$ and followed by final extension at $72^{\circ} \mathrm{C}$ for $2 \mathrm{~min}$. Negative controls were performed using the reaction mixture without template. Extracted DNA of Metarhizium brunneum Cb15-III was used as a template in the positive control. Presence of Metarhizium was confirmed on a $2 \%$ agarose gel.

\subsection{Processing of microbial community datasets}

Generated sequencing data were initially quality filtered with the Trimmomatic tool version 0.36 (Bolger et al., 2014). Low quality reads were truncated if the quality dropped below 15 in a sliding window of $4 \mathrm{bp}$. Subsequently, all reads shorter than $100 \mathrm{bp}$ and orphan reads were removed. Remaining sequences were merged, quality-filtered and further processed with USEARCH version 10.0.240 (Edgar, 2010). Filtering included the removal of reads shorter than 250 bp or longer than 490 (fungi) or shorter than 400 or longer than 470 bp (bacteria) as well as the removal low quality reads (expected error $>1$ ) and reads with more than one ambitious base.

Processed sequences of all samples were dereplicated, concatenated, and obtained unique sequences were denoised and clustered into zero-radius operational taxonomic units (zOTUs) with the unoise3 algorithm implemented in USEARCH version 10.0.240 (Edgar, 2010). All OTUs consisting of one single sequence (singletons) were removed. Subsequently, remaining chimeric sequences were removed using UCHIME (Edgar et al. 2011) in reference mode with the SILVA SSU Ref NR 99132 database (Quast et al., 2013) as reference data set for bacteria and the QIIME release of the UNITE database version 7.2 (Kõljalg et al., 2013) 
for fungi. Filtered sequences were mapped on remaining unique sequences to determine the occurrence and abundance of each unique sequence in every sample. To assign taxonomy of bacteria and fungi, chimera-free sequences were classified by BLAST alignment against the most recent SILVA database (Quast et al., 2013) and the most recent UNITE database (Kõljalg et al., 2013), repectively, with an e-value threshold of 1e-20. Concatenated sequences of all sequences were mapped on the final set of unique sequences to calculate the evenness and abundance of each unique sequence in all samples. All non-bacterial or non-fungal zOTUs were removed based on their taxonomic classification in the respective database. Final zOTU tables for bacteria and fungi are provided in Tables S4 and S5, respectively. Only zOTUs occurring in more than one sample were considered for further statistical analysis. Samples with less than 22 (bacteria) and 16 (fungi) sequences per sample were removed prior statistical analysis, resulting in 229 samples for bacteria, and 231 samples for fungi.

\subsection{Statistical Analysis}

All statistical analyses were performed using R version 3.4.0 (R Core Team, 2016) and the packages therein. Differences were considered as statistically significant with $p \leq 0.05$. Differences in alpha or beta diversity as well as sequencing depth with regard to cropping system, treatment and inoculation (yes/no) were tested by a Kruskal-Wallis test. There were no significant differences of the mean sequencing depths between the intercropping or monocropping systems, treatments or inoculation. In consequence, zOTU tables were not rarefied as recommended by McMurdie and Holmes (2014).

A variety of alpha diversity indices (Richness, Shannon index of diversity and Michaelis Menten Fit) were calculated using the R-packages picante version 1.6-2 (Kembel et al., 2010) and $d r c$ version 3.0-1 (Ritz and Streigbig, 2016). Sample coverage was estimated using the Michaelis-Menten Fit calculated in R. For this purpose, richness and rarefaction curves were calculated utilizing the picante package (Kembel et al., 2010). OTU tables were rarefied using the rrarefy function in vegan version 2.4.4 and samples with less than 17,177 (soil bacteria), 4,172 (rhizosphere soil bacteria), 508 (root bacteria), 22 (leaves bacteria), 6,105 (soil, fungi), 596 (rhizosphere soil, fungi), 61 (root, fungi) and 16 (leaves, fungi) sequences were removed prior alpha diversity analysis. Richness and diversity were calculated using the specnumber and diversity functions, respectively. The Michaelis-Menten Fit was subsequently calculated from generated rarefaction curves using the MM2 model within the $d r c$ package (Ritz and Streibig, 2016). All alpha diversity indices were calculated 10 times. The average from each iteration was used for further statistical analysis. Final tables 
containing bacterial and fungal richness and diversity are provided in Tables S6 and S7, respectively.

Differences in community composition were investigated by permutational multivariate analysis of variance (PERMANOVA; Anderson, 2001) based on Bray-Curtis distance matrices using 999 permutations. A significant $p$-value in PERMANOVA for betadiversity can be driven by true biological differences, differences within treatment (variance) or both (Anderson, 2001). In case of significant $p$-values in PERMANOVA, we tested for differences in homogeneity using permutational analysis of multivariate dispersions (PERMDISP, Anderson, 2006) with 999 permutations. NMDS, PERMANOVA and PERMDISP were run using functions; metaMDS, adonis and betadisper, respectively, in the $\mathrm{R}$ package vegan (Oksanen et al., 2016). To investigate in differences between cropping cropping regimes, pairwise Adonis with $p$-value adjustment " $\mathrm{BH}$ " based on Bray-Curtis distances were used (Martinez Arbizu, 2017). Bacterial and fungal communities were tested separately. Differences with regard to crop species were tested after exclusion of unplanted soil samples. The effect of cropping systems and inoculation on diversity and richness of fungi and bacteria in all investigated compartments were analyzed separately to avoid spatial pseudoreplication. Global effects (calculated for both sampling times together) of plant compartment and crop species on fungal and bacterial communities were tested with strata $=$ pot, as we had pseudoreplicated data. The two sampling dates were also analyzed separately as to assess whether the observed effects at harvest 1 would be maintained at harvest 2 .

Data (including plant and soil parameter as well as alpha-diversity) were tested for normal distribution with shapiro.test Test and homogeneity of variance with leveneTest function with the package car version 2.1-5 (Fox and Weisberg, 2011). Differences between measured environmental and plant parameters were calculated with Kruskal-Wallis test followed by multiple comparing using dunnTest with Benjamini-Hochberg $p$-value adjustment or Tukey's post hoc test using the HSD.test function in the R package FSA version 0.8.17 (Ogle, 2016) and agricolae version 1.2-8 (De Mendiburu, 2014), respectively.

To identify zOTUs highly associated to application with respect to plant compartment and harvest, multipattern analyses were applied. For that purpose, bacteria and fungi were investigated using the multipatt function from the IndicSpecies package version 1.7.6 (DeCáceres and Legendre, 2009). Only fungal and bacterial zOTUs found in at least three samples were used. The biserial coefficients $(R)$ with a particular plant species and treatment were corrected for unequal sample size using the function r.g (Tichy and Chytry, 2006). 


\section{Results and Discussion}

\subsection{Edaphic properties and plant parameters}

We investigated in several edaphic properties such as total organic carbon and nitrogen, $\mathrm{pH}-$ value and soil moisture, as previous studies have been shown that cropping system or application of microorganisms can change soil chemical characteristics (Xiao et al., 2004; Raya-Diaz et al., 2017). In agreement with these previous studies, we found a significantly higher $\mathrm{pH}$-value in MW compared to XW (Kruskal-Wallis-test (KW-test), with bidest $\mathrm{x}^{2}=3.88, \mathrm{df}=1, p=0.048$; with $\mathrm{KCl}, \mathrm{x}^{2}=5.24, \mathrm{df}=1, p=0.022$ ), whereas inoculation did not influence $\mathrm{pH}$-value after five weeks of plant growth (Table 3). In contrast, soil moisture was not influenced when comparing these treatments $(27.65 \pm 1.18 \%)$. Total nitrogen as well as $\mathrm{C}: \mathrm{N}$ ratio in the faba bean rhizosphere was significantly influenced by application for harvest 2, showing lowest nitrogen values under application (KW-test, nitrogen, $x^{2}=9.07, \mathrm{df}=1$, $p=0.002 ; \mathrm{C}: \mathrm{N}, \mathrm{x}^{2}=4.03, \mathrm{df}=1, p=0.044$; Table 2). Similar, the inoculated wheat rhizosphere had significantly lower nitrogen content compared to the control treatment (KW-test, H1, $\left.\mathrm{x}^{2}=5.29, \mathrm{df}=1, p=0.021 ; \mathrm{H} 2, \mathrm{x}^{2}=10.83, p=0.001\right)$. In addition, the combination of cropping system and inoculation significantly affected nitrogen content in the wheat and faba bean rhizosphere (KW-test, wheat, $\mathrm{x}^{2}=12.38, \mathrm{df}=3, p=0.01$; faba bean, $\mathrm{x}^{2}=14.08, \mathrm{df}=3, p<0.001$ ). Nitrogen content was significantly lower in the cropping regimes XBF/XWF compared to $\mathrm{XB} / \mathrm{XW}$ and $\mathrm{MB} / \mathrm{MW}$ but only at harvest 2 . Previously, it has been reported that intercropping can increase wheat nitrogen accumulation in soil but decrease this parameter in faba bean which is in contrast to our observation (Xiao et al., 2004). We speculate that the significant decrease in nitrogen in the intercropping treatment could be partly explained by the limited available space for roots. This was much reduced in the containers after a growing period of seven weeks and interspecific competition for nutrients may thus have increased between the two crop plants. We further speculate that our applied fungus played an important role in altering nutrient availability in the rhizosphere between the two crop species as previously assumed (Behie and Bidochka, 2014).

Intercropping or the application of $M$. brunneum have been reported to enhance plant growth and biomass production (Xiao et al., 2004; Zhang et al., 2010; Krell et al., 2018). In line with these results, we found that plant height of wheat was significantly higher under intercropping compared to monoculture (Table 4). Faba bean plants were taller when inoculated with the entomopathogenic fungal isolate, but significantly only for the $4^{\text {th }}$ week of plant growing (KW-test, $\left.\mathrm{x}^{2}=4.48, \mathrm{df}=1, p=0.034\right)$. After seven weeks of growing $(\mathrm{H} 2)$, wheat 
aerial plant biomass $\left(\mathrm{KW}\right.$-test $\left.\mathrm{x}^{2}=7.77, \mathrm{df}=1, p=0.005\right)$, leaf nitrogen $\left(\mathrm{KW}\right.$-test, $\mathrm{x}^{2}=6.62, \mathrm{df}=1$, $p=0.01)$ and water content (KW-test, $\left.\mathrm{x}^{2}=9.28, \mathrm{df}=1, \mathrm{p}=0.002\right)$ were significantly higher in XW compared to MW (Table 3, 5). In addition, the C:N ratio in leaves was significantly lower in XW compared to MW (KW-test, $\left.\mathrm{x}^{2}=7.71, \mathrm{df}=1, p=0.005\right)$. Combination of application and cropping system showed that the $\mathrm{C}: \mathrm{N}$ ratio in leaves were significantly lower in the cropping regime XWF compared to MW. In faba bean roots, total carbon had significantly lower values in the cropping regime XBF compared to MBF. In contrast to the rhizosphere soil, plants especially wheat were mainly affected by differences between cropping systems than fungal application. However the combination of both treatments showed a significant influence, similar to the rhizosphere. We speculate that fungal application might play a direct role in shifting the balance of inter- and intraspecific competition between plants as already indicated in arbuscular mycorrhizal fungal inoculation experiments (Moora and Zobel, 1995; Hodge, 2003).

\subsection{Overall bacterial and fungal community}

The response of bacterial and fungal communities of faba bean and wheat towards inoculation with Metarhizium under different cropping systems was assessed by Illumina (MiSeq) sequencing targeting the bacterial 16S rRNA gene and the fungal internal transcribed spacer (ITS) region, respectively. After removal of low quality reads, PCR artefacts (chimeras), nontarget sequences and plant-derived contaminations, a total of 4,790,788 (bacteria) and 4,271,395 (fungi) high-quality reads were obtained (Tables S4 and S5). Prior to analyses, samples with less than 16 (fungi) or 22 (bacteria) as well as singletons were removed, resulting in 231 and 227 samples for fungi and bacteria, respectively. Sequence numbers per sample varied between 22 to 89,115 (average 20,916.7) for bacteria and between 16 to 112,646 (average 18,490.2) for fungi. Although samples were rarefied to low sequencing numbers, rarefaction curves (Figures S1-S8) and calculated Michaelis-Menten Fit confirmed that the majority of bacterial and fungal diversity was recovered by the surveying effort (Tables S6 and S7).

The eight dominant bacterial phyla $(>0.5 \%$ of all sequences across all samples) were Proteobacteria (66.64\%), Actinobacteria (19.11\%), Acidobacteria (3.49\%), Firmicutes (2.58\%), Chloroflexi (2.64\%), Gemmatimonadetes (2.05\%), Verrrucomicrobia (1.02\%) and Bacteroides (0.75\%). The Proteobacteria were dominated by Gammaproteobacteria $(37.32 \%)$, followed by Alphaproteobacteria (27.7\%). The abundant bacterial phyla were present in all samples and accounted for $98.28 \%$, of all sequences analysed in this study. At family level, 
Rhizobiaceae (21.21\%) and Burkholderiaceae (18.44\%) were predominant (Figure 2). Abundant genera were, for example, Allorhizobium-Neorhizobium-Pararhizobium-Rhizobium (20.91\%), Alicycliphilus (12.38\%) Halomonas (3.84\%), Lysobacter (2.7\%), Sphingomonas $(2.32 \%)$ and Shewanella $(2.05 \%)$.

Fungi were represented by four abundant phyla $(>0.5 \%$ of all sequences across all samples): Ascomycota (43.78\%), Basidiomycota (6.53\%), Mortierellomycota (4.36\%) and Mucoromycota (2.25\%). Approximately $43 \%$ of all sequences belonged to unidentified fungi. The dominant fungal families were Nectriaceae (8.56\%), Mortierellaceae (3.94\%), Phaeosphaeriaceae (3.41\%) and Pleosporaceae (3.24\%) (Figure 3). At genus level: Dactylonectria (3.94\%), Mortierella (3.08\%), Chaetomium (2.43\%), Rhizopus (2.22\%), Gibellulopsis (2.19\%), Alternaria (2.18\%), Gibberella (2.15\%) and Cladosporium (2.11\%) were more frequent. Members of the genus Metarhizium accounted for $0.08 \%$ of all sequences. Abundant bacterial and fungal taxa were also found in previous studies investigating in plant-associated microbial communities (Gdanetz et al., 2017; Zhou et al., 2017; Li et al., 2018).

\subsection{Spatial and temporal distribution of Metarhizium species in soil and plants after application}

We found 6 zOTUs: two belonging to M. anisopliae (0.077\%), one M. marquandii $(0.0024 \%)$, one M. carneum (0.002\%) and two belonging to M. flavoviride $(0.0015 \%)$. The identity of all Metarhizium zOTUs were higher than $99.721 \%$. Both M. flavoviride zOTUs occurred mainly in unplanted control soil (Table 6). zOTUs belonging to M. marquandii as well as M. carneum were detected in unplanted soil, rhizosphere soil and within roots in non-inoculated and inoculated treatments for both harvests. M. anisopliae was found more often in inoculated roots and leaves, especially in the treatment XBF and XWF in roots.

Conventional PCR approach with Metarhizium clade 1 specific primers also confirmed presence of Metarhizium spp. in the samples of harvest 1 (Figure S9-S16). However, we also observed positive bands with the correct amplicon length in several of the control samples. Previous studies reported that different Metarhizium species can be found naturally in agricultural soils including M. brunneum, M. carneum or M. flavoviride (Steinwender et al., 2014; Kepler et al., 2015; Mayerhofer et al., 2017). As we used agricultural soil from an arable field, we hypothesize that some of the different Metarhizium species might origin from it. We further speculate that one of the M. anisopliae zOTU is our inoculated fungus because the main occurrence was in inoculated planted treatments and relative abundance in the 
dataset was highest compared to the other Metarhizium zOTUs. However, we cannot confirm this assumption with our approach.

\subsection{Bacterial and fungal communities are strongly affected by crop species and plant compartment}

According to our first hypothesis that cop species and plant compartment affect microbial community composition and diversity, we calculated diversity (represented by the Shannon index H') and richness (number of observed unique sequences). Bacterial diversity and richness were significantly influenced by the crop plant species grown. The wheat root endosphere had a significantly higher bacterial diversity (KW-test, H1, $\mathrm{x}^{2}=13.73$, $\mathrm{df}=1$, $p<0.001 ; \mathrm{H} 2, \mathrm{x}^{2}=29.27, p<0.001$ ) and richness (KW-test, $\mathrm{H} 1, \mathrm{x}^{2}=18.73, \mathrm{df}=1, p<0.001 ; \mathrm{H} 2$, $\left.\mathrm{x}^{2}=29.27, p<0.001\right)$ compared to faba bean. Similar wheat rhizosphere showed higher diversity compared to faba bean but specific for harvest 2 (KW-test, $\mathrm{x}^{2}=6.79, \mathrm{df}=1, p=0.009$ ). In contrast, leaf endosphere showed higher bacterial diversity in faba bean compared to wheat for harvest 2 (KW-test, $\left.\mathrm{H} 2, \mathrm{x}^{2}=5.0, \mathrm{df}=1, p=0.025\right)$. Similar to bacteria, fungi showed significantly higher diversity $\left(\mathrm{KW}\right.$-test, $\left.\mathrm{x}^{2}=10.19, \mathrm{df}=1, p=0.001\right)$ and richness (KW-test, $\left.\mathrm{x}^{2}=6.35, \mathrm{df}=1, p=0.012\right)$ in the wheat rhizosphere compared to faba bean in harvest 2 , whereas diversity $\left(\mathrm{KW}\right.$-test, $\left.\mathrm{x}^{2}=6.35, \mathrm{df}=1, p=0.012\right)$ and richness $\left(\mathrm{KW}\right.$-test, $\left.\mathrm{x}^{2}=4.86, \mathrm{df}=1, p=0.02\right)$ in the faba bean leaf endosphere was higher compared to wheat.

In addition to differences in richness and diversity, crop species and plant compartment significantly influenced microbial community composition in soil and endosphere. Compartment explained $32.7 \%$ and $23.1 \%$ of the variance in the bacterial and fungal dataset (PERMANOVA, $p=0.001, p=0.001$ ) and dispersion among compartments was heterogeneous (PERMDISP, $\mathrm{F}=5.60, p=0.001 ; \mathrm{F}=39.79, p=0.001$ ). Crop species explained most of the variance in the root and leaf endosphere of the bacterial and fungal dataset (Table 7). Several taxa were more abundant in one of the two crop species (Figure 2, 3). Higher relative abundances of several bacterial genera including Rhizobium (66.60\%), Alicycliphilus (7.48\%) and Halomonas (7.31\%) were recorded in faba bean compared to wheat plants, whereas the opposite was observed for Alicycliphilus (30.58\%), Rhizobium (9.06\%) and Sphingomonas (5.41\%). The fungal genera Dactylonectria (11.78\%), Cladosporium (4.65\%) and Alternaria (4.37\%) were more abundant in faba bean plants. As plant species select microbial communities, each plant species can harbor specific microbial members as shown previously (Wemheuer et al., 2017; Zhou et al., 2017). Similar, each plant compartment represents distinct niches in terms of nutrient 
availability, or exposure to abiotic or biotic factors which selects for a specific microbial assembly (Gdanetz et al., 2017; Wallace et al., 2018). The rhizosphere is strongly influenced by plant metabolism and differences in composition and quantity of root exudates between plant species such as legumes and grasses can influence soil microbial communities (Liu et al., 2017; Siczek et al., 2018). Differences in plant physiology such as different rooting structure or chemical composition between plants (Roumet et al., 2008) might also affect endophytic community.

\subsection{M. brunneum application significantly affected microbial communities}

We further expected that M. brunneum application and establishment of an endophytic fungus in plant tissues creates a long lasting effect on bacterial and fungal communities. Fungal diversity and richness in wheat rhizosphere and leaves were affected by M. brunneum application and fungi showed a decrease in diversity (KW-test, $\mathrm{rz}, \mathrm{x}^{2}=4.81, \mathrm{df}=1, p=0.028$; $1 \mathrm{v}$, $\left.\mathrm{x}^{2}=9.42, p=0.002\right)$ and richness (KW-test, $\left.\mathrm{rz}, \mathrm{x}^{2}=7.41, \mathrm{df}=1, p=0.006 ; 1 \mathrm{v}, \mathrm{x}^{2}=9.42, p=0.002\right)$ in inoculated wheat plants for harvest 2 (Table 9). In contrast, bacterial diversity (KW-test, rz, $\left.\mathrm{x}^{2}=8.59, \mathrm{df}=1, p=0.003 ; \mathrm{lv}, \mathrm{x}^{2}=4.48, p=0.03\right)$ and richness $\left(\mathrm{KW}\right.$-test, $\mathrm{rz}, \mathrm{x}^{2}=4.5, \mathrm{df}=1$, $\left.p=0.034 ; \mathrm{lv}, \mathrm{x}^{2}=4.65, p=0.031\right)$ in wheat rhizosphere and leaves were significantly higher or lower in inoculated plants specific for harvest 2 (Table 8). Previously, Rabiey et al., (2017) reported that soil inoculation with the fungus Piriformospora indica increased the fungal diversity in soil and root endosphere of wheat in a pot experiment which was in contrast to our results; however they also reported an increase of bacterial diversity which was in line with our results. We speculate that these observations are related to specific responses of bacteria and fungi to our applied strain.

To identify the influence of M.brunneum application on microbial community composition, we performed a NMDS (non-metric multidimensional scaling) analysis based on Bray-Curtis dissimilarities. NMDS showed distinct clustering according to application which was mainly observed in bacterial leaf endosphere (Figure 4). Permutational multivariate analysis of variance (PERMANOVA) also showed that M.brunneum application significantly influenced bacterial $\left(\mathrm{H} 1, \mathrm{R}^{2}=11.7 \%, p=0.004, \mathrm{H} 2, \mathrm{R}^{2}=4.1, p=0.028\right)$ and fungal $\left(\mathrm{H} 1, \mathrm{R}^{2}=4.6 \%, p=0.028, \mathrm{H} 2, \mathrm{R}^{2}=7.4, p=0.001\right)$ community composition in the rhizosphere, whereas root community was unaffected (Table 7). In accordance to this, Ardanov and coworkers (2012) showed compartment specific effects of the substrate inoculation of Methylobacterium spp. on bacteria. Application only changed bacterial composition in potato shoots, whereas root endophytes were not influenced. In contrast to our study, Zimmermann 
et al., (2016) observed that seed coating with Fusarium oxysporum did not alter indigenous fungal community structure in the rhizosphere of maize, whereas soil type and plant growth stage showed the strongest effect on fungi.

In the present study, we still found significant effects of M.brunneum application on bacterial and fungal communities in the plant endosphere and rhizosphere after seven weeks of plant growing. As we investigated only in one plant growth stage (vegetative phase), we do not know how long effects of M.brunneum application last on plant and its plant microbiome which is also important to know in case of biological control options. In contrast to our findings, several studies reported that application of an entomopathogenic fungus showed no or transient changes on microbial communities (Hirsch et al., 2013; Hong et al., 2017; Mayerhofer et al., 2017). We speculate that these discrepancies to our results might be related to different inoculated agents, crop species or even growth stage of plant (Aguilar-Trigueros and Rillig 2016; Gadhave et al. 2018; Liu et al. 2018). Recently, Gadhave et al. (2018) showed that impacts of application on bacterial community in the broccoli root endosphere were dependent on Bacillus species. Similarly, Aguilar-Trigueros and Rillig (2016) observed that each plant species responded differently to application such as improved plant growth which was dependent on the identity of the inoculated fungus. Further reasons for contradictory results might be the usage of different inoculation methods or different investigated compartments. It is well-known that these factors can influence inoculation or colonization efficiency (Tefera and Vidal, 2009; Akutse et al., 2013; Greenfield et al., 2016; Jaber and Enkerli, 2016) and as a result may also affect plant microbiome.

\subsection{Cropping system influenced effect of M.brunneum application on plant microbiome}

We further evaluated whether cropping system had an influence on microbial communities. We found that cropping system exhibited significantly higher microbial diversity and richness in XW compared to MW (Table 8, 9). However, this was only observed for fungi in the root endosphere (KW-test, shannon, $\mathrm{x}^{2}=4.51, \mathrm{df}=1, p=0.03$, richness, $\mathrm{x}^{2}=4.17$, $p=0.04$ ) and for bacteria in the rhizosphere (KW-test, shannon, $\mathrm{x}^{2}=5.81, \mathrm{df}=1, p=0.015$; richness, $\left.\mathrm{x}^{2}=7.82, p=0.005\right)$. In faba bean rhizosphere, we showed the opposite trend, thus bacterial diversity $\left(\mathrm{KW}\right.$-test, $\left.\mathrm{x}^{2}=5.22, \mathrm{df}=1, p=0.022\right)$ and richness $\left(\mathrm{KW}\right.$-test, $\mathrm{x}^{2}=4.17$, $p=0.04$ ) was significantly higher in MB compared to XB. Our observations were in line with previous studies which found that intercropping increased microbial diversity in the rhizosphere and bulk soil (Yang et al., 2016; Li and Wu, 2018). Yang et al., (2016) investigated in 10 different spring crops grown in monoculture and intercropping system and 
found that intercropping increased bacterial diversity in the rhizosphere, however, responses were also crop species dependent. In line with this, Li and Wu (2018) showed that from seven intercropping systems only the combination of cucumber/mustard and cucumber/trifolium increased bacterial and fungal diversity in bulk soil compared to cucumber monoculture.

In the present study, we showed that cropping system significantly affected bacterial community composition in plant endosphere whereas fungi were only influenced in rhizosphere soil (Table 7). Previous studies also reported significant effects of cropping system on bacterial and fungal community composition in different compartments (Zhang et al., 2010; Wang et al., 2012; Granzow et al., 2017). Recently, Granzow et al., (2017) showed that cropping system affected bacterial and fungal communities in bulk and rhizosphere soil as well as fungal composition in roots, whereas leaf endophytes were unaffected which is in contrast to our results. In contrast to our study, they used commercial available soil and different crop genotypes which might influence the response of the microbiome in a different way (Wagner et al., 2016).

Consistent with our third hypothesis, we observed that cropping system influenced the effect of M. brunneum application on bacterial and fungal communities. For example, we found significantly lower bacterial diversity and richness in XBF rhizosphere compared to MB, whereas XWF rhizosphere had significantly higher diversity and richness compared to MWF at harvest 1 (Table 8). In the root endosphere, bacteria showed highest diversity and richness under $\mathrm{MBF}$ compared to $\mathrm{MB}$ and/or $\mathrm{XBF}$ at harvest 2. In contrast, effects of cropping regimes on fungal alpha-diversity were only found in harvest 2 (Table 9). For example, fungi had significantly higher diversity and richness in the root endopshere of XWF compared to MW or MWF. Partly in line with this observation, previous studies showed that the combination of cropping system and rhizobium inoculation can influence bacterial diversity or abundance in the root endosphere and rhizosphere soil of faba bean or maize (Zhang et al., 2011; Zhang et al., 2015). Zhang et al., (2011) reported that intercropping and rhizobial seed inoculation increased bacterial diversity compared to monoculture in the root endosphere of faba bean but they also indicated that plant growth stage was the main factor influencing bacterial community and its response towards rhizobial inoculation and cropping system.

Evaluation of microbial community composition with NMDS showed similar clustering of fungal root community towards cropping regimes in harvest 2 (Figure 5). Pairwise Adonis analysis confirmed that fungal root community was significantly altered between the cropping regimes XW and XWF, MW and XWF as well as between MWF and 
XWF (Table S9). Here, we demonstrated that plant compartment but also sampling time exhibited strong effects on bacterial and fungal communities and their response towards cropping regimes which is consistent with our last hypothesis. Although we could not confirm the occurrence of the applied Metarhizium species with our approach, we speculate that $M$. brunneum application played an important role in the observed results for alpha- and betadiversity; however we cannot clearly say whether inoculation influenced bacterial or fungal response towards cropping systems or that cropping system changed response of microbial communities towards inoculation. We further hypothesize that $M$. brunneum application might have changed nutrient accumulation or indirectly changed plant root exudation pattern of plants ( $\mathrm{Gu}$ et al., 2016). Previous studies reported that entomopathogenic fungi produce siderophores and/or organic acids that can alter availability of certain nutrients (Krasnoff et al., 2014; Sánchez-Rodriguez et al., 2016; Krell et al., 2018). It is well-known that nitrogen and carbon can strongly influence microbial communities (Wan et al., 2015; Kaiser et al., 2016). In agreement with our assumption, we observed that especially nutrient availability (nitrogen and carbon) within the different plant compartments changed according to inoculation and cropping system. For example, C:N ratio under XWF in the rhizosphere increased similar to bacterial diversity and richness. Carbon in roots significantly decreased in XBF compared to MBF similar to bacterial diversity.

\subsection{Predominant and associated bacterial taxa differ between $M$. brunneum application and control treatment}

Fungal inoculum as invading agent might antagonistic interact or compete for resources and niches with other microorganisms which in turn results in an increase or depletion of specific microorganisms (de Boer, 2017). Results of the relative abundance might indicate this assumption, as we observed that inoculation induced the proliferation of specific bacteria. For example, Halomonas (17.23\%) and Shewanella (11.21\%) were frequently found in inoculated rhizosphere samples, but were almost absent $(<0.01 \%$ abundance $)$ in rhizosphere soil of noninoculated treatments (Figure 2). The opposite effect was observed in the leaf endosphere. Here, Halomonas $(62.25 \%)$ and Shewanella (28.46\%) were mainly found in non-inoculated faba bean plants. In addition, both bacterial genera were complete absent in the soil for harvest 2. Interestingly, these bacteria were mainly reported in plant growth promoting, biological control or in bioremediation (Tiwari et al., 2011; Jha, Gontia and Hartmann, 2012; Gong et al., 2015). Previous studies also showed that inoculation of bacteria or fungi may 
change abundances of specific (beneficial) bacterial and fungal taxa in the rhizosphere, endosphere or episphere (Hong et al., 2017; Gadhave et al., 2018; Liu et al., 2018).

To identify bacterial and fungal taxa responsible for the observed differences among application, we performed a multipattern analysis to investigate which microorganisms are significantly associated with those treatments (Table S8). In general, soil communities harbored more associated zOTUs than endophyte communities which is most probably related with higher sequence numbers in soil compared to endosphere samples. Although we did not observe a significant difference in microbial community composition between control and inoculated unplanted soil samples, we found 199 (2.47\% of all bacterial taxa included in the analysis) and $65(2.31 \%)$ significantly associated bacterial taxa for fungal application and control treatment in harvest 1 . Several associated bacterial taxa for fungal application included zOTUs belonging to Haliangium. In contrast, $48(1.70 \%)$ fungal taxa were significantly associated with M. brunneum application, whereas only one taxon with control samples for unplanted soil. Members of Haliangium spp. are known to produce haliangicin an antifungal metabolite that can inhibit growth of several fungi (Fudou et al., 2001). Moreover, few zOTUs belonging to Halomonas and Shewanella were significantly and uniquely associated with fungal application in the rhizosphere of harvest 1. In plant endosphere, we found that both zOTUs were significantly associated with control plants for harvest 1 . Furthermore, we found several zOTUs of Sphingomonas significantly and uniquely associated with M. brunneum application in leaf and root endosphere as well as in the rhizosphere soil for harvest 2. Plant-associated Sphingomonas members have been shown to be effective agents against the plant pathogen Pseudomonas syringae (Innerebner et al., 2011). In addition, Hong et al., (2017) reported an increase of Sphingomonas abundance after M. anisopliae leaf application and similar to Innerebner et al., (2011) they indicated that these bacteria might contribute to facilitate plant disease resistance and/or stress response. Because of this complexity of interactions between microorganisms, and between microorganisms and plant, the effects of fungal application on plant and microbiome are difficult to predict.

\section{Conclusion}

To date, the combined effect of cropping system and fungal inoculation on fungal and bacterial communities in endosphere and rhizosphere soil of two important crop species have not been studied using large-scale metabarcoding. In line with our first hypothesis we found that crop species and compartment exhibited a strong influence on the plant microbiome. $M$. brunneum application changed bacterial and fungal community composition at both sampling 
times, whereas response of alpha-diversity showed some variance between sampling time. Furthermore, cropping system, crop species and plant compartment were important in changing the effect of fungal application on bacterial and fungal communities. The present findings increase our understanding of how the application of an entomopathogenic fungus affects microbial community which might gain further importance for biological control strategies in the future. However, we need long-term studies to properly quantify observed effects under field conditions.

\section{Acknowledgment}

This study is part of the project IMPAC ${ }^{3}$ and was funded by the Federal Ministry of Education and Research (FKZ 031A351A). The authors thank Prof. Dr. Wolfgang Link from the Working Group "Breeding Research Faba Bean" (Division of Plant Breeding at the University of Göttingen) for providing the seed material. 


\section{Tables}

Table 1. Sampling numbers for each container and harvest.

\begin{tabular}{|c|c|c|c|c|c|}
\hline $\begin{array}{c}\text { Treatments } \\
\text { /Compartments }\end{array}$ & Unplanted soil & Rhizosphere & Roots & Leaves & Plants/treatment \\
\hline CS & $1(3 / 3)$ & - & - & - & - \\
\hline \multicolumn{6}{|c|}{ Harvest 1} \\
\hline $\mathrm{C}$ & $1(5 / 5)$ & - & - & - & - \\
\hline CF & $1(5 / 5)$ & - & - & - & - \\
\hline MB & - & $1(5 / 5)$ & $1(5 / 5)$ & $1(3 / 4)$ & 5 \\
\hline $\mathbf{X B}$ & - & $1(5 / 5)$ & $1(5 / 4)$ & $1(4 / 2)$ & 5 \\
\hline MW & - & $2(5 / 5)$ & $2(5 / 5)$ & $2(4 / 5)$ & 10 \\
\hline XW & - & $2(5 / 5)$ & $2(5 / 5)$ & $2(5 / 5)$ & 10 \\
\hline MBF & - & $1(5 / 5)$ & $1(5 / 4)$ & $1(3 / 4)$ & 5 \\
\hline $\mathbf{X B F}$ & - & $1(5 / 5)$ & $1(5 / 5)$ & $1(2 / 4)$ & 5 \\
\hline MWF & - & $2(5 / 5)$ & $2(5 / 4)$ & $2(4 / 5)$ & 10 \\
\hline XWF & - & $2(5 / 5)$ & $2(5 / 5)$ & $2(5 / 5)$ & 10 \\
\hline \multicolumn{6}{|c|}{ Harvest 2} \\
\hline MB & - & $2(5 / 5)$ & $2(5 / 4)$ & $2(0 / 3)$ & 10 \\
\hline $\mathbf{X B}$ & - & $2(5 / 5)$ & $2(5 / 4)$ & $2(1 / 2)$ & 10 \\
\hline MW & - & $3(5 / 5)$ & $3(5 / 5)$ & $3(5 / 5)$ & 15 \\
\hline XW & - & $3(5 / 5)$ & $3(5 / 5)$ & $3(5 / 5)$ & 15 \\
\hline MBF & - & $2(4 / 5)$ & $2(5 / 3)$ & $2(4 / 5)$ & 10 \\
\hline XBF & - & $2(5 / 5)$ & $2(5 / 5)$ & $2(2 / 2)$ & 10 \\
\hline MWF & - & $3(4 / 5)$ & $3(5 / 5)$ & $3(5 / 5)$ & 15 \\
\hline XWF & - & $3(5 / 5)$ & $3(5 / 5)$ & $3(5 / 4)$ & 15 \\
\hline Total & 13 & 80 & 160 & 160 & $60(\mathrm{FB}), 100(\mathrm{~W})$ \\
\hline
\end{tabular}

Each container was replicated five times. Abbreviations: W, wheat; FB, faba bean; F, inoculated samples; MW, wheat in monoculture; $\mathrm{MB}$, faba bean in monoculture, $\mathrm{XB}$, faba bean samples in intercropping; $\mathrm{XW}$, wheat samples in intercropping; SC, starting soil; C unplanted control soil. Number in brackets refers to the number of samples left after removal of samples with too low sequencing numbers. The first number refers to bacteria, the second to fungi. 
Table 2. Edaphic properties (mean $\pm \mathrm{SE})$.

Harvest 1

Harvest 2

\begin{tabular}{c|ccc|ccc|}
\hline Treatment & $\mathbf{C}_{\text {total }}(\mathbf{\%})$ & $\mathbf{N}_{\text {total }}(\%)$ & $\mathbf{C}: \mathbf{N}$ ratio & $\mathbf{C}_{\text {total }}(\%)$ & $\mathbf{N}_{\text {total }}(\%)$ & $\mathbf{C}: \mathbf{N}$ ratio \\
\hline $\mathbf{C}$ & $2.01 \pm 0.01$ & $0.21 \pm 0.00$ & $9.69 \pm 0.16$ & $1.95 \pm 0.01$ & $0.20 \pm 0.00$ & $9.60 \pm 0.03$ \\
$\mathbf{C F}$ & $1.98 \pm 0.02$ & $0.21 \pm 0.00$ & $9.48 \pm 0.14$ & $1.93 \pm 0.02$ & $0.21 \pm 0.00$ & $9.45 \pm 0.09$ \\
\hline B & $2.03 \pm 0.02$ & $0.22 \pm 0.00$ & $9.53 \pm 0.10$ & $2.01 \pm 0.03$ & $\mathbf{0 . 2 0} \pm \mathbf{0 . 0 0 a}$ & $\mathbf{1 0 . 0 6} \pm \mathbf{0 . 1 2 a}$ \\
B_F & $2.01 \pm 0.01$ & $0.21 \pm 0.00$ & $9.49 \pm 0.06$ & $1.93 \pm 0.05$ & $\mathbf{0 . 1 8} \pm \mathbf{0 . 0 1 b}$ & $\mathbf{1 0 . 7 3} \pm \mathbf{0 . 3 0 b}$ \\
\hline W & $2.06 \pm 0.02$ & $\mathbf{0 . 2 1} \pm \mathbf{0 . 0 0 a}$ & $9.61 \pm 0.05$ & $2.00 \pm 0.02$ & $\mathbf{0 . 2 0} \pm \mathbf{0 . 0 0 b}$ & $10.15 \pm 0.05$ \\
W_F & $2.05 \pm 0.03$ & $\mathbf{0 . 2 1} \pm \mathbf{0 . 0 0 b}$ & $9.79 \pm 0.15$ & $1.88 \pm 0.07$ & $\mathbf{0 . 1 8} \pm \mathbf{0 . 0 1 a}$ & $10.74 \pm 0.15$ \\
\hline XB & $2.04 \pm 0.01$ & $0.21 \pm 0.00$ & $\mathbf{9 . 6 3} \pm \mathbf{0 . 0 9 a}$ & $1.91 \pm 0.05$ & $0.18 \pm 0.01$ & $10.51 \pm 0.32$ \\
MB & $2.00 \pm 0.02$ & $0.21 \pm 0.00$ & $\mathbf{9 . 3 9} \pm \mathbf{0 . 0 5 b}$ & $2.02 \pm 0.03$ & $0.20 \pm 0.00$ & $10.32 \pm 0.19$ \\
\hline XW & $2.08 \pm 0.03$ & $0.21 \pm 0.00$ & $9.84 \pm 0.14$ & $1.87 \pm 0.07$ & $0.18 \pm 0.01$ & $10.43 \pm 0.30$ \\
MW & $2.03 \pm 0.02$ & $0.21 \pm 0.00$ & $9.56 \pm 0.06$ & $2.00 \pm 0.03$ & $0.19 \pm 0.00$ & $10.46 \pm 0.15$ \\
\hline XB & $2.04 \pm 0.03$ & $0.21 \pm 0.00$ & $9.66 \pm 0.18$ & $1.98 \pm 0.04$ & $\mathbf{0 . 2 0} \pm \mathbf{0 . 0 0 a}$ & $9.99 \pm 0.12$ \\
XBF & $2.03 \pm 0.01$ & $0.21 \pm 0.00$ & $9.59 \pm 0.05$ & $1.84 \pm 0.12$ & $\mathbf{0 . 1 7} \pm \mathbf{0 . 0 0 b}$ & $11.04 \pm 0.57$ \\
MB & $2.02 \pm 0.04$ & $0.22 \pm 0.00$ & $9.39 \pm 0.06$ & $2.04 \pm 0.05$ & $\mathbf{0 . 2 0} \pm \mathbf{0 . 0 0 a}$ & $10.13 \pm 0.21$ \\
MBF & $2.00 \pm 0.02$ & $0.21 \pm 0.00$ & $9.37 \pm 0.08$ & $2.01 \pm 0.04$ & $\mathbf{0 . 1 9} \pm \mathbf{0 . 0 0 a b}$ & $10.48 \pm 0.3$ \\
\hline XW & $2.05 \pm 0.02$ & $0.21 \pm 0.00$ & $\mathbf{9 . 5 7} \pm \mathbf{0 . 0 9 b}$ & $1.97 \pm 0.02$ & $\mathbf{0 . 2 0} \pm \mathbf{0 . 0 0 a}$ & $9.97 \pm 0.1$ \\
XWF & $2.11 \pm 0.05$ & $0.21 \pm 0.00$ & $\mathbf{1 0 . 1 1} \pm \mathbf{0 . 2 a}$ & $1.77 \pm 0.12$ & $\mathbf{0 . 1 7} \pm \mathbf{0 . 0 1 b}$ & $10.88 \pm 0.54$ \\
MW & $2.08 \pm 0.02$ & $0.21 \pm 0.00$ & $\mathbf{9 . 6 5} \pm \mathbf{0 . 0 3 a b}$ & $2.03 \pm 0.03$ & $\mathbf{0 . 2 0} \pm \mathbf{0 . 0 0 a}$ & $10.33 \pm 0.15$ \\
MWF & $1.98 \pm 0.02$ & $0.21 \pm 0.00$ & $\mathbf{9 . 4 7} \pm \mathbf{0 . 1 b}$ & $1.98 \pm 0.04$ & $\mathbf{0 . 1 9} \pm \mathbf{0 . 0 0 a b}$ & $10.59 \pm 0.28$ \\
\hline
\end{tabular}

Different letters in columns indicate statistically significant differences between treatments $(\mathrm{p} \leq 0.05$, means \pm

$\mathrm{SE}$ ). Abbreviations: $\mathrm{MB} / \mathrm{MW}$, faba bean/wheat grown in monoculture; $\mathrm{XB} / \mathrm{XW}$, faba bean/wheat intercropped;

$\mathrm{C}$, control unplanted soil; F, inoculated samples.

Table 3. Biomass $[\mathrm{g}]$ and $\mathrm{pH}-\mathrm{value}(\operatorname{mean} \pm \mathrm{SE})$.

\begin{tabular}{c|ccccccccc} 
& \multicolumn{2}{c}{ Roots } & \multicolumn{2}{c}{ Aerial parts } & \multicolumn{2}{c}{ Shoot/Root ratio } & pH-bidest & pH-KCl \\
\hline Treatment & H1 & H2 & H1 & H2 & H1 & H2 & H1 & H1 \\
\hline XB & $3.72 \pm 0.35$ & $8.75 \pm 0.50$ & $13.27 \pm 0.95$ & $36.70 \pm 2.55$ & $3.73 \pm 0.31$ & $4.19 \pm 0.16$ & $7.46 \pm 0.02$ & $6.88 \pm 0.04$ \\
MB & $4.40 \pm 0.47$ & $8.04 \pm 0.58$ & $16.21 \pm 1.35$ & $37.94 \pm 1.32$ & $3.91 \pm 0.37$ & $4.91 \pm 0.32$ & $7.41 \pm 0.03$ & $6.89 \pm 0.02$ \\
\hline XW & $1.53 \pm 0.28$ & $4.61 \pm 0.58$ & $3.50 \pm 0.34$ & $\mathbf{1 0 . 6 1} \pm \mathbf{0 . 7 1 a}$ & $2.93 \pm 0.52$ & $2.44 \pm 0.20$ & $\mathbf{7 . 4 5} \pm \mathbf{0 . 0 1 a}$ & $\mathbf{6 . 9 2} \pm \mathbf{0 . 0 2 a}$ \\
MW & $1.82 \pm 0.41$ & $4.56 \pm 0.74$ & $3.73 \pm 0.49$ & $\mathbf{7 . 5 0} \pm \mathbf{0 . 3 3 b}$ & $2.45 \pm 0.27$ & $1.94 \pm 0.25$ & $\mathbf{7 . 5 0} \pm \mathbf{0 . 0 1 b}$ & $\mathbf{6 . 9 6} \pm \mathbf{0 . 0 1 b}$ \\
\hline B & $3.98 \pm 0.29$ & $8.84 \pm 0.58$ & $13.96 \pm 1.32$ & $37.29 \pm 2.48$ & $3.54 \pm 0.27$ & $4.31 \pm 0.32$ & $7.45 \pm 0.01$ & $6.86 \pm 0.03$ \\
B_F & $4.14 \pm 0.53$ & $7.95 \pm 0.49$ & $15.52 \pm 1.15$ & $37.35 \pm 1.48$ & $4.10 \pm 0.38$ & $4.79 \pm 0.20$ & $7.42 \pm 0.03$ & $6.90 \pm 0.02$ \\
\hline W & $1.70 \pm 0.26$ & $4.98 \pm 0.75$ & $3.54 \pm 0.36$ & $9.34 \pm 0.86$ & $2.36 \pm 0.26$ & $2.17 \pm 0.28$ & $7.48 \pm 0.01$ & $6.94 \pm 0.01$ \\
W_F & $1.65 \pm 0.43$ & $4.09 \pm 0.40$ & $3.69 \pm 0.47$ & $8.70 \pm 0.60$ & $3.02 \pm 0.52$ & $2.22 \pm 0.17$ & $7.47 \pm 0.02$ & $6.94 \pm 0.02$ \\
\hline
\end{tabular}

Different letters in columns indicate statistically significant differences between treatments $(\mathrm{p} \leq 0.05$, means \pm $\mathrm{SE}$ ). Abbreviations: B, faba bean; $\mathrm{W}$, wheat; $\mathrm{MB} / \mathrm{MW}$, faba bean/wheat grown in monoculture; $\mathrm{XB} / \mathrm{XW}$, faba bean/wheat intercropped; $\mathrm{F}$, inoculated samples. 
Table 4. Plant height $[\mathrm{cm}]$ and thermal images $\left[{ }^{\circ} \mathrm{C}\right]$ from $4^{\text {th }}$ to $7^{\text {th }}$ week of the experiment.

\begin{tabular}{c|cccc|}
\hline \multicolumn{7}{|c}{ 4 weeks } & 5 weeks (H1) & 6 weeks & 7 weeks ( H2) \\
\hline XB & $23.1 \pm 0.9$ & $29.4 \pm 0.9$ & $37.7 \pm 0.9$ & $44.4 \pm 1.2$ \\
MB & $22.8 \pm 0.6$ & $31.3 \pm 0.8$ & $38.3 \pm 0.8$ & $46.1 \pm 0.9$ \\
\hline XW & $33.9 \pm 1.3$ & $\mathbf{3 7 . 1} \pm \mathbf{1 . 2 a}$ & $\mathbf{3 7 . 9} \pm \mathbf{1 . 1 a}$ & $\mathbf{3 8 . 5} \pm \mathbf{0 . 8 a}$ \\
MW & $33.5 \pm 0.4$ & $\mathbf{3 4 . 9} \pm \mathbf{0 . 6 b}$ & $\mathbf{3 5 . 0} \pm \mathbf{0 . 6 b}$ & $\mathbf{3 7 . 0} \pm \mathbf{1 . 3 b}$ \\
\hline B & $\mathbf{2 1 . 8} \pm \mathbf{0 . 7 b}$ & $29.6 \pm 1.0$ & $37.6 \pm 1.0$ & $43.7 \pm 1.1$ \\
B_F & $\mathbf{2 4 . 1} \pm \mathbf{0 . 6 a}$ & $31.1 \pm 0.7$ & $38.4 \pm 0.7$ & $46.8 \pm 0.9$ \\
\hline W_F & $34.6 \pm 0.5$ & $36.3 \pm 0.9$ & $36.8 \pm 0.8$ & $37.4 \pm 0.6$ \\
\hline X & $32.9 \pm 1.2$ & $35.6 \pm 1.1$ & $36.1 \pm 1.1$ & $38.0 \pm 1.4$ \\
\hline M & & Thermal Images & & $19.37 \pm 0.32$ \\
\hline Inoculated & $17.04 \pm 0.32$ & $17.15 \pm 0.33$ & $\mathbf{1 7 . 4 0} \pm \mathbf{0 . 1 8 a}$ & $19.82 \pm 0.31$ \\
\hline
\end{tabular}

Different letters in columns indicate statistically significant differences between treatments $(\mathrm{p} \leq 0.05$, means \pm SE). Abbreviations: B, faba bean; W, wheat; MB/MW, faba bean/wheat grown in monoculture; XB/XW, faba bean/wheat intercropped; F, inoculated samples; M, includes MB and MW; X, intercropping. 
Table 5. Water content, total organic carbon and nitrogen in roots and leaves for harvest 2 (mean \pm SE).

\begin{tabular}{|c|c|c|c|c|}
\hline & $\mathbf{C}_{\text {total }}(\%)$ & $\mathbf{N}_{\text {total }}(\%)$ & $\mathrm{C}: \mathrm{N}$ ratio & Water content $[\%]$ \\
\hline \multicolumn{5}{|c|}{ Roots } \\
\hline B & $11.06 \pm 1.01$ & $0.91 \pm 0.08$ & $12.14 \pm 0.26 a$ & $64.67 \pm 3.37$ \\
\hline B_F & $14.24 \pm 2.44$ & $0.87 \pm 0.08$ & $16.31 \pm 2.67 \mathrm{~b}$ & $54.42 \pm 10.21$ \\
\hline $\mathbf{W}$ & $4.12 \pm 0.68$ & $0.28 \pm 0.03$ & $14.37 \pm 0.88$ & $32.33 \pm 4.91$ \\
\hline $\mathbf{W}_{-} \mathbf{F}$ & $3.23 \pm 0.23$ & $0.24 \pm 0.01$ & $13.36 \pm 0.70$ & $54.27 \pm 7.78$ \\
\hline $\mathbf{X B}$ & $9.98 \pm 0.85 a$ & $0.79 \pm 0.07$ & $12.70 \pm 0.24$ & $60.29 \pm 5.34$ \\
\hline MB & $15.32 \pm 2.28 b$ & $1.00 \pm 0.08$ & $15.74 \pm 2.76$ & $58.79 \pm 9.63$ \\
\hline $\mathbf{X W}$ & $3.24 \pm 0.16$ & $0.25 \pm 0.00$ & $12.90 \pm 0.46$ & $46.64 \pm 7.86$ \\
\hline MW & $4.21 \pm 0.77$ & $0.27 \pm 0.03$ & $14.94 \pm 0.96$ & $37.52 \pm 6.32$ \\
\hline $\mathbf{X B}$ & $10.55 \pm 1.07 \mathrm{ab}$ & $0.85 \pm 0.09$ & $12.38 \pm 0.42$ & $60.79 \pm 6.00$ \\
\hline $\mathbf{X B F}$ & $9.40 \pm 1.40 \mathrm{a}$ & $0.72 \pm 0.10$ & $13.01 \pm 0.19$ & $59.79 \pm 9.61$ \\
\hline MB & $11.56 \pm 1.82 \mathrm{ab}$ & $0.96 \pm 0.13$ & $11.88 \pm 0.33$ & $68.55 \pm 2.76$ \\
\hline MBF & $19.07 \pm 3.63 b$ & $1.02 \pm 0.09$ & $19.60 \pm 5.16$ & $49.04 \pm 19.03$ \\
\hline $\mathbf{X W}$ & $3.23 \pm 0.16$ & $0.25 \pm 0.00$ & $12.84 \pm 0.52$ & $34.46 \pm 10.02$ \\
\hline XWF & $3.24 \pm 0.34$ & $0.25 \pm 0.01$ & $12.97 \pm 0.92$ & $61.87 \pm 8.04$ \\
\hline MW & $5.01 \pm 1.30$ & $0.30 \pm 0.06$ & $15.89 \pm 1.43$ & $30.20 \pm 2.40$ \\
\hline MWF & $3.20 \pm 0.37$ & $0.23 \pm 0.01$ & $13.74 \pm 1.15$ & $46.68 \pm 13.41$ \\
\hline \multicolumn{5}{|c|}{ Leaves } \\
\hline B & $45.22 \pm 1.23$ & $3.53 \pm 0.11$ & $12.85 \pm 0.20$ & $88.61 \pm 0.20$ \\
\hline B_F & $44.12 \pm 0.16$ & $3.39 \pm 0.11$ & $13.15 \pm 0.49$ & $88.95 \pm 0.36$ \\
\hline $\mathbf{W}$ & $42.42 \pm 0.09$ & $1.94 \pm 0.12$ & $22.66 \pm 1.52$ & $82.12 \pm 0.68$ \\
\hline $\mathbf{W}_{-} \mathbf{F}$ & $42.73 \pm 0.17$ & $2.20 \pm 0.21$ & $20.96 \pm 2.04$ & $82.21 \pm 1.40$ \\
\hline $\mathbf{X B}$ & $44.17 \pm 0.23$ & $3.44 \pm 0.04$ & $12.83 \pm 0.13$ & $88.89 \pm 0.23$ \\
\hline MB & $45.17 \pm 1.22$ & $3.48 \pm 0.15$ & $13.16 \pm 0.51$ & $88.67 \pm 0.34$ \\
\hline $\mathbf{X W}$ & $42.43 \pm 0.08$ & $2.40 \pm 0.15 a$ & $18.29 \pm 1.16 \mathrm{a}$ & $84.18 \pm 0.55 a$ \\
\hline MW & $42.69 \pm 0.16$ & $1.77 \pm 0.12 b$ & $25.06 \pm 1.52 b$ & $80.14 \pm 0.89 b$ \\
\hline $\mathbf{X B}$ & $44.01 \pm 0.38$ & $3.40 \pm 0.05$ & $12.96 \pm 0.12$ & $88.65 \pm 0.29$ \\
\hline $\mathbf{X B F}$ & $44.32 \pm 0.29$ & $3.49 \pm 0.06$ & $12.71 \pm 0.23$ & $89.13 \pm 0.37$ \\
\hline MB & $46.44 \pm 2.43$ & $3.66 \pm 0.22$ & $12.74 \pm 0.39$ & $88.57 \pm 0.31$ \\
\hline MBF & $43.91 \pm 0.11$ & $3.29 \pm 0.21$ & $13.58 \pm 0.96$ & $88.77 \pm 0.65$ \\
\hline $\mathbf{X W}$ & $42.40 \pm 0.10$ & $2.21 \pm 0.11 \mathrm{ab}$ & $19.37 \pm 1.00 \mathrm{ab}$ & $83.73 \pm 0.53 a b$ \\
\hline XWF & $42.47 \pm 0.15$ & $2.63 \pm 0.30 \mathrm{a}$ & $16.94 \pm 2.31 \mathrm{a}$ & $84.74 \pm 1.06 a$ \\
\hline MW & $42.44 \pm 0.15$ & $1.67 \pm 0.12 b$ & $25.95 \pm 2.01 b$ & $80.52 \pm 0.73 a b$ \\
\hline MWF & $42.93 \pm 0.25$ & $1.87 \pm 0.21 \mathrm{ab}$ & $24.17 \pm 2.46 a b$ & $79.67 \pm 1.94 b$ \\
\hline
\end{tabular}

Different letters in columns indicate statistically significant differences between treatments $(p \leq 0.05$, means \pm

$\mathrm{SE}$ ). Abbreviations: MB/MW, faba bean/wheat grown in monoculture; XB/XW, faba bean/wheat intercropped;

$\mathrm{F}$, inoculated samples. Note: water content refers here to the absolute water content. 
Table 6. Spatial and temporal distribution of Metarhizium species in soil and plants.

inoculated

non-inoculated

\begin{tabular}{|c|c|c|c|c|c|c|c|c|}
\hline & Lv & Ro & $\mathbf{R z}$ & Soil & Lv & Ro & $\mathbf{R z}$ & Soil \\
\hline \multicolumn{9}{|c|}{ Harvest 1} \\
\hline M. anisopliae_SH200393.07FU & 0.285 & 0.522 & 0.0048 & 0 & 0 & 0 & 0.0004 & 0 \\
\hline M. carneum & 0 & 0 & 0.0016 & 0.003 & 0 & 0 & 0.0024 & 0.0026 \\
\hline M. flavoviride_SH214395.07FU & 0 & 0 & 0 & 0 & 0 & 0 & 0.0001 & 0.042 \\
\hline M. marquandii_SH217934.07FU & 0 & 0 & 0.0028 & 0.0026 & 0 & 0 & 0.0014 & 0.003 \\
\hline Total & 0.285 & 0.522 & 0.009 & 0.0055 & $\mathbf{0}$ & $\mathbf{0}$ & 0.0044 & 0.0477 \\
\hline \multicolumn{9}{|c|}{ Harvest 2} \\
\hline M. anisopliae_SH200393.07FU & 0 & 0.1316 & 0.0394 & NA & 0 & 0.0002 & 0 & NA \\
\hline M. carneum & 0 & 0.0047 & 0.0017 & NA & 0 & 0 & 0.0123 & NA \\
\hline M.flavoviride_SH214395.07FU & 0 & 0 & 0.0006 & NA & 0 & 0 & 0.0006 & NA \\
\hline M. marquandii_SH217934.07FU & 0 & 0.0216 & 0.0003 & NA & 0 & 0 & 0.0026 & NA \\
\hline Total & $\mathbf{0}$ & 0.1579 & 0.042 & & 0 & 0.0002 & 0.0155 & \\
\hline
\end{tabular}

Numbers refer to the relative abundance in the dataset. Abbreviations: Lv, leaves; Ro, roots; Rz, rhizosphere soil; Soil, unplanted soil.

Table 7. Effect of cropping system, inoculation and crop species on bacterial and fungal community compositions.

Bacteria Fungi

\begin{tabular}{|c|c|c|c|c|c|c|c|c|}
\hline & \multicolumn{2}{|c|}{ H1 } & \multicolumn{2}{|c|}{ H2 } & \multicolumn{2}{|c|}{ H1 } & \multicolumn{2}{|c|}{ H2 } \\
\hline & $R^{2}(\%)$ & $p$ & $R^{2}(\%)$ & $p$ & $\mathbf{R}^{2}(\%)$ & $p$ & $\mathbf{R}^{2}(\%)$ & $p$ \\
\hline \multicolumn{9}{|c|}{ Rhizosphere soil } \\
\hline \multirow{3}{*}{$\begin{array}{c}\text { Inoculation } \\
\text { Cropping System } \\
\text { Crop species } \\
\end{array}$} & 11.7 & 0.004 & 4.1 & 0.028 & 4.6 & 0.028 & 7.4 & 0.001 \\
\hline & 2.4 & 0.324 & 3.6 & 0.095 & 2.5 & 0.475 & 4.5 & 0.021 \\
\hline & 3.4 & 0.221 & 8.9 & 0.001 & 3.8 & 0.064 & 8.8 & 0.001 \\
\hline \multicolumn{9}{|c|}{ Roots } \\
\hline \multirow{3}{*}{$\begin{array}{c}\text { Inoculation } \\
\text { Cropping System } \\
\text { Crop species } \\
\end{array}$} & 1.6 & 0.833 & 1.4 & 0.668 & 2.8 & 0.366 & 3.2 & 0.273 \\
\hline & 3.6 & 0.001 & 0.9 & 0.899 & 2.2 & 0.633 & 5.4 & 0.076 \\
\hline & 1.6 & 0.649 & 6.1 & 0.001 & 16.9 & 0.001 & 24.7 & 0.001 \\
\hline \multicolumn{9}{|c|}{ Leaves } \\
\hline \multirow{3}{*}{$\begin{array}{c}\text { Inoculation } \\
\text { Cropping System } \\
\text { Crop species }\end{array}$} & 12.7 & 0.006 & 9.8 & 0.038 & 2.4 & 0.713 & 5.2 & 0.096 \\
\hline & 2.5 & 0.56 & 9.4 & 0.032 & 2.8 & 0.532 & 3.3 & 0.367 \\
\hline & 12.9 & 0.004 & 7.9 & 0.06 & 9.1 & 0.001 & 20.1 & 0.001 \\
\hline
\end{tabular}

Results of the permutational multivariate analysis of variance (PERMANOVA) with Bray-Curtis distances testing for the different treatments. Cropping systems compares monoculture versus intercropping. Inoculation compares inoculated versus non-inoculated samples. Statistically significant differences $(\mathrm{p} \leq 0.05)$ between the treatments for each plant compartment are written in bold. 
Table 8. Bacterial richness and diversity with regard to plant compartment, harvest and cropping regime.

Bacteria

\begin{tabular}{|c|c|c|c|c|}
\hline \multirow[b]{2}{*}{ Treatment } & \multicolumn{2}{|c|}{ Richness } & \multicolumn{2}{|c|}{ Diversity } \\
\hline & H1 & H2 & H1 & $\mathrm{H} 2$ \\
\hline \multicolumn{5}{|c|}{ Unplanted soil } \\
\hline C & $2688.74 \pm 386.25 a b$ & NA & $6.82 \pm 0.35$ & NA \\
\hline CF & $2974.66 \pm 106.16 a$ & NA & $7.00 \pm 0.15$ & NA \\
\hline CS & $2658.17 \pm 110.06 b$ & NA & $6.85 \pm 0.05$ & NA \\
\hline
\end{tabular}

Rhizosphere soil

\begin{tabular}{|c|c|c|c|c|c|}
\hline \multirow{4}{*}{ 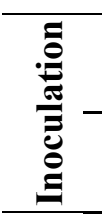 } & \multirow{2}{*}{$\begin{array}{c}\text { Faba bean control } \\
\text { Faba bean inoculated }\end{array}$} & $1245.54 \pm 76.63 a$ & $1225.68 \pm 110.67$ & $6.30 \pm 0.19$ & $6.22 \pm 0.34$ \\
\hline & & $790.00 \pm 590.35 b$ & $1220.20 \pm 171.63$ & $4.65 \pm 2.34$ & $6.27 \pm 0.17$ \\
\hline & \multirow{2}{*}{$\begin{array}{c}\text { Wheat control } \\
\text { Wheat inoculated }\end{array}$} & $1282.82 \pm 114.47$ & $1209.49 \pm 152.08 a$ & $6.38 \pm 0.21$ & $6.30 \pm 0.22 a$ \\
\hline & & $1046.07 \pm 574.83 \mathrm{~A}$ & $1449.94 \pm 100.94 \mathrm{Bb}$ & $5.42 \pm 2.05$ & $6.64 \pm 0.14 b$ \\
\hline \multirow{4}{*}{ ع } & $\overline{X B}$ & $933.89 \pm 490.80 a$ & $1209.72 \pm 156.12$ & $5.20 \pm 1.95 a$ & $6.25 \pm 0.18$ \\
\hline & MB & $1136.28 \pm 427.48 b$ & $1243.00 \pm 102.62$ & $5.87 \pm 1.60 \mathrm{~b}$ & $6.23 \pm 0.39$ \\
\hline & $\mathbf{X W}$ & $1375.46 \pm 137.84 a$ & $1313.05 \pm 178.68$ & $6.51 \pm 0.24 a$ & $6.46 \pm 0.24$ \\
\hline & MW & $953.43 \pm 506.66 \mathrm{~b}$ & $1320.49 \pm 188.54$ & $5.29 \pm 1.97 \mathrm{~b}$ & $6.44 \pm 0.27$ \\
\hline \multirow{8}{*}{ 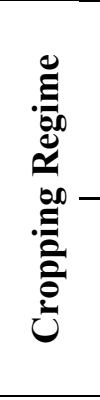 } & XB & $1213.38 \pm 80.60 \mathrm{ab}$ & $1229.08 \pm 119.21$ & $6.20 \pm 0.21 \mathrm{ab}$ & $6.25 \pm 0.20$ \\
\hline & XBF & $654.40 \pm 538.27 \mathrm{a}$ & $1190.36 \pm 199.28$ & $4.20 \pm 2.46 a$ & $6.25 \pm 0.18$ \\
\hline & MB & $1277.70 \pm 64.27 \mathrm{~b}$ & $1222.28 \pm 115.50$ & $6.40 \pm 0.13 b$ & $6.20 \pm 0.47$ \\
\hline & MBF & $959.50 \pm 637.81 \mathrm{ab}$ & $1294.80 \pm 48.08$ & $5.20 \pm 2.40 \mathrm{ab}$ & $6.31 \pm 0.17$ \\
\hline & $\mathbf{X W}$ & $1298.36 \pm 152.90 \mathrm{ab}$ & $1194.12 \pm 149.56$ & $6.36 \pm 0.27 \mathrm{ab}$ & $6.31 \pm 0.23$ \\
\hline & XWF & $1452.56 \pm 67.16 \mathrm{a}$ & $1431.98 \pm 118.78$ & $6.66 \pm 0.09 a$ & $6.61 \pm 0.16$ \\
\hline & MW & $1267.28 \pm 74.16 \mathrm{ab}$ & $1224.86 \pm 170.53$ & $6.39 \pm 0.15 a b$ & $6.30 \pm 0.24$ \\
\hline & MWF & $639.58 \pm 570.82 b$ & $1479.87 \pm 72.76$ & $4.19 \pm 2.38 \mathrm{~b}$ & $6.68 \pm 0.10$ \\
\hline \multirow{5}{*}{ 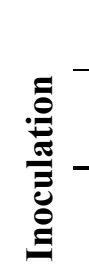 } & \multicolumn{5}{|c|}{ Roots } \\
\hline & \multirow{2}{*}{$\begin{array}{c}\text { Faba bean control } \\
\text { Faba bean inoculated }\end{array}$} & $39.69 \pm 108.20$ & $9.18 \pm 4.44$ & $1.03 \pm 1.62$ & $0.55 \pm 0.12 a$ \\
\hline & & $16.76 \pm 14.99$ & $13.13 \pm 9.59$ & $0.76 \pm 0.28$ & $0.70 \pm 0.18 b$ \\
\hline & \multirow{2}{*}{$\begin{array}{c}\text { Wheat control } \\
\text { Wheat inoculated }\end{array}$} & $87.49 \pm 43.34 \mathrm{~A}$ & $170.35 \pm 67.61 B$ & $2.86 \pm 0.99 \mathrm{~A}$ & $4.29 \pm 0.76 \mathrm{~B}$ \\
\hline & & $80.86 \pm 58.82 \mathrm{~A}$ & $173.49 \pm 56.66 \mathrm{~B}$ & $2.42 \pm 1.71 \mathrm{~A}$ & $4.13 \pm 0.88 B$ \\
\hline \multirow{4}{*}{ 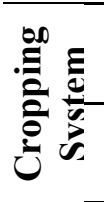 } & $\overline{X B}$ & $9.77 \pm 12.15$ & $8.23 \pm 4.93$ & $0.59 \pm 0.22$ & $0.59 \pm 0.11$ \\
\hline & MB & $46.68 \pm 106.40$ & $14.08 \pm 8.78$ & $1.20 \pm 1.58$ & $0.67 \pm 0.21$ \\
\hline & $\mathbf{X W}$ & $98.21 \pm 47.95$ & $162.00 \pm 72.34$ & $3.17 \pm 1.13$ & $4.05 \pm 0.95$ \\
\hline & MW & $70.14 \pm 51.24$ & $181.84 \pm 48.33$ & $2.11 \pm 1.46$ & $4.37 \pm 0.63$ \\
\hline \multirow{8}{*}{ 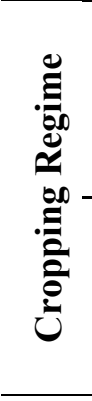 } & $\overline{X B}$ & $6.22 \pm 2.20$ & $11.62 \pm 5.07 a b$ & $0.54 \pm 0.11$ & $0.61 \pm 0.14 a b$ \\
\hline & $\mathrm{XBF}$ & $13.32 \pm 17.20$ & $4.84 \pm 0.55 \mathrm{a}$ & $0.64 \pm 0.29$ & $0.58 \pm 0.08 a b$ \\
\hline & MB & $73.16 \pm 153.42$ & $6.74 \pm 1.95 a$ & $1.53 \pm 2.30$ & $0.50 \pm 0.08 a$ \\
\hline & MBF & $20.20 \pm 13.43$ & $21.42 \pm 5.91 \mathrm{~b}$ & $0.87 \pm 0.24$ & $0.83 \pm 0.16 b$ \\
\hline & XW & $90.28 \pm 37.01$ & $184.02 \pm 87.05$ & $2.99 \pm 0.67$ & $4.45 \pm 0.77$ \\
\hline & XWF & $106.14 \pm 60.38$ & $139.98 \pm 54.64$ & $3.35 \pm 1.54$ & $3.65 \pm 1.01$ \\
\hline & MW & $84.70 \pm 53.26$ & $156.68 \pm 47.34$ & $2.74 \pm 1.31$ & $4.13 \pm 0.79$ \\
\hline & MWF & $55.58 \pm 50.41$ & $207.00 \pm 37.83$ & $1.49 \pm 1.44$ & $4.62 \pm 0.35$ \\
\hline \multirow{4}{*}{ 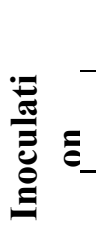 } & \multicolumn{5}{|c|}{ Leaves } \\
\hline & Faba bean control & $5.36 \pm 0.89$ & $4.10 \pm \mathrm{NA}$ & $1.44 \pm 0.15$ & $1.04 \pm \mathrm{NA}$ \\
\hline & Faba bean inoculated & $6.82 \pm 3.17$ & $9.26 \pm 2.08$ & $1.38 \pm 0.47$ & $1.87 \pm 0.32$ \\
\hline & Wheat control & $4.59 \pm 3.35 \mathrm{~A}$ & $7.97 \pm 1.87 \mathrm{Ba}$ & $0.88 \pm 0.72$ & $1.51 \pm 0.37 \mathrm{a}$ \\
\hline
\end{tabular}




\begin{tabular}{|c|c|c|c|c|c|}
\hline & Wheat inoculated & $6.70 \pm 5.36$ & $4.87 \pm 3.10 \mathrm{~b}$ & $1.18 \pm 0.98$ & $0.88 \pm 0.72 b$ \\
\hline \multirow{4}{*}{ ع } & $\mathbf{X B}$ & $6.35 \pm 2.88$ & $8.90 \pm 1.56$ & $1.50 \pm 0.40$ & $1.82 \pm 0.26$ \\
\hline & MB & $5.58 \pm 1.25$ & $8.52 \pm 3.06$ & $1.33 \pm 0.17$ & $1.75 \pm 0.48$ \\
\hline & $\mathbf{X W}$ & $6.11 \pm 4.34$ & $7.26 \pm 2.22$ & $1.18 \pm 0.84$ & $1.40 \pm 0.45$ \\
\hline & MW & $5.06 \pm 4.86$ & $5.58 \pm 3.46$ & $0.83 \pm 0.88$ & $0.99 \pm 0.76$ \\
\hline \multirow{8}{*}{ 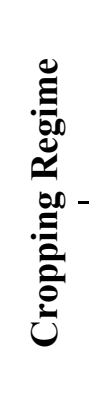 } & $\mathbf{X B}$ & $5.70 \pm 0.82$ & $4.10 \pm \mathrm{NA}$ & $1.50 \pm 0.13$ & $1.04 \pm \mathrm{NA}$ \\
\hline & XBF & $7.65 \pm 5.87$ & $8.90 \pm 1.56$ & $1.52 \pm 0.87$ & $1.82 \pm 0.26$ \\
\hline & MB & $4.90 \pm 0.92$ & NA & $1.37 \pm 0.16$ & NA \\
\hline & MBF & $6.27 \pm 1.30$ & $9.40 \pm 2.41$ & $1.29 \pm 0.19$ & $1.89 \pm 0.37$ \\
\hline & $\mathbf{X W}$ & $5.40 \pm 4.37$ & $8.00 \pm 2.59$ & $1.11 \pm 0.90$ & $1.53 \pm 0.52$ \\
\hline & XWF & $6.82 \pm 4.70$ & $6.52 \pm 1.73$ & $1.25 \pm 0.87$ & $1.26 \pm 0.36$ \\
\hline & MW & $3.58 \pm 1.40$ & $7.94 \pm 1.08$ & $0.58 \pm 0.33$ & $1.48 \pm 0.18$ \\
\hline & MWF & $6.55 \pm 6.87$ & $3.22 \pm 3.44$ & $1.08 \pm 1.24$ & $0.50 \pm 0.82$ \\
\hline
\end{tabular}

Diversity is expressed as Shannon values and richness is based on the number of unique OTUs. Small and large letters in columns and rows indicate statistically significant differences between the treatments in each compartment ( $\mathrm{p} \leq 0.05$, means $\pm \mathrm{SD})$. Abbreviations: $\mathrm{MB} / \mathrm{MW}$, faba bean/wheat grown in monoculture; $\mathrm{XB} / \mathrm{XW}$, faba bean/ wheat intercropping, C, control unplanted soil; F, inoculated samples, CS, control starting soil.

Table 9. Fungal richness and diversity with regard to plant compartment, harvest and cropping regime.

Fungi

\begin{tabular}{c|ccc|cc}
\hline \multirow{2}{*}{ Treatment } & \multicolumn{2}{c}{ Richness } & \multicolumn{2}{c}{ Diversity } \\
\cline { 2 - 5 } & \multicolumn{2}{|c}{ H1 } & H2 & H1 \\
C & $380.00 \pm 71.74$ & NA & $4.14 \pm 0.51$ & NA \\
CF & $399.02 \pm 47.94$ & NA & $4.37 \pm 0.14$ & NA \\
CS & $410.77 \pm 26.57$ & NA & $4.15 \pm 0.11$ & NA \\
\hline
\end{tabular}

Rhizosphere soil

\begin{tabular}{|c|c|c|c|c|c|}
\hline \multirow{4}{*}{ 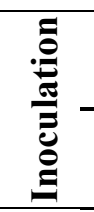 } & \multirow{2}{*}{$\begin{array}{c}\text { Faba bean control } \\
\text { Faba bean inoculated }\end{array}$} & $131.02 \pm 21.72$ & $113.63 \pm 22.03$ & $3.81 \pm 0.36$ & $3.58 \pm 0.54$ \\
\hline & & $139.29 \pm 17.50 \mathrm{~A}$ & $95.39 \pm 34.79 B$ & $3.90 \pm 0.31 \mathrm{~A}$ & $3.36 \pm 0.70 \mathrm{~B}$ \\
\hline & \multirow{2}{*}{$\begin{array}{c}\text { Wheat control } \\
\text { Wheat inoculated }\end{array}$} & $127.11 \pm 10.17 \mathrm{~A}$ & $143.02 \pm 12.11 B a$ & $3.76 \pm 0.24 A$ & $4.01 \pm 0.15 B a$ \\
\hline & & $129.62 \pm 16.02$ & $111.42 \pm 35.58 b$ & $3.89 \pm 0.26$ & $3.30 \pm 1.13 b$ \\
\hline \multirow{4}{*}{ 递 } & $\mathbf{X B}$ & $135.71 \pm 21.83$ & $117.40 \pm 18.24$ & $3.84 \pm 0.38$ & $3.73 \pm 0.37$ \\
\hline & MB & $134.60 \pm 18.41$ & $91.62 \pm 34.33$ & $3.88 \pm 0.28$ & $3.21 \pm 0.73$ \\
\hline & $\mathbf{X W}$ & $131.46 \pm 11.72$ & $135.12 \pm 18.26$ & $3.90 \pm 0.19$ & $3.93 \pm 0.33 a$ \\
\hline & MW & $125.27 \pm 14.31$ & $119.32 \pm 38.58$ & $3.76 \pm 0.30$ & $3.39 \pm 1.15 b$ \\
\hline \multirow{8}{*}{ 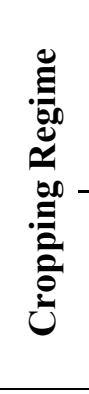 } & $\mathbf{X B}$ & $134.48 \pm 29.40$ & $121.60 \pm 19.28$ & $3.85 \pm 0.46$ & $3.83 \pm 0.33$ \\
\hline & XBF & $136.94 \pm 14.28$ & $113.20 \pm 18.24$ & $3.83 \pm 0.35$ & $3.62 \pm 0.41$ \\
\hline & MB & $127.56 \pm 12.93$ & $105.66 \pm 23.69$ & $3.77 \pm 0.28$ & $3.33 \pm 0.63$ \\
\hline & MBF & $141.64 \pm 21.71$ & $77.58 \pm 39.97$ & $3.98 \pm 0.28$ & $3.10 \pm 0.87$ \\
\hline & $\mathbf{X W}$ & $129.18 \pm 11.49$ & $143.30 \pm 11.20 \mathrm{a}$ & $3.82 \pm 0.22$ & $4.06 \pm 0.16 a$ \\
\hline & XWF & $133.74 \pm 12.81$ & $126.94 \pm 21.39 \mathrm{ab}$ & $3.97 \pm 0.14$ & $3.80 \pm 0.42 a b$ \\
\hline & MW & $125.04 \pm 9.49$ & $142.74 \pm 14.30 \mathrm{a}$ & $3.70 \pm 0.28$ & $3.97 \pm 0.14 a b$ \\
\hline & MWF & $125.50 \pm 19.25$ & $95.90 \pm 42.11 b$ & $3.81 \pm 0.34$ & $2.80 \pm 1.44 b$ \\
\hline & \multicolumn{5}{|c|}{ Roots } \\
\hline \multirow{3}{*}{ 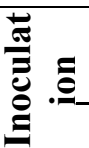 } & \multirow{2}{*}{$\begin{array}{c}\text { Faba bean control } \\
\text { Faba bean inoculated }\end{array}$} & $14.40 \pm 2.69$ & $16.64 \pm 5.56$ & $1.90 \pm 0.24$ & $1.97 \pm 0.46$ \\
\hline & & $18.16 \pm 7.16$ & $22.39 \pm 6.81$ & $2.20 \pm 0.59$ & $2.51 \pm 0.50$ \\
\hline & Wheat control & $13.12 \pm 5.65$ & $14.01 \pm 6.40$ & $1.67 \pm 0.63$ & $1.65 \pm 0.83$ \\
\hline
\end{tabular}




\begin{tabular}{|c|c|c|c|c|c|}
\hline & Wheat inoculated & $12.01 \pm 3.40$ & $18.18 \pm 7.71$ & $1.70 \pm 0.54$ & $2.14 \pm 0.78$ \\
\hline \multirow{4}{*}{ 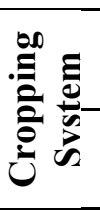 } & \multirow{2}{*}{$\begin{array}{l}\mathrm{XB} \\
\mathrm{MB}\end{array}$} & $16.22 \pm 5.84$ & $21.95 \pm 6.47$ & $1.98 \pm 0.49$ & $2.38 \pm 0.50$ \\
\hline & & $17.14 \pm 6.48$ & $16.27 \pm 5.92$ & $2.23 \pm 0.47$ & $2.05 \pm 0.57$ \\
\hline & \multirow{2}{*}{$\begin{array}{l}\text { XW } \\
\text { MW }\end{array}$} & $14.66 \pm 5.32 \mathrm{a}$ & $19.80 \pm 7.07 a$ & $1.95 \pm 0.58 \mathrm{a}$ & $2.26 \pm 0.79 a$ \\
\hline & & $10.30 \pm 2.27 \mathrm{~b}$ & $12.39 \pm 5.45 \mathrm{~b}$ & $1.39 \pm 0.42 b$ & $1.52 \pm 0.70 b$ \\
\hline \multirow{8}{*}{ 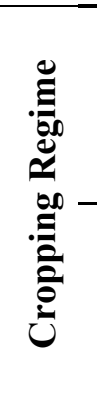 } & & $14.60 \pm 2.25$ & $19.80 \pm 5.51$ & $1.87 \pm 0.27$ & $2.15 \pm 0.31$ \\
\hline & XBF & $17.52 \pm 7.73$ & $23.24 \pm 7.25$ & $2.07 \pm 0.64$ & $2.52 \pm 0.57$ \\
\hline & \multirow{2}{*}{$\begin{array}{c}\text { MB } \\
\text { MBF }\end{array}$} & $14.00 \pm 4.53$ & $14.28 \pm 4.91$ & $1.97 \pm 0.24$ & $1.83 \pm 0.54$ \\
\hline & & $19.23 \pm 7.56$ & $20.25 \pm 7.42$ & $2.40 \pm 0.55$ & $2.47 \pm 0.44$ \\
\hline & XW & $16.72 \pm 6.20$ & $14.38 \pm 5.85 a$ & $2.06 \pm 0.68$ & $1.69 \pm 0.76 a$ \\
\hline & XWF & $12.60 \pm 3.82$ & $25.22 \pm 2.20 \mathrm{~b}$ & $1.84 \pm 0.51$ & $2.84 \pm 0.16 b$ \\
\hline & \multirow{2}{*}{$\begin{array}{l}\text { MW } \\
\text { MWF }\end{array}$} & $9.52 \pm 1.01$ & $13.64 \pm 7.60 \mathrm{a}$ & $1.28 \pm 0.22$ & $1.60 \pm 0.98 \mathrm{a}$ \\
\hline & & $11.28 \pm 3.18$ & $11.14 \pm 2.27 \mathrm{a}$ & $1.53 \pm 0.60$ & $1.44 \pm 0.36 a$ \\
\hline \multirow{5}{*}{ 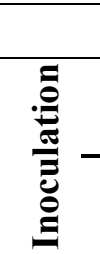 } & \multicolumn{5}{|c|}{ Leaves } \\
\hline & \multirow{2}{*}{$\begin{array}{c}\text { Faba bean control } \\
\text { Faba bean inoculated }\end{array}$} & $8.95 \pm 2.89$ & $7.54 \pm 3.34$ & $1.96 \pm 0.42$ & $1.64 \pm 0.71$ \\
\hline & & $6.44 \pm 1.76$ & $5.66 \pm 2.78$ & $1.57 \pm 0.37$ & $1.24 \pm 0.61$ \\
\hline & \multirow{2}{*}{$\begin{array}{c}\text { Wheat control } \\
\text { Wheat inoculated }\end{array}$} & $4.47 \pm 2.32$ & $5.52 \pm 1.03 a$ & $1.02 \pm 0.68$ & $1.27 \pm 0.26 a$ \\
\hline & & $4.95 \pm 2.72$ & $4.13 \pm 0.73 \mathrm{~b}$ & $1.10 \pm 0.70$ & $0.90 \pm 0.24 b$ \\
\hline \multirow{4}{*}{ 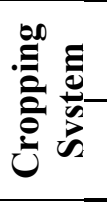 } & \multirow{2}{*}{$\begin{array}{l}\mathrm{XB} \\
\mathrm{MB}\end{array}$} & $6.78 \pm 1.33$ & $6.10 \pm 0.85$ & $1.68 \pm 0.24$ & $1.49 \pm 0.05$ \\
\hline & & $8.06 \pm 3.18$ & $6.51 \pm 3.34$ & $1.78 \pm 0.55$ & $1.39 \pm 0.72$ \\
\hline & \multirow{2}{*}{$\begin{array}{l}\text { XW } \\
\text { MW }\end{array}$} & $4.73 \pm 2.20$ & $4.98 \pm 1.37$ & $1.07 \pm 0.62$ & $1.11 \pm 0.37$ \\
\hline & & $4.69 \pm 2.84$ & $4.76 \pm 0.92$ & $1.05 \pm 0.75$ & $1.08 \pm 0.26$ \\
\hline \multirow{8}{*}{ 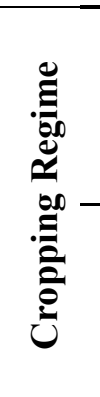 } & \multirow{4}{*}{$\begin{array}{c}\text { XB } \\
\text { XBF } \\
\text { MB } \\
\text { MBF }\end{array}$} & $6.15 \pm 1.06$ & $8.75 \pm 2.47$ & $1.54 \pm 0.22$ & $1.99 \pm 0.34$ \\
\hline & & $7.10 \pm 1.48$ & $6.10 \pm 0.85$ & $1.75 \pm 0.25$ & $1.49 \pm 0.05$ \\
\hline & & $10.35 \pm 2.40$ & $6.73 \pm 4.10$ & $2.17 \pm 0.32$ & $1.41 \pm 0.86$ \\
\hline & & $5.78 \pm 1.96$ & $5.48 \pm 3.36$ & $1.39 \pm 0.42$ & $1.15 \pm 0.71$ \\
\hline & \multirow{4}{*}{$\begin{array}{c}\text { XW } \\
\text { XWF } \\
\text { MW } \\
\text { MWF }\end{array}$} & $4.72 \pm 2.46$ & $5.78 \pm 1.33$ & $1.06 \pm 0.67$ & $1.34 \pm 0.35$ \\
\hline & & $4.74 \pm 2.21$ & $3.98 \pm 0.46$ & $1.08 \pm 0.65$ & $0.82 \pm 0.11$ \\
\hline & & $4.22 \pm 2.44$ & $5.26 \pm 0.65$ & $0.98 \pm 0.77$ & $1.20 \pm 0.16$ \\
\hline & & $5.16 \pm 3.41$ & $4.26 \pm 0.93$ & $1.12 \pm 0.83$ & $0.96 \pm 0.30$ \\
\hline
\end{tabular}

Diversity is expressed as Shannon values and richness is based on the number of unique OTUs. Small and large letters in columns and rows indicate statistically significant differences between the treatments in each compartment ( $\mathrm{p} \leq 0.05$, means $\pm \mathrm{SD})$. Abbreviations: $\mathrm{MB} / \mathrm{MW}$, faba bean/wheat grown in monoculture; $\mathrm{XB} / \mathrm{XW}$, faba bean/ wheat intercropping, C, control unplanted soil; F, inoculated samples; CS, control starting soil. 
Figures
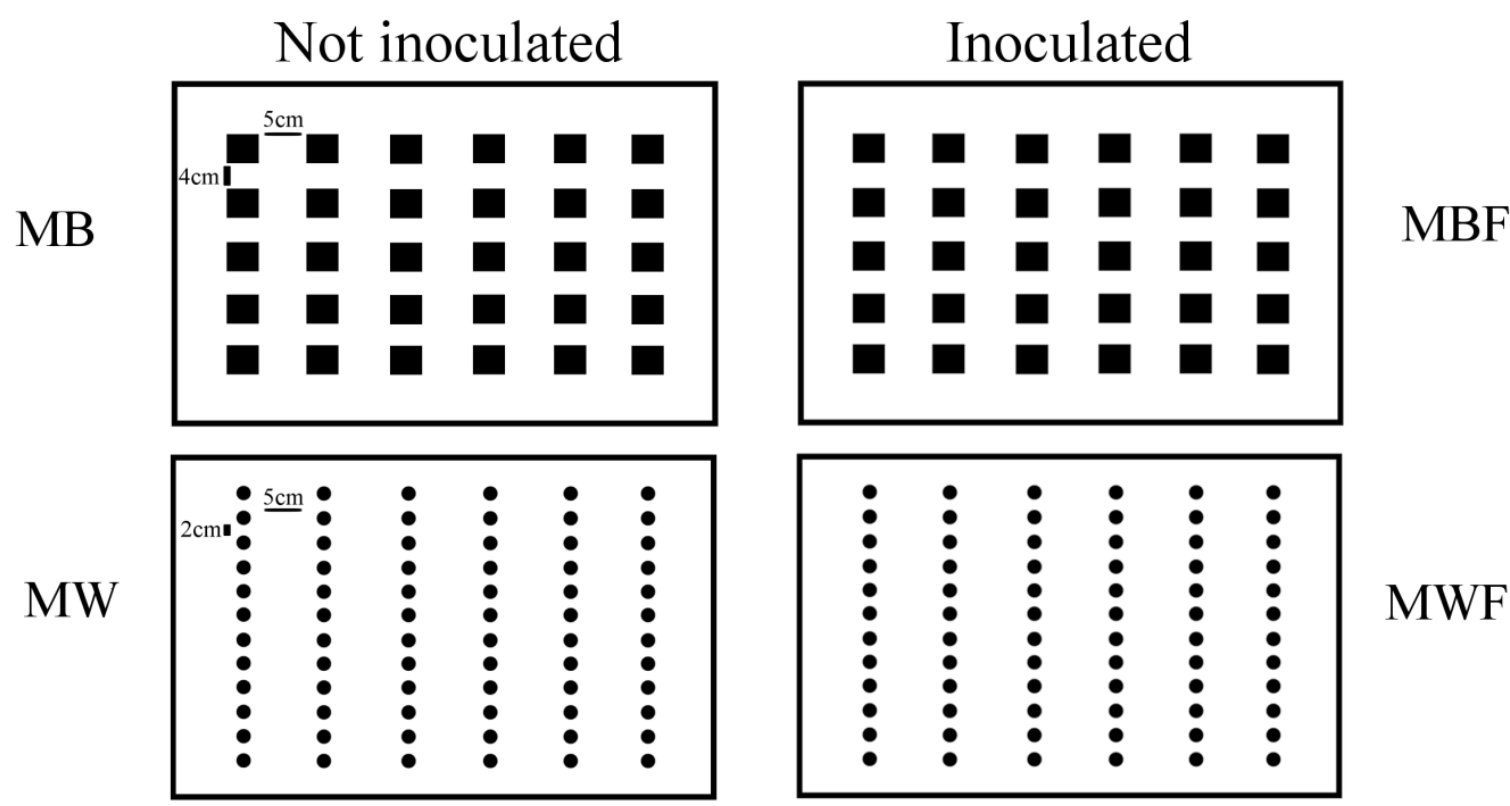

MWF
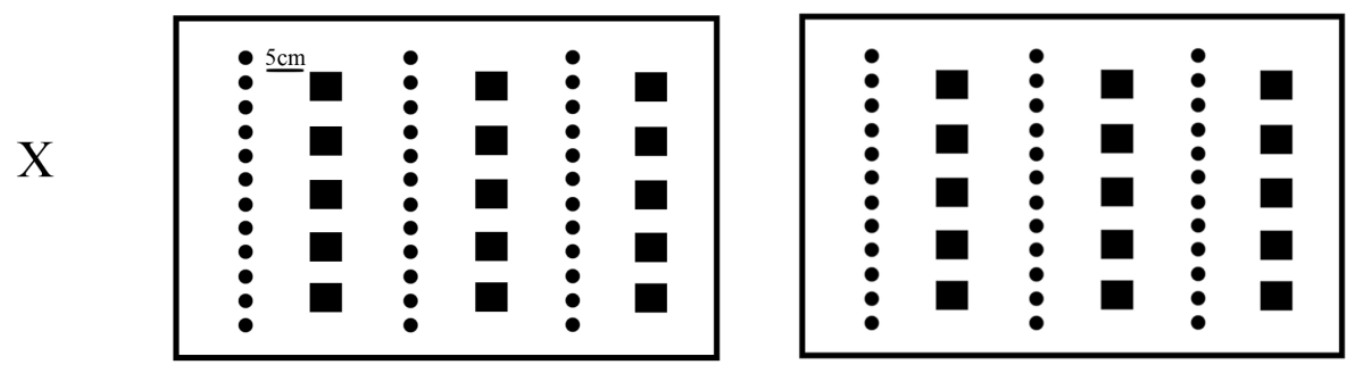

XF
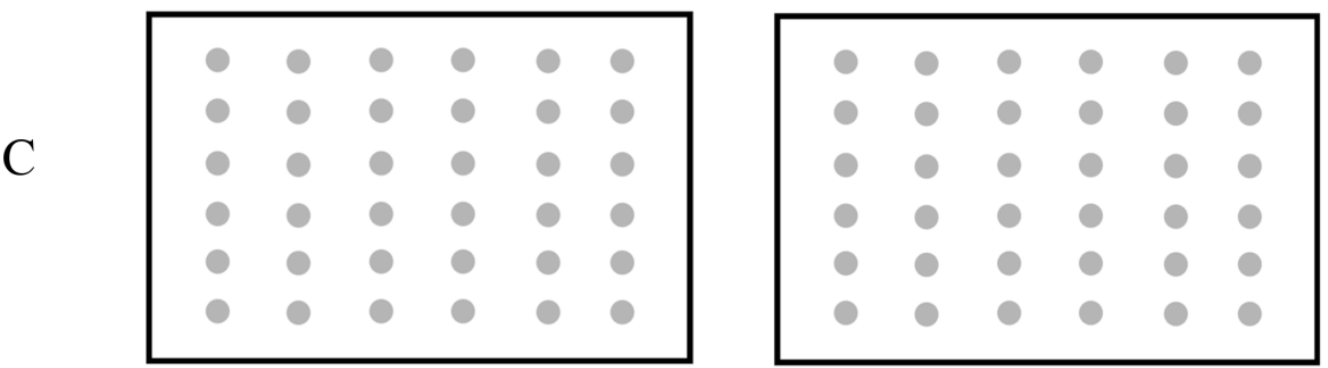

CF

Figure 1. Experimental design of the sudy. $\mathrm{MB} / \mathrm{MW}$, faba bean/ wheat grown in monoculture; $\mathrm{X}$, intercropping; $\mathrm{C}$, unplanted soil which contained glassbeads; F, inoculated samples. 
A

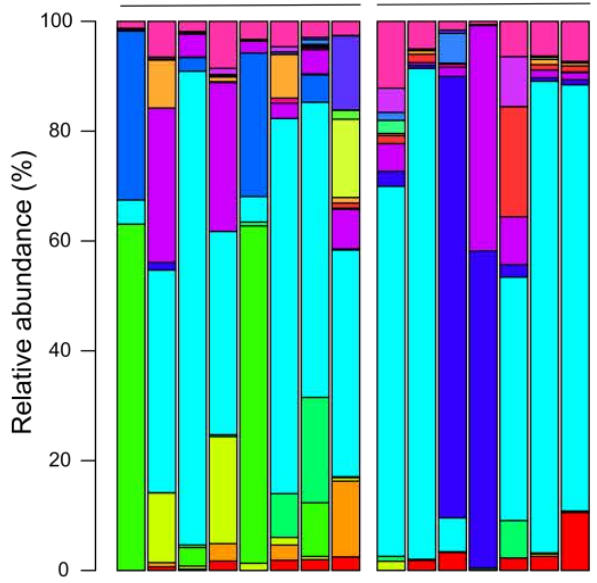

\section{others}

- Actinobacteria; Corynebacteriales; Corynebacteriaceae

- Actinobacteria; Corynebacteriales; Nocardiaceae

Actinobacteria; Micrococcales; Microbacteriaceae

Actinobacteria; Micrococcales; Promicromonosporaceae

- Actinobacteria; Pseudonocardiales; Pseudonocardiaceae

- Firmicutes; Bacillales; Paenibacillaceae

Firmicutes; Bacillales; Thermoactinomycetaceae

- Alphaproteobacteria; Caulobacterales; Caulobacteraceae

- Alphaproteobacteria; Rhizobiales; Beijerinckiaceae

- Alphaproteobacteria; Rhizobiales; Devosiaceae

- Alphaproteobacteria; Rhizobiales; Devosiaceae

- Alphaproteobacteria; Sphingomonadales; Sphingomonadaceae

- Gammaproteobacteria; Alteromonadales; Shewanellaceae

- Gammaproteobacteria; Betaproteobacteriales; Burkholderiaceae

- Gammaproteobacteria; Enterobacteriales; Enterobacteriaceae

- Gammaproteobacteria; Oceanospirillales; Halomonadaceae

Gammaproteobacteria; Pseudomonadales; Pseudomonadaceae

- Gammaproteobacteria; Xanthomonadales; Rhodanobacteraceae

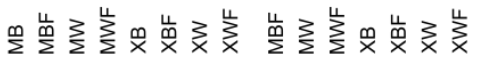

B

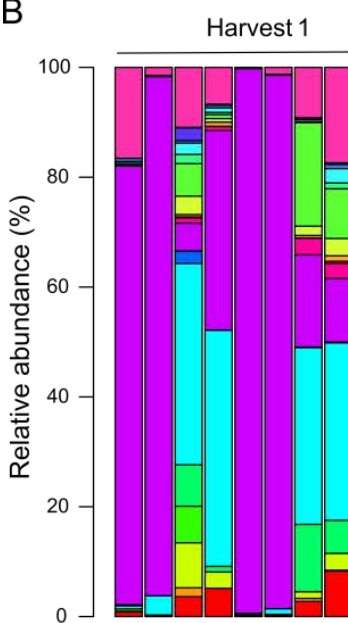

Harvest 2

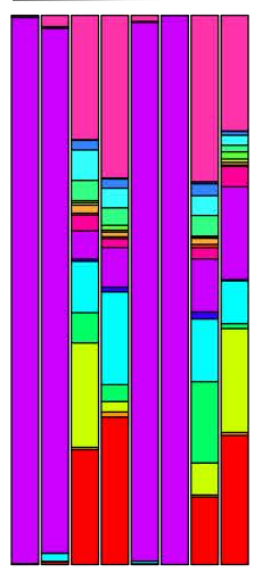

= others

- Actinobacteria; Corynebacteriales; Corynebacteriaceae

- Actinobacteria; Corynebacteriales; Nocardiaceae

Actinobacteria; Micrococcales; Microbacteriaceae

- Actinobacteria; Micrococcales; Promicromonosporaceae

Actinobacteria; Pseudonocardiales; Pseudonocardiacea

- Firmicutes; Bacillales; Paenibacillaceae

Firmicutes; Bacillales; Thermoactinomycetaceae

- Alphaproteobacteria; Caulobacterales; Caulobacteraceae

- Alphaproteobacteria; Rhizobiales; Beijerinckiaceae

- Alphaproteobacteria; Rhizobiales; Devosiaceae

- Alphaproteobacteria; Rhizobiales; Devosiaceae

- Alphaproteobacteria; Sphingomonadales; Sphingomonadaceae

- Gammaproteobacteria; Alteromonadales; Shewanellaceae

- Gammaproteobacteria; Betaproteobacteriales; Burkholderiaceae

- Gammaproteobacteria; Enterobacteriales; Enterobacteriacea

- Gammaproteobacteria; Oceanospirillales; Halomonadaceae

- Gammaproteobacteria; Pseudomonadales; Pseudomonadaceae

- Gammaproteobacteria; Xanthomonadales; Rhodanobacteracea

- Gammaproteobacteria; Xanthomonadales; Xanthomonadaceae

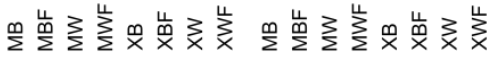

C

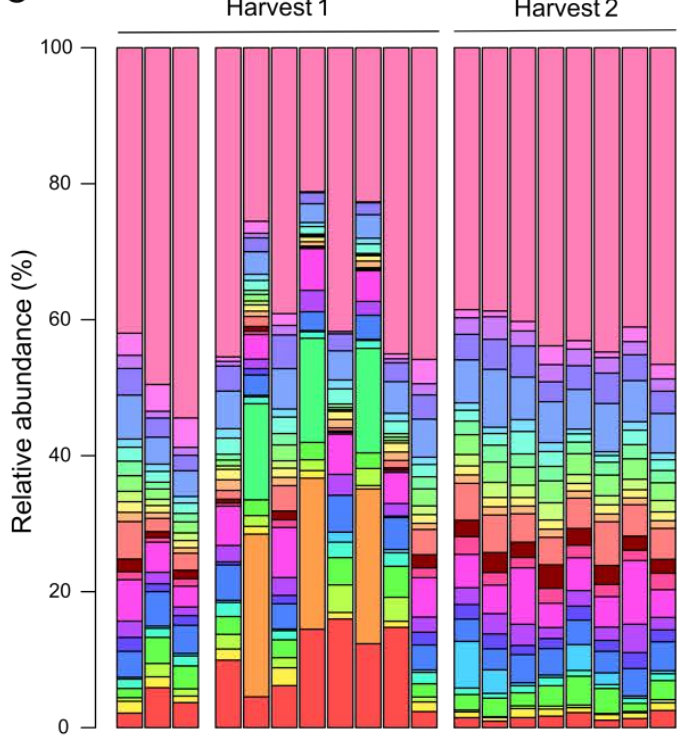

others

Acidobacteria; Subgroup 6; uncultured

Actinobacteria: Frankiales; Geodermatophilacea

- Actinobacteria; Gaiellales; Gaiellaceae

Actinobacteria; Gaiellales; uncultured

Actinobacteria; MB-A2-108; uncultured

Actinobacteria; MB-A2-108; uncultured

Actinobacteria; Micrococcales; Intrasporangiaceae

Actinobacteria; Micrococcales; Microbacteriaceae

Actinobacteria; Micromonosporales; Micromonosporaceae

Actinobacteria; Microtrichales; llumatobacteraceae

Actinobacteria; Microtrichales; uncultured

- Actinobacteria; Propionibacteriales; Nocardioidaceae

- Actinobacteria; Propionibacteriales; Propionibacteriaceae

- Actinobacteria; Pseudonocardiales; Pseudonocardiaceae

- Actinobacteria; Solirubrobacterales; 67-14

- Actinobacteria; Solirubrobacterales; Solirubrobacteraceae

- Chloroflexi; KD4-96; uncultured

- Gemmatimonadetes; Gemmatimonadales; Gemmatimonadaceae

Alphaproteobacteria; Rhizobiales; Rhizobiaceae

Alphaproteobacteria; Rhizobiales; Xanthobacteraceae

Gammaproteobacteria; Alteromonadales; Shewanellaceae

Gammaproteobacteria; Betaproteobacteriales; Burkholderiaceae

Gammaproteobacteria; Betaproteobacteriales; SC-I-84

Gammaproteobacteria; Incertae Sedis; Unknown Family

Gammaproteobacteria; Oceanospirillales; Halomonadaceae

Gammaproteobacteria; Xanthomonadales; Xanthomonadaceae

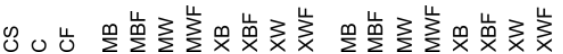

Figure 2. Abundant bacterial families with regard to plant compartment and cropping regime. Only treatments with an average abundance $>0.05 \%$ are shown. Mean relative abundances of each taxa were calculated for each sample. MB/MW, faba bean/wheat grown in monoculture; XB/XW, faba bean/wheat intercropped; $\mathrm{C}$, control unplanted soil; $\mathrm{F}$, inoculated samples; CS, control starting soil. A, leaf; $\mathbf{B}$, root; $\mathbf{C}$, unplanted and rhizosphere soil. 

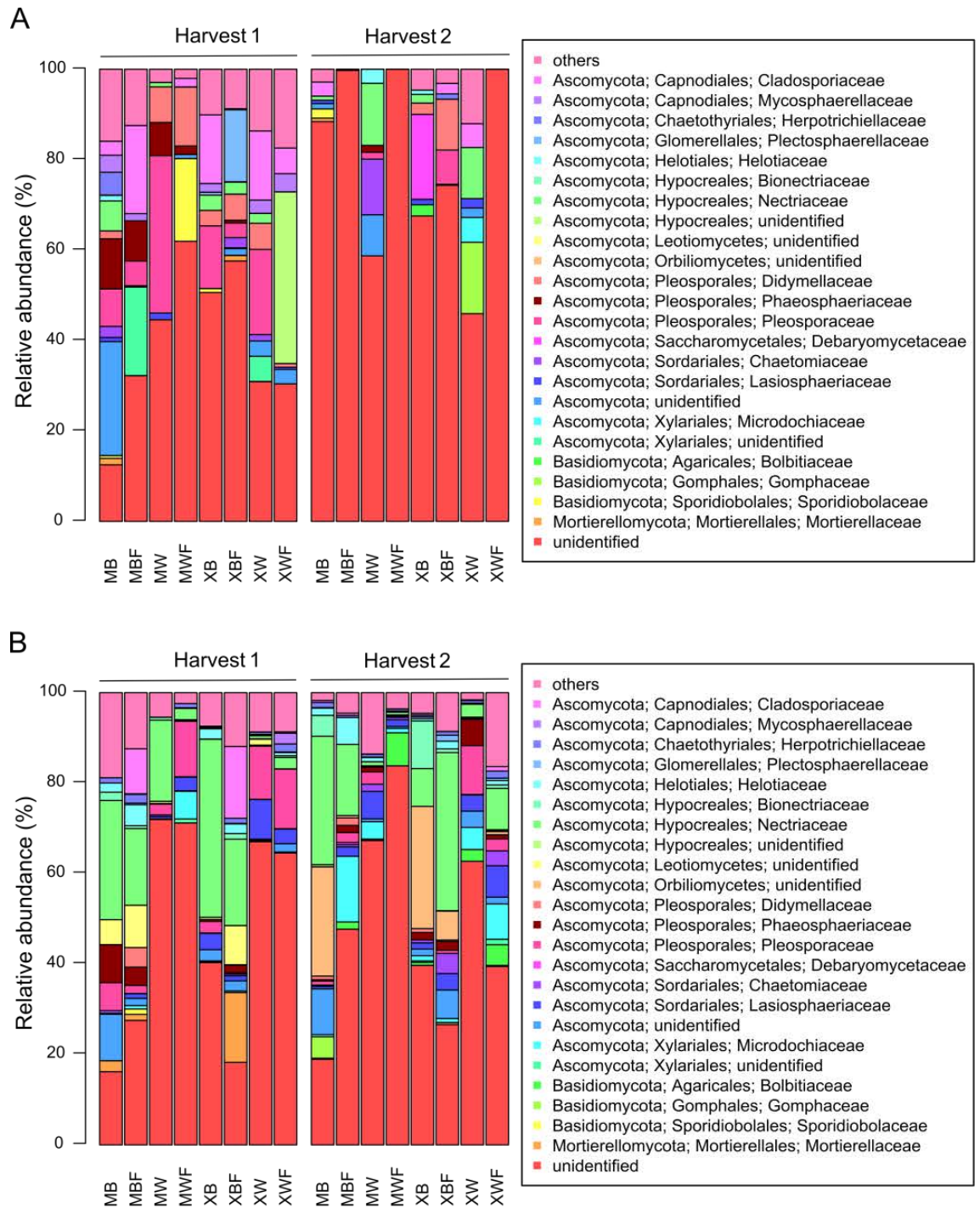

C

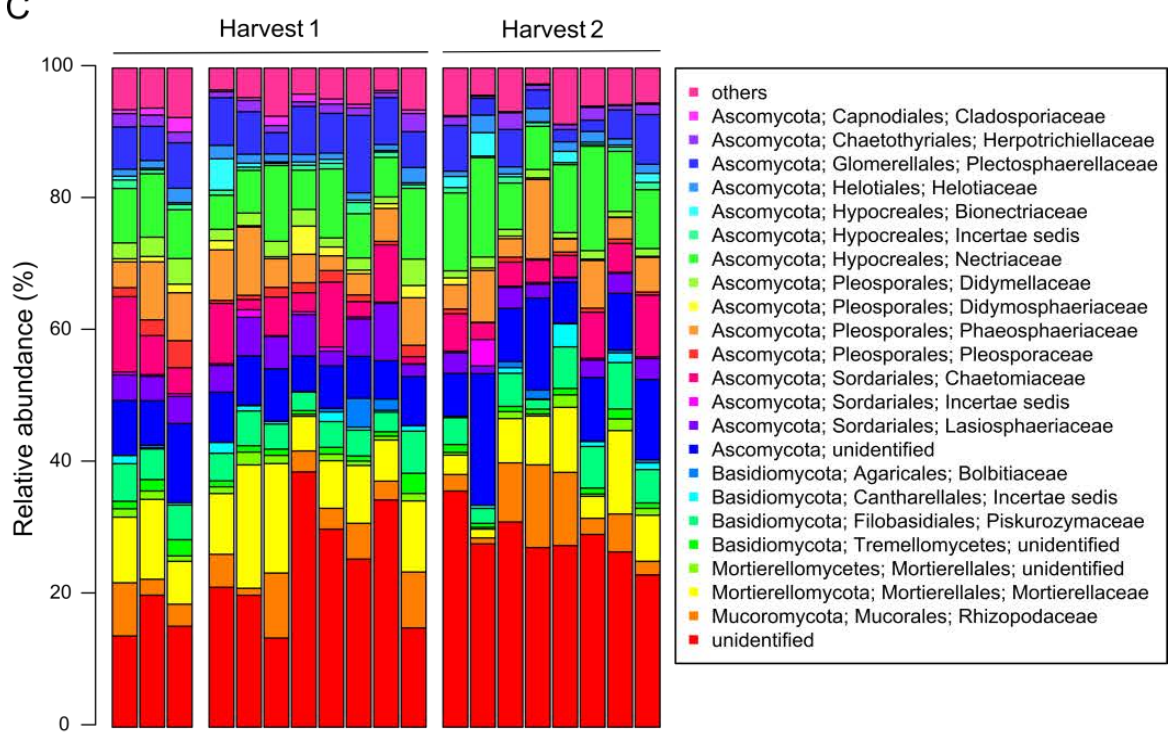

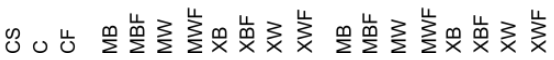

Figure 3. Abundant fungal families with regard to plant compartment and cropping regime. Only treatments with an average abundance $>0.05 \%$ are shown. Mean relative abundances of each taxa were calculated for each sample. MB/MW, faba bean/wheat grown in monoculture; XB/XW, faba bean/wheat intercropped; $\mathrm{C}$, control unplanted soil; $\mathrm{F}$, inoculated samples; CS, control starting soil. A, leaf; B, root; $\mathbf{C}$, unplanted and rhizosphere soil. 

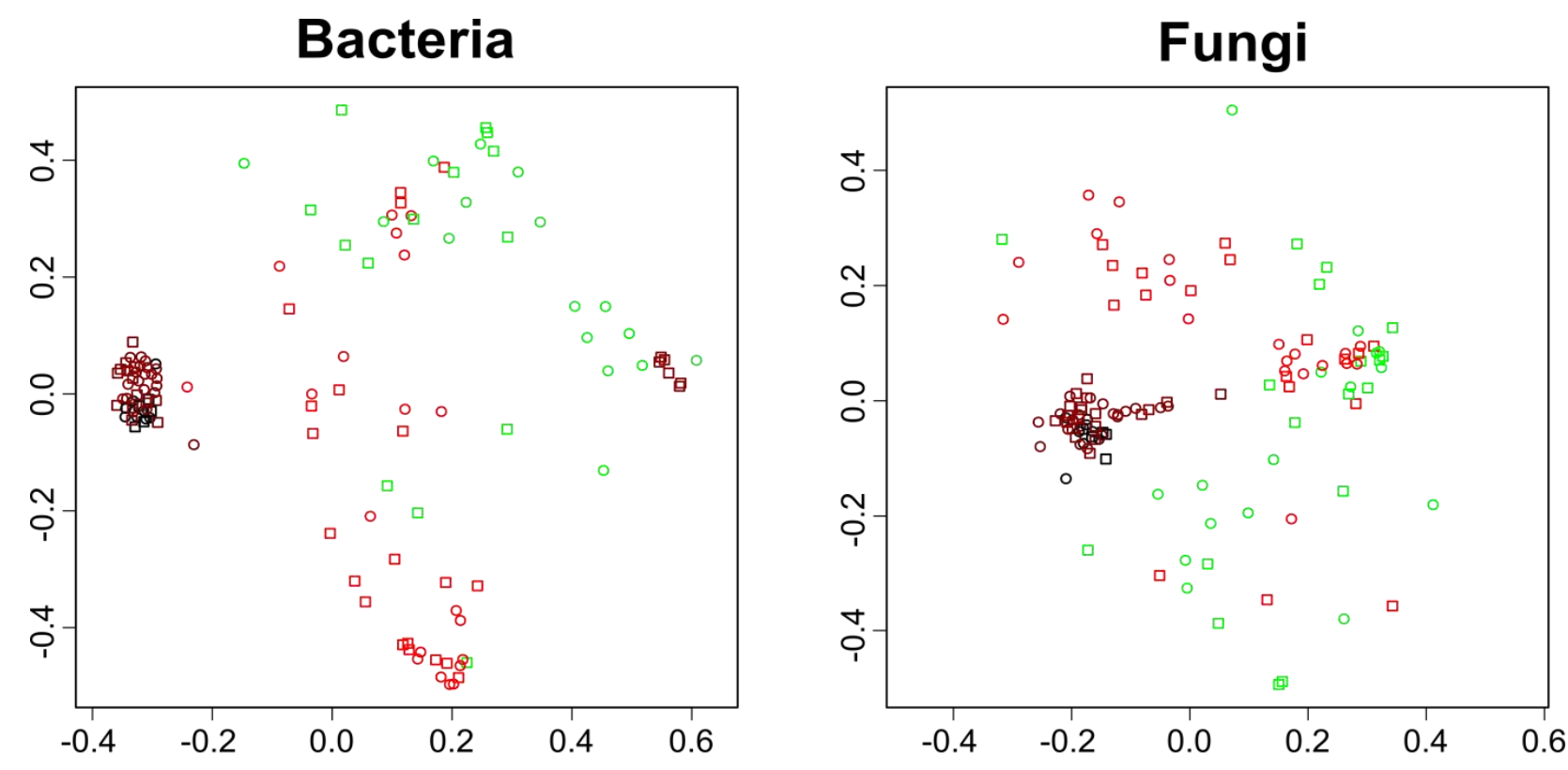

\begin{tabular}{|c|c|c|}
\hline & 1 & Figure 4. Response of \\
\hline & 2 & bacterial and fungal \\
\hline & 3 & communities in different \\
\hline & 4 & compartments \\
\hline & 5 & inoculation. \\
\hline thit & 6 & ordination of microbial \\
\hline latec & & $\begin{array}{l}\text { communities is color-coded } \\
\text { by the respective }\end{array}$ \\
\hline _eaf Endosph & lepe & compartment and different \\
\hline $\begin{array}{l}\text { Root Endosph } \\
\text { Rhizosphere S }\end{array}$ & $\begin{array}{l}\text { tere } \\
\text { sóil }\end{array}$ & $\begin{array}{l}\text { symbols } \\
\text { inoculation. Ordination is }\end{array}$ \\
\hline Soil & $\begin{array}{l}12 \\
13\end{array}$ & $\begin{array}{l}\text { based on } \text { Bray-Curtis } \\
\text { dissimilarities. }\end{array}$ \\
\hline
\end{tabular}
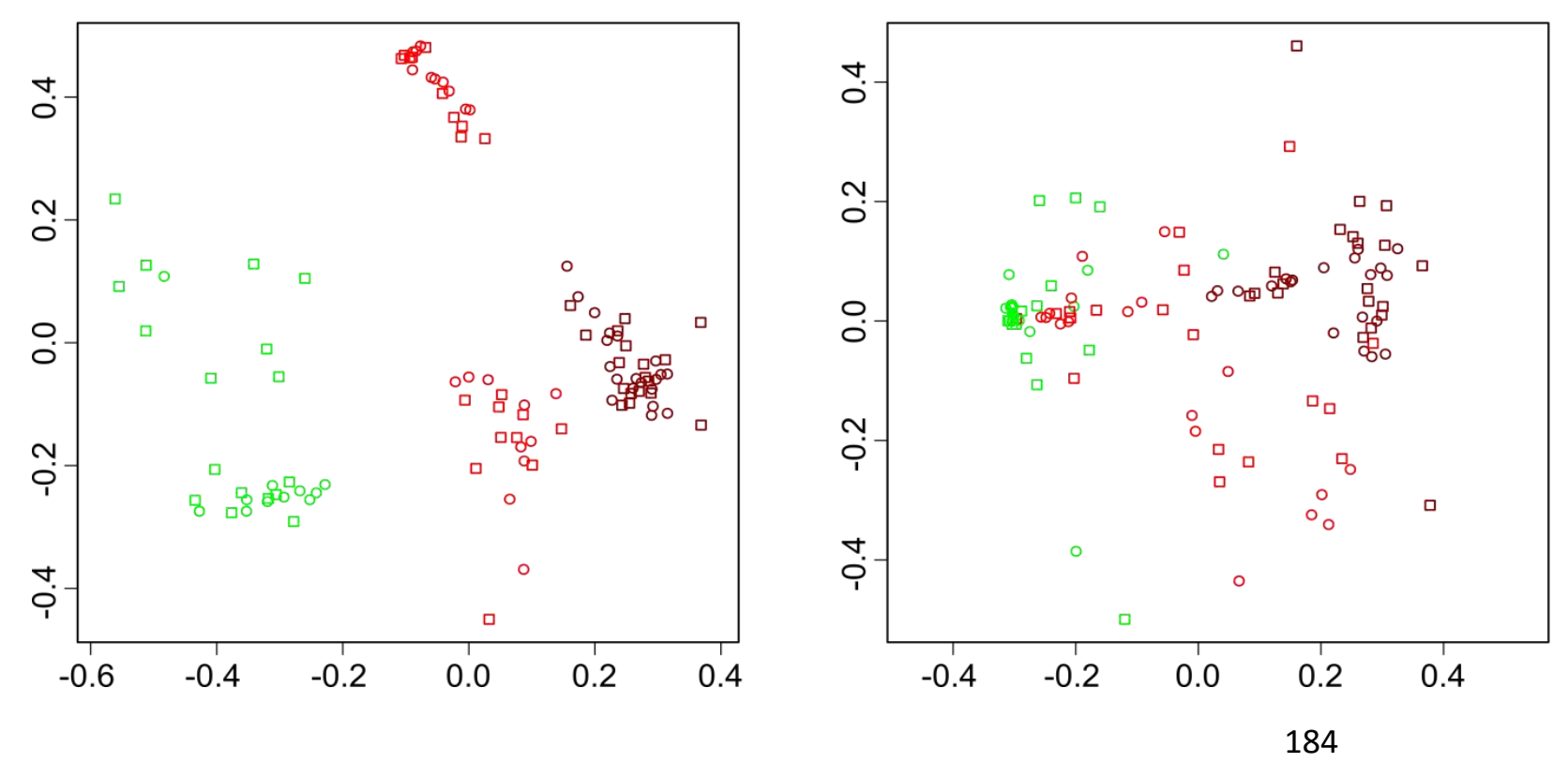

Harvest 2

$\square$ inoculated 22

O non-inoculated 4

- Leaf Endosphere

- Root Endosphere

- Rhizosphere Soil 


\section{Bacteria}
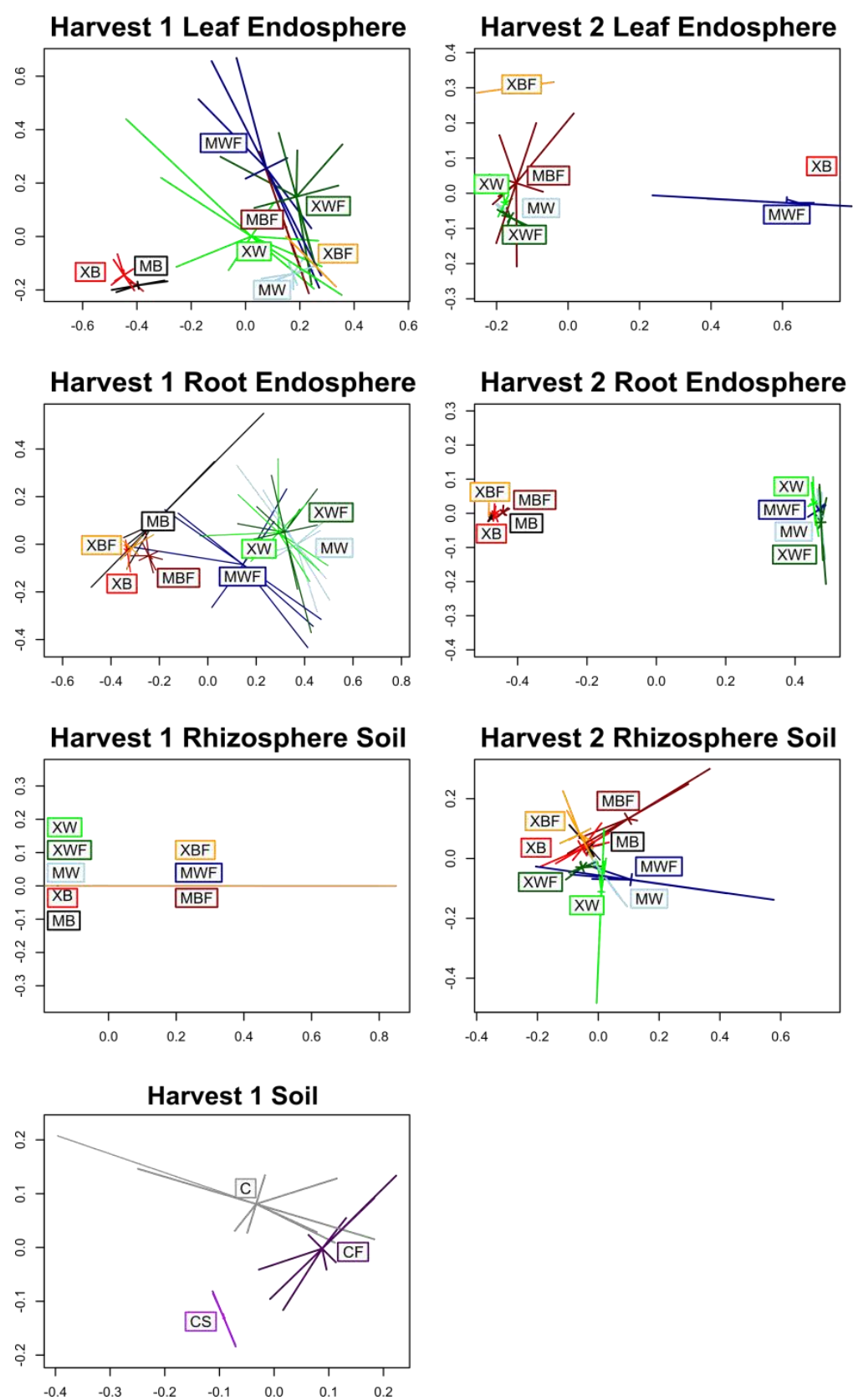

\section{Fungi}

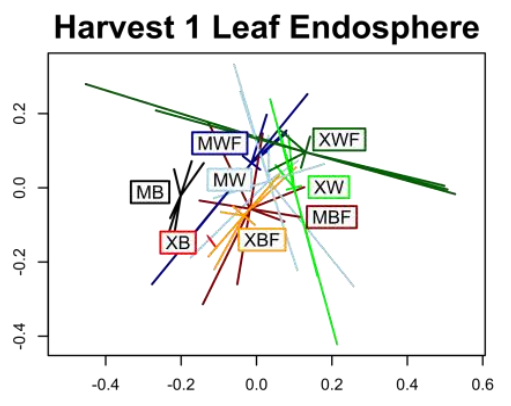

Harvest 1 Root Endosphere

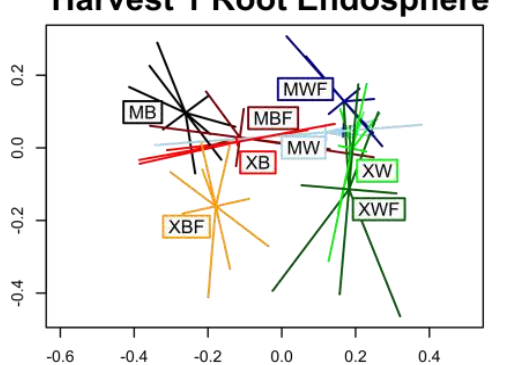

Harvest 1 Rhizosphere Soil

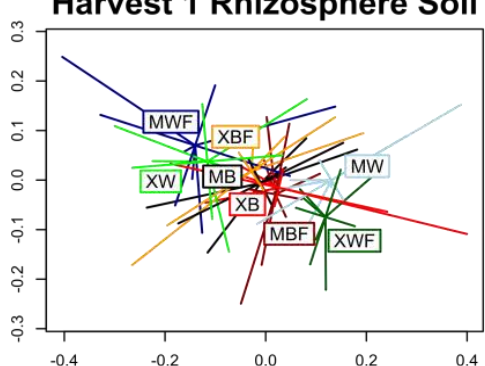

Harvest 1 Soi

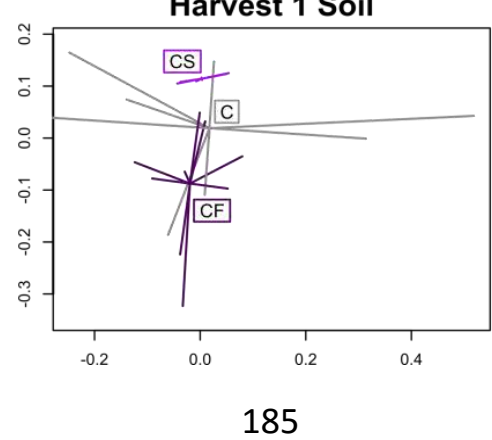

\section{Harvest 2 Leaf Endosphere}

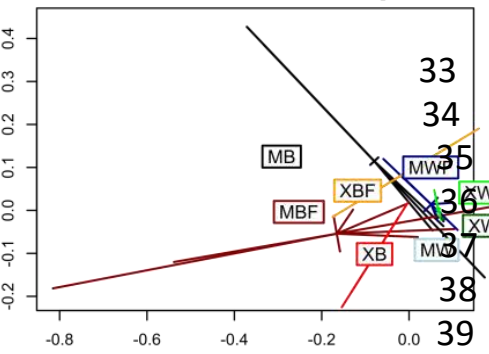

40

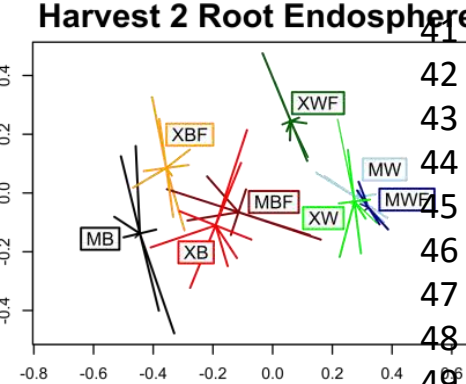

Harvest 2 Rhizosphere Soil

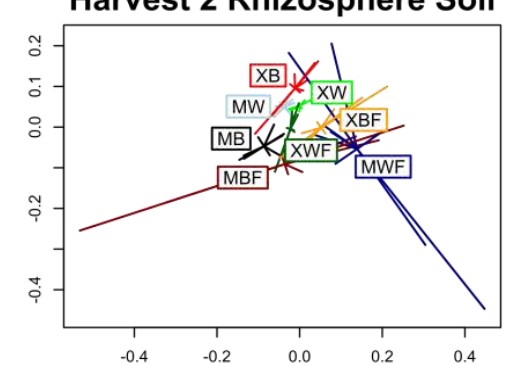

Figure 5. Response of bacterial and fungal communities in different compartments towards cropping regimes. NMDS ordination of microbial communities is color-coded by the respective cropping regime. Ordination is based on Bray-Curtis dissimilarities between samples. MB/MW, faba bean/wheat grown in monoculture; XB/XW, faba bean/wheat intercropped; $\mathrm{C}$, control unplanted soil; $\mathrm{F}$, inoculated samples; CS, control starting soil. 


\section{References}

Aguilar-Trigueros CA, Rillig MC. 2016. Effect of different root endophytic fungi on plant community structure in experimental microcosms. Ecology and Evolution. Nov;6:8149-8158.

Akutse KS, Maniania NK, Fiaboe KKM, Van den Berg J, Ekesi S. 2013. Endophytic colonization of Vicia faba and Phaseolus vulgaris (Fabaceae) by fungal pathogens and their effects on the life-history parameters of Liriomyza huidobrensis (Diptera: Agromyzidae). Fungal Ecology. Aug;6:293-301.

Anderson MJ. 2001. A new method for non-parametric multivariate analysis of variance. Austral Ecology. Feb;26:32-46.

Anderson MJ. 2006. Distance-based tests for homogeneity of multivariate dispersions. Biometrics. Mar;62:245-253.

Andreote FD, da Rocha UN, Araujo WL, Azevedo JL, van Overbeek LS. 2010. Effect of bacterial inoculation, plant genotype and developmental stage on root-associated and endophytic bacterial communities in potato (Solanum tuberosum). Antonie Van Leeuwenhoek International Journal of General and Molecular Microbiology. May;97:389-399.

Ardanov P, Sessitsch A, Haggman H, Kozyrovska N, Pirttila AM. 2012. MethylobacteriumInduced Endophyte Community Changes Correspond with Protection of Plants against Pathogen Attack. Plos One. Oct; 7.

Barrs HD, Weatherley PE. 1962. A Re-Examination of the Relative Turgidity Technique for Estimating Water Deficits in Leaves. Australian Journal of Biological Sciences 15 (3):413428.

Batta YA. 2013. Efficacy of endophytic and applied Metarhizium anisopliae (Metch.) Sorokin (Ascomycota: Hypocreales) against larvae of Plutella xylostella L. (Yponomeutidae: Lepidoptera) infesting Brassica napus plants. Crop Protection. Feb;44:128-134.

Behie SW, Bidochka MJ. 2014. Nutrient transfer in plant-fungal symbioses. Trends in Plant Science. Nov;19:734-740.

Bing LA, Lewis LC. 1991. SUPPRESSION OF OSTRINIA-NUBILALIS (HUBNER) (LEPIDOPTERA, PYRALIDAE) BY ENDOPHYTIC BEAUVERIA-BASSIANA (BALSAMO) VUILLEMIN. Environmental Entomology. Aug;20:1207-1211.

Bolger AM, Lohse M, Usadel B. 2014. Trimmomatic: a flexible trimmer for Illumina sequence data. Bioinformatics. Aug;30:2114-2120.

Chelius MK, Triplett EW. 2001. The diversity of archaea and bacteria in association with the roots of Zea mays L. Microbial Ecology. Apr;41:252-263.

Clifton EH, Jaronski ST, Coates BS, Hodgson EW, Gassmann AJ. 2018. Effects of endophytic entomopathogenic fungi on soybean aphid and identification of Metarhizium isolates from agricultural fields. Plos One. Mar;13.

Clifton EH, Jaronski ST, Hodgson EW, Gassmann AJ. 2015. Abundance of Soil-Borne Entomopathogenic Fungi in Organic and Conventional Fields in the Midwestern USA with an Emphasis on the Effect of Herbicides and Fungicides on Fungal Persistence. Plos One. Jul;10.

de Boer W. 2017. Upscaling of fungal-bacterial interactions: from the lab to the field. Current Opinion in Microbiology. Jun;37:35-41.

de Caceres M, Legendre P. 2009. Associations between species and groups of sites: indices and statistical inference. Ecology. Dec;90:3566-3574. 
de Faria MR, Wraight SP. 2007. Mycoinsecticides and Mycoacaricides: A comprehensive list with worldwide coverage and international classification of formulation types. Biological Control. Dec;43:237-256.

de Mendiburu F. 2014. Statistical Procedures for Agricultural Research. Package "Agricolae" Version 1.4-4. Comprehensive R Archive Network, Institute for Statistics and Mathematics, Vienna.

Edgar RC. 2010. Search and clustering orders of magnitude faster than BLAST. Bioinformatics. Oct;26:2460-2461.

Edgar RC, Haas BJ, Clemente JC, Quince C, Knight R. 2011. UCHIME improves sensitivity and speed of chimera detection. Bioinformatics. Aug;27:2194-2200.

Fox J, Weisberg S. 2011. An R companion to applied regression. Second Edition. Sage.

Fudou R, Iizuka T, Sato S, Ando T, Shimba N, Yamanaka S. 2001. Haliangicin, a novel antifungal metabolite produced by a marine myxobacterium 2. Isolation and structural elucidation. Journal of Antibiotics. Feb;54:153-156.

Gadhave KR, Devlin PF, Ebertz A, Ross A, Gange AC. 2018. Soil inoculation with Bacillus spp. modifies root endophytic bacterial diversity, evenness and community composition in a context-specific manner. Microbiology Ecology. Mar; 1-10.

Gdanetz K, Trail F. 2017. The wheat microbiome under four management strategies, and potential for endophytes in disease protection. Phytobiomes. Oct;158-168.

Gong AD, Li HP, Shen L, Zhang JB, Wu AB, He WJ, Yuan QS, He JD, Liao YC. 2015. The Shewanella algae strain YM8 produces volatiles with strong inhibition activity against Aspergillus pathogens and aflatoxins. Frontiers in Microbiology. Oct;6.

Granzow S, Kaiser K, Wemheuer B, Pfeiffer B, Daniel R, Vidal S, Wemheuer F. 2017. The Effects of Cropping Regimes on Fungal and Bacterial Communities of Wheat and Faba Bean in a Greenhouse Pot Experiment Differ between Plant Species and Compartment. Frontiers in Microbiology. May;8.

Greenfield M, Jimenez MIG, Ortiz V, Vega FE, Kramer M, Parsa S. 2016. Beauveria bassiana and Metarhizium anisopliae endophytically colonize cassava roots following soil drench inoculation. Biological Control. Apr;95:40-48.

Gu Y, Wei Z, Wang XQ, Friman VP, Huang JF, Wang XF, Mei XL, Xu YC, Shen QR, Jousset A. 2016. Pathogen invasion indirectly changes the composition of soil microbiome via shifts in root exudation profile. Biology and Fertility of Soils. Oct;52:997-1005.

Hess M, Barralis G, Bleiholder H, Buhr L, Eggers T, Hack H, Stauss R. 1997. Use of the extended $\mathrm{BBCH}$ scale - general for the descriptions of the growth stages of mono- and dicotyledonous weed species. Weed Research. Dec;37:433-441.

Hirsch J, Galidevara S, Strohmeier S, Devi KU, Reineke A. 2013. Effects on Diversity of Soil Fungal Community and Fate of an Artificially Applied Beauveria bassiana Strain Assessed Through 454 Pyrosequencing. Microbial Ecology. Oct;66:608-620.

Hodge A. 2003. Plant nitrogen capture from organic matter as affected by spatial dispersion, interspecific competition and mycorrhizal colonization. New Phytologist. Jan; 157:303-314.

Hong MS, Peng GX, Keyhani NO, Xia YX. 2017. Application of the entomogenous fungus, Metarhizium anisopliae, for leafroller (Cnaphalocrocis medinalis) control and its effect on rice phyllosphere microbial diversity. Applied Microbiology and Biotechnology. Sep;101:6793-6807. 
Hummel RL, Walgenbach JF, Barbercheck ME, Kennedy GG, Hoyt GD, Arellano C. 2002. Effects of production practices on soil-borne entomopathogens in western North Carolina vegetable systems. Environmental Entomology. Feb;31:84-91.

Innerebner G, Knief C, Vorholt JA. 2011. Protection of Arabidopsis thaliana against LeafPathogenic Pseudomonas syringae by Sphingomonas Strains in a Controlled Model System. Applied and Environmental Microbiology. May;77:3202-3210.

Jaber LR, Enkerli J. 2016. Effect of seed treatment duration on growth and colonization of Vicia faba by endophytic Beauveria bassiana and Metarhizium brunneum. Biological Control. Dec;103:187-195.

Jha B, Gontia I, Hartmann A. 2012. The roots of the halophyte Salicornia brachiata are a source of new halotolerant diazotrophic bacteria with plant growth-promoting potential. Plant and Soil. Jul;356:265-277.

Kaiser K, Wemheuer B, Korolkow V, Wemheuer F, Nacke H, Schoning I, Schrumpf M, Daniel R. 2016. Driving forces of soil bacterial community structure, diversity, and function in temperate grasslands and forests. Scientific Reports. Sep; 6.

Kembel SW, Cowan PD, Helmus MR, Cornwell WK, Morlon H, Ackerly DD, Blomberg SP, Webb CO. 2010. Picante: R tools for integrating phylogenies and ecology. Bioinformatics. Jun;26:1463-1464.

Kepler RM, Ugine TA, Maul JE, Cavigelli MA, Rehner SA. 2015. Community composition and population genetics of insect pathogenic fungi in the genus Metarhizium from soils of a long-term agricultural research system. Environmental Microbiology. Aug;17:2791-2804.

Kõljalg U, Nilsson RH, Abarenkov K, Tedersoo L, Taylor AFS, Bahram M, Bates ST, Bruns TD, Bengtsson-Palme J, Callaghan TM, et al. 2013. Towards a unified paradigm for sequence-based identification of fungi. Molecular Ecology. Nov;22:5271-5277.

Krasnoff SB, Keresztes I, Donzelli BGG, Gibson DM. 2014. Metachelins, Mannosylated and N-Oxidized Coprogen-Type Siderophores from Metarhizium robertsii. Journal of Natural Products. Jul;77:1685-1692.

Krell V, Unger S, Jakobs-Schoenwandt D, Patel AV. 2018. Endophytic Metarhizium brunneum mitigates nutrient deficits in potato and improves plant productivity and vitality. Fungal Ecology. Aug;34:43-49.

Lacey LA, Grzywacz D, Shapiro-Ilan DI, Frutos R, Brownbridge M, Goettel MS. 2015. Insect pathogens as biological control agents: Back to the future. Journal of Invertebrate Pathology. Nov;132:1-41.

Lane DJ. 1991. "16S/23S rRNA sequencing," in Nucleic Acids Techniques in Bacterial Systematics, eds E. Stackebrandt andM. Goodfellow (Chichester: John Wiley \& Sons), 115147.

Le Cocq K, Gurr SJ, Hirsch PR, Mauchline TH. 2017. Exploitation of endophytes for sustainable agricultural intensification. Molecular Plant Pathology. Apr;18:469-473.

Li P, Ye SF, Liu H, Pen AH, Ming F, Tang XM. 2018. Cultivation of Drought-Tolerant and Insect-Resistant Rice Affects Soil Bacterial, but Not Fungal, Abundances and Community Structures. Frontiers in Microbiology. Jun;9.

Li S, Wu FZ. 2018. Diversity and Co-occurrence Patterns of Soil Bacterial and Fungal Communities in Seven Intercropping Systems. Frontiers in Microbiology. Jul;9. 
Liu CM, Yang ZF, He PF, Munir S, Wu YX, Ho HH, He YQ. 2018. Deciphering the bacterial and fungal communities in clubroot-affected cabbage rhizosphere treated with Bacillus Subtilis XF-1. Agriculture Ecosystems \& Environment. Mar;256:12-22.

Liu YC, Qin XM, Xiao JX, Tang L, Wei CZ, Wei JJ, Zheng Y. 2017. Intercropping influences component and content change of flavonoids in root exudates and nodulation of Faba bean. Journal of Plant Interactions. 12:187-192.

Martinez Arbizu P. 2017. Pairwiseadonis: Pairwise multilevel comparison using adonis. R Package Version 0.0.1.

Mayerhofer J, Eckard S, Hartmann M, Grabenweger G, Widmer F, Leuchtmann A, Enkerli J. 2017. Assessing effects of the entomopathogenic fungus Metarhizium brunneum on soil microbial communities in Agriotes spp. biological pest control. Fems Microbiology Ecology. Oct;93.

McKinnon AC, Glare TR, Ridgway HJ, Mendoza-Mendoza A, Holyoake A, Godsoe WK, Bufford JL. 2018. Detection of the Entomopathogenic Fungus Beauveria bassiana in the Rhizosphere of Wound-Stressed Zea mays Plants. Frontiers in Microbiology. Jun;9.

McMurdie PJ, Holmes S. 2014. Waste Not, Want Not: Why Rarefying Microbiome Data Is Inadmissible. Plos Computational Biology. Apr;10.

Moora M, Zobel M. 1996. Effect of arbuscular mycorrhiza on inter- and intraspecific competition of two grassland species. Oecologia. Oct;108:79-84.

Nübel U, Engelen B, Felske A, Snaidr J, Wieshuber A, Amann RI, Ludwig W, Backhaus H. 1996. Sequence heterogeneities of genes encoding 16S rRNAs in Paenibacillus polymyxa detected by temperature gradient gel electrophoresis. Journal of Bacteriology. Oct;178:56365643.

Ogle DH. 2016. Introductory fisheries analyses with R. Chapman \& Hall/CRC.

Oksanen O, Blanchet FG, Kindt R, Legendre P, Minchin PR, O'Hara RB, Simpson GL, Solymos P, Stevens MHH, Wagner H. 2016. Vegan: Community Ecology Package. R Package Version 2.3-5.

Ortiz-Urquiza A, Luo ZB, Keyhani NO. 2015. Improving mycoinsecticides for insect biological control. Applied Microbiology and Biotechnology. Feb;99:1057-1068.

Quast C, Pruesse E, Yilmaz P, Gerken J, Schweer T, Yarza P, Peplies J, Glockner FO. 2013. The SILVA ribosomal RNA gene database project: improved data processing and web-based tools. Nucleic Acids Research. Jan;41:D590-D596.

R Core Team. 2016. R: A Language and Environment for Statistical Computing. Vienna: R Foundation for Statistical Computing. Available online at: http://www.R-project.org

Rabiey M, Ullah I, Shaw LJ, Shaw MW. 2017. Potential ecological effects of Piriformospora indica, a possible biocontrol agent, in UK agricultural systems. Biological Control. Jan;104:19.

Raya-Diaz S, Sánchez-Rodriguez AR, Segura-Fernandez JM, del Campillo MD, QuesadaMoraga E. 2017. Entomopathogenic fungi-based mechanisms for improved Fe nutrition in sorghum plants grown on calcareous substrates. Plos One. Oct;12.

Ritz C, Streibig JC. 2016. Package 'drc' Analysis of dose-response curves. Version 3.0-1.

Roumet C, Lafont F, Sari M, Warembourg F, Garnier E. 2008. Root traits and taxonomic affiliation of nine herbaceous species grown in glasshouse conditions. Plant and Soil. Nov;312:69-83. 
Sánchez-Rodriguez AR, Barron V, Del Campillo MC, Quesada-Moraga E. 2016. The entomopathogenic fungus Metarhizium brunneum: a tool for alleviating Fe chlorosis. Plant and Soil. Sep;406:295-310.

Sánchez-Rodriguez AR, Raya-Diaz S, Zamarreno AM, Garcia-Mina JM, del Campillo MC, Quesada-Moraga E. 2018. An endophytic Beauveria bassiana strain increases spike production in bread and durum wheat plants and effectively controls cotton leafworm (Spodoptera littoralis) larvae. Biological Control. Jan;116:90-102.

Sasan RK, Bidochka MJ. 2012. The insect-pathogenic fungus Metarhizium robertsii (Clavicipitaceae) is also an endophyte that stimulates plant root development. American Journal of Botany. Jan; 99:101-107.

Schneider S, Widmer F, Jacot K, Kolliker R, Enkerli J. 2012. Spatial distribution of Metarhizium clade 1 in agricultural landscapes with arable land and different semi-natural habitats. Applied Soil Ecology. Jan;52:20-28.

Schwarzenbach K, Enkerli J, Widmer F. 2009. Effects of biological and chemical insect control agents on fungal community structures in soil microcosms. Applied Soil Ecology. May;42:54-62.

Siczek A, Frac M, Kalembasa S, Kalembasa D. 2018. Soil microbial activity of faba bean (Vicia faba L.) and wheat (Triticum aestivum L.) rhizosphere during growing season. Applied Soil Ecology. Sep;130:34-39.

Steinwender BM, Enkerli J, Widmer F, Eilenberg J, Thorup-Kristensen K, Meyling NV. 2014. Molecular diversity of the entomopathogenic fungal Metarhizium community within an agroecosystem. Journal of Invertebrate Pathology. Nov;123:6-12.

Tefera T, Vidal S. 2009. Effect of inoculation method and plant growth medium on endophytic colonization of sorghum by the entomopathogenic fungus Beauveria bassiana. Biocontrol. Oct;54:663-669.

Tichy L, Chytry M. 2006. Statistical determination of diagnostic species for site groups of unequal size. Journal of Vegetation Science. Dec;17:809-818.

Tiwari S, Singh P, Tiwari R, Meena KK, Yandigeri M, Singh DP, Arora DK. 2011. Salttolerant rhizobacteria-mediated induced tolerance in wheat (Triticum aestivum) and chemical diversity in rhizosphere enhance plant growth. Biology and Fertility of Soils. Nov;47:907916.

Toju H, Tanabe AS, Yamamoto S, Sato H. 2012. High-Coverage ITS Primers for the DNABased Identification of Ascomycetes and Basidiomycetes in Environmental Samples. Plos One. Jul;7.

Vidal S, Jaber LR. 2015. Entomopathogenic fungi as endophytes: plant-endophyte-herbivore interactions and prospects for use in biological control. Current Science. Jul;109:46-54.

Wagner MR, Lundberg DS, del Rio TG, Tringe SG, Dangl JL, Mitchell-Olds T. 2016. Host genotype and age shape the leaf and root microbiomes of a wild perennial plant. Nature Communications. Jul;7.

Wan XH, Huang ZQ, He ZM, Yu ZP, Wang MH, Davis MR, Yang YS. 2015. Soil C:N ratio is the major determinant of soil microbial community structure in subtropical coniferous and broadleaf forest plantations. Plant and Soil. Feb;387:103-116.

Wang Y, Marschner P, Zhang FS. 2012. Phosphorus pools and other soil properties in the rhizosphere of wheat and legumes growing in three soils in monoculture or as a mixture of wheat and legume. Plant and Soil. May;354:283-298. 
Wallace J, Laforest-Lapointe I, Kembel SW. 2018. Variation in the leaf and root microbiome of sugar maple (Acer saccharum) at an elevational range limit. Peerj. Aug;6.

Wemheuer F, Kaiser K, Karlovsky P, Daniel R, Vidal S, Wemheuer B. 2017. Bacterial endophyte communities of three agricultural important grass species differ in their response towards management regimes. Scientific Reports. Jan;7.

Wemheuer F, Wemheuer B, Kretzschmar D, Pfeiffer B, Herzog S, Daniel R, Vidal S. 2016. Impact of grassland management regimes on bacterial endophyte diversity differs with grass species. Letters in Applied Microbiology. Apr;62:323-329.

Wemheuer B, and Wemheuer F. 2017. "Assessing bacterial and fungal diversity in the plants endosphere," in Metagenomics - Methods and Protocols, Vol. 1539, edsW. Streit, and R. Daniel (New York, NY: Humana Press), 75-84.

White TJ, Bruns T, Lee S, and Taylor J. 1990. "Amplification and direct sequencing of fungal ribosomal RNA genes for phylogenetics," in PCR Protocols: a Guide to Methods and Applications, eds M. A. Innis, D. H. Gelfand, J. J. Sninsky, and T. J.White (New York, NY: Academic Press). 18, 315-322.

Xiao YB, Li L, Zhang FS. 2004. Effect of root contact on interspecific competition and N transfer between wheat and fababean using direct and indirect N-15 techniques. Plant and Soil. May;262:45-54.

Yang ZP, Yang WP, Li SC, Hao JM, Su ZF, Sun M, Gao ZQ, Zhang CL. 2016. Variation of Bacterial Community Diversity in Rhizosphere Soil of Sole-Cropped versus Intercropped Wheat Field after Harvest. Plos One. Mar;11.

Yao Z, He D, Lei Y. 2018. Thermal imaging for early nondestructive detection of wheat stripe rust. ASABE Annual International Meeting;1801728.

Zhang NN, Sun YM, Li L, Wang ET, Chen WX, Yuan HL. 2010. Effects of intercropping and Rhizobium inoculation on yield and rhizosphere bacterial community of faba bean (Vicia faba L.). Biology and Fertility of Soils. Aug;46:625-639.

Zhang YZ, Wang ET, Li M, Li QQ, Zhang YM, Zhao SJ, Jia XL, Zhang LH, Chen WF, Chen WX. 2011. Effects of rhizobial inoculation, cropping systems and growth stages on endophytic bacterial community of soybean roots. Plant and Soil. Oct;347:147-161.

Zhang NN, Sun YM, Wang ET, Yang JS, Yuan HL, Scow KM. 2015. Effects of intercropping and Rhizobial inoculation on the ammonia-oxidizing microorganisms in rhizospheres of maize and faba bean plants. Applied Soil Ecology. Jan;85:76-85.

Zhou Y, Zhu HH, Fu SL, Yao Q. 2017. Variation in Soil Microbial Community Structure Associated with Different Legume Species Is Greater than that Associated with Different Grass Species. Frontiers in Microbiology. May;8.

Zimmermann J, Musyoki MK, Cadisch G, Rasche F. 2016. Biocontrol agent Fusarium oxysporum f.sp strigae has no adverse effect on indigenous total fungal communities and specific AMF taxa in contrasting maize rhizospheres. Fungal Ecology. Oct;23:1-10. 


\section{Supplementary Material}

Supplementary figures and tables are provided on DVD, under the following paths:

Chapter 6/ Figure S1-S8 Rarefaction curves

Chapter 6/ Figure S9-S16 PCR control for the presence of Metarhizium

Chapter 6/ Table S2 Edaphic and Plant parameters

Chapter 6/ Table S3 Thermal images

Chapter 6/ Table S4 Bacterial OTU Table

Chapter 6/ Table S5 Fungal OTU Table

Chapter 6/ Table S6 Bacterial Sequencing Characteristics

Chapter 6/ Table S7 Fungal Sequencing Characteristics

Chapter 6/ Table S8 Associated species

Table S1. Sampling dates for investigated edaphic properties and plant parameters.

\begin{tabular}{|c|c|c|c|}
\hline $\begin{array}{c}\text { Investigated } \\
\text { Parameter/Harvest }\end{array}$ & H1 & H2 & Weekly \\
\hline Water content & unplanted, rhizosphere soil & roots, aerial parts & - \\
\hline RWC & - & leaves & - \\
\hline $\mathbf{N}_{\text {total }}$ & unplanted, rhizosphere soil & unplanted, rhizosphere soil, roots, & - \\
\hline $\mathbf{C}_{\text {total }}$ & unplanted, rhizosphere soil & unplanted, rhizosphere soil, roots, \\
leaves & - \\
\hline pH & unplanted, rhizosphere soil & - & - \\
\hline Plant height & - & - & yes \\
\hline Thermal images & - & - & yes \\
\hline Biomass & roots, aerial parts & roots, aerial parts & - \\
\hline
\end{tabular}

Abbreviations: RWC, relative water content; $\mathrm{H} 1 / \mathrm{H} 2$, refers to harvest/sampling time. 
Table S9. Effect of cropping regimes and compartment on bacterial and fungal community composition.

\begin{tabular}{|c|c|c|c|c|c|c|c|c|}
\hline & \multicolumn{4}{|c|}{ Bacteria } & \multicolumn{4}{|c|}{ Fungi } \\
\hline & \multicolumn{2}{|c|}{ H1 } & \multicolumn{2}{|c|}{ H2 } & \multicolumn{2}{|c|}{ H1 } & \multicolumn{2}{|c|}{ H2 } \\
\hline & $\mathbf{R}^{2}$ & $p$ & $\mathbf{R}^{2}$ & $p$ & $\mathbf{R}^{2}$ & $p$ & $\mathbf{R}^{2}$ & $p$ \\
\hline \multicolumn{9}{|c|}{ Unplanted soil } \\
\hline C vs CF & 0.061 & 0.834 & NA & NA & 0.108 & 0.358 & NA & NA \\
\hline C vs CS & 0.285 & 0.093 & NA & NA & 0.219 & 0.293 & NA & NA \\
\hline CF vs CS & 0.416 & 0.087 & $\mathrm{NA}$ & $\mathrm{NA}$ & 0.259 & 0.243 & $\mathrm{NA}$ & NA \\
\hline \multicolumn{9}{|c|}{ Rhizosphere soil } \\
\hline MB vs MBF & 0.243 & 0.263 & 0.270 & 0.587 & 0.098 & 0.695 & 0.237 & 0.125 \\
\hline MB vs XB & 0.141 & 0.313 & 0.156 & 0.587 & 0.055 & 0.827 & 0.342 & 0.056 \\
\hline MB vs XBF & 0.218 & 0.309 & 0.130 & 0.587 & 0.031 & 0.961 & 0.136 & 0.324 \\
\hline MBF vs XB & 0.281 & 0.168 & 0.116 & 0.587 & 0.151 & 0.687 & 0.296 & 0.036 \\
\hline MBF vs XBF & 0.031 & 0.741 & 0.104 & 0.587 & 0.085 & 0.764 & 0.148 & 0.250 \\
\hline XB vs XBF & 0.214 & 0.498 & 0.031 & 0.868 & 0.061 & 0.764 & 0.228 & 0.125 \\
\hline MW vs MWF & 0.305 & 0.168 & 0.099 & 0.587 & 0.191 & 0.687 & 0.367 & 0.036 \\
\hline MW vs XW & 0.324 & 0.168 & 0.033 & 0.800 & 0.175 & 0.687 & 0.169 & 0.176 \\
\hline MW vs XWF & 0.232 & 0.263 & 0.096 & 0.587 & 0.063 & 0.764 & 0.093 & 0.554 \\
\hline MWF vs XW & 0.235 & 0.309 & 0.047 & 0.587 & 0.044 & 0.827 & 0.374 & 0.036 \\
\hline MWF vs XWF & 0.355 & 0.077 & 0.172 & 0.587 & 0.283 & 0.289 & 0.293 & 0.109 \\
\hline XW vs XWF & 0.698 & 0.075 & 0.115 & 0.587 & 0.301 & 0.289 & 0.140 & 0.324 \\
\hline \multicolumn{9}{|c|}{ Roots } \\
\hline MB vs MBF & 0.080 & 0.889 & 0.382 & 0.046 & 0.069 & 0.836 & 0.410 & 0.054 \\
\hline MB vs XB & 0.111 & 0.563 & 0.189 & 0.189 & 0.220 & 0.399 & 0.315 & 0.105 \\
\hline MB vs XBF & 0.096 & 0.731 & 0.340 & 0.172 & 0.073 & 0.771 & 0.219 & 0.140 \\
\hline MBF vs XB & 0.250 & 0.193 & 0.145 & 0.293 & 0.117 & 0.548 & 0.192 & 0.379 \\
\hline MBF vs XBF & 0.167 & 0.319 & 0.235 & 0.187 & 0.050 & 0.857 & 0.340 & 0.057 \\
\hline XB vs XBF & 0.046 & 0.731 & 0.123 & 0.345 & 0.214 & 0.441 & 0.284 & 0.067 \\
\hline MW vs MWF & 0.178 & 0.497 & 0.156 & 0.189 & 0.017 & 0.857 & 0.157 & 0.267 \\
\hline MW vs XW & 0.089 & 0.569 & 0.101 & 0.502 & 0.043 & 0.771 & 0.029 & 0.883 \\
\hline MW vs XWF & 0.073 & 0.569 & 0.062 & 0.617 & 0.048 & 0.771 & 0.507 & 0.024 \\
\hline MWF vs XW & 0.088 & 0.497 & 0.145 & 0.236 & 0.037 & 0.835 & 0.197 & 0.171 \\
\hline MWF vs XWF & 0.162 & 0.497 & 0.245 & 0.086 & 0.056 & 0.771 & 0.803 & 0.024 \\
\hline XW vs XWF & 0.058 & 0.753 & 0.201 & 0.131 & 0.025 & 0.916 & 0.474 & 0.024 \\
\hline \multicolumn{9}{|c|}{ Leaves } \\
\hline MB vs MBF & 0.846 & 0.175 & NA & NA & 0.216 & 0.289 & 0.076 & 0.646 \\
\hline MB vs XB & 0.133 & 0.952 & NA & $\mathrm{NA}$ & 0.413 & 0.289 & 0.193 & 0.646 \\
\hline MB vs XBF & 0.940 & 0.175 & NA & NA & 0.237 & 0.283 & 0.331 & 0.509 \\
\hline MBF vs XB & 0.861 & 0.115 & 0.453 & 0.197 & 0.393 & 0.362 & 0.049 & 0.879 \\
\hline MBF vs XBF & 0.159 & 0.977 & 0.253 & 0.197 & 0.122 & 0.581 & 0.156 & 0.554 \\
\hline XB vs XBF & 0.945 & 0.133 & 0.880 & 0.350 & 0.208 & 0.597 & 0.277 & 1.000 \\
\hline MW vs MWF & 0.510 & 0.133 & 0.947 & 0.053 & 0.135 & 0.454 & 0.323 & 0.068 \\
\hline MW vs XW & 0.262 & 0.254 & 0.181 & 0.197 & 0.194 & 0.289 & 0.152 & 0.255 \\
\hline MW vs XWF & 0.464 & 0.133 & 0.296 & 0.109 & 0.031 & 0.733 & 0.633 & 0.068 \\
\hline
\end{tabular}




\begin{tabular}{|c|c|c|c|c|c|c|c|c|}
\hline MWF vs XW & 0.024 & 0.977 & 0.928 & 0.053 & 0.045 & 0.683 & 0.137 & 0.329 \\
\hline MWF vs XWF & 0.026 & 0.977 & 0.875 & 0.053 & 0.111 & 0.487 & 0.264 & 0.281 \\
\hline XW vs XWF & 0.003 & 0.994 & 0.141 & 0.327 & 0.160 & 0.364 & 0.364 & 0.068 \\
\hline
\end{tabular}

Results of pairwise adonis testing for the different cropping regimes. Statistically significant differences $(\mathrm{p} \leq 0.05)$ between the treatments for each plant compartment are written in bold.

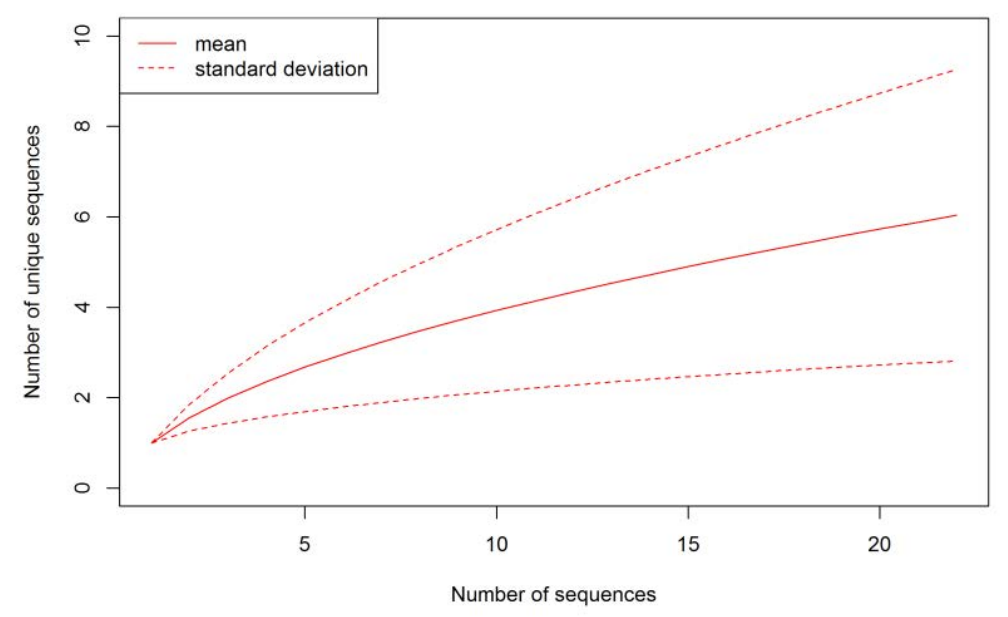

Figure S1. Rarefaction curve for bacterial leaf endophytes. Only the mean of all curves and the standard deviation are shown.

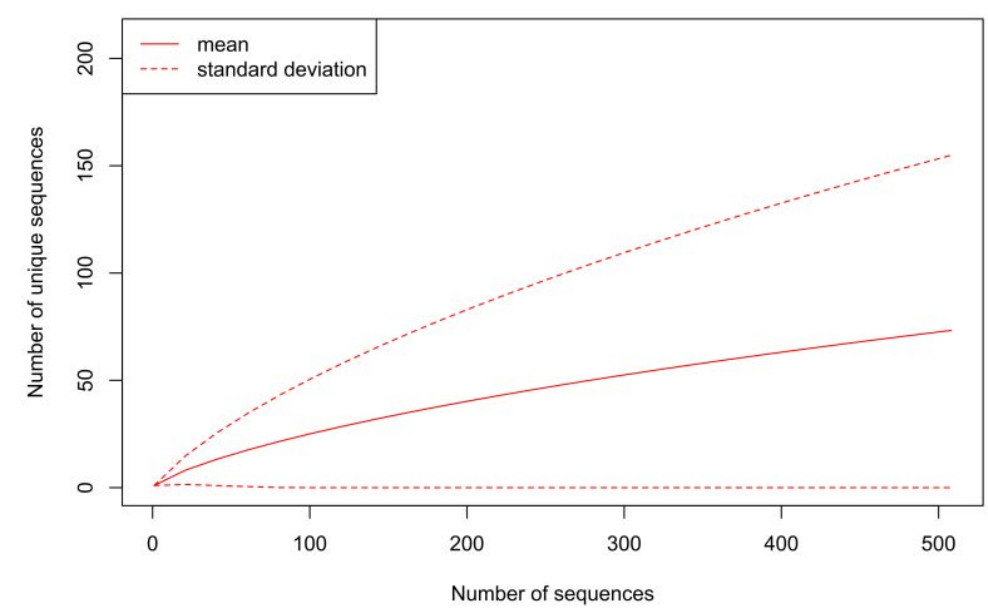

Figure S2. Rarefaction curve for bacterial root endophytes. Only the mean of all curves and the standard deviation are shown. 


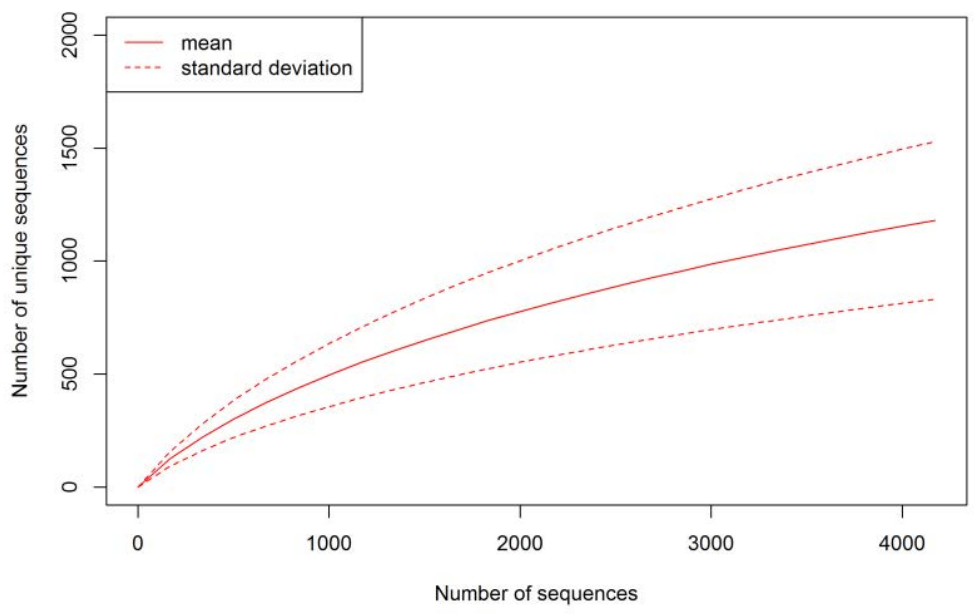

Figure S3. Rarefaction curve for bacteria in the rhizosphere soil. Only the mean of all curves and the standard deviation are shown.

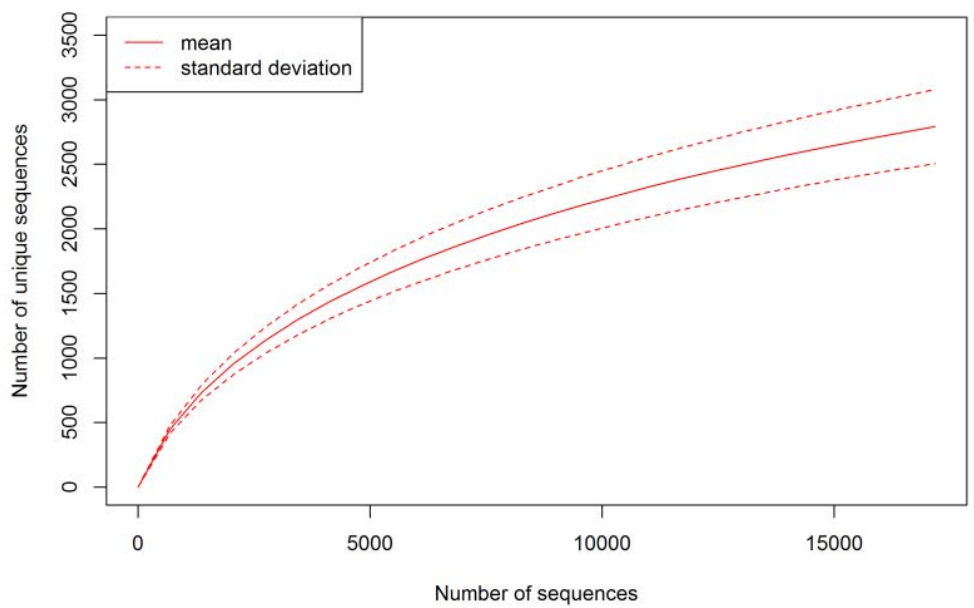

Figure S4. Rarefaction curve for bacteria in soil. Only the mean of all curves and the standard deviation are shown.

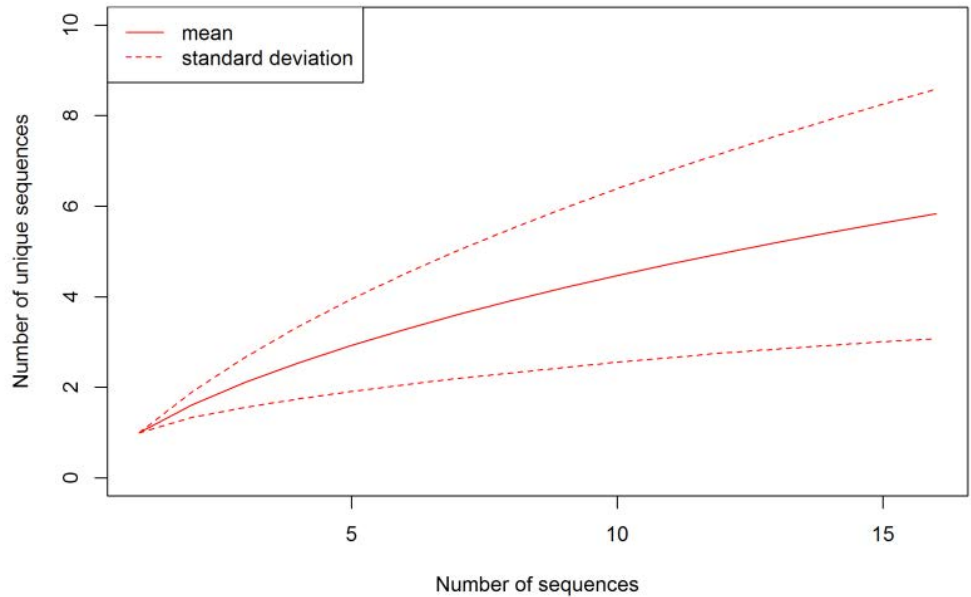

Figure S5. Rarefaction curve for fungal leaf endophytes. Only the mean of all curves and the standard deviation are shown. 


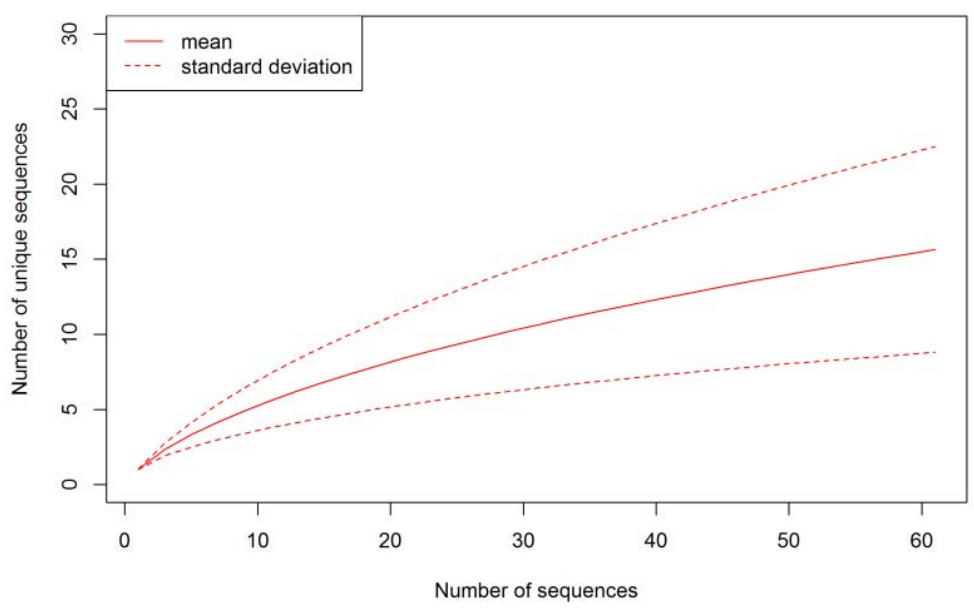

Figure S6. Rarefaction curve for fungal root endophytes. Only the mean of all curves and the standard deviation are shown.

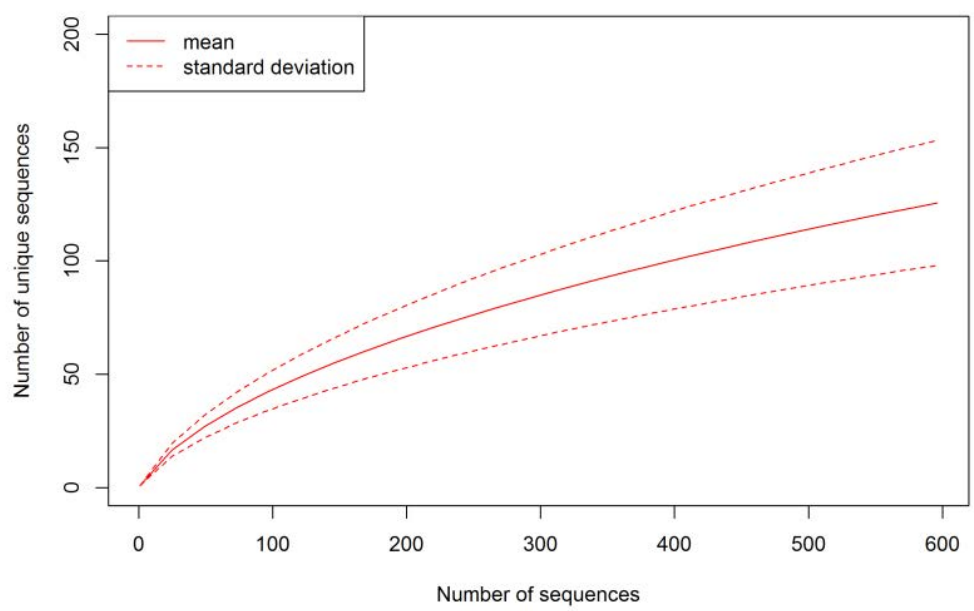

Figure S7. Rarefaction curve for fungi in the rhizosphere soil. Only the mean of all curves and the standard deviation are shown.

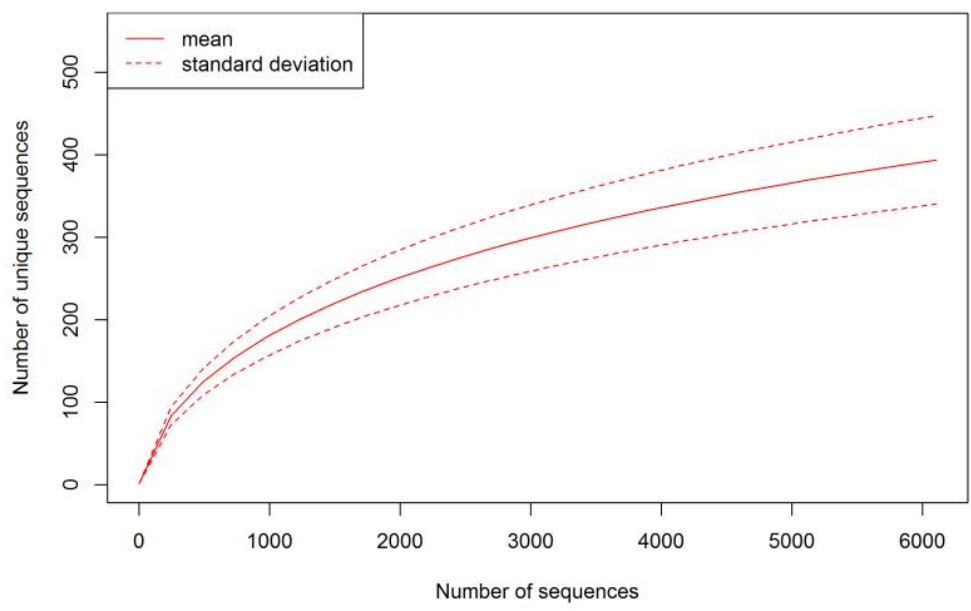

Figure S8. Rarefaction curve for fungi in soil. Only the mean of all curves and the standard deviation are shown. 


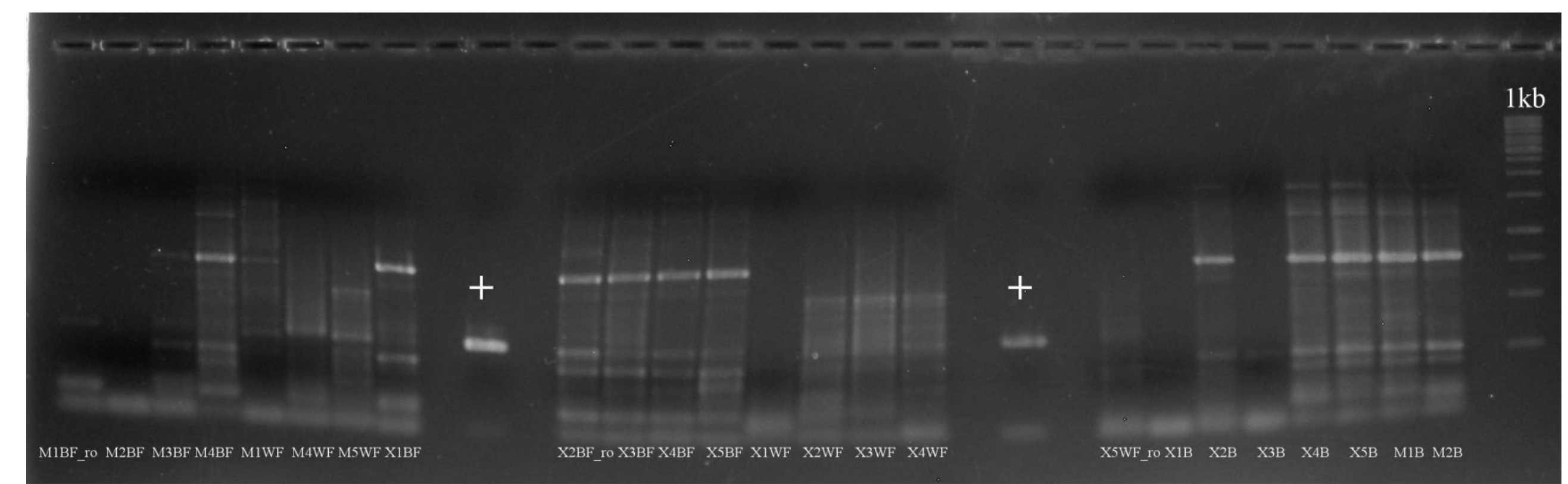

Figure S9. Control of conventional PCR for the presence of Metarhizium in root samples. Positive control: Metarhizium brunneum Cb15-III. Samples were labeled as in Table S7. 


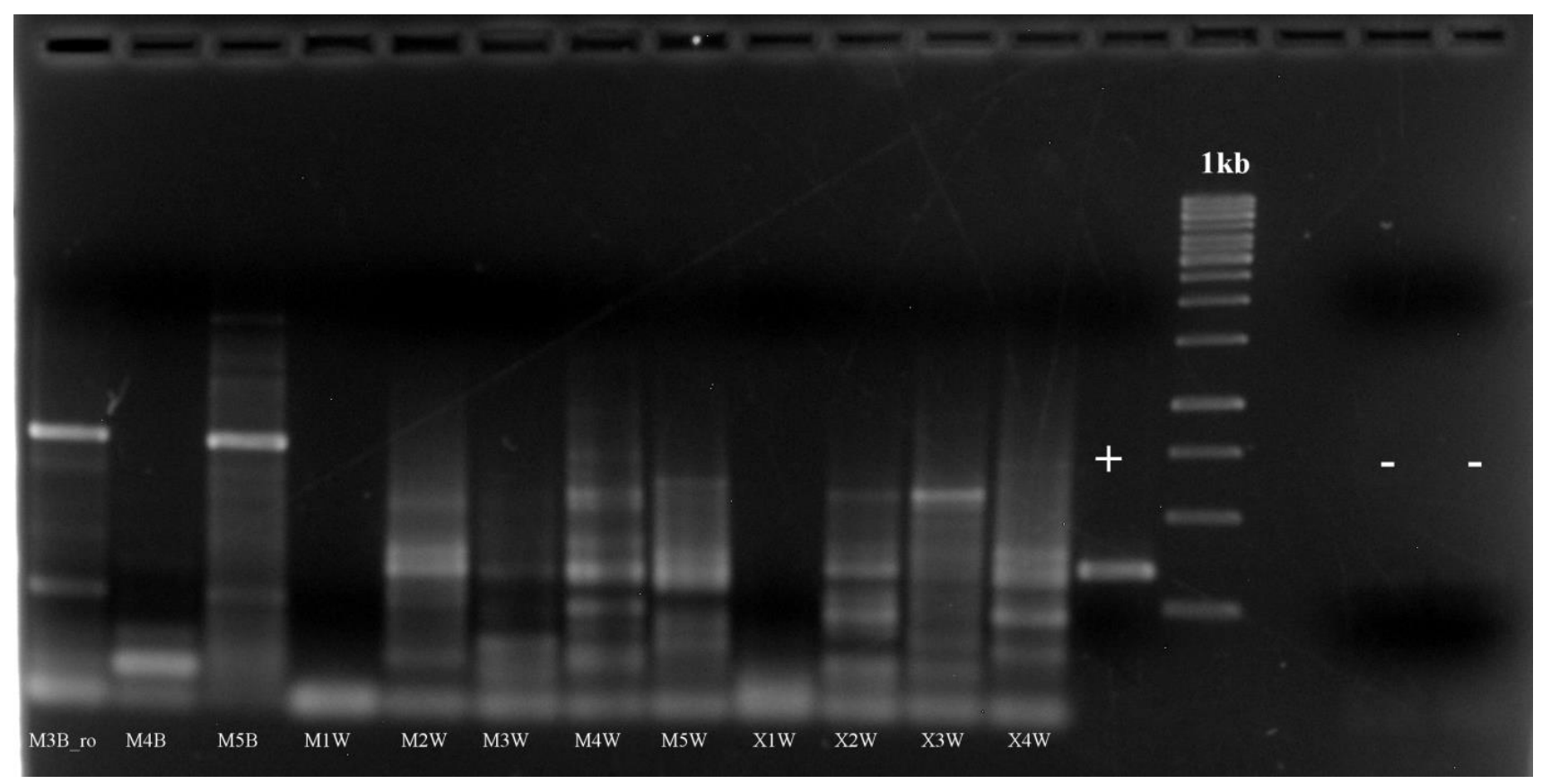

Figure S10. Control of conventional PCR for the presence of Metarhizium in root samples. Positive control: Metarhizium brunneum Cb15-III. Samples were labeled as in Table S7.

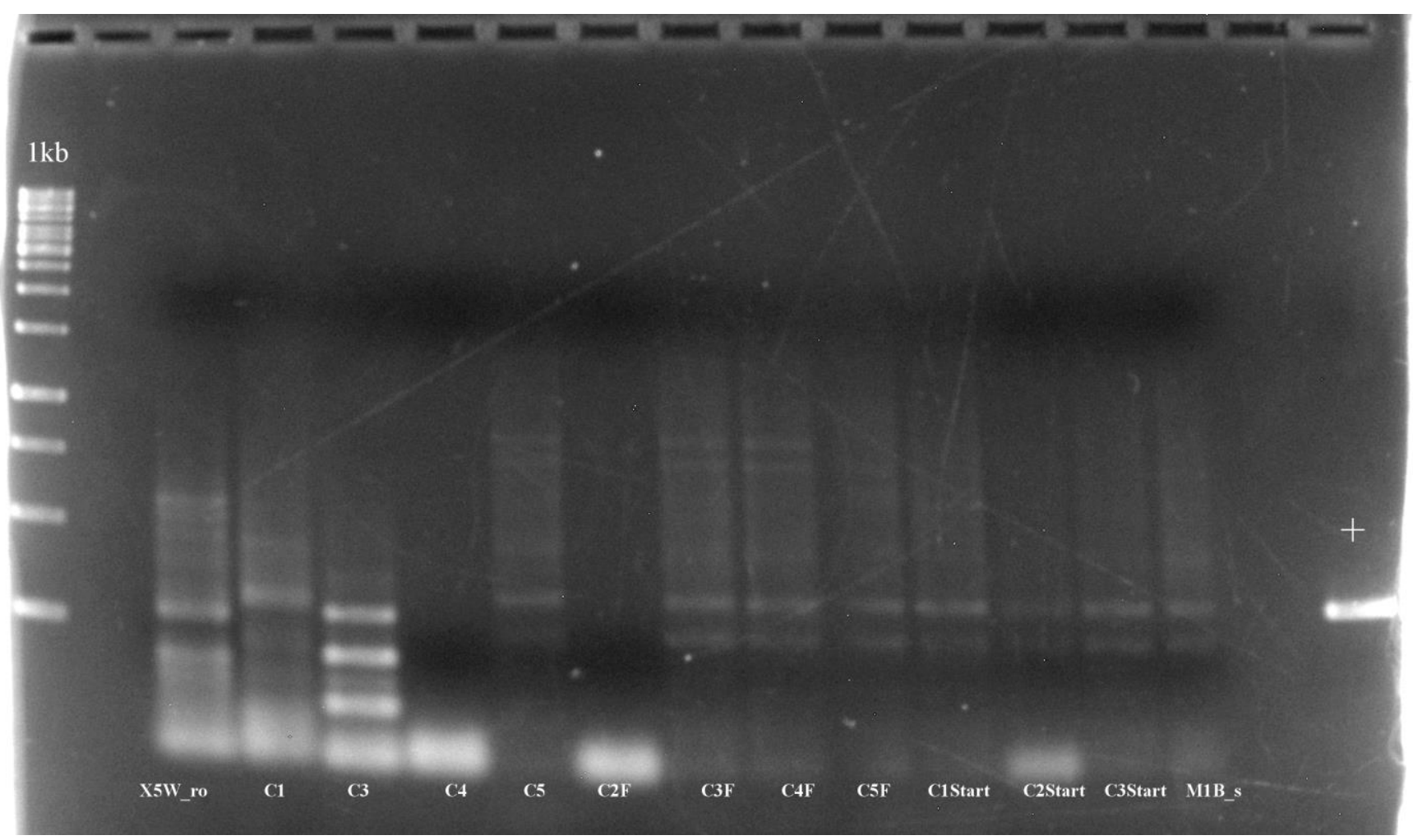

Figure S11. Control of conventional PCR for the presence of Metarhizium in root, rhizosphere and unplanted soil samples. Positive control: Metarhizium brunneum Cb15-III. Samples were labeled as in Table S7. 


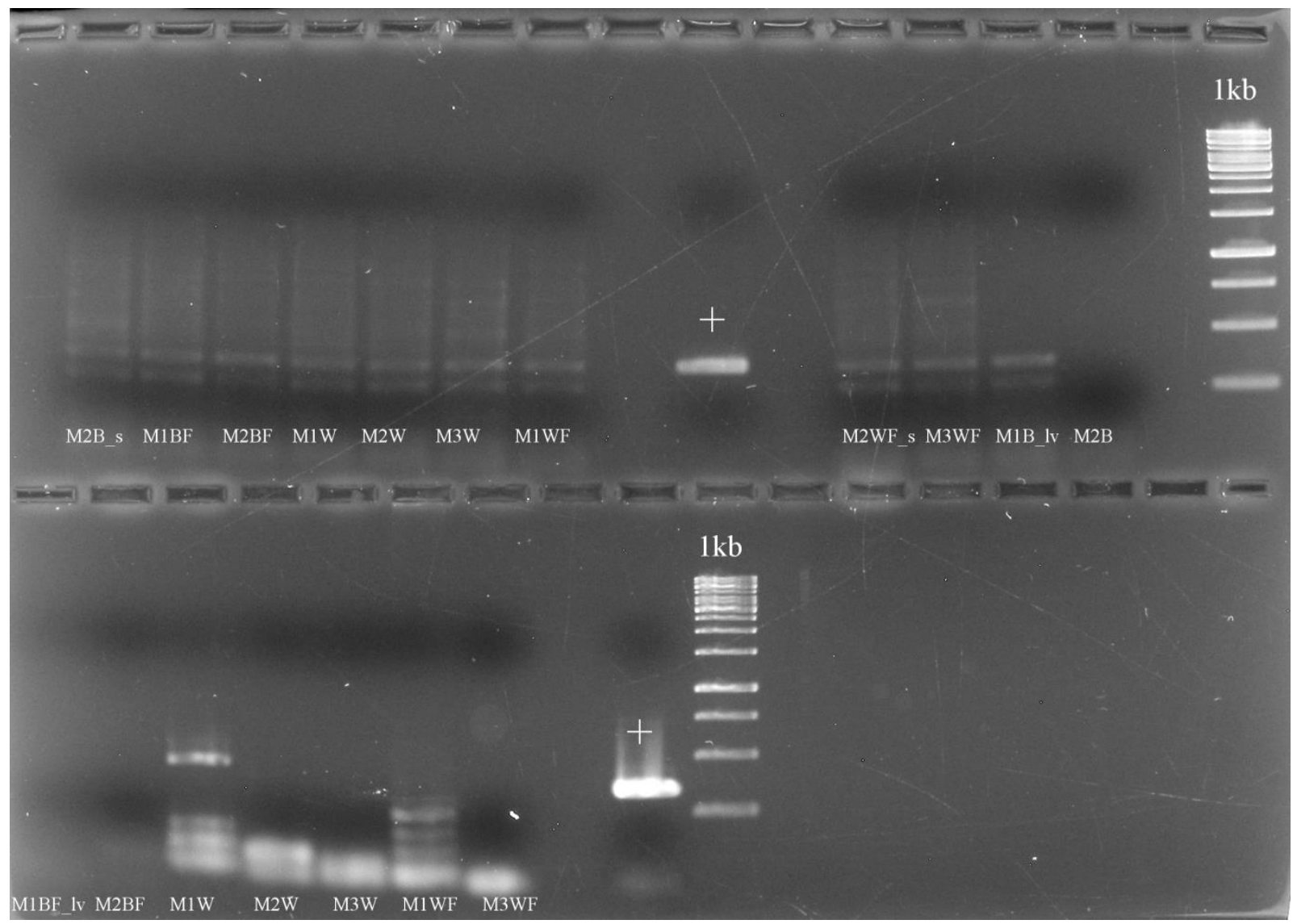

Figure S12. Control of conventional PCR for the presence of Metarhizium in rhizosphere soil and leaf samples. Positive control: Metarhizium brunneum Cb15-III.

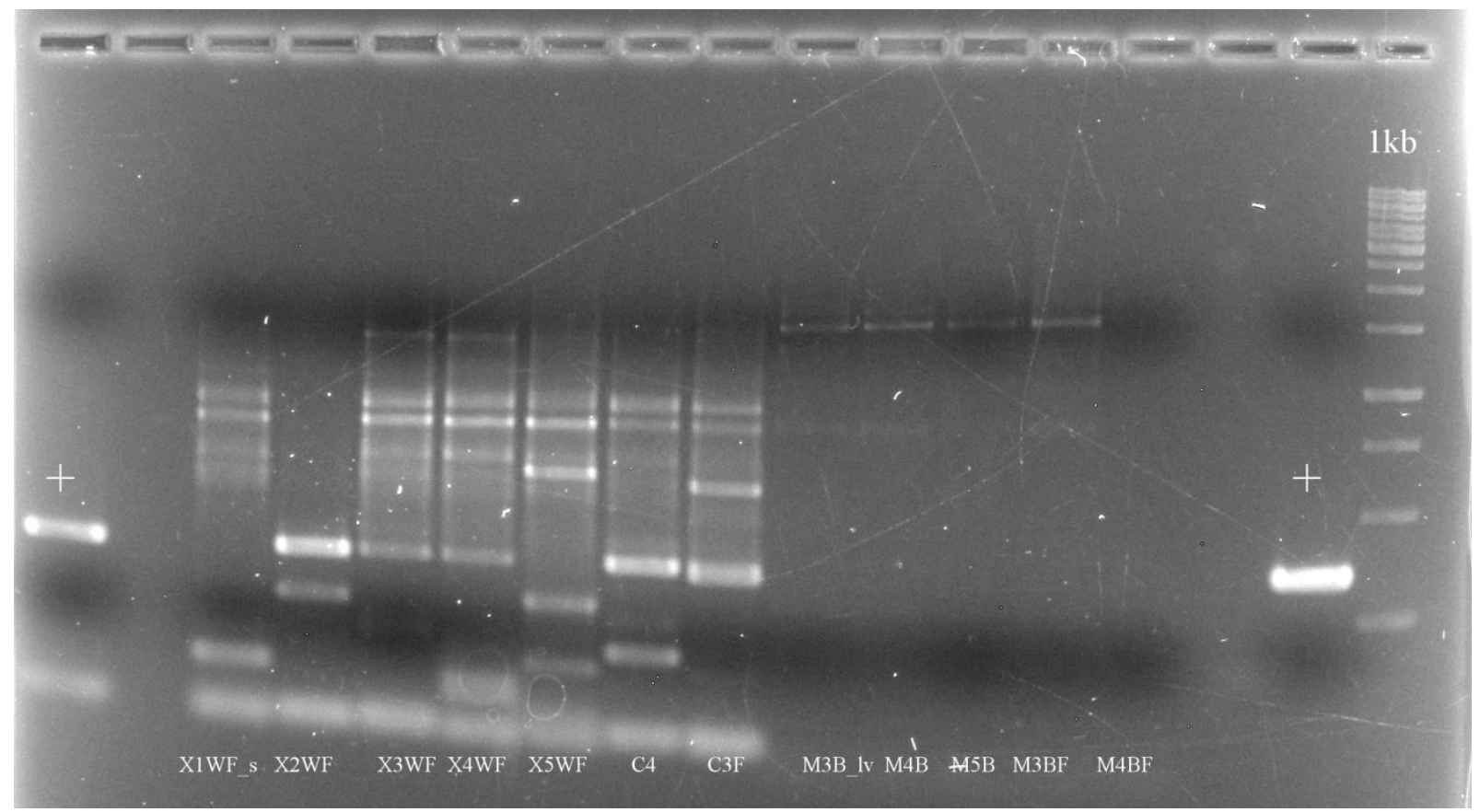

Figure S13. Control of conventional PCR for the presence of Metarhizium in leaf, rhizosphere and unplanted soil samples. Positive control: Metarhizium brunneum Cb15-III. Samples were labeled as in Table S7. 


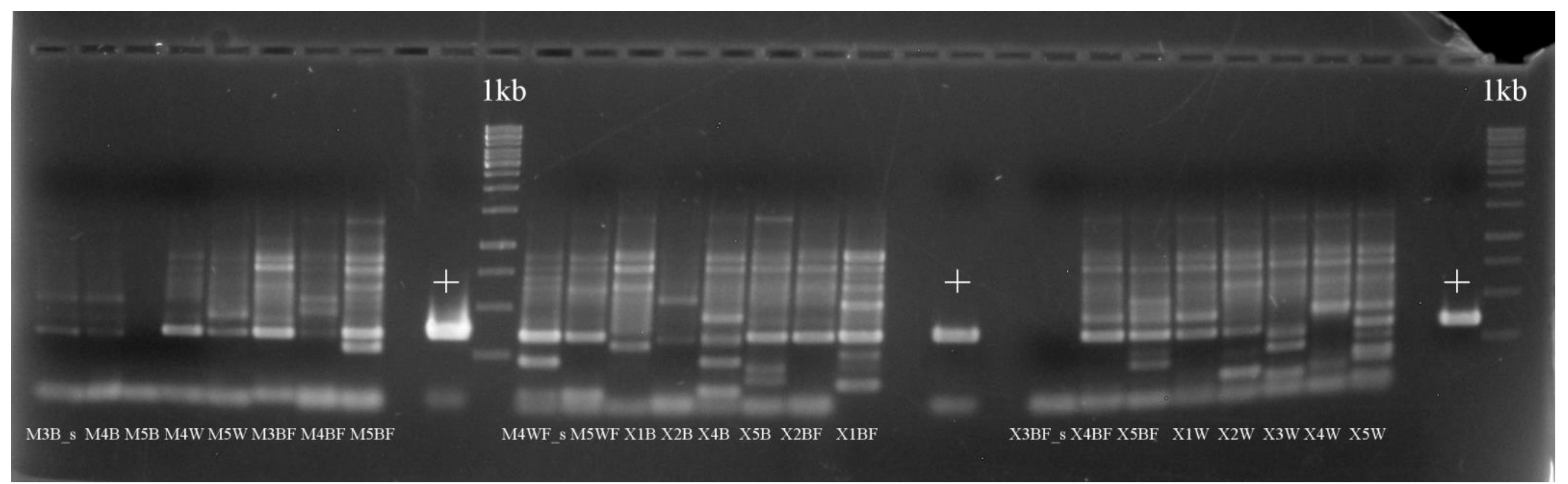

Figure S14. Control of conventional PCR for the presence of Metarhizium in rhizosphere soil samples. Positive control: Metarhizium brunneum Cb15-III. Samples were labeled as in Table S7. 


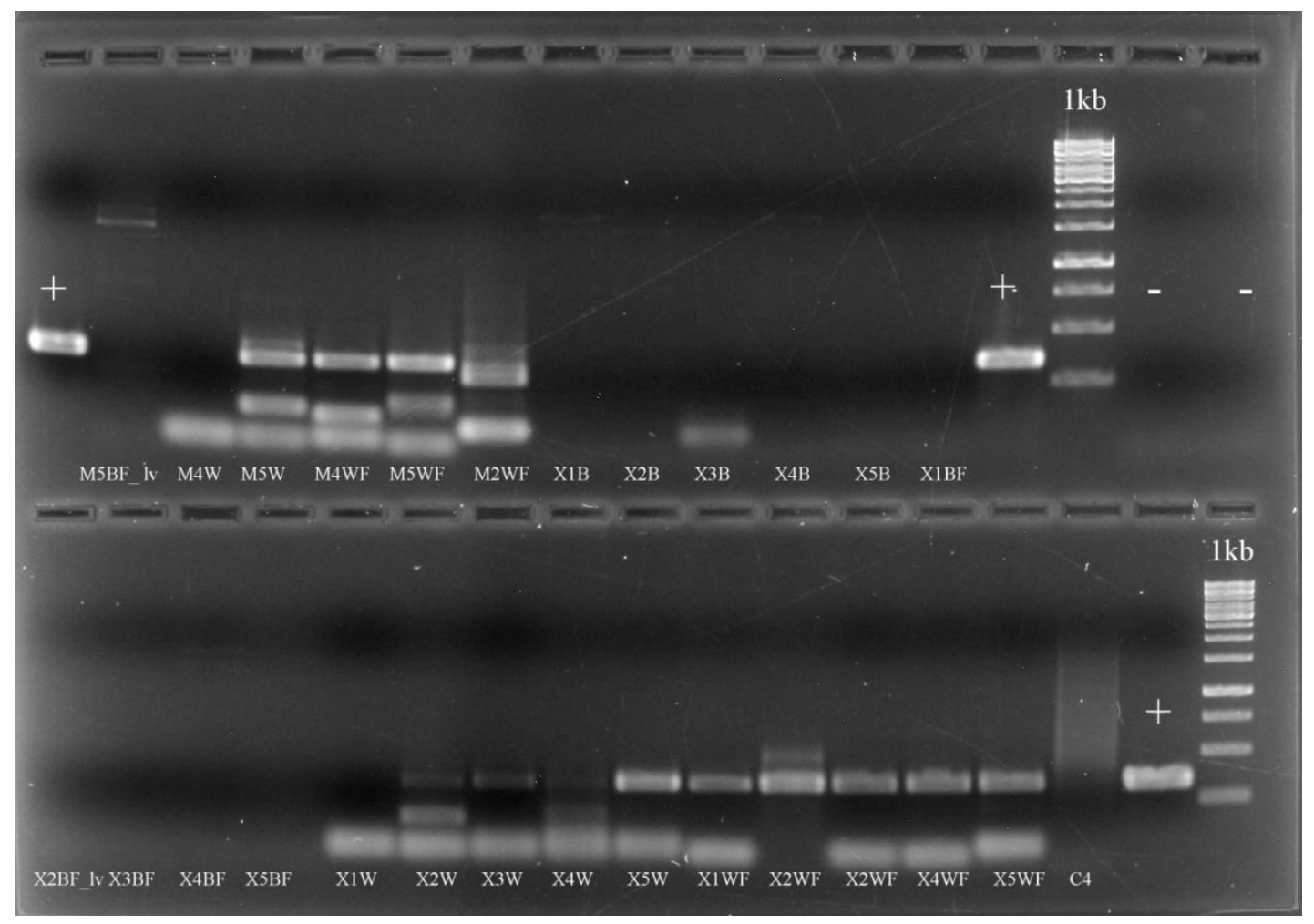

Figure S15. Control of conventional PCR for the presence of Metarhizium in leaf and unplanted soil samples. Positive control: Metarhizium brunneum Cb15-III. Samples were labeled as in Table S7.

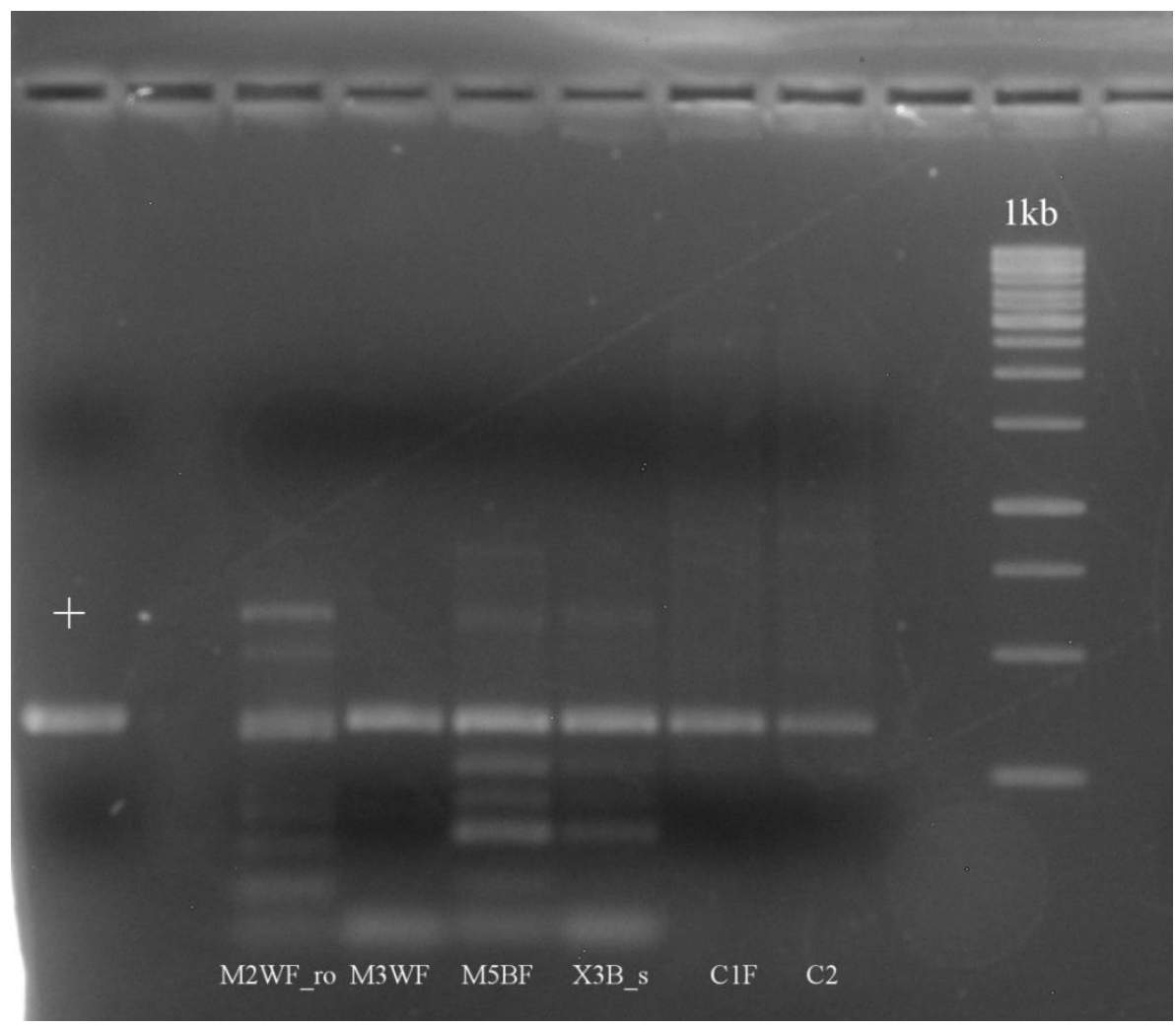

Figure S16. Control of conventional PCR for the presence of Metarhizium in root, rhizosphere and unplanted soil samples. Positive control: Metarhizium brunneum Cb15-III. Samples were labeled as in Table S7. 


\section{Chapter 7}

Draft genome sequence of the endophyte Bacillus mycoides strain GM5LP isolated from Lolium perenne

Jacqueline Hollensteiner, Anja Poehlein, Sandra Granzow, Heiko Liesegang, Rolf Daniel, Stefan Vidal and Franziska Wemheuer

Published in Genome Announcements 6. 


\title{
Draft Genome Sequence of the Endophyte Bacillus mycoides Strain GM5LP Isolated from Lolium perenne
}

\author{
Franziska Wemheuera,b \\ aGenomic and Applied Microbiology \& Göttingen Genomics Laboratory, Institute of Microbiology and \\ Genetics, University of Göttingen, Göttingen, Germany

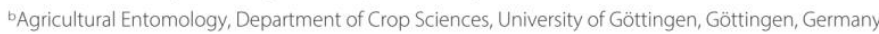

Jacqueline Hollensteiner,a (-) Anja Poehlein, a Sandra Granzow, ${ }^{\mathrm{b}}$ Heiko Liesegang, ${ }^{\text {a }}$ (1) Rolf Daniel,a Stefan Vidal,

ABSTRACT Bacillus mycoides GM5LP is a Gram-positive endophytic bacterium isolated from aerial plant tissues of Lolium perenne $\mathrm{L}$. The $6.0-\mathrm{Mb}$ draft genome harbors 6,132 protein-coding sequences, some of which might be involved in the biosynthesis of antimicrobial substances.

pecies of the Bacillus genus are common members of the plant microbiome $(1,2)$ Several bacilli are important plant growth-promoting bacteria, as they produce a wide range of antimicrobial and antifungal substances and thus can act as biological control agents of various phytopathogens (3-5). The genome of the endophytic Bacillus mycoides strain GM5LP was sequenced to explore its genomic features and its potential as a biocontrol agent.

We isolated B. mycoides GM5LP from surface-sterilized aerial tissues of healthy Lolium perenne plants. Genomic DNA was extracted using the MasterPure complete DNA purification kit (Epicentre, Madison, WI, USA). The obtained DNA was used to generate Illumina shotgun paired-end sequencing libraries. Sequencing was performed employing a MiSeq system and the MiSeq reagent kit version 3 (600 cycles), as recommended by the manufacturer (Illumina, San Diego, CA, USA). Quality filtering was performed using Trimmomatic version 0.32 (6) and resulted in 2,866,928 paired-end reads. De novo genome assembly was performed with the SPAdes genome assembler version 3.8 .0 (7). The assembly resulted in 101 contigs (>500 bp), with an average coverage of $93 \times$. The assembly was validated and the read coverage determined with Qualimap version 2.1 (8).

The draft genome of B. mycoides GM5LP consisted of $6,016,834 \mathrm{bp}$, with an overall GC content of $35.08 \%$. Gene prediction and annotation were performed using Prokka (Rapid Prokaryotic Genome Annotation) version 1.11 (9). The draft genome harbored 15 rRNA genes, 96 tRNA genes, 2,355 protein-coding genes with functional predictions, and 3,777 genes coding for hypothetical proteins. Multilocus sequence typing (MLST) based on seven housekeeping genes ( $g / p, g m k$, ilvD, pta, pur, pyc, and tpi) was performed according to Priest et al. (10). The analysis revealed that strain GM5LP clusters with Bacillus weihenstephanensis within the Bacillus cereus sensu lato group. Bacillus weihenstephanensis was recently reclassified as a heterotypic synonym of Bacillus mycoides (11).

Secondary metabolite gene prediction using antiSMASH 3.0 .5 (12) resulted in 47 predicted gene clusters, including bacteriocin, terpene, lantipeptide, lassopeptide, and siderophore gene clusters. Three novel nonribosomal polyketide synthetase (NRPS) clusters were identified. Genes involved in bacteriocin production might be beneficial for plant growth (13) and the control of other bacteria (14). A siderophore gene cluster similar to a catecholate petrobactin cluster known to be involved in virulence of Bacillus anthracis was identified (15). A lassopeptide gene cluster with $100 \%$ of genes exhibiting

Received 7 December 2017 Accepted 19 December 2017 Published 25 January 2018 Citation Hollensteiner J, Poehlein A, Granzow S, Liesegang H, Daniel R, Vidal S, Wemheuer F. 2018. Draft genome sequence of the endophyte Bacillus mycoides strain GM5LP isolated from Lolium perenne. Genome Announc 6:e01517-17. https://doi.org/10.1128 Announc 6:e01517-17. Copyright $\odot 2018$ Hollensteiner et al. This is an open-access article distributed under the terms of the Creative Commons Attribution 4.0 International license.

Address correspondence to Franziska Wemheuer, fwemheu@gwdg.de. 
similarity to a paeninodin $(16,17)$ biosynthetic gene cluster known from Paenibacillus dendritiformis was detected. Paeninodin belongs to the ribosomally synthesized and posttranslationally modified peptides (RiPPs) that harbor pharmacologically relevant compounds, as they exhibit a wide range of antimicrobial or antiviral activities (18). A complete biosynthesis gene cluster was identified for polyhydroxyalkanoate (PHA), a compound often used in medicine or agriculture (19). Several plant growth-promoting bacteria produce PHAs, which hold advantageous characteristics of enhanced root colonization or plant growth promotion (20). The genome sequence of B. mycoides strain GM5LP will facilitate further studies on the potential of this bacterium as a producer of antimicrobial substances.

Accession number(s). The whole-genome shotgun project has been deposited at DDBJ/ENA/GenBank under the accession number MKZP00000000. The version described here is version MKZP01000000.

\section{ACKNOWLEDGMENTS}

We thank the Ministry of Science and Culture of Lower Saxony and the Niedersächsisches Vorab for funding and Melanie Heinemann for technical support.

The funder had no role in the study design, data collection, and interpretation, or the decision to submit the work for publication.

\section{REFERENCES}

1. Wemheuer F, Kaiser K, Karlovsky P, Daniel R, Vidal S, Wemheuer B. 2017. Bacterial endophyte communities of three agricultural important grass species differ in their response towards management regimes. Sci Rep 7:40914. https://doi.org/10.1038/srep40914.

2. Robinson RJ, Fraaije BA, Clark IM, Jackson RW, Hirsch PR, Mauchline TH. 2016. Endophytic bacterial community composition in wheat (Triticum aestivum) is determined by plant tissue type, developmental stage and soil nutrient availability. Plant Soil 405:381-396. https://doi.org/10.1007/ s11104-015-2495-4.

3. Hollensteiner J, Wemheuer $F$, Harting R, Kolarzyk AM, Diaz Valerio SM Poehlein A, Brzuszkiewicz EB, Nesemann K, Braus-Stromeyer SA, Braus GH, Daniel R, Liesegang H. 2016. Bacillus thuringiensis and Bacillus weihenstephanensis inhibit the growth of phytopathogenic Verticil lium species. Front Microbiol 7:2171. https://doi.org/10.3389/fmicb .2016 .02171 .

4. Cherif A, Ouzari H, Daffonchio D, Cherif H, Ben Slama K, Hassen A, Jaou S, Boudabous A. 2001. Thuricin 7: a novel bacteriocin produced by Bacillus thuringiensis BMG17, a new strain isolated from soil. Lett Appl Microbiol 32:243-247. https://doi.org/10.1046/j.1472-765X.2001.00898.x.

5. Abriouel H, Franz CMAP, Omar NB, Gálvez A. 2011. Diversity and applications of Bacillus bacteriocins. FEMS Microbiol Rev 35:201-232. https:// doi.org/10.1111/j.1574-6976.2010.00244.x.

6. Bolger AM, Lohse M, Usadel B. 2014. Trimmomatic: a flexible trimmer for Illumina sequence data. Bioinformatics 30:2114-2120. https://doi.org/10 .1093/bioinformatics/btu170.

7. Bankevich A, Nurk S, Antipov D, Gurevich AA, Dvorkin M, Kulikov AS, Lesin VM, Nikolenko SI, Pham S, Prjibelski AD, Pyshkin AV, Sirotkin AV, Vyahhi N, Tesler G, Alekseyev MA, Pevzner PA. 2012. SPAdes: a new genome assembly algorithm and its applications to single-cell sequenc ing. J Comput Biol 19:455-477. https://doi.org/10.1089/cmb.2012.0021.

8. García-Alcalde F, Okonechnikov K, Carbonell J, Cruz LM, Götz S, Tarazon S, Dopazo J, Meyer TF, Conesa A. 2012. Qualimap: evaluating nextgeneration sequencing alignment data. Bioinformatics 28:2678-2679. https://doi.org/10.1093/bioinformatics/bts503.

9. Seemann T. 2014. Prokka: rapid prokaryotic genome annotation. Bioinformatics 30:2068-2069. https://doi.org/10.1093/bioinformatics/btu153.

10. Priest FG, Barker M, Baillie LWJ, Holmes EC, Maiden MCJ. 2004. Population structure and evolution of the Bacillus cereus group. J Bacterio 186:7959-7970. https://doi.org/10.1128/JB.186.23.7959-7970.2004.
11. Liu Y, Lai Q, Shao Z. 2017. Genome analysis-based reclassification of Bacillus weihenstephanensis as a later heterotypic synonym of Bacillus mycoides. Int J Syst Evol Microbiol. https://doi.org/10.1099/ijsem.0 002466.

12. Weber T, Blin K, Duddela S, Krug D, Kim HU, Bruccoleri R, Lee SY, Fischbach MA, Müller R, Wohlleben W, Breitling R, Takano E, Medema MH. 2015. antiSMASH 3.0-a comprehensive resource for the genome mining of biosynthetic gene clusters. Nucleic Acids Res 43:W237-W243. https://doi.org/10.1093/nar/gkv437.

13. Lee KD, Gray EJ, Mabood F, Jung WJ, Charles T, Clark SRD, Ly A, Souleimanov A, Zhou X, Smith DL. 2009. The class Ild bacteriocin thuricin-17 increases plant growth. Planta 229:747-755. https://doi.org/ 10.1007/s00425-008-0870-6.

14. Scholz R, Vater J, Budiharjo A, Wang Z, He Y, Dietel K, Schwecke T, Herfort S, Lasch P, Borriss R. 2014. Amylocyclicin, a novel circular bac teriocin produced by Bacillus amyloliquefaciens FZB42. J Bacteriol 196: 1842-1852. https://doi.org/10.1128/JB.01474-14.

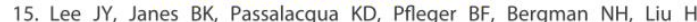
Håkansson K, Somu RV, Aldrich CC, Cendrowski S, Hanna PC, Sherman DH. 2007. Biosynthetic analysis of the petrobactin siderophore pathway from Bacillus anthracis. J Bacteriol 189:1698-1710. https://doi.org/10 $.1128 / \mathrm{JB} .01526-06$.

16. Zhu S, Hegemann JD, Fage CD, Zimmermann M, Xie X, Linne U, Marahiel MA. 2016. Insights into the unique phosphorylation of the lasso peptide paeninodin. J Biol Chem 291:13662-13678. https://doi.org/10.1074/jbc M116.722108.

17. Hegemann JD, Zimmermann M, Xie X, Marahiel MA. 2015. Lasso peptides: an intriguing class of bacterial natural products. Acc Chem Res 48:1909-1919. https://doi.org/10.1021/acs.accounts.5b00156.

18. Maksimov MO, Pan SJ, James Link A. 2012. Lasso peptides: structure, function, biosynthesis, and engineering. Nat Prod Rep 29:996-1006. https://doi.org/10.1039/c2np20070h

19. Valappil SP, Boccaccini AR, Bucke C, Roy I. 2007. Polyhydroxyalkanoates in Gram-positive bacteria: insights from the genera Bacillus and Streptomyces. Antonie Van Leeuwenhoek 91:1-17. https://doi.org/10.1007/ s10482-006-9095-5.

20. Saharan BS, Grewal A, Kumar P. 2014. Biotechnological production of polyhydroxyalkanoates: a review on trends and latest developments. Chin J Biol 2014:1-18. https://doi.org/10.1155/2014/802984. 


\section{Chapter 8}

Draft genome sequence of Pseudomonas putida strain GM4FR, and endophytic bacterium isolated from Festuca rubra $\mathrm{L}$.

Franziska Wemheuer, Jacqueline Hollensteiner, Anja Poehlein, Sandra Granzow, Rolf Daniel, Stefan Vidal and Bernd Wemheuer

Published in Genome Announcements 5. 


\section{Draft Genome Sequence of Pseudomonas putida Strain GM4FR, an Endophytic Bacterium Isolated from Festuca rubra $\mathrm{L}$.}

Franziska Wemheuer, ${ }^{\mathrm{a}, \mathrm{b}}$ Jacqueline Hollensteiner, ${ }^{\mathrm{b}}$ (1) Anja Poehlein, Sandra Granzow, ${ }^{\text {a Rolf Daniel, }}$ ' Stefan Vidal, ${ }^{a}$ Bernd Wemheuer ${ }^{b}$ Agricultural Entomology, Department of Crop Sciences, Georg-August University Göttingen, Göttingen, Germanya; Genomic and Applied Microbiology \& Göttingen Genomics Laboratory, Institute of Microbiology and Genetics, Georg-August University Göttingen, Göttingen, Germany

ABSTRACT Pseudomonas putida GM4FR is an endophytic bacterium isolated from aerial plant tissues of Festuca rubra L. Functional annotation of the draft genome $(7.1 \mathrm{Mb})$ revealed 6,272 predicted protein-encoding genes. The genome provides in sights into the biocontrol and plant growth-promoting potential of $P$. putida GM4FR.

eneficial plant-associated bacteria promote plant growth and health using a variety of mechanisms, including the production of phytohormones $(1,2)$. These bacteria can enhance the resistance of their host plant against biotic and abiotic stressors (2). Several members of the genus Pseudomonas are known as plant growth-promoting bacteria $(2,3)$. These include $P$. putida strains, which have been shown to act as efficient biocontrol agents against phytopathogens and nematodes $(3,4)$.

Here, we report the draft genome sequence of the endophyte $P$. putida GM4FR. This strain was isolated from surface-sterilized aerial tissues of healthy Festuca rubra L. plants. Samples were collected from the GrassMan experimental field (5). Genomic DNA of $P$. putida GM4FR was extracted using the MasterPure complete DNA purification kit (Epicentre, Madison, WI, USA). Obtained DNA was used to generate Illumina paired-end sequencing libraries. Sequencing was performed by employing a MiSeq system and the MiSeq reagent kit version 3 (600 cycles) as recommended by the manufacturer (Illumina, San Diego, CA, USA). Quality filtering using Trimmomatic version 0.32 (6) resulted in 5,419,862 paired-end reads. De novo genome assembly was performed with the SPAdes genome assembler version 3.8 .0 (7). The assembly resulted in 79 contigs ( $>500 \mathrm{bp}$ ) and an average coverage of 144 -fold. The assembly was validated and the read coverage determined with QualiMap version 2.1 (8).

The draft genome of $P$. putida strain GM4FR consists of 7,064,252 bp with an overal $\mathrm{G}+\mathrm{C}$ content of $63.45 \%$. Gene prediction and annotation were performed using Rapid Prokaryotic Genome Annotation (Prokka) (9). The draft genome harbored 10 rRNA genes, 55 tRNA genes, 2,867 protein-encoding genes with functional prediction, and 3,405 genes coding for hypothetical proteins. For phylogenetic classification of P. putida GM4FR, multilocus-sequence typing was performed according to Gomila et al (10). The closest relative of the $P$. putida strain GM4FR is $P$. putida KT2440, which is a derivate of the soil isolate $\mathrm{mt}-2$ (11) and able to colonize the rhizosphere of several important crop plants (12).

BlastKOALA (13) analysis of the GM4FR genome revealed a gene encoding for a putative nematicidal protein (AidA) (14). Additionally, putative genes encoding insecticidal proteins such as fitD/mcf (K19615) and tccC (K11021) were identified. These insecticidal toxins are known from plant-associated $P$. fluorescens and $P$. protegens providing protective effects for their host plants (15-17). An antiSMASH 3.0.5 (18) analysis predicted two bacteriocin gene clusters, an arylpolyene gene cluster, and a
Received 24 January 2017 Accepted 27 January 2017 Published 30 March 2017 Citation Wemheuer F, Hollensteiner Poehlein A Granzow S, Daniel R, Vidal S, Wemheuer B. 2017. Draft genome sequence of Pseudomonas putida strain GM4FR, an endophytic bacterium isolated from Festuca rubra L. Genome Announc 5:e00086-17. https:/doi.org/10.1128/genomeA.00086-17. Copyright $\odot 2017$ Wemheuer et al. This is an open-access article distributed under the terms of the Creative Commons Attribution 4.0 of the Creative Comm
International license. Address correspondence to Franziska Wemheuer, fwemheu@gwdg.de. 
nonribosomal polyketide synthetase (NRPS) cluster with no or low $(<35 \%)$ similarity to known clusters. From the identified NRPS cluster, $9 \%$ of genes showed similarities to a pyoverdine gene cluster of $P$. protegens and $P$. aeruginosa (19). Pyoverdines are important virulence factors such as fluorescent siderophores and required in pathogenesis (20).

Accession number(s). This whole-genome shotgun project has been deposited at DDBJ/ENA/GenBank under the accession MKZO00000000. The version described here is version MKZO01000000.

\section{ACKNOWLEDGMENTS}

We thank the Ministry of Science and Culture of Lower Saxony and the "Niedersächsisches Vorab" for funding as part of the Cluster of Excellence "Functional Biodiversity Research." The funder had no role in the study design, data collection and interpretation, or the decision to submit the work for publication.

We thank Melanie Heinemann for technical support.

\section{REFERENCES}

1. Farrar K, Bryant D, Cope-Selby N. 2014. Understanding and engineering beneficial plant-microbe interactions: plant growth promotion in energy crops. Plant Biotechnol J 12:1193-1206. https://doi.org/10.1111/pbi .12279 .

2. Bhattacharyya PN, Jha DK. 2012. Plant growth-promoting rhizobacteria (PGPR): emergence in agriculture. World J Microbiol Biotechnol 28: 1327-1350. https://doi.org/10.1007/s11274-011-0979-9.

3. Siddiqui ZA, Akhtar MS. 2008. Effects of fertilizers, AM fungus and plant growth promoting rhizobacterium on the growth of tomato and on the reproduction of root-knot nematode Meloidogyne incognita. J Plant reproduction of root-knot nematode Meloidogyne incognita.

4. Akhtar MS, Siddiqui ZA. 2007. Biocontrol of a chickpea root-rot disease complex with Glomus intraradices, Pseudomonas putida and Paenibacillus polymyxa. Australas Plant Pathol 36:175-180. https://doi.org/10.1071/ AP07006.

5. Wemheuer F, Wemheuer B, Kretzschmar D, Pfeiffer B, Herzog S, Daniel R, Vidal S. 2016. Impact of grassland management regimes on bacterial endophyte diversity differs with grass species. Lett Appl Microbiol 62: 323-329. https://doi.org/10.1111/lam.12551.

6. Bolger AM, Lohse M, Usadel B. 2014. Trimmomatic: A flexible trimmer for Illumina sequence data. Bioinformatics 30:2114-2120. https://doi.org/10 1093/bioinformatics/btu170.

7. Bankevich A, Nurk S, Antipov D, Gurevich AA, Dvorkin M, Kulikov AS, Lesin VM, Nikolenko SI, Pham S, Prjibelski AD, Pyshkin AV, Sirotkin AV, Vyahhi N, Tesler G, Alekseyev MA, Pevzner PA. 2012. SPAdes: a new genome assembly algorithm and its applications to single-cell sequencing. J Comput Biol 19:455-477. https://doi.org/10.1089/cmb.2012.0021.

8. García-Alcalde F, Okonechnikov K, Carbonell J, Cruz LM, Götz S, Tarazona S, Dopazo J, Meyer TF, Conesa A. 2012. Qualimap: evaluating next, Deneration sequencing alignment data. Bioinformatics 28:2678-2679. https://doi.org/10.1093/bioinformatics/bts503.

9. Seemann T. 2014. Prokka: rapid prokaryotic genome annotation. Bioin9. Seemann T. 2014. Prokka: rapid prokaryotic genome annotation. Bioin-
formatics 30:2068-2069. https://doi.org/10.1093/bioinformatics/btu153.

10. Gomila M, Peña A, Mulet M, Lalucat J, Garcia-Valdés E. 2015. Phylogenomics and systematics in Pseudomonas. Front Microbiol 6:214. https:// doi.org/10.3389/fmicb.2015.00214

11. Franklin FC, Bagdasarian M, Bagdasarian MM, Timmis KN. 1981. Molecular and functional analysis of the TOL plasmid pWWO from Pseudomonas putida and cloning of genes for the entire regulated aromatic ring meta cleavage pathway. Proc Natl Acad SciU S A 78:7458-7462 https:/ doi.org/10.1073/pnas.78.12.7458.

12. Molina L, Ramos C, Duque E, Ronchel MC, García JM, Wyke L, Ramos JL. 2000. Survival of Pseudomonas putida KT2440 in soil and in the rhizosphere of plants under greenhouse and environmental conditions. Soil Biol Biochem 32:315-321. https://doi.org/10.1016/50038 $-0717(99) 00156-X$.

13. Kanehisa M, Sato Y, Morishima K. 2016. BlastKOALA and GhostKOALA KEGG tools for functional characterization of genome and metagenome sequences. J Mol Biol 428:726-731. https://doi.org/10.1016/.j.jmb.2015 .11 .006 .

14. Huber B, Feldmann F, Köthe M Vandamme P. Wopperer J, Riedel K, Eberl L. 2004. Identification of a novel virulence factor in Burkholderia cenocepacia H111 required for efficient slow killing of Caenorhabditis elegans.
Infect Immun 72:7220-7230. https://doi.org/10.1128/IAI.72.12.7220 Infect Immu

15. Péchy-Tarr M, Bruck DJ, Maurhofer M, Fischer E, Vogne C, Henkels MD, Donahue KM, Grunder J, Loper JE, Keel C. 2008. Molecular analysis of a novel gene cluster encoding an insect toxin in plant-associated strains of Pseudomonas fluorescens. Environ Microbiol 10:2368-2386. https://do .org/10.1111/j.1462-2920.2008.01662.x.

16. Rangel LI, Henkels MD, Shaffer BT, Walker FL, Davis EW, Stockwell VO, Bruck D, Taylor BJ, Loper JE. 2016. Characterization of toxin complex gene clusters and insect toxicity of bacteria representing four subgroups gene clusters and insect toxicity of bacteria representing four subgroups of Pseudomonas fluorescens.
$.1371 /$ journal.pone. 0161120 .

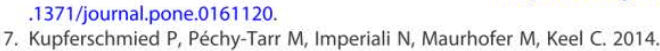
Domain shuffling in a sensor protein contributed to the evolution of insect pathogenicity in plant-beneficial Pseudomonas protegens. PLoS Pathog 10:e1003964. https://doi.org/10.1371/journal.ppat.1003964.

18. Weber T, Blin K, Duddela S, Krug D, Kim HU, Bruccoleri R, Lee SY, Fischbach MA, Müller R, Wohlleben W, Breitling R, Takano E, Medema Fisch bach MA, MMSH $3.0-$ Com mining of biosynthetic gene clusters. Nucleic Acids Res 43:W237-W243. mining of biosynthetic gene clusters.
https://doi.org/10.1093/nar/gkv437.

19. Stintzi A, Cornelis P, Hohnadel D, Meyer JM, Dean C, Poole K, Kourambas S, Krishnapillai V. 1996. Novel pyoverdine biosynthesis gene(s) of Pseudomonas aeruginosa PAO. Microbiology 142:1181-1190. https://doi.org/ 10.1099/13500872-142-5-1181

20. Jimenez PN, Koch G, Thompson JA, Xavier KB, Cool RH, Quax WJ. 2012. The multiple signaling systems regulating virulence in Pseudomonas aeruginosa. Microbiol Mol Biol Rev 76:46-65. https://doiorg/10.1128/ MMBR.05007-11. 


\section{Chapter 9}

First insights into the draft genome sequence of the endophyte Paenibacillus amylolyticus strain GM1FR, isolated from Festuca rubra L.

Anja Poehlein, Jacqueline Hollensteiner, Sandra Granzow, Bernd Wemheuer, Stefan Vidal and Franziska Wemheuer

Published in Genome Announcements 6. 


\section{First Insights into the Draft Genome Sequence of the Endophyte Paenibacillus amylolyticus Strain GM1FR, Isolated from Festuca rubra L.}

(D) Anja Poehlein, ${ }^{\mathrm{a}}$ Jacqueline Hollensteiner, ${ }^{\mathrm{a}}$ Sandra Granzow, ${ }^{\mathrm{b}}$ Bernd Wemheuer, ${ }^{\mathrm{a}}$ Stefan Vidal,b Franziska Wemheuer,b

aGenomic and Applied Microbiology and Göttingen Genomics Laboratory, Institute of Microbiology and

Genetics, University of Göttingen, Göttingen, Germany

bDepartment of Crop Sciences, Agricultural Entomology, University of Göttingen, Göttingen, Germany

ABSTRACT Paenibacillus amylolyticus strain GM1FR is an endophyte isolated from aerial plant tissues of Festuca rubra L. Here, we report the draft genome sequence (7.3 Mb) of GM1FR containing 6,241 protein-coding genes, some of which are potentially involved in plant growth promotion and biocontrol.

everal strains of the genus Paenibacillus from the plant endosphere are known as plant growth-promoting bacteria $(1,2)$. They are able to produce plant growthregulating substances such as cytokinin (3) and indole-3-acetic acid (4). In addition, some Paenibacillus species act as biocontrol agents against various important phytopathogens and pests $(1,2)$. We sequenced the genome of the endophyte Paenibacillus sp. GM1FR to determine its potential as a biocontrol agent.

Paenibacillus amylolyticus strain GM1FR was isolated from surface-sterilized aerial tissues of healthy Festuca rubra L. plants. Genomic DNA was extracted using the MasterPure complete DNA purification kit (Epicentre, Madison, WI, USA). The obtained DNA was used to generate Illumina shotgun paired-end sequencing libraries. Sequencing was performed employing the MiSeq system with the MiSeq reagent kit version 3 (600 cycles) as recommended by the manufacturer (Illumina, San Diego, CA, USA). Quality filtering using Trimmomatic version 0.32 (5) resulted in 3,268,102 paired-end reads. The de novo genome assembly was performed with the SPAdes genome assembler version 3.8 .0 (6). The assembly resulted in 67 contigs ( $>500 \mathrm{bp}$ ) and an average coverage of 92 -fold. The assembly was validated and the read coverage was determined with QualiMap version 2.1 (7). Gene prediction and annotation were performed using Prokka (rapid prokaryotic genome annotation) version 1.11 (8).

The draft genome of strain GM1FR consisted of 7,281,281 bp with an overall GC content of $45.47 \%$. It harbored 11 rRNAs, 99 tRNAs, and 6,241 protein-coding genes, including 2,454 genes with functional annotation. A phylogenetic analysis based on multilocus sequence typing using four genes (gapA, groEL, gyrA, and pgi) (9) revealed that strain GM1FR clusters with the species $P$. amylolyticus (10).

A total of 58 potential gene clusters involved in secondary metabolite production were identified using antiSMASH version 3.0 .5 (11). The majority of these clusters showed no or weak similarity to known clusters. Three putative nonribosomal peptide synthetase (NRPS) gene clusters were identified. One cluster with $62 \%$ of the genes exhibited similarity to a pelgipeptin biosynthetic gene cluster. Pelgipeptin exhibits antimicrobial activity against many pathogenic fungi and bacteria $(12,13)$. A lassopeptide gene cluster with $40 \%$ of the genes sharing similarity to a paeninodin biosynthetic gene cluster was detected. Paeninodin is pharmacologically relevant, as it provides a wide range of antimicrobial and antiviral activities $(14,15)$. Finally, a transAT polyketide synthaseNRPS gene cluster was identified with orthologous genes for each of the genes of a

Received 6 December 2017 Accepted 15 December 2017 Published 25 January 2018 Citation Poehlein A, Hollensteiner J, Granzow S, Wemheuer B, Vidal S, Wemheuer F. 2018. First insights into the draft genome sequence of the endophyte Paenibacillus amylolyticus strain GMIFR, isolated from Festuca rubro Genome Announc 6e01516-17. hitps//do .org/10.1128/genomeA.01516-17. Copyright $\odot 2018$ Poehlein et al. This is an open-access article distributed under the terms of the Creative Commons Attribution 4.0 International license. Address correspondence to Franziska Wemheuer, fwemheu@gwdg.de. 
paenilarvins biosynthetic gene cluster. Paenilarvins, which are known for having strong antifungal activities, are produced by the honey bee pathogen P. larvae (16). However, it has not been determined if strain GM1FR has antifungal activities. The strain Paenibacillus amylolyticus GM1FR contains multiple gene clusters assigned to plant growth and protection as well as health promotion.

Accession number(s). This whole-genome shotgun project has been deposited at DDBJ/ENA/GenBank under the accession number MKZL00000000. The version described here is the first version, MKZL01000000.

\section{ACKNOWLEDGMENTS}

We thank the Ministry of Science and Culture of Lower Saxony and the "Niedersächsisches Vorab" for funding and Melanie Heinemann for technical support.

The research leading to these results has received funding from the Ministry of Science and Culture of Lower Saxony and the "Niedersächsisches Vorab" as part of the Cluster of Excellence "Functional Biodiversity Research." The funders had no role in the study design, data collection, and interpretation, or the decision to submit the work for publication.

\section{REFERENCES}

1. Son SH, Khan Z, Kim SG, Kim YH. 2009. Plant growth-promoting rhizobacteria, Paenibacillus polymyxa and Paenibacillus lentimorbus suppress disease complex caused by root-knot nematode and fusarium wilt fungus. J Appl Microbiol 107:524-532. https://doi.org/10.1111/j.1365-2672 2009.04238.x.

2. Grady EN, MacDonald J, Liu L, Richman A, Yuan ZC. 2016. Current knowledge and perspectives of Paenibacillus: a review. Microb Cell Fac 15:203. https://doi.org/10.1186/s12934-016-0603-7.

3. Timmusk S, Nicander B, Granhall U, Tillberg E. 1999. Cytokinin production by Paenibacillus polymyxa. Soil Biol Biochem 31:1847-1852. https:// doi.org/10.1016/S0038-0717(99)00113-3.

4. Da Mota FF, Gomes EA, Seldin L. 2008. Auxin production and detection of the gene coding for the Auxin Efflux Carrier (AEC) protein in Paenibacillus polymyxa. J Microbiol 46:257-264. https://doi.org/10.1007/ s12275-007-0245-x.

5. Bolger AM, Lohse M, Usadel B. 2014. Trimmomatic: a flexible trimmer for Illumina sequence data. Bioinformatics 30:2114-2120. https://doi.org/10 $.1093 /$ bioinformatics/btu170

6. Bankevich A, Nurk S, Antipov D, Gurevich AA, Dvorkin M, Kulikov AS, Lesin VM, Nikolenko SI, Pham S, Prjibelski AD, Pyshkin AV, Sirotkin AV, Vyahhi N, Tesler G, Alekseyev MA, Pevzner PA. 2012. SPAdes: a new genome assembly algorithm and its applications to single-cell sequencing. J Comput Biol 19:455-477. https://doi.org/10.1089/cmb.2012.0021. ing. J Comput Biol 19:455-477. https://doi.org/10.1089/cmb.2012.0021.
7. García-Alcalde F, Okonechnikov K, Carbonell J, Cruz LM, Götz S, Tarazona S, Dopazo J, Meyer TF, Conesa A. 2012. Qualimap: evaluating next-generation sequencing alignment data. Bioinformatics 28:2678-2679. https://doi.org/ 10.1093/bioinformatics/bts503.

8. Seemann T. 2014. Prokka: rapid prokaryotic genome annotation. Bioin formatics 30:2068-2069. https://doi.org/10.1093/bioinformatics/btu153.

9. liyama K, Nishi O, Mon H, Lee JM, Kusakabe T, Asano S-I, Yasunaga-Aok C, Shimizu S. 2013. Phylogenetic analysis of Paenibacillus popilliae and its related taxa based on housekeeping genes. J Insect Biotechnol Sericol 82:1-11.

10. Akuzawa S, Nagaoka J, Kanekatsu M, Kubota E, Ohtake R, Suzuki T, Kanesaki Y. 2016. Draft genome sequence of Paenibacillus amylolyticus Heshi-A3, isolated from fermented rice bran in a Japanese fermented seafood dish. Genome Announc 4(2):e00218-16. https://doi.org/10.1128/ genomeA.00218-16.

11. Weber T, Blin K, Duddela S, Krug D, Kim HU, Bruccoleri R, Lee SY, Fischbach MA, Müller R, Wohlleben W, Breitling R, Takano E, Medema MH. 2015. antiSMASH 3.0 - a comprehensive resource for the genome mining of biosynthetic gene clusters. Nucleic Acids Res 43:W237-W243. https://do org/10.1093/nar/gkv437.

12. Ding R, Wu XC, Qian CD, Teng Y, Li O, Zhan ZJ, Zhao YH. 2011. Isolation and identification of lipopeptide antibiotics from Paenibacillus elgii B69 with inhibitory activity against methicillin-resistant Staphylococcus aureus. J Microbiol 49:942-949. https://doi.org/10.1007/s12275-011-1153-7.

13. Wu XC, Shen XB, Ding R, Qian CD, Fang HH, Li O. 2010. Isolation and partial characterization of antibiotics produced by Paenibacillus elgii B69. FEMS Microbiol Lett 310:32-38. https://doi.org/10.1111/j.1574-6968.2010 .02040.x.

14. Hegemann JD, Zimmermann M, Xie X, Marahiel MA. 2015. Lasso peptides: an intriguing class of bacterial natural products. Acc Chem Res 48: 1909-1919. https://doi.org/10.1021/acs.accounts.5b00156.

15. Maksimov MO, Pan SJ, Link AJ. 2012. Lasso peptides: structure, function biosynthesis, and engineering. Nat Prod Rep 29:996-1006. https://do .org/10.1039/c2np20070h.

16. Sood S, Steinmetz H, Beims H, Mohr KI, Stadler M, Djukic M, von der Ohe W, Steinert M, Daniel R, Müller R. 2014. Paenilarvins: iturin family lipopeptides from the honey bee pathogen Paenibacillus larvae. Chembiochem 15:1947-1955. https://doi.org/10.1002/cbic.201402139. 
Chapter 10

\section{General Discussion}


The main focus of this thesis was to increase our understanding and knowledge about plantassociated microbial communities including bacteria and fungi in winter wheat (Triticum aestivum L.) and winter faba bean (Vicia faba L.) and their response towards different cropping systems. We investigated the influence of cropping systems on microbial community composition and diversity in soil and endosphere under greenhouse conditions (Chapter 2, 4, 5 and 6). In addition, we examined the effect of water deficit on plant physiological parameters (Chapter 3) and on the active (RNA-based) bacterial and fungal communities (Chapter 4, 5). Furthermore, we investigated how the application of an entomopathogenic fungus affects plant-associated bacterial and fungal communities (Chapter 6). In the last three chapters, we analyzed the draft genome sequences of different isolated bacterial endophytes in grasses (Chapter 7, 8, 9).

Despite their important role in promoting plant growth and health, the response of the endophytic community towards agricultural practices including intercropping or inoculation of entomopathogenic fungi is still poorly understood (Table 1). Moreover, research mainly investigated bacterial or fungal communities separately; however bacteria and fungi co-occur and can interact within the different plant compartments (Sloan and Lebeis, 2015; Cocq et al., 2017). As these microorganisms have different lifestyles within plants (Hardoim et al., 2008; Deveau et al., 2018), it can be expected that they also respond differently towards agricultural practices. Furthermore, previous studies applied different community profiling techniques such as T-RFLP (Zhang et al., 2010; Zhang et al., 2011) or DGGE (Song et al., 2007a, Yang et al., 2016) to investigate in the effect of intercropping systems. However, none of these molecular techniques provides such a high level of taxonomic resolution than NGS-based sequencing and analysis of 16S rRNA gene and ITS region amplicons (Prosser et al., 2010). In contrast to these studies (Table 1), we investigated in the entire microbial (bacteria and fungi) communities in different plant compartments of two important crop species under different cropping systems. 
Table 1. Studies investigating in microbial communities between monoculture and intercropping systems. Only relevant studies are shown.

\begin{tabular}{|c|c|c|c|c|c|c|}
\hline Reference & Method & $\begin{array}{c}\text { Investigation } \\
\text { on }\end{array}$ & $\begin{array}{l}\text { Investigated } \\
\text { crop species }\end{array}$ & Compartment & Effect on & Effect? \\
\hline $\begin{array}{c}\text { Song et al., } \\
2007 \mathrm{a}\end{array}$ & DGGE & $\mathrm{AOB}$ & $\begin{array}{l}\text { faba bean, } \\
\text { maize, } \\
\text { wheat }\end{array}$ & $\begin{array}{c}\text { rhizosphere } \\
\text { soil }\end{array}$ & composition & yes \\
\hline $\begin{array}{c}\text { Song et al., } \\
2007 b\end{array}$ & DGGE & bacteria & $\begin{array}{l}\text { faba bean, } \\
\text { maize, } \\
\text { wheat }\end{array}$ & $\begin{array}{c}\text { rhizosphere } \\
\text { soil }\end{array}$ & $\begin{array}{l}\text { composition/ } \\
\text { diversity }\end{array}$ & yes/yes \\
\hline $\begin{array}{c}\text { Sun et al., } \\
2009\end{array}$ & T-RFLP & bacteria, AOB & $\begin{array}{c}\text { alfalfa, } \\
\text { siberian wild } \\
\text { rye }\end{array}$ & $\begin{array}{c}\text { rhizosphere } \\
\text { soil }\end{array}$ & $\begin{array}{l}\text { composition } \\
\text { /abundance }\end{array}$ & $\begin{array}{c}\text { bacteria,no; } \\
\text { AOB, yes/ } \\
\text { bacteria,yes; } \\
\text { AOB, yes }\end{array}$ \\
\hline $\begin{array}{l}\text { Zhang et } \\
\text { al., } 2010\end{array}$ & $\begin{array}{l}\text { T-RFLP/ } \\
\text { ARDRA }\end{array}$ & bacteria & faba bean & $\begin{array}{c}\text { rhizosphere } \\
\text { soil }\end{array}$ & $\begin{array}{l}\text { composition } \\
\text { / diversity }\end{array}$ & yes/no \\
\hline $\begin{array}{c}\text { Fan et al., } \\
2011\end{array}$ & T-RFLP & $\mathrm{AOB}, \mathrm{AOA}$ & $\begin{array}{c}\text { faba bean, } \\
\text { maize }\end{array}$ & $\begin{array}{c}\text { rhizosphere } \\
\text { soil }\end{array}$ & $\begin{array}{l}\text { composition/ } \\
\text { abundance }\end{array}$ & $\begin{array}{l}\text { both no / } \\
\text { AOB yes, } \\
\text { AOA no }\end{array}$ \\
\hline $\begin{array}{l}\text { Zhang et } \\
\text { al., } 2011\end{array}$ & $\begin{array}{c}\text { T-RFLP/ 16S } \\
\text { RNA clone } \\
\text { libraries }\end{array}$ & bacteria & faba bean & $\begin{array}{c}\text { root } \\
\text { endosphere }\end{array}$ & $\begin{array}{l}\text { composition/ } \\
\text { diversity }\end{array}$ & yes/yes \\
\hline $\begin{array}{c}\text { Qiao et al., } \\
2012\end{array}$ & DGGE & bacteria & $\begin{array}{l}\text { common } \\
\text { vetch, oat }\end{array}$ & $\begin{array}{c}\text { rhizosphere } \\
\text { soil }\end{array}$ & diversity & yes \\
\hline $\begin{array}{l}\text { Wang et al., } \\
2012\end{array}$ & DGGE & $\begin{array}{c}\text { fungi, } \\
\text { bacteria, } \\
\text { AOA, AOB, } \\
\text { ALP gene, } \\
\text { nifH gene }\end{array}$ & $\begin{array}{c}\text { faba bean, } \\
\text { lupine, } \\
\text { wheat }\end{array}$ & $\begin{array}{c}\text { rhizosphere } \\
\text { soil }\end{array}$ & composition & $\begin{array}{l}\text { bacteria, no; } \\
\text { fungi, yes; } \\
\text { AOB, yes; } \\
\text { ALP, no; } \\
\text { nifH, yes }\end{array}$ \\
\hline $\begin{array}{l}\text { Zhang et } \\
\text { al., } 2015\end{array}$ & qPCR/ T-RFLP & $\begin{array}{l}\text { bacteria, } \\
\text { archaea, } \\
\text { AOB, } \\
\text { AOA }\end{array}$ & $\begin{array}{l}\text { faba bean, } \\
\text { maize }\end{array}$ & $\begin{array}{c}\text { rhizosphere } \\
\text { soil }\end{array}$ & $\begin{array}{l}\text { composition } \\
\text { /diversity }\end{array}$ & $\begin{array}{c}\text { bacteria, yes; } \\
\text { AOB,no / } \\
\text { bacteria, } \\
\text { AOB, yes }\end{array}$ \\
\hline $\begin{array}{l}\text { Li et al., } \\
2016\end{array}$ & $\begin{array}{l}454- \\
\text { pyrosequencing }\end{array}$ & bacteria & $\begin{array}{l}\text { mulberry, } \\
\text { soybean }\end{array}$ & $\begin{array}{c}\text { rhizosphere } \\
\text { soil }\end{array}$ & $\begin{array}{l}\text { composition/ } \\
\text { diversity }\end{array}$ & yes/yes \\
\hline $\begin{array}{c}\text { Yang et al., } \\
2016\end{array}$ & DGGE & bacteria & $\begin{array}{l}\text { several } \\
\text { crops }\end{array}$ & $\begin{array}{c}\text { rhizosphere } \\
\text { soil }\end{array}$ & diversity & yes \\
\hline $\begin{array}{c}\text { Granzow } \\
\text { et al., }\end{array}$ & MiSeq & $\begin{array}{c}\text { fungi, } \\
\text { bacteria }\end{array}$ & $\begin{array}{c}\text { faba bean, } \\
\text { wheat }\end{array}$ & $\begin{array}{c}\text { bulk and } \\
\text { rhizosphere }\end{array}$ & $\begin{array}{c}\text { composition/ } \\
\text { diversity }\end{array}$ & $\begin{array}{c}\text { both yes/ } \\
\text { bacteria,yes; }\end{array}$ \\
\hline
\end{tabular}




\begin{tabular}{|c|c|c|c|c|c|c|}
\hline $\begin{array}{c}\text { 2017, } \\
\text { (Chapter } \\
\text { 2) }\end{array}$ & & & & $\begin{array}{l}\text { soil, root and } \\
\text { leaf } \\
\text { endosphere }\end{array}$ & & $\begin{array}{c}\text { fungi, } \\
\text { between } \\
\text { intercropping }\end{array}$ \\
\hline $\begin{array}{c}\text { Taschen et } \\
\text { al., } 2017\end{array}$ & $\begin{array}{c}\text { qPCR (RNA- } \\
\text { based) }\end{array}$ & $\begin{array}{l}\alpha, \beta, \gamma^{-} \\
\text {proteobacteria, } \\
\text { acidobacteria, } \\
\text { actinobacteria, } \\
\text { bacteriodetes, } \\
\text { firmicutes }\end{array}$ & pea, wheat & $\begin{array}{c}\text { rhizosphere } \\
\text { soil }\end{array}$ & $\begin{array}{l}\text { composition/ } \\
\text { abundance }\end{array}$ & yes/yes \\
\hline $\begin{array}{c}\mathrm{Li} \text { and } \mathrm{Wu} \text {, } \\
2018\end{array}$ & MiSeq & fungi, bacteria & $\begin{array}{l}\text { several } \\
\text { crops }\end{array}$ & bulk soil & $\begin{array}{l}\text { composition/ } \\
\text { diversity }\end{array}$ & no/yes \\
\hline
\end{tabular}

Abbreviations: ARDRA, amplified 16SrDNA restriction analysis, DGGE, denaturing gradient gel electrophoresis; T-RFLP, terminal restriction fragment length polymorphism; qPCR, real-time quantitative PCR; AOA, ammonia-oxidizing archaea; AOB, ammonia-oxidizing bacteria, ALP, P mobilizer; nifH, $\mathrm{N}_{2}$-fixers.

\subsection{Plant-associated microbial communities and their response towards cropping} systems

In line with our first hypothesis, we observed that cropping system significantly affected bacterial and fungal community composition (Chapter 2, 4, 5, 6). Moreover, we showed that plant related traits including crop species and plant compartment were important in influencing the response of microbial communities towards cropping systems. For example, bacterial community composition was only significantly different between monoculture and row intercropping in the bulk soil of wheat (Chapter 2). In contrast, fungal community composition was significantly different between monoculture and row intercropping in the root endosphere of faba bean and wheat as well as in the bulk soil of faba bean (Chapter 2). Other studies (Song et al., 2007b; Wang et al., 2012) indicated that crop species can exhibit a strong influence on microbial community composition that can change response towards cropping system. Wang et al. (2012) observed that fungal community composition in wheat rhizosphere was significantly different in monoculture compared to intercropping system, whereas in lupine rhizosphere no difference was observed between the cropping systems.

We showed that that alpha diversity which included diversity (represented by Shannon diversity index H') and richness (number of observed unique sequences) was significantly influenced by cropping system but crop species and compartment determined responses. For example, we showed that fungal diversity and richness was significantly affected by cropping system but this was only observed in wheat root endosphere whereas bacteria were only influenced in wheat and faba bean rhizosphere (Chapter 6). In this Chapter, wheat in intercropping system tended to have higher bacterial and fungal diversity and richness but 
specific for the compartment. In accordance to our results, previous studies showed that intercropping can increase microbial diversity in the rhizosphere and bulk soil (Song et al., 2007b; Yang et al., 2016; Li and Wu, 2018). For example, Yang et al., (2016) investigated in 10 different spring crops grown in monoculture and intercropping system and found that intercropping increased bacterial diversity in the rhizosphere, however, responses were crop species dependent. In contrast, in Chapter 2 differences in microbial diversity and richness was only attributed to differences between mixed and row intercropping or mixed intercropping and monoculture. However, we used in this experiment commercially available soil but also different plant genotypes compared to Chapter 4-6. As previous studies have shown, soil type, plant species and even genotypes influenced microbial communities in soil and endosphere and thus, response towards cropping systems might also differ dependent on these paramters (Wagner et al., 2016; Cobb et al., 2017; Wemheuer et al., 2017). In line with this assumption, we observed in Chapter 4 that significant differences between monoculture and intercropping systems for bacterial diversity and richness were only found in the leaf endosphere of the faba bean genotype S_062, whereas bacterial endophytes in faba bean genotype S_004 were unaffected.

In Chapter 4/5 and 6, we showed strikingly different results regarding the response of bacterial and fungal alpha-diversity towards cropping systems. Although we used the same experimental setup for the pot experiment as well as the same soil type and crop genotype, we found in Chapter 4 and 5 no response of the bacterial and fungal diversity in the rhizosphere soil towards cropping systems. However, in these Chapters we used different molecular approaches (e.g, different extraction kits, nested vs. direct PCR), which might influence results. Furthermore, the entire (DNA-based) microbial community also includes dead cells or dormant microorganisms, whereas the active (RNA-based) microbial community is only a fraction of the entire community which is metabolically active (Blagodatskaya and Kuzyakov, 2013) and thus, responses might differ towards environmental changes as also indicated in previous research on drought and fertilizer effects (Barnard et al., 2013; Herzog et al., 2015). However, research with a combined approach of active and entire microbial communities is needed to further elucidate the effects of cropping systems.

As microbial diversity is related to ecosystem function, an increase of microbial diversity through intercropping system might contribute to enhance plant health and growth (Eisenhauer et al., 2012; Andreote and Silva, 2017). However, in this thesis, we only performed short-term experiments under greenhouse conditions and thus, it is difficult to extrapolate results to natural field conditions. As indicated by previous studies, significant 
effects on soil microbiome through plant diversity might increase with experimental duration (Song et al., 2007b; Eisenhauer et al., 2012). Eisenhauer et al., (2012) posited that long-term species-rich plant communities experience predominantly facilitative net effects by soil biota and promoting plant growth through arbuscular mycorrhizal fungi or plant growth promoting rhizobacteria, whereas species-poor plant communities such as monocultures are subject to antagonistic net soil effects due to the accumulation of pathogens. Thus, we need more longterm field studies which also investigate in different crop species/genotype combinations to select the most suitable crops for intercropping systems that not only benefit agricultural production but also microbial communities.

\subsection{Response of the active microbial community towards water deficit}

In accordance to our hypothesis, we showed in the Chapters 4 and 5 that the abiotic factor drought significantly influenced bacterial and fungal communities in the rhizosphere but also bacterial leaf endophytes. Moreover, fungal and bacterial communities in the rhizosphere soil exhibited different responses towards water deficit. Our results indicate that the fungal community was more sensitive towards water deficit compared to bacteria in the rhizosphere. In accordance with this assumption were previous findings (Kaisermann et al., 2015; He et al., 2017). On the other hand, studies have shown that fungi were more resistant towards drought compared to bacteria (Barnard et al., 2013; Meisner et al., 2018) or that both exhibited a similar response (Sayer et al., 2017; Kaurin et al., 2018). These contradictory findings between studies might be attributed to different investigated compartments (bulk vs. rhizosphere soil), differences in experimental settings such as drought intensities or soil characteristics, and precipitation history in soil which has been shown to affect microbial communities and their response towards drought (Santos-Medellin et al., 2017; Kaisermann et al., 2015; Kaisermann et al. 2017). In the present study, crop species and genotype played an important role in influencing fungal alpha-diversity and bacterial community composition in the rhizosphere towards water deficit. As previously shown (Henry et al., 2007; Preece and Peñuelas, 2016), water deficit can lead to plant stress which can also change root exudation pattern and thus, the response of soil microbial communities.

Similar to the rhizosphere, response of bacterial leaf endophytes (Chapter 4) were dependent on faba bean genotype, resulting in a decrease in diversity and richness in genotype S_062 under water deficit. Partly in accordance to our observation, previous studies demonstrated that water deficit decreased bacterial diversity in the root endosphere of several plant species (Naylor et al., 2017; Fitzpatrick et al., 2018). As shown in Chapter 3, plant 
response including physiological and biochemical changes towards water deficit can be genotype specific which might also affect the endosphere microbiome. In line with this assumption, we observed that chlorophyll concentration and all three soluble sugars (glucose, sucrose, and fructose) in leaves significantly changed according to water deficit in genotype S_062.

Moreover, we found that differences between water treatments were pronounced for a specific cropping system but dependent on crop genotype. For example, fungal diversity and richness was significantly lower in the rhizosphere of S4_FBM_D compared to S4_FBM_C. In addition, the combination of water deficit and cropping system changed associated microbial communities but also microbial interactions. We assume that inter- and intraspecific competition between plants for water (or nutrients) in the specific cropping system had differenct effects on each crop species and thus, on their associated microbial communities as indicated in previous research (Granzow et al., 2017; Kaisermann et al., 2017). Obtained results highlight that crop genotype played key roles in the susceptibility of the active microbial communities towards drought. Thus, choosing the best genotype suitable for a specific cropping system might be important to mitigate future drought events while maintaining agricultural productivity.

\subsection{Crop species and cropping system influenced the effect of $M$. brunneum seed application on plant-associated microbial communities}

In line with our third hypothesis, we showed in Chapter 6 that M.brunneum application affected microbial community composition and alpha-diversity but responses were strongly determined by plant compartment and crop species. For example, bacterial community composition was affected through inoculation in the rhizosphere soil and leaf endosphere. In contrast, fungal community composition only exhibited significant differences in the rhizosphere soil. In accordance to this, Ardanov and coworkers (2012) showed compartment specific effects of the substrate inoculation of Methylobacterium spp. on bacteria. Application only changed bacterial composition in potato shoots, whereas root endophytes were not influenced. In contrast to our results, Zimmermann et al., (2016) observed that seed coating with Fusarium oxysporum did not alter indigenous fungal community composition in the rhizosphere of maize, whereas soil type and plant growth stage showed the strongest effect on fungi. In addition, microbial diversity and richness showed harvest date- and kingdomspecific responses towards M. brunneum application. A significantly lower fungal diversity and richness was observed in the leaf endosphere and rhizosphere soil of inoculated wheat 
compared to control plants after seven weeks of growth. In contrast, bacterial diversity and richness in wheat rhizosphere and leaves were significantly higher in inoculated plants specific for harvest 1 or 2. Previously, Rabiey et al., (2017) reported that soil inoculation with the fungus Piriformospora indica increased the fungal diversity in soil and root endosphere of wheat in a pot experiment which was in contrast to our results; however they also reported an increase of bacterial diversity which was in line with our results. We speculate that discrepancies to our results might be related to specific responses of bacteria and fungi to the inoculated agent and that crop species and growth stage of plant might modify these responses as indicated in previous research (Aguilar-Trigueros and Rillig, 2016; Gadhave et al., 2018; Liu et al., 2018).

Moreover, we observed that the combination of cropping system and M.brunneum application altered bacterial and fungal community composition and diversity. We found that significant differences between cropping system were most pronounced between inoculated plants. For example, fungi in the root endosphere showed in the cropping regime XWF the highest diversity and richness, whereas in the cropping regime MWF the lowest diversity and richness. In contrast, bacterial diversity and richness was significantly higher in the rhizosphere of XWF compared to MWF. In line with this, we observed alterations in nitrogen and carbon which might explain these findings. We speculate that changes in nutrients might be related to M.brunneum application as previous studies have reported that this fungus is able to alter availability of certain nutrients through the production of siderophores and/ or organic acids (Krasnoff et al., 2014; Sánchez-Rodriguez et al., 2016; Krell et al., 2018). Overall, our findings highlight the importance to investigate the separate and combined effect of cropping system and application of entomopathogenic fungi on plant-associated microbial communities.

\subsection{Draft genomes of different endophytic bacteria in grasses}

As the plant endosphere is a great reservoir of beneficial microorganisms (Rascovan et al., 2018), we investigated in the last Chapters $(7,8,9)$, the draft genomes of three endophytic bacteria, namely Bacillus mycoides (Strain GM5LP), Pseudomonas putida (Strain GM4FR) and Paenibacillus amylolyticus (Strain GM1FR) isolated from Lolium perenne and Festuca rubra L., respectively. We identified several genes of Pseudomonas putida which were encoding for a putative nematicidal protein (AidA) as well as insecticidal proteins such as fitD/mcf and tccC. These insecticidal toxins have been shown to provide protective effects for their plant hosts from Pseudomonas spp. (Péchy-Tarr et al., 2008). In Paenibacillus 
amylolyticus we identified genes which exhibited similarity to pelgipeptin biosynthetic gene cluster. Pelgipeptin is known for their antimicrobial activity against several plant pathogenic fungi and bacteria (Wu et al., 2010; Ding et al., 2011). Furthermore, in the draft genome of Bacillus mycoides we found several predicted gene clusters including bacteriocin, terpene, lantipeptide, lassopeptide and siderophore. For example, previous studies showed that bacteriocin production might be beneficial for plant growth (Lee et al., 2009) and in influencing other bacteria (Scholz et al., 2014). In general, Pseudomonas spp. and the class Bacilli are extensively studied plant-associated bacteria and have the potential as biocontrol agent that contribute to nutrient acquisition and growth promotion for plant host (Barnett et al., 2017; Levy et al., 2017). However, further research is needed to validate these findings.

\subsection{Concluding remarks and outlook}

With the results of this thesis, we confirmed our general hypothesis that cropping system altered bacterial and fungal community composition as well as diversity. However, effect of cropping system was strongly shaped by plant related traits including crop species/ genotype and plant compartment (Chapter 2, 4, 5, 6) which supports our second assumption. Furthermore, we observed that water deficit and M.brunneum seed inoculation altered microbial communities; but effects were dependent on plant compartment and crop species/genotype (Chapter 4, 5, 6). Furthermore, bacterial and fungal communities responded differently towards agricultural practices and environmental changes which confirmed our last hypothesis. As beneficial plant-associated microorganisms are key promoter in plant growth and health, it is important to know which factors shape microbial community composition and diversity. Obtained results of this thesis might contribute to understand the complex interactions between plants, associated microorganisms and their environment that influence agricultural productivity.

\subsection{References}

Aguilar-Trigueros CA, Rillig MC. 2016. Effect of different root endophytic fungi on plant community structure in experimental microcosms. Ecology and Evolution. Nov;6:8149-8158.

Andreote FD, Silva M. 2017. Microbial communities associated with plants: learning from nature to apply it in agriculture. Current Opinion in Microbiology. Jun;37:29-34.

Ardanov P, Sessitsch A, Haggman H, Kozyrovska N, Pirttila AM. 2012. MethylobacteriumInduced Endophyte Community Changes Correspond with Protection of Plants against Pathogen Attack. Plos One. Oct;7.

Barnard RL, Osborne CA, Firestone MK. 2013. Responses of soil bacterial and fungal communities to extreme desiccation and rewetting. Isme Journal. Nov; 7:2229-2241. 
Barnett S, Zhao S, Ballard R, Franco C. 2017. Selection of microbes for control of Rhizoctonia root rot on wheat using a high throughput pathosystem. Biological Control. Oct; 113:45-57.

Blagodatskaya E, Kuzyakov Y. 2013. Active microorganisms in soil: Critical review of estimation criteria and approaches. Soil Biology \& Biochemistry. Dec;67:192-211.

Cobb AB, Wilson GWT, Goad CL, Bean SR, Tesso TT, Wilson JD. 2017. Assessing the influence of farm fertility amendments, field management, and sorghum genotypes on soil microbial communities and grain quality. Applied Soil Ecology. Oct;119:367-374.

Deveau A. Bonito G, Uehling J, Paoletti M, Becker M, Bindschedler S, Hacquard S, Herve V, Labbe J, Lastovetsky OA, Mieszkin S, Millet LJ, Vajna B, Junier P, Bonfante P, Krom BP, Olsson S, Elsas JD, Wick LY. 2018. Bacterial-fungal interactions: ecology, mechanisms and challenges. FEMS Microbiol Rev. May; 42: 335-352.

Ding R, Wu XC, Qian CD, Teng Y, Li O, Zhan ZJ, Zhao YH. 2011. Isolation and identification of lipopeptide antibiotics from Paenibacillus elgii B69 with inhibitory activity against methicillin-resistant Staphylococcus aureus. Journal of Microbiology. Dec;49:942949.

Eisenhauer N, Reich PB, Scheu S. 2012. Increasing plant diversity effects on productivity with time due to delayed soil biota effects on plants. Basic and Applied Ecology. Nov;13:571578.

Fan FL, Zhang FS, Lu YH. 2011. Linking plant identity and interspecific competition to soil nitrogen cycling through ammonia oxidizer communities. Soil Biology \& Biochemistry. Jan;43:46-54.

Fitzpatrick CR, Copeland J, Wang PW, Guttman DS, Kotanen PM, Johnson MTJ. 2018. Assembly and ecological function of the root microbiome across angiosperm plant species. Proceedings of the National Academy of Sciences of the United States of America. Feb;115:E1157-E1165.

Gadhave KR, Devlin PF, Ebertz A, Ross A, Gange AC. 2018. Soil inoculation with Bacillus spp. modifies root endophytic bacterial diversity, evenness and community composition in a context-specific manner. Microbiology Ecology. Mar; 1-10.

Granzow S, Kaiser K, Wemheuer B, Pfeiffer B, Daniel R, Vidal S, Wemheuer F. 2017. The Effects of Cropping Regimes on Fungal and Bacterial Communities of Wheat and Faba Bean in a Greenhouse Pot Experiment Differ between Plant Species and Compartment. Frontiers in Microbiology. May;8.

Hardoim PR, van Overbeek LS, van Elsas JD. 2008. Properties of bacterial endophytes and their proposed role in plant growth. Trends in Microbiology. Oct;16:463-471.

He D, Shen WJ, Eberwein J, Zhao Q, Ren LJ, Wu QLL. 2017. Diversity and co-occurrence network of soil fungi are more responsive than those of bacteria to shifts in precipitation seasonality in a subtropical forest. Soil Biology \& Biochemistry. Dec;115:499-510.

Henry A, Doucette W, Norton J, Bugbee B. 2007. Changes in crested wheatgrass root exudation caused by flood, drought, and nutrient stress. Journal of Environmental Quality. May-Jun;36:904-912.

Herzog S, Wemheuer F, Wemheuer B, Daniel R. 2015. Effects of Fertilization and Sampling Time on Composition and Diversity of Entire and Active Bacterial Communities in German Grassland Soils. Plos One. Dec;10. 
Kaisermann A, de Vries FT, Griffiths RI, Bardgett RD. 2017. Legacy effects of drought on plant-soil feedbacks and plant-plant interactions. New Phytologist. Sep;215:1413-1424.

Kaisermann A, Maron PA, Beaumelle L, Lata JC. 2015. Fungal communities are more sensitive indicators to non-extreme soil moisture variations than bacterial communities. Applied Soil Ecology. Feb;86:158-164.

Kaurin A, Mihelic R, Kastelec D, Grcman H, Bru D, Philippot L, Suhadolc M. 2018. Resilience of bacteria, archaea, fungi and N-cycling microbial guilds under plough and conservation tillage, to agricultural drought. Soil Biology \& Biochemistry. May;120:233-245.

Krasnoff SB, Keresztes I, Donzelli BGG, Gibson DM. 2014. Metachelins, Mannosylated and N-Oxidized Coprogen-Type Siderophores from Metarhizium robertsii. Journal of Natural Products. Jul; 77:1685-1692.

Krell V, Unger S, Jakobs-Schoenwandt D, Patel AV. 2018. Endophytic Metarhizium brunneum mitigates nutrient deficits in potato and improves plant productivity and vitality. Fungal Ecology. Aug;34:43-49.

Le Cocq K, Gurr SJ, Hirsch PR, Mauchline TH. 2017. Exploitation of endophytes for sustainable agricultural intensification. Molecular Plant Pathology. Apr;18:469-473.

Lee KD, Gray EJ, Mabood F, Jung WJ, Charles T, Clark SRD, Ly A, Souleimanov A, Zhou XM, Smith DL. 2009. The class IId bacteriocin thuricin-17 increases plant growth. Planta. Mar;229:747-755.

Levy A, Gonzalez IS, Mittelviefhaus M, Clingenpeel S, Paredes SH, Miao JM, Wang KR, Devescovi G, Stillman K, Monteiro F, et al. 2018. Genomic features of bacterial adaptation to plants. Nature Genetics. Jan;50:138-+.

Li S, Wu FZ. 2018. Diversity and Co-occurrence Patterns of Soil Bacterial and Fungal Communities in Seven Intercropping Systems. Frontiers in Microbiology. Jul;9.

Li X, Sun ML, Zhang HH, Xu N, Sun GY. 2016. Use of mulberry-soybean intercropping in salt-alkali soil impacts the diversity of the soil bacterial community. Microbial Biotechnology. May;9:293-304.

Liu CM, Yang ZF, He PF, Munir S, Wu YX, Ho HH, He YQ. 2018. Deciphering the bacterial and fungal communities in clubroot-affected cabbage rhizosphere treated with Bacillus Subtilis XF-1. Agriculture Ecosystems \& Environment. Mar;256:12-22.

Meisner A, Jacquiod S, Snoek BL, ten Hooven FC, van der Putten WH. 2018. Drought Legacy Effects on the Composition of Soil Fungal and Prokaryote Communities. Frontiers in Microbiology. Mar;9.

Naylor D, DeGraaf S, Purdom E, Coleman-Derr D. 2017. Drought and host selection influence bacterial community dynamics in the grass root microbiome. Isme Journal. Dec;11:2691-2704.

Pechy-Tarr M, Bruck DJ, Maurhofer M, Fischer E, Vogne C, Henkels MD, Donahue KM, Grunder J, Loper JE, Keel C. 2008. Molecular analysis of a novel gene cluster encoding an insect toxin in plant-associated strains of Pseudomonas fluorescens. Environmental Microbiology. Sep;10:2368-2386.

Preece C, Peñuelas J. 2016. Rhizodeposition under drought and consequences for soil communities and ecosystem resilience. Plant and Soil. Dec;409:1-17.

Prosser J, Jansson JK, Liu WT. 2010. Nucleic-acid-based characterization of community structure and function. In: Liu WT, Jannson JK (eds). Environmental Molecular Microbiology. Caister Academic Press: Norfolk, 63-86. 
Qiao YJ, Li ZZ, Wang X, Zhu B, Hu YG, Zeng ZH. 2012. Effect of legume-cereal mixtures on the diversity of bacterial communities in the rhizosphere. Plant Soil and Environment. Apr;58:174-180.

Rabiey M, Ullah I, Shaw LJ, Shaw MW. 2017. Potential ecological effects of Piriformospora indica, a possible biocontrol agent, in UK agricultural systems. Biological Control. Jan;104:19.

Sánchez-Rodriguez AR, Barron V, Del Campillo MC, Quesada-Moraga E. 2016. The entomopathogenic fungus Metarhizium brunneum: a tool for alleviating Fe chlorosis. Plant and Soil. Sep;406:295-310.

Santos-Medellin C, Edwards J, Liechty Z, Nguyen B, Sundaresan V. 2017. Drought Stress Results in a Compartment-Specific Restructuring of the Rice Root-Associated Microbiomes. Mbio. Jul-Aug;8.

Rascovan N, Carbonetto B, Perrig D, Diaz M, Canciani W, Abalo M, Alloati J, GonzalezAnta, Vazquez MP. 2018.Integrated analysis of root microbiomes of soybean and wheat from agricultural fields. Scientific Reports. Jun; 6:28084.

Sayer EJ, Oliver AE, Fridley JD, Askew AP, Mills RTE, Grime JP. 2017. Links between soil microbial communities and plant traits in a species-rich grassland under long-term climate change. Ecology and Evolution. Feb;7:855-862.

Scholz R, Vater J, Budiharjo A, Wang ZY, He YQ, Dietel K, Schwecke T, Herfort S, Lasch P, Borriss R. 2014. Amylocyclicin, a Novel Circular Bacteriocin Produced by Bacillus amyloliquefaciens FZB42. Journal of Bacteriology. May;196:1842-1852.

Sloan SS, Lebeis SL. 2015. Exercising influence: distinct biotic interactions shape root microbiomes. Current Opinion in Plant Biology. Aug;26:32-36.

Song YN, Marschner P, Li L, Bao XG, Sun JH, Zhang FS. 2007. Community composition of ammonia-oxidizing bacteria in the rhizosphere of intercropped wheat (Triticum aestivum L.), maize (Zea mays L.), and faba bean (Vicia faba L.). Biology and Fertility of Soils. Dec;44:307-314.

Song YN, Zhang FS, Marschner P, Fan FL, Gao HM, Bao XG, Sun JH, Li L. 2007. Effect of intercropping on crop yield and chemical and microbiological properties in rhizosphere of wheat (Triticum aestivum L.), maize (Zea mays L.), and faba bean (Vicia faba L.). Biology and Fertility of Soils. Jun;43:565-574.

Sun YM, Zhang NN, Wang ET, Yuan HL, Yang JS, Chen WX. 2009. Influence of intercropping and intercropping plus rhizobial inoculation on microbial activity and community composition in rhizosphere of alfalfa (Medicago sativa L.) and Siberian wild rye (Elymus sibiricus L.). Fems Microbiology Ecology. Nov;70:218-226.

Taschen E, Amenc L, Tournier E, Malagoli P, Fustec J, Bru D, Philippot L, Bernard L. 2017. Cereal-legume intercropping modifies the dynamics of the active rhizospheric bacterial community. Rhizosphere 3: 191-195.

Wagner MR, Lundberg DS, del Rio TG, Tringe SG, Dangl JL, Mitchell-Olds T. 2016. Host genotype and age shape the leaf and root microbiomes of a wild perennial plant. Nature Communications. Jul;7.

Wang Y, Marschner P, Zhang FS. 2012. Phosphorus pools and other soil properties in the rhizosphere of wheat and legumes growing in three soils in monoculture or as a mixture of wheat and legume. Plant and Soil. May;354:283-298. 
Wemheuer F, Kaiser K, Karlovsky P, Daniel R, Vidal S, Wemheuer B. 2017. Bacterial endophyte communities of three agricultural important grass species differ in their response towards management regimes. Scientific Reports. Jan;7.

Wu XC, Shen XB, Ding R, Qian CD, Fang HH, Li O. 2010. Isolation and partial characterization of antibiotics produced by Paenibacillus elgii B69. Fems Microbiology Letters. Sep;310:32-38.

Yang ZP, Yang WP, Li SC, Hao JM, Su ZF, Sun M, Gao ZQ, Zhang CL. 2016. Variation of Bacterial Community Diversity in Rhizosphere Soil of Sole-Cropped versus Intercropped Wheat Field after Harvest. Plos One. Mar;11.

Zhang NN, Sun YM, Li L, Wang ET, Chen WX, Yuan HL. 2010. Effects of intercropping and Rhizobium inoculation on yield and rhizosphere bacterial community of faba bean (Vicia faba L.). Biology and Fertility of Soils. Aug;46:625-639.

Zhang NN, Sun YM, Wang ET, Yang JS, Yuan HL, Scow KM. 2015. Effects of intercropping and Rhizobial inoculation on the ammonia-oxidizing microorganisms in rhizospheres of maize and faba bean plants. Applied Soil Ecology. Jan;85:76-85.

Zhang YZ, Wang ET, Li M, Li QQ, Zhang YM, Zhao SJ, Jia XL, Zhang LH, Chen WF, Chen WX. 2011. Effects of rhizobial inoculation, cropping systems and growth stages on endophytic bacterial community of soybean roots. Plant and Soil. Oct;347:147-161.

Zimmermann J, Musyoki MK, Cadisch G, Rasche F. 2016. Biocontrol agent Fusarium oxysporum f.sp strigae has no adverse effect on indigenous total fungal communities and specific AMF taxa in contrasting maize rhizospheres. Fungal Ecology. Oct;23:1-10. 


\section{Acknowledgment}

This thesis would be not possible with all the help and support of so many people!

First of all, many thanks to Prof. Dr. Stefan Vidal for offering me the opportunity to work on such interesting and challenging topic as well as thank you for your continuous support and encouragement during my $\mathrm{PhD}$ thesis.

I am very grateful to Dr. Franziska Wemheuer who introduced me into the field of microbial ecology. You were always amazingly patient, provided me with valuable advices when needed and you gave me always critical feedback for my manuscripts! Further thanks should go to Dr. Bernd Wemheuer, who told me a lot about bioinformatics, analysis and R.

I would like to thank Prof. Dr. Rolf Daniel for giving me the opportunity to work in his laboratory.

Further thanks should go to my colleagues who helped me during the harvests of my experiments as well as with my samples: Birgit Pfeiffer, Hadis Yayanti, Paul Götsch, Avril von Hoyningen-Huene, Sarah Demirkale, Annika Lingner and also thanks to the people which I maybe did not mention. :

I would like to thank all my colleagues from the Agricultural Entomology but also from the AG Daniel. It was a really nice time!

Finally, thanks to my friends and family and especially Dennis, who always supported and encouraged me during my $\mathrm{PhD}$ time. 


\section{Curriculum Vitae}

\section{Sandra Granzow}

Geburtsdatum- und ort: 04.12.1989, Witzenhausen

Nationalität: Deutsch

\section{Wissenschaftlicher Werdegang}

Juni 2015-

Oktober 2018

Oktober 2012-

März 2015

Oktober 2009-

September 2012
Wissenschaftlicher Mitarbeiter

Georg-August-Universität Göttingen

Abteilung: Agrarentomologie

Promotionsstudium Agrarwissenschaften (PAG)

Georg-August-Universität Göttingen

Promotion in der Abteilung Agrarentomologie

\section{Studium in Biodiversität, Ökologie und Evolution}

Georg-August-Universität Göttingen

Schwerpunkt: Evolution

Abschluss: Master of Science

Masterarbeit: Influence of wounding on fungal volatile formation and fungivore foraging behaviour

\section{Studium in Biologie}

Georg-August-Universität Göttingen

Schwerpunkt: Verhaltens- und Neurobiologie

Abschluss: Bachelor of Science

Bachelorarbeit: Soziale Netzwerkanalyse einer Rhesusaffengruppe 


\section{Schule}

August 2006-

Berufliches Gymnasium, Berufliche Schulen des Werra-

Juni 2009

Meissner-Kreises in Witzenhausen

Schwerpunkt: Biotechnologie

Abschluss: Hochschulreife

\section{Tagungen}

2016: Braunschweig; Thünen Symposium on Soil Metagenomics

2016: Potsdam; Plant2030

2017: Göttingen; European Conference on Prokaryotic and Fungal Genomics

2017: Potsdam; Plant2030

2018: Potsdam; Plant2030

\section{Veröffentlichungen}

Hollensteiner J, Poehlein A, Granzow S, Liesegang H, Daniel R, Vidal S and Wemheuer F (2018) Draft genome sequence of the endophyte Bacillus mycoides strain GM5LP isolated from Lolium perenne. Genome Announcements 6:e01517-17.

Poehlein A, Hollensteiner J, Granzow S, Wemheuer B, Vidal S and Wemheuer F (2018) First insights into the draft genome sequence of the endophyte Paenibacillus amylolyticus strain GM1FR, isolated from Festuca rubra L..Genome Announcements 6:e01516-17.

Granzow S, Kaiser K, Wemheuer B, Pfeiffer B, Daniel R, Vidal S and Wemheuer F (2017) The effects of cropping regimes on fungal and bacterial communities of wheat and faba bean in a greenhouse pot experiment differ between plant species and compartment. Frontiers in Microbiology 8:902.

Wemheuer F, Hollenstein J, Poehlein A, Granzow S, Daniel R, Vidal S and Wemheuer B (2017) Draft genome sequence of Pseudomonas putida strain GM4FR, an endophytic bacterium isolated from Festuca rubra L. Genome Announcements 5:e00086-17. 


\section{Declarations}

I, hereby, declare that this Ph.D. dissertation has not been presented to any other examining body either in its present or a similar form.

Furthermore, I also affirm that I have not applied for a Ph.D. at any other higher school of education.

Göttingen,

\section{Sandra Granzow}

I, hereby, solemnly declare that this dissertation was undertaken independently and without any unauthorized aid.

Göttingen, 